\title{
AN INVESTIGATION OF E-GLASS STRUCTURE WITH DIFFERENT FILLER MATERIAL UNDER VIBRATION AND BENDING LOADING
}

\author{
A Thesis \\ Presented to the Faculty of \\ California Polytechnic State University, San Luis Obispo
}
In Partial Fulfillment of the Requirements
for the Degree of Master of Science
in Aerospace Engineering

by

John R. Parra

June 2009 
(C) 2009

John R. Parra

ALL RIGHTS RESERVED 


\section{APPROVAL PAGE}

TITLE: An Investigation of E-glass Structure with Different Filler Material under Vibration and Bending Loading

AUTHOR: John R. Parra

DATE SUBMITTED: June 2009

Dr. Faysal Kolkailah

Committee Member

Dr. Eltahry Elghandour

Committee Member

Dr. Daniel Biezad

Committee Member

Mr. Hans Lambrecht

Committee Member
Signature

Signature

Signature

Signature 


\section{ABSTRACT \\ An Investigation of E-glass Structure with Different Filler Material under \\ Vibration and Bending Loading}

By

\section{John R. Parra}

This thesis investigation involved the development of fiberglass laminated manhole covers with different inorganic fillers and to study the static and dynamic behavior of the material by performing experimental and numerical analysis. First part of this study was to design a press mold of manhole cover by using Solid Works software which was later used to build several negative and positive molds from urethane liquid rubber and develop procedures on how to manufacture the mold and composite specimens. For specimen preparation, a total of ten $9 \times 1.5$ in laminated beams of fiberglass with limestone/high-density adhesive filler were made and used to perform static and dynamic tests to determine mechanical properties of material. All test specimens had 4 plies of E-glass woven roving fabric and 3 to 1 epoxy ratio which was later mixed with different limestone filler quantities of 20,30, and 40 grams and a high-density adhesive filler quantity of 30 grams. In addition, ten 11-inch diameter fiberglass-filler manhole cover plates were also created and used to perform experimental tests of flexural strength in order to study the monotonic behavior under bending loads of each fiberglass polymer matrix composite structure. A $13 \times 13$ inch aluminum frame with a thickness of 0.2 in was also used to secure and control the added filler's thickness for each laminated specimen during the curing process. Second part of this study was to obtain numerical results by using Abaqus software for finite element analysis and compare them with experimental analysis.

The test specimens for this thesis investigation did not follow the ASTM D-3753 standards due to the limited accessibility of testing equipment. Instead test samples represented an 11-inch diameter meter manhole cover. The manhole cover laminates were made from fiberglass-filler polymer matrix material. Test specimens had an intermediate fiber volume fraction $\left(0.47<\mathrm{V}_{\mathrm{f}}<0.51\right)$ which explained why test specimens experienced brittle failure with fiber pullout during tensile testing. The static and dynamic test results showed that the laminates made with fiberglass and filler experienced lower performance in stiffness and flexural strength. Test specimens also followed a similar trend in mode shapes, natural frequencies, and damping behavior during vibration analysis. The experimental results showed that laminates with less filler experienced higher modes within the specified frequency range. This was expected since 
the material property of filler increased the overall stiffness and damping behavior in composite material. In addition, it was also shown that for most brittle materials, the ultimate strength in compression or bending was much larger than the ultimate strength in tension. This was due to the presence of flaws, such as microscopic cracks or cavities, which tend to weaken the material in tension, while not appreciably affecting its resistance to compressive failure.

For the numerical analysis, laminated plates with higher filler content showed the lowest strength. The discrepancy between the strength of the FEA models and the experimental data was attributed to inaccurate strength properties. High error percentages was also found between experimental and FEA in predicting the trend of stiffness of the plates.

In addition to the tension and compression test results from the supporting analysis, laminate $\mathrm{L}_{259}$ experienced the highest maximum load and strength. This was largely due to the increase modification of the 9-ply increase and the added limestone filler of 259 grams. Not only did it increase the test specimen's thickness but also provided significant strength and stiffness improvements in both tension and compression.

The indentation test results from the supporting analysis indicated that laminate $\mathrm{HD}_{30}$ experienced the highest maximum load with a corresponding maximum displacement of 0.8899 in. This result was as expected due since the laminate's high-density adhesive filler properties which provided substantial strength and stiffness qualities. As expected, laminate $\mathrm{L}_{\mathrm{B} 0}$ had the lowest overall performance because its polymer matrix composition did not have any filler; and therefore, lack in overall strength. Laminate $\mathrm{HD}_{30}$ had the best performance of the limestone filler laminates. It exhibited a corresponding maximum load and displacement of $645 \mathrm{lbf}$ and 0.7476 in respectively. Although both laminates $\mathrm{HD}_{30}$ and $\mathrm{L}_{30}$ had similar results, laminate $\mathrm{HD}_{30}$ still managed to experience better performance with an approximate load difference of $23 \mathrm{lbf}$. Therefore, although test specimen $\mathrm{HD}_{30}$ had a better overall performance, the production cost savings of limestone filler, makes it a more economical reinforcing filler option for creating laminated manhole covers. 


\section{ACKNOWLEDGEMENTS}

I want to first thank my thesis advisor, Dr. Faysal Kolkailah, and my professor, Dr. Eltahry Elghandour for providing me with opportunity to work on such exciting project; Dr. Daniel Biezad for supporting me and being part of my thesis defense committee; and Dr. Mitra for his suggestions and advice during the analytical and numerical phases of my project. I am grateful for their understanding, support, and dedicated assistance at all stages of this thesis investigation.

Thanks to all my friends and family relatives who supported and believed in me from the beginning of my career. It's immeasurable how impactful it is to have the support of great friends and family relatives.

I would also like to give thanks to my family. Without their love, guidance, and support, I would not be anywhere near where I am today. Thanks to my father and mother who inspired and motivated me to achieve my dreams and most importantly, who were there during the prosperous and difficult times of my career. Also, thanks to my sisters who always believed in their big brother; and my beloved wife Marian for her patience and support throughout this long process of my thesis.

In addition, I would also like to thank Brady Mitchell for initializing this thesis investigation and for designing the solid models of the Cal Poly manhole cover and press mold. I would also like to thank Michelle Griffith for her generosity and kindness in assisting me in the mold making process. Public Works of San Luis Obispo for providing me the Christy H-8 support fixture for my test specimens. Stephen Hausler for his talent and experience in creating the mold plugs using the CNC Mill tool machine; Nathan Servillo for his time in explaining me the benefits of LFM's fiberglass products; Horacio Heredia and Wilson Wong for their assistance during bending testing, and Walter Zuluaga for his encouragement and persuasion to continue my thesis; and Hans Lambrecht for his assistance, participation, and patience during the completion of my thesis.

Finally, I most importantly thank God for giving me the opportunity to pursue and fulfill my professional career. 


\section{TABLE OF CONTENTS}

LIST OF TABLES. XII

LIST OF FIGURES. XV

LIST OF SYMBOLS XXIII

1 INTRODUCTION. . .1

1.1 Motivation .................................................................................................................................................................

1.1.1 Problems and Rehabilitation Methods for Common Manhole …........................................................

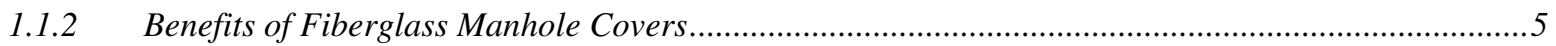

1.1.3 Standard Testing Methods for Fiberglass Manholes .......................................................................

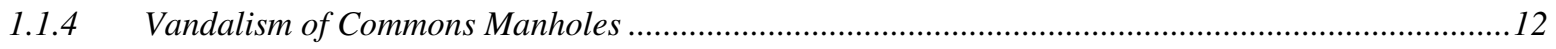

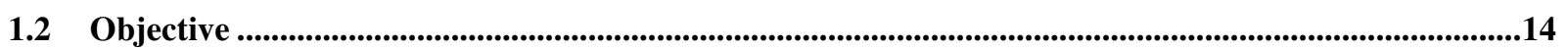

$1.3 \quad$ Literature Review..............................................................................................................................................15

1.3.1 Composite Materials and Applications...................................................................................... 15

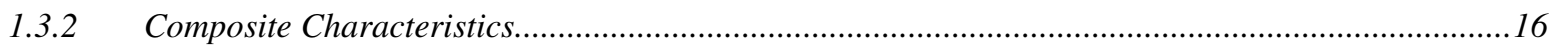

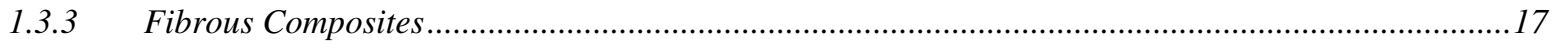

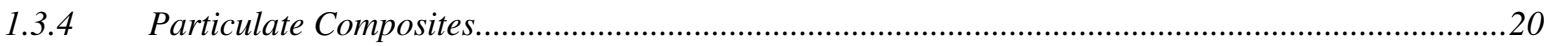

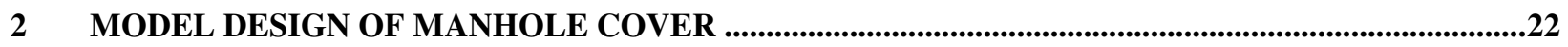

2.1 Design Considerations for Cal Poly Manhole Cover...........................................................................................22

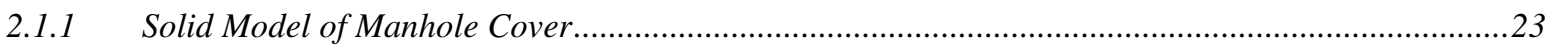

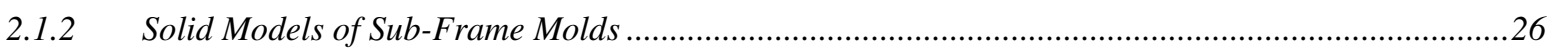

2.4 Design Considerations for Press Mold .................................................................................................................27

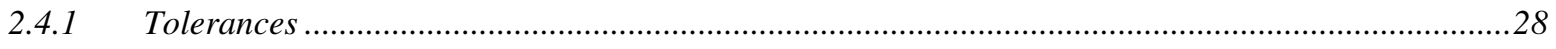

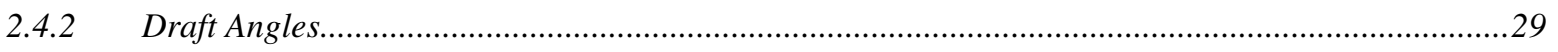

2.5 Material Considerations for Making Press Mold ..................................................................................................30

3 MANUFACTURING PROCESS OF MANHOLE COVER MOLDS .........................................................32

3.1 Making Plugs Using CNC Mill Machine ...................................................................................................................32 

4.3 Fiberglass Laminates

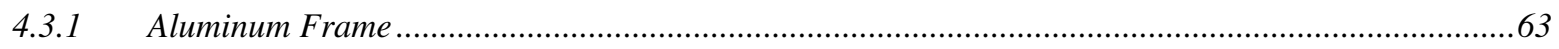

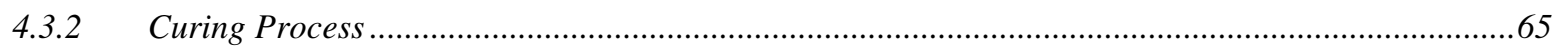

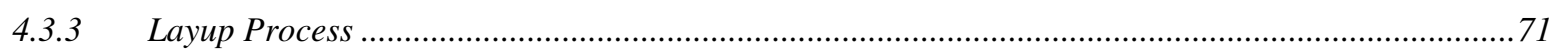

4.4 Fiberglass Manhole Cover Plates.............................................................................................................................74

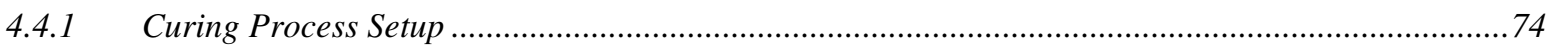

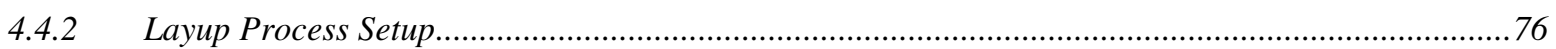

4.5 Thick-Resin Fiberglass Manhole Covers...............................................................................................................82

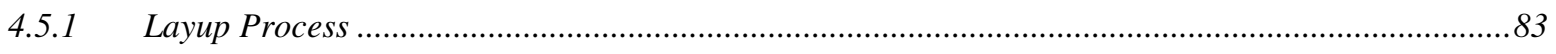

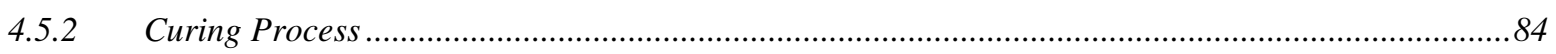

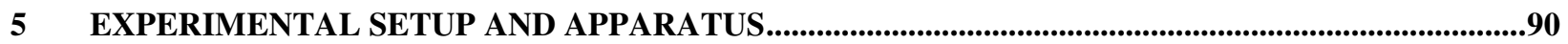

5.1 Weight Fraction Testing ..................................................................................................................................90

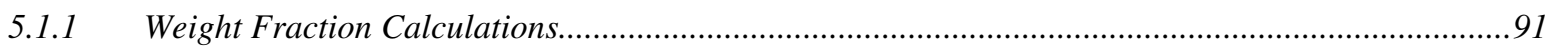

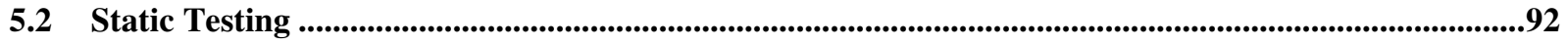

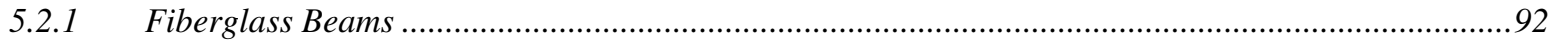

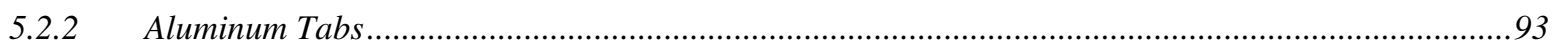

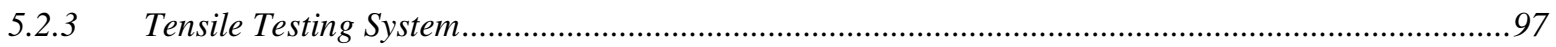

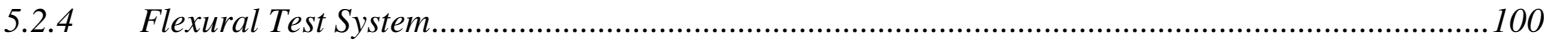

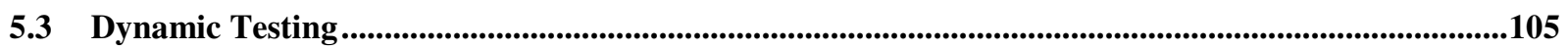

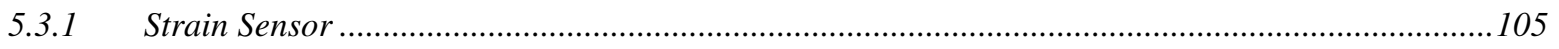

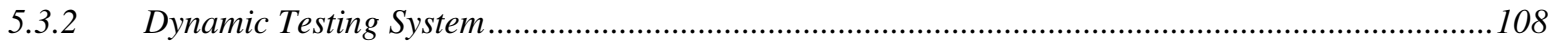

6 RESULTS AND DISCUSSION OF EXPERIMENTAL ANALYSIS................................................113

6.1 Volume Fraction Analysis..................................................................................................................................113

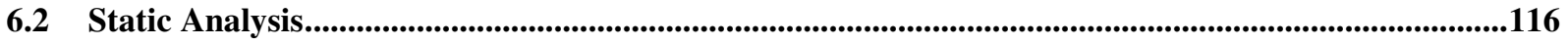

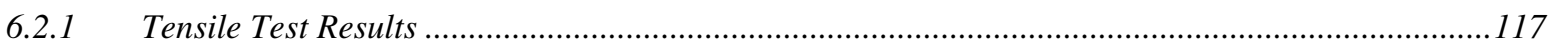

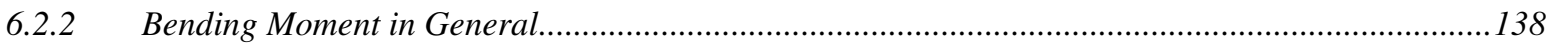

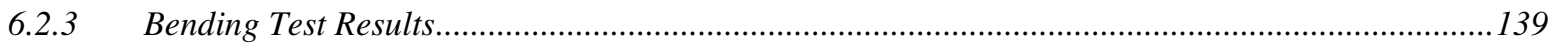

6.2.4 Comparison of Bending Test Results ..................................................................................150

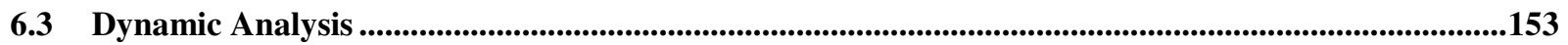




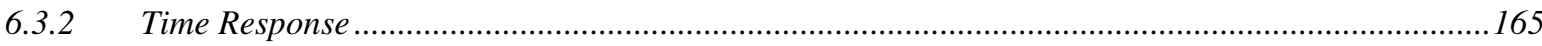

7.1 Finite Element Analysis

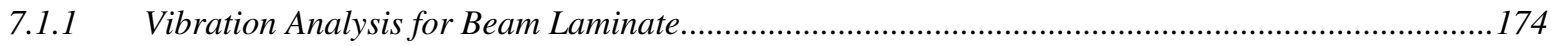

7.1.2 Bending Analysis for Manhole Cover Plate........................................................................... 185

$8 \quad$ RESULTS AND DISCUSSION OF ANALYTICAL ANALYSIS ..................................................196

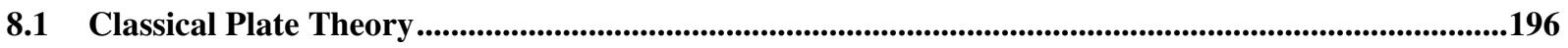

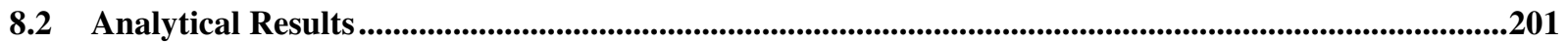

9 COMPARISON OF STATIC AND DYNAMIC RESULTS .............................................................202

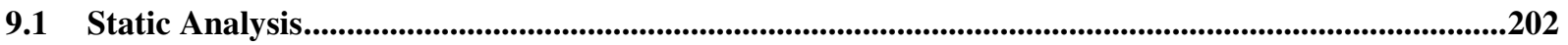

9.1.1 Comparison of Elastic and Flexural Modulus......................................................................202

9.1.2 Comparison of Bending Load and Maximum Deflection..........................................................203

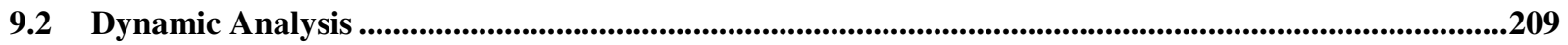

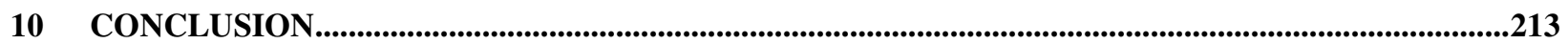

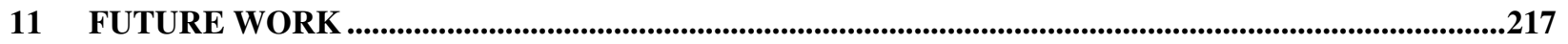

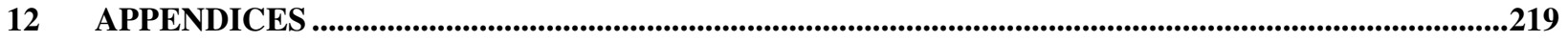

Appendix A: Static Tensile Test Settings for Instron Merlin Software .......................................................219

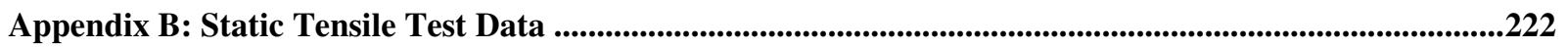

Appendix C: Dynamic Test Procedures for LabView ...............................................................................232

Appendix D: Material Characteristics of Glass Fiber ...................................................................................237

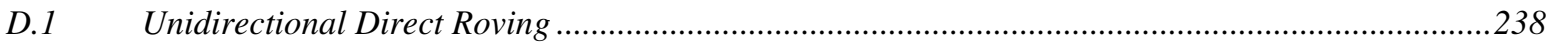

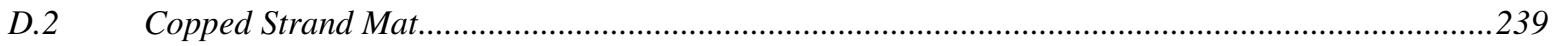

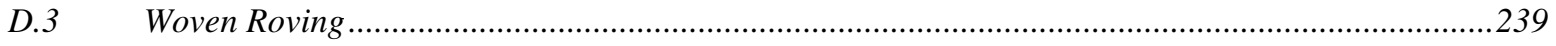

Appendix E: Composite Matrices in General............................................................................................240

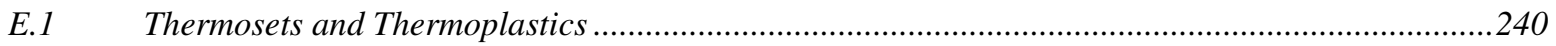

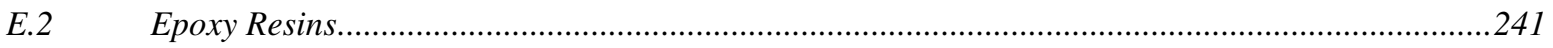




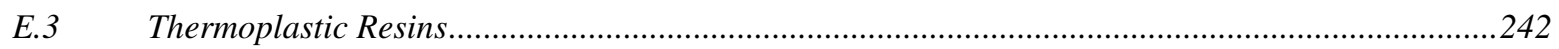

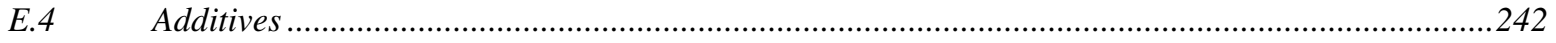

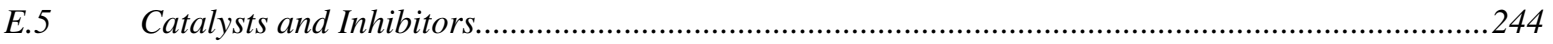

Appendix F: Inorgranic Fillers in General .................................................................................................245

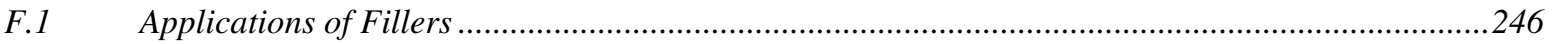

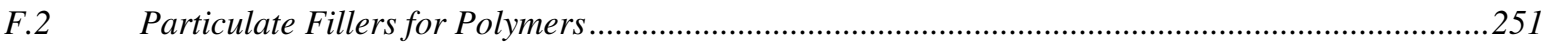

Appendix G: Material Charactersitics of Limestone...............................................................................253

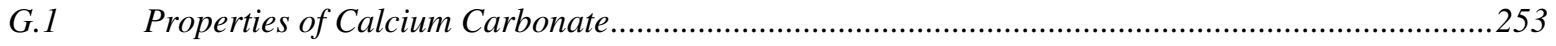

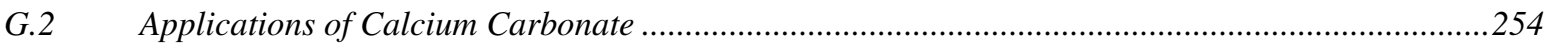

Appendix H: Initial Design Consideration for Bending Test Apparatus ..................................................255

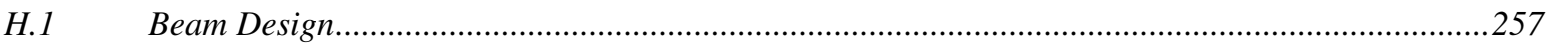

Appendix I: Supporting Static Analysis for Thin-Laminated Manhole Cover Plates ...................................259

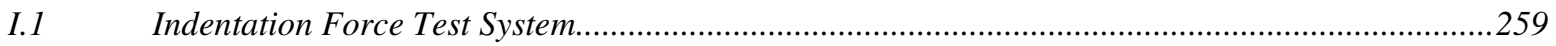

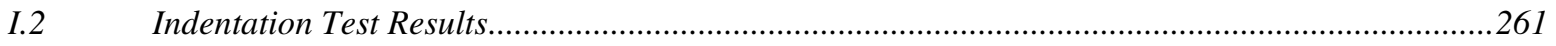

Appendix J: Supporting Static Analysis for Thick-Resin Laminated Manhole Cover Specimens...............271

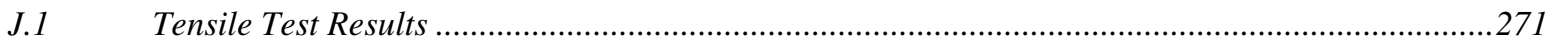

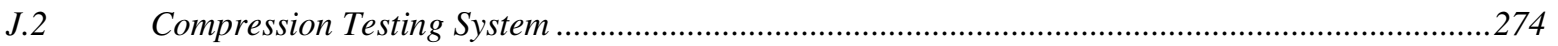

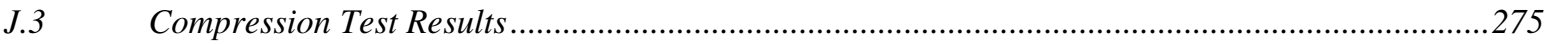

13 REFERENCES 284 


\section{LIST OF TABLES}

Table 1.1: Suggested Manhole Inspection Frequency. ...................................................................... 3

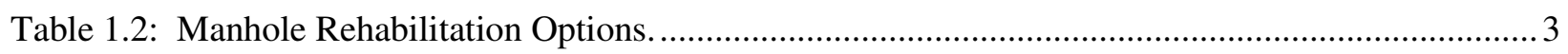

Table 1.3: Present Worth Cost of Typical Manhole Rehabilitation Method. ........................................... 4

Table 1.4: Cost Summary of Fiberglass and Iron Cast Manhole Covers................................................. 7

Table 1.5: ASTM Loading Rate Requirements for FRP Manholes................................................... 10

Table 1.6: ASTM D-3753 Standards for Limestone Filler. ............................................................... 11

Table 1.7: ASTM Material Properties Requirements for FRP Manholes................................................ 12

Table 2.1: Comparison of Different Materials Used for Mold Making................................................. 31

Table 3.1: Summary of CNC Mill Operations and Tool Cutter Sizes .................................................... 35

Table 3.2 : Specification Chart for Different Mold-Making Materials................................................... 39

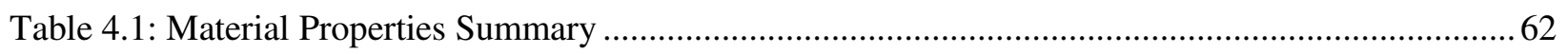

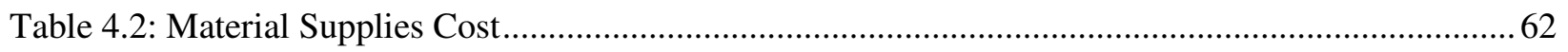

Table 4.2: Summary of Total Load Used for Curing Process of Fiberglass Plates...................................6 68

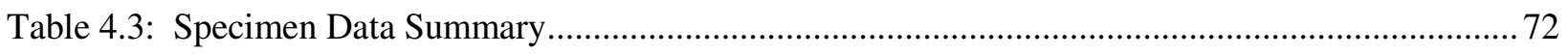

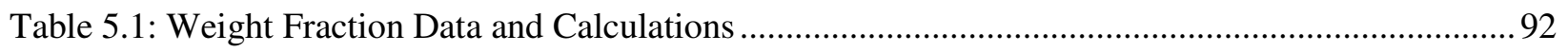

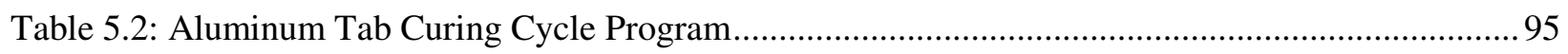

Table 6.1: Mechanical Properties of Matrix and Fiber ...................................................................... 115

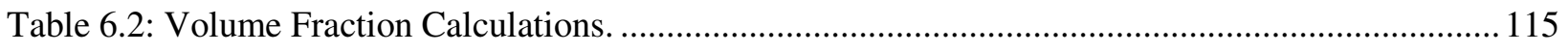

Table 6.3: Dimension Summary of Fiberglass Laminated Beams ...................................................... 118

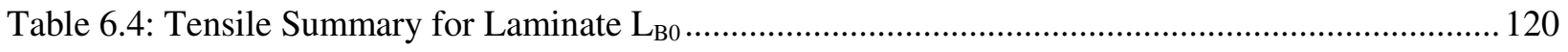

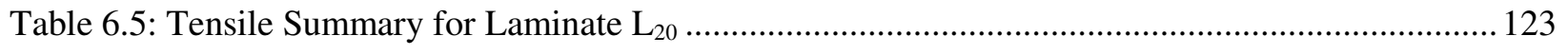

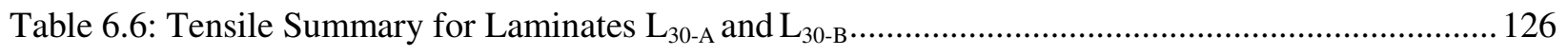

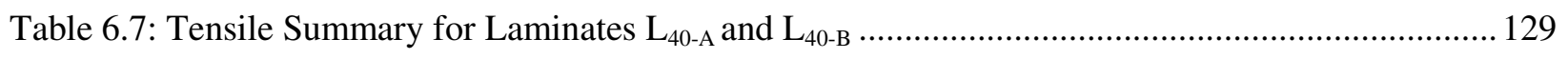

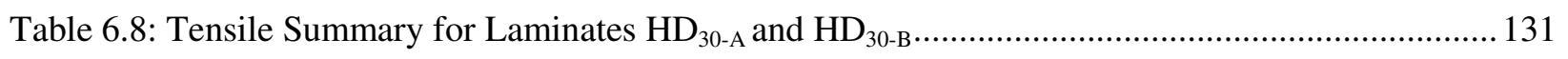

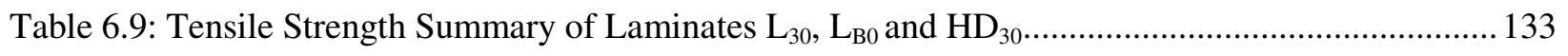


Table 6.10: Experimental Tensile Summary of All Laminated Beams. 133

Table 6.11: Tensile Testing Percent Difference Summary. 134

Table 6.12: Dimension Summary of Fiberglass Laminated Manhole Cover Specimens. 141

Table 6.13: Material Properties for All Plates Under Bending Loads ..... 151

Table 6.14: Summary of Maximum Deflections due to Bending Loads 152

Table 6.15: Natural Frequency and Amplitude Response for Composite $\mathrm{L}_{20}$. 155

Table 6.16: Natural Frequency and Amplitude Response for Composite $\mathrm{L}_{30}$. 156

Table 6.17: Natural Frequency and Amplitude Response for Composite $\mathrm{L}_{40}$. 157

Table 6.18: Frequency Extraction Analysis Comparison with Limestone Filler. 159

Table 6.19: Natural Frequency and Amplitude Response for Composite $\mathrm{HD}_{30}$ 160

Table 6.20: Modal Analysis Comparison with Limestone Filler 162

Table 6.21: Natural Frequency and Amplitude Response for Composite $\mathrm{L}_{\mathrm{B} 0}$ 163

Table 6.22: Different Bending Loading Comparison for Laminated Beams 165

Table 7.1: Dimensions Used for Composite Beams Dynamic Simulation 176

Table 7.2: Material Properties for Laminate $\mathrm{L}_{20}$ 179

Table 7.3: Natural Frequency for Laminate $\mathrm{L}_{20}$ 182

Table 7.4: Material Properties for Laminate $\mathrm{L}_{30}$ 182

Table 7.5: Natural Frequency for Laminate $\mathrm{L}_{30} \ldots$ 183

Table 7.6: Material Properties for Laminate $\mathrm{L}_{40}$ 183

Table 7.8: Natural Frequency for Laminate $\mathrm{L}_{40}$....... 183

Table 7.9: Material Properties for Laminate $\mathrm{HD}_{30}$ 183

Table 7.10: Natural Frequency for Laminate $\mathrm{HD}_{30}$ 184

Table 7.11: Material Properties for Laminate $\mathrm{L}_{\mathrm{B} 0}$ 184

Table 7.12: Natural Frequency for Laminate $\mathrm{L}_{\mathrm{B} 0}$ 184

Table 7.13: Frequency Comparison for Isotropic Laminated Beams 185

Table 7.14: Dimensions Used for Composite Plate Bending Simulation 186

Table 7.15: Flexural Summary for Laminate $L_{20}$. 192 


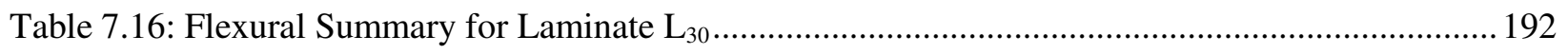

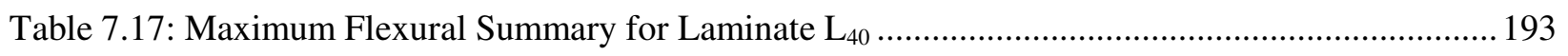

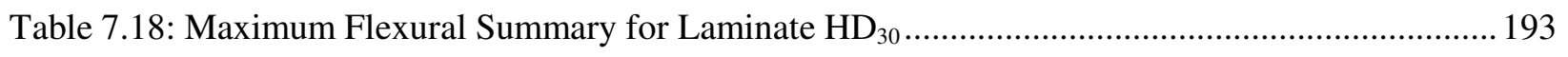

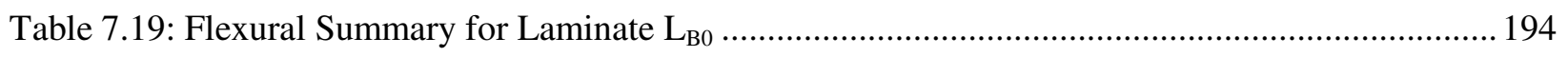

Table 7.20: Comparison of Maximum Deflection for Isotropic Plates at Different Loads...................... 194

Table 8.1: Delfection Summary for Isotropic Plates under Bending Loading ......................................201

Table 9.1: Material Property Summary for Isotropic Beams and Plates..............................................202

Table 9.2: Maximum Deflection Summary due to Bending Loads .................................................... 204

Table 9.3: Percent Error Summary for Isotropic Plate Subjected to Bending Loads.............................. 206

Table 9.4: Different Bending Loading Comparison for Laminated Beams ......................................... 210

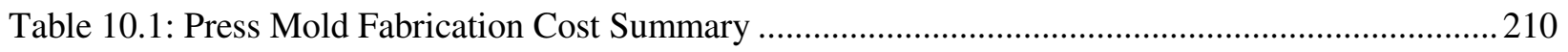




\section{LIST OF FIGURES}

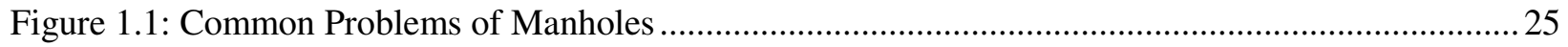

Figure 1.2: Fiberglass Reinforced Polyester Manhole Wetwells and Covers ..........................................2 27

Figure 1.3: A Single Piece Unit of Fiberglass Reinforced Polyester (FRP) Manhole..............................28

Figure 1.4: Design Requirements of Standardized Fiberglass Manhole (LFM)..................................... 32

Figure 1.5: A Manhole Cover Stolen from the Streets of Philadelphia. ..................................................... 36

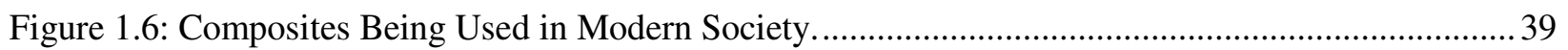

Figure 1.7: Short Fiber and Long Fiber Reinforced Composites...................................................... 40

Figure 1.8: Fiberglass Reinforced Composites Being Used in Modern Society..................................... 41

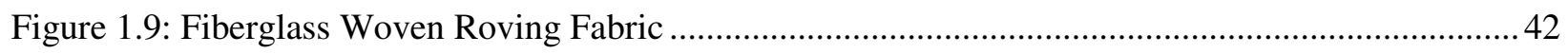

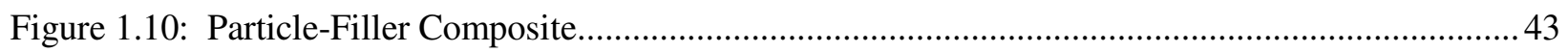

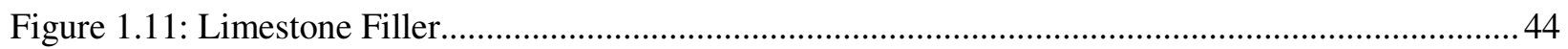

Figure 2 1: Basic Schematic of Manhole Cover with Sub-Frame ....................................................... 45

Figure 2.2: Side View of Most Common Styles for Manhole Covers .................................................... 46

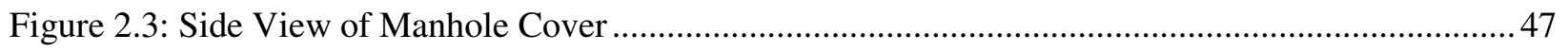

Figure 2.4: Top and Bottom Views of Manhole Cover ............................................................................ 47

Figure 2.5: Enlarged Views of Engraved Lettering and Mustang Logo .............................................. 48

Figure 2.6: Spider Web Structure of Manhole Cover .............................................................................. 48

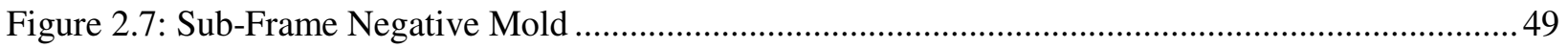

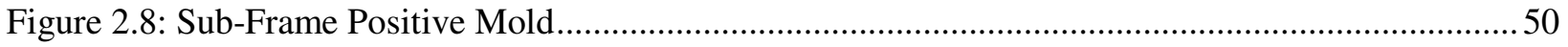

Figure 2.9: Side View of Press Mold with Test Specimen ....................................................................51

Figure 2.10: Schematic of Mold's Corner Design: a) Right Angle b) Draft Angle .................................52

Figure 3.1: CNC Mill Machine Used to Create Manhole Cover Plugs.....................................................55

Figure 3.2: Front Sliding Doors of CNC Mill Machine's XYZ-Axis .....................................................56

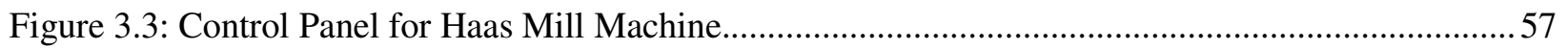

Figure 3.4: Umbrella-Style Tool Changer with Cutting Tools .............................................................58 
Figure 3.5: Measuring and Securing High-Density Foam for CNC Operations .59

Figure 3.6: Centering Operation .59

Figure 3.7: Removing High-Density Foam Debris with Air Pressure Gun 60

Figure 3.8: Sanding Manhole Cover Plug..... 60

Figure 3.9: Customized Cal Poly Manhole Cover Plug.... 61

Figure 3.10: Urethane Liquid Rubber Gallon Kit 62

Figure 3.11: Man O’ War Spar Oil-Based and Water-Based Varnishes. 63

Figure 3.12: Testing for Side Effects of Sealants on a Piece of High-Density Foam. 63

Figure 3.13: Oil-Based Varnish Sealant and Plug 64

Figure 3.14: Removing Excess Oil-Based Varnish from Plug with Paint Brush. 65

Figure 3.15: Plug Inside Wooden Frame's Retaining Walls Used to Create Negative Mold..... 65

Figure 3.16: Laguna's Modeling Clay .66

Figure 3.17: Clay along Corner's of Wooden Frame to Prevent Resin Leakage .66

Figure 3.18: Smooth-On Universal Mold Release Agent 67

Figure 3.19: Formulation of Air Bubbles within Urethane Resins 68

Figure 3.20: Gently Stirring and Mixing Urethane Compound to Minimize Air Bubbles 69

Figure 3.21: Pouring Mixed Urethane Resin into Wooden Frame .70

Figure 3.22: Urethane Liquid Rubber Solution Covering Plug 70

Figure 3.23: Using Rubber Mallets to Remove Air Bubbles from Mold. .71

Figure 3.24: Removing Wooden Frame's Retaining Walls from the Cured Mold....................................72

Figure 3.25: Bottom Side of Cured Rubber Mold and Plug ….............................................................. 72

Figure 3.26: Screws Inserted Backside for Separating Plug from Rubber Mold ..................................... 73

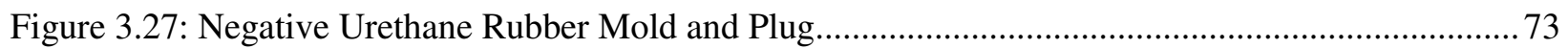

Figure 3.28: Negative Rubber Mold of Manhole Cover ........................................................................ 74

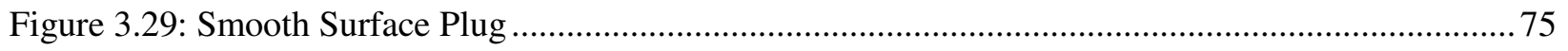

Figure 3.30: Alignment of Smooth Surface Plug with Wooden Frame ................................................... 75

Figure 3.31: Weights Placed on Frame's Corners to Prevent Slippage .................................................... 76 
Figure 3.32: Green Bagging Film and Non-Porous Release Film .76

Figure 3.33: Smooth Surface Plug Immersed in Urethane Liquid Rubber Solution.................................78

Figure 3.34: Smooth Surface Plug inside Negative Mold after Cured Process. ....................................... 78

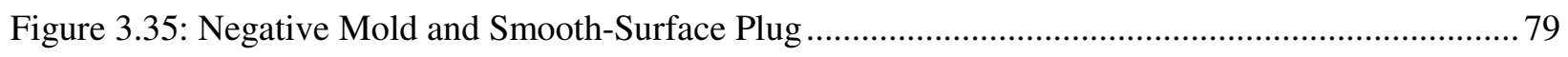

Figure 3.36: Negative Smooth-Surface Mold with Retaining Walls ..................................................... 79

Figure 3.37: Urethane Liquid Rubber left for Overnight Curing ........................................................ 81

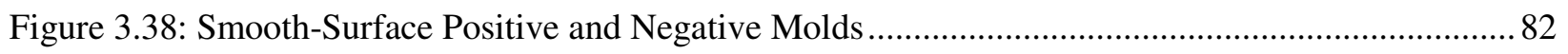

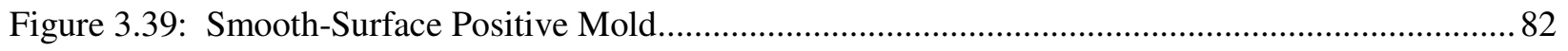

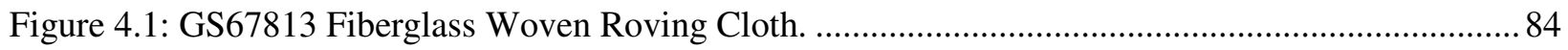

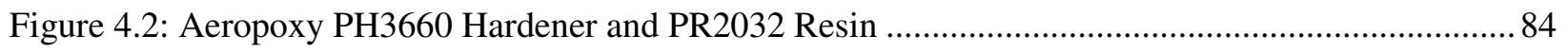

Figure 4.3: High-Density Adhesive and Calcium Carbonate Filler ..................................................... 85

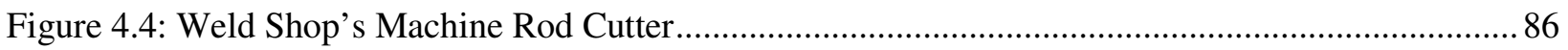

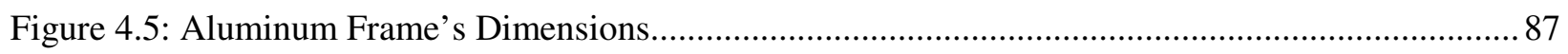

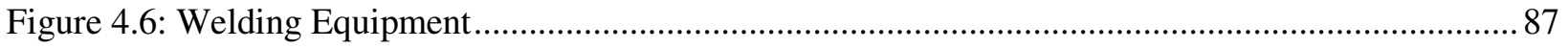

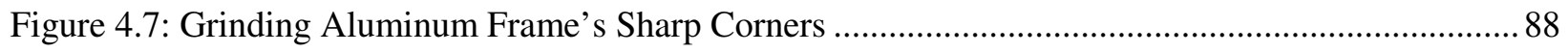

Figure 4.8: Final Product of Aluminum Frame after Sanding .......................................................... 88

Figure 4.9: Sealing Aluminum Frame with Black-Thick Tape and Release Film ................................. 89

Figure 4.10: Vacuum Bagging Layup with Aluminum Frame for Laminate........................................90

Figure 4.11: Vacuum Bag Lay-Up Arrangement............................................................................ 91

Figure 4.12: Weight and Aluminum Plate used during Curing Process ................................................92

Figure 4.13: Four Compressors Used for Making Fiberglass Laminates ............................................. 93

Figure 4.14: Overall Setup of Vacuum Bagging on Metal-Vacuum Table ............................................93

Figure 4.15: Top View of Vacuum Bag and Compressor Arrangement................................................. 94

Figure 4.16: Digital Scale Used to Weight Fiberglass Sheets ............................................................. 95

Figure 4.17: Applying Epoxy and Filler on Fiberglass Laminates ..................................................... 96

Figure 4.18: Fiberglass Laminated Plate After Curing ...................................................................... 97

Figure 4.19: Initial Vacuum Bag Setup and Female Mold's Cavity ....................................................98 
Figure 4.20:Final Vacuum Bag Setup for Manhole Cover Specimen.

Figure 4.21: Layup Process for Making Manhole Cover Specimens 100

Figure 4.22: Positive Mold Attached with Negative Mold 101

Figure 4.23: Manhole Cover Press Mold Setup 101

Figure 4.24: Manhole Cover Laminate After Curing 102

Figure 4.25: Removing Manhole Cover Laminate's Edges with Tile Saw 102

Figure 4.26: Final Product of Fiberglass Manhole Cover...... 103

Figure 4.27: Cavity Created by Male Mold 103

Figure 4.28: Manhole Cover Flat Specimen Compared with Meter Manhole Cover 104

Figure 4.29: Fiberglass-Filler Laminated Plate on top of Manhole 104

Figure 4.30: Wooden Rods Used to Create Thicker Resin/Filler Manhole Covers... 105

Figure 4.31: Nine-Layered Sheets of Fiberglass Fabric 105

Figure 4.32: The Fiberglass Wet Layup Process ...... 107

Figure 4.33: Blue Peel-Ply with White Breather on Top of Female Mold 107

Figure 4.34: Resin Trap Apparatus 108

Figure 4.35: Vacuum Bag Setup 109

Figure 4.36: Vacuum Bag With and Without Upper Aluminum Plate 109

Figure 4.37: The Overall Curing Setup 110

Figure 4.38: Cured Thick Resin-Filler Manhole Cover Plate 110

Figure 4.39: Sanding Fiberglass Manhole Cover Edges

Figure 4.40: Final Product of Thick Resin-Filler Manhole Cover Specimen ... 111

Figure 4.41: Test Specimen Defects from Improper Curing Process. 112

Figure 5.1: Fume Hood and Ceramic Furnace. 113

Figure 5.2: Fiberglass Square Before and After Cooking. 114

Figure 5.3: Thin Laminated Beams Used for Tensile Testing..... 115

Figure 5.4: Tile Saw Used to Cut Beam Specimens 116

Figure 5.5: Pre-Preparation Elements Used to Attach Aluminum Tabs 117 
Figure 5.6: Tetrahedron Composite Press Oven

Figure 5.7: Aluminum Tab Curing Cycle ......

Figure 5.8: Aluminum Tabs Attached to Composite Beam Specimens.

Figure 5.9: Static Testing System

Figure 5.10: Instron Extensometer.

Figure 5.11: Tensile Testing Before Fracture 122

Figure 5.12: Beam Specimens After Tensile Testing.... 123

Figure 5.13: Christy H-8 Specimen Support Fixture 124

Figure 5.14: Bending Test Method Using the Christy Support Fixture. 125

Figure 5.15: Data Acquisition and Actuator Control System for MTS 322 Model. 126

Figure 5.16: Head Piece Fixture Used for Bending Tests 126

Figure 5.17: Tire Cross-Section Used to Distribute Axial Load Uniformly on Specimens 127

Figure 5.18: Final Bending Apparatus Setup for Testing Manhole Cover Specimens. 128

Figure 5.19: Strain Gage Sensor 129

Figure 5.20: M-Bond 200 Adhesive and 200 Catalyst-B 130

Figure 5.21: Soldering Apparatus 130

Figure 5.22: Laminated Beam Specimens Before Dynamic Testing 131

Figure 5.23: Magnetic Shaker 132

Figure 5.24: Aluminum Clamp Configuration 132

Figure 5.25: Clamp Dimensions 133

Figure 5.26: Laminated Beam Specimen Attached to Electronic Shaker 133

Figure 5.27: Dynamic Testing Software Program 134

Figure 5.28: National Instruments SCB-100. 135

Figure 5.29: Dynamic Testing System. 135

Figure 6.1: Hexagonal Fibers Alignment 136

Figure 6.2: Unit-Cell Triangles. 136

Figure 6.3: Rectangular Array Fiber Alignment 137 
Figure 6.4: Tensile Stress-Strain Curves for Various Fibers

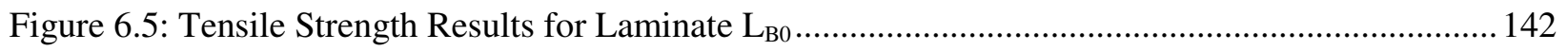

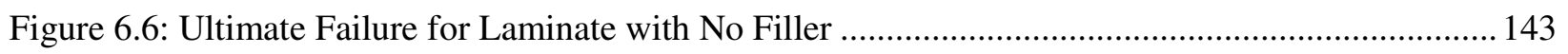

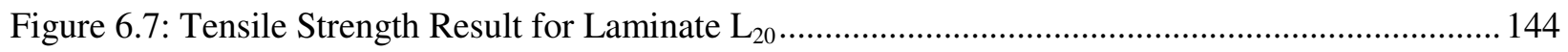

Figure 6.8: Ultimate Failure for Laminate with 20 grams of Limestone Filler .................................... 145

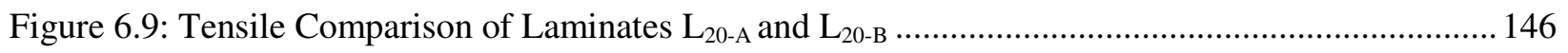

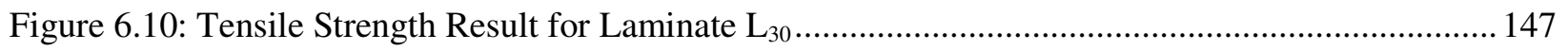

Figure 6.11: Ultimate Failure for Laminates with 30 grams of Limestone Filler................................. 148

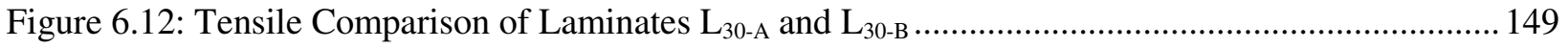

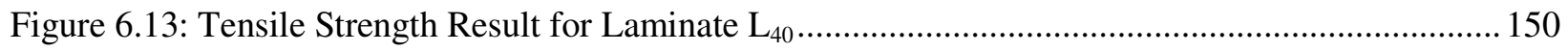

Figure 6.14: Ultimate Failure for Laminates with 40 grams of Limestone Filler .................................. 151

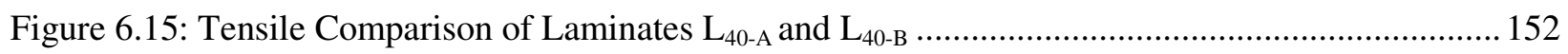

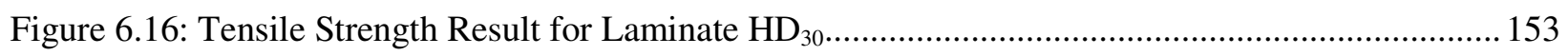

Figure 6.17: Ultimate Failure for Laminates with 30 grams of High-Density Filler ............................. 154

Figure 6.18: Tensile Strength Result Comparison between Laminates $\mathrm{L}_{30}, \mathrm{~L}_{\mathrm{B} 0}$ and $\mathrm{HD}_{30} \ldots \ldots \ldots \ldots \ldots \ldots \ldots . \ldots \ldots$

Figure 6.19: Brittle Failure with Fiber Pullout due to Longitudinal Tensile Loading ............................ 158

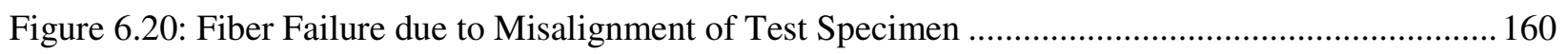

Figure 6.21: Schematic of Compressive and Tensile Bending Stresses on Beam .................................. 162

Figure 6.22: Variations of Normal Stress and Shear Stress for a Rectangular Cross Section .................. 163

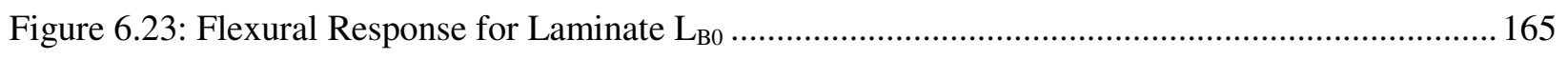

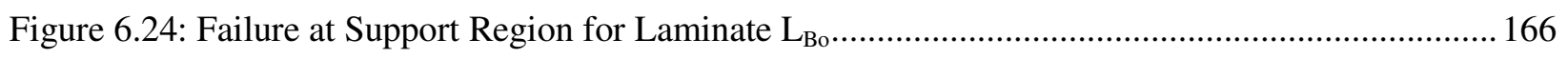

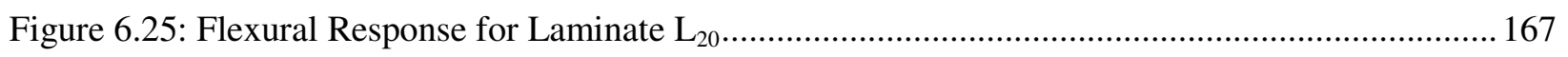

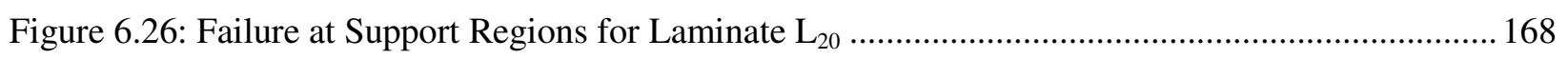

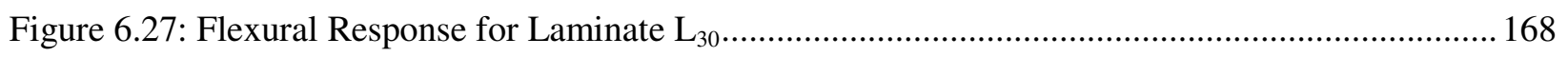

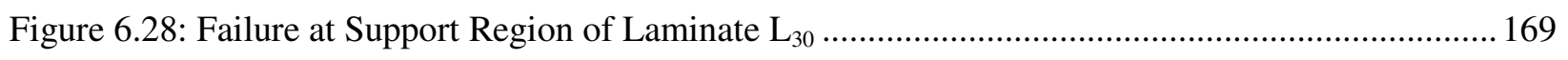

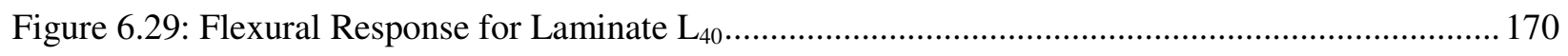

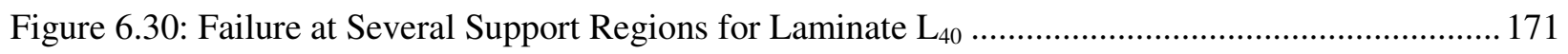


Figure 6.31: Flexural Response for Laminate $\mathrm{HD}_{30}$ 171

Figure 6.32: Failure Result for Laminate $\mathrm{HD}_{30}$ 172

Figure 6.33: Flexural Response Comparison for Laminates with Limestone Filler 173

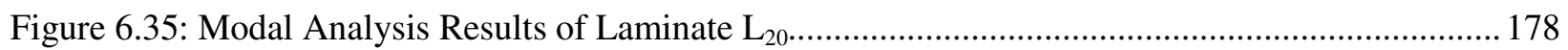

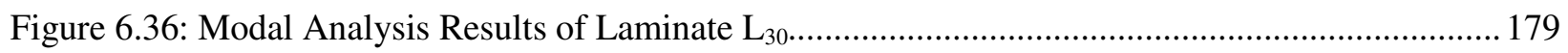

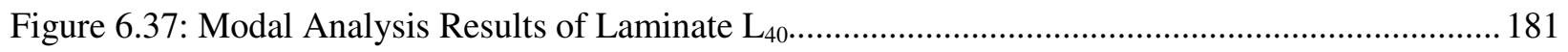

Figure 6.38: Modal Analysis Comparison of Laminates with Limestone Filler.................................... 182

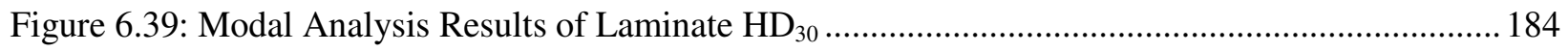

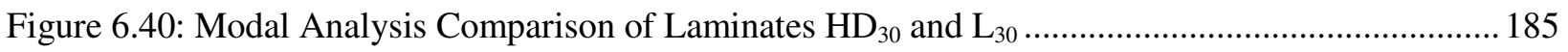

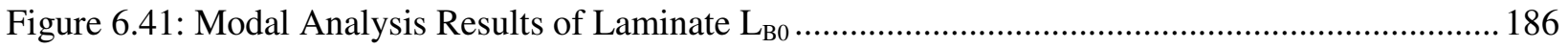

Figure 6.42: Frequency Analysis Summary of All Laminated Beams ................................................. 189

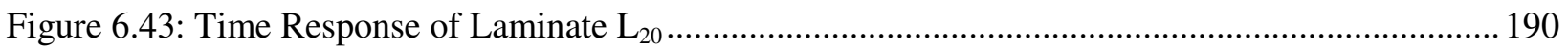

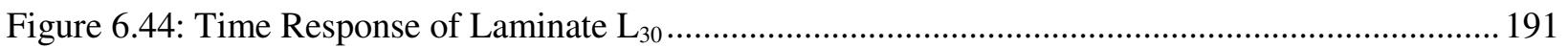

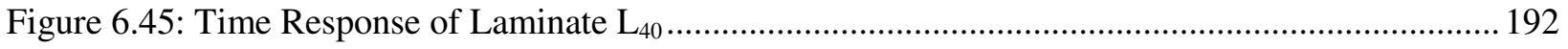

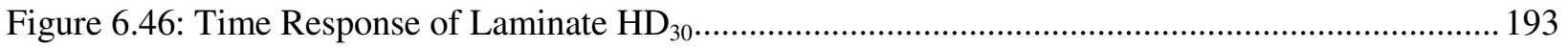

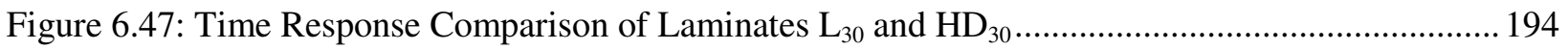

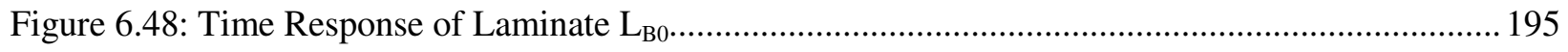

Figure 6.49: Time Response Comparison of All Fiberglass Laminates ............................................... 195

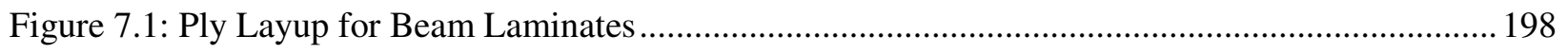

Figure 7.2: Geometry Used for Composite Beam Dynamic Simulation................................................ 199

Figure 7.3: Finite Element Mesh for Laminated Beam.................................................................... 200

Figure 7.4: Top View of Fixed Boundary Condition at Beam's Edge ................................................. 201

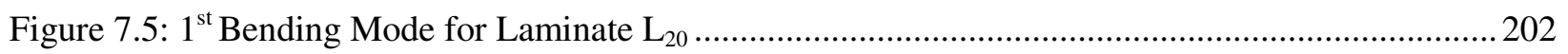

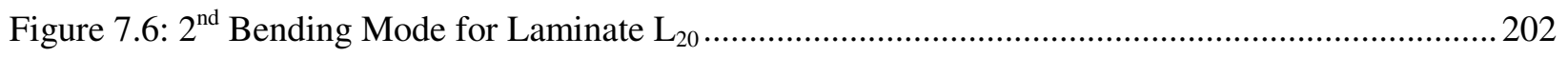

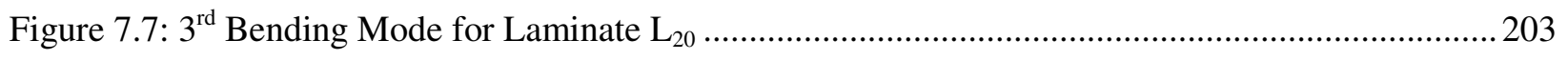

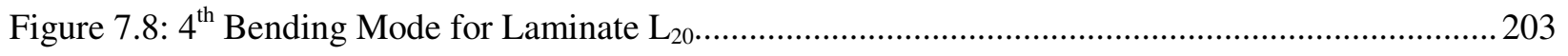

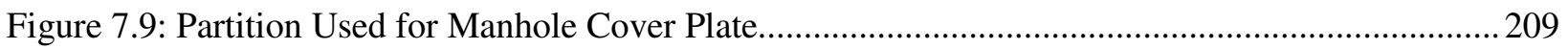


Figure 7.10: Detail of Finite Element Mesh Applied to Fiberglass Plate

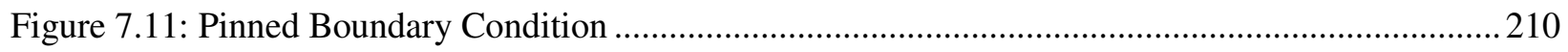

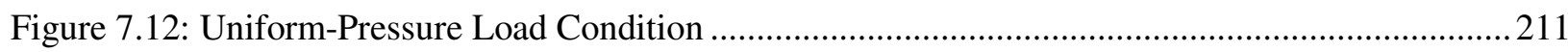

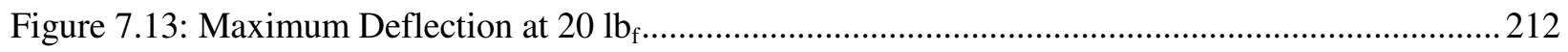

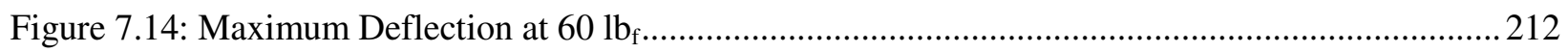

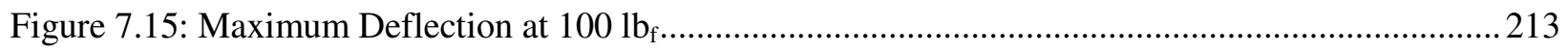

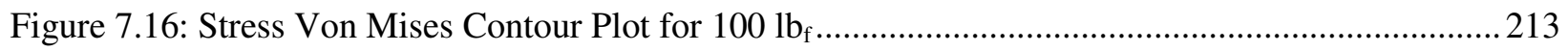

Figure 8.1: Plate Element Subjected to Bending, Twisting and Transverse Loads ...............................218

Figure 9.1: Simply Supported Plate inside Sub-Frame Support Fixture ...............................................2229

Figure 9.2: Simply Constrained Plate Subjected to Axial Loading …................................................230 


\section{LIST OF SYMBOLS}

Symbol

A

$\mathrm{A}_{\mathrm{c}}$

$\mathrm{A}^{*}$

b

B

$\mathrm{B}_{0}$

$\mathrm{B}^{*}$

CG

$\mathrm{C}^{*}$

D*

E

Eerror

$\mathrm{E}_{\text {exp }}$

$\mathrm{E}_{\text {fchord }}$

$\mathrm{E}_{\text {theor }}$

F

$\mathrm{F}_{\mathrm{s}}$

$\mathrm{h}$

$\mathrm{H}$

$\mathrm{HD}_{30}$

$\mathrm{L}$

$\mathrm{L}_{20}$

$\mathrm{L}_{30}$

$\mathrm{L}_{40}$

$\mathrm{m}$

M

r

$\mathrm{R}$
Description

$\underline{\text { Unit }}$

Gravitational Acceleration $\left(32.174 \mathrm{ft} / \mathrm{s}^{2}\right)$

$\mathrm{ft} / \mathrm{s}^{2}$

Cross-Sectional Area

in $^{2}$

Manhole Frame Diameter

in

Specimen Width

Specimen Depth

in

No Filler (Fiberglass Only)

Frame Inside Diameter

in

Center of Gravity of Cantilever Beam

in

Drop Ring Diameter

in

Drop Ring Depth

Young's Modulus of Elasticity

in

Percent Error of Elastic Modulus

ksi

Experimental Elastic Modulus

Flexural Chord Modulus of Elasticity

Theoretical Elastic Modulus

Force (Load) Vector

$\%$

$\mathrm{ksi}$

ksi

ksi

$1 b_{\mathrm{f}}$

Shear Force

$\mathrm{lb}_{\mathrm{f}}$

Specimen Height

in

Specimen Depth

in

30 grams of Westin System 404 High-Density Filler

Beam Length or Support Span Length

in

20 grams of Limestone Filler

30 grams of Limestone Filler

40 grams of Limestone Filler

Slope of Secant of Load-Deflection Curve

Bending Moment

$\mathrm{lb}_{\mathrm{f}}$-in

Radius of Unit Cell

$\mathrm{nm}$

Radius of PVC Pipe in 


\section{Greek}

$\delta$

$\varepsilon$

E

$\rho_{\mathrm{f}}$

$\rho_{\mathrm{m}}$

$\sigma$

$\sigma_{\mathrm{c}}$

$\sigma_{\mathrm{t}}$

$\sigma_{\text {theor }}$

$\sigma_{\text {error }}$

$\sigma_{\exp }$

$\tau$

\section{Subscripts}

$\mathrm{aq}$

c

$\exp$

$\mathrm{f}$

g

1

$\mathrm{m}$

n

S

t
Thickness of Layer

Volume Fraction of the Fiber $\%$

Weight Fraction of the Composite $\%$

Weight Fraction of the Fiber \%

Mid-Span Deflection of Specimen in

Outer Surface Strain at Mid-Span of Specimen

Tensile Strain

Density of the Fiber $\quad \mathrm{g} / \mathrm{in}^{3}$

Density of the Matrix g/in

Normal Stress ksi

Compressive Normal Stress ksi

Tensile Normal Stress ksi

Theoretical Ultimate Tensile Stress ksi

Percent Error of Ultimate Tensile Stress ksi

Experimental Ultimate Tensile Stress ksi

Shear Stress ksi

Aqueous

Cross-Section or Compression

Experimental

Fiber

Gaseous

Liquid

Matrix

Number of Atoms

Solid

Tension 


\section{INTRODUCTION}

\subsection{Motivation}

Bending loads may also be expected in many of the engineering application of fiberglass reinforced composite materials, such as, stationary fiberglass manhole covers being flexed by axial loads exerted by vehicles. This application can be determined not only by the usual design parameters, but by its flexural strength properties. However, their complex material behavior makes analysis of these structures a significant challenge.

The advanced composite modeling and industry leading simulation programs make analysis of these challenging materials straight forward and allow to accurately predicting damage, failure, and delamination. This understanding is explained through a discussion of experimental and numerical methods, effect of material and testing variables from bending load results. It is also critical to have a good understanding of bending behavior of composite for safe and efficient structural designs in order to develop composites with good bending and tensile properties. In this paper the type of composites that will be focused are fiberglass/filler laminated composites being subjected to bending and dynamic loading.

\subsubsection{Problems and Rehabilitation Methods for Common Manhole}

The mechanical characteristics of fiber composites are also a great value to some applications of civil infrastructure, particularly in the replacement of iron cast manhole covers.

Manholes are the principal means of access for collection and treatment system maintenance but over short time duration, pre-cast iron, brick, and concrete manhole will deteriorate due to exposure to waste water gases such as hydrogen sulfide or experience structural degradation due to loss of ground lateral support, thus decaying concrete manholes are in constant need of costly 
repairs. The following illustration shows the different severe conditions that affect a manhole's structural integrity.

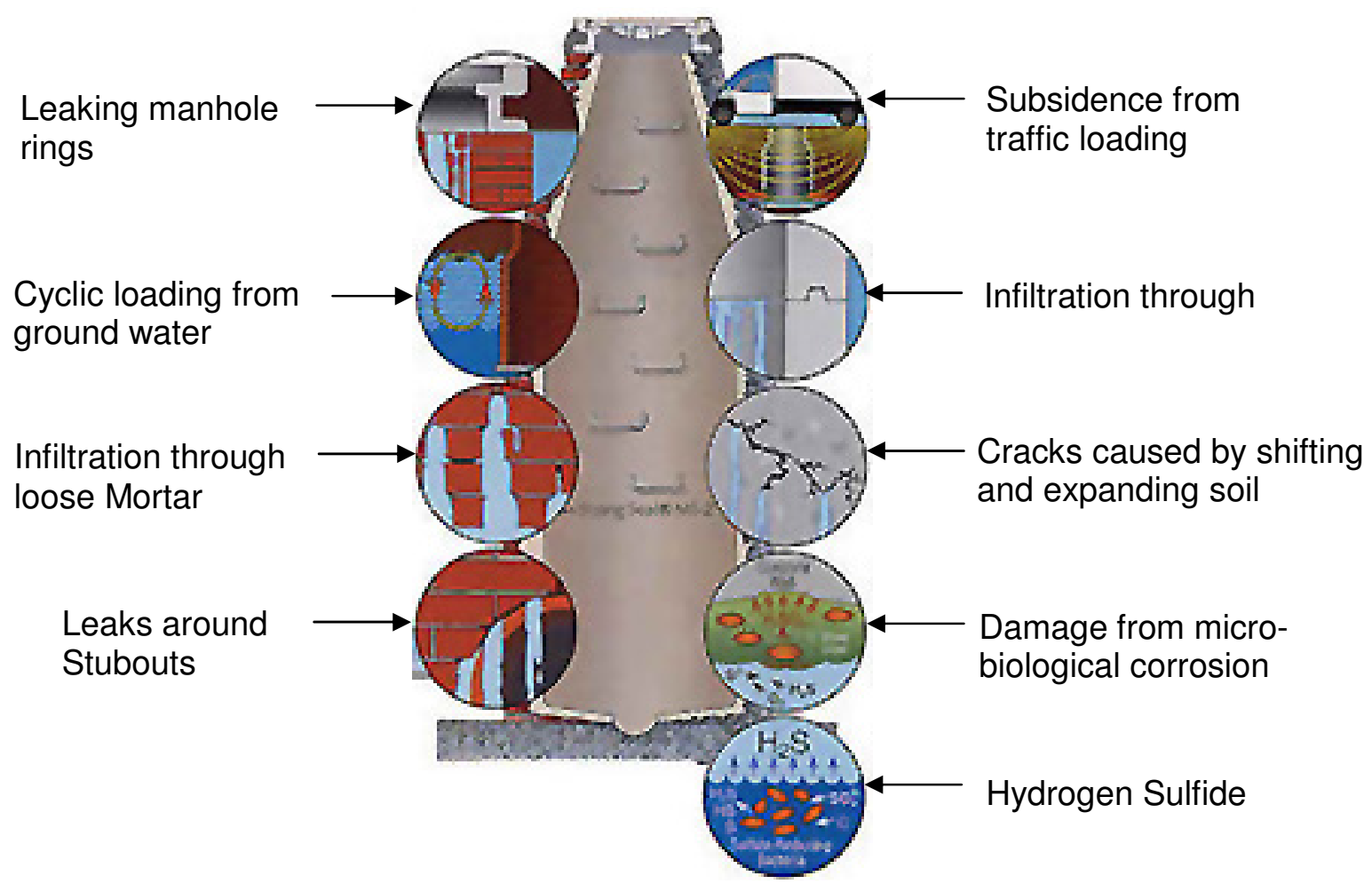

Figure 1.1: Common Problems of Manholes [23]

Manhole inspection programs can be phased or if needed, be performed in an overall program during a relatively short-time span. The frequency of inspections is service area dependent but should be longer than 10 to 15 years [23]. Table 1.1 shows a of the suggested manhole inspection frequency. 
Table 1.1: Suggested Manhole Inspection Frequency

\begin{tabular}{|c|c|}
\hline Manhole Condition & Inspection Frequency (yrs) \\
\hline General & $10-15$ maximum \\
\hline Corrosion/Other Maintenance Problems & $1-2$ \\
\hline Designated Critical Sewers & $1-3$ \\
\hline Creek/stream Locations & $1-2$ \\
\hline New/Rehabilitated Manholes & $\begin{array}{c}1 \text { then adjust appropriately } 10-25 \\
\text { Year repair life } 2-5 \\
\geq 50 \text { year repair life } 10-15\end{array}$ \\
\hline
\end{tabular}

Methods used to rehabilitate manholes are the following: chemical grouting, coating systems, structural liners, frame, cover and chimney rehabilitation. Table 1.2 shows a summary of various manhole rehabilitation options and benefits.

Table 1.2: Manhole Rehabilitation Options

\begin{tabular}{|c|c|c|}
\hline Rehabilitation Options & Principal Advantages & Principal Disadvantages \\
\hline Replace cover only & $\begin{array}{c}\text { Proper fit \& } \\
\text { Eliminates holes/cover } \\
\text { leakage }\end{array}$ & $\begin{array}{c}\text { May not seal properly w/ existing frame } \\
\text { at bearing surface }\end{array}$ \\
\hline Seal cover w/ gasket & $\begin{array}{l}\text { Eliminates inflow \& } \\
\text { Inexpensive }\end{array}$ & $\begin{array}{l}\text { Gaskets can become loose, leak, and } \\
\text { can drop it into sewer \& } \\
\text { Difficult to install properly }\end{array}$ \\
\hline Asphalt Mastic & $\begin{array}{l}\text { Eliminates inflow \& } \\
\text { Inexpensive }\end{array}$ & $\begin{array}{l}\text { Gaskets can become loose, leak, and } \\
\text { can drop it into sewer \& } \\
\text { Difficult to install properly }\end{array}$ \\
\hline $\begin{array}{l}\text { Replacement of manhole } \\
\text { frame/cover }\end{array}$ & $\begin{array}{l}\text { Improves service life \& } \\
\text { Reduces cover leakage }\end{array}$ & $\begin{array}{l}\text { Excavation required \& } \\
\text { Expensive due to pavement } \\
\text { replacement }\end{array}$ \\
\hline
\end{tabular}


Table 1.3 shows a summary of the present worth cost of typical manhole rehabilitation method. The costs and anticipated life of the rehabilitation method should be reviewed for each project considering local conditions that will have an impact on a particular item.

Table 1.3: Present Worth Cost of Typical Manhole Rehabilitation Method

\begin{tabular}{|c|c|c|c|c|}
\hline Methods & Initial Cost Range \$ & Anticipated Life (yrs) & Periods (yrs) & Present Worth \$ \\
\hline Replace cover & $120-240$ & $10-30$ & 1 & $120-500$ \\
\hline Replace frame & $415-685$ & $10-40$ & 1 & $415-685$ \\
\hline $\begin{array}{c}\text { Seal existing } \\
\text { cover }\end{array}$ & $20-50$ & 8 & 7.1 & $105-263$ \\
\hline $\begin{array}{c}\text { Seal frame/ } \\
\text { applied seal }\end{array}$ & $250-350$ & 7 & 3.33 & $1620-2505$ \\
\hline $\begin{array}{c}\text { Chemical grout } \\
\text { sealing }\end{array}$ & $540-835$ & 15 & & 25025 \\
\hline
\end{tabular}

Consequently, manhole companies such as LFM from Giddings-Texas [34] and the Hunan Timelion Composite Material Company, one of the largest manufacturers that specialize in producing fiberglass manhole covers in China [15], are currently building fiberglassreinforced polyester (FRP) manholes and covers. Fig. 1.2 shows the final products of the fiberglass reinforced manhole cover made by these companies.

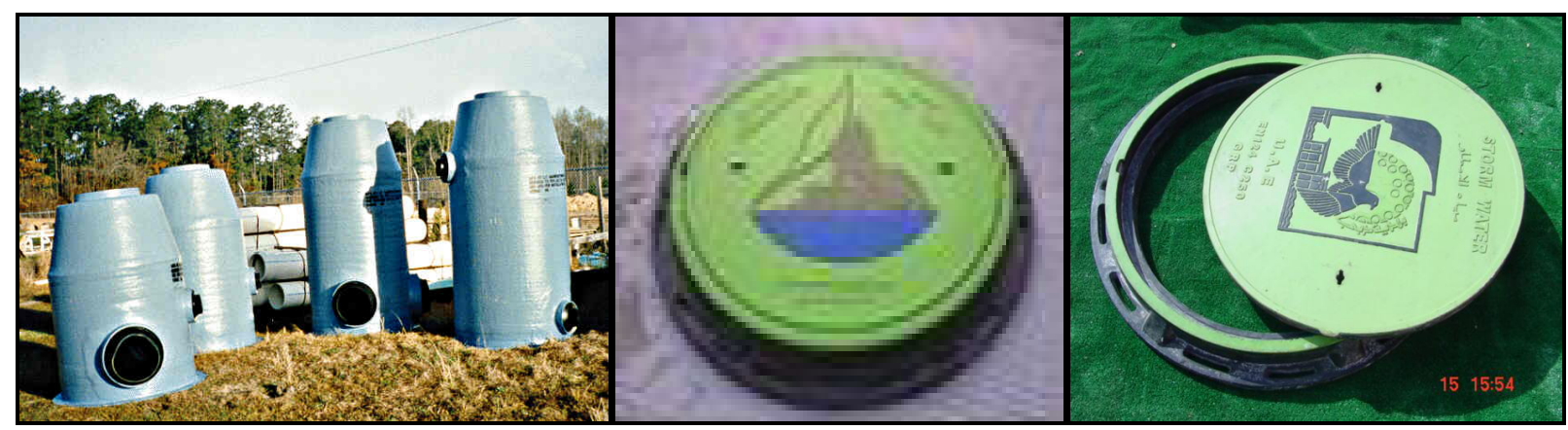

Figure 1.2: Fiberglass Reinforced Polyester Manhole Wetwells [34] and Covers [15] 


\subsubsection{Benefits of Fiberglass Manhole Covers}

FRP manholes have the same and more advantages than iron/concrete manholes since they are made in a single piece unit and built to meet or exceed all American Society of Testing Materials (ASTM), specifically, ASTM D-3753 specifications. They can also be inserted into pre-existing iron cast or pre-cast concrete manholes. Fiberglass reinforced polymer manholes are manufactured from commercial Grade "E" type glass in the form of continuous roving and chop roving and commercial grade unsaturated polyester resin or vinyl ester resin. Fig. 1.3 shows a standard fiberglass reinforced polyester manhole.

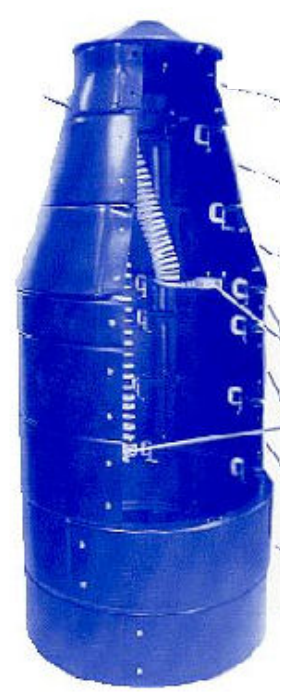

Figure 1.3: A Single Piece Unit of Fiberglass Reinforced Polyester (FRP) Manhole [28]

FRP manholes also offer additional benefits and advantages compared to common pre-cast concrete manholes. These benefits are in the areas of:

1. Reliability

2. Serviceability

3. Durability

4. Environmental Sensitivity

5. Economy 
Reliability - Their standard monolithic design reduces infiltration and eliminates the need for future rehabilitation caused by microbiologically induced corrosion. Their single-piece unit and lightweight characteristics also makes them easier to install and less complicated than preconcrete manholes.

Serviceability - FRP manholes have more head room than traditional pre-cast concrete manholes since the shaft diameter typically 4 or 5 feet are maintained throughout the depth of the shaft; whereas, pre-cast concrete manholes are generally constructed with a 30-inch neck that only bells out to four or five feet near the bottom. In addition the walls of the fiberglass manholes are smoother than concrete and less likely to build up a coating of effluent material. The larger opening and smooth walls also allow for better lighting conditions; hence, a better working environment for the technician. Consequently, FRP manholes have a minimal maintenance period of 50 years.

Durability - Fiberglass reinforced polyester manholes have higher loading capacity than steel and concrete due to its high strength to weight ratio properties. They resist degradation from groundwater, sewage and corrosive chemicals far more effectively than concrete. They can be subjected to abusive wear and tear environment without degrading or corroding their structural integrity. They are not electrical conductive so very safe around power lines and do not absorb moisture or weaken significantly due to sunlight. Fiberglass reinforced manholes do not experience thermal expansion or contraction issues compared to pre-cast concrete or steel. FRP manholes also resist structural fatigue better than either concrete or brick manholes which can be seriously weakened due to movement caused by traffic, shifting soil, temperature changes, and cyclic groundwater loading. As a result, FRP manholes will not crack, crumble, or leak during their normal design life of 50 years minimum. 
Environmental Sensitivity - FRP manholes vastly reduce the possibility of ground water infiltration. They prevent groundwater under hydrostatic pressure finding its way through fatigue cracks and seriously weakened joints to serve deterioration of the structure, seriously endangering the surface and surrounding environment. Fiberglass manholes are anti-corrosive and do not suffer microbiologically induced corrosion (MIC) which is a result of acid-producing bacteria known as Thiobacillus (concretivorous). These microorganisms produce hydrogen sulfide-rich effluents that produce sulfuric acid as a waste product, which can quickly destroy ordinary concrete-based materials in municipal sewer systems; hence, leading to sewer and groundwater contamination.

Economy - Fiberglass lightweight makes it very simple and reduces installation cost compared to pre-cast concrete manholes. Ground water resources are protected and expensive manhole rehabilitation to prevent ground water contamination can be often avoided definitely. Overall, their reliability, serviceability, durability, and environmental sensitivity benefits, as previously discussed, reduced the amount of time and costs for delivery, installation, and rehabilitation compared to traditional pre-cast concrete manholes. Although the initial cost is likely to be more expensive, the maintenance and reliability benefits of fiberglass reinforced manhole covers would ultimately surpass the iron cast manhole covers and eventually decrease its overall cost. The following table shows the present worth cost summary of manhole rehabilitation method between fiberglass and iron cast manhole covers.

Table 1.4: Cost Summary of Fiberglass and Iron Cast Manhole Covers

\begin{tabular}{|c|c|c|c|c|}
\hline Method & \multicolumn{2}{|c|}{ Fiberglass } & \multicolumn{2}{c|}{ Iron Cast } \\
\hline Material Type & Cover & Cover / Sub-Frame & Cover & Cover / Sub-Frame \\
\hline Initial Cost Range (\$) & $300-400$ & 900 & $120-500$ & $415-685$ \\
\hline Anticipated Life (yrs) & $50+$ & $50+$ & $10-50$ & $10-50$ \\
\hline
\end{tabular}


The final product will not only improve the strength properties of existing materials by making them stronger for high bending loading and lighter to reduce injury during opening and closure, but also improve the environment: by making them recyclable since unwanted fiberglass manhole covers can later be used for making particulate fillers, improve the quality of air or water public systems due to its has flame retardant and anti-corrosive properties, and reduced noise pollution under traffic movements or rebound when sealed properly.

\subsubsection{Standard Testing Methods for Fiberglass Manholes}

The ASTM D-3753 standard requires that separate tests need to be conducted on different FRP manholes. Test samples need to be the actual pieces of manhole or samples manufactured in a manner consistent with the manhole component construction. Properties of individual fiberglass manholes may vary somewhat from those measured in tests, but should always meet or exceed ASTM D-3753 standards. Fig. 1.4 shows workmanship and dimension requirements that are dictated by ASTM D-3753 standards for fiberglass reinforced polyester manholes. 


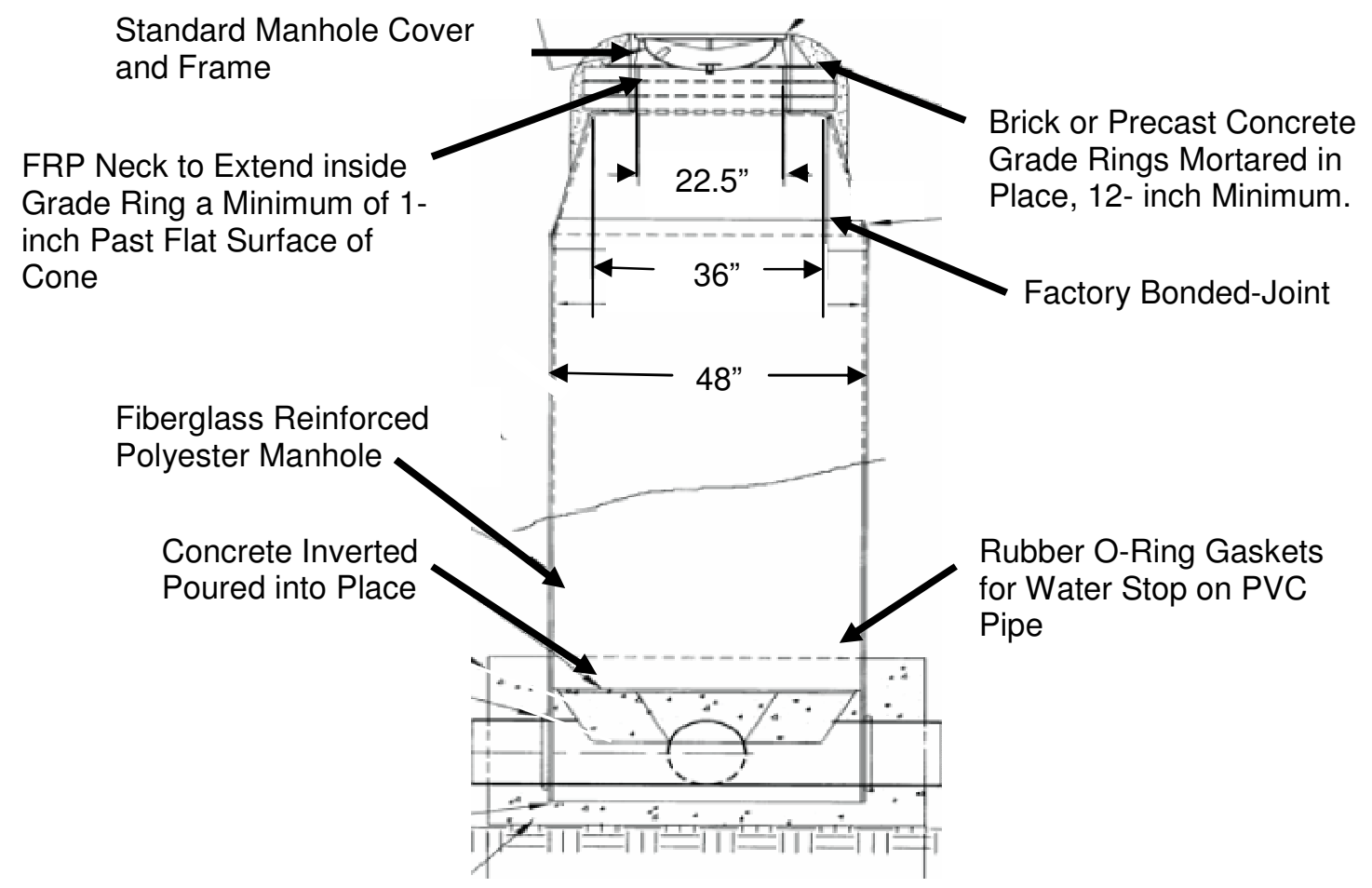

Figure 1.4: Design Requirements of Standardized Fiberglass Manhole (LFM)

The following are the general workmanship requirements that are applied for the performance testing of fiberglass reinforced polyester manholes in compliance with ASTM D3753.

Load Rating - the finished manhole (minimum 36 inch cylinder length) is loaded vertically with cover and supporting ring installed in accordance with ASTM D-3753 (section 8.4.1.1) for concentric manholes. Load is applied eccentrically in 2,000 lbs increments with close visual inspection at each increment and deflection measurement. The complete manhole requires a minimum dynamic-load rating of $16,000 \mathrm{lbs}$ when tested in accordance with ASTM D-3753. Maximum deflection for this testing is 0.25 inch at the point of load application when loaded to 24,000 psi. The load is increased to $40,000 \mathrm{lbs}$ and the complete manhole shall not leak, crack or suffer other damage. Table 1.5 shows the ASTM standard loading rate requirements. 


\section{Table 1.5: ASTM Loading Rate Requirements for FRP Manholes}

\begin{tabular}{|c|c|}
\hline Loading Rate & Deflection \\
\hline Max. deflection at $24,000 \mathrm{lbs}$ & $0.25 \mathrm{in}$ \\
\hline Visual damage at $40,000 \mathrm{lbs}$ & None \\
\hline
\end{tabular}

Cylinder Stiffness - the cylindrical portion of the manhole is to be tested in accordance with ASTM D-2412. This type of test method is used to find the external loading characteristics of plastic pipe by parallel plate loading in order to determine the stiffness properties of the manhole's cylinder portion.

Soundness - in order to determine soundness, as air or water test is applied to the manhole test sample. Hence, the entire manhole must be inspected for leaks while maintaining the pressure between 3 to 5 pounds per inch-square. Any leakage through the laminate is cause for failure of the test.

Chemical Resistance - manholes tested in accordance with the ASTM C-581 to determine the chemical resistance of chemical thermosetting resins used in fiberglass reinforced structures intended for liquid services. Actual pieces of manhole or samples manufactured in a manner consistent with the manhole component construction are used as test samples. Different $\mathrm{pH}$ levels are used for testing the chemical resistance of the material. Sulfuric acid is used mainly to simulate sewage since it is the most corrosive material found in sanitary sewers.

Fillers and Additives - Fillers, when used, shall be inert to the environment and manhole construction. Sand shall not be accepted as approved filler. Additives, such as thixotropic agents, catalysts, promoters, etc., may be added as required by the specific manufacturing process to be used to meet the requirements of the ASTM D-3753 standard. The resulting reinforced-plastic material must meet the requirements of this specification. For this study, 
calcium calcite (limestone) filler was used to create the fiberglass manhole cover laminates. Table 1.6 shows a summary of the limestone properties:

Table 1.6: ASTM D-3753 Standards for Limestone Filler

\begin{tabular}{|l|c|}
\hline \multicolumn{1}{|c|}{ Property } & Value Range \\
\hline Ultimate Compressive Strength & 4,000 psi to $20,000 \mathrm{psi}$ \\
\hline Ultimate Shear Strength & $900 \mathrm{psi}$ to $1,800 \mathrm{psi}$ \\
\hline Ultimate Tensile Strength & $300 \mathrm{psi}$ to $715 \mathrm{psi}$ \\
\hline Modulus of Elasticity & $3.3 \mathrm{Msi}$ to $5.4 \mathrm{Msi}$ \\
\hline Poisson's Ratio & 0.27 \\
\hline Bulk Specific Gravity & $2.1 \mathrm{~min}$. to $2.75 \mathrm{max}$. \\
\hline Coefficient of Thermal Expansion & $.0000024 \mathrm{in} / \mathrm{in} / 0$ to $.0000030 \mathrm{in} / \mathrm{in} / \mathrm{o}$ \\
\hline Abrasion resistance & $6 \mathrm{~min}$. to $17 \mathrm{max}$. \\
\hline
\end{tabular}

Material Properties - several tests are made on actual pieces of manholes or samples manufactured consistent in all aspects with the construction of the manholes in order to determine the material composition, compressive strength, flexural strength and modulus, and hardness. The following are test methods used to determine material properties:

- ASTM D-2584: Test Method for Ignition Loss of Cured Reinforced Resins

- ASTM D-695: Test Methods for Compressive Properties of Rigid Plastics

- ASTM D-790: Test Method for Flexural Properties of Unreinforced/Reinforced Plastics

- ASTM D-2583: Test for Indentation Hardness of Rigid Plastics using Barcol Impressor

Table 1.7 shows the material properties for fiberglass reinforced polyester manhole according to ASTM D-3753 standards. The material properties of the manhole's main sections 
(cone and cylinder) are tested with their corresponding diameter sizes of 48 inch and 42 inch, respectively. Material composition percentage (resin, glass, and sand), compressive and flexural properties (hoop strength, axial strength, and modulus), and barcol hardness is determined by using test method. The compressive property test methods require flat specimen; therefore, no cone results for modulus in hoop and axial directions. In addition, to accommodate structural loads, thickness ranges from 0.30 in to 0.50 in.

Table 1.7: ASTM Material Properties Requirements for FRP Manholes

\begin{tabular}{|l|c|c|}
\hline \multicolumn{1}{|c|}{ Material Property } & Hoop Direction & Axial Direction \\
\hline Tensile Strength & $9,700 \mathrm{psi}$ & $5,000 \mathrm{psi}$ \\
\hline Tensile Modulus & $0.6 \times 10^{6} \mathrm{psi}$ & $0.7 \times 10^{6} \mathrm{psi}$ \\
\hline Compressive Strength & $18,000 \mathrm{psi}$ & $5,000 \mathrm{psi}$ \\
\hline Compressive Modulus & $\mathrm{n} / \mathrm{a}$ & $\mathrm{n} / \mathrm{a}$ \\
\hline Flexural Strength & $26,000 \mathrm{psi}$ & $4,500 \mathrm{psi}$ \\
\hline Flexural Modulus & $1.4 \times 10^{6}$ & $0.7 \times 10^{6} \mathrm{psi}$ \\
\hline
\end{tabular}

Consequently, fiberglass manholes need to meet all loading requirements with no leakage or other evidence of damage before or after load testing. The manhole cylinders need to satisfy all stiffness requirements of the specification. Chemical resistance requirements need to exceed by the constructions/structures used in both the cone and the cylinder of the manhole. Material properties also need to be established for the construction of the manhole cone and cylinder.

\subsubsection{Vandalism of Commons Manholes}

In addition, fiberglass reinforced manhole covers would also save cities a lot of money since thousands of cast iron manhole covers in cities across the country and other parts of the 
world are being pilfered. The cast iron covers, which typically weigh between 100 and 200 pounds, are being taken by opportunistic thieves responding to the increased value of scrap metal and the burgeoning demand for recycled metals in China, India, South Korea, Colombia and other developing nations. Scrap metal sold for $\$ 77$ per ton in $2001, \$ 300$ per ton in 2004 , and today it's nearly $\$ 500$ [31]. According to some law enforcement officials, stealing the covers is usually a two- or three-man operation, in which the thieves remove the covers out of their holes with crowbars, throw them in the backs of vans or trucks, and take them to scrap metal yards, where they get $\$ 10$ to $\$ 20$ per cover. A city may spend $\$ 500$ to replace a single manhole cover, including material and labor costs to manufacture a new cover, as a result, the city of Philadelphia spent more than $\$ 300,000$ to replace a total of 600 manhole covers stolen in 2008 [31]. Fig. 1.5 shows example of a stolen manhole cover causing a dangerous threat to pedestrians who may unexpectedly fall into an open sewer hole.

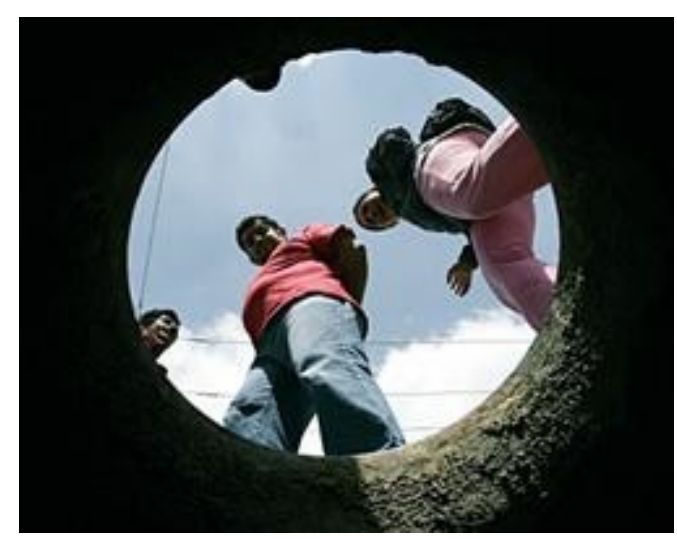

Figure 1.5: A Manhole Cover Stolen from the Streets of Philadelphia [31]

This type of vandalism can be prevented by replacing iron cast covers with FRP manhole covers. A unique feature that FRP manhole covers have compared to iron or steel manhole covers is that they are secured with a special key and socket; thus, making them tamper-resistant. 
For example, L.F.M. Inc uses 0.75 inch recessive blots to secure their fiberglass manhole covers to sub-frame structure [34]. And if the lock mechanism was not enough to secure or prevent a FRP manholes cover to be stolen for scrap, then melting it would only decrease and change its structural integrity due to fiber de-bonding and delamination; thus saving money to municipalities globally by disheartening thieves from stealing them.

\section{$1.2 \quad$ Objective}

Although fiberglass reinforced polyester manholes and wetwalls have been proven by the American Society for Testing Materials (ASTM) and are currently being used in some parts of the world, there still exists a lack of investigation for testing manhole covers made with different inorganic fillers under static and dynamic behavior. The filler would not only improve the mechanical properties of fiber-reinforced polymer matrix composite not otherwise achieved by the resin ingredients alone but also lower the overall manufacturing costs by decreasing the amount of organic (fiber) content without adversely affecting the composite's mechanical properties. The main objective will be to experimentally and numerically investigate different fiberglass polymer matrix composites with different amounts of fillers and understand how it behaves under bending and vibration loads. The materials that will mainly be used for the composite laminated test specimens will consist of E-glass woven roving fabric, epoxy, and filler. Two types of inorganic fillers will be used for this study, calcium carbonate and highdensity adhesive fillers. Also, the effect of volume fraction of the composite structure's stiffness will be considered.

First part of this study will be to design a mold of manhole cover by using Solid Works software and develop procedures on how to manufacture the mold and composite laminated specimens. Static and dynamic test methods will be perform in order to determine mechanical 
properties and dynamic behavior of test specimens. In addition, experimental tests of flexural strength and impact will be also performed in order to determine mechanical properties and dynamic behavior under bending loads of each fiber-reinforced polymer matrix structure. Second part of this study will be to obtain numerical results by using Abaqus software for finite element analysis and compare them with experimental analysis.

\subsection{Literature Review}

\subsubsection{Composite Materials and Applications}

Composite materials are defined as two or more separate materials combined on a macroscopic scale to form a new useful material. This usually results in a material with most or all of the benefits, but with little or no weaknesses, of the individual components. Examples of engineering use of composites date back to the use of straw in clay as construction material by the Egyptians. Modern composites using fiber-reinforced matrices of various types have created a revolution in high-performance structures in recent years. Advanced materials offer significant advantages in strength and stiffness coupled with light weight, relative to conventional metallic materials. Along with this structural performance comes the freedom to select the orientation of the fibers for optimum performance. Modern composites have been described as being revolutionary in the sense that the material can be designed as well as structure. Fig. 1.6 shows different examples of how composites are part of today's industrial and commercial society. 


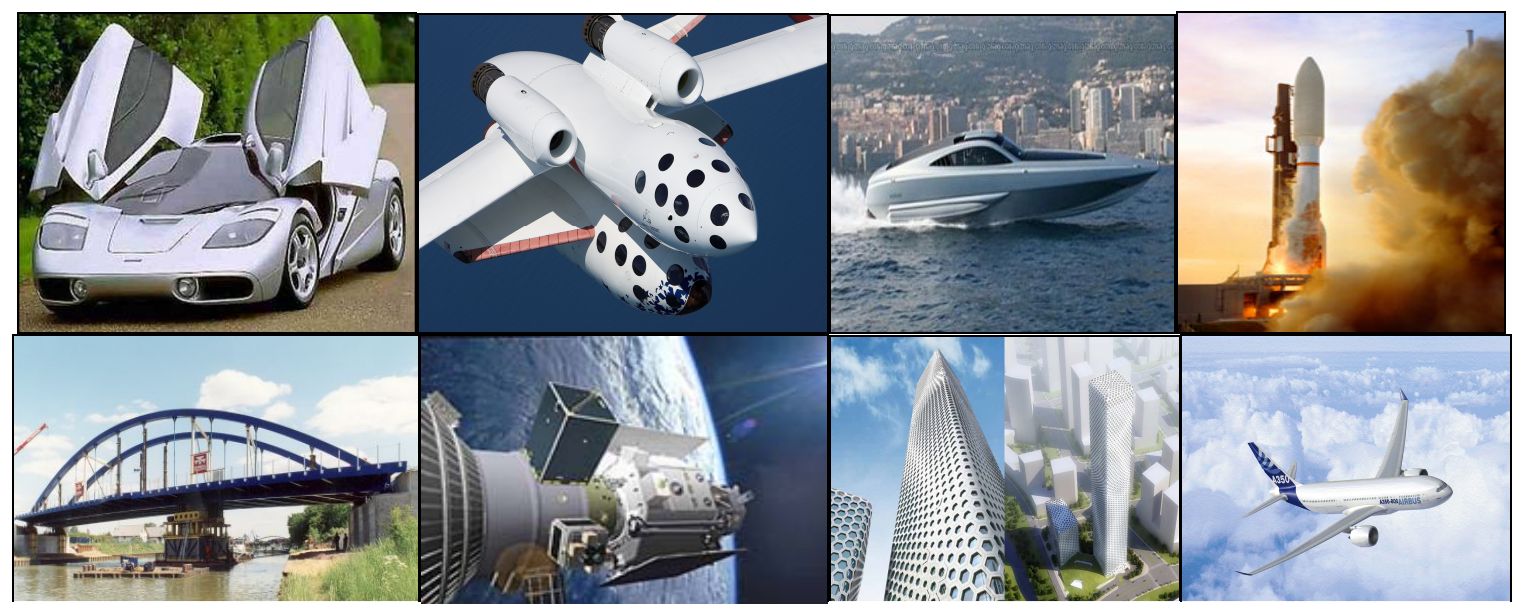

Figure 1.6: Composites Being Used in Modern Society

\subsubsection{Composite Characteristics}

Composites consist of one or more discontinuous phases embedded in a continuous phase. The discontinuous phase is usually harder and stronger than the continuous phase and is called the reinforcement or reinforcing material, whereas the continuous phase is termed the matrix. Properties of composites are strongly influenced by the properties of their constituents, or the constituents may interact in a synergistic way so as to provide properties in the composite that are not accounted for by a simple volume-fraction sum of the properties of the constituents. Thus in describing a composite material as a system, it is crucial to specify the geometry of the reinforcement with reference to the system where the geometry of the reinforcement may be described by the shape, size, and size distribution.

Most composites materials developed thus far have been fabricated to improve mechanical properties such as strength, stiffness, toughness, and high-temperature performance. It is natural to study composites that have a common strengthening mechanism together. The strengthening mechanism strongly depends on the geometry of the reinforcement. Therefore, it is quite convenient to classify composite materials on the basis of the geometry of a representative 
unit of reinforcement. For example, a fiber is characterized by its length being much greater than its cross-sectional dimensions. Fibrous composites are sometimes referred to as fibrous composites, whereas, particle-reinforced composites are called particulate composites

\subsubsection{Fibrous Composites}

Fibrous composites are very effective in improving the fracture resistance of the matrix and are characterized by its length being greater than its cross-sectional dimensions. Flaws in the form of cracks that lie perpendicular to the direction of applied loads are particularly detrimental to the strength. Therefore, compared with the strength of the bulk material, man-made filaments or fibers of nonpolymetric materials exhibit much higher strengths along their lengths since large flaws, which may be present in the bulk material, are minimized because of the small crosssectional dimensions of the fiber. For example, the high strength of glass fibers is attributed to a defect-free surface, whereas graphite and aramid fibers attain their strength as a result of improved orientation of their atomic or molecular structure. In addition, fibers due to their small cross-sectional dimensions are not directly usable in engineering applications. Hence, they are embedded in matrix materials to form fibrous composites where the matrix serves to bind the fibers together, transfer loads to the fibers, and protect them against environmental attack and damage due to handling. Fig. 1.7 shows two types of fibrous composites used as reinforcement.
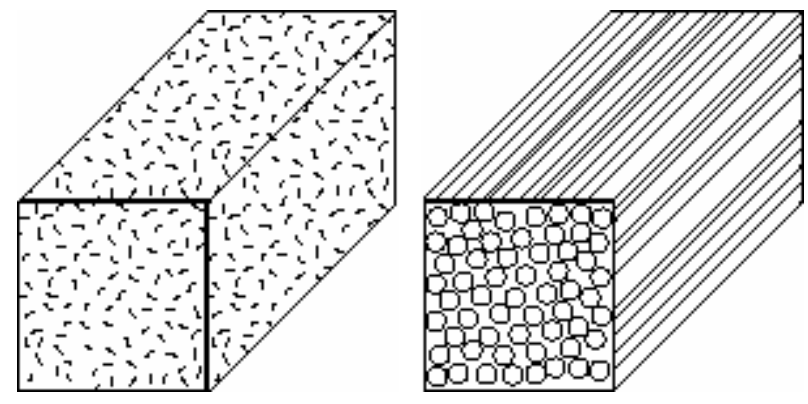

Figure 1.7: Short Fiber and Long Fiber Reinforced Composites 
An example of common fiber-reinforced composite material used in modern society is fiberglass or also known as glass-fiber. Fiberglass composites are the most diversely used and are manufactured in the largest quantities of all fiber-reinforced composites due to simple manufacturing and relatively low cost. Fiberglass composite material composed of silica-based $\left(\mathrm{SiO}_{2}\right)$ fine fibers and used as a reinforcing agent for many polymer products is known as fiberglass reinforced polymer or polyester (FRP) since polyester is the polymer product. The mechanical characteristics of fiberglass reinforced polymer composites are a great value to some civil infrastructure applications since they offer significant advantages in strength and stiffness coupled with light weight, and anti-corrosiveness relative to conventional materials, such as metal and concrete. Some examples of specific fiberglass reinforced products are the following: highway dividers, trash containers, traffic and light signs, bridge decks, oil and gas storage tanks, manhole wetwalls and sewerage covers. Fig. 1.8 show different examples of how fiberglass reinforced composites are part of today's industrial and commercial society.

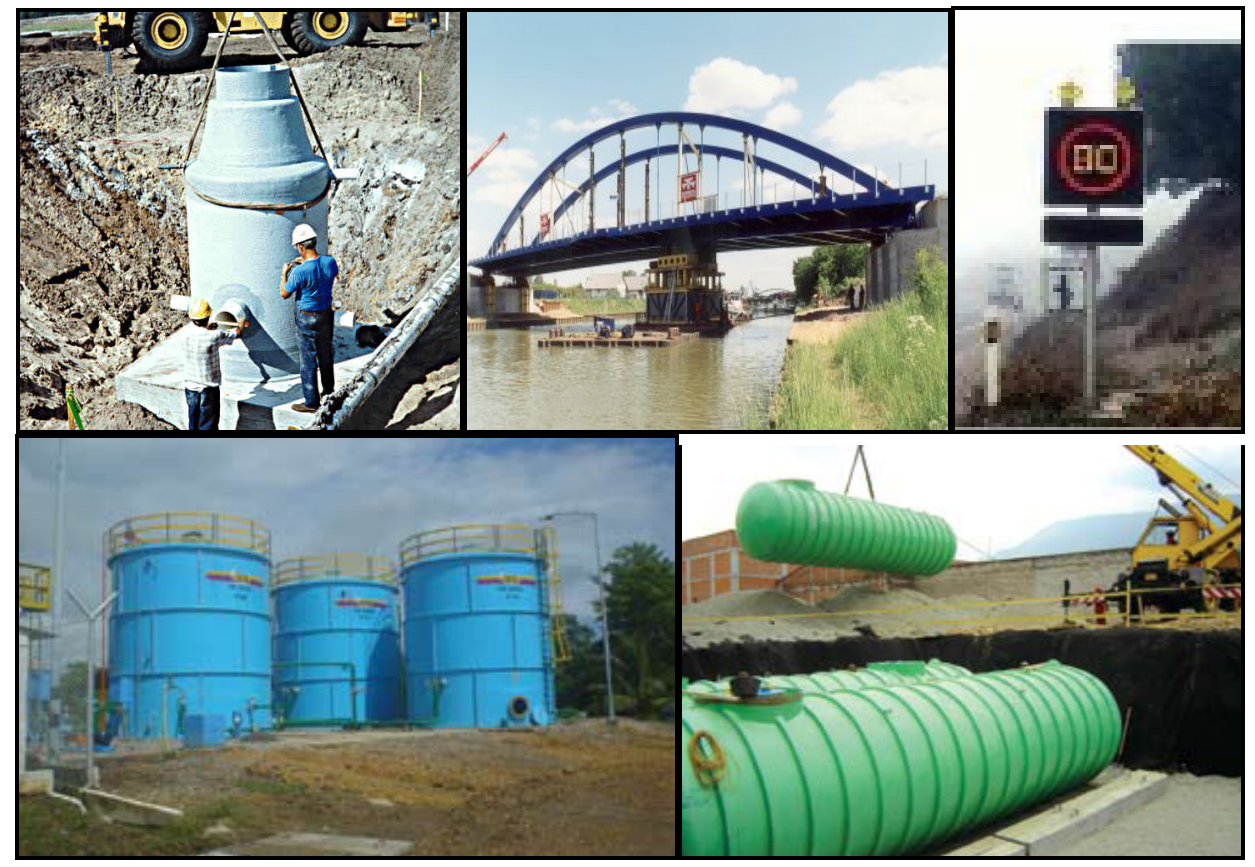

Figure 1.8: Fiberglass Reinforced Composites Being Used in Modern Society 
As shown in Fig 1.9, E-glass woven roving are bi-directional fabric made by interweaving roving (a collection of specific numbers of untwisted continuous filaments) which has excellent tensile and flexural strength and impact-resistant property due to its higher fiber content.

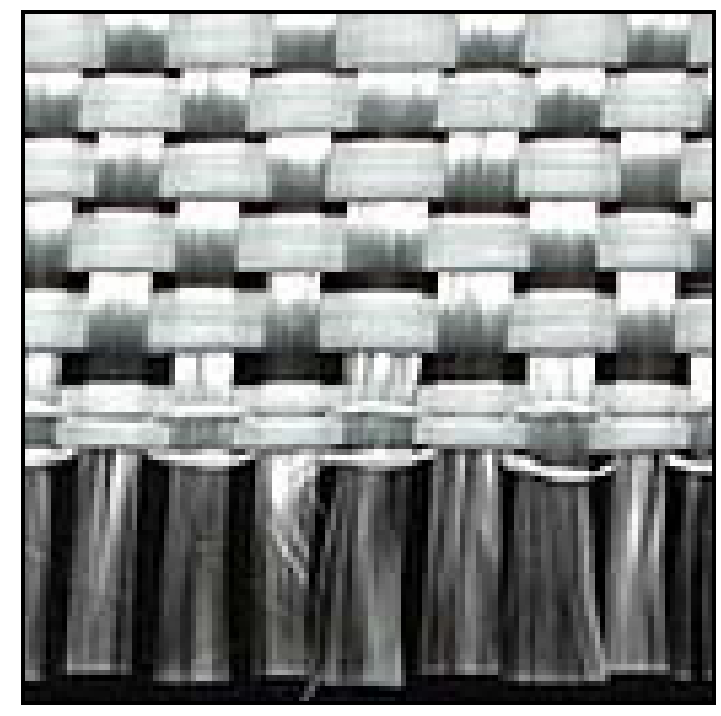

Figure 1.9: Fiberglass Woven Roving Fabric

Fiberglass woven roving is basically a heavier version of fiberglass cloth and is compatible with many resin systems such as polyester, vinyl ester and epoxy resins. They are high-performance reinforcement widely used in hand layup and automated processes for the production of boats, vehicle components, pressure tank, vessels, plane and automotive parts, furniture, and sport facilities large size objects, such as boats, vehicle components, and pressure tanks, as previously seen above. For this project, fiberglass woven roving was mainly used for test specimens due its excellent tensile strength and since it was generously provided by the Cal Poly's Aero-Composite Laboratory. 


\subsubsection{Particulate Composites}

Particulate composites are non-fibrous and generally have no long dimension with the exception of the platelets. They are not very effective in improving fracture resistance compared to fibrous composites. However, particles of rubberlike substances in brittle polymer matrices improve fracture resistance by promoting and then arresting crazing in the brittle matrices. Other types of particle, such as ceramic, metal, or inorganic particles, produce reinforcing effects in metallic matrices by different strengthening mechanisms. The particles in particulate composite create constraints on the plastic deformation of the matrix material between them because of their inherent hardness relative to the matrix. The particles also share the load, but to a much smaller extent than those fibers in fibrous composites that lie parallel to the direction of the load. Consequently, the particles are effective in enhancing the stiffness of the composites but do not offer the potential for much strengthening, an example of this are particle fillers, which is shown in the figure below.

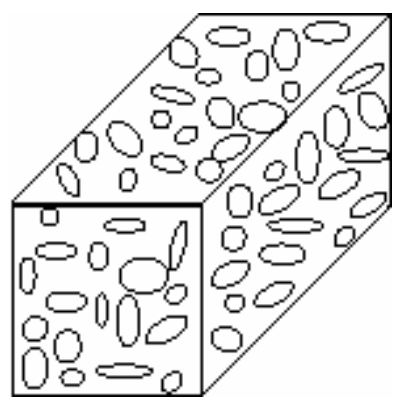

\section{Figure 1.10: Particle-Filler Composite}

Fillers are also used in reinforced composites. Their main purpose is not only to reduce the cost, but to also enhance performance improvements of a composite that might not otherwise be achieved by the reinforcement and resin ingredients alone. Furthermore they improve the mechanical properties of reinforced composites by providing the following: flame retardancy and 
smoke performance by reducing organic content in composite laminates, increasing water/weathering resistance, enhancing surface smoothness, increasing stiffness and hardness/tear resistance, improving thermal expansion control and dimensional control of molded parts since filled resins shrink less than unfilled resins, and increasing impact resistance. Fig. 1.11 shows calcium carbonate also known as "limestone," which is an inorganic filler used by L.F. Manufacturing (LFM) Inc. to build fiberglass reinforced manholes.

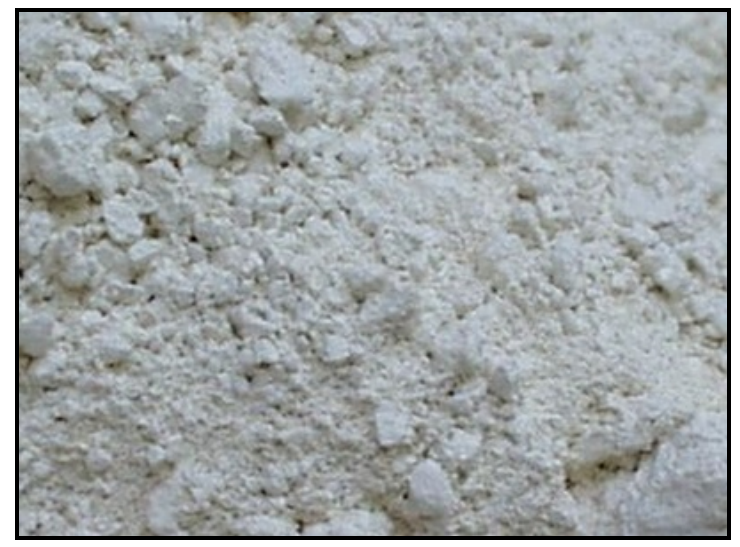

Figure 1.11: Limestone Filler

Currently, a material company, called Solvay Corporation, use coated precipitated calcium carbonate (CPCC) in order to improve gelation and processing, surface finish and impact resistance in extrusion profile polyvinyl chloride (PVC) compounds [28]. CPCC is a unique additive which can provide both a processing aid and improve impact resistance without any adverse effects. In this investigation the type of filler that will be used on the fiberglass laminated composites is limestone powder filler since it was generously donated by LFM Inc and currently implemented in all types of industry to improve the mechanical properties of reinforced materials by adding tensile strength and anti-corrosive properties, and making them very economical by reducing the need to install and repair. 


\section{MODEL DESIGN OF MANHOLE COVER}

\subsection{Design Considerations for Cal Poly Manhole Cover}

No plan for fiberglass sewer piping is complete without consideration of the manholes. As previously mentioned, manholes are an essential and integral part of any sewer system since they provide means for entering and maintaining the system. The Cal Poly manhole cover was modeled using the ASTM D-3753 specifications which dictate the design and installation considerations for a reinforced-polyester fiberglass manhole cover. According to the ASTM standards, the manhole shall provide an area from which a grade ring or brick can be installed to accept a typical metal ring (sub-frame) and cover and have the strength to support a traffic load without damage to the manhole. Fig. 2.1 shows a basic schematic design of a manhole cover with the sub-frame structure supporting it. This design was considered for the Cal Poly manhole cover but was not implemented since the sub-frame structure would be too costly and difficult to create with the existing lab equipment provided by Cal Poly's Aerospace Composite Laboratory, specifically during the layup and curing processes. Consequently, the manhole cover was the primary emphasize of this investigation.

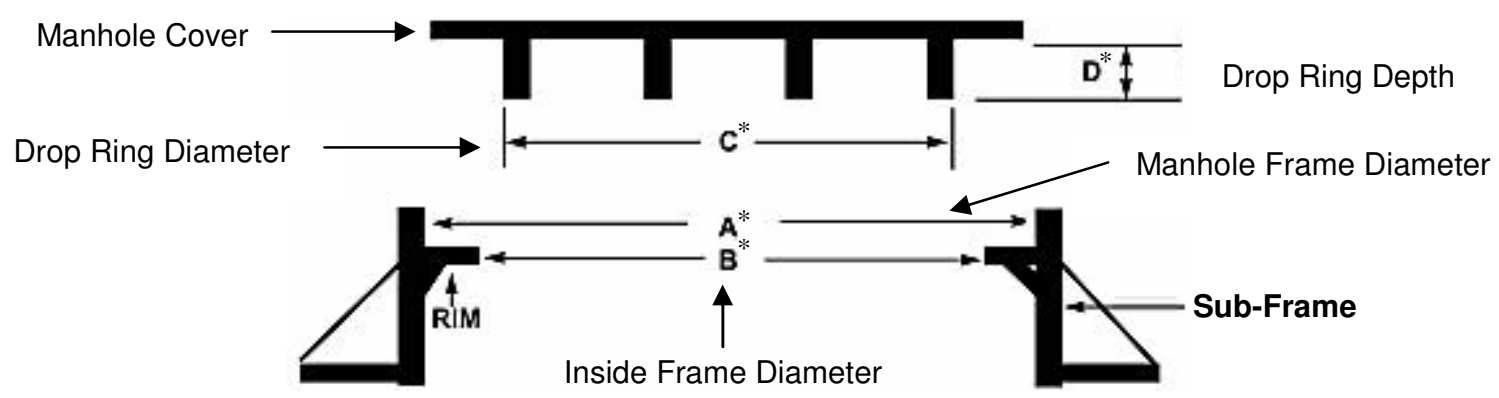

Figure 2.1: Basic Schematic of Manhole Cover with Sub-Frame 
Fig. 2.2 shows the different styles of manhole covers which are most commonly used in today's sewer systems. Style B is a manhole cover that has a rectangular shape, whereas, Style A has more of an angular shape at the bottom of manhole, as seen in Fig. 2.2. Style A was the manhole design selected for the Cal Poly manhole cover design since it was easier and less expensive to design and manufacture using the CNC mill machine.
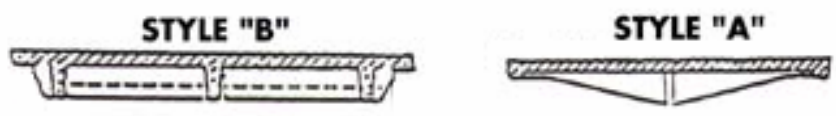

Figure 2.2: Side View of Most Common Styles for Manhole Covers

Consequently, the press mold method was selected to make the customized manhole cover since it was more economical and less complex to manufacture when compared to other mold casting methods, such as, epoxy tooling, injection and fiberglass molding, and vacuum assisted resin transfer molding (VARTM).

\subsubsection{Solid Model of Manhole Cover}

The Cal Poly manhole cover had an initial diameter of 48 -inches which is the standard size specified by ASTM D-3753 guidelines. The diameter of manhole cover was later reduced to a size of 11-inch since it was the maximum size that can fit in the Aero-Structures lab's composite press oven and the Aero-Hanger's curing oven. In addition, the design of the 11-inch diameter manhole cover was still applicable for this investigation since its standard size used for water meters.

The primary goal of the Solid Works program was to design the CP manhole cover to desired specifications. The manhole cover models were exported from Solid Works into a CNC 
mill program in order to construct negative and positive molds of manhole covers which will be discussed in section 2.4. Fig. 2.3 shows the side view of the manhole cover and its dimensions.

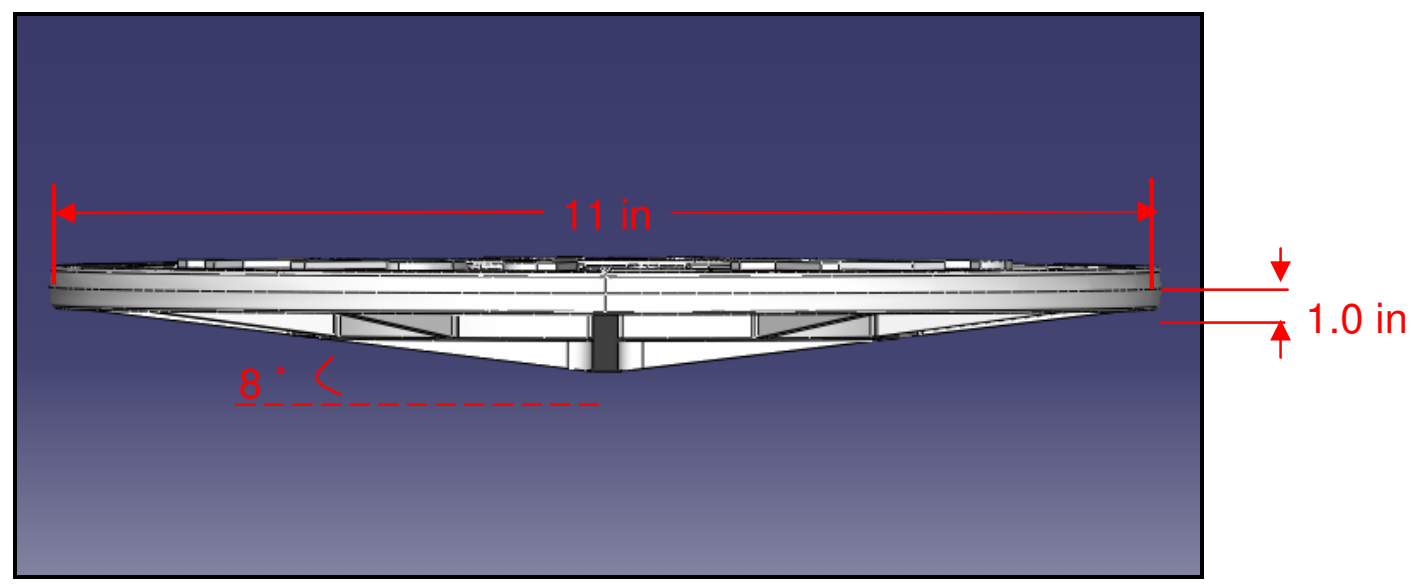

Figure 2.3: Side View of Manhole Cover

Fig. 2.4 depicts the front and back side of the manhole cover. The front side of manhole cover is inscribed with 4 concentric circles and 10 lines intersecting at the center. All engraved lines or grooves located on the top of manhole cover were increase by 1-mm in width and depth. The back side shows four quadrants with distinctive web features which help to support loads. The design was based on existing manhole covers used on the streets of major American cities such as New York, Chicago, and Los Angeles.

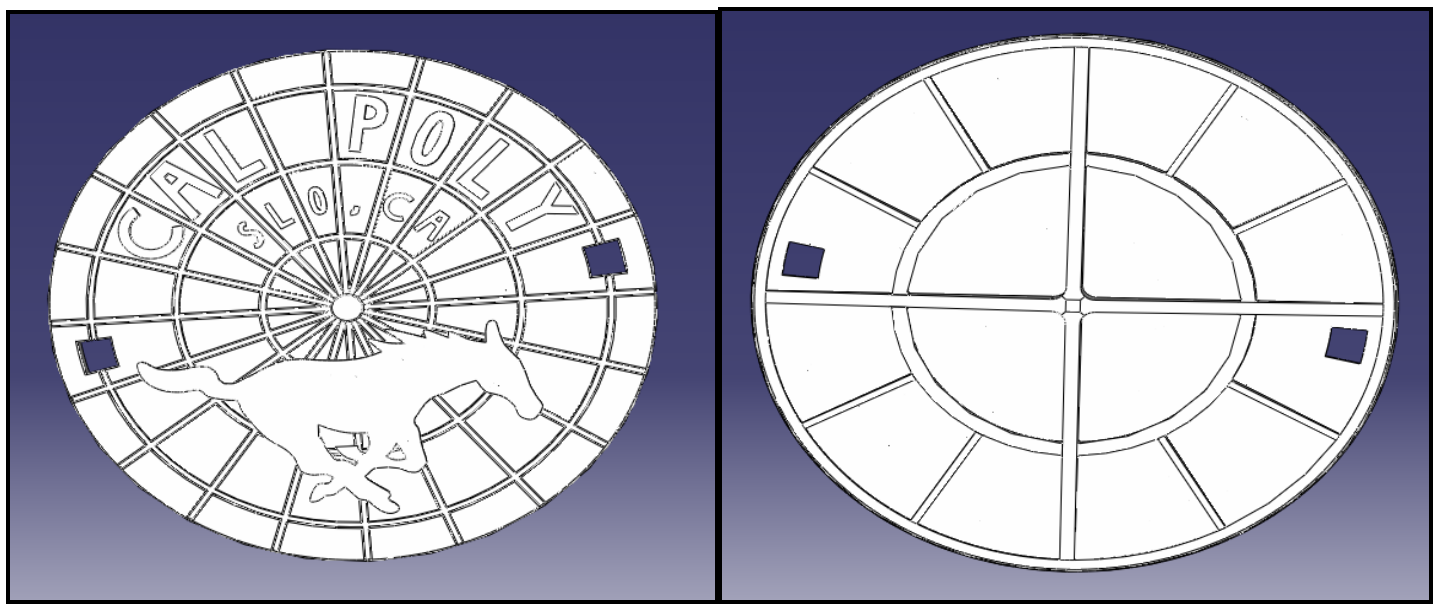

Figure 2.4: Top and Bottom Views of Manhole Cover 
The Cal Poly letters and mustang logo were added to the manhole cover do not serve any other purpose but to enhance the appearance of the manhole, as seen in Fig. 2.5.

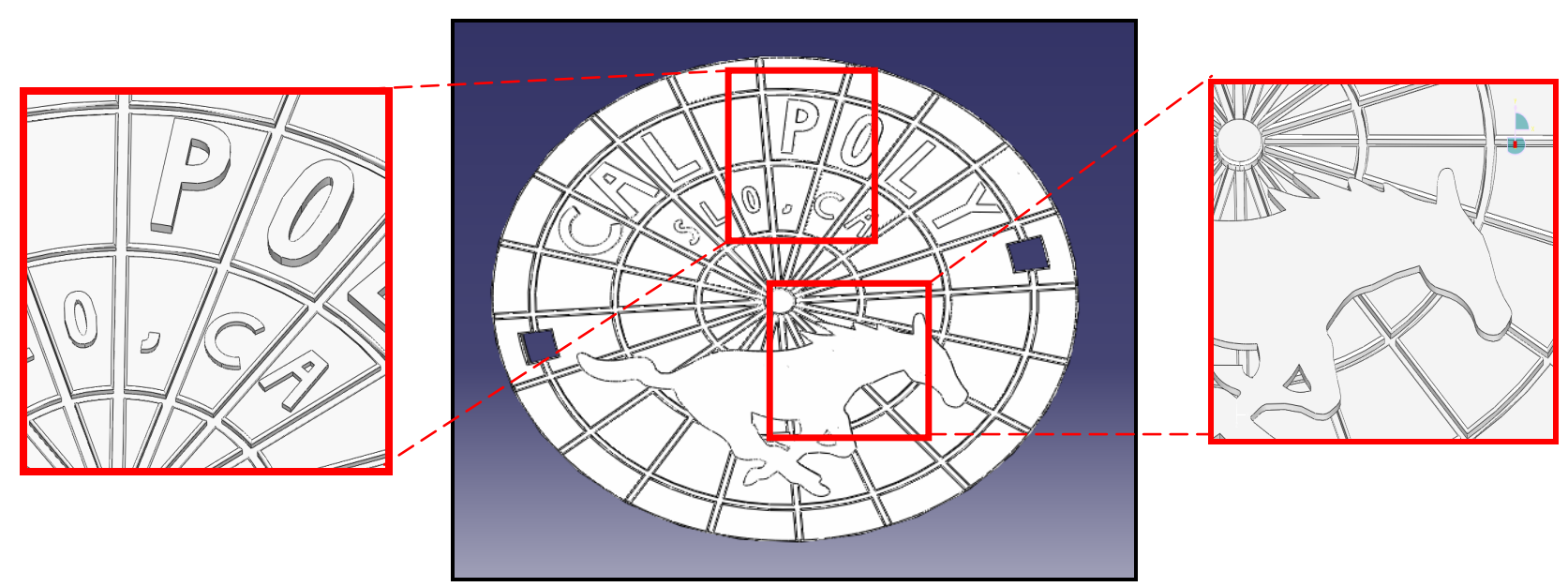

Figure 2.5: Enlarged Views of Engraved Lettering and Mustang Logo

Fig. 2.6 shows the same lower-surface features used in existing manhole covers. A rib ring was designed at the center of the manhole in order to attach the spider web structure. The spider web and rib-ring structure design is used to reduce and support the traffic load exerted on the upper surface of the manhole cover. Consequently, the bottom surface of the manhole cover was designed in a three-dimensional spider web pattern to provide much greater strength without increasing the cover's weight.

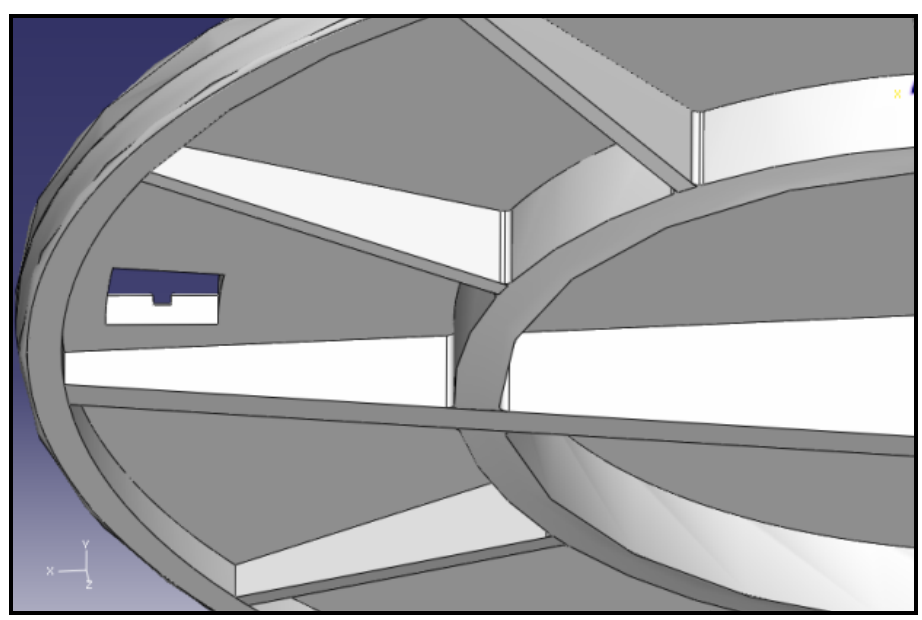

Figure 2.6: Spider Web Structure of Manhole Cover 


\subsubsection{Solid Models of Sub-Frame Molds}

The following figures (which were intended to be created by CNC machining) are different views of the sub-frame's negative and positive molds. The sub-frame molds where not made due to the high cost in CNC manufacturing and aluminum which is approximately $\$ 1,000$ for a 12 inch by 12-inch aluminum block. Fig. 2.7 shows different views of the sub-frame negative mold.
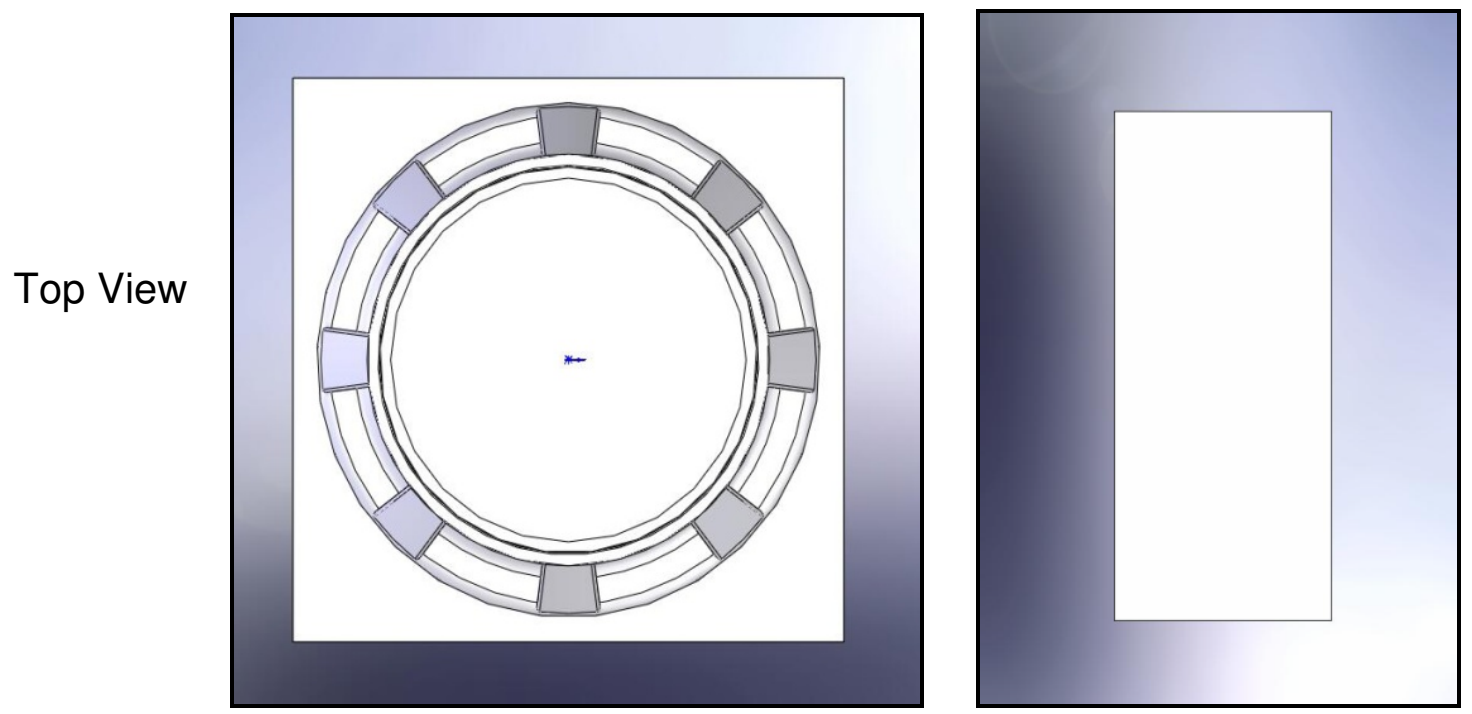

Side View

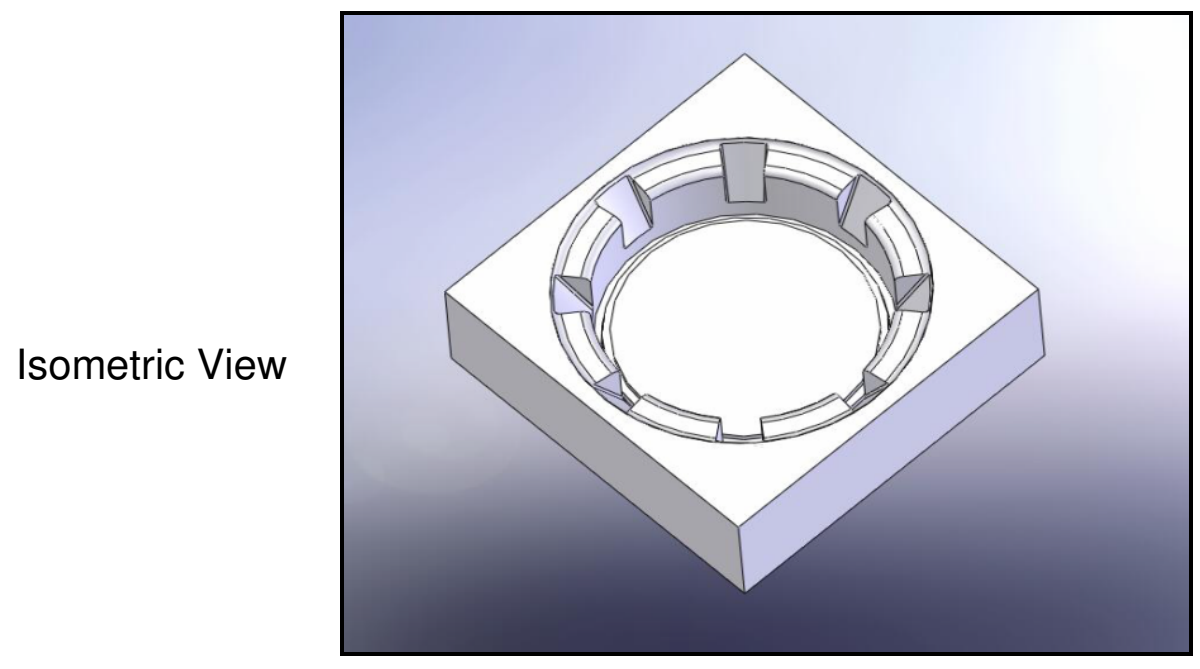

Figure 2.7: Sub-Frame Negative Mold 
Fig. 2.8 shows the sub-frame positive mold which was also not made due to high production costs. One noticeable feature of the positive mold was its ring ribs located on the subframe's center.
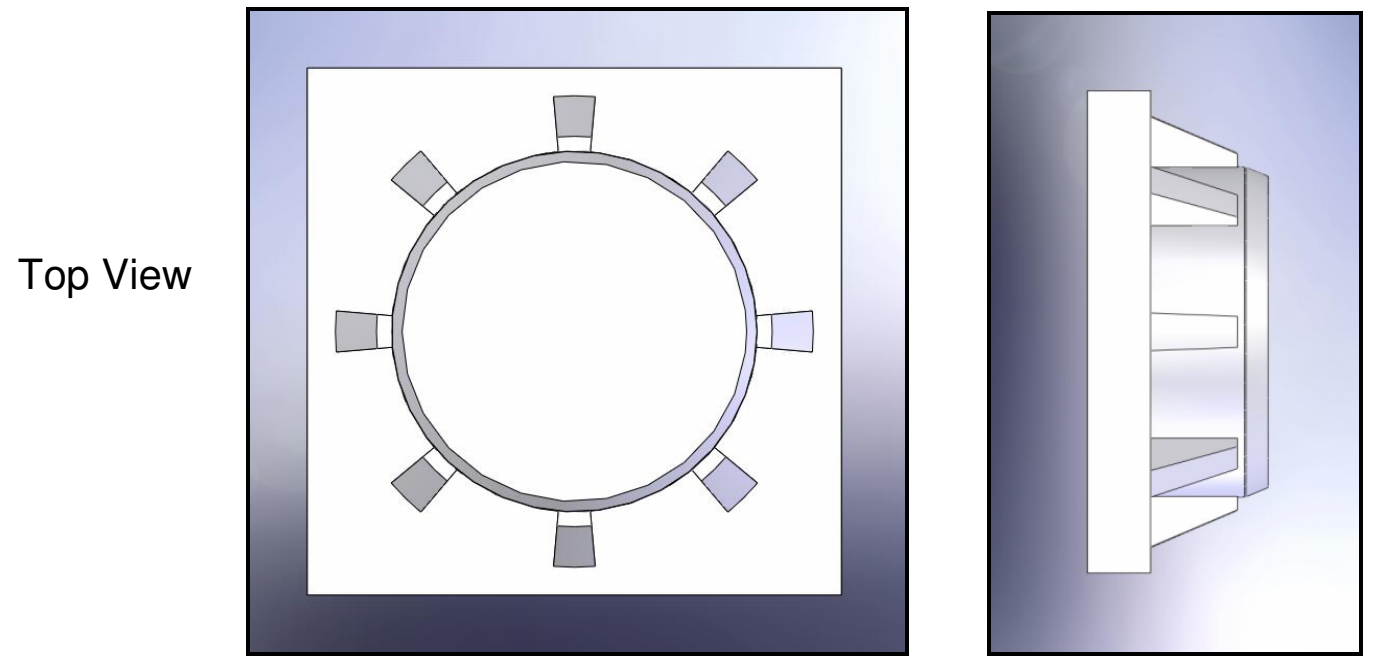

Side View

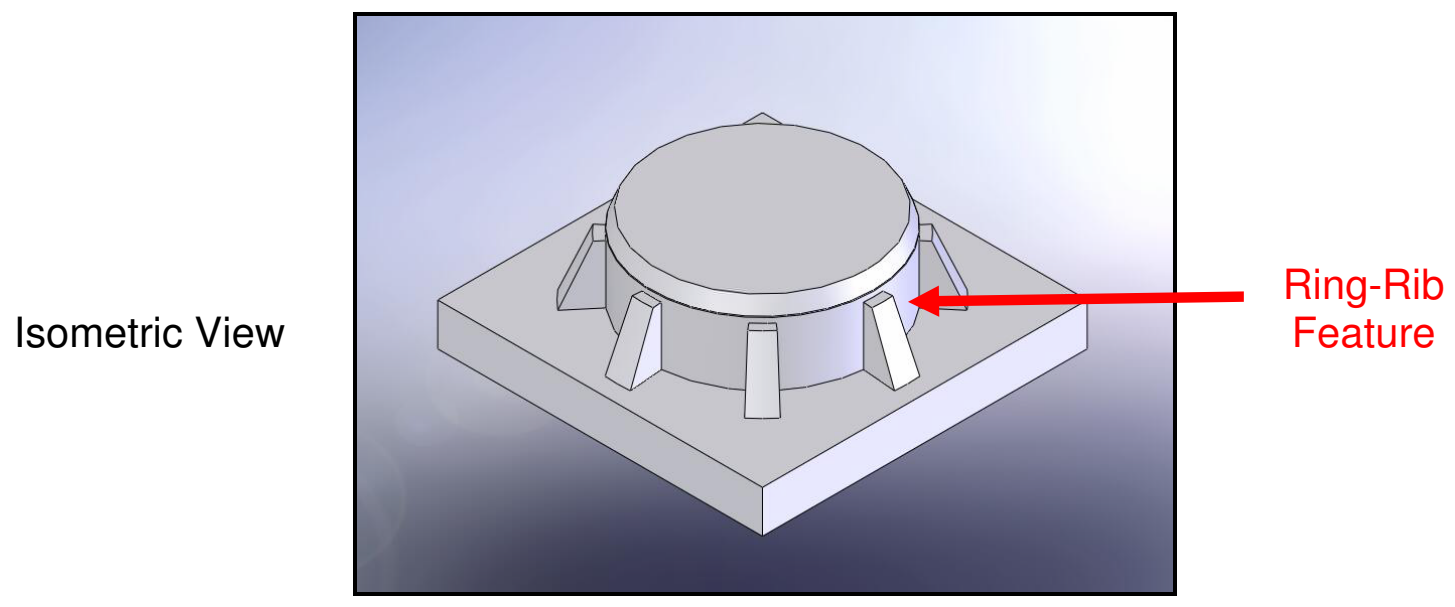

Figure 2.8: Sub-Frame Positive Mold

\subsection{Design Considerations for Press Mold}

The solid model of the manhole cover, previously discussed in Section 2.3, was the final design of the plug used to make the press molds. The goal of the press mold was to build fiberglass manhole covers by controlling the thickness of the filler and wetted fiberglass inside 
the female mold. The desired amount of filler will not only help improve the composite's matrix characteristics but also reduce the fiber quantity by increasing the filler used for the manhole covers; thus, decreasing the manufacturing and production cost. Fig. 2.9 shows the schematic of the positive (male) and negative (female) press mold used to make the copied parts of the fiberglass manhole cover.

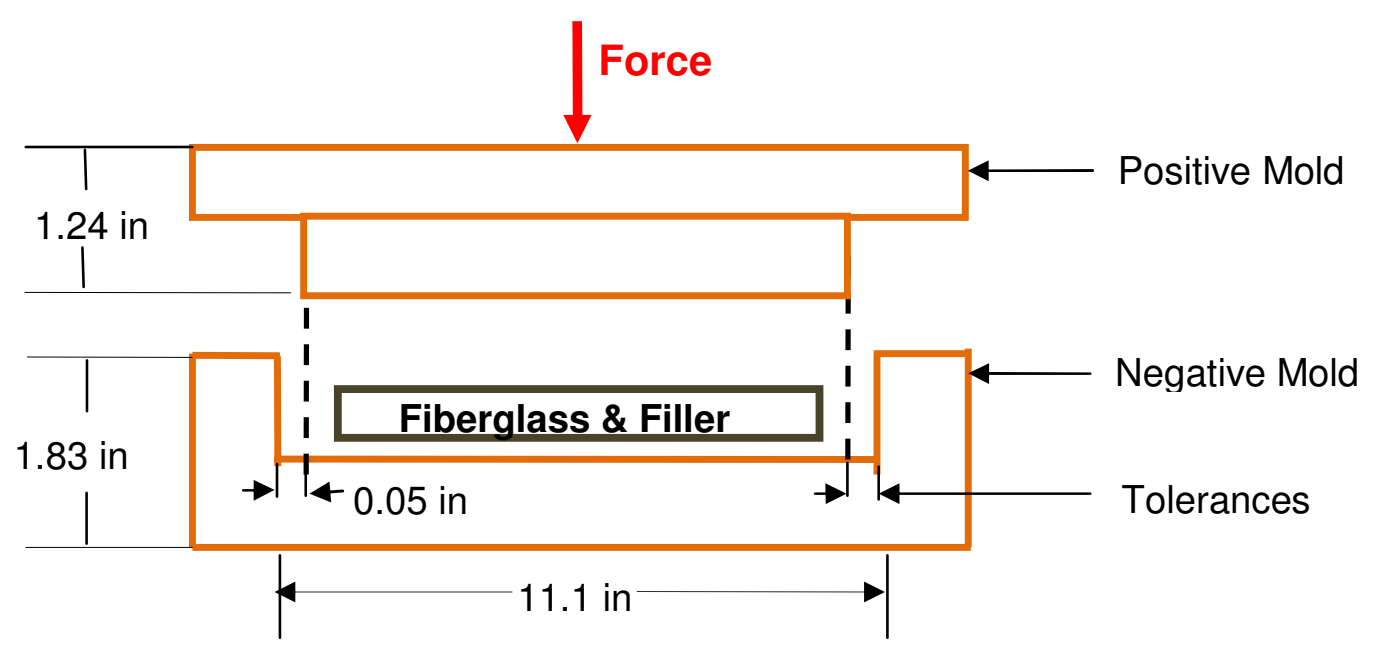

Figure 2.9: Side View of Press Mold with Test Specimen

Index pins were initially considered in the press mold design for securing both male and female molds; however, they were not implemented since the load of weights and the suction pressure of vacuum bag would create sufficient pressure to seal the press mold completely, which will be discussed in Section 6.3 .

\subsubsection{Tolerances}

For the mold design, tolerances were needed in order to press the positive mold against the wet fiberglass and allow excess filler to move freely along the walls of the negative mold's cavity during the curing process. Consequently, the male's diameter needed to be smaller than the female mold's diameter. The tolerances were 0.05 inches and 0.4 inches of the positive male mold's diameter and height, respectively. The mustang logo or lettering was not used for the 
positive mold since they were already engraved in the female mold, instead only a smooth and flat surface was required on the positive plug.

\subsubsection{Draft Angles}

In addition, draft angles of $5^{\circ}$ for the plug were also considered in order to ease the separation of the fiberglass specimen from the urethane mold and pressing right-angle blanks by uniform compression. It is well known that the effect of the pressing pressure results in friction on the walls of rigid dies which support the development of heterogeneous density. The maximum efficiency of loading are obtained at the edges of the positive mold, the minimum efficiency on the lower surface of the negative mold. Therefore, draft angle on the press mold would not only would it facilitate the part and mold separation but also enhance the material properties of the test specimen due to pressing right-angled blanks by uniform compression. Fig. 2.10 shows a schematic of this comparison.

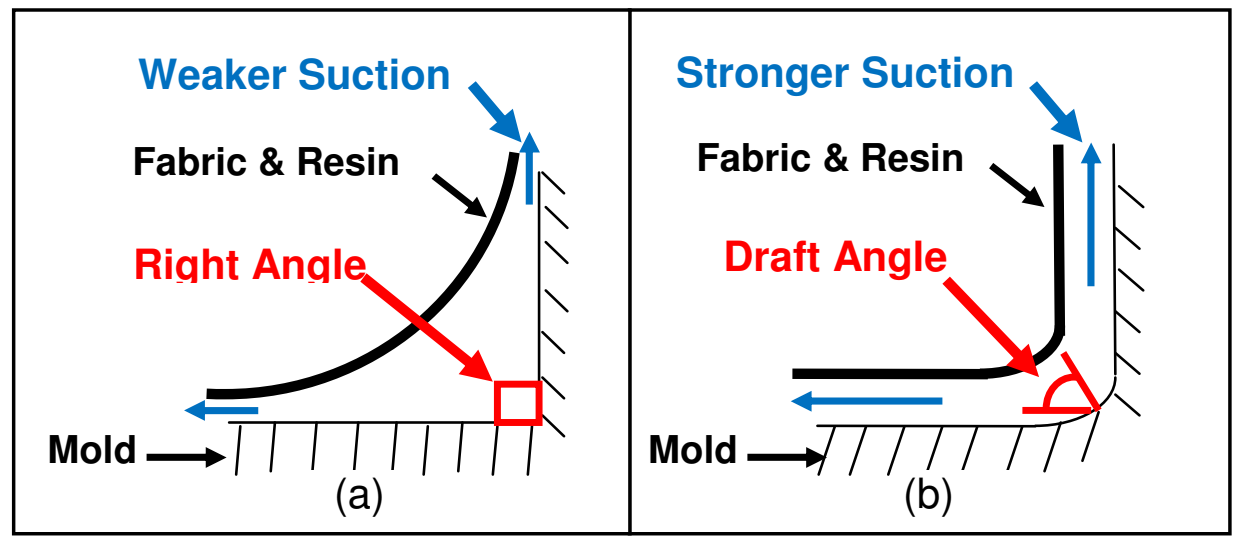

Figure 2.10: Schematic of Mold's Corner Design: a) Right Angle b) Draft Angle

Fig. 2.10-a shows a weaker suction pressure created by the mold's right angle corners which introduce blanks or air voids between the resin and mold; thus decreasing the overall strength of composite. Fig. 2.10-b shows the press mold with draft angle corners provide better 
suction pressure and uniform compression force to reduce right-angle blanks. Consequently, the pressing of right-angled air voids increase strength properties of test specimen by improving the fabric and resin distribution along the mold's walls. Although draft angles were initially considered, they were not implemented in final design since using release film provided easy part separation from mold, and the vacuum table supplied high suction pressure to minimize any air void between resin and mold.

\subsection{Material Considerations for Making Press Mold}

Different materials were researched for making the press mold. The main goal for selecting a material appropriate for this investigation was that it needed to be affordable, fast and easy to use, make accurate detail molds, and have high-temperature and loading resistance properties during curing process for mass production (mold's lifetime in terms of its ability to produce duplicate parts.) This in return would make a low-cost press mold that fabricates test specimens in a short-time and cost effective manner. From the different materials considered for this investigation urethane liquid rubber was selected for the press mold.

Urethane rubber is used for hundreds of industrial and art-related applications. It is the easiest to use of all mold rubbers since it can be poured, brushed on or sprayed onto most prepared surfaces and cure with negligible shrinkage. It is very economical, reproduces exceptional detail and is best suited for production casting of concrete, gypsum, and wax. A disadvantage of urethane liquid rubber is that it has adhesive properties; hence without proper surface preparation (sealer and release agent) will bond to several surfaces, such as the part to the mold. Urethanes are also moisture sensitive, meaning that relatively dry environments are necessary for mold making success. Overall, this urethane material was well suited for the type of mold needed for this project since it was cost effective, very easy to use, and had great tear 
and tensile strength $(72,000 \mathrm{psi})$ characteristics as well as impact and abrasion resistance after curing [34]. The following table below shows a summary of the advantages and disadvantages of the various materials used for mold making and casting:

Table 2.1: Comparison of Different Materials Used for Mold Making.

\begin{tabular}{|c|c|c|}
\hline Material & Advantages & Disadvantages \\
\hline Aluminum/Alloy & $\begin{array}{l}\text {-has very high tensile and heat resistance } \\
\text {-easier to machined than other metals } \\
\text {-high mold lifetime and work-life period } \\
\text {-great for mass production }\end{array}$ & $\begin{array}{l}\text {-very expensive to purchase material } \\
\text {-very expensive to manufacture molds } \\
\text {-incompatibility with composite products } \\
\text { - high thermal coefficient expansion }\end{array}$ \\
\hline $\begin{array}{l}\text { Urethane Liquid } \\
\text { Rubber }\end{array}$ & $\begin{array}{l}\text { - easily poured or sprayed onto surfaces } \\
\text {-cure with negligible shrinkage } \\
\text {-economical and affordable } \\
\text {-reproduced with exceptional detail } \\
\text {-great for production casting of composite }\end{array}$ & $\begin{array}{l}\text {-need to mix ratio properly } \\
\text {-need sealer/release agent for separation } \\
\text {-moisture sensitive (dry environment) } \\
\text {-harmful if inhaled or direct contact to skin }\end{array}$ \\
\hline $\begin{array}{c}\text { Urethane Liquid } \\
\text { Plastic }\end{array}$ & $\begin{array}{l}\text {-tremendous versatility and economy } \\
\text {-easy to use for mold making } \\
\text {-available as rigid or semi-rigid } \\
\text {-ideal for models and industrial parts }\end{array}$ & $\begin{array}{l}\text {-more expensive than polyester resin } \\
\text {-moisture sensitive (dry environment) } \\
\text {-harmful if inhaled or direct contact to skin } \\
\text {-incompatibility with silicone rubber products }\end{array}$ \\
\hline $\begin{array}{l}\text { Silicone Liquid } \\
\text { Rubber }\end{array}$ & $\begin{array}{l}\text {-does not stick to surfaces } \\
\text {-can be poured, brushed-on, or sprayed } \\
\text {-chemical and heat resistant } \\
\text {-Non-hazardous if directly applied to skin }\end{array}$ & $\begin{array}{l}\text {-are very expensive } \\
\text {-require precise measurement } \\
\text {-require vacuum degassing before pouring } \\
\text {-more easily inhibited by contaminates }\end{array}$ \\
\hline $\begin{array}{c}\text { Epoxy Tooling } \\
\text { Resins }\end{array}$ & $\begin{array}{l}\text {-short time required for accurate mold } \\
\text { - low cost of materials } \\
\text {-significant savings in tool-making labor } \\
\text {-very heat resistant }\end{array}$ & $\begin{array}{l}\text { - need for an accurate prototype part to } \\
\text { duplicate } \\
\text { - limited mold's lifetime to produce duplicate } \\
\text { parts } \\
\text { - less strength compared to other materials } \\
\text { - weaker in tensile or shear loads }\end{array}$ \\
\hline
\end{tabular}




\subsection{Making Plugs Using CNC Mill Machine}

The manhole cover molds were constructed in a two-part configuration, negative mold and positive mold. The first step required to make the mold is to create a plug or buck which is an original part that is to be copied; hence, the Cal Poly manhole cover plugs were made from high-density foam and later CNC machined using the Haas Vertical Toolroom Mill in the Aerohanger, as seen in Fig. 3.1.

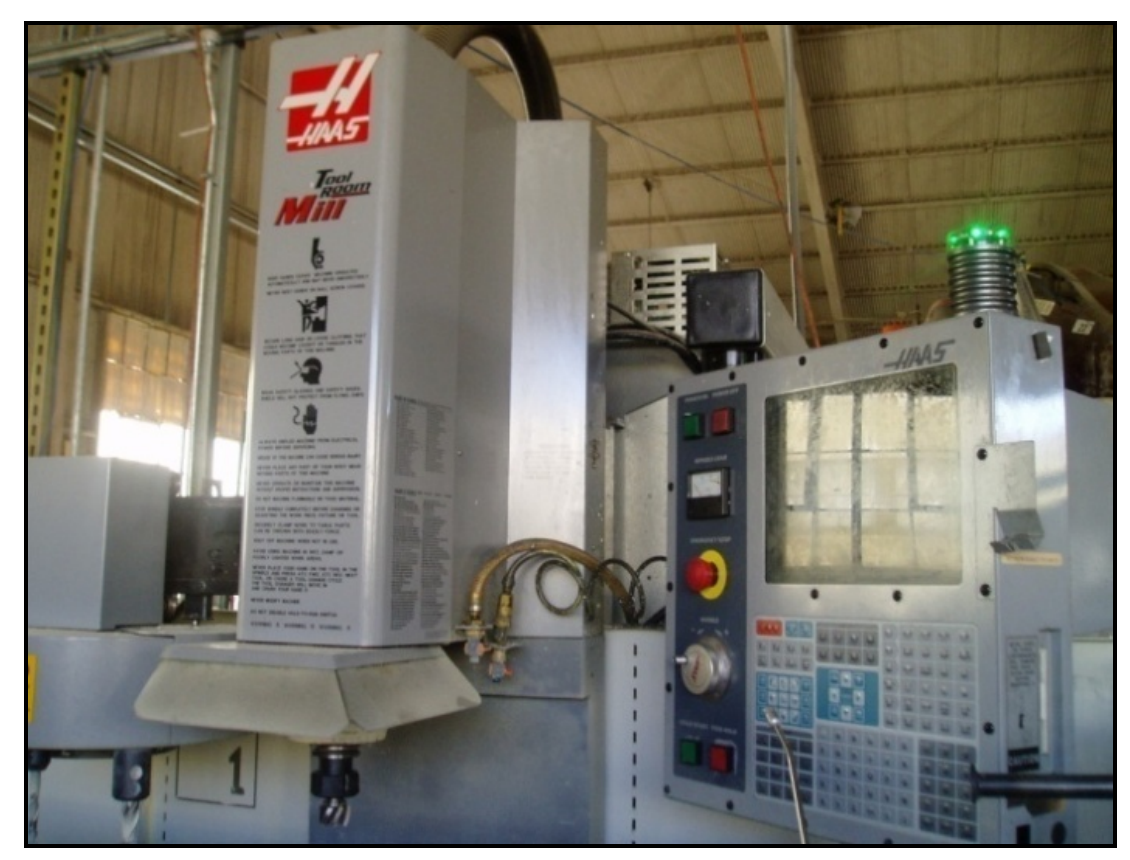

Figure 3.1: CNC Mill Machine Used to Create Manhole Cover Plugs

The CNC mill machine travel range is approximately $16 \times 12 \times 10$ in on the xyz-planes with a table weight capacity up to 5 tons, as seen in Fig. 3.2. 


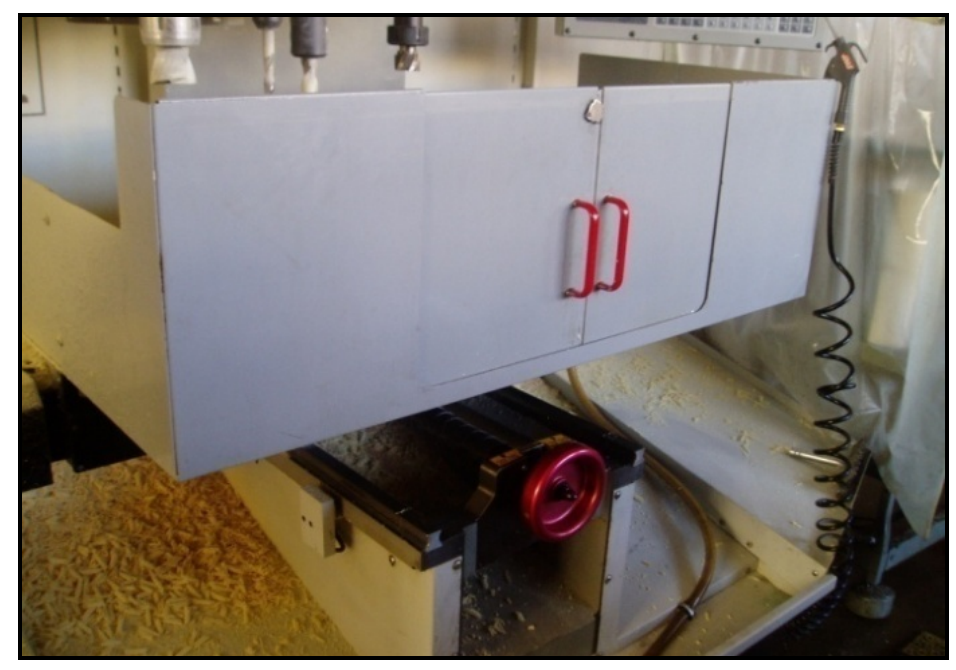

Figure 3.2: Front Sliding Doors of CNC Mill Machine's XYZ-Axis

Mastercam Version 9 was the CNC program used to manufacture the manhole cover plug. The manhole cover CAD files which were originally created in Solid Works were imported into the Mastercam program in order to create the part using the mill machine. The dimension size of the plug was scaled to half original size of CAD model due to design constraints previously mentioned in Section 2.3. In addition, Haas Toolroom Mill is a state-of-the-art CNC machine tool that maintains accuracies within tenths of thousandths $(0.0001)$ of an inch, resulting in precision that is not dependent on the ability to fit out-of-tolerance parts [Haas]. The control panel has several functions that allow the operator to control manufacturing processes, as seen in the Fig. 3.3. 


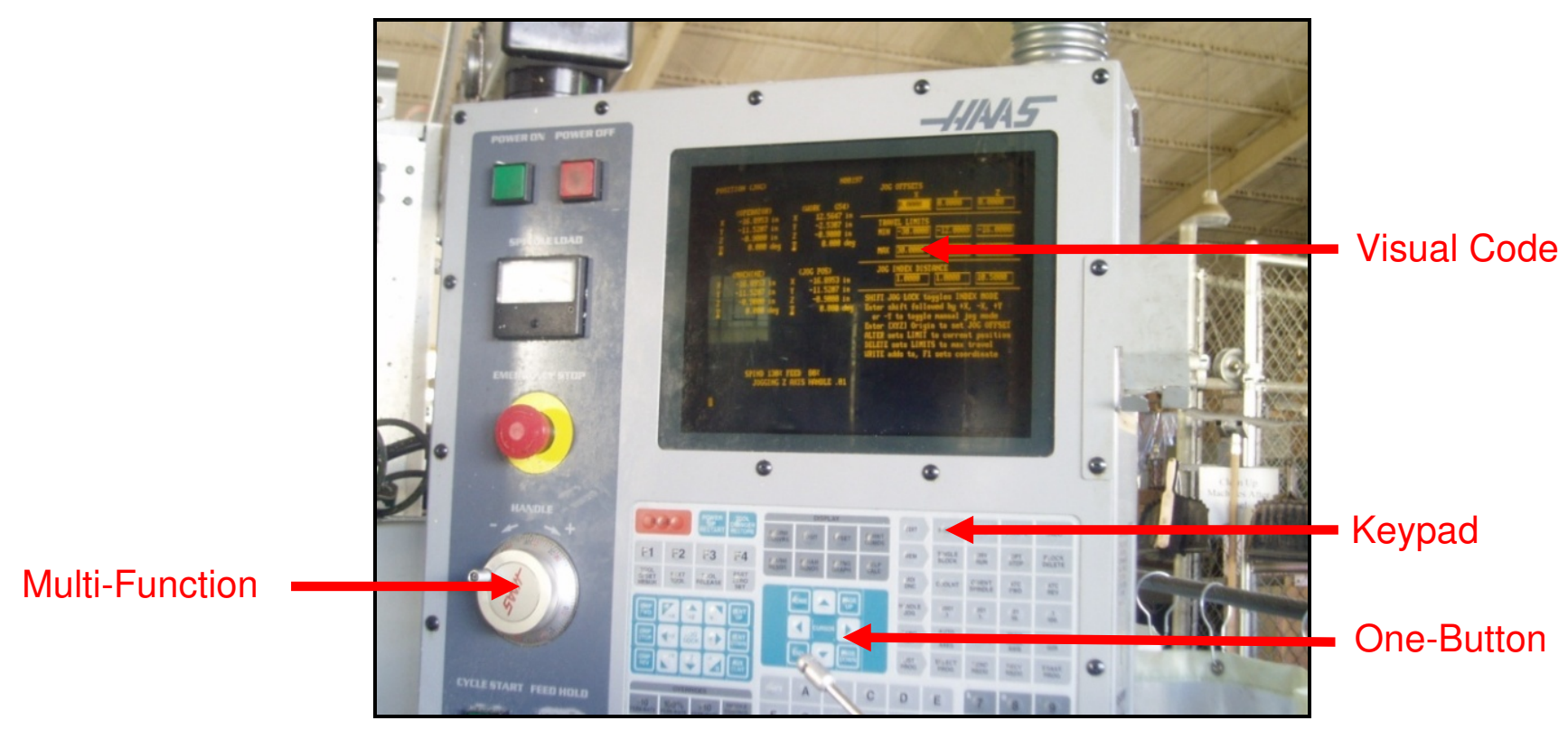

Figure 3.3: Control Panel for Haas Mill Machine

The Haas keypad has more than 130 keys. All common functions, including a full alphanumeric keyboard, are clearly labeled for operator ease. The control panel also has advanced program editing that allows the operator to edit programs in a dual-window format. One-button feature are common-multi-step functions, such as powering up the next tool or setting tool offsets, which have been reduced to a single button. The multi-function jog handle provides the operator to use to cursor through the program for faster editing, or scan through offsets parameters, override spindle or federate commands, and step through hundred lines of code with one rotation of the handle. Finally, the Haas visual quick code programming system is a conversational programming system that uses a graphical interface to make simple G-code programs which allows the operator to select the operation from an on-screen list (e.g., bolt-hole circle, drilling, tapping, pocket milling).

The manhole cover plug was created by using all the Haas features that was previously mentioned. Different cutting tools were used to cut the high-density foam plug. Each cutting tool was carefully selected based on the desired size and dimensions dictated by the Mastercam 
program. Cutting tools had to be attached with high-capacity cartridge spindles to provide high axial thrust capacity while generating minimal heat during the cutting process. The cartridge spindles had a high-cutting speed of 4,000 rpms for increased accuracy and time savings [Haas]. The electronic tool changer is an umbrella-style carrousel that cutting tools are mounted-on, as seen in Fig. 3.4.

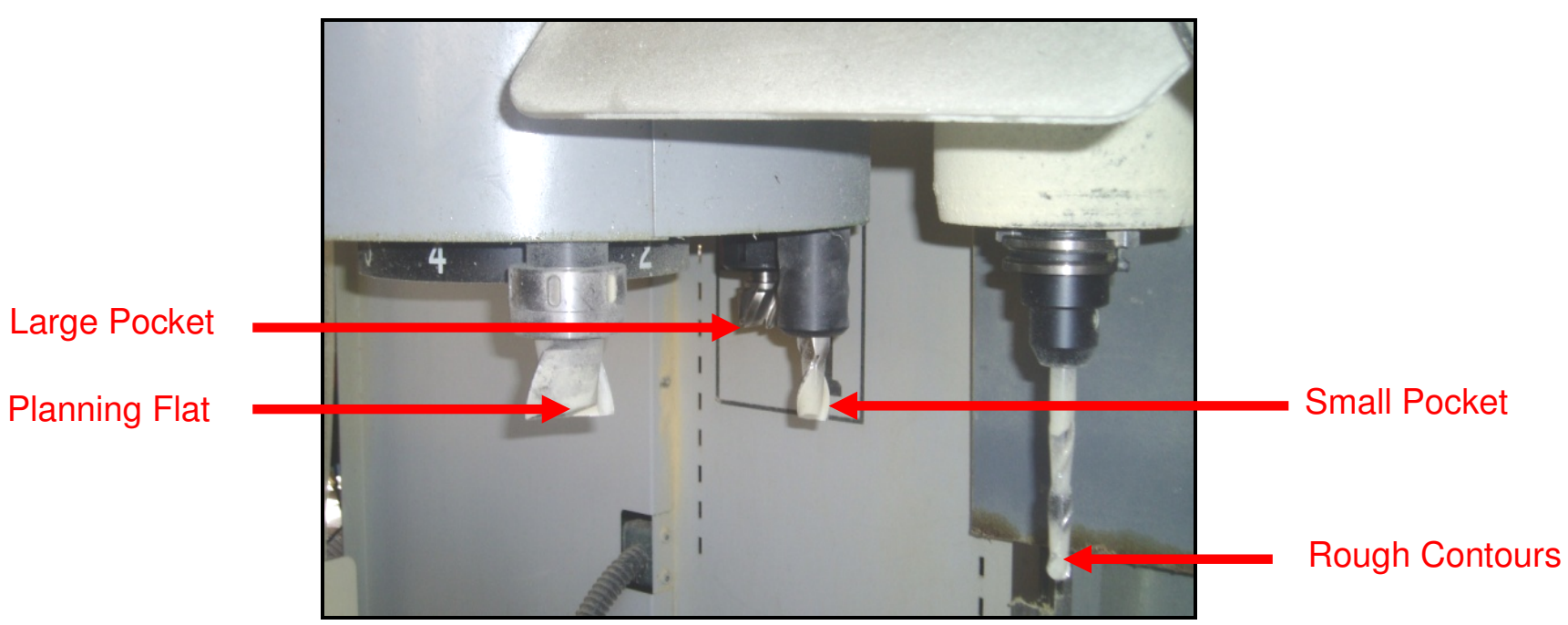

Figure 3.4: Umbrella-Style Tool Changer with Cutting Tools

Cutting tools were automatically changed between cutting tasks, thus faster tool changes increase productivity and reduce setup times. Table 3.1 shows the different processes with the corresponding tool cutters used to create the plug.

Table 3.1: Summary of CNC Mill Operations and Tool Cutter Sizes

\begin{tabular}{|c|c|}
\hline CNC Mill Operation & Tool Cutter Size (in) \\
\hline Small Pocket & 0.875 \\
\hline Large Pocket & 1.5 \\
\hline Rough Contours & 0.5 \\
\hline Planning Flat Surface & 2 \\
\hline
\end{tabular}


A 12 by 12 -in of high-density foam was measured and cut to create the manhole cover plug. Eight screws were drilled into the high-density foam's sides and clamped onto a 14 inch by 14 inch wooden board with four vices in order to support and secure the high-density foam from moving during $\mathrm{CNC}$ operations, as seen in Figure 3.5.

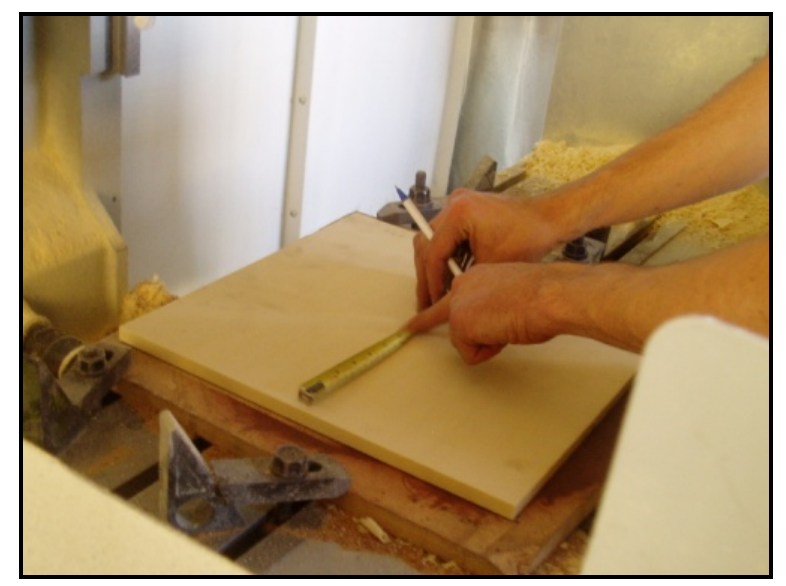

\section{Figure 3.5: Measuring and Securing High-Density Foam for CNC Operations}

After securing the high-density foam and selecting the proper tool bits, the CNC operation is ready to undergo the milling process. Figure 3.6 shows the mill operation referred as "centering" which helps to the center of density square foam into create the manhole's circular shape.

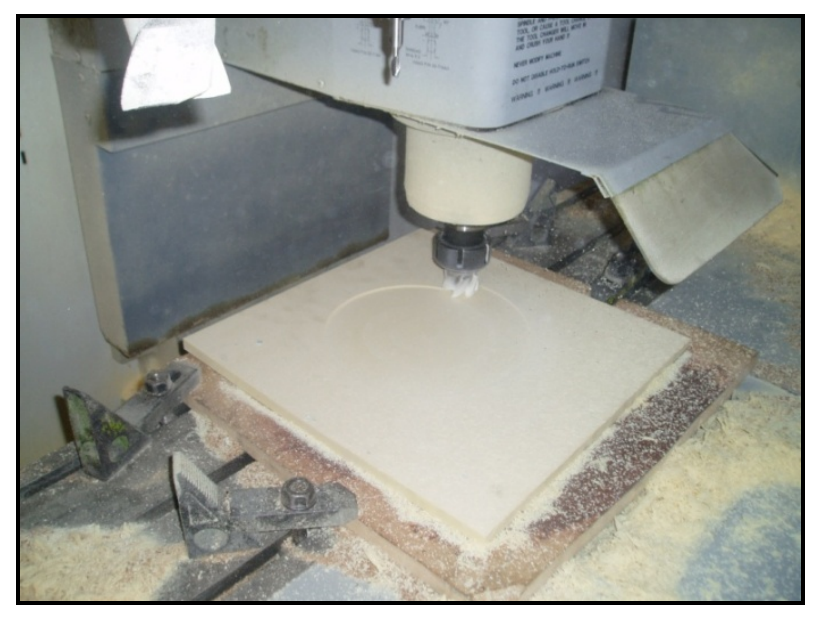

Figure 3.6: Centering Operation 
Figure 3.7 shows high-density foam debris was removed with air pressure gun since the CNC machine was not able to run will coolant since it would damage clog up the coolant system and foam would absorb the coolant thus damaging the texture of mold.

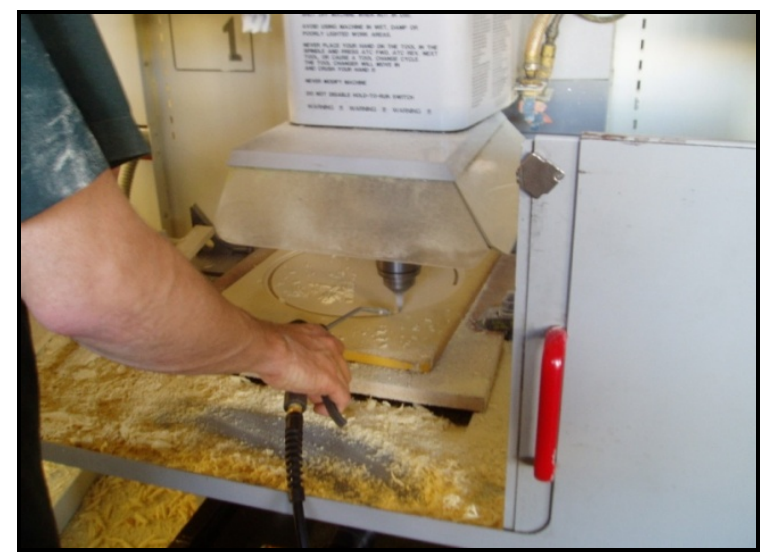

Figure 3.7: Removing High-Density Foam Debris with Air Pressure Gun

After manhole cover plug was created due to milling operation, it was deburred with the Aero-Hanger's vertical sander in order to round the edges, as seen in Fig. 3.8.

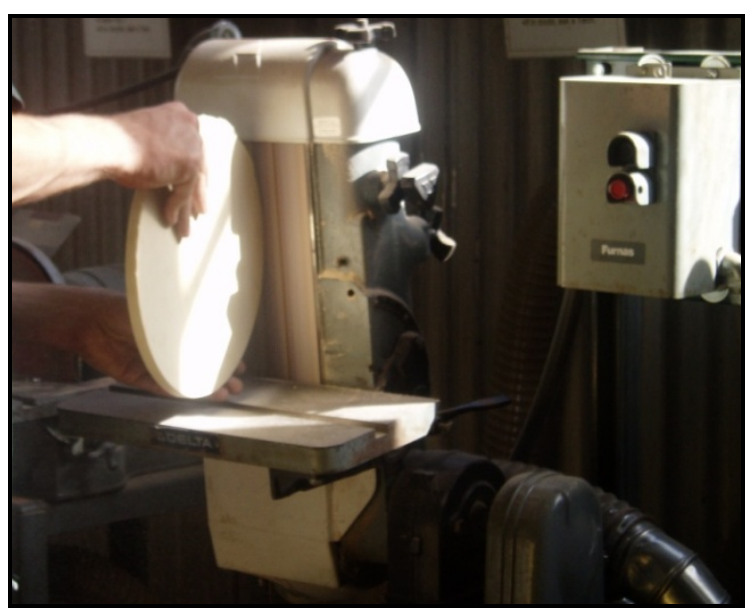

\section{Figure 3.8: Sanding Manhole Cover Plug}

Fig. 3.9 shows the final CNC machined plug of the Cal Poly manhole cover which was later used to create the female mold for this project. 


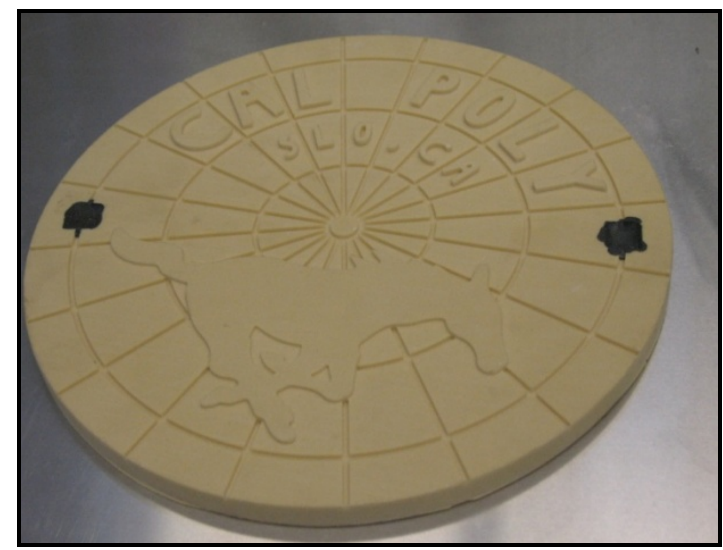

Figure 3.9: Customized Cal Poly Manhole Cover Plug

\subsection{Using Urethane Rubber Molds}

\subsubsection{Urethane Liquid Rubber}

The female/male molds were made from urethane liquid rubber resin. The urethane liquid rubber (PMC-790) was purchased from the Reynolds Advanced Materials Company of North Hollywood, CA. They have been supplying different types of materials needed for mold making and casting since 1963. The Smooth-On's PMC-790 Gallon Kit is the urethane liquid rubber material used for creating the press molds, as seen in Figure 3.10. PMC-790 is a new shore $90 \mathrm{~A}$ industrial urethane rubber compound designed to meet most stringent requirements of industrial production applications. The hard rubber that is created after curing has superior tear and tensile strength (72,000 psi) characteristics as well as impact and abrasion resistance [34], as previously discussed in section 3.4. PMC-790 is also used for a variety of industrial applications including making concrete stamping pads, mold liners, and molds for casting concrete. It is also good for making ball mill liners, industrial rollers and belts, rubber mechanical parts and for bonding itself or other substrates to metal [34]. PMC-790 Gallon Kit is very economical since it can be purchased for an approximately $\$ 197$ and can produce four 16 in x 3 in rectangular press molds. 


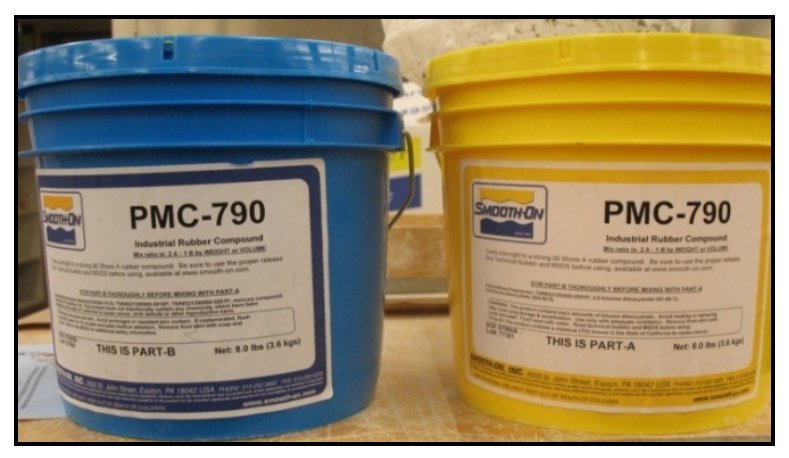

Figure 3.10: Urethane Liquid Rubber Gallon Kit

The PMC-790 is an industrial rubber compound that consists of two part resin, Part-A is the blue container and Part-B is the yellow container, as seen in the figure above. Part-A consist of di-(methlthylthio) toluene and mercury compound, whereas, Part-B consist of polyurethane prepolymer and 4-toluene disocyanate. Table 3.2 shows the specification of urethane liquid rubber and other materials used to for mold making and casting:

Table 3.2: Specification Chart for Different Mold-Making Materials

\begin{tabular}{|c|c|c|c|c|c|c|}
\hline Material & Pot Life & Viscosity & Curing & Durometer & Color & Tear Strength \\
\hline $\begin{array}{c}\text { Urethane Liquid } \\
\text { Plastic }\end{array}$ & $20 \mathrm{~min}$ & $4,400 \mathrm{cps}$ & $16 \mathrm{hrs}$ & $88 \mathrm{D}$ & $\begin{array}{c}\text { Metal } \\
\text { Gray }\end{array}$ & $6,200 \mathrm{psi}$ \\
\hline $\begin{array}{c}\text { Urethane Liquid } \\
\text { Rubber }\end{array}$ & $20 \mathrm{~min}$ & $1800 \mathrm{cps}$ & $16 \mathrm{hrs}$ & $90 \mathrm{~A}$ & $\begin{array}{c}\text { Clear } \\
\text { Amber }\end{array}$ & $300 \mathrm{psi}$ \\
\hline $\begin{array}{c}\text { Silicone Liquid } \\
\text { Rubber }\end{array}$ & $45 \mathrm{~min}$ & $35,000 \mathrm{cps}$ & $24 \mathrm{hrs}$ & $50 \mathrm{~A}$ & Blue & $155 \mathrm{psi}$ \\
\hline $\begin{array}{c}\text { Epoxy Tooling } \\
\text { Resins }\end{array}$ & Varies & $5,000 \mathrm{cps}$ & $24 \mathrm{hrs}$ & $90 \mathrm{D}$ & Amber & $30,000 \mathrm{psi}$ \\
\hline $\begin{array}{c}\text { Rigid Urethane } \\
\text { Foam }\end{array}$ & $1 \mathrm{~min}$ & $200 \mathrm{cps}$ & $2 \mathrm{hrs}$ & $\mathrm{N} / \mathrm{A}$ & Tan & N/A \\
\hline
\end{tabular}




\subsection{Making Negative Mold}

\subsubsection{Sealing the Negative Plug}

A coating sealant needs to be applied to the plug in order to seal and protect the plug from the urethane resin rubber solution that will be used to create the molds. Two types of sealants (water-based and oil-based varnish) were tested. The sealants used were water-based and Man $O^{\prime}$ War oil-based varnishes, as seen in Fig. 3.11.

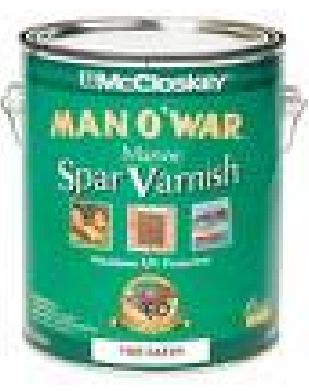

Figure 3.11: Man O' War Spar Oil-Based and Water-Based Varnishes

The water and oil-based varnishes were coated with a paint brush onto a piece of highdensity foam material in order to observe any detrimental effects that the resin may cause to the foam. As seen below, the water-based varnish had a smoother and lighter texture coating, whereas, the oil-based varnish had a thicker texture coating.

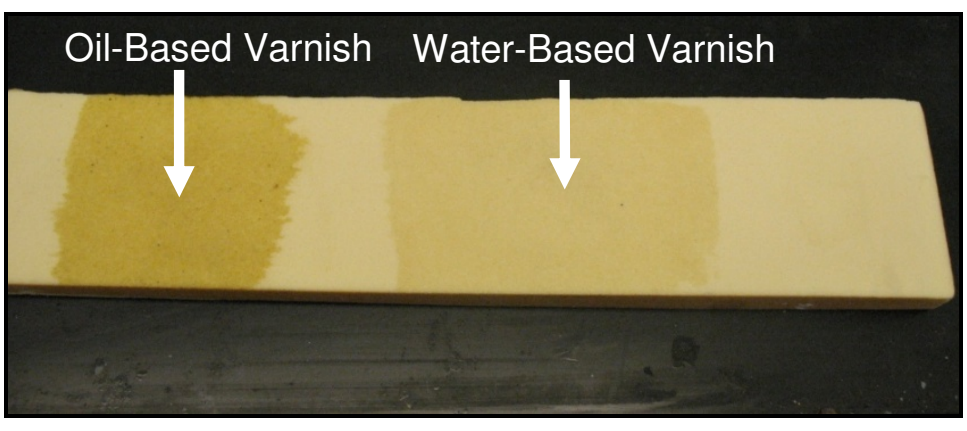

Figure 3.12: Testing for Side Effects of Sealants on a Piece of High-Density Foam 
Fig. 3.13 shows the oil-based varnish was selected since it had a thicker coating, thus providing a better protective-coating sealant for the plug.

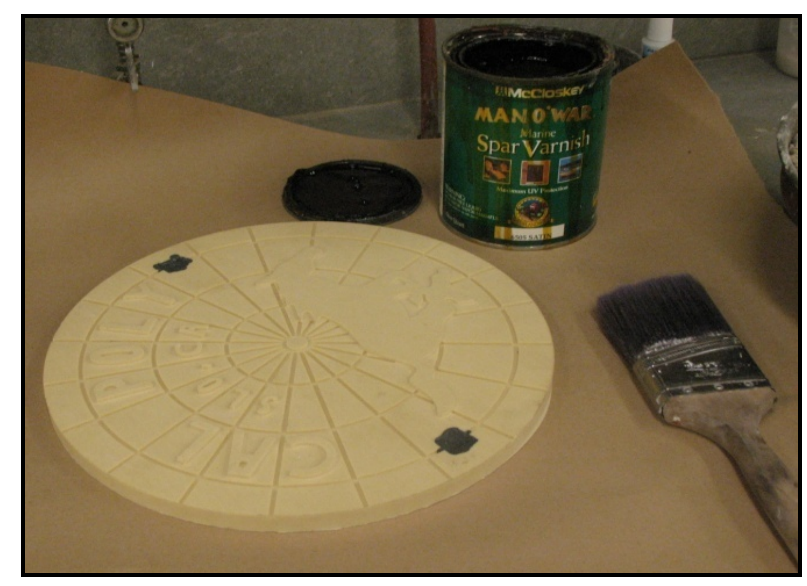

\section{Figure 3.13: Oil-Based Varnish Sealant and Plug}

A $20 \times 20$ in piece of cardboard was placed underneath the plug to later remove any excess oil-based varnish. The oil-based sealant was coated and spread on the manhole cover plug completely, as seen in Figure 3.14. It was essential that the plug was cover with the sealant completely in order to ensure that the plug would be protected from the resin. Hence, four coatings of the oil-based varnish were needed in order to ensure best results. After the oil-based varnish was spread on the plug evenly, excess varnish had to be removed from the plug in order to avoid any varnish build-up that will later dry and act as barrier; thus creating inaccurate detail finishes to the mold. Finally, the plug was then stored and left to dry in a secured area for four days. 


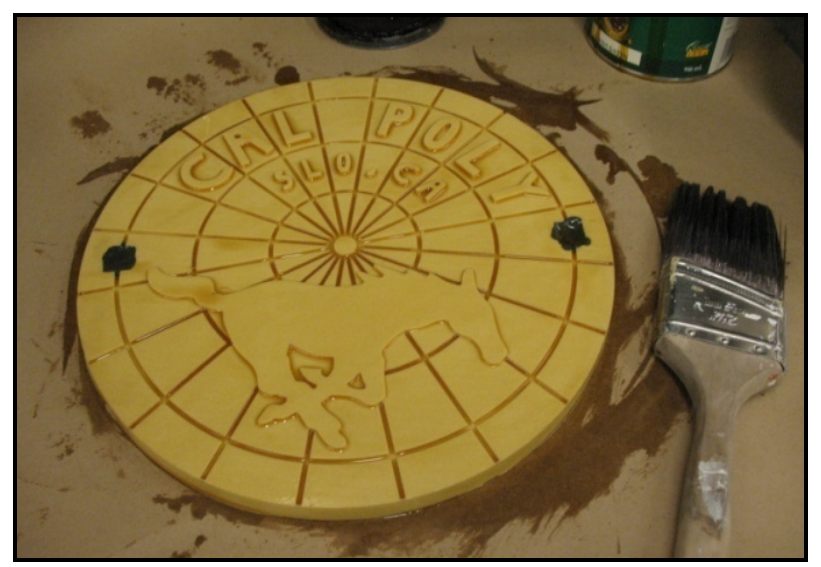

Figure 3.14: Removing Excess Oil-Based Varnish from Plug with Paint Brush

\subsubsection{Creating Wooden Frame}

After the plug is dry, the next step is to create a wooden frame (retaining walls) that will enclose the plug in order to contain the urethane liquid rubber resin that will be poured in order to make the negative mold. The retaining walls were made from ply-wood and cut into 4 pieces of 16-inch in length and 3-inch in height. Each corner of the walls was carefully nailed with two 1-inch nails. The plug of the manhole cover was placed in the center of the wooden retaining walls, as seen in the Figure 3.15.

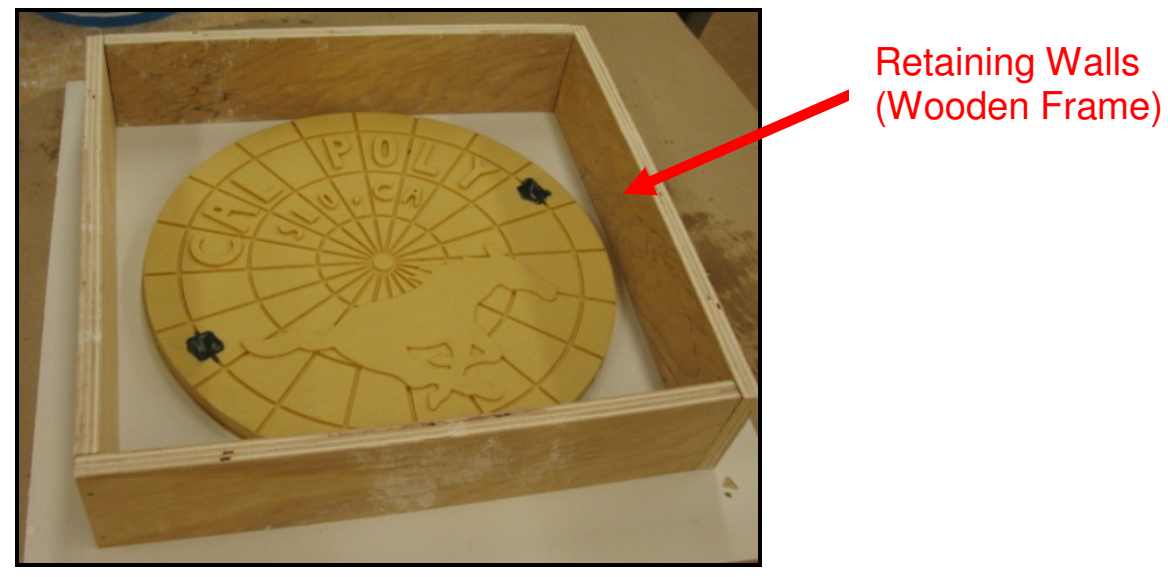

Figure 3.15: Plug Inside Wooden Frame's Retaining Walls Used to Create Negative Mold 


\subsubsection{Modeling Clay}

After the corners were nailed together, Laguna's modeling clay was then added along the wooden frame model's bottom and corners.

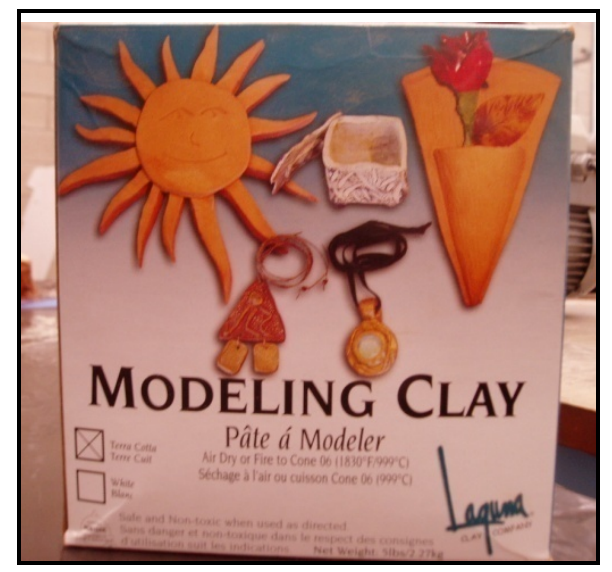

Figure 3.16: Laguna's Modeling Clay

This was performed in order to prevent any resin leakage due to non-visible gaps between the corners and bottom of the wooden frame, as seen in Fig. 3.17. Modeling clay or sculptor clay can be either used to secure or prevent resin slippage.

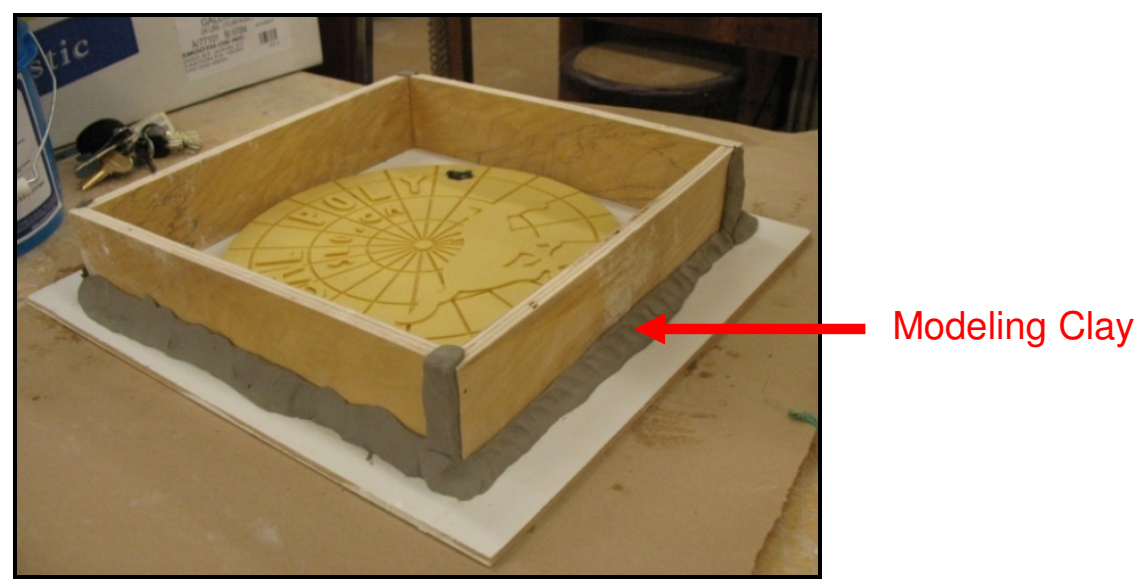

Figure 3.17: Clay along Corner's of Wooden Frame to Prevent Resin Leakage 


\subsubsection{Creating Spraying Mold Release Agent}

After adding sculptor clay along the corners and bottom of the wooden frame, Smooth-On Universal Mold Release, as seen in the Fig. 3.18, was sprayed on the plug thoroughly before mixing the urethane resin. The mold release is needed to separate the part from the mold and lengthen production life of the rubber mold. For best results, hold spray can 12-inches away from mold surface.

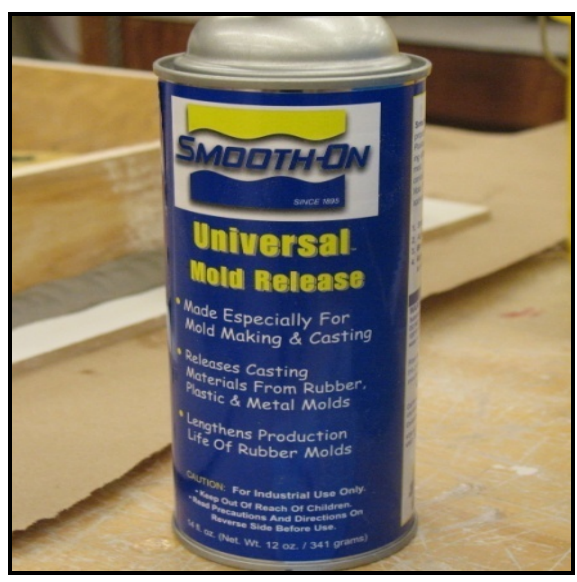

\section{Figure 3.18: Smooth-On Universal Mold Release Agent}

In addition, a paint brush was used to disperse the mold release's coating evenly to mold and wooden frame surfaces. Finally, another light-mist coating of release agent was applied and left alone for 5 minutes before adding the mixed urethane rubber compound.

\subsubsection{Air Bubbles in Urethane Resins}

Urethane resins are moisture sensitive, and often air bubbles found in cured urethane plastic are a result of a reaction between the plastic in its liquid state and moisture coming from humidity [34], as seen in Fig. 3.19. 


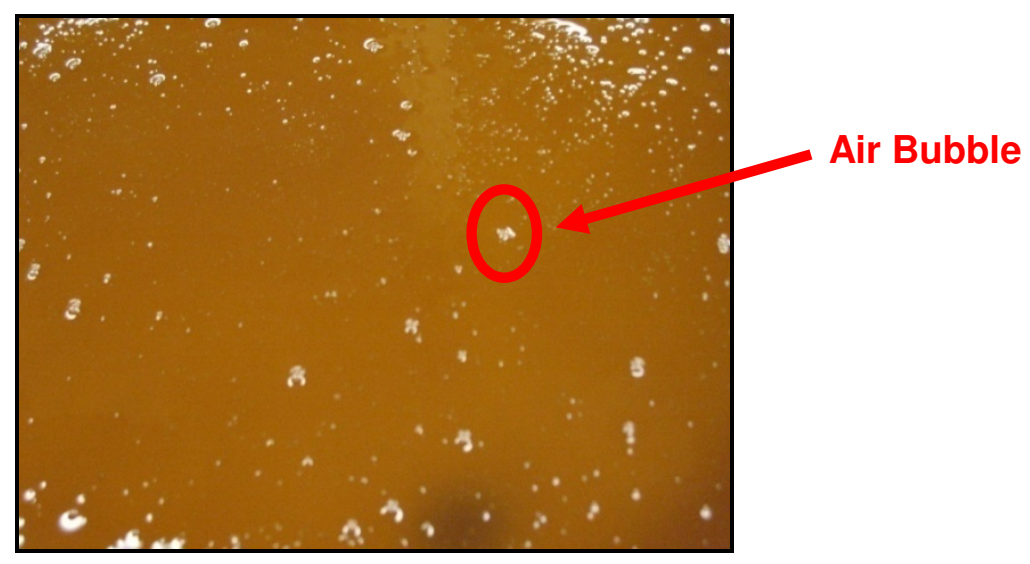

Figure 3.19: Formulation of Air Bubbles within Urethane Resins

Therefore, it is highly recommended to work in a humidity-controlled environment (air conditioning) with as low a relative humidity as possible. Also, it is recommended to use urethane plastic with a shorter pot life since it will have less time to react with ambient moisture, thus reducing air bubbles. Consequently, another way to prevent air bubble formulation in the urethane solution is by stirring gently and pouring the resin with uniform flow.

\subsubsection{Measuring and Mixing Urethane Liquid Rubber Solution}

The Smooth-On PMC-790's Part-A is mixed with Part-B with a mix ratio of 2A:1B by volume; hence, a plastic container with a 4-inch diameter and a 7-inch height was used for measuring. The container was later marked at a height of 4.25 inches which was the assumed height used to measure the volume of urethane liquid rubber needed to construct the negative mold. It was required that Part-B is stirred thoroughly before mixing with Part-A. It was also needed to gently and smoothly stir the rubber compound in order to minimize air bubbles forming in the final rubber compound mold. Part-B was then ready to be mixed with Part-A. The proper amounts of Part-A and B were dispensed into a new mixing container with a slowuniform flow in order to reduce air bubbles, as seen in Fig. 3.20. 


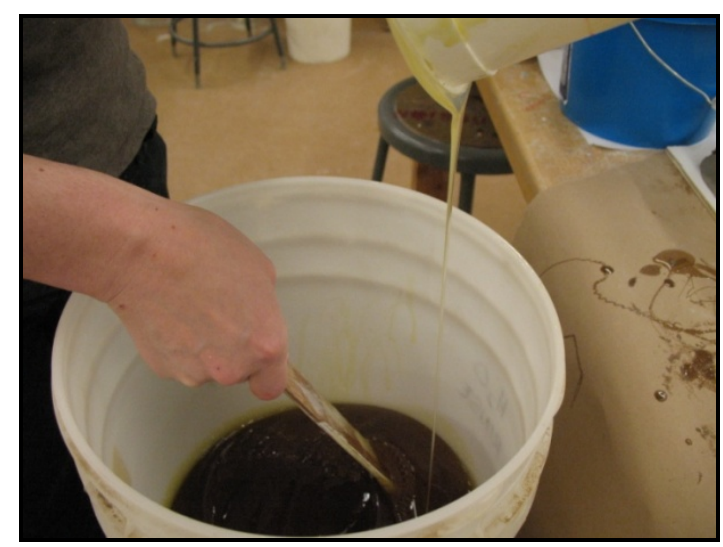

Figure 3.20: Gently Stirring and Mixing Urethane Compound to Minimize Air Bubbles

After dispensing entire quantity into a new, clean mixing container, the urethane solution is then mixed thoroughly for at least 3 minutes while also making sure that solution is scraped from getting stuck on the sides of the mixing container. Once again, it was important to carefully mix and stir mixture slowly to reduce air bubbles. Also, although the Smooth-On product is formulated to minimize air bubbles in cured rubber, vacuum degassing will further reduce the entrapped air [34]. In addition, if mixing large quantities (16 lbs/ $7 \mathrm{kgs}$ or more) at one time, use a mechanical mixer for 3 minutes followed by careful hand mixing for 1 minute as directed above [34].

\subsubsection{Pouring Mixed Urethane Resin into Wooden Frame Mold}

The mixed urethane resin was then carefully poured on negative plug inside the wooden frame, as seen in Fig. 3.21. For best results, the urethane resin mixture was poured in a single spot, preferably at the lowest point of the containment field until it covered the plug completely. Again, a constant flow was maintained to minimize entrapped air in urethane solution. 


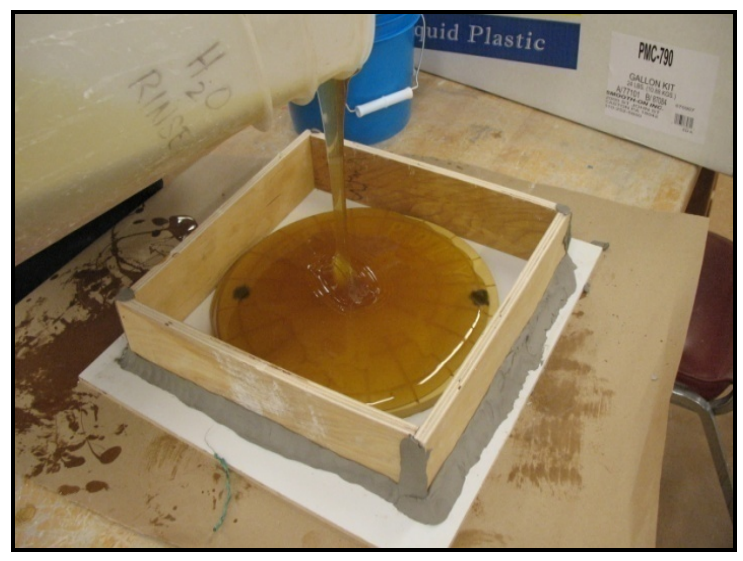

\section{Figure 3.21: Pouring Mixed Urethane Resin into Wooden Frame}

The urethane mixture was then momentarily left alone for the rubber solution to seek its level up and over the plug. The liquid rubber solution should level-off at least 0.5 inches over highest point of the model surface, as seen in Fig. 3.22. The total of height of the poured urethane solution within the wooden frame was approximately 2.57 inches.

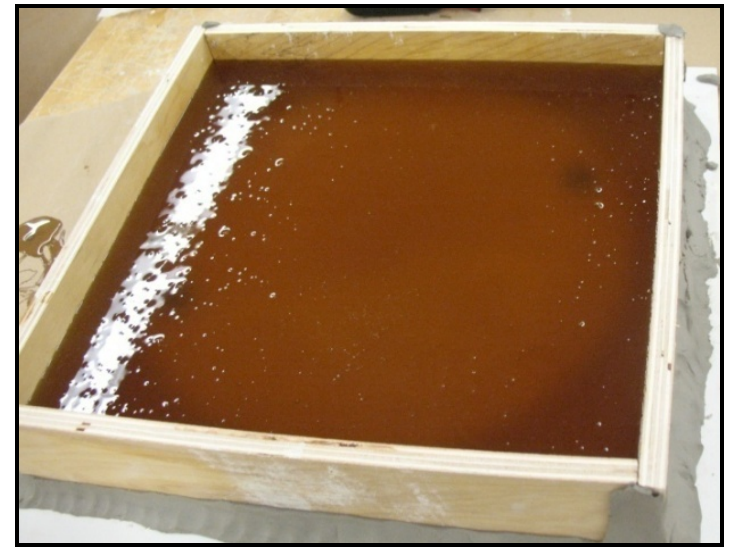

Figure 3.22: Urethane Liquid Rubber Solution Covering Plug

After the urethane liquid rubber solution was poured in the wooden frame model, rubber mallets were used to stomp on the table and around wooden frame model in order to cause air bubbles to rise on top of liquid rubber solution. Fig. 3.23 shows how the rubber mallets were 
hammered on the table until no more air bubbles were raised onto the liquid rubber mixture's surface.

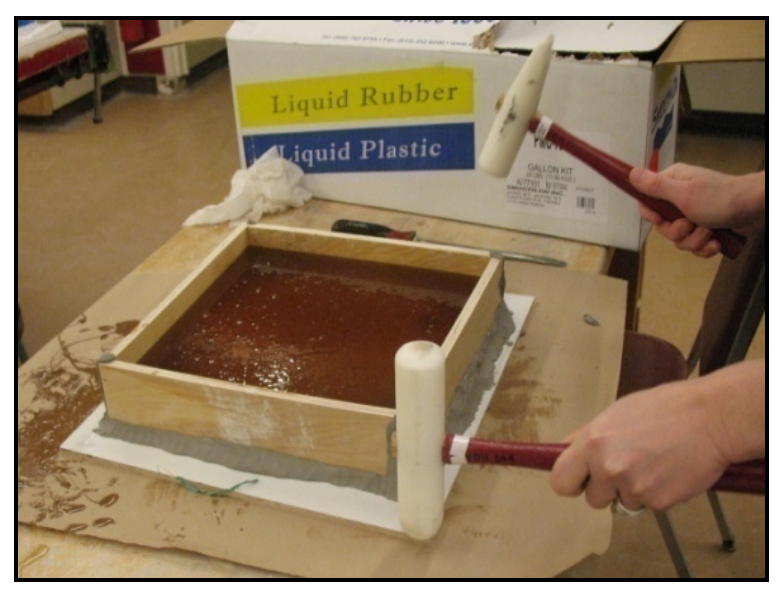

\section{Figure 3.23: Using Rubber Mallets to Remove Air Bubbles from Mold}

\subsubsection{Curing Process}

The urethane liquid rubber solution was left to cure overnight (at least 16 hours) and at room temperature $\left(77^{\circ} \mathrm{F}\right)$ before demolding. The cure time can be reduced with mild heat or by adding Smooth-On's "Kick-It" cure accelerator. It was also important not to cure the urethane liquid rubber when the temperature is less than $65^{\circ} \mathrm{F}$. This will help with the curing process to a strong 90 shore $A$ rubber compound post curing [34]. In addition, after the rubber has cured at room temperature, heating the rubber to $150^{\circ} \mathrm{F}$ for 4 to 8 hours will increase physical properties and performance.

\subsubsection{Separating Urethane Rubber Mold from Plug}

The urethane rubber mold was separated from plug by first using a hammer to carefully remove the wooden frame's retaining walls from the cured mold, as seen in Fig. 3.24. 


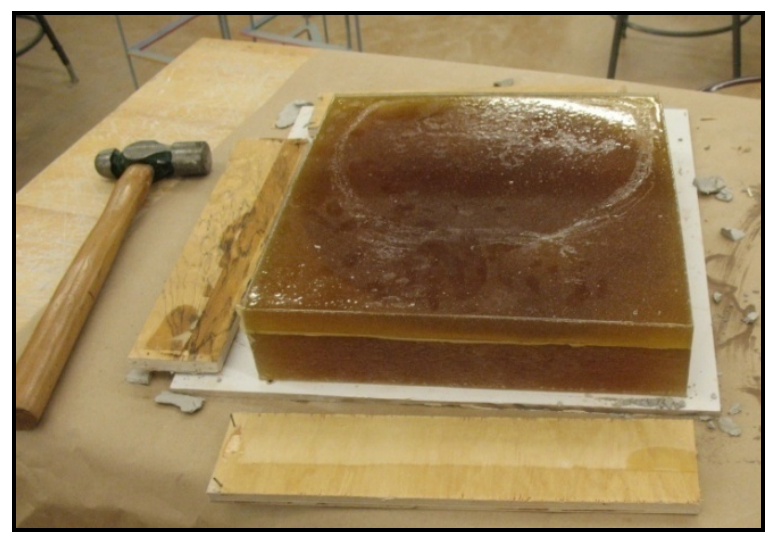

Figure 3.24: Removing Wooden Frame's Retaining Walls from the Cured Mold

The next step was to flip the cured mold upside down. A razor blade was used to trace and cut along the plug's outer edges in order to initiate a separation gap between the rubber mold and plug, as seen in Fig. 3.25. The razor blade had to be carefully inserted between the rubber mold and plug in order not to damage the mold cavity.

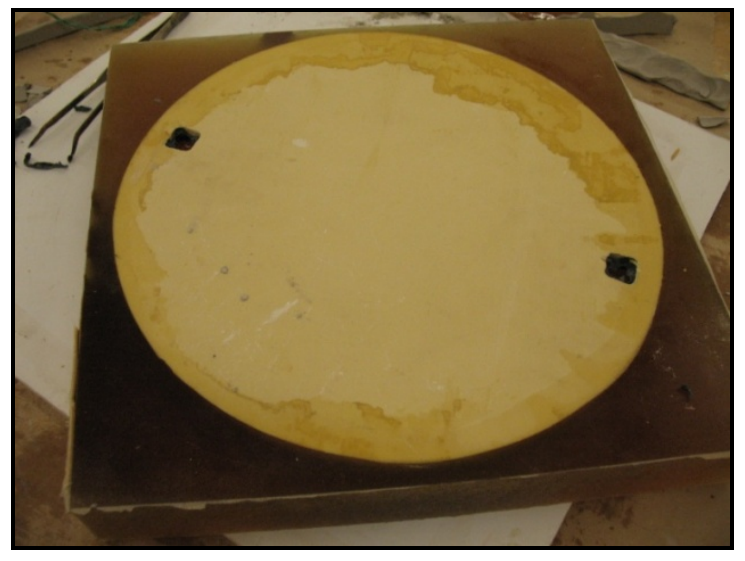

\section{Figure 3.25: Bottom Side of Cured Rubber Mold and Plug}

Two screws were later inserted carefully into the plug's backside, as seen in Figure 3.26. The two screws provided leverage for separating plug from rubber mold. 


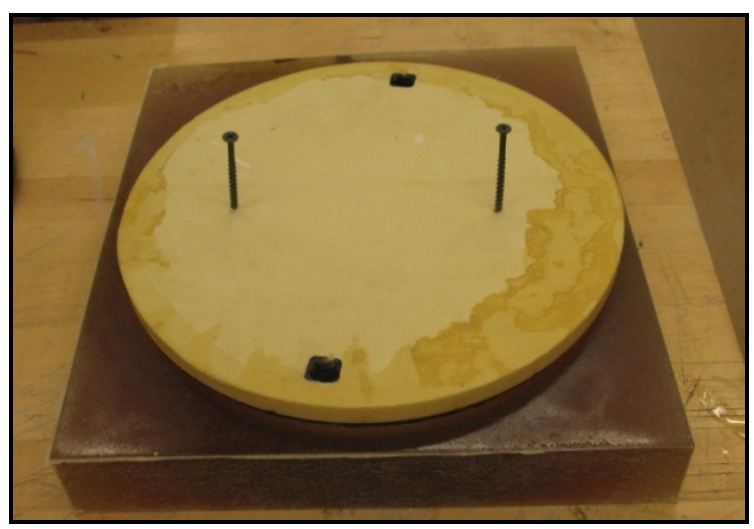

Figure 3.26: Screws Inserted Backside for Separating Plug from Rubber Mold

The plug was separated from the rubber mold by pulling onto the screws with pliers while pressing down on to the mold's corners. The result of this process is shown in

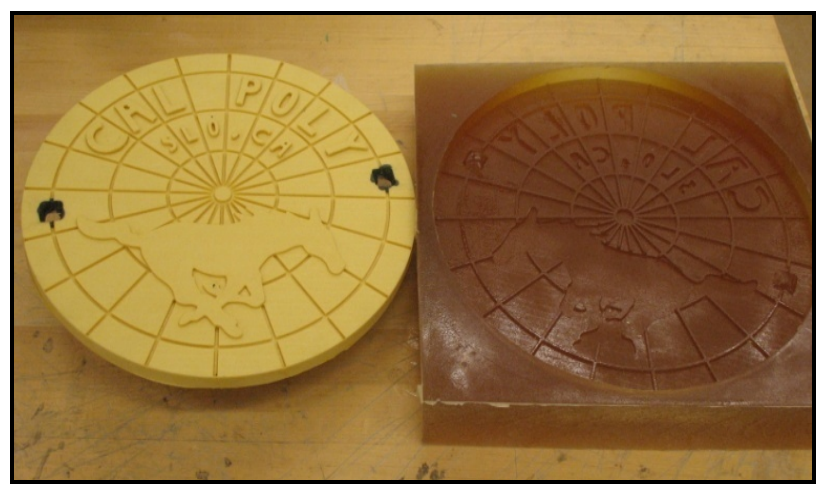

Figure 3.27: Negative Urethane Rubber Mold and Plug

Fig. 3.28 shows the final product was a negative urethane rubber mold of the plug. The plug was intact while the rubber mold had preserved the fine details of the manhole cover. The negative rubber mold's physical characteristics were the following: dark amber in color, a strong irritating odor due to the urethane compound, stickiness due to the release agent, heavy in weight, and hard in texture. 


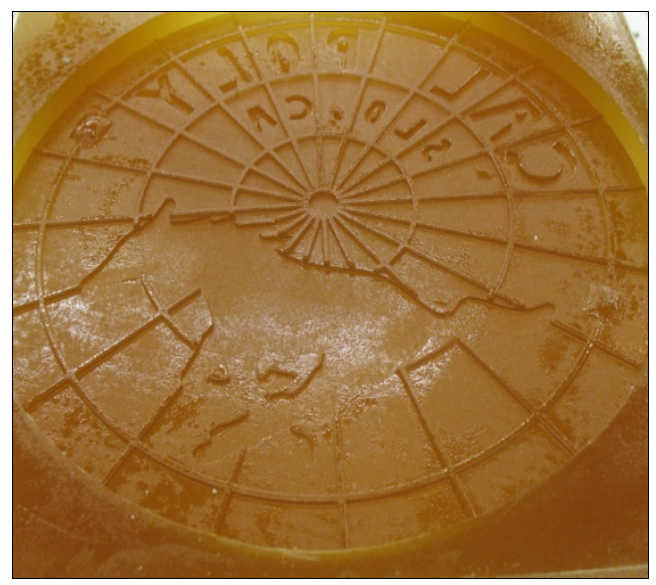

Figure 3.28: Negative Rubber Mold of Manhole Cover

Finally, mold release agent will be applied to the rubber mold before each casting. The type of release agent depends on material being casted. Consequently, the proper release agent for wax, liquid or thermosetting materials is Universal Mold Release.

\subsection{Making Negative Smooth-Surface Mold}

A second positive mold was created with several modifications, as previously mentioned in Section 4.1. A positive mold with a smooth surface, reduced diameter, and tolerances would not only improved manhole cover detail features but also enhance its physical characteristics by allowing excess resin to move freely between molds during curing process; thus, as seen in Fig. 3.29, a new high-density plug with the added modifications was created by using the CNC Mill machine. Consequently, the same procedure of making positive mold was repeated for creating the positive smooth-surface mold. 


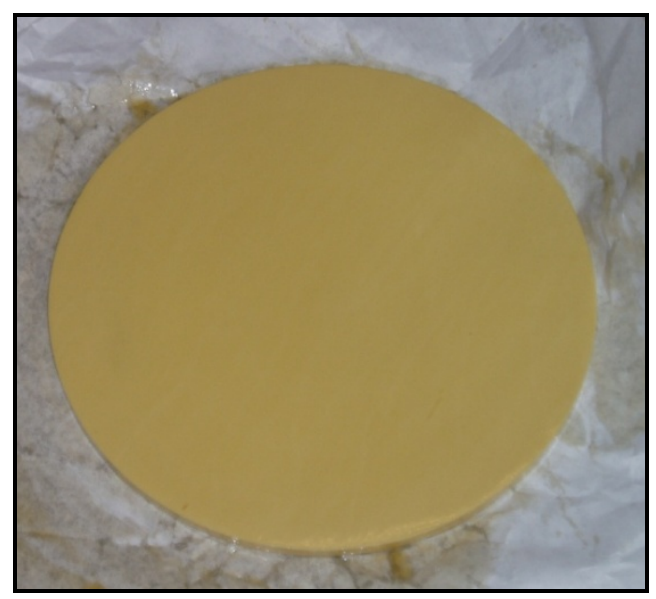

Figure 3.29: Smooth Surface Plug

\subsubsection{Creating Wooden Frame}

A smooth-surface negative mold had to be created before making the smooth-surface positive. Four pieces of $16 \times 3$ in ply-wood were cut and placed around the smooth surface plug in order to contain the urethane liquid rubber resin. Plug and wooden frame's sides were measured and marked at the middle ( 8 inches from edge) in order to precisely align the plug in the center of frame, as seen in Fig. 3.30. This was created to provide additional urethane rubber for supporting the extra load needed on the press mold for improving the quality of the curing process. Each corner of the wooden retaining walls was carefully nailed with two 1-inch nails.

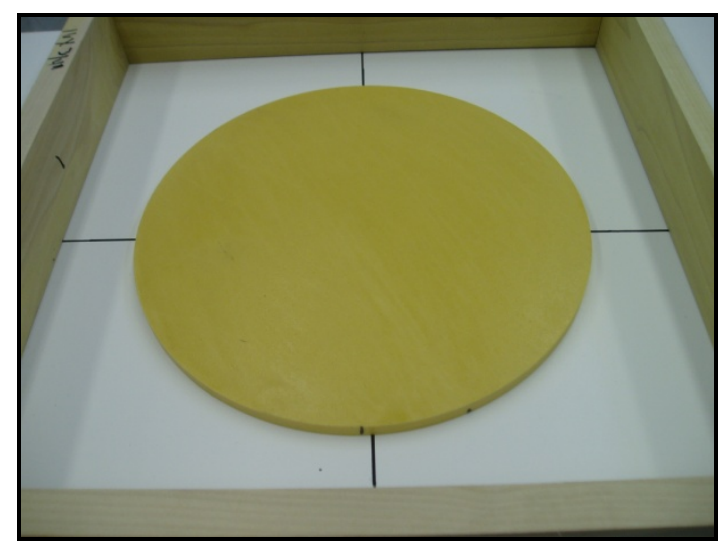

Figure 3.30: Alignment of Smooth Surface Plug with Wooden Frame 
Modeling clay was added to wooden frame's bottom and corners in order to prevent resin slippage. Several weights of $10 \mathrm{lbs}$ were placed on wooden frame's corners to further secure urethane liquid slippage, as seen in Fig. 3.31.

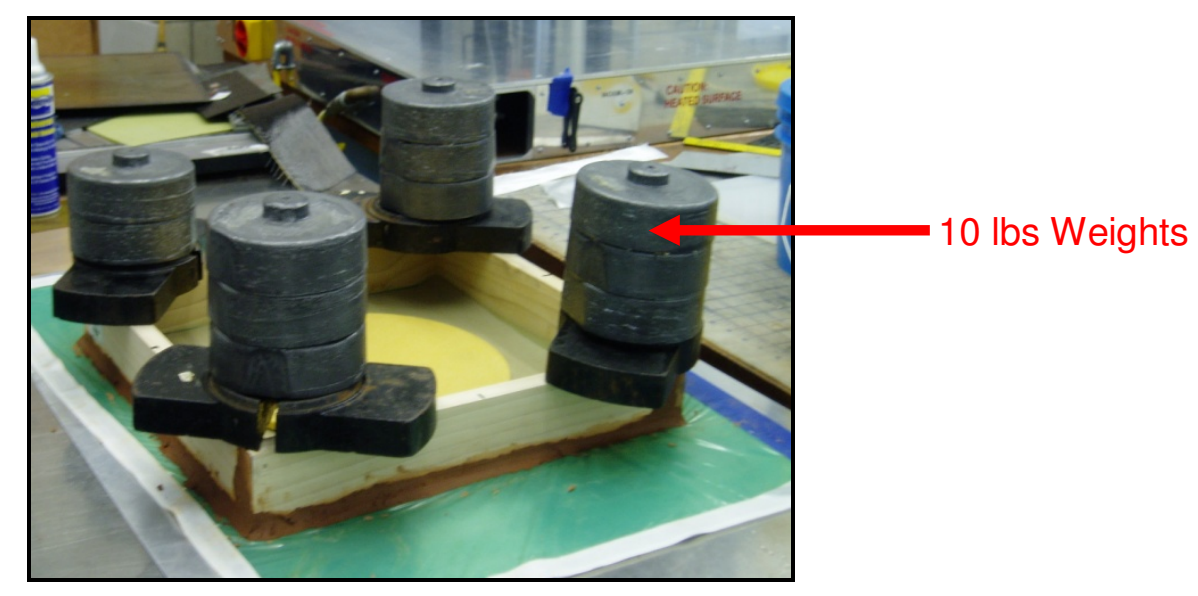

Figure 3.31: Weights Placed on Frame's Corners to Prevent Slippage

In additional, green bagging film and non-porous brown release film was placed underneath the smooth high-density plug to ensure full mold separation, as seen in Fig. 3.32.

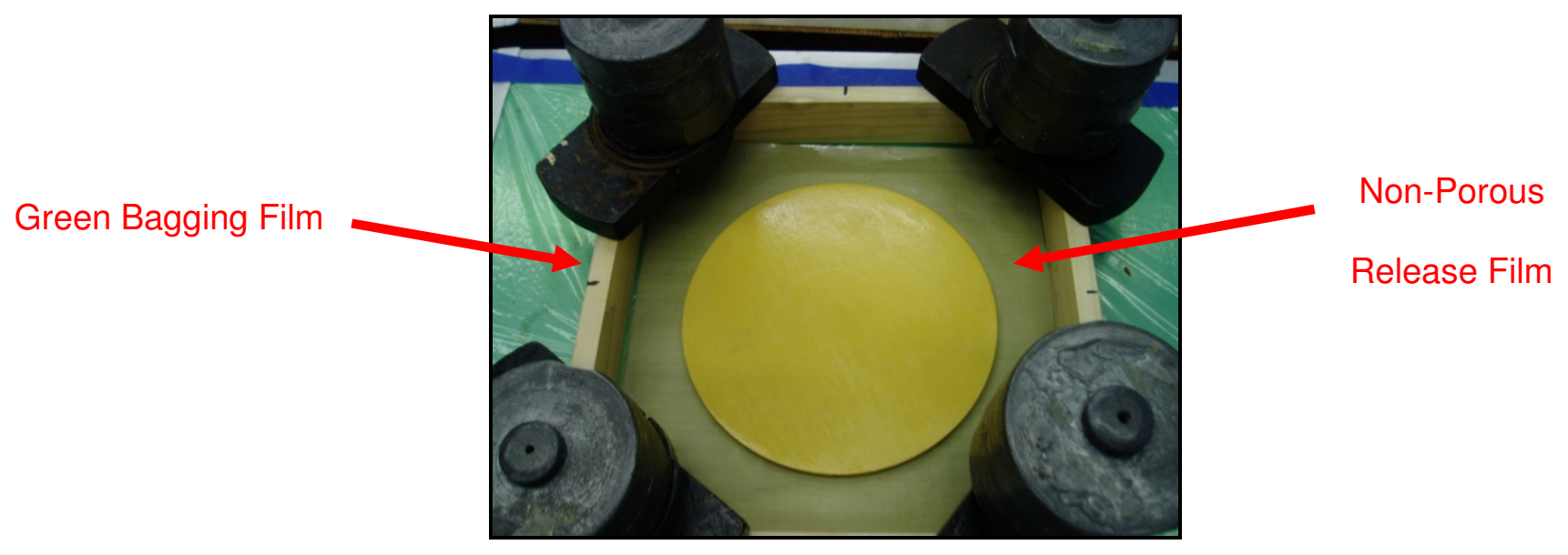

Figure 3.32: Green Bagging Film and Non-Porous Release Film 


\subsubsection{Spraying Mold Release Agent}

Smooth-On Universal Mold Release was sprayed on the smooth surface plug and inside wooden frame. Another coating of the mold release agent was sprayed and left alone for 5 minutes before adding the mixed liquid urethane rubber compound.

\subsubsection{Measuring and Mixing Urethane Liquid Rubber Solution}

Smooth-On PMC-790's Part-A was mixed with Part-B with a mix ratio of 2A:1B by volume for the positive mold. A new plastic container with a 4 inch diameter and a 7 inch height was used for measuring. The container was again marked at a height of 4.25 inches.

Again, it was required that Part-B is gently stirred thoroughly before mixing with Part-A. Part-B was then ready to be mixed with Part-A. After dispensing entire quantity into a new, clean mixing container, the urethane solution was mixed gently for at least 3 minutes while also making sure that solution is scraped from getting stuck on the sides of the mixing container.

\subsubsection{Pouring Mixed Urethane Resin into Wooden Frame Mold}

The mixed urethane resin was then carefully poured on the positive plug inside the wooden frame. Again, an uniform flow was maintained to minimize entrapped air in urethane solution. The urethane mixture was then momentarily left alone for the rubber solution to seek its level up and over the plug. After the urethane liquid rubber solution was poured in the wooden frame model, rubber mallets were again used to stomp on the table and around wooden frame model in order to create air bubbles to rise on top of liquid rubber solution. 


\subsubsection{Curing Process}

The urethane liquid rubber solution was left to cure overnight and at room temperature before de-molding, as seen in Fig. 3.33.

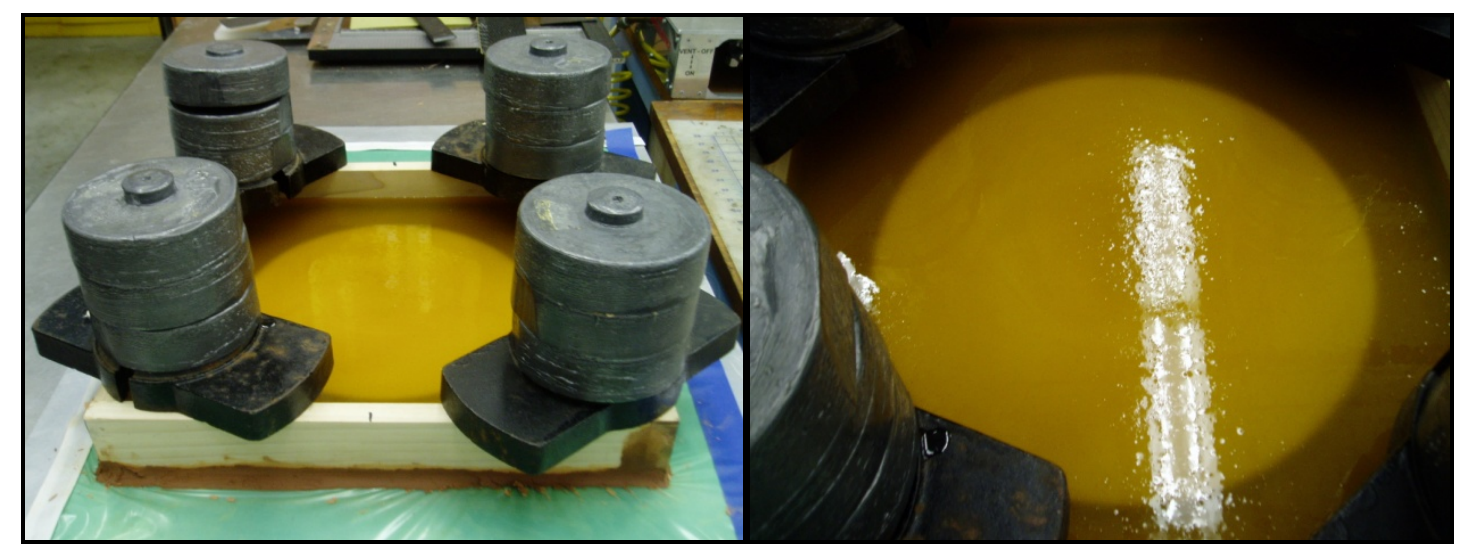

Figure 3.33: Smooth Surface Plug Immersed in Urethane Liquid Rubber Solution

\subsubsection{Separating Urethane Rubber Mold from Plug}

A hammer was used to remove the wooden frame's retaining walls from the cured mold, as seen in Fig. 3.34.

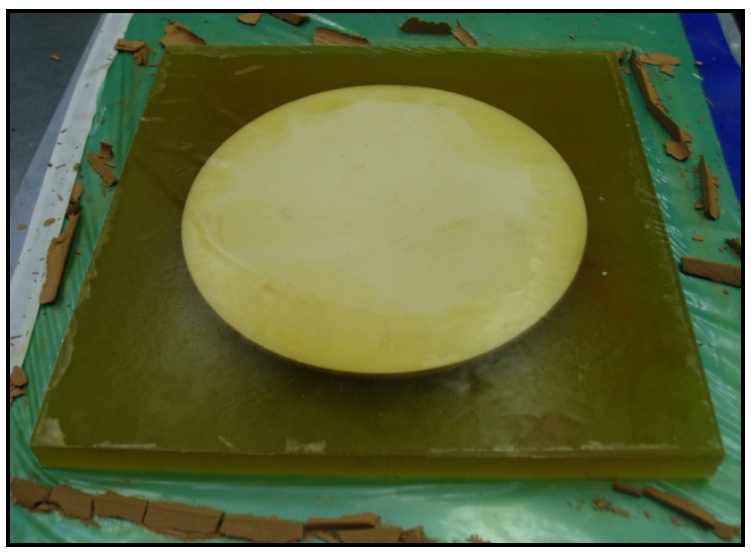

Figure 3.34: Smooth Surface Plug inside Negative Mold after Cured Process. 
A razor blade was inserted between the smooth surface plug and cured mold in order to initiate a separation gap between them. Pressure was applied on the cured mold by bending and pressing down on to the mold's corners in order to allow the plug to separate easily from the negative mold. Fig. 3.35 shows the final product of the negative mold which is a replication of the smooth-surface plug.

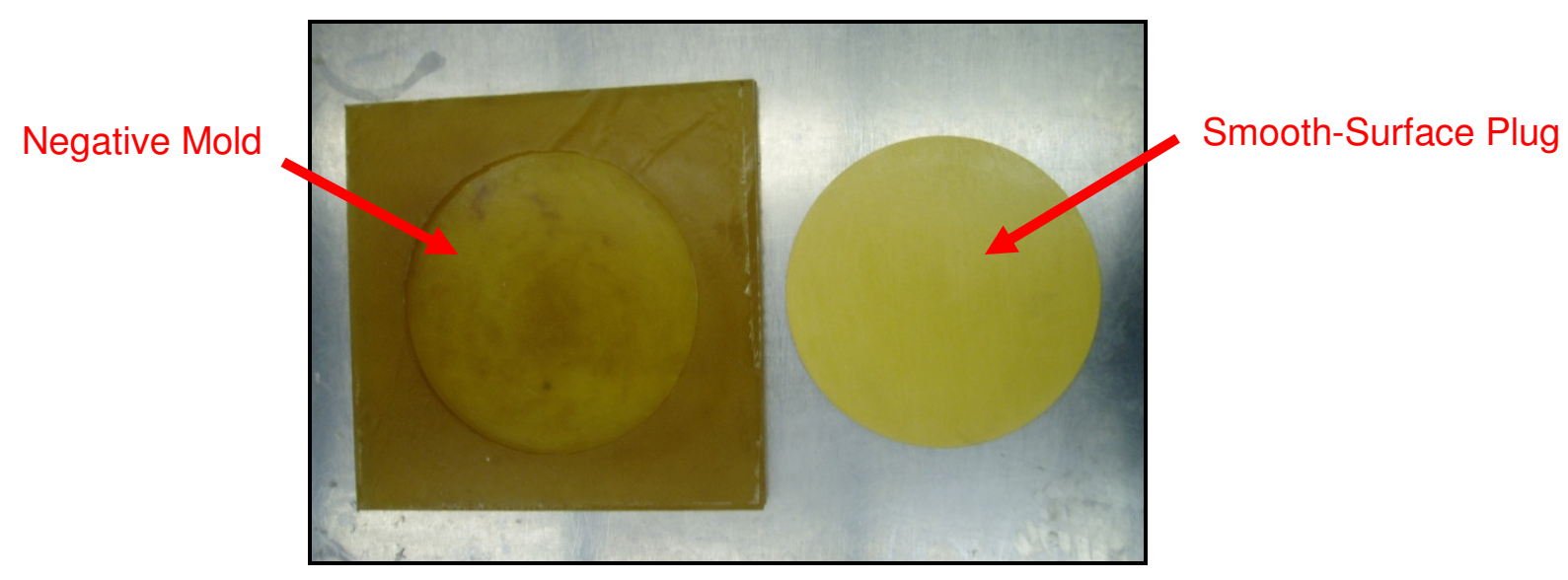

Figure 3.35: Negative Mold and Smooth-Surface Plug

\subsection{Making Positive Smooth-Surface Mold}

The smooth-surface negative mold was used to create the positive smooth-surface mold which will be used for the press molding the fiberglass manhole cover specimens, as seen in Fig. 3.36 .

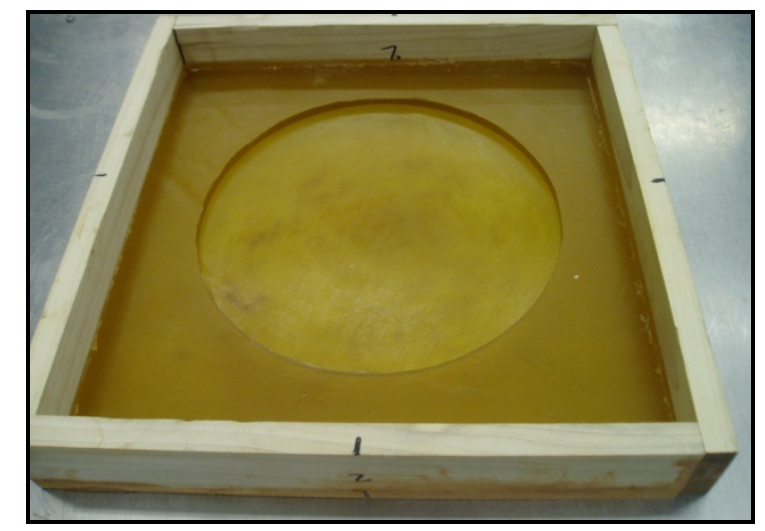

Figure 3.36: Negative Smooth-Surface Mold with Retaining Walls 


\subsubsection{Creating Wooden Frame}

The same wooden frame of the smooth-surface negative mold was used to contain the urethane liquid rubber resin for the smooth-surface positive mold. As previously mentioned, each corner of the wooden retaining walls was nailed with two 1-inch nails. Modeling clay was added to wooden frame's bottom and corners in order to prevent resin slippage. Several weights of 10 lbs were placed on wooden frame's corners to further secure urethane liquid slippage, as seen in Fig. 3.37

\subsubsection{Spraying Mold Release Agent}

Smooth-On Universal Mold Release was sprayed on the smooth-surface negative mold and inside wooden frame. Another coating of the mold release agent was sprayed and left alone for 5 minutes before adding the mixed liquid urethane rubber compound.

\subsubsection{Measuring and Mixing Urethane Liquid Rubber Solution}

Smooth-On PMC-790's Part-A was mixed with Part-B with a mix ratio of 2A:1B by volume. A new plastic container with a 4 inch diameter and a 7 inch height was used for measuring. The container was again marked at a height of 4.25 inches.

Again, it was required that Part-B is gently stirred thoroughly before mixing with Part-A. Part-B was then ready to be mixed with Part-A.

After dispensing entire quantity into a new, clean mixing container, the urethane solution was mixed gently for at least 3 minutes while also making sure that solution is scraped from getting stuck on the sides of the mixing container. 


\subsubsection{Pouring Mixed Urethane Resin into Wooden Frame Mold}

The mixed urethane resin was then carefully poured inside the wooden frame and on the negative mold. Again, a uniform flow was maintained to minimize entrapped air in urethane solution. The urethane mixture was then momentarily left alone for the rubber solution to seek its level up and over the negative mold. After the urethane liquid rubber solution was poured in the wooden frame, rubber mallets were used to create air bubbles to rise on top of liquid rubber solution.

\subsubsection{Curing Process}

Fig. 3.37 shows how the urethane liquid rubber solution was left to cure overnight and at room temperature before de-molding.

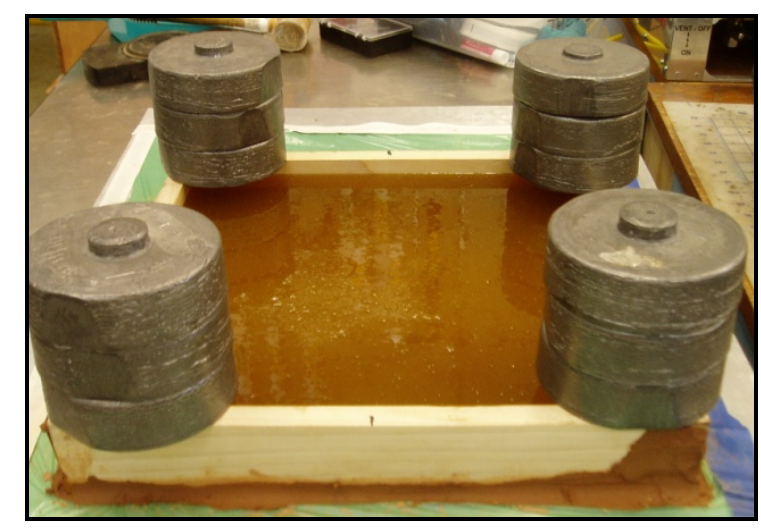

Figure 3.37: Urethane Liquid Rubber left for Overnight Curing

\subsubsection{Separating Smooth-Surface Positive Mold from Negative Mold}

A hammer was used to remove the wooden frame's retaining walls from the cured mold. A razor blade was inserted between the smooth surface plug and cured mold in order to initiate a separation gap between them. Pressure was applied on the cured mold by bending and pressing down on to the mold's corners in order to allow the positive mold to separate easily from the 
negative mold. Fig. 3.38 shows both smooth-surface positive and negative molds after separation.

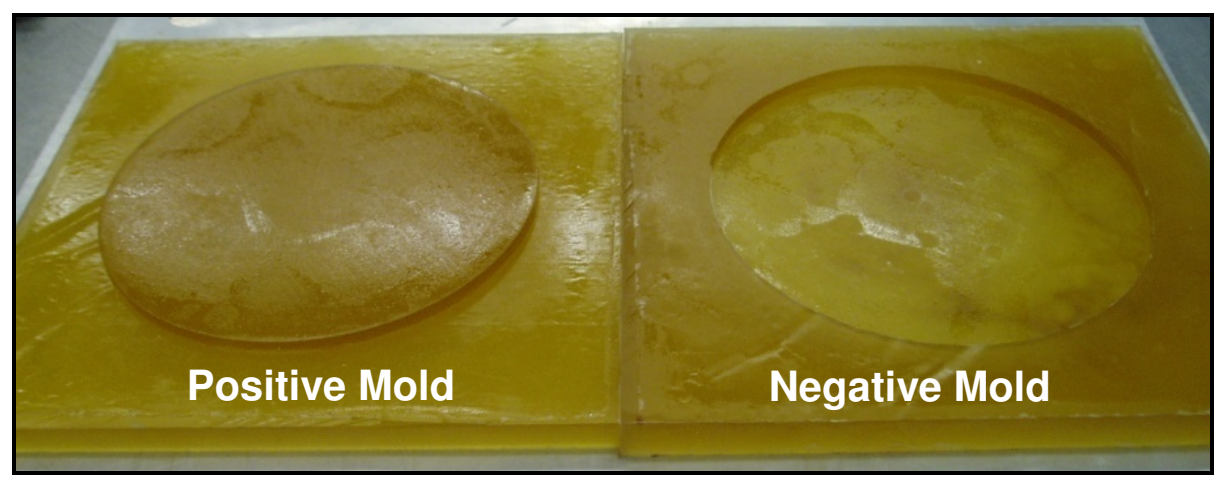

Figure 3.38: Smooth-Surface Positive and Negative Molds

The final product was a smooth-surface positive urethane rubber mold, as seen in Fig. 3.39. The positive mold was intact while preserving the fine details of the manhole cover. The positive rubber mold had the same physical characteristics as the negative mold.

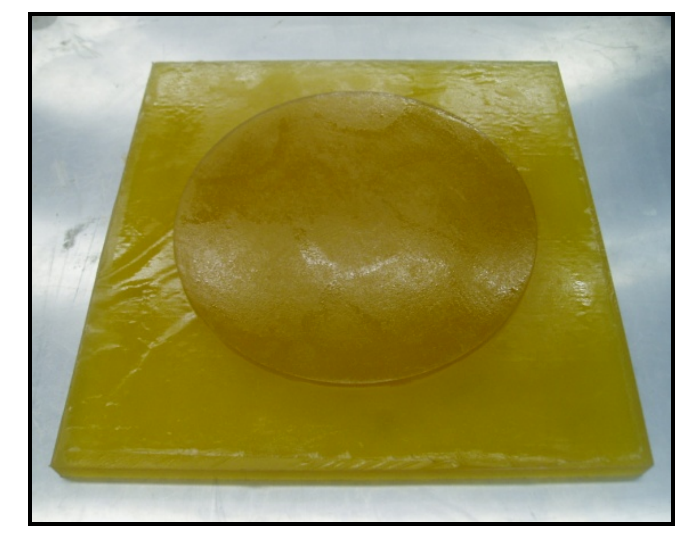

Figure 3.39: Smooth-Surface Positive Mold 


\section{FABRICATION PROCESS OF TEST SPECIMENS}

\subsection{Specimen Preparation}

The fiberglass plates were manufactured in the Aerospace Structures and Composites Lab on Cal Poly's campus in building 41, Room 136. Two options for manufacture are either using a vacuum bag or a tetrahedron composite press. The composite press allows for a better quality of plate finish since is possible to control a cure cycle force and heat. It is limited in size by a $12 \mathrm{x}$ 12 in press area between two galvanized aluminum plates. Hence, vacuum bagging was used instead since it allowed manufacturing fiberglass manholes covers from urethane manhole molds while with no size constraint and maintaining high pressure. Both fiberglass manhole covers and fiberglass laminates were constructed by using this technique. The tetrahedron composite press was only used to place $1.5 \times 1.5$ in aluminum tabs on $9 \times 1.5$ in test specimens from the 12 -inch fiberglass square plates.

All specimens were made of fiberglass and used 3 to 1 epoxy ratio. Several specimens were made with different limestone filler quantities of 20,30, and 40 grams and Westin High Density filler quantity of 40 grams. Each specimen was placed inside an aluminum frame and cured with high pressure. The aluminum frame was used to secure and control the added filler's thickness during the curing process. Each fiberglass specimen was later used for static, dynamic, and impact testing. 


\subsection{Materials}

Fig. 4.1 show the E-glass (GS67813) woven-roving cloth that was used to make all specimens.

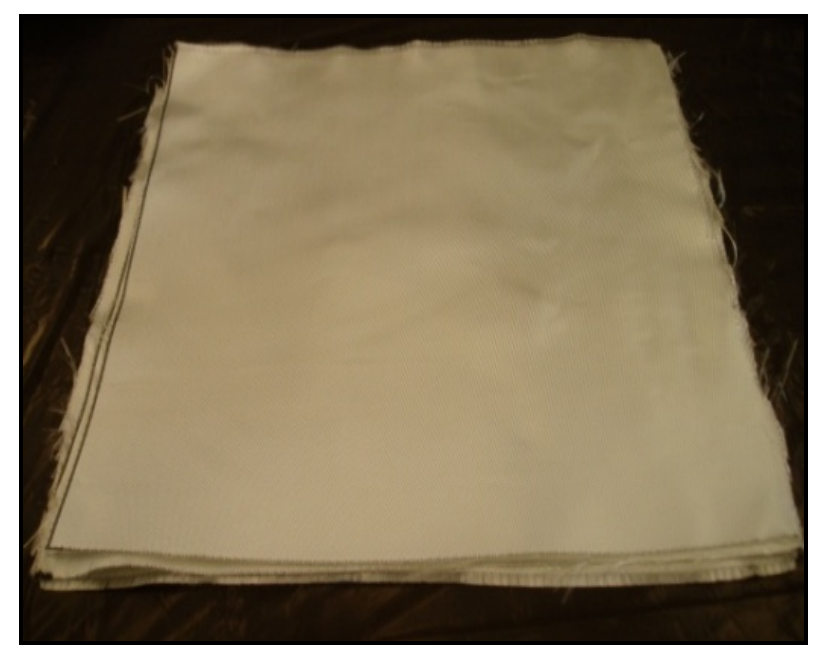

Figure 4.1: GS67813 Fiberglass Woven Roving Cloth

Aeropoxy PR2032 epoxy resin and Aeropoxy PH3630 epoxy hardener were used to make the fiberglass plates, which are seen in the Fig. 4.2.

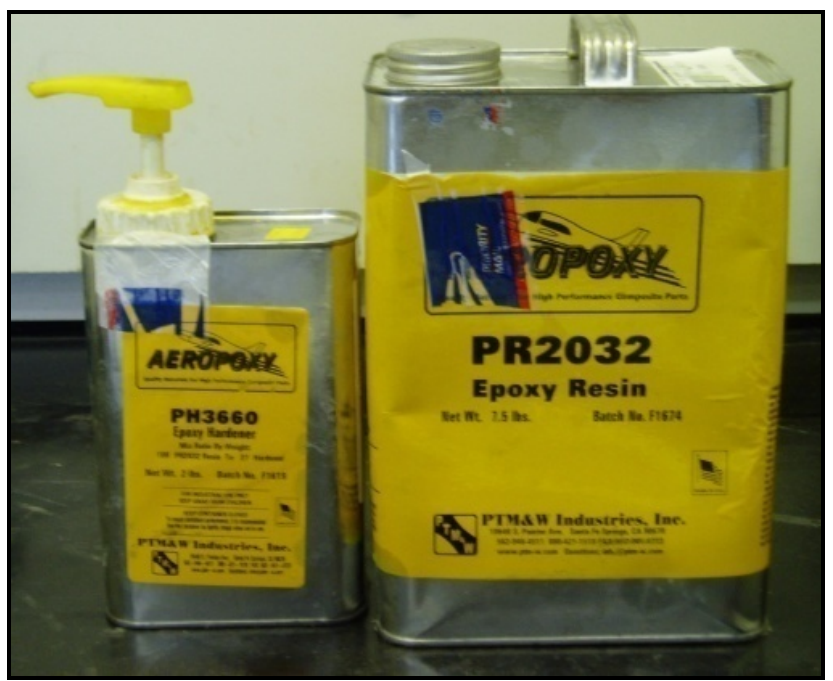

Figure 4.2: Aeropoxy PH3660 Hardener and PR2032 Resin 
Fig. 4.3 shows the Aero-Composite lab's West System 404 High-Density adhesive filler and L.F. Manufacturing Inc.'s calcium carbonate filler that was mixed in the epoxy to make test specimens in order to improve test specimen's matrix characteristics.

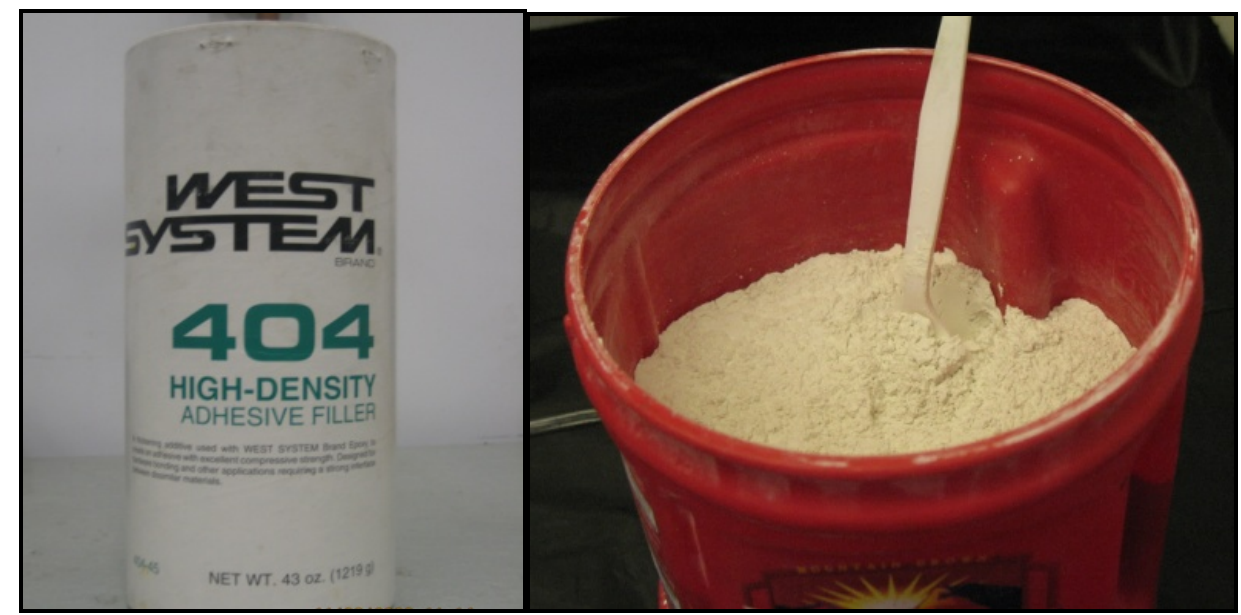

Figure 4.3: High-Density Adhesive and Calcium Carbonate Filler

Table 4.1 shows the material properties for each component of the plates.

\section{Table 4.1: Material Properties Summary}

\begin{tabular}{|l|c|c|c|c|}
\hline \multicolumn{1}{|c|}{ Property } & $\begin{array}{c}\text { PR2032 Resin w/ } \\
\text { PH3630 Hardener }\end{array}$ & $\begin{array}{c}\text { GS67813 Woven } \\
\text { Roving Fiber }\end{array}$ & $\begin{array}{c}\text { Limestone } \\
\left(\mathrm{CaC}_{3}\right) \text { Filler }\end{array}$ & $\begin{array}{c}\text { West System } \\
\text { High Density 404 }\end{array}$ \\
\hline Density $\left({\left.\mathrm{Ib} / \mathrm{in}^{3}\right)}^{3}\right.$ & 0.042 & 0.0896 & 0.0979 & $\mathrm{n} / \mathrm{a}$ \\
\hline Specific Volume (in $\left.{ }^{3} / \mathrm{lb}\right)$ & 23.8 & 11.2 & 10.3 & $\mathrm{n} / \mathrm{a}$ \\
\hline Young's Modulus (psi) & $2.8 \times 10^{6}$ & $10.5 \times 10^{6}$ & $5.37 \times 10^{6}$ & $\mathrm{n} / \mathrm{a}$ \\
\hline Ultimate Tensile Strength (psi) & $4.6 \times 10^{3}$ & $3.4 \times 10^{5}$ & $20 \times 10^{3}$ & $\mathrm{n} / \mathrm{a}$ \\
\hline
\end{tabular}

Table 4.2 shows the approximate cost for materials needed to fabricate the laminated test specimens. According to L.F. Manufacturing Inc., a $50 \mathrm{lbs}$ bag of limestone filler is purchased for only \$1 which is more economical than West System’s High Density 404 filler. 
Table 4.2: Material Supplies Cost

\begin{tabular}{|c|c|c|c|c|}
\hline Material & $\begin{array}{c}\text { PR2032 Resin w/ } \\
\text { PH3630 Hardener }\end{array}$ & $\begin{array}{c}\text { GS67813 Woven } \\
\text { Roving Fiber }\end{array}$ & $\begin{array}{c}\text { Limestone } \\
\left(\mathrm{CaC}_{3}\right) \text { Filler }\end{array}$ & $\begin{array}{c}\text { West System High } \\
\text { Density } 404\end{array}$ \\
\hline Cost & $\$ 47.25 / \mathrm{qrt}$ & $\$ 10.20 / \mathrm{yrd}$ & $\$ 1 / 50 \mathrm{lbs}$ & $\$ 12.85 / \mathrm{lbs}$ \\
\hline
\end{tabular}

\subsection{Fiberglass Laminates}

\subsubsection{Aluminum Frame}

The frame was constructed by cutting four pieces from aluminum bars by using the machine rod cutter provided by Cal Poly's welding shop, as seen in Fig. 4.4.

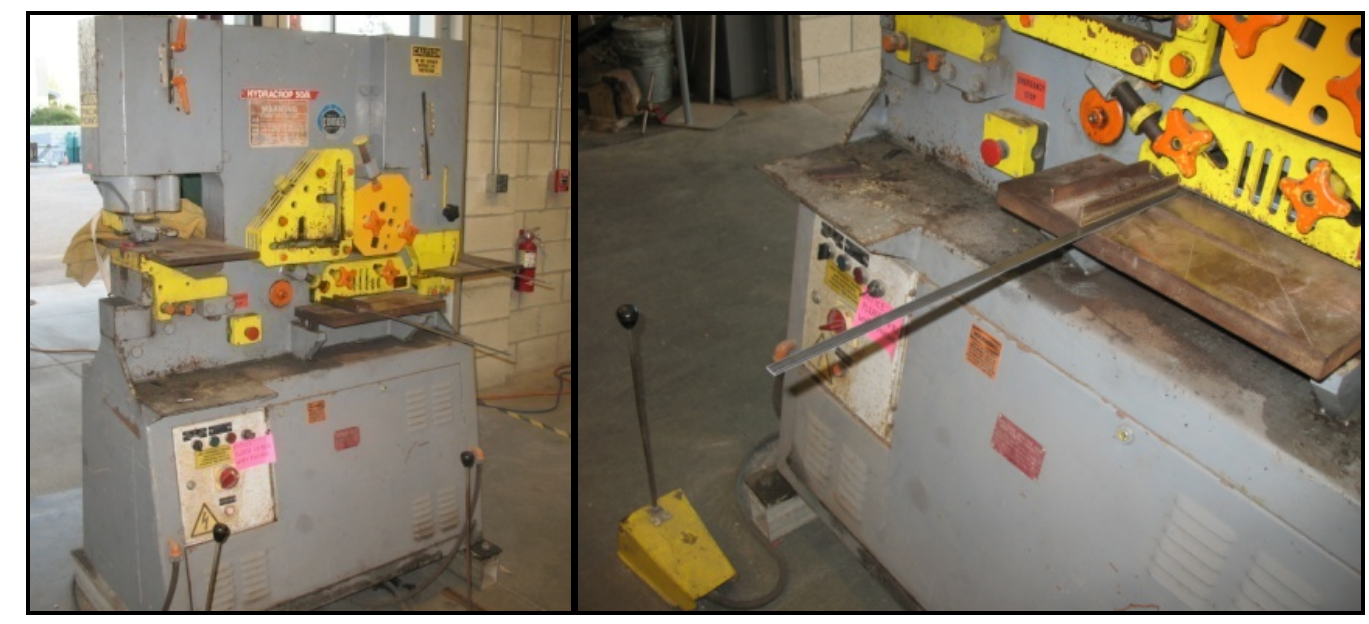

Figure 4.4: Weld Shop's Machine Rod Cutter

The aluminum frame's purpose is the following: to control the filler's thickness during the lay-up process, to contain the added filler within the fiberglass specimen, and to prevent filler's thickness from deforming when applying high pressure loads during the vacuum/curing process. The original aluminum rod had a length of 36.25 in and was later cut into a square area of $11 \times 11 \mathrm{in}^{2}$. The aluminum frame's thickness was 0.123 in with a width of $0.5 \mathrm{in}$. The inner aluminum frame had a square dimension of $10 \times 10$ in, as seen in Fig. 4.5. 


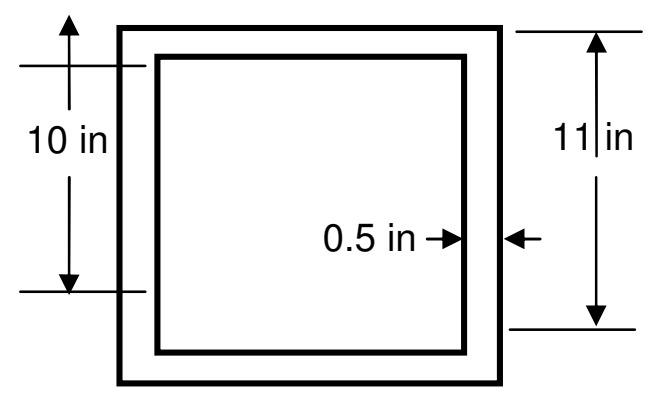

Figure 4.5: Aluminum Frame's Dimensions.

The four aluminum bar's cut corners were then welded together by a Cal Poly manufacturing student. The welding operation was performed inside the manufacturing department's welding shop. Fig. 4.6 shows the welding equipment used to assemble the aluminum frame.

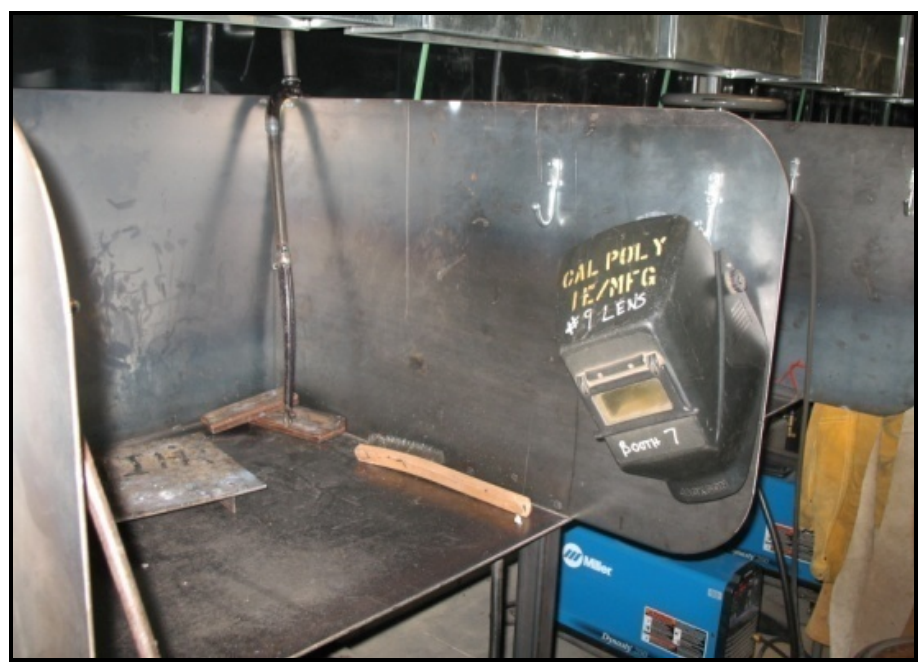

Figure 4.6: Welding Equipment

The aluminum bars' sharp corners were later sanded with a grinder, as seen in Fig. 4.7. The sharp corners were smoothed in order to prevent puncturing a hole into the specimen or vacuum bagging material, thus decreasing the curing process efficiency. 


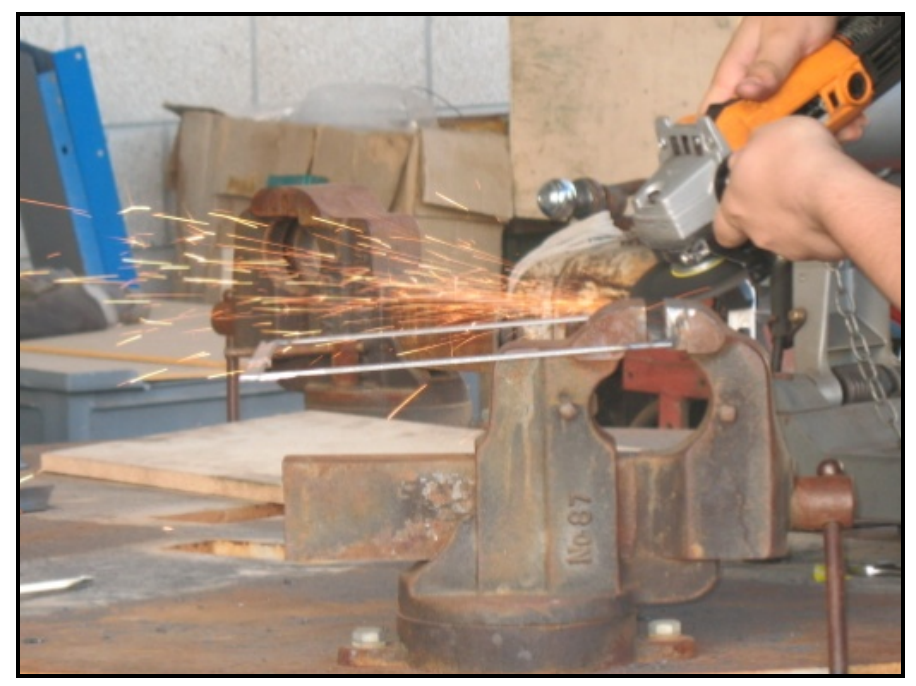

Figure 4.7: Grinding Aluminum Frame's Sharp Corners

Fig. 4.8 shows the final product of the aluminum frame after sanding its sharp edges. A total of two aluminum square frames were made to increase specimen production during curing process.

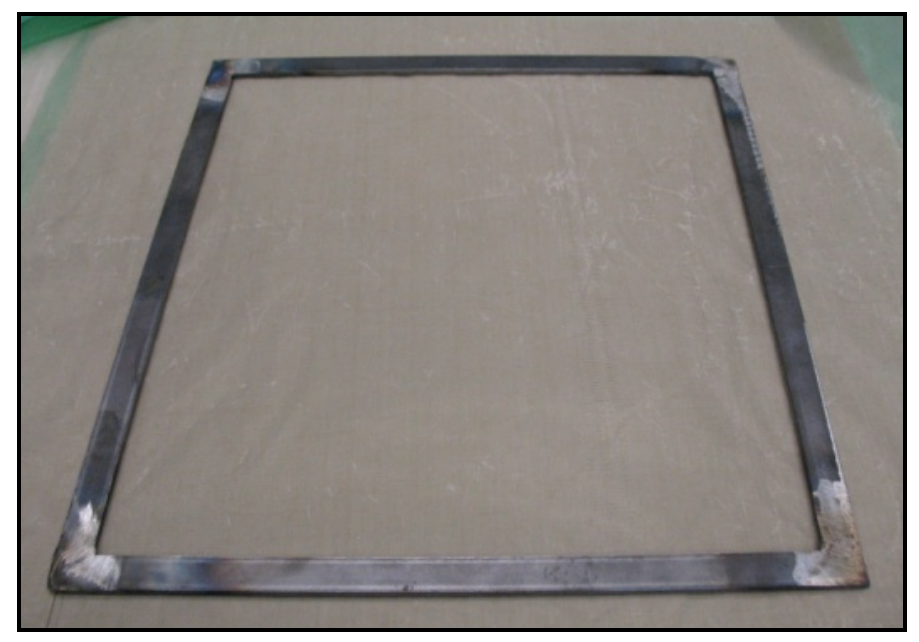

Figure 4.8: Final Product of Aluminum Frame after Sanding

\subsubsection{Curing Process}

The welded aluminum frame was placed on the top of metal vacuum table, as seen in Fig.

4.9. Breather fabric was cut and placed around the aluminum frame to induce suction inside the 
frame's cavity, while making sure that the compressor air duct was not blocked. A $26 \times 26$ in of clear sheet of release film was cut and placed on top of the aluminum frame. Fig. 4.9 also shows black-thick tape was placed around breather fabric and onto the release film material in order to seal the mold-vacuum bag for the aluminum frame. The goal of this setup was to use the welded aluminum frame, representing the negative manhole mold which was previously discussed in manhole cover mold section, to improve the quality of the fiberglass laminate by maintaining constant filler thickness. The fiberglass laminate would be later placed on top of the aluminum frame enclosed by the vacuum bag which will be discussed more in detail in the layup process of fiberglass plate.

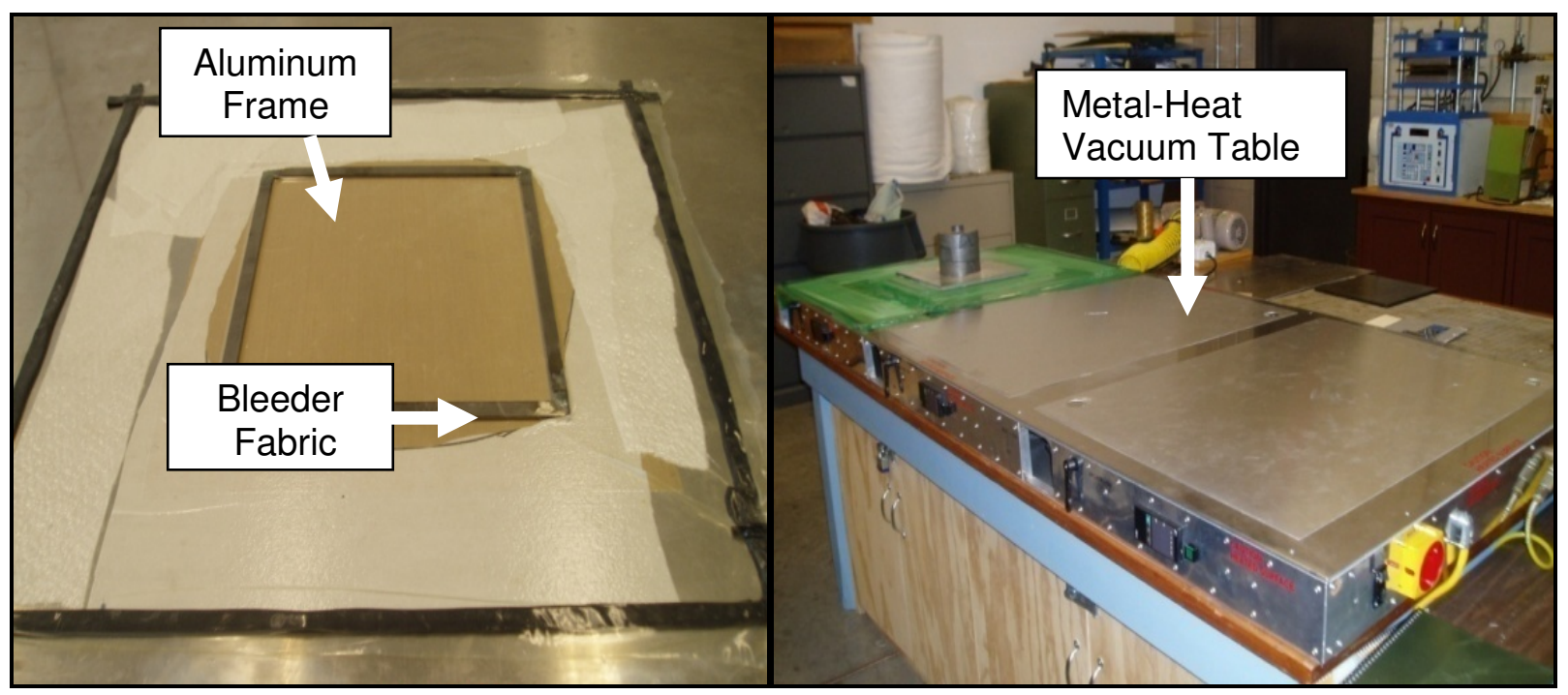

Figure 4.9: Sealing Aluminum Frame with Black-Thick Tape and Release Film

A $16 \times 16$ in sheet of 4500-P porous release film was cut and placed on the top moldvacuum bag of the aluminum frame as seen in Fig. 4.10. A thin sheet of bleeder fabric was later added to the porous film release fabric to absorb any excessive resin. Teflon non-porous release peel ply was placed on top of the bleeder fabric. Both bleeder fabric and non-porous release peel ply were cut with the same dimensions as porous release film. Another vacuum bagging sheet 
with dimension of $28 \times 36$ in was placed on top of the non-porous release peel ply and black gum was put between the layers of green material in order to seal the vacuum bag.

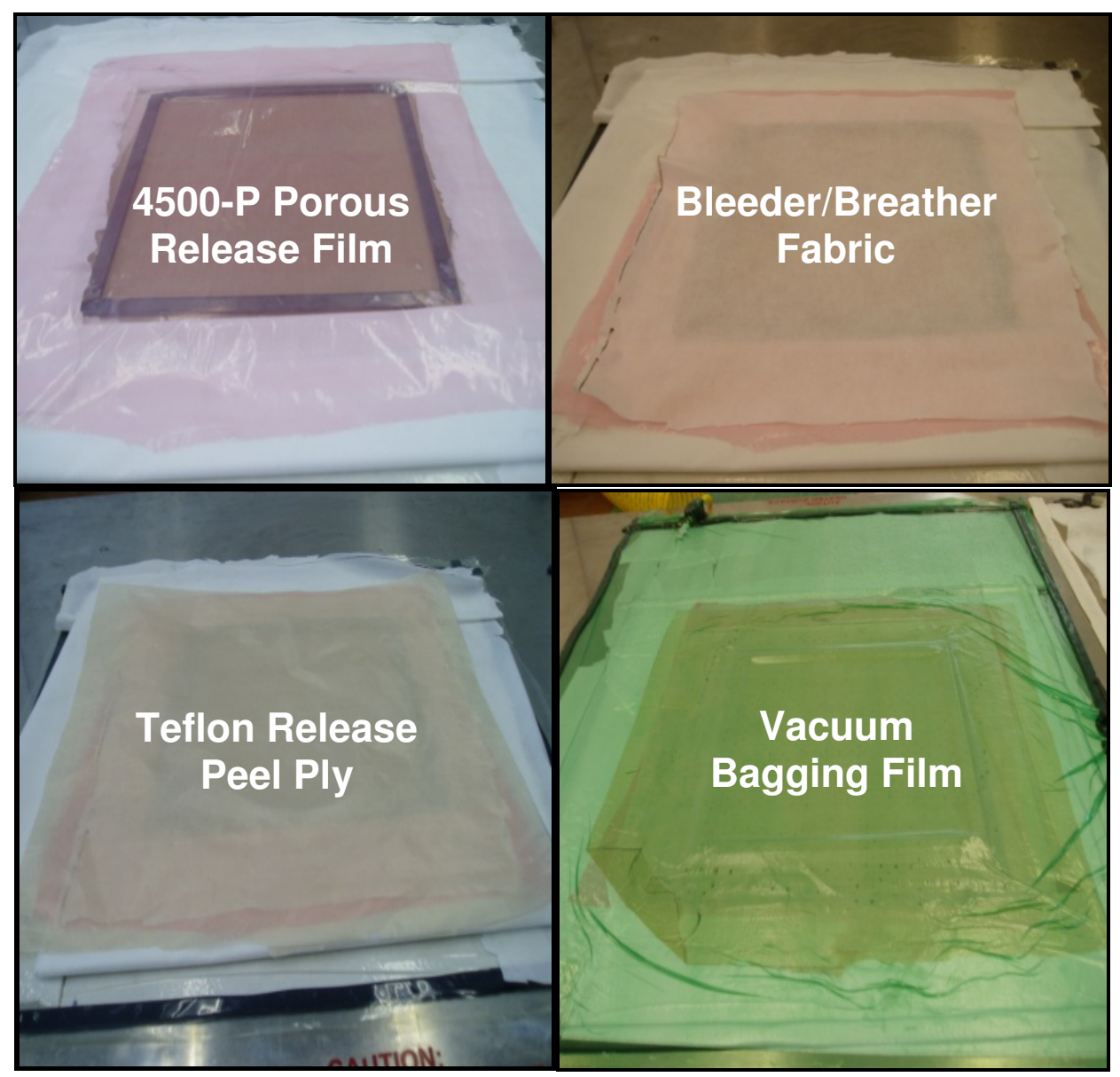

Figure 4.10: Vacuum Bagging Layup with Aluminum Frame for Laminate

A $9 \times 9$ in aluminum plate was placed on top of the vacuum bagging film and inside the aluminum frame. The aluminum plate's purpose was to support the applied load exerted on the composite laminate in order to ensure constant filler thickness during curing process. The aluminum plate's sharp corners were also sanded in order to prevent puncturing a hole in the vacuum bagging film which would reduce pressure. Fig. 4.11 shows the final layer arrangement of the vacuum bagging setup. 
Vacuum Bagging Film

Teflon Non-Porous Release Peel Ply

Breather/Bleeder Cloth

Porous Release Film

Composite Plate

Clear Non-Porous Release Film

\section{Aluminum Plate}
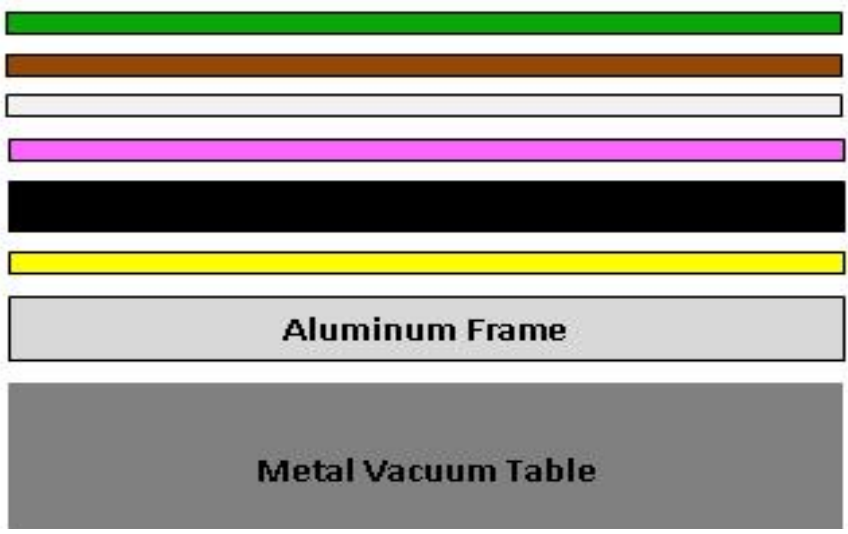

Figure 4.11: Vacuum Bag Lay-Up Arrangement

Different weights found in the Aerospace Structures and Composites Laboratory was mounted on top of the aluminum plate, as seen in Fig. 4.12. During the curing process, a range of 325 to $525 \mathrm{lbs}$ was used to sustain the required pressure. The selected loads was $525 \mathrm{lbs}$ since it makes the fiberglass plates stronger and have a smooth surface finish; hence, better quality of fiberglass laminates compared to the $325 \mathrm{lbs}$. A total of $525 \mathrm{lbs}$ of weight was applied to the composite laminate during the curing process, as seen in Table 4.2.

Table 4.2: Summary of Total Load Used for Curing Process of Fiberglass Plates

\begin{tabular}{|c|c|c|c|}
\hline Shape & Load & Number of Weights & Total Load \\
\hline & $10 \mathrm{lbs}$ & 45 & $450 \mathrm{lbs}$ \\
\hline & $10 \mathrm{lbs}$ & 4 & $40 \mathrm{lbs}$ \\
\hline 0 & $10 \mathrm{lbs}$ & 1 & $10 \mathrm{lbs}$ \\
\hline & $25 \mathrm{lbs}$ & 1 & $25 \mathrm{lbs}$ \\
\hline Total & $55 \mathrm{lbs}$ & 51 & $525 \mathrm{lbs}$ \\
\hline
\end{tabular}


The weights represented the increase pressure that would be performed using the tetrahedron composite press. Fig. 4.12 shows the added weight and aluminum plate used for increasing pressure during the curing process.

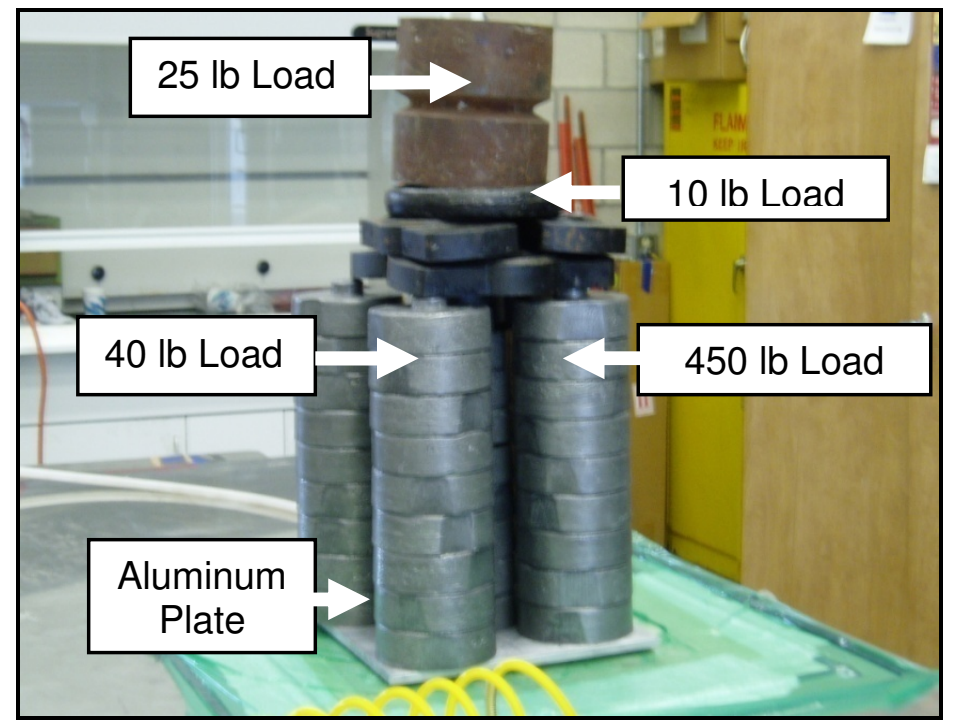

Figure 4.12: Weight and Aluminum Plate used during Curing Process

The metal-table vacuum pump and small compressor was used for the mold-vacuum bag while two-large external compressors were used to increase the pressure needed for constructing the composite laminates, as seen in Fig. 4.13. A total of four pumps were used for this process. 


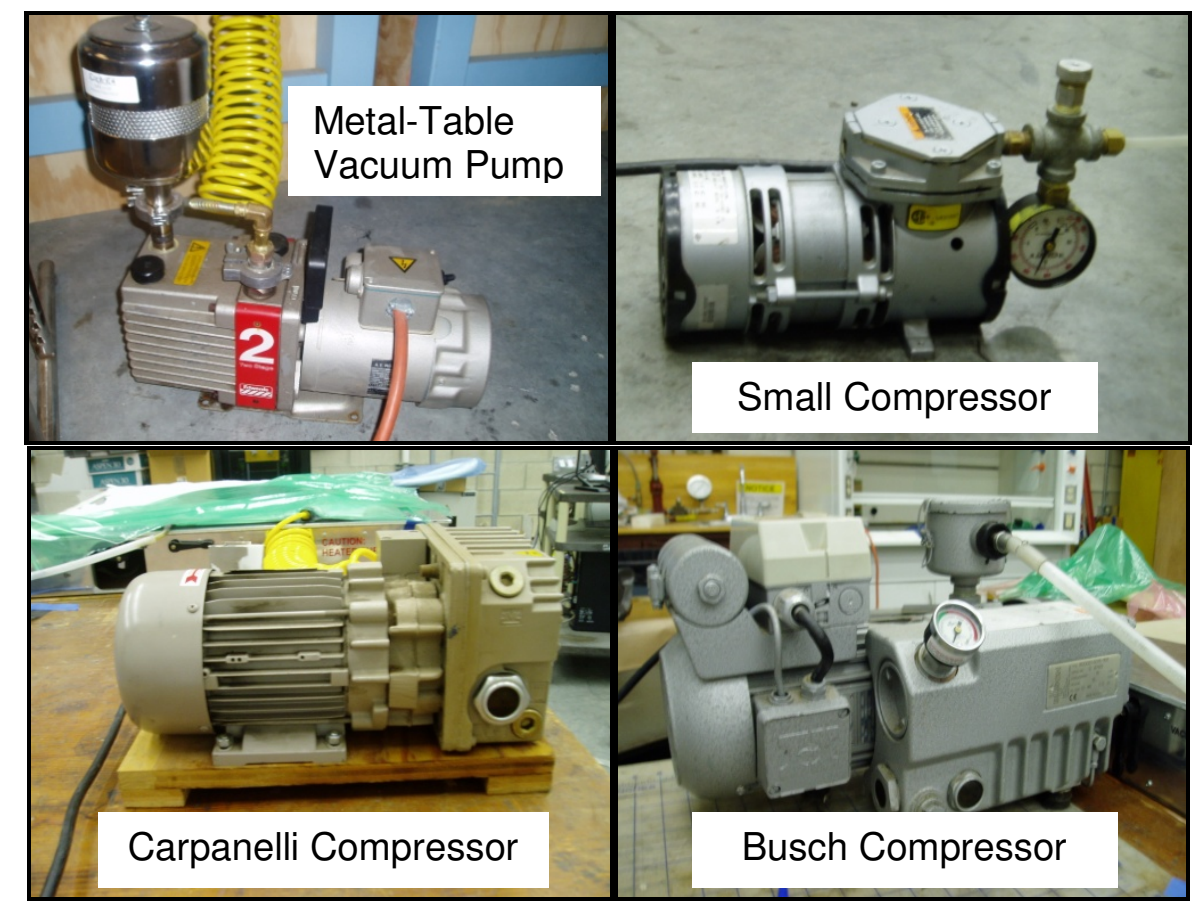

Figure 4.13: Four Compressors Used for Making Fiberglass Laminates

The metal-vacuum table (2-stage pump) compressor and small compressor were used for sealing the vacuum bag that contained the aluminum frame. Fig. 4.14 shows the larger compressors (Carpanelli and Busch) used for sealing the vacuum bag that contained the fiberglass laminates; thus providing stronger suction pressure and better quality of the composite plates.

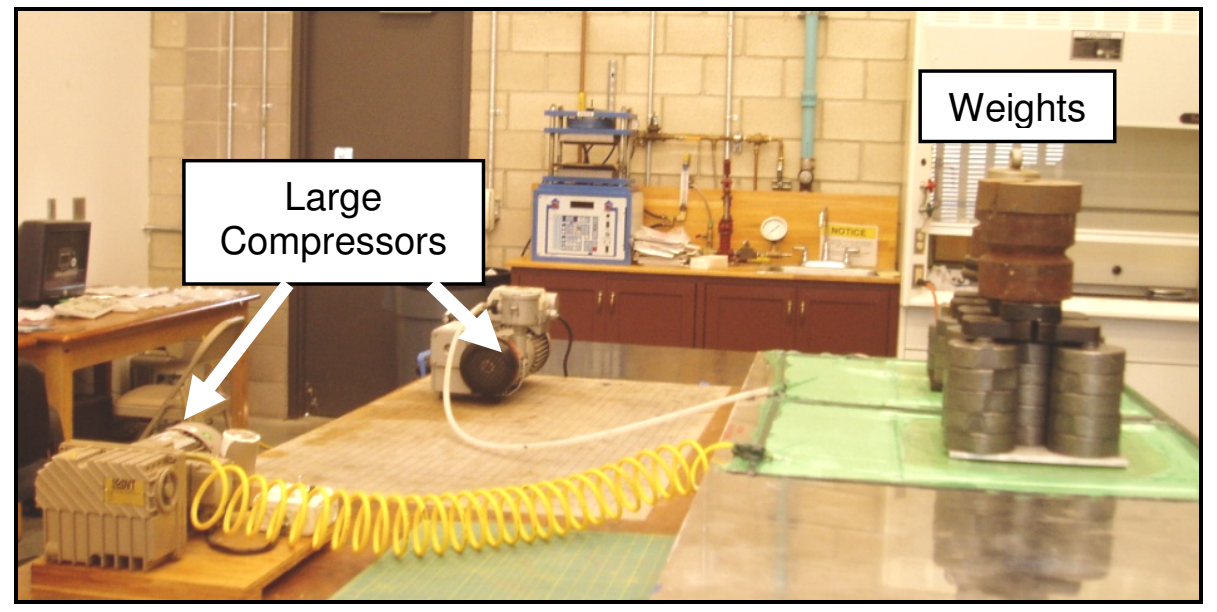

Figure 4.14: Overall Setup of Vacuum Bagging on Metal-Vacuum Table 
The schematic of the vacuum bagging technique and compressors is more clearly shown in Fig. 4.15.

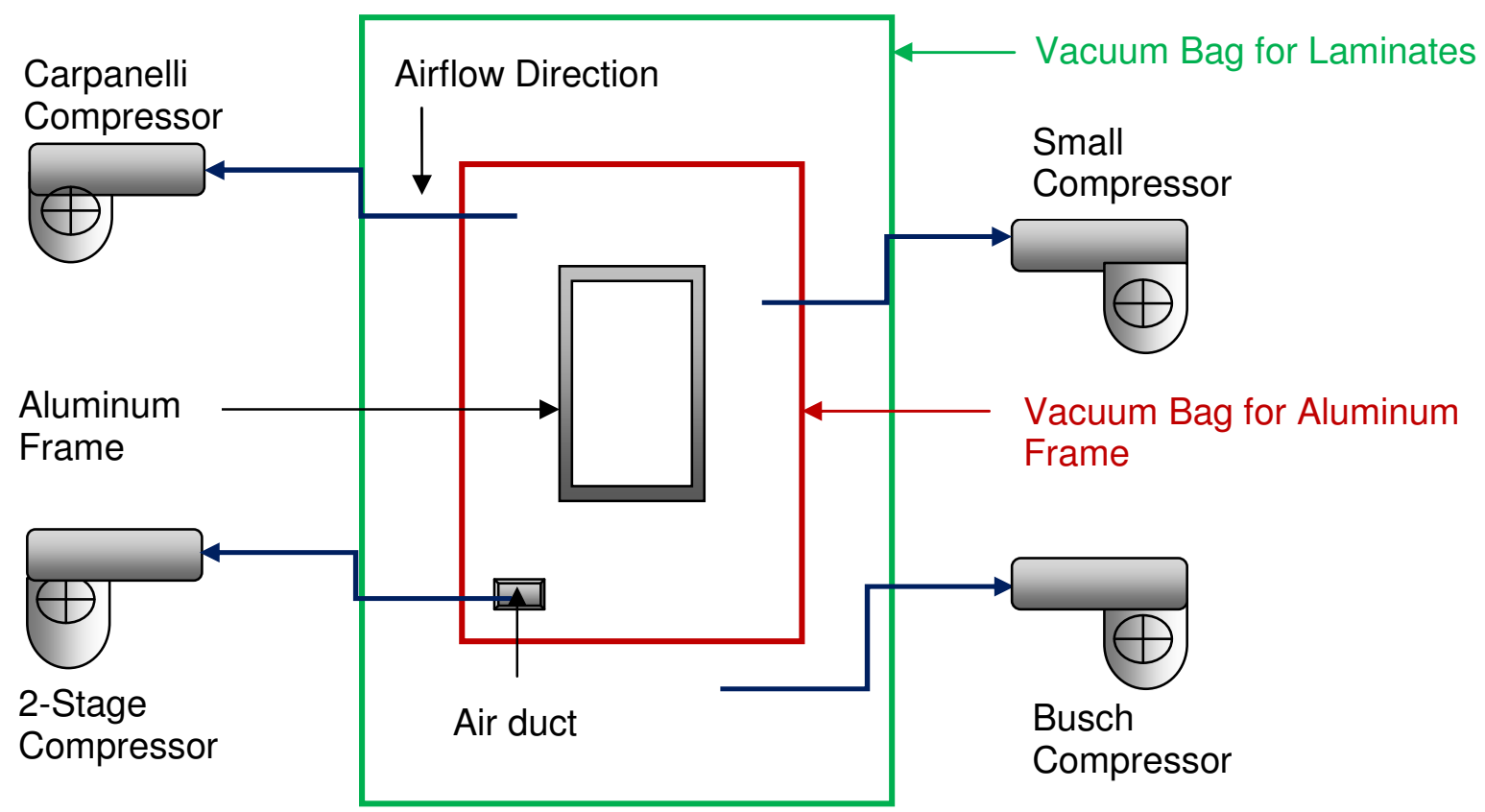

Figure 4.15: Top View of Vacuum Bag and Compressor Arrangement

Adding two external large compressors with a maximum suction pressure of 15 Torrents each also helped to improve the composite plate's quality. Consequently, a combination of both weights and compressors increased the overall pressure needed to improve the strength characteristics of the fiberglass laminates.

\subsubsection{Layup Process}

Four $13 \times 13$ in sheets of fiberglass were cut and weighed together to obtain the total mass of fibers for each plate using a digital scale, as seen in Fig. 4.16. For this project, only four plies of fiberglass were used for each laminate. A total of six fiberglass plates were created and used to make all test specimens. 


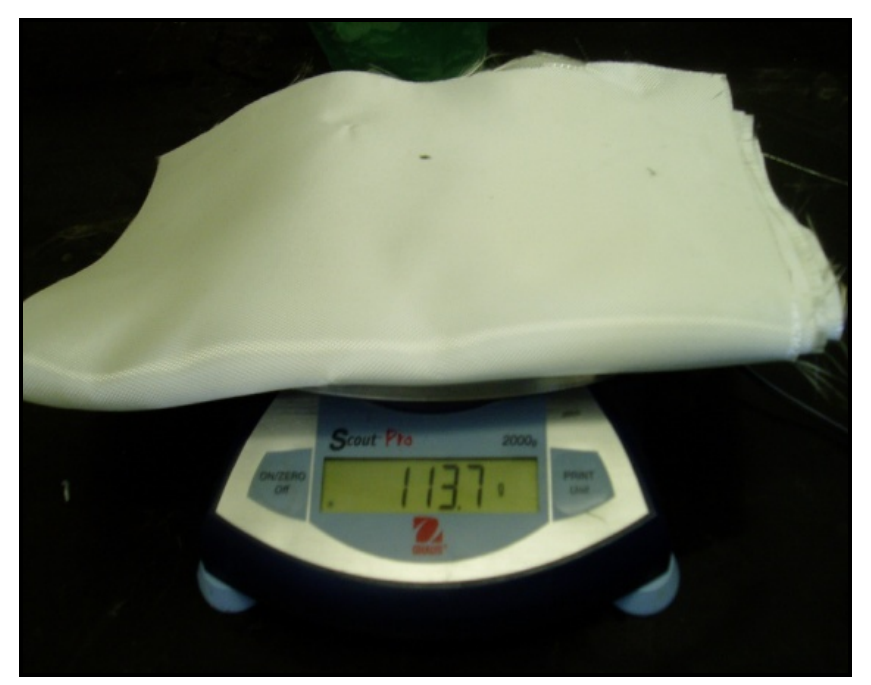

Figure 4.16: Digital Scale Used to Weight Fiberglass Sheets

A 3:1 ratio of resin to hardener was used to create a mixture of epoxy with the same mass as the fibers. For all plates, 75 grams of resin epoxy and 25 grams of hardener with the same 3:1 ratio were added to the mixture, hence adding an average total fiber mass of 109.1 grams and a total matrix mass of 130 grams. The average measured mass for the total mass of filler was 30 grams. All fiberglass plates were made with the same epoxy ratio but with different filler amounts. Table 4.3 shows a summary of the various plates with different filler and fiber weights.

Table 4.3: Specimen Data Summary

\begin{tabular}{|c|c|c|c|c|c|}
\hline Specimen \# & $\mathrm{L}_{20}$ & $\mathrm{~L}_{30}$ & $\mathrm{~L}_{40}$ & $\mathrm{HD}_{30}$ & $\mathrm{~L}_{\mathrm{B} 0}$ \\
\hline Filler Type & Limestone & Limestone & Limestone & West 404 & No Filler \\
\hline \# Ply & 4 & 4 & 4 & 4 & 4 \\
\hline Resin: Hardener (g) & $75: 25$ & $75: 25$ & $75: 25$ & $75: 25$ & $75: 25$ \\
\hline Filler Weight (g) & 20 & 30 & 40 & 30 & 0 \\
\hline Matrix Weight (g) & 120 & 130 & 140 & 140 & 100.0 \\
\hline Fiber Weight (g) & 104.3 & 100.5 & 108.1 & 119.2 & 109.3 \\
\hline Total Weight (g) & 224.3 & 230.5 & 248.1 & 259.2 & 209.3 \\
\hline
\end{tabular}


Each specimen was identified by a number and letter as seen in above table. Specimens $\mathrm{L}_{20}$, $\mathrm{L}_{30}$, and $\mathrm{L}_{40}$ designate fiberglass laminates were made with 20 grams, 30 grams, and 40 grams of calcium calcite filler, respectively. Both specimen $\mathrm{HD}_{30}$ and $\mathrm{L}_{\mathrm{B} 0}$ designate fiberglass laminates created with 30 grams of high-density adhesive filler and fiberglass only (no filler), respectively. For plate preparation, a plastic bag was cut and placed on top of a table. It was secured with carpenter's tape in order to prevent fiber plates from changing orientation during layup process. A thin layer of epoxy mixed with the proper amount of calcium calcite filler was applied to each layer of fiberglass as shown in Fig. 4.17.

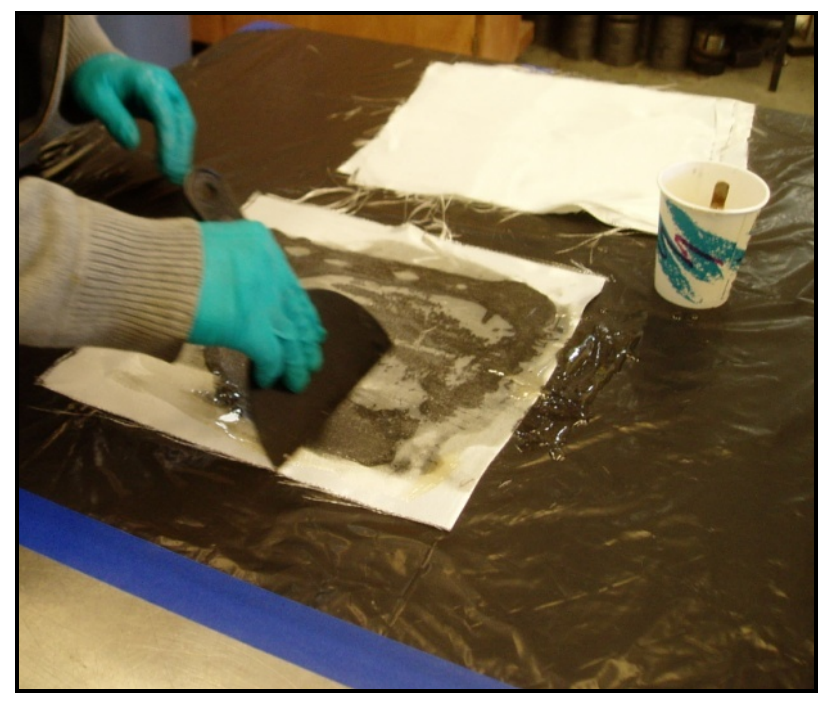

\section{Figure 4.17: Applying Epoxy and Filler on Fiberglass Laminates}

All four layers were then placed on top of each other, with the fibers oriented in the same direction. The wet laminates were then placed on the aluminum frame into the vacuum bag as shown in Fig. 4.15. Then all four compressors were turned-on to allow the laminate to cure overnight for 12 hours. Fig. 4.18 shows the finished 13 in x 13 in fiberglass plate after curing. The laminated plates were then cut into several beams for experimental testing. 


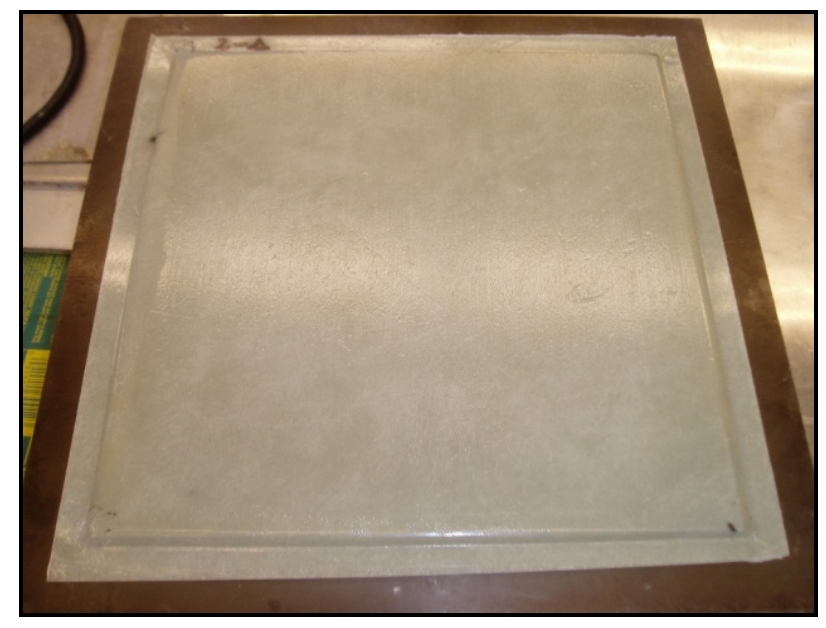

Figure 4.18: Fiberglass Laminated Plate After Curing

\subsection{Fiberglass Manhole Cover Plates}

Part of this investigation involved performing bending tests on the fiberglass manhole covers plates; hence, tests specimens of fiberglass Cal Poly manhole covers were constructed by using urethane-rubber press molds.

\subsubsection{Curing Process Setup}

The first step required to make the test specimens of the fiberglass manhole cover was to make a vacuum bag for the female mold. This was performed by placing the female mold of the manhole cover on top of the metal-vacuum table. A $25 \times 25$ in pink release film was cut and placed on top of the female mold and around the metal-vacuum table's air duct. The pink release film protected the female mold and allowed to separate the part from mold easily without adding mold release agents.

An external compressor was also added to the vacuum bag to increase suction pressure. A piece of breather fabric was placed on the tip of the compressor's tube in order to provide noninterrupted airflow between film release and surface of metal-vacuum table, thus enhancing the detail quality of the female mold. Yellow rubber tape was later added onto the release film's 
edges and pump's tube to seal the vacuum bag for the female mold. The vacuum bag of the female mold was later covered with thin breather fabric while maintaining a circle around the female mold's cavity, as seen in Fig. 4.19. The bleeder fabric again allowed the airflow to move freely from the female mold's center to the compressor's tube, thus curing the wet composite completely. In addition, the breather fabric also covered the table's air duct to allow suction from the compressor. The same vacuum bag arrangement of the aluminum was used for the female mold which can be seen in Fig. 4.19.

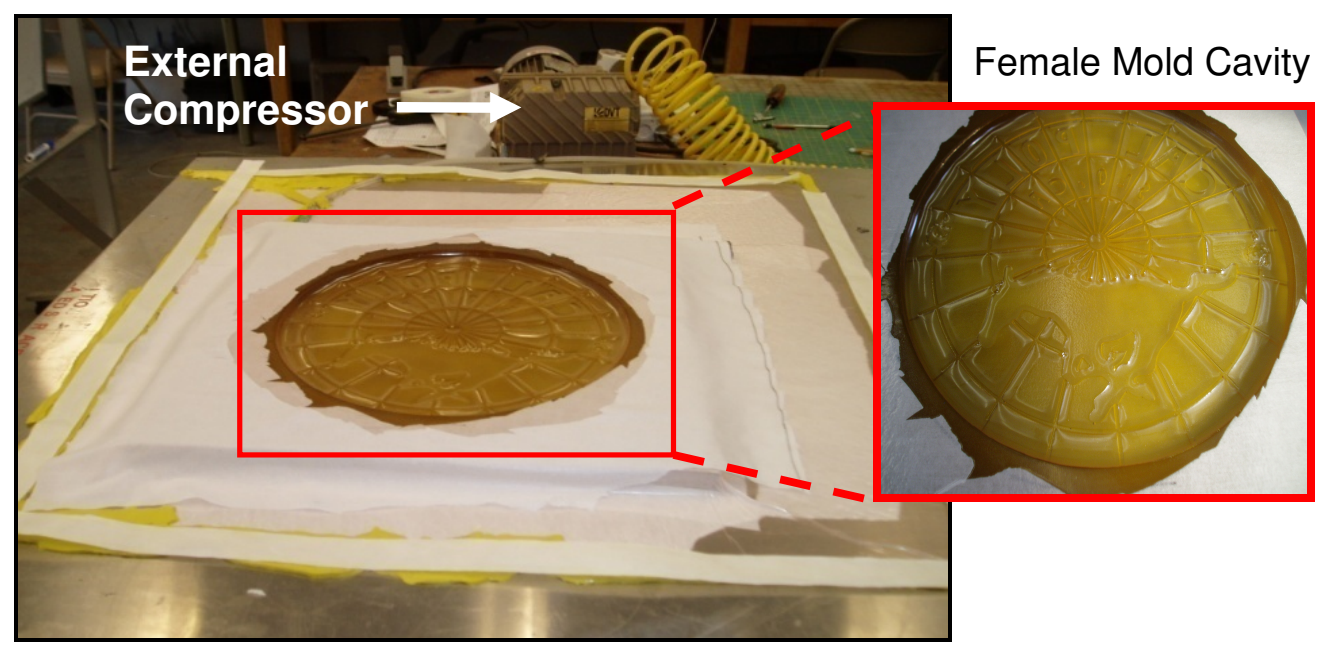

Figure 4.19: Initial Vacuum Bag Setup and Female Mold's Cavity

The next step was to create a vacuum bag for the fiberglass laminates that would be placed inside the female mold's cavity. The same vacuum bag layup arrangement described in Fig. 4.11 and in Fig. 4.15 was used to for this process. A $16 \times 16$ in sheet of 4500-P porous release film was cut and placed on the top mold-vacuum bag of the aluminum frame. A thin sheet of bleeder fabric was later added to the porous film release fabric to absorb any excessive resin. Teflon non-porous release peel ply was placed on top of the bleeder fabric. Both bleeder fabric and non-porous release peel ply were cut with the same dimensions as porous release film. 
Another vacuum bagging sheet of release film with dimension of $33 \times 33$ in was cut and used to cover the vacuum bag of female mold and wet laminates. Several pieces of yellow-rubber tape were put between the layers of green release material in order to seal the vacuum bag. Finally, the metal-vacuum table's pump and two large-external pumps (described in Section 6.4) were turned-on in order to listen for the sound of air escaping from the vacuum bag. The high suction pressure caused the release film to take shape of the female mold, as seen in Fig. 4.20.

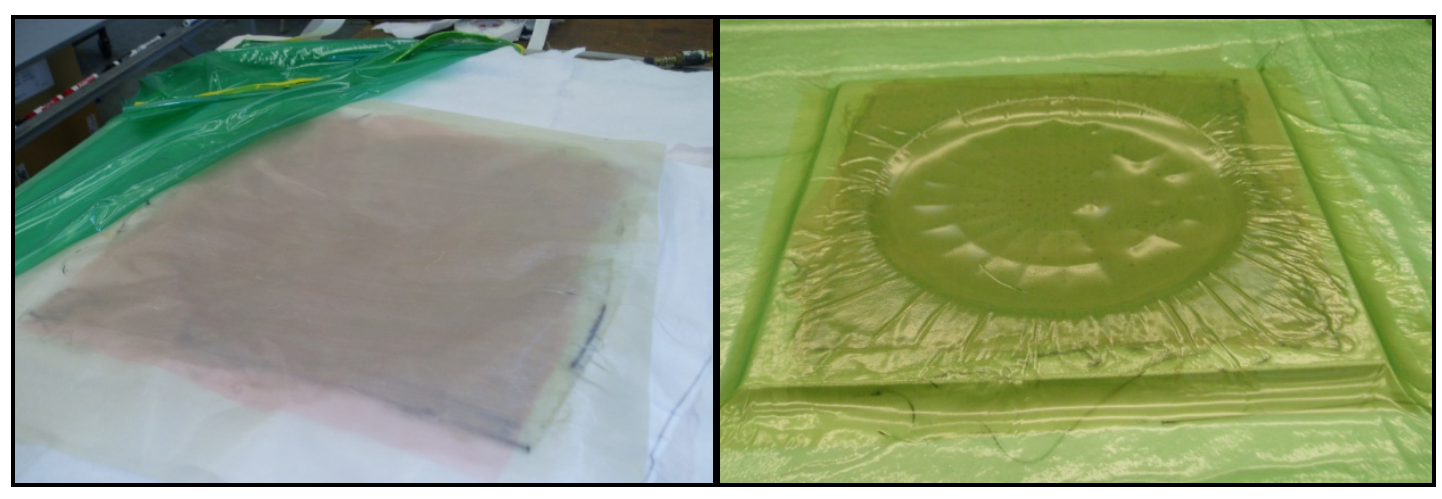

Figure 4.20: Final Vacuum Bag Setup for Manhole Cover Specimen

\subsubsection{Layup Process Setup}

The same layup process described in Section 6.3.3 was used for the making the fiberglass manhole cover specimens. Four pieces of 13 x 13 in (E-glass) fiberglass sheets were cut. Proper weight of filler and epoxy was measured using digital scale. A single ply of fiberglass was equivalent to weight of 36.5 grams, whereas, four plies had a total weight of 134 grams. A 3 to 1 mixing epoxy ratio of Aeropoxy's resin to hardener (75 grams to 25 grams, respectively) and an initial weight of 30 grams of (limestone or Westin High-Density) filler was measured in different mixing cups. Both hardener and resin were mixed and stirred for 2 minutes. Filler was later added into epoxy batch and stirred for another 2 minutes. The mixed epoxy batch was poured onto the first ply of fiberglass. A spatula was used to disperse the mixed epoxy completely on the 
fiberglass sheet. The same procedure, as described above, was repeated for rest of plies. Although fiberglass woven roving is independent of orientation, each ply had to be properly stacked by facing in the same direction in order to have a better finished product of specimen. Fig. 4.21 shows the wooden roller used to remove excess the epoxy and air bubbles found inside on each wet fiberglass ply.

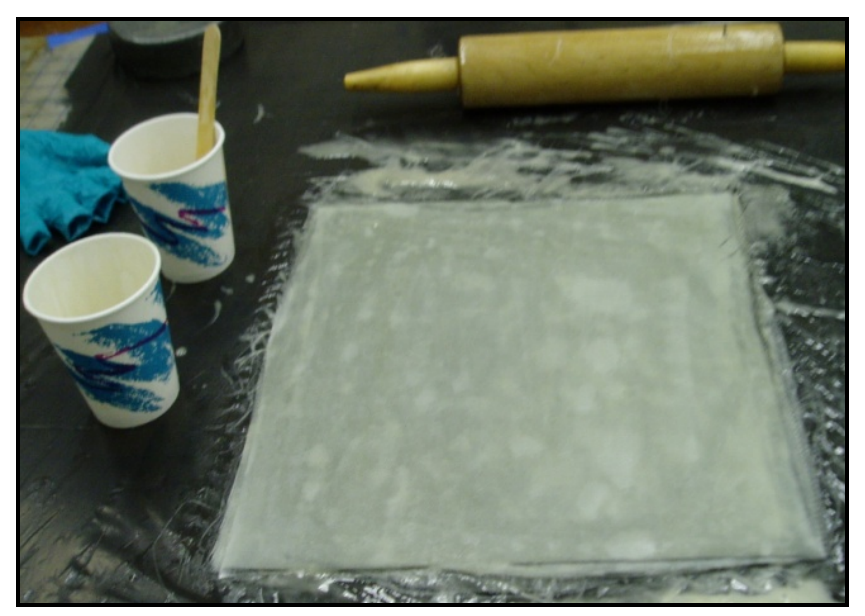

Figure 4.21: Layup Process for Making Manhole Cover Specimens

Fig. 4.22 shows the male mold placed on top of the female mold. The male mold's diameter was reduced to 11 inches in order to meet female mold's design constraint of 0.05 inches. Consequently, the male mold achieved the female mold's specified tolerance range by providing the clearance required for fiberglass fabric and excess epoxy to move along its sides when applying the load. 


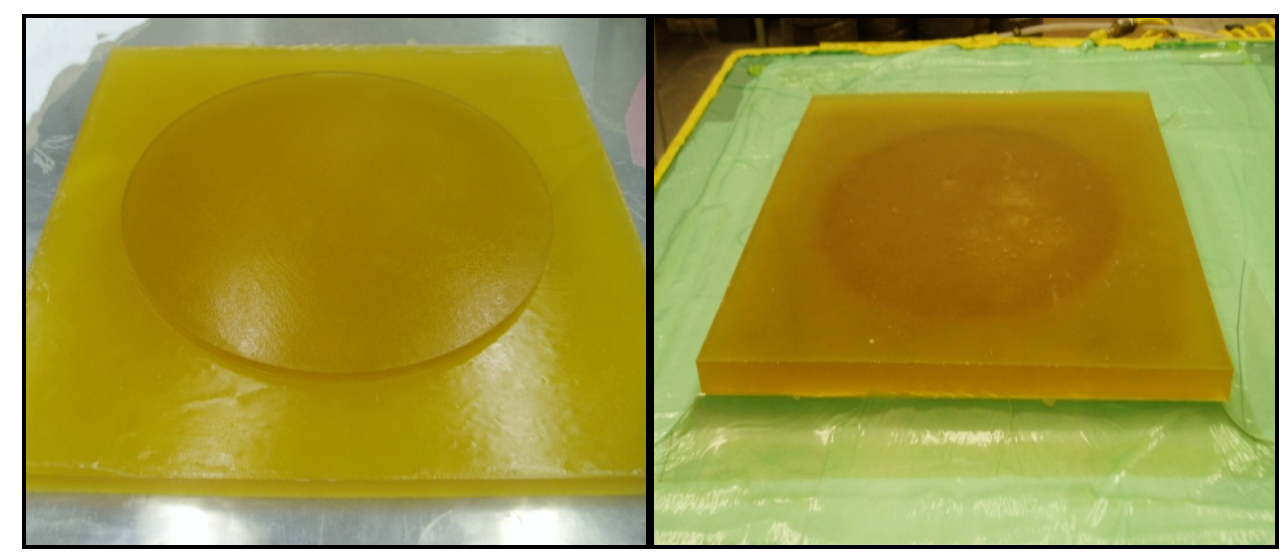

Figure 4.22: Positive Mold Attached with Negative Mold

Fig. 4.23 shows the final configuration for the manhole cover press mold. A total load of 525 pounds was applied onto the press mold in order to be consistent with the test specimens previously mentioned in Section 6.4. The overall curing process for the specimen was 12 hours.

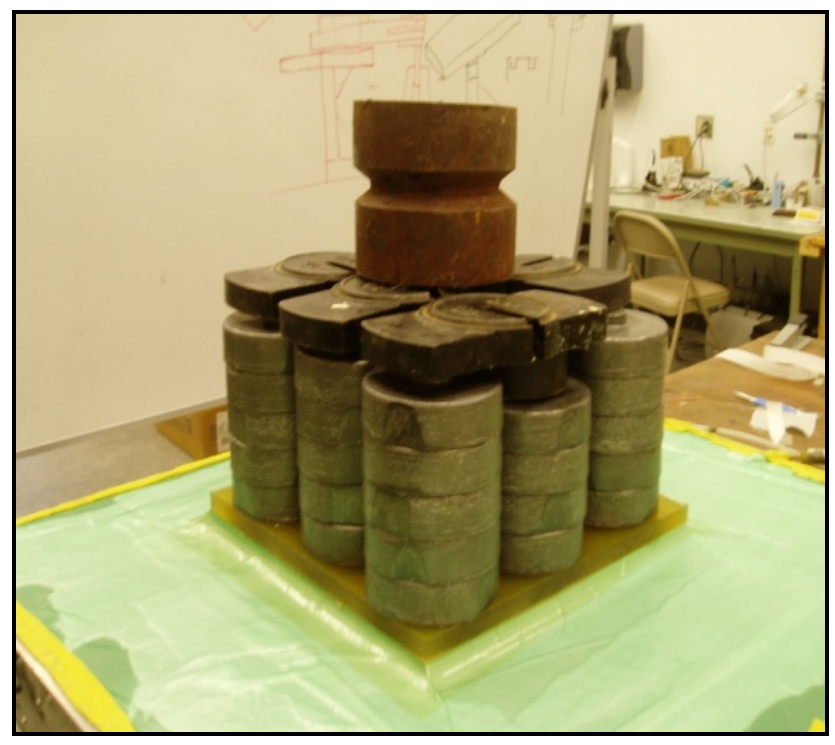

Figure 4.23: Manhole Cover Press Mold Setup

Fig. 4.24 shows the post-cured laminate of the fiberglass manhole cover. 


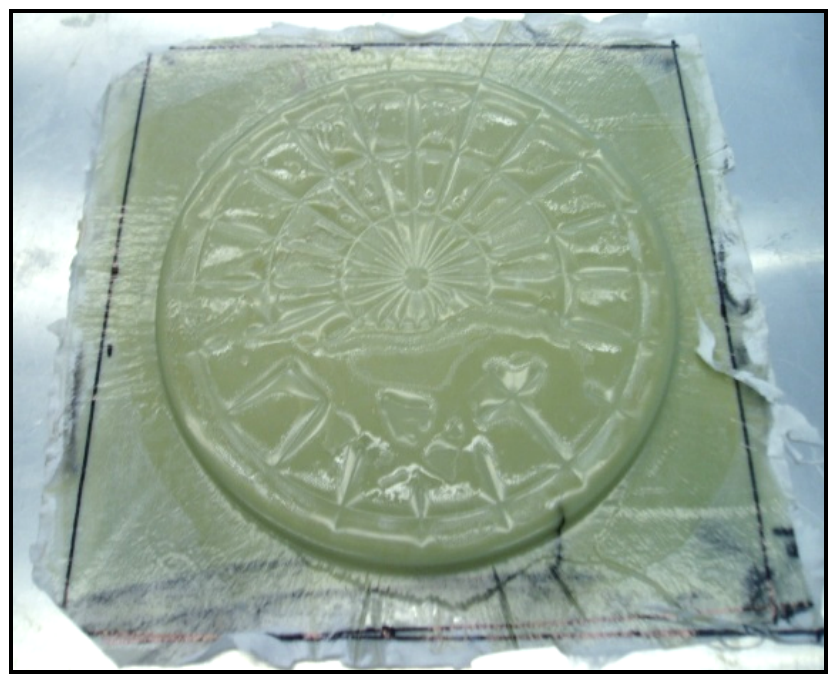

Figure 4.24: Manhole Cover Laminate After Curing

Fig. 4.25 shows the laminated plate's edges being cut into a manhole cover specimen for experimental testing. All thin laminated manhole covers were later sanded and deburred by using the vertical belt sander.

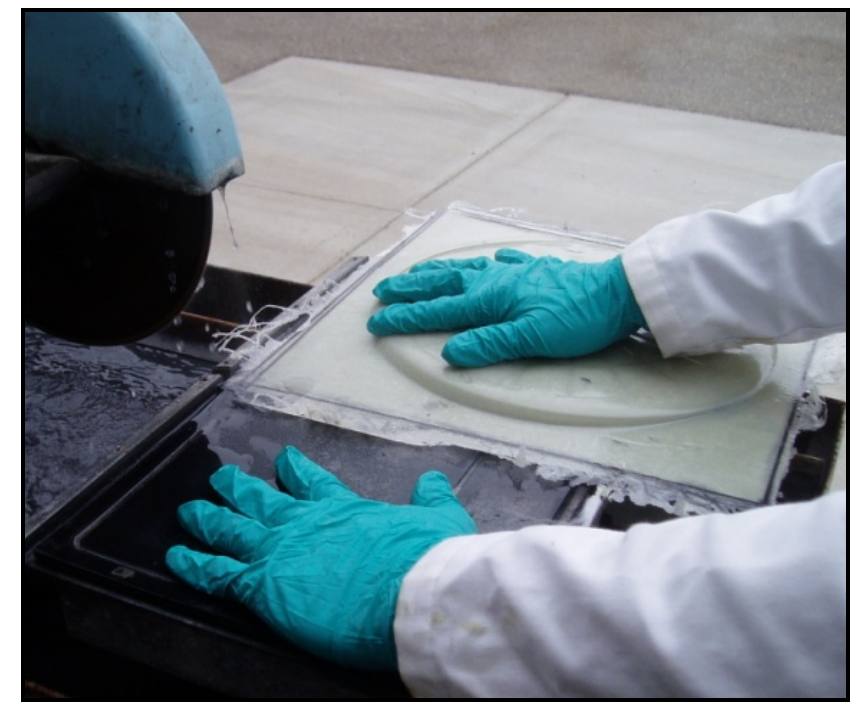

Figure 4.25: Removing Manhole Cover Laminate's Edges with Tile Saw

Fig. 4.26 shows final product of the fiberglass manhole cover that will be used for bending analysis. 


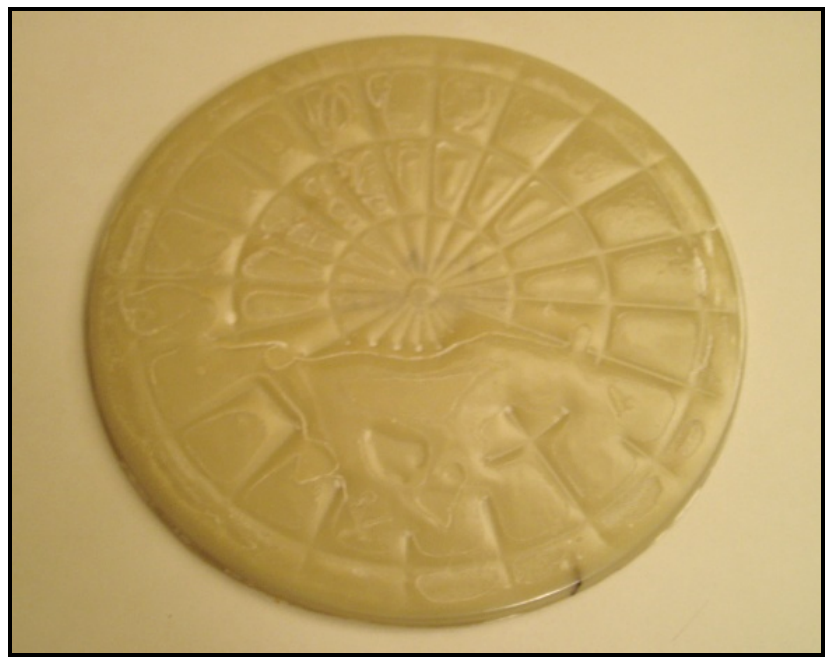

Figure 4.26: Final Product of Fiberglass Manhole Cover

Unfortunately, all fiberglass manhole cover laminates created from this method have a cavity on the back side due to the protruding diameter of the positive mold, as seen in Fig. 4.27.

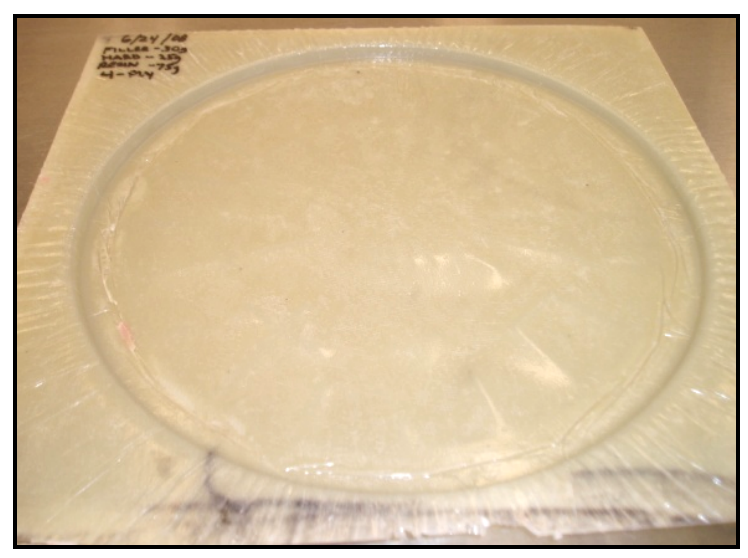

Figure 4.27: Cavity Created by Male Mold

The cavities on their backsides were later removed by using the vertical belt sander. Fig. 4.28 shows the sanded fiberglass manhole cover plate and some of the physical similarities compared with an 11 in diameter water meter cover. 


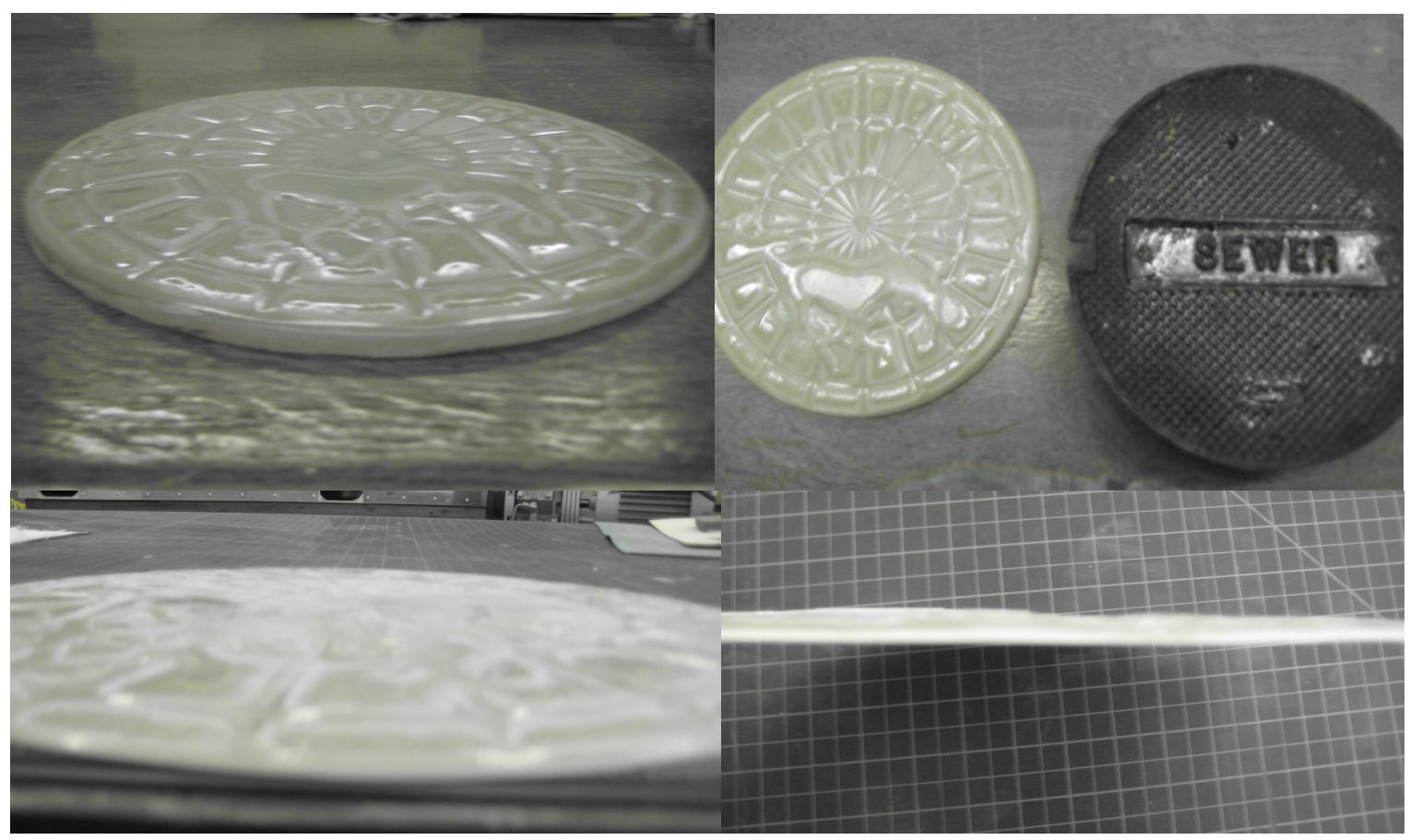

Figure 4.28: Manhole Cover Flat Specimen Compared with Meter Manhole Cover

The fiberglass-filler manhole cover specimen (thin-laminated plate) was sanded to meet the 11 inch diameter of the iron-cast ring of the Christy $\mathrm{H}-8$. Fig. 4.29 shows a laminated composite specimen inside the ring support structure.

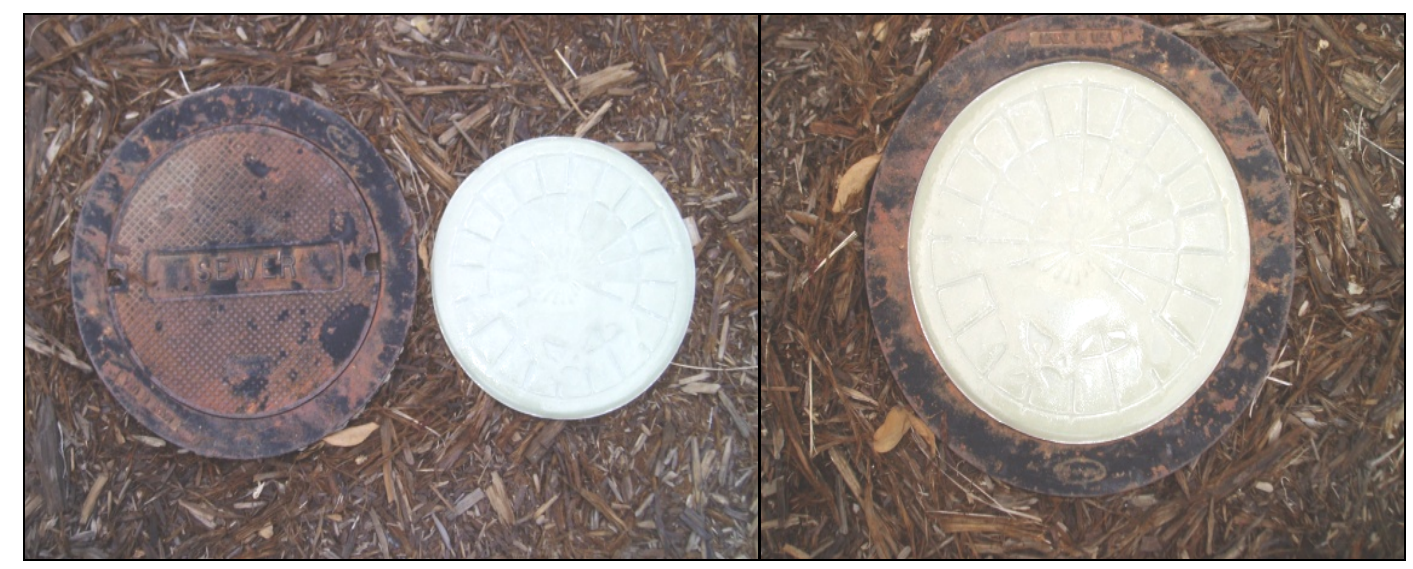

Figure 4.29: Fiberglass-Filler Laminated Plate on top of Manhole 


\subsection{Thick-Resin Fiberglass Manhole Covers}

The next goal was to create a new manhole cover that would represent more like a regular manhole cover. The fabrication process of the new design manhole cover test specimen involved increasing the number of plies and thickness by adding more filler. The purpose was to increase manhole covers thickness and fill the mold cavity by maintaining a constant uniform thickness of epoxy and filler. Four pieces of 15 x 15 in rounded wooden rods with a height of 0.3 in were placed on top of the urethane-rubber negative mold, as seen in Fig. 4.30.

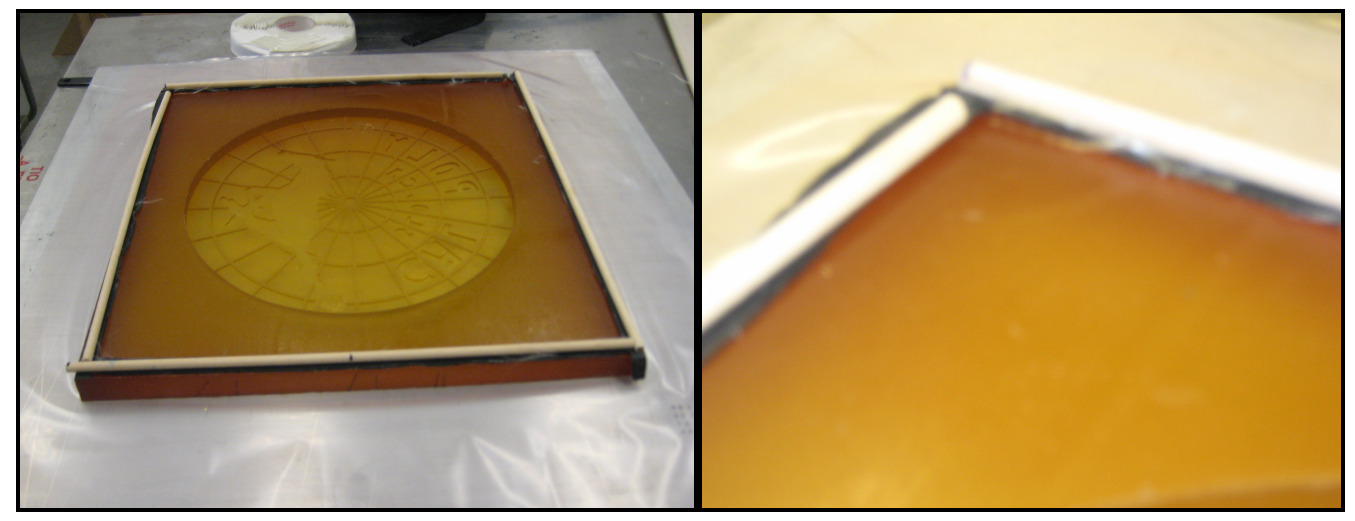

Figure 4.30: Wooden Rods Used to Create Thicker Resin/Filler Manhole Covers

Fig. 4.31 shows the nine plies of $14.5 \times 14.5$ in (E-glass) fiberglass sheet that were cut. The 9-ply sheets had a total thickness of 0.09 inches.

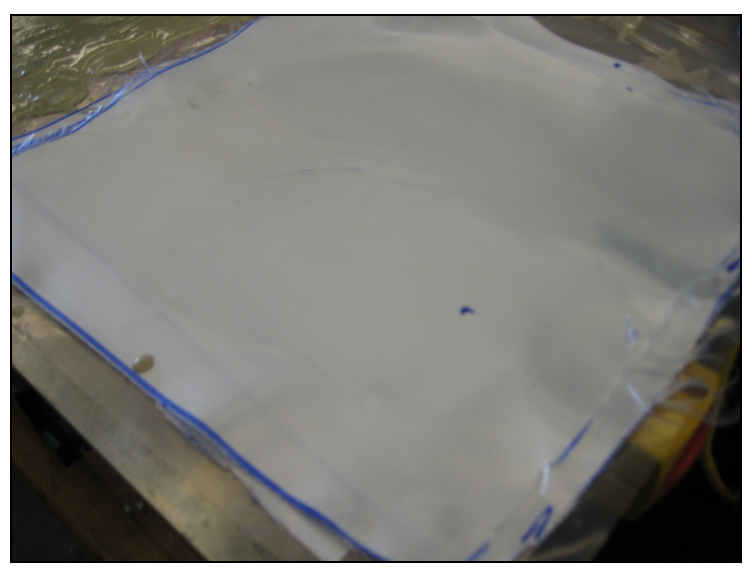

Figure 4.31: Nine-Layered Sheets of Fiberglass Fabric 


\subsubsection{Layup Process}

The amount of epoxy used to make the test specimens was calculated by volume. The volume of $63.075 \mathrm{in}^{3}$ was calculated by multiplying the negative mold's cavity area of $210.25 \mathrm{in}^{2}$ by the mold's height of 0.3 in. The measured height of the 0.3 in would also be the final thickness of the fiberglass manhole cover specimen. Although the Dixie cups varied in dimension due to their taper shape, their bottom diameter was measured to be a 3 in with a radius of $1.5 \mathrm{in}$. The mixing cup's area was $7.06 \mathrm{in}^{2}$. The amount of epoxy was found by calculating the fiberglass fabric sheet volume which was $18.92 \mathrm{in}^{3}$. The epoxy's volume of $44.16 \mathrm{in}^{3}$ needed to make manhole cover specimens was calculated by subtracting the negative mold's volume from the specimen's volume. Finally, the resin and hardener was increased to 382 and 127.3 grams, respectively while using a 3 to 1 mixing epoxy ratio of Aeropoxy and $258.8 \mathrm{~g}$ of limestone filler.

Both hardener and resin were mixed and stirred for 2 minutes. Filler was later added into epoxy batch and stirred for another 2 minutes. The mixed epoxy batch was poured onto the first ply of fiberglass. A spatula was used to disperse the mixed epoxy completely on the fiberglass sheet. The same procedure, as described above, was repeated for rest of plies. Although fiberglass woven roving is independent of orientation, each ply had to be properly stacked by facing in the same direction in order to have a better finished product of specimen. Fig. 4.32 shows the wet fiberglass ply process. 


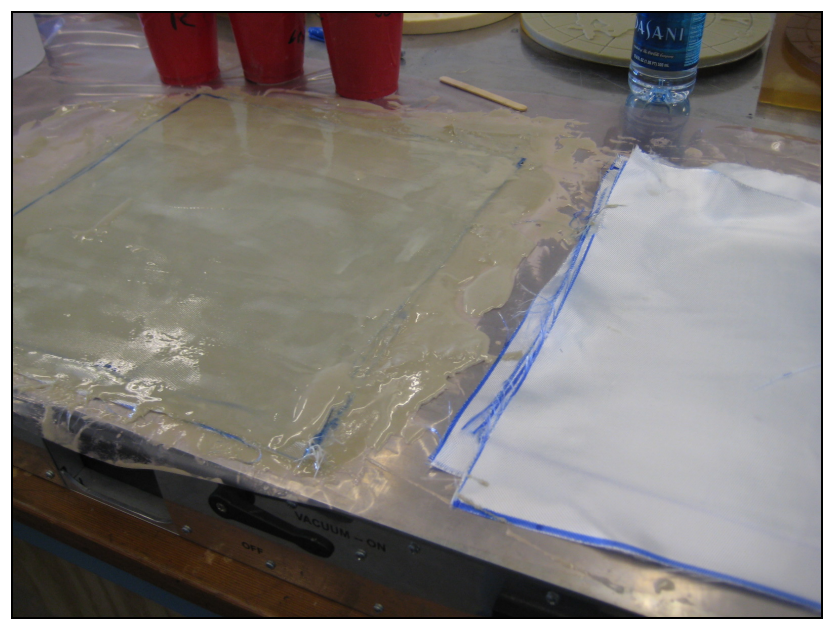

Figure 4.32: The Fiberglass Wet Layup Process

\subsubsection{Curing Process}

The curing process was very similar to the procedure previously mentioned in Section 4.4.1. This was performed by spraying several coats of mold release agents and placing the wetted fiberglass fabric sheets inside the female mold. A 16 x 16 in blue peel-ply was cut and placed on top of the wetted fiberglass sheets in order to ease separation of part from mold. Several pieces breather cloth was used to increase the airflow of the suction pressure, as seen in Fig. 4.33.

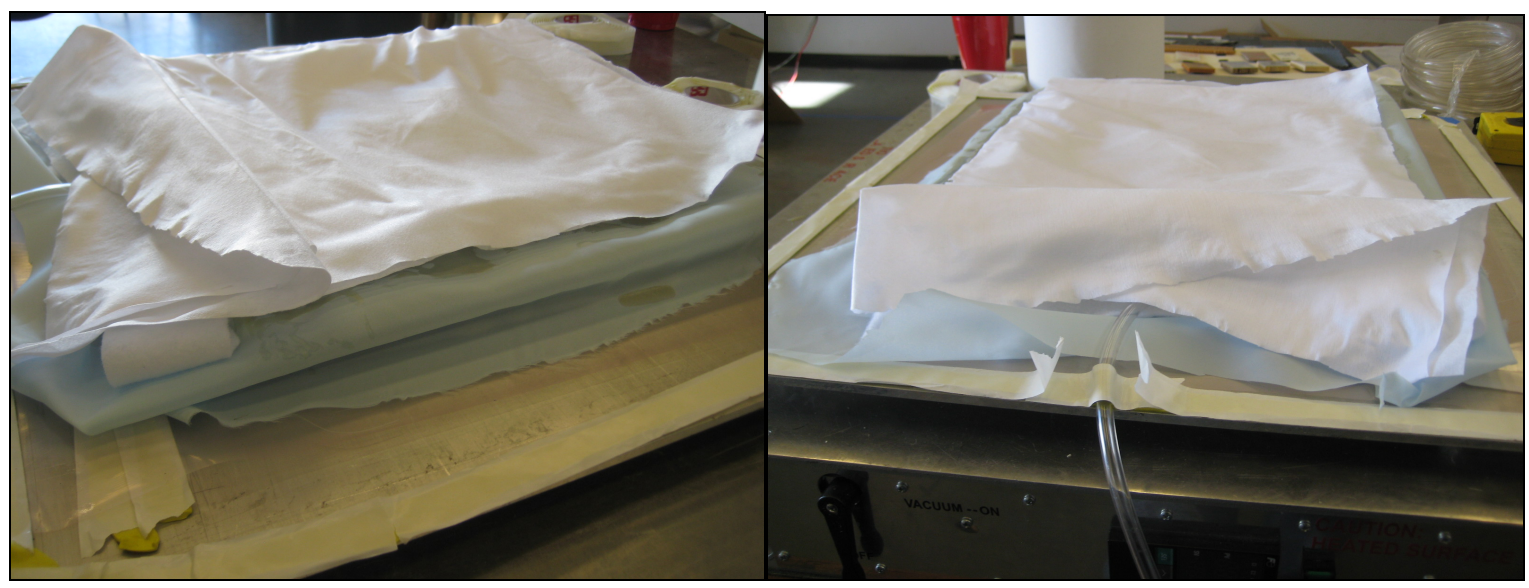

Figure 4.33: Blue Peel-Ply with White Breather on Top of Female Mold 
Fig. 4.34 shows a resin trap connected to an external compressor in order to trap any excess resin inside the vacuum bag of the press mold. A piece of breather fabric was placed on the tip of the compressor's tube in order to increase suction pressure and provide non-interrupted airflow between blue peel-ply and wetted fiberglass fabric sheets, thus enhancing the detail quality of the final product.

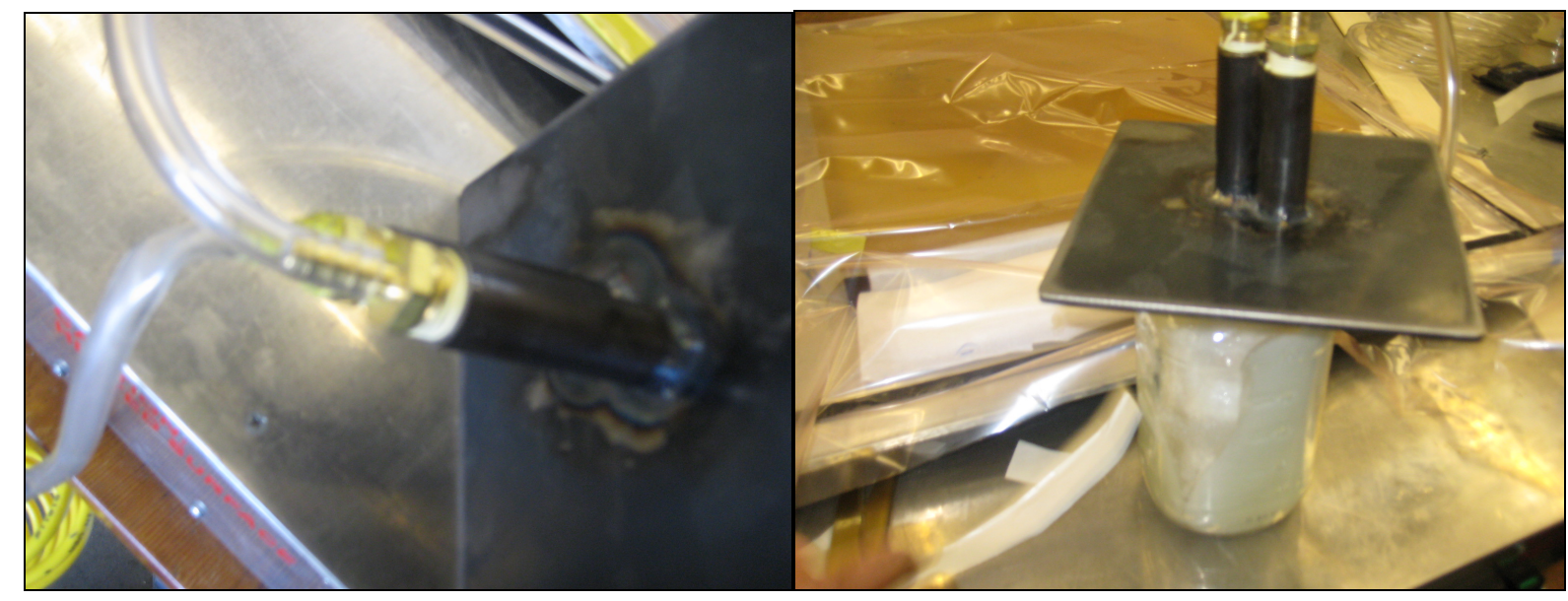

Figure 4.34: Resin Trap Apparatus

Yellow rubber tape was later added onto the male mold's corner in order to prevent puncture on the vacuum bag during cuing. The yellow rubber tape was also used to seal the release film's edges of vacuum bag. Consequently, the bleeder fabric again allowed more airflow to move freely from the female mold's center to the compressor's tube, thus curing the wet composite completely, as seen in Fig. 4.35. 


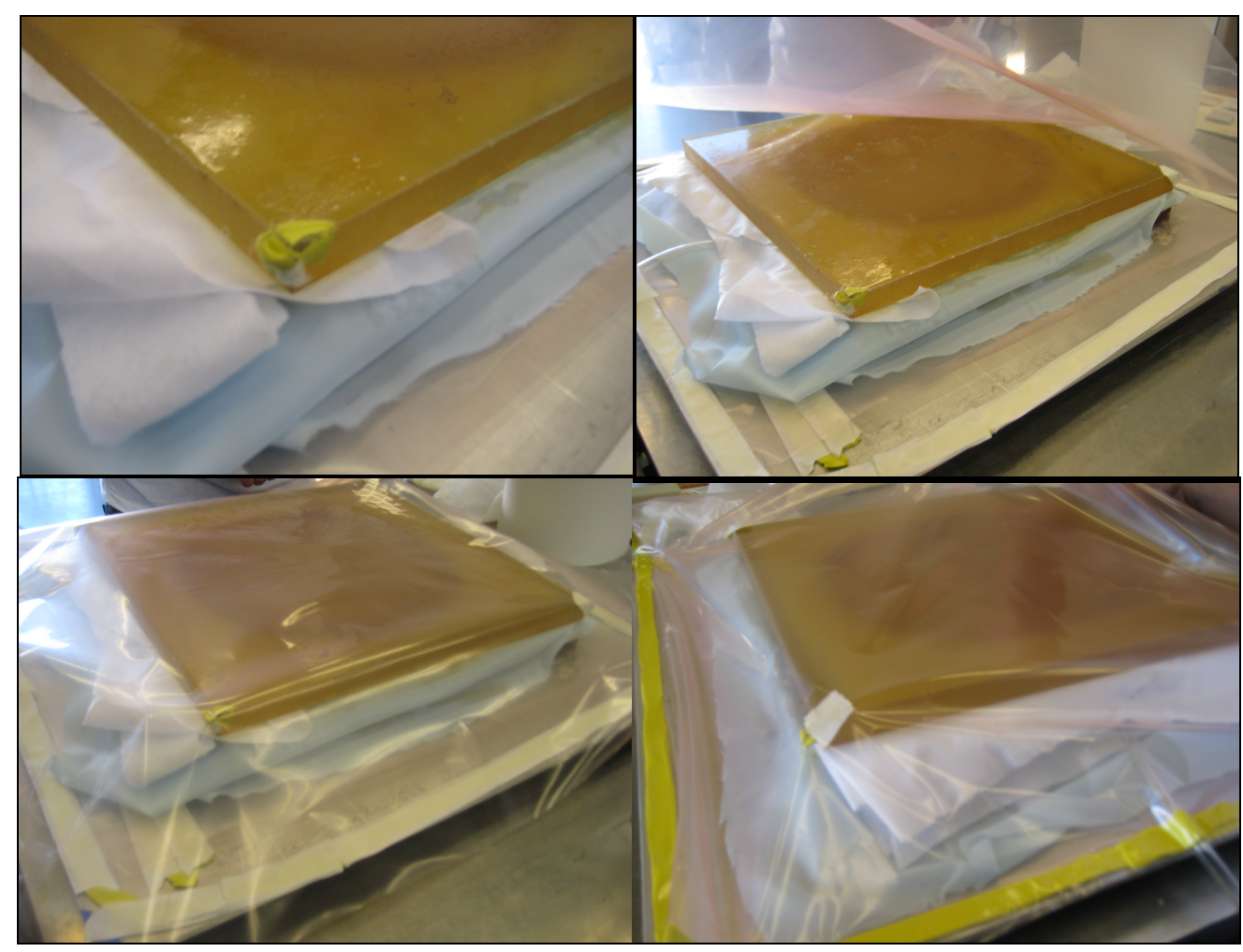

Figure 4.35: Vacuum Bag Setup

A total of two compressors were used for the curing process and ensure a stronger suction pressure due to non-visible air leaks. The press mold was inside the vacuum bag later placed on an aluminum plate and set on the floor, as seen in Fig. 4.36.

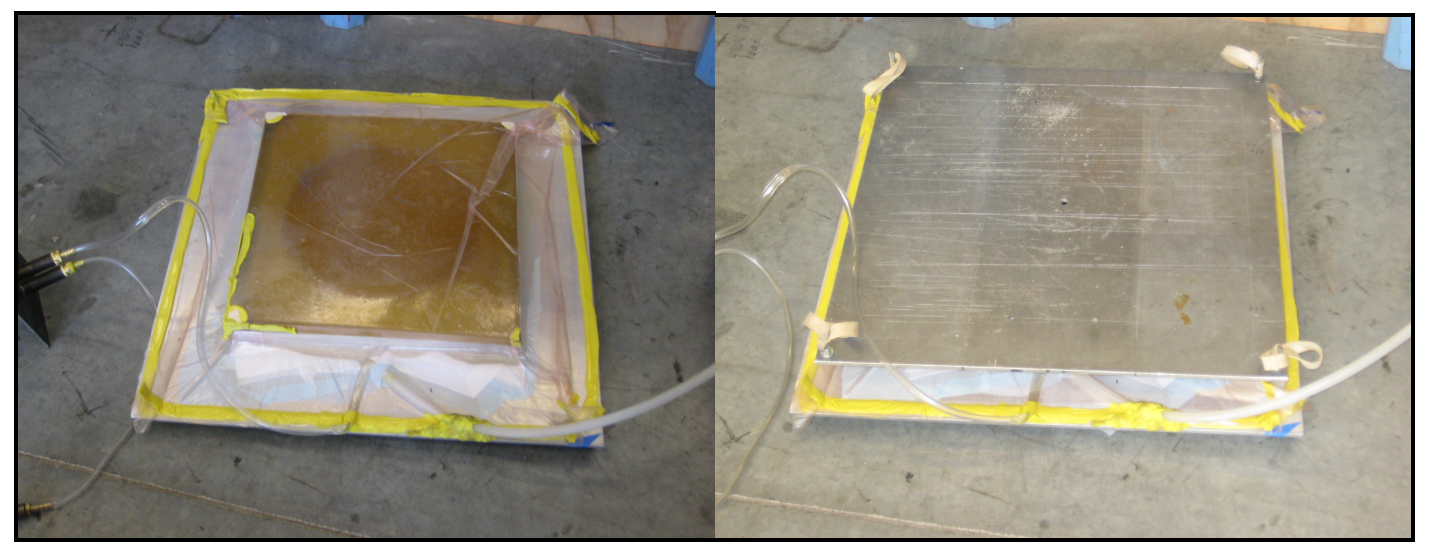

Figure 4.36: Vacuum Bag With and Without Upper Aluminum Plate 
A total of $600 \mathrm{lbs}$ of weights was added onto the aluminum plate in order to increase the overall pressure, as seen in Fig. 4.37. The vacuum bag was then left to cure for a total of $8 \mathrm{hrs}$.

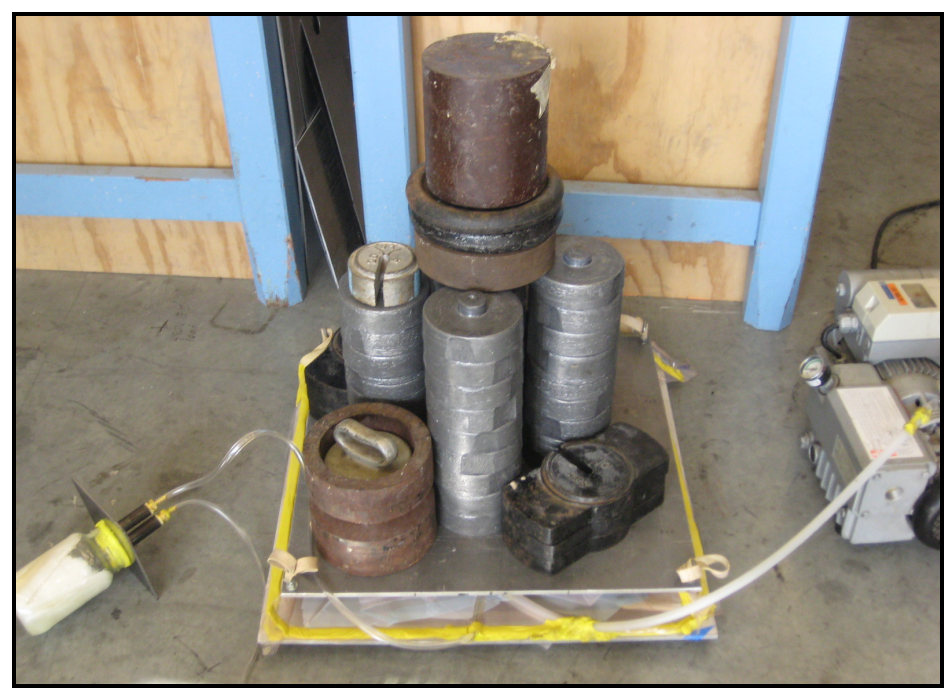

Figure 4.37: The Overall Curing Setup

Fig. 4.38 shows the final product of the thick resin-filler laminated manhole cover. The tile saw was used to cut the sides of the cured laminated plate in order to make four $9 \times 1.3$ in test specimens for static testing which is discussed in more detail in the Appendix $\mathbf{J}$.

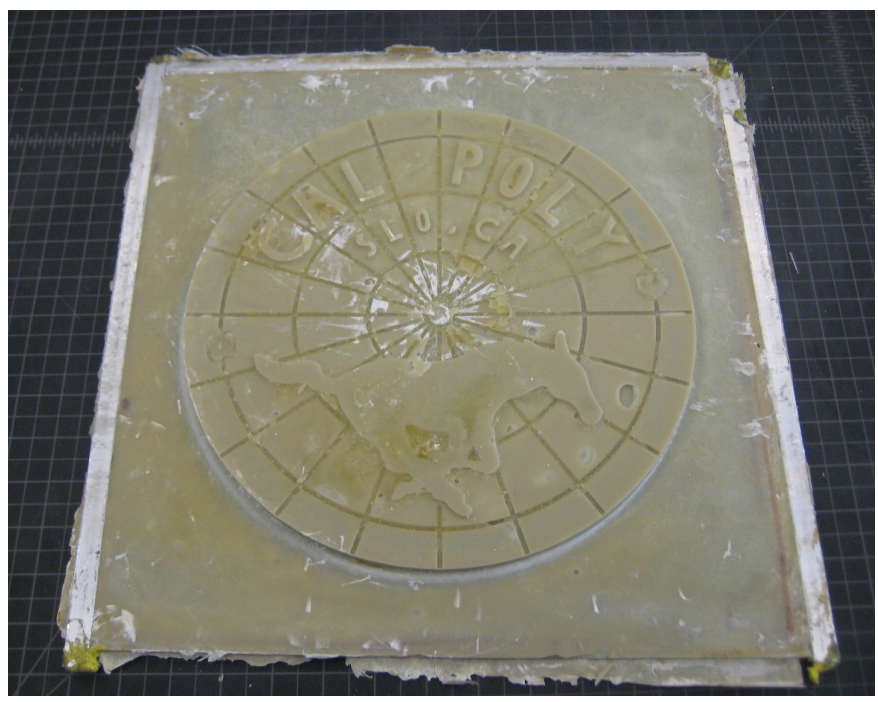

Figure 4.38: Cured Thick Resin-Filler Manhole Cover Plate 
After the thick-resin manhole cover specimen was cured and later was deburred by using the vertical belt sander which was provided in the Cal Poly's Aero-Composite Lab.

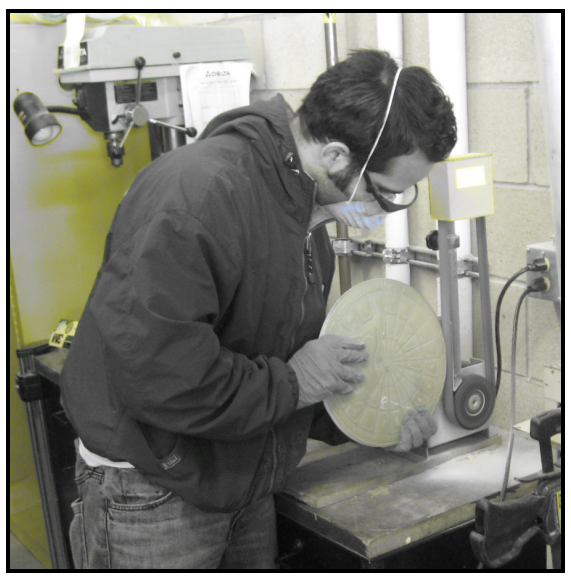

Figure 4.39: Sanding Fiberglass Manhole Cover Edges

The thick resin-filler manhole cover specimen was sanded to meet the sub-frame's ironcast ring diameter of $11 \mathrm{in}$. Fig. 4.40 shows the final product of the fiberglass manhole cover specimen was later placed inside the Christy H-8 support fixture.

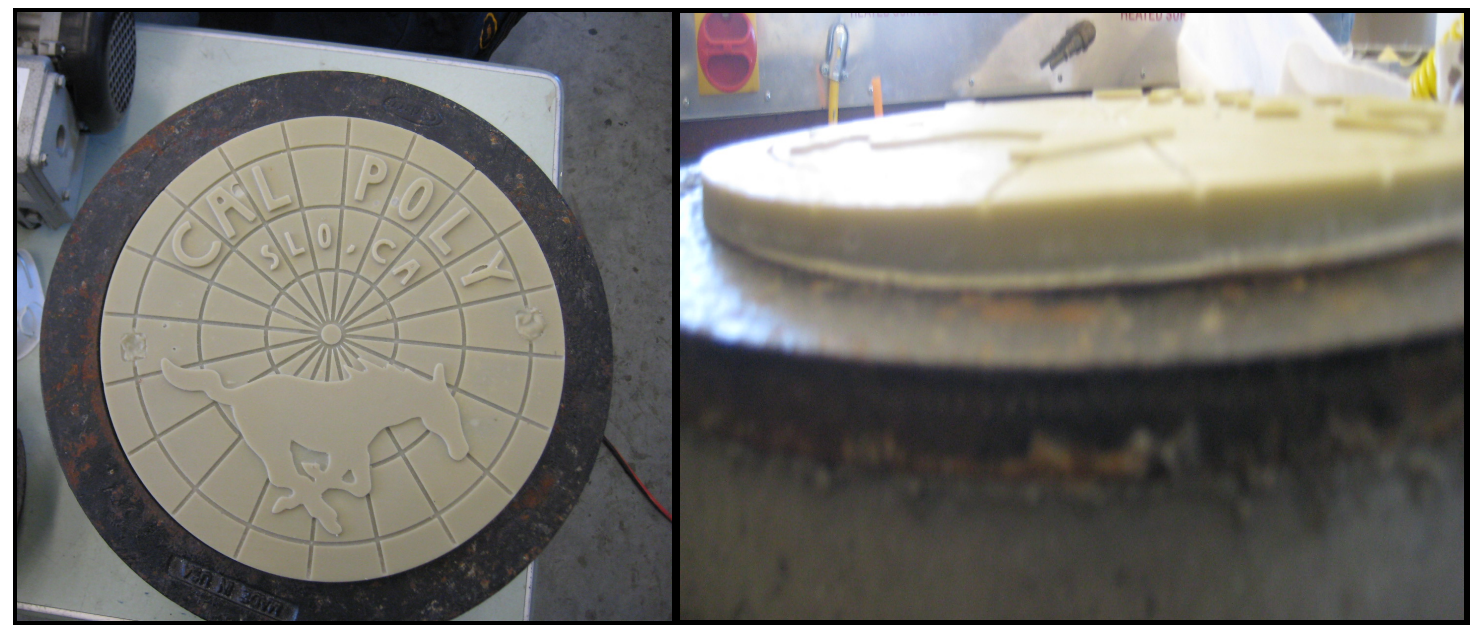

Figure 4.40: Final Product of Thick Resin-Filler Manhole Cover Specimen 
Fig. 4.41 shows several observed irregularities after the post curing process. The holes were air voids created from insufficient polymerization between the fiber and epoxy due to lack of pressure. The non-uniform surfaces and uneven edges of the bottom side of the laminated manhole cover specimen were due to lack of pressure and placing the wetted fiberglass sheets incorrectly inside the negative manhole cover mold.

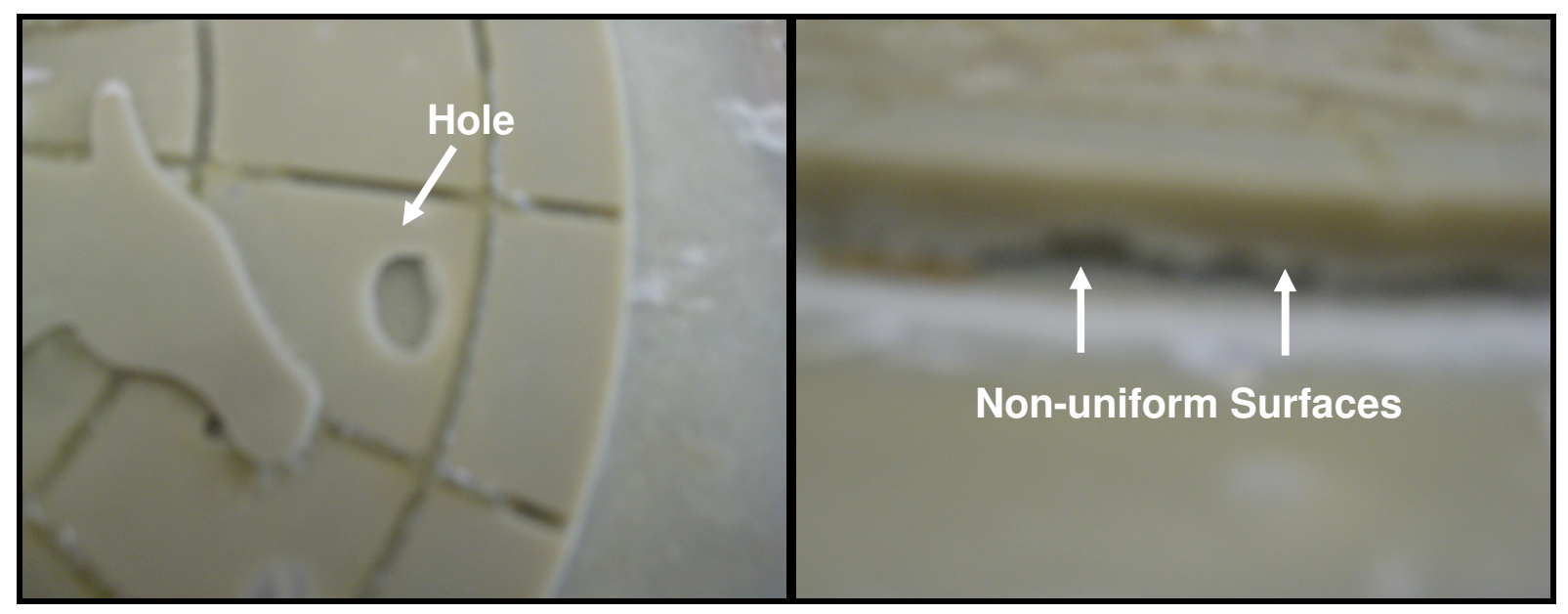

Figure 4.41: Test Specimen Defects from Improper Curing Process.

The final test specimen's defects were mainly due to poor fabrication, such as, lack of pressure due to improper vacuum bagging setup, not distributing epoxy uniformly on each fiberglass piece during wet layup, and premature curing due to the increase of epoxy batch. Although bending analysis was not performed on the thick resin-filler manhole cover specimen, it was still used for presentation purposes. Several fiberglass beams were statically tested under tensile and compression which is further discussed in the supporting analysis section of the Appendices. 


\section{EXPERIMENTAL SETUP AND APPARATUS}

\subsection{Weight Fraction Testing}

After cutting the fiberglass plates it was important to ensure that all plates had roughly the same mass fractions. The mass fractions make sure that the volume ratios of matrix to fiber and the material properties are the same for each plate. The mass or weight fraction was calculated by using the tile saw to cut 1 inch squares of each laminated plate.

The initial weight and volume of the laminated square was measured and recorded. Using a Thermolyne Type 1300 Furnace to cook the laminate, the furnace was placed in the fume hood and heated to 700 degrees Fahrenheit, as seen in Fig. 5.1.

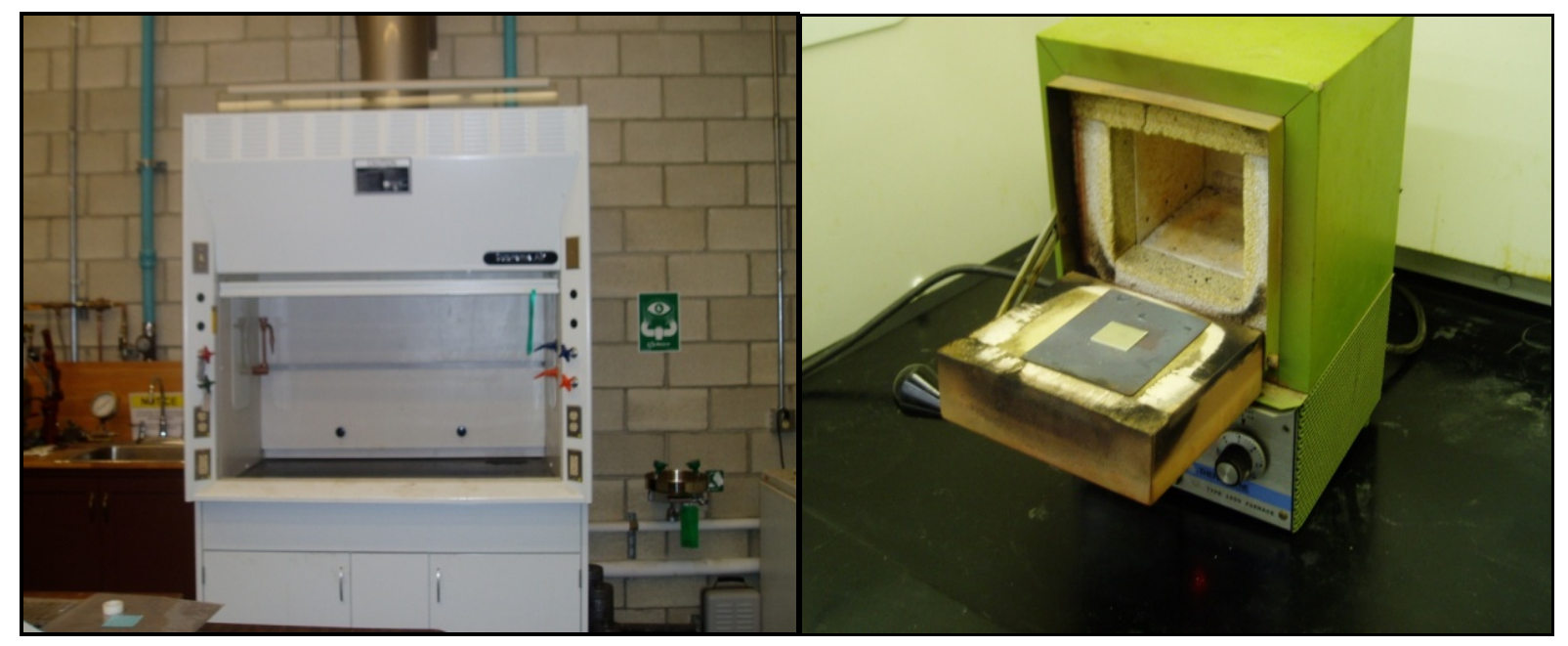

Figure 5.1: Fume Hood and Ceramic Furnace

The square was placed on a steel plate and cooked in the oven until all of the epoxy was visually melted and the individual sheets of the square separated, as seen in Fig. 5.2. 


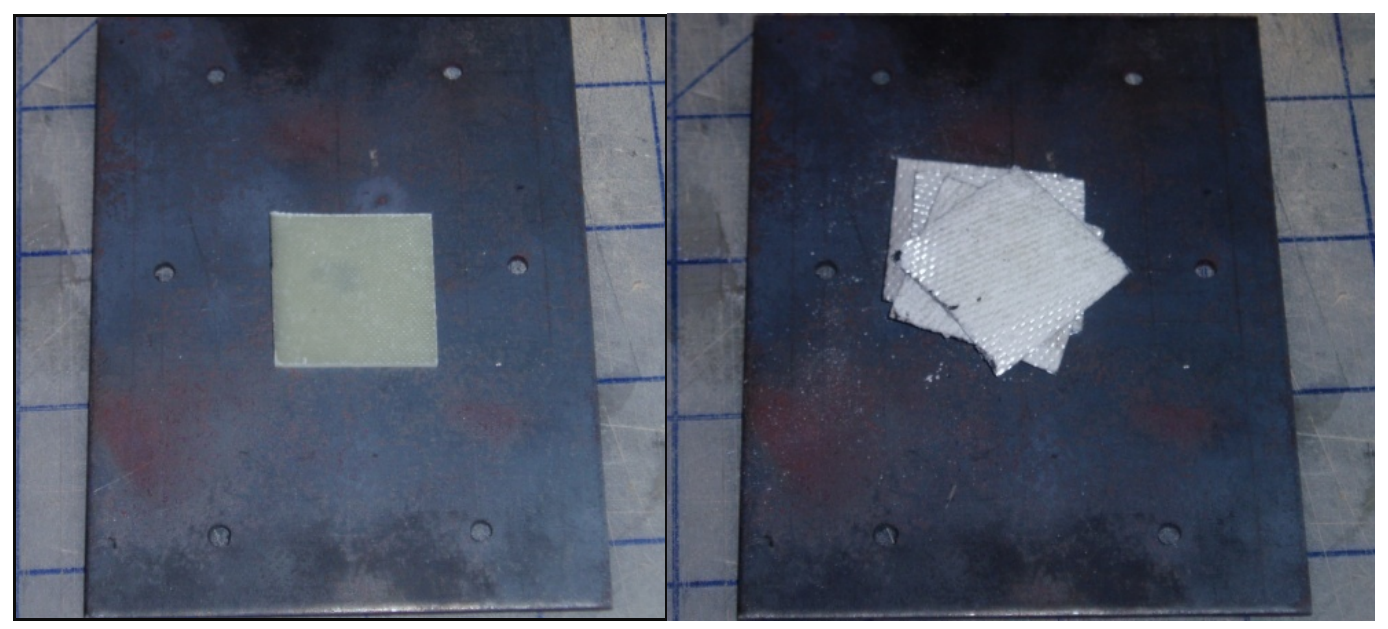

Figure 5.2: Fiberglass Square Before and After Cooking

\subsubsection{Weight Fraction Calculations}

The cooking process occurred for approximately 45 minutes until the laminated square became flexible and white. The remaining fibers were then weighted and measured. The mass ratio of fiber to total composite was found from Eqn. 5.1 below:

$$
\text { Weight } \%=\frac{W_{f}}{W_{c}}
$$

The weight fraction is defined by dividing the weight of the fibers, $W_{f}$, by the total original weight of the composite, $W_{c}$. For the three composite plates with limestone filler, the weight fractions ranged from $62 \%$ to $69 \%$. The weight fractions value of the composite with high-density filler was 59\%; whereas, the laminate with no filler had a mass fraction of $61 \%$. All specimens had similar weight fraction values; hence, it was close enough to make the assumption that all woven-roving fiberglass plates had the same material properties. Table 5.1 displays the data and calculations from the weight fraction analysis. 
Table 5.1: Weight Fraction Data and Calculations

\begin{tabular}{|c|c|c|c|c|c|}
\hline Data & $\mathrm{L}_{20}$ & $\mathrm{~L}_{30}$ & $\mathrm{~L}_{40}$ & $\mathrm{HD}_{30}$ & $\mathrm{~L}_{\mathrm{B} 0}$ \\
\hline Length (in) & 0.978 & 1.036 & 0.997 & 0.983 & 0.953 \\
\hline Width (in) & 0.913 & 0.968 & 0.964 & 0.973 & 0.929 \\
\hline Thickness (in) & 0.043 & 0.049 & 0.062 & 0.049 & 0.036 \\
\hline Volume (in ${ }^{3}$ ) & 0.038 & 0.049 & 0.060 & 0.047 & 0.032 \\
\hline Mass of Laminate (g) & 1.0 & 1.0 & 1.3 & 1.2 & 1.0 \\
\hline Mass of Fiber (g) & 0.69 & 0.67 & 0.81 & 0.71 & 0.61 \\
\hline Mass of Matrix (g) & 0.31 & 0.33 & 0.49 & 0.49 & 0.39 \\
\hline Weight Fraction (\%) & 69.0 & 67.0 & 62.0 & 59.0 & 61.0 \\
\hline
\end{tabular}

\subsection{Static Testing}

\subsubsection{Fiberglass Beams}

Once the fiberglass laminated plate had been fabricated, it was cut into several beams. They had an average dimension of $9 \times 1.5$ in and thickness of 0.05 in, as seen in Fig. 5.3. The fiberglass beams will be used to obtain the desired longitudinal, transverse Young's Modulus, and the effective torsional stiffness. The beams were cut not depending on a particular orientation since they were made from weave-roving fiberglass fabric.

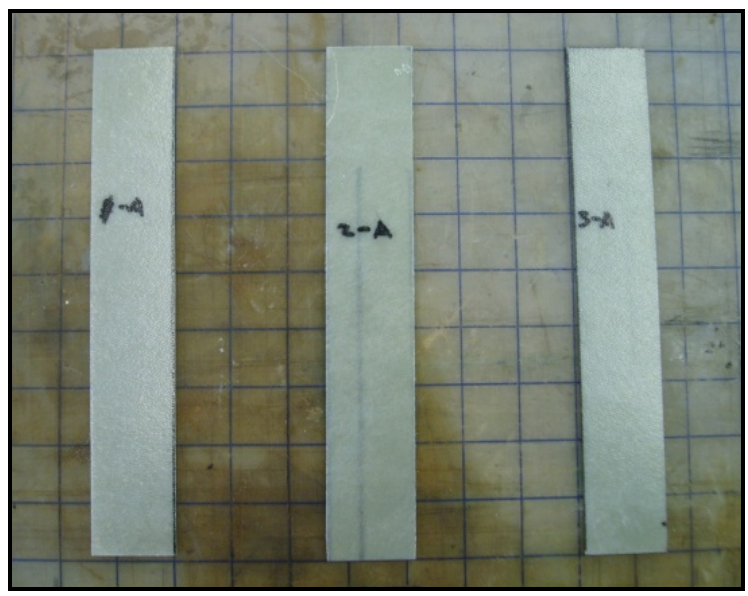

Figure 5.3: Thin Laminated Beams Used for Tensile Testing 
The Young's Modulus in the longitudinal direction and transverse direction could be measured experimentally by static testing. The experimental results from the beam theoretical analysis could also be used to determine the torsional stiffness. Fig. 5.4 shows the diamondtipped saw blade or tile saw used to cut the laminated beam specimens.

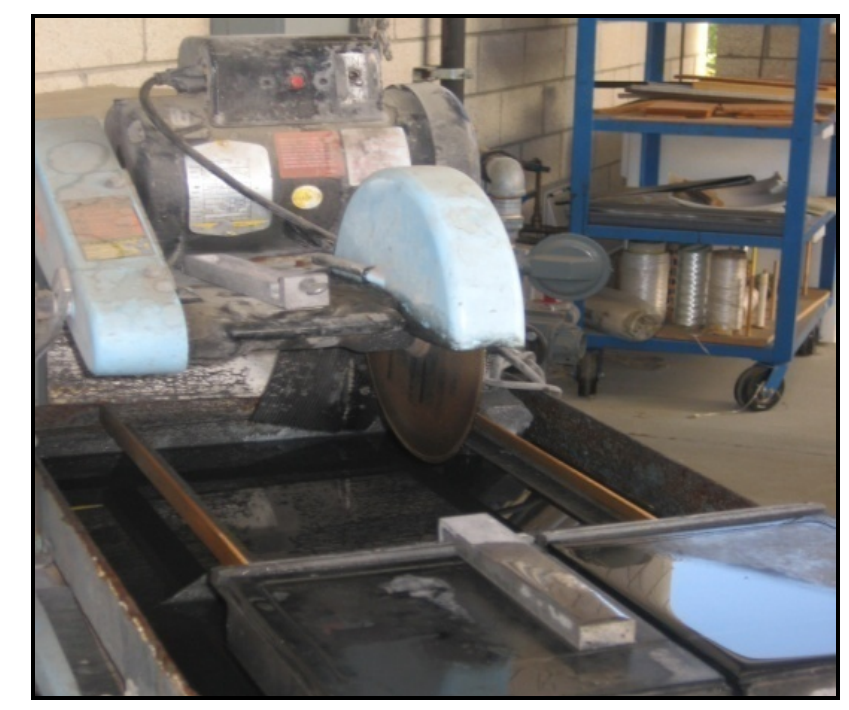

Figure 5.4: Tile Saw Used to Cut Beam Specimens

\subsubsection{Aluminum Tabs}

Once the strain gages were properly installed on the beams, they were ready for static testing. After the bending test, it was desired to also do tensile tests on the beams. For this to occur, aluminum tabs had to be bonded to the ends of the beams so that the Instron machine could securely grip them. The machine cannot be connected directly to the fiberglass since, not only would this create a stress concentration, but the connection would not be very rigid, which is desired to ensure the specimen does not slip during testing. Aluminum tabs with nominal dimensions of $1.5 \times 1.5$ in were used for the fiberglass-filler laminated beams. Additionally, the aluminum tabs were indented using a flat heat screwdriver so that both surfaces would be rough and ideal for bonding. Before bonding could occur, the bonding area on the specimen was 
sanded again using fine grit sand paper. Each surface was then cleaned using acetone and blotted dry. 3M Scotch-Weld 2216 B/A Gray Epoxy Adhesive Tube Kit was used to attach the aluminum tabs to the specimens. The epoxy adhesive consisting of Part A (Gray) and Part B (Off-White) were thoroughly mixed using a plastic lid. The proper mixing ratio of the epoxy adhesive was 3 to 2 by volume. The work life of mixed materials at 73 degrees Fahrenheit is approximately 90 minutes. Fig. 5.5 shows the items used to attach the aluminum tabs on beam specimens.

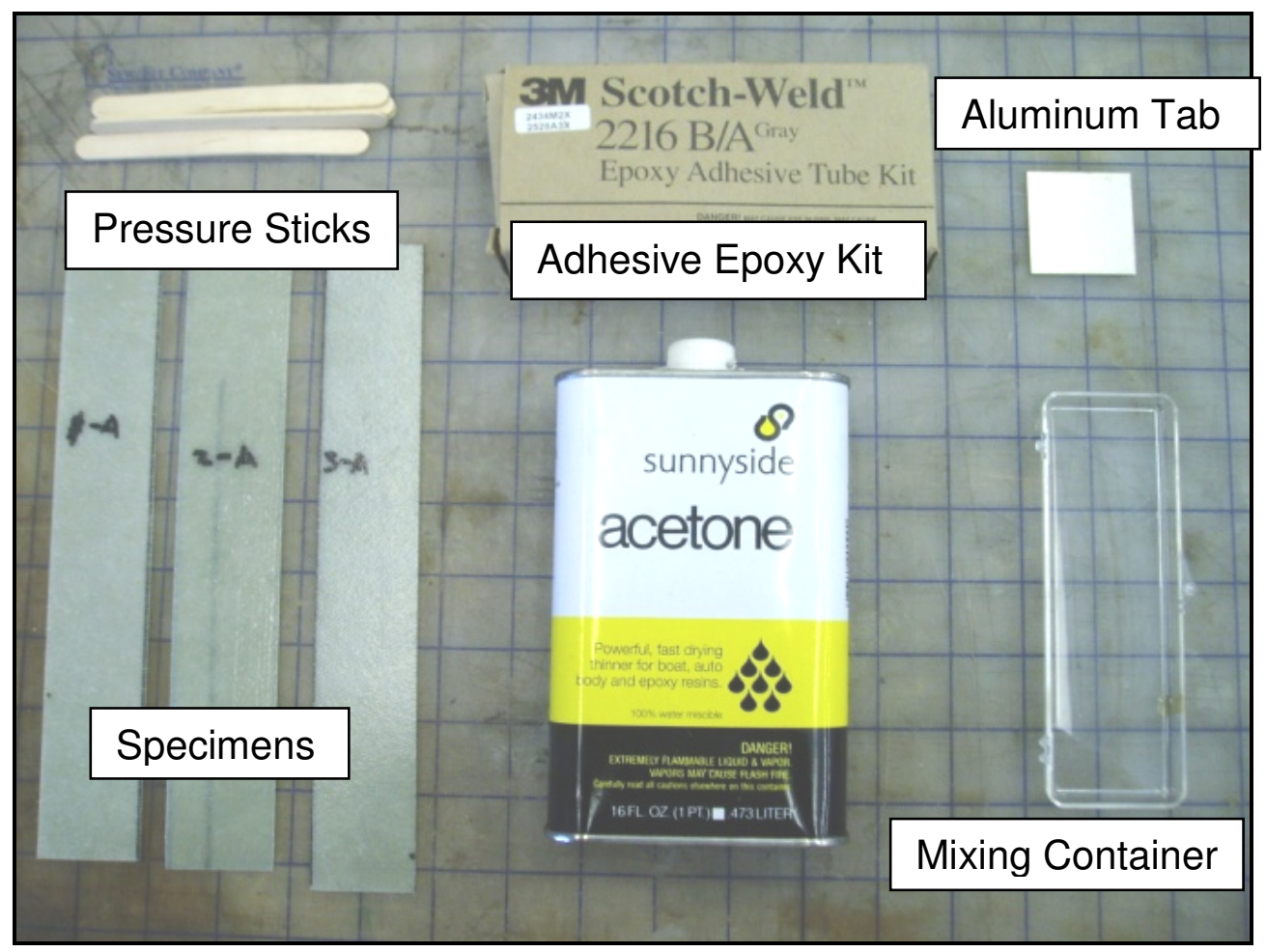

Figure 5.5: Pre-Preparation Elements Used to Attach Aluminum Tabs

The epoxy adhesive mixture was then added to the bonding area located on the beam's tip. The aluminum tab was placed on the epoxy while applying pressure by moving it around in circular motions over the bonding area. With the epoxy properly applied and aluminum tabs in place, the specimen underwent a specific curing process inside of a tetrahedron composite press 
oven, as seen in Figure 5.6. The composite press oven consists of two 12 x 12 in galvanized aluminum metal plates used to compress the aluminum tabs onto specimens.

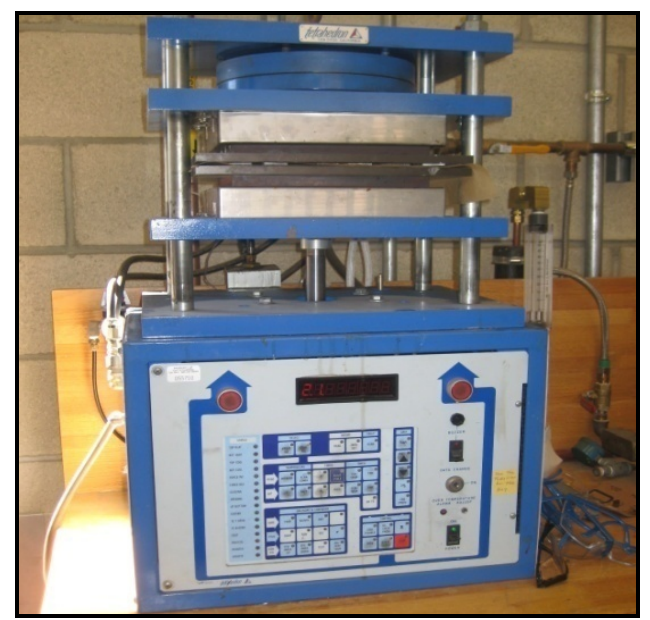

\section{Figure 5.6: Tetrahedron Composite Press Oven}

The composite press oven helped to minimize the air bubbles in the epoxy between the specimen and aluminum tab, since air bubbles will weaken the bond, and reduce the thickness of the actual epoxy in the bond in order to decrease the risk that Instron machine will shear the aluminum tabs off the specimens during tensile testing.

The curing cycle shown in Fig 5.7 was programmed into the press, and the force level was checked to ensure it reached steady state. Table 5.2 summarizes the curing cycle parameters used to program the Tetrahedron composite press oven.

Table 5.2: Aluminum Tab Curing Cycle Program

\begin{tabular}{|l|c|c|c|}
\hline \multicolumn{1}{|c|}{ Process } & Step 1 & Step 2 & Step 3 \\
\hline Initial Temperature $\left({ }^{\circ} \mathrm{F}\right)$ & 100 & 80 & \multirow{2}{*}{ End } \\
\cline { 1 - 3 } Temperature Rate $\left({ }^{\circ} \mathrm{F} / \mathrm{min}\right)$ & 4 & 4 & \\
\cline { 1 - 3 } Force $(\mathrm{lb})$ & 400 & 400 & \\
\hline Force Rate $(\mathrm{Ib} / \mathrm{min})$ & 12,000 & 12,000 & \\
\cline { 1 - 3 } Final Temperature $\left({ }^{\circ} \mathrm{F}\right)$ & 70 & 70 & \\
\hline Time $(\mathrm{hrs})$ & 4 & 8 & \\
\hline
\end{tabular}


There are few setup procedures that must be performed to composite press machine before the cycling parameters are set. The dial gauge must be first set to 120 psi and the cooling gauge to $40 \mathrm{psi}$. The composite press machine supplied a uniform load of $400 \mathrm{lbs}$ to the aluminum tabs throughout the curing process. The composite press oven also heated the fiberglass beams following the curing cycle seen in Fig. 5.7. Starting at room temperature, the press machine heated at a temperature rate of 4 degrees Fahrenheit per minute to a temperature of 100 degrees Fahrenheit. This temperature was constant for $4 \mathrm{hrs}$ and was then reduced to 80 degrees Fahrenheit for 8 hrs. This curing process allowed for a rigid bond of the aluminum tabs to the beams.

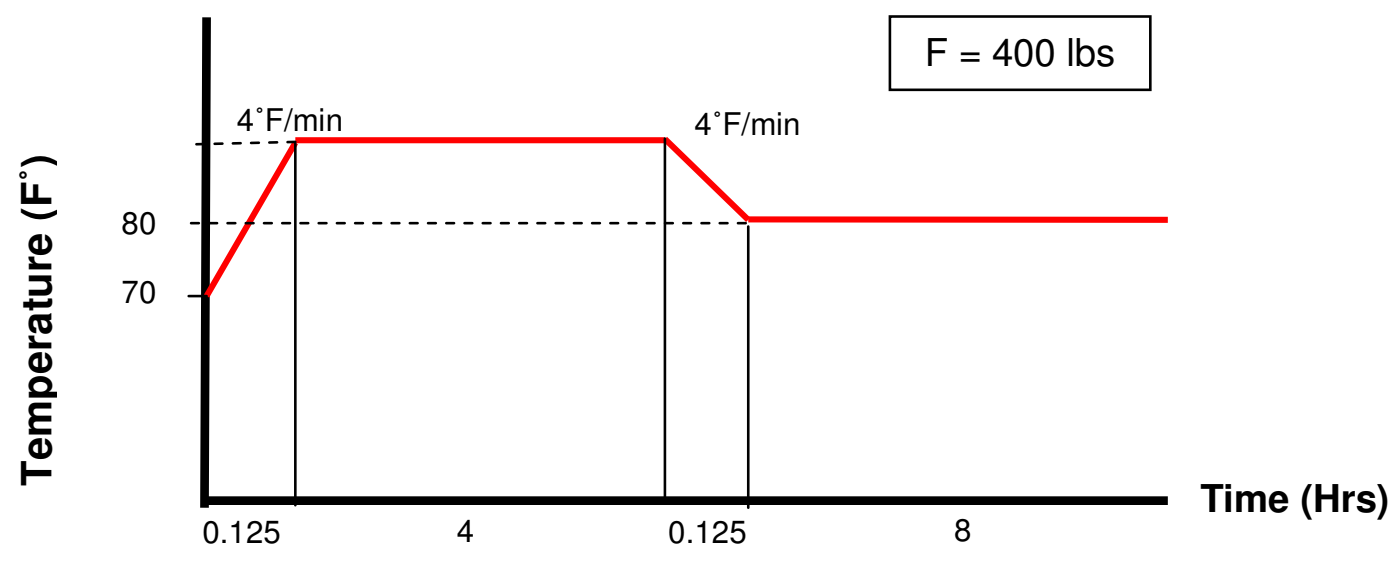

Figure 5.7: Aluminum Tab Curing Cycle

Fig. 5.8 shows the fiberglass beams with the aluminum tabs after curing for $12 \mathrm{hrs}$ in the composite press oven. Specimens were later statically and dynamically tested by using the AeroInstron 8801 machine and MB Electronics electronic shaker table. 


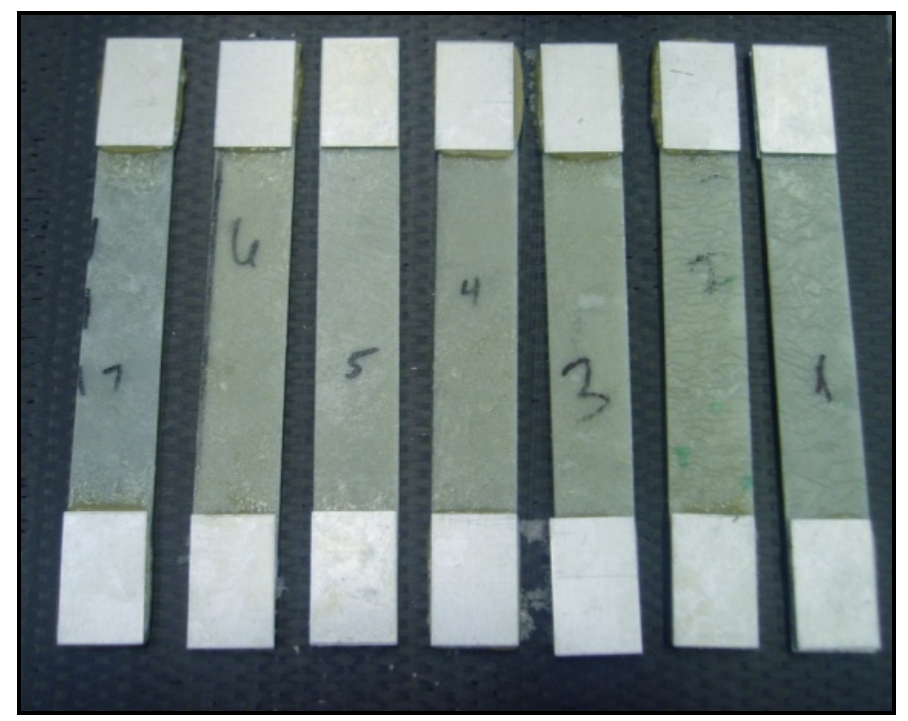

\section{Figure 5.8: Aluminum Tabs Attached to Composite Beam Specimens}

\subsubsection{Tensile Testing System}

The fiberglass-filler laminated beams were tested using the Aero-Composite lab's Instron 8801 machine along with its corresponding Merlin Instron Software Program Version 5.51.00 and Instron control panel, as seen in Fig. 5.9. The software program was used to record data of the material properties and strength characteristics of the fiberglass laminated test samples. The tested samples included one 9-ply fiberglass laminated beam (which consisted of the thick resinlimestone filler) and five 4-ply fiberglass laminated beams (which consisted of various limestone and high density filler amounts.) Each laminated test specimen had a dimension of 9 x 1.5 in. The control panel was used to calibrate the tensile machine. Load, strain, and specimen specifications where later inserted into the Merlin software before tensile testing. The tensile testing system was performed and setup accordingly to the ASTM standards. 


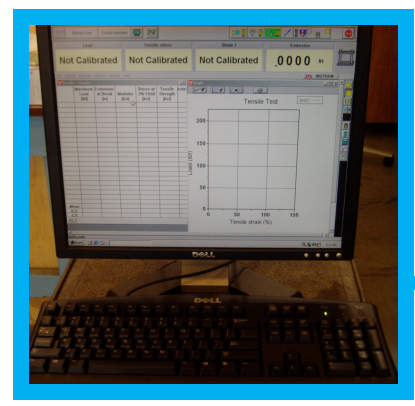

Software Program
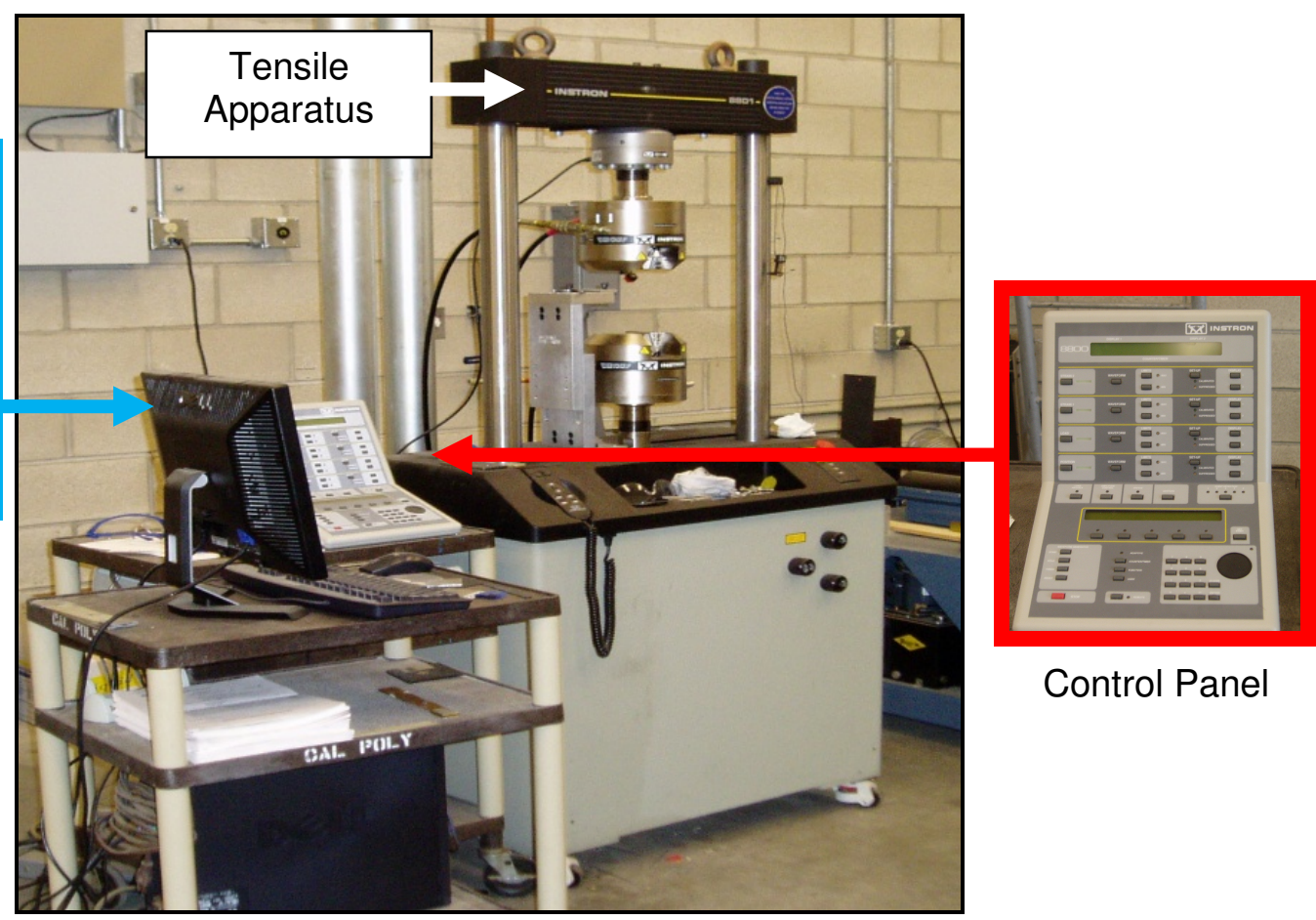

Control Panel

Figure 5.9: Static Testing System

The Instron 2620-826 extensometer was used to record the strain in the longitudinal direction and to send the data to the Merlin software. Fig. 5.10 shows the extensometer schematics.

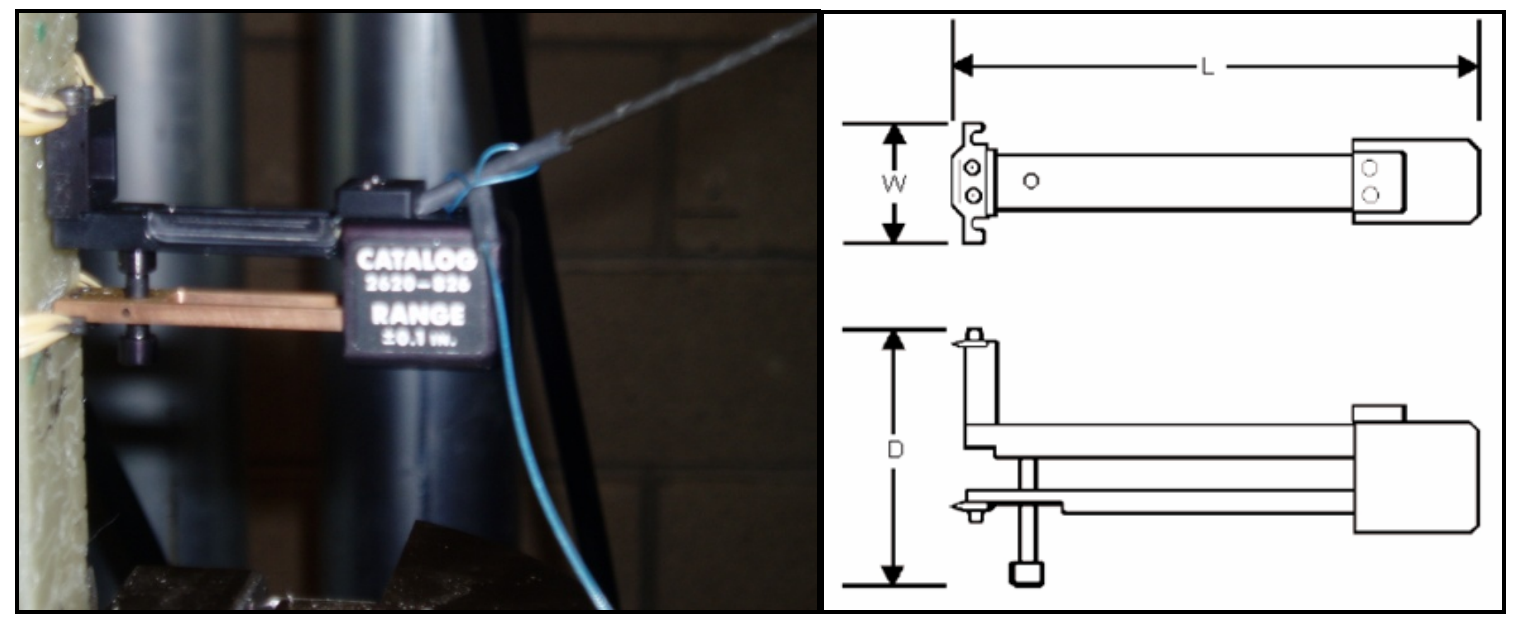

Figure 5.10: Instron Extensometer 
Each fiberglass beam was placed vertically in the Instron machine and clamped down using the Instron control key pad, and the extensometer was attached to the center of the laminate with a rubber band. The Instron machine apparatus before testing is shown in Fig. 5.11.

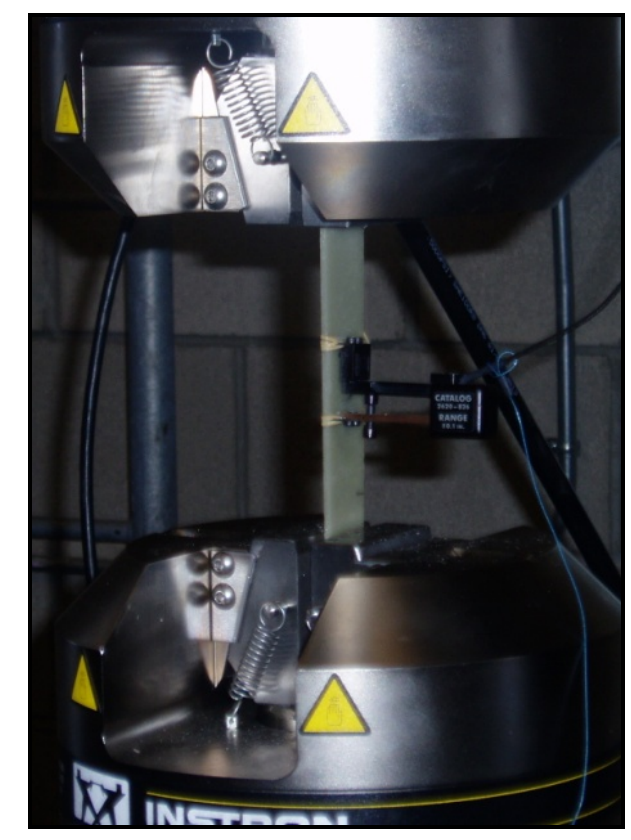

Figure 5.11: Tensile Testing Before Fracture

The laminated beams were now ready for testing. The Merlin software was run and the Instron machine performed the test until the laminate fractured. In addition, during the early phase of the testing, the extensometer was immediately removed from the specimen so it would not break when the laminate fractured. After testing, the data recorded in the Merlin program was saved and the laminate was removed from the Instron machine. The data was saved by saving the file of the tensile testing results, as a raw data and ASCII raw data, located in the Merlin software's data folder. The raw data was later opened, copied, and pasted into an Excel worksheet. This data was used to calculate the experimental Young's Modulus of Elasticity and to graph the following: stress versus strain and maximum load versus displacement. Figure 5.12 
shows the fiberglass beams after tensile testing with their corresponding fractures at different locations.

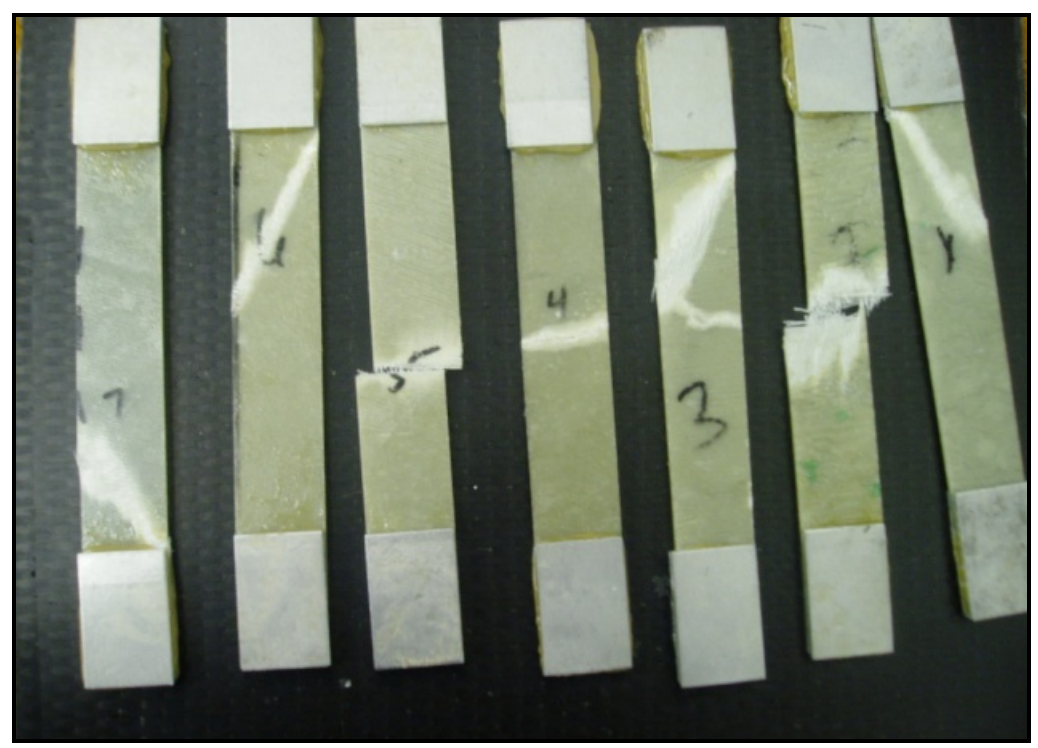

Figure 5.12: Beam Specimens After Tensile Testing

\subsubsection{Flexural Test System}

The bending test was performed by following the standard test method for flexural properties of polymer materials (ASTM D-7264) with the exception that the test specimens were not rectangular and supported in a beam configuration. Instead the test involved laminated manhole cover specimens and a sub-frame fixture which consist of a pre-cast concrete base with an ironcast ring, called "Christy H-8", as seen in Fig. 5.13. The dimensions of the specimen support fixture which was donated by San Luis Obispo's Public Works had a height of 18 inch and a diameter of $11 \mathrm{in}$. The significance of this test was to determine the flexural properties (including strength, stiffness, and deflection) of 4-ply laminated plates representing a simply supported manhole cover under a concentrated-uniform load at constant loading rate of $0.5 \mathrm{in} / \mathrm{min}$ with a sampling rate of $0.5 \mathrm{~s}(20$ hertz). 


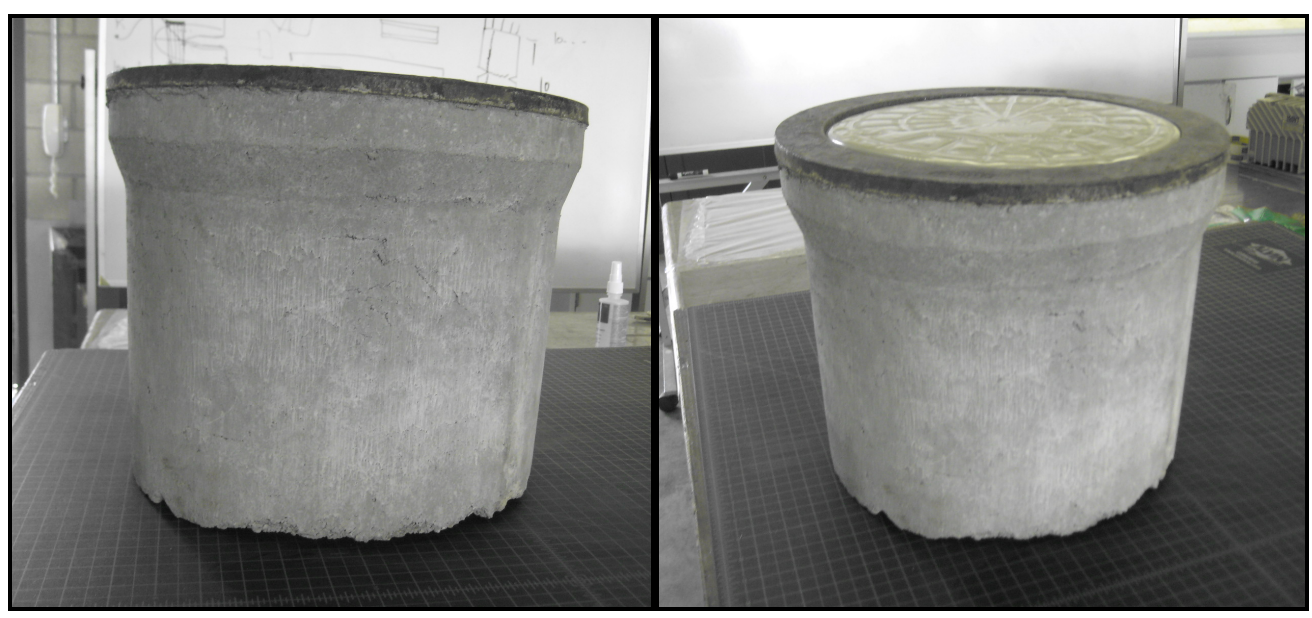

Figure 5.13: Christy H-8 Specimen Support Fixture

The bending analysis involved a quasi-static, low-speed test. It is generally used for making quantitative measurements involving damage resistance of continuous-fiber reinforced composite materials. The bending load is applied to the specimen by slowly pressing a loading nose (instrumentation head-piece) into the test specimen's surface for measuring deflection. The test requires that the specimen is designed so that it can be simply supported to a stationary fixture. Although these tests may be used to screen material for damage tolerance resistance, it is limited to use with composites consisting of layers of unidirectional fibers or layers of fabric. Loading is applied by device capable of delivering a constant speed loading rate at a maximum load of $80,000 \mathrm{lbs}$. The loading rate was $0.5 \mathrm{in} / \mathrm{min}$ with a sampling rate of $0.5 \mathrm{sec}$ ( $20 \mathrm{hertz})$. For this project, the test was performed by using the MTS 322 Flex Frame hydraulic actuator apparatus, as seen in Fig. 5.14. 


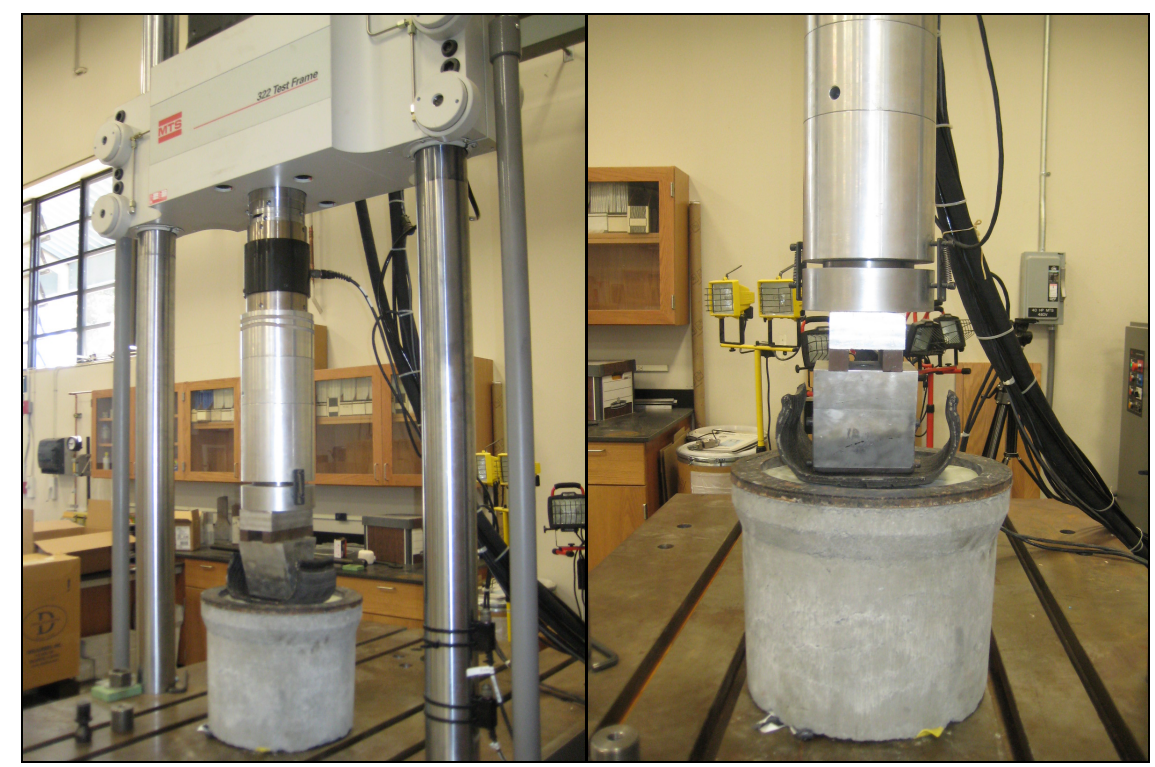

Figure 5.14: Bending Test Method Using the Christy Support Fixture

The bending test machine was used to measure the axial deflection or displacement created by the concentrated load applied at the center of each laminated specimen. The MTS 322 model consist of the following: a steel loading nose or head piece with a fixed roller diameter of 0.98, a mandrel which is used to clamp, secure, and load vertically the head piece, a steel table to press and hold specimens, data acquisition and hydraulic actuator control system. The actuator control system uses a MTS Flex Test SE software program to run the specified commands from computer (data acquisition system) and reads adjustments from the MTS 322 machine. The computer was used to measure the applied point load and displacement in the axial direction. It used the software program called "Station Manager" which measured and recorded all testing data. Fig. 5.15 shows both the data acquisition and actuator control system respectively. 


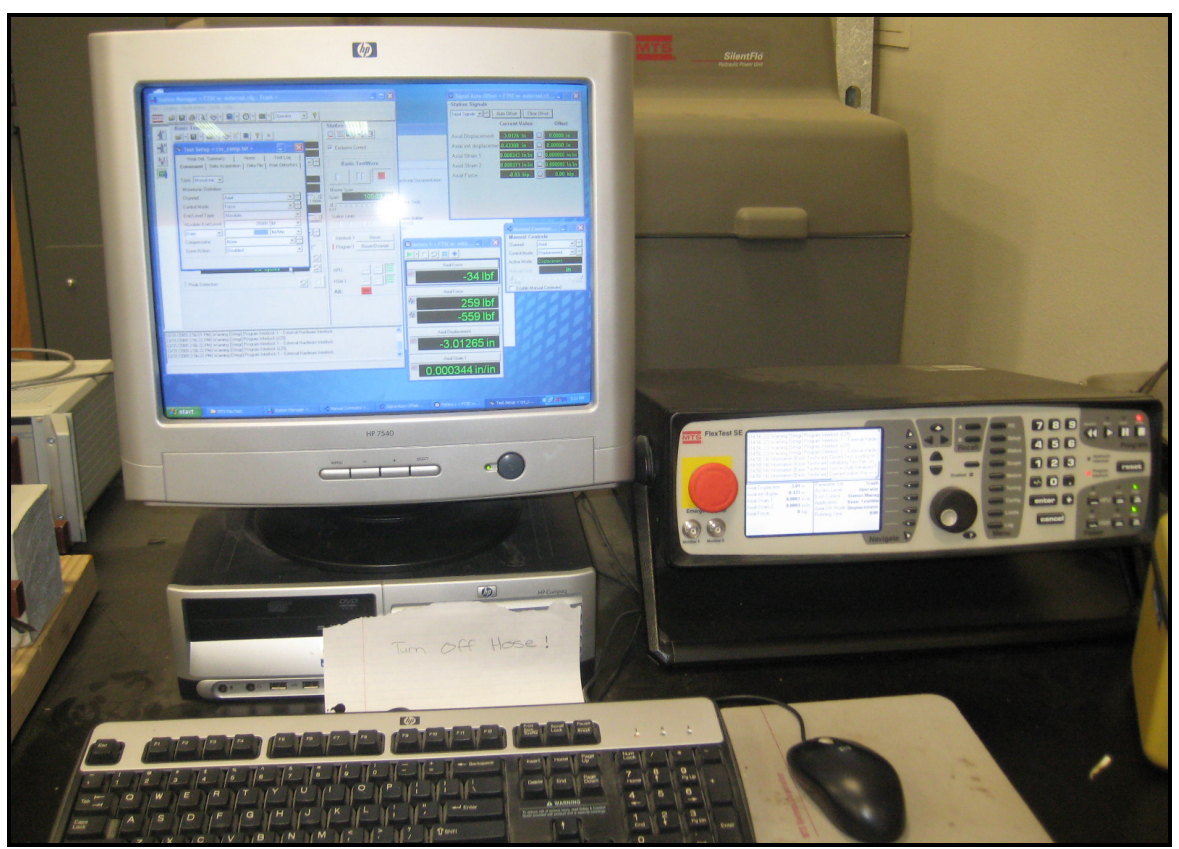

\section{Figure 5.15: Data Acquisition and Actuator Control System for MTS 322 Model}

Although specimens' cross-sections were not rectangular and did not have two reaction loads at the supports, the test was still loaded axially with a concentrated-uniform force midway between the supports and at the center of its cross-section; hence, somewhat representing a threepoint bending configuration. Fig. 5.16 shows the different views of the loading nose fixture.

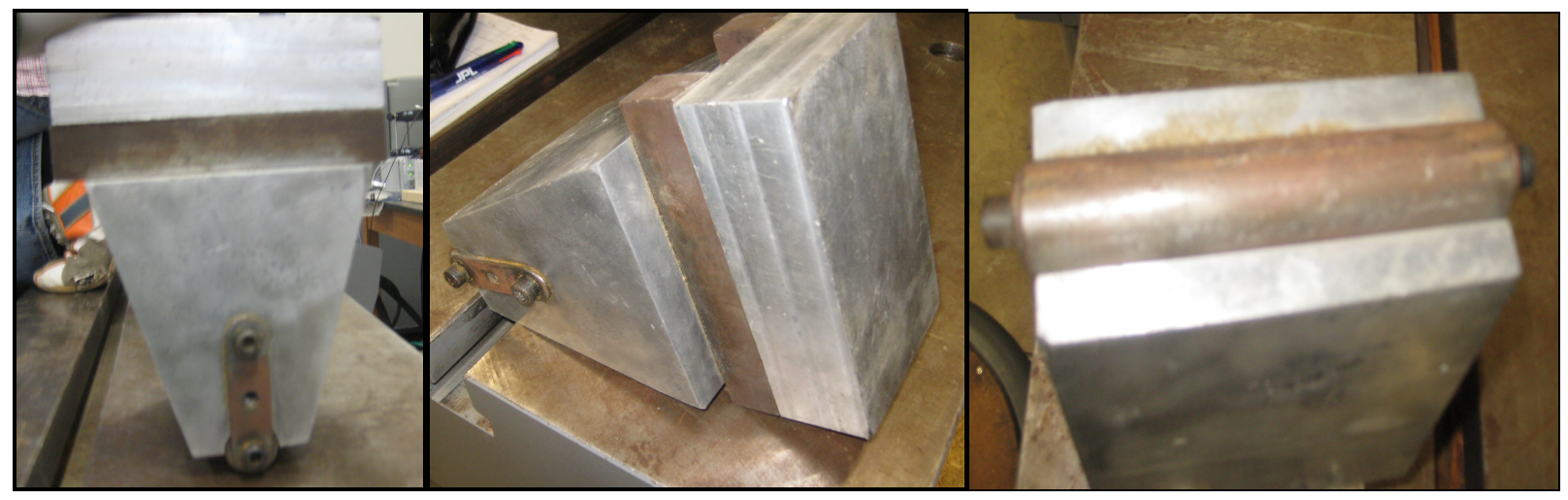

Figure 5.16: Head Piece Fixture Used for Bending Tests

This type of nose loading fixture was selected for the measuring the maximum bending deflection of the fiberglass manhole cover laminates' center created by a concentrated-uniform 
line loading. The fixed loading head piece was made of aluminum with a total mass of $7175 \mathrm{~g}$. The dimensions of the loading nose were the following: a bottom length of 5 in, and a height of 8.25 in with a diameter of 0.98 in. The goal was to determine the maximum deflection exerted by the maximum axial force of a vehicle's tire on a fiberglass manhole cover. Consequently, a $6 \mathrm{x}$ 11 in cross section of an old GoodYear tire was cut and used to cushion the concentrated load applied on the manhole cover laminates, as seen in Fig. 5.17. The actual foot print exerted by the cylindrical surface of the head piece had an approximate contact surface area of $0.35 \times 5$ in. The rubber tire had a thickness of 0.5 in with a total mass of $585 \mathrm{~g}$. The loading nose ideally should uniformly contact the test specimens across its width; therefore, lack of uniform contact can affect flexural properties by initiating damage due to crushing and by non-uniformly loading the beam. The tire piece was used for this purpose and to represent a more realistic scenario of automobile exerting its own weight on a manhole cover.

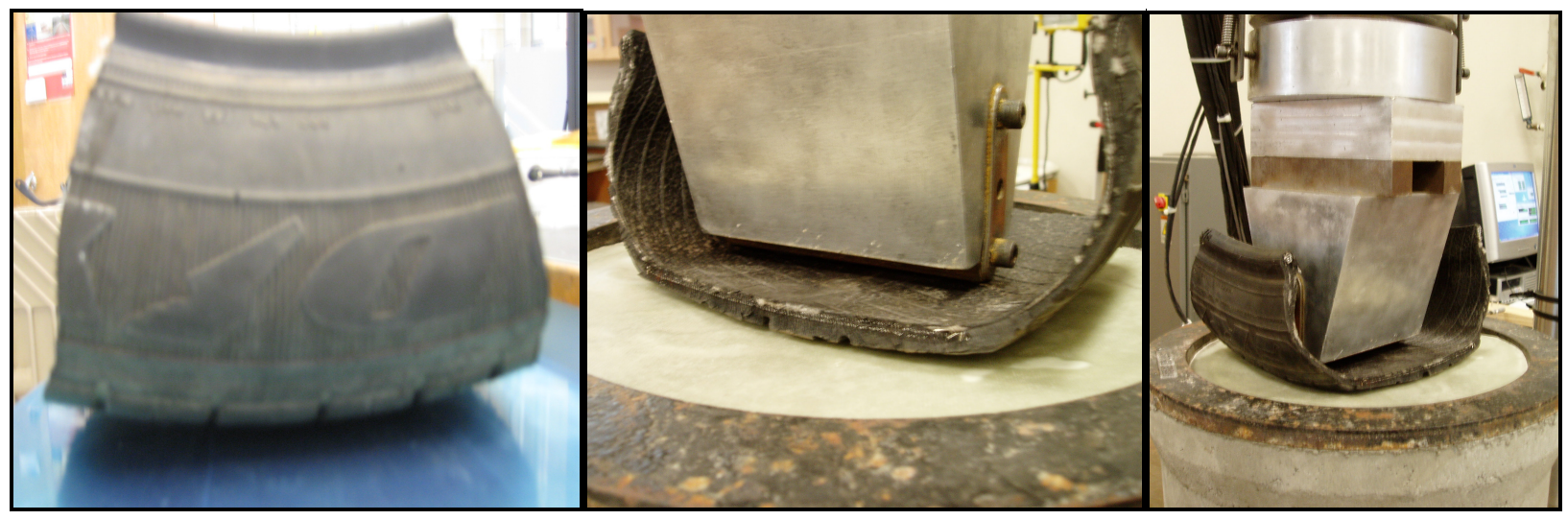

Figure 5.17: Tire Cross-Section Used to Distribute Axial Load Uniformly on Specimens

Fig. 5.18 shows the final apparatus setup with the concrete sub-frame fixture used to simply support the fiberglass manhole cover test specimen during bending analysis. 


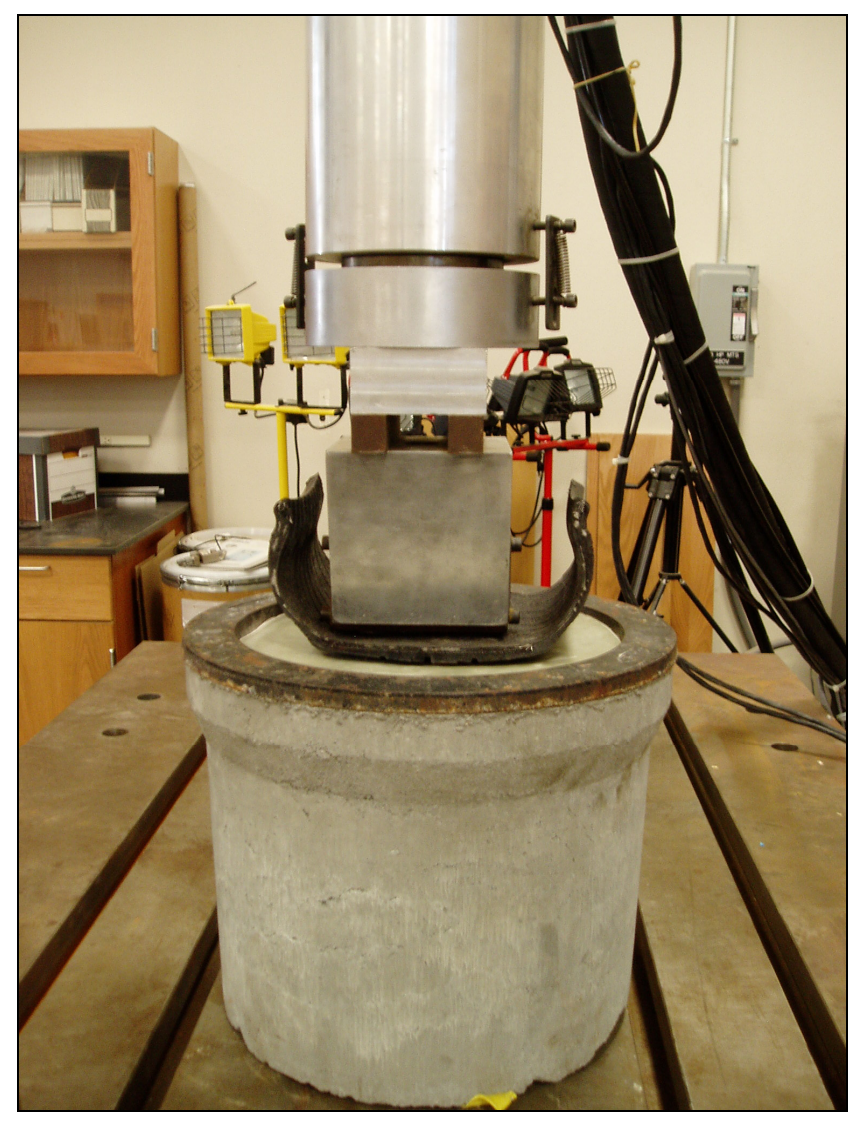

Figure 5.18: Final Bending Apparatus Setup for Testing Manhole Cover Specimens.

\subsection{Dynamic Testing}

\subsubsection{Strain Sensor}

With the experimental specimens fabricated and cut to the desired test dimensions, ceramic strain sensor were cut into $1 \times 1$ in pieces and mounted in a longitudinal orientation on the beam specimens. Each laminated beam had a single piezoelectric ceramic strain sensor with a gage factor of 2.11 and a resistance of 120 Ohms. A stable and creep-free installation of the strain sensor is desired to avoid abnormalities in the strain measurements. A strain sensor is capable of detecting the smallest effects of an imperfect bond, thus precaution was taken to ensure the bond was of the highest quality. Finally, each strain gage was connected to an M-Line CPF-75C bondable terminal, as seen in Fig. 5.19. 


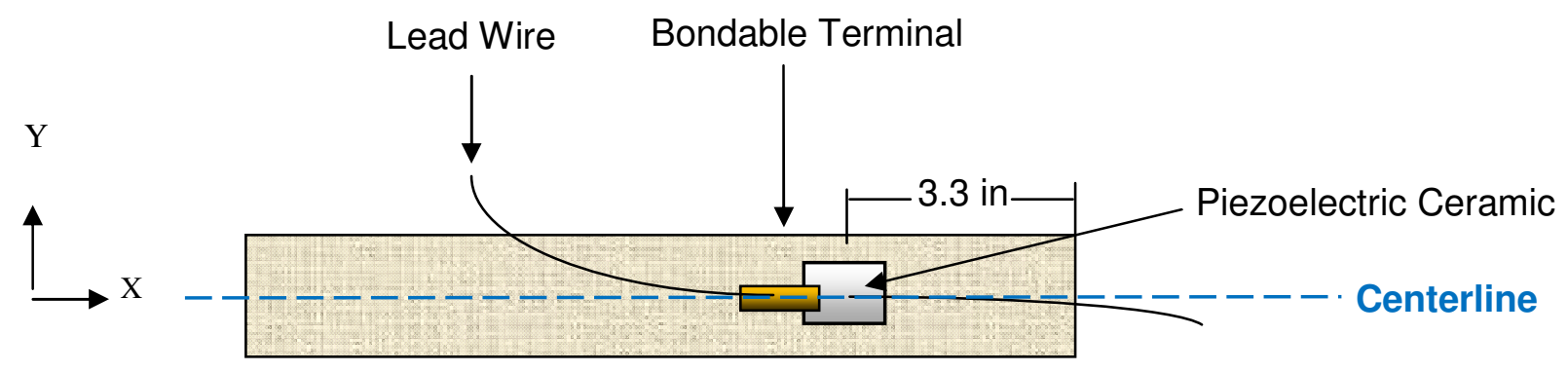

Figure 5.19: Strain Sensor Configuration

The area upon which the strain sensor will be mounted was sanded 3.3 in away from the beam's end to ensure there will be adequate bonding between the strain sensor and the specimen. This was done with very smooth grit sandpaper to create a rough surface without damaging the beam. The surfaces of the beam upon which bonding would occur were cleaned using M-Line Rosin Solvent and blotted dry. To assist in lining up the strain sensors correctly, a centerline was drawn on the beam. The ceramic strain sensor and connection terminal were placed on the beam with the metal side up in the desired orientation and scotch tape was used to pull these items back from the beam. With the scotch tape pulled back, M-Line 200 Catalyst-B was applied to the underside of the strain sensor and terminal using brush strokes in only one direction. A thin, uniform coat of Catalyst-B was applied to each surface and allowed to air dry. One to two drops of M-Line 200 Bond Adhesive was placed on each bonding area. Fig. 5.20 show both adhesive and catalyst used to bond strain sensor and terminal on beam specimen. 


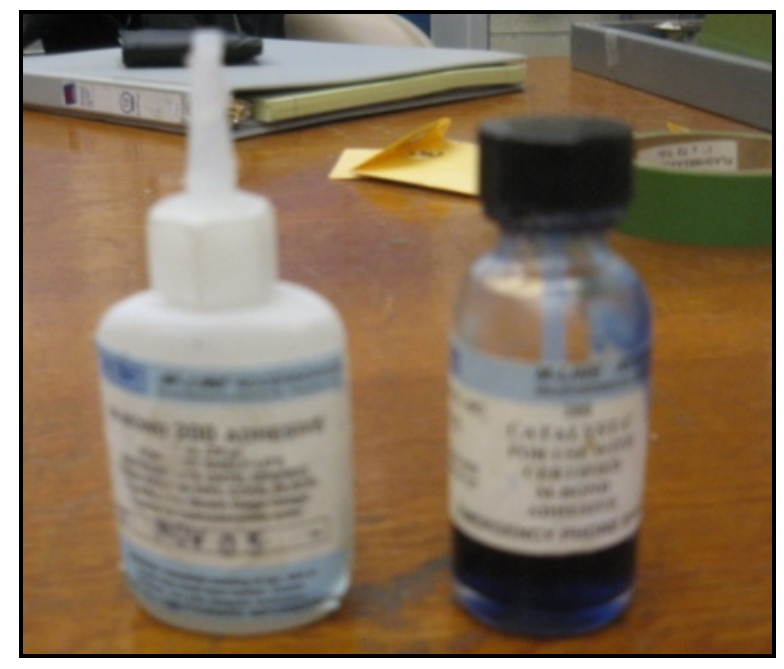

Figure 5.20: M-Bond 200 Adhesive and 200 Catalyst-B

Using the scotch tape, the strain sensor and terminal were folded over to bond with the test section. Uniform pressure was applied to the bond area for at least one minute to ensure a fine bond. Once all items were bonded to the specimen, wires from the strain sensor to the terminals were attached using a soldering iron, as seen in Fig. 5.21.

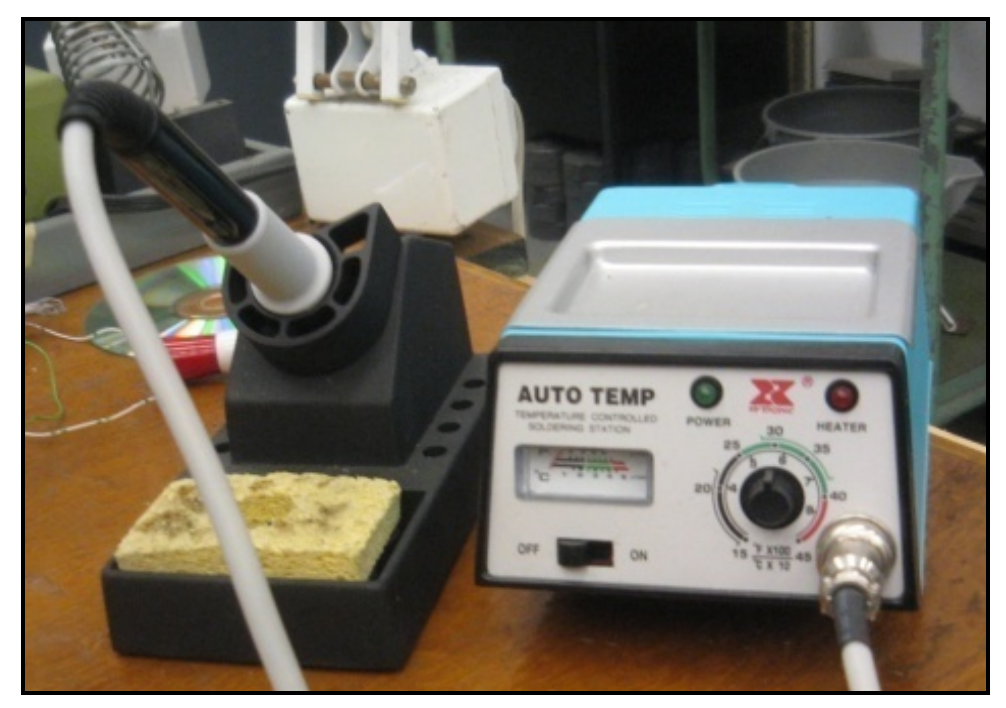

Figure 5.21: Soldering Apparatus 
With the bonding adhesive completely dry and all wires securely soldered, all terminal/strain sensor combinations were tested for the proper resistance of $120 \mathrm{Ohms}$. After the ceramic strain sensor and bondable terminals are attached, the wires that are connected to the LabVIEW program are soldered on using the same process. After the soldering is complete, each specimen is ready to be tested. The final configuration of the piezoelectric ceramic strain sensor, the bondable terminal, and the wires is shown in Fig. 5.22. The strain gage installation was identical for all fiberglass beams.

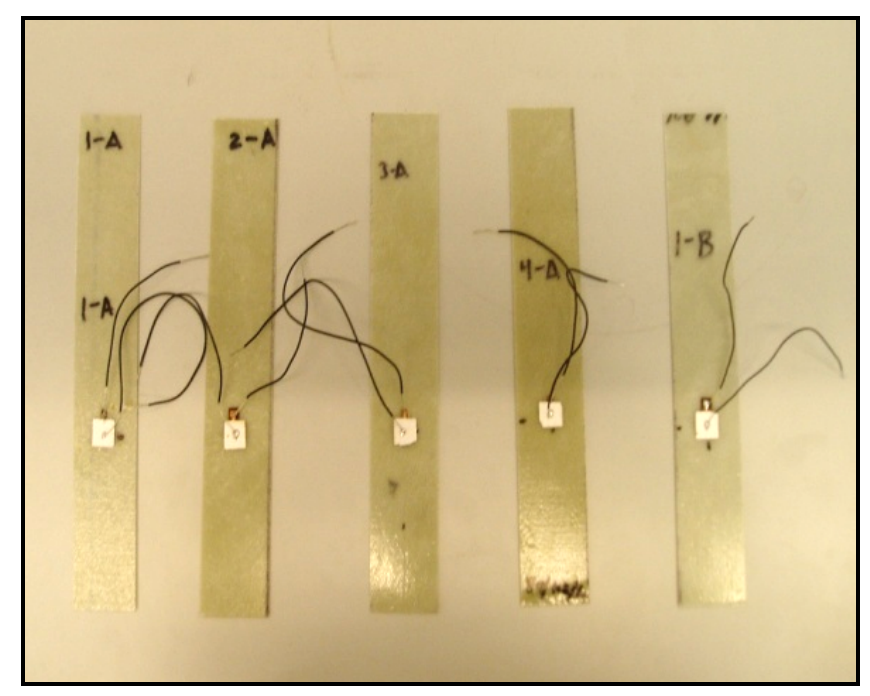

Figure 5.22: Laminated Beam Specimens Before Dynamic Testing

\subsubsection{Dynamic Testing System}

The fiberglass beams were dynamically tested by using a single degree of freedom rotational magnetic shake table manufactured by MB Electronics, shown in Figure 5.23. 


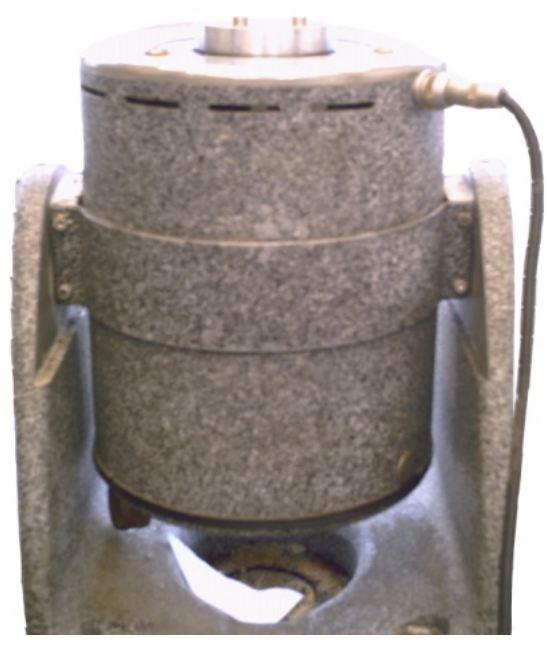

Figure 5.23: Magnetic Shaker

The fiberglass beams were attached to the magnetic shake table by a clamp manufactured by Dan Powell who was the lab-technician for the Cal Poly Aero-Composite Laboratory. The clamp was CNC machined from a single piece of Aluminum 2024, as shown in Fig. 5.24 and its dimensions are given in Fig. 5.25.

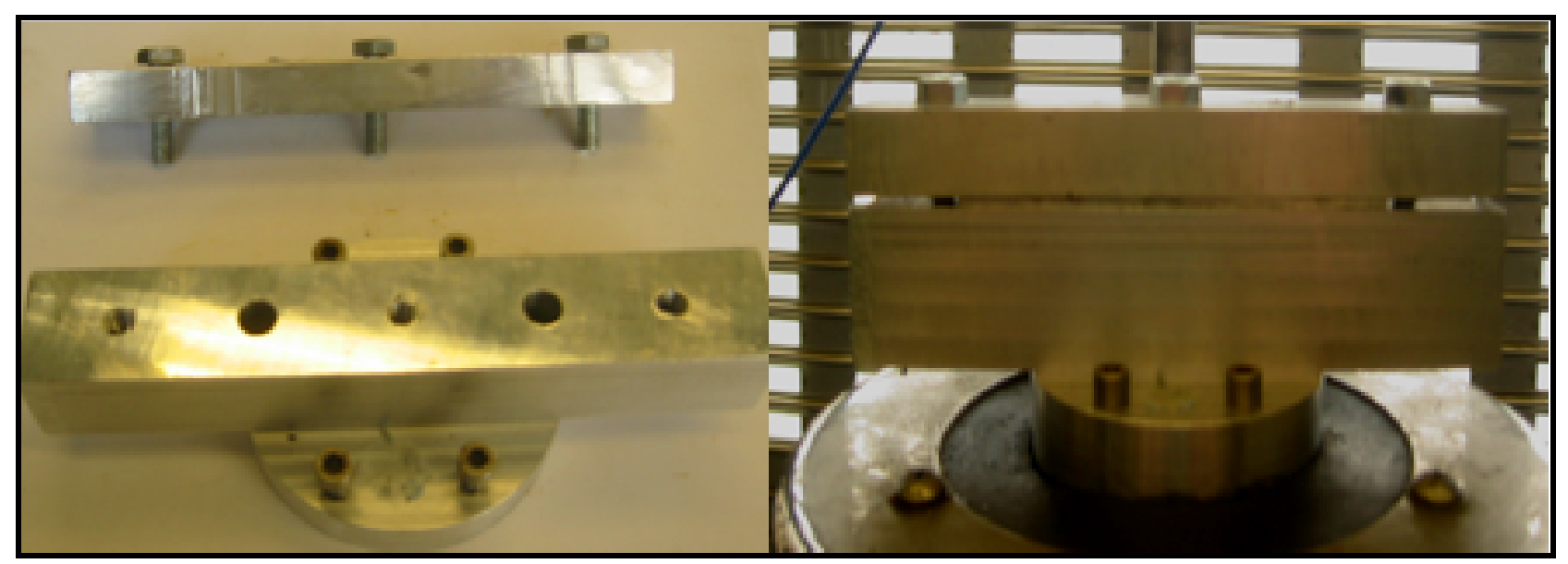

Figure 5.24: Aluminum Clamp Configuration

The clamp was attached to the shake table using six screws that reduces the amount of structural noise and creates a better ground for accelerometer servos, which for this project were not used for dynamic testing. Fig. 5.25 shows the clamp's dimension. 


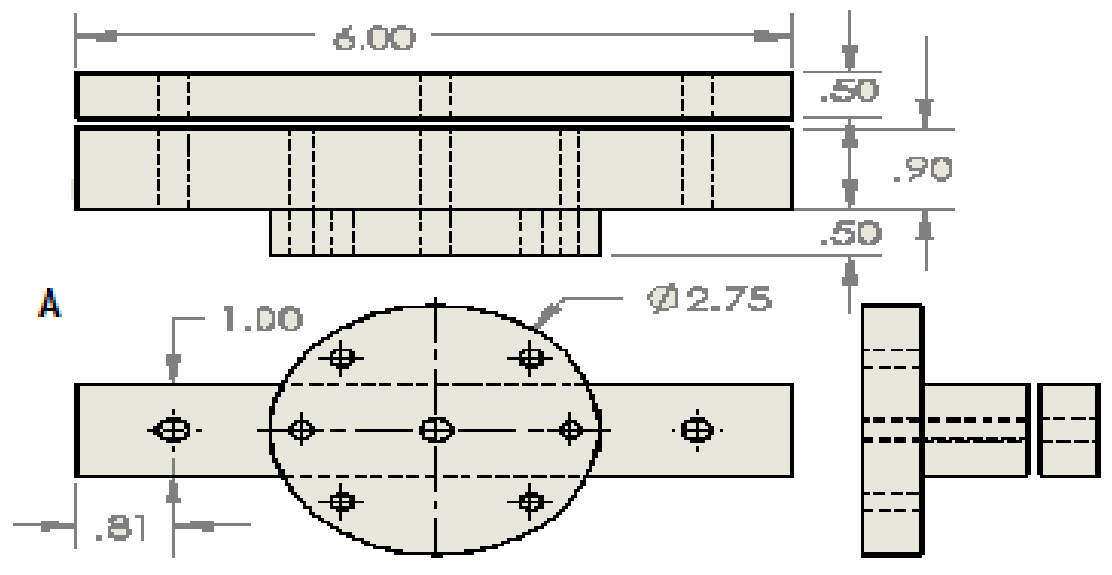

Figure 5.25: Clamp Dimensions

The beams are subjected to a frequency range of about 15 to $500 \mathrm{Hertz}$ in order to capture the first several modes of the natural frequencies. LabVIEW was the software program used to obtain the data and record the results, along with the piezoceramic strain sensor. The beam was then attached to the clamp by placing it between the two screws and tightening them as shown in Figure 5.26.

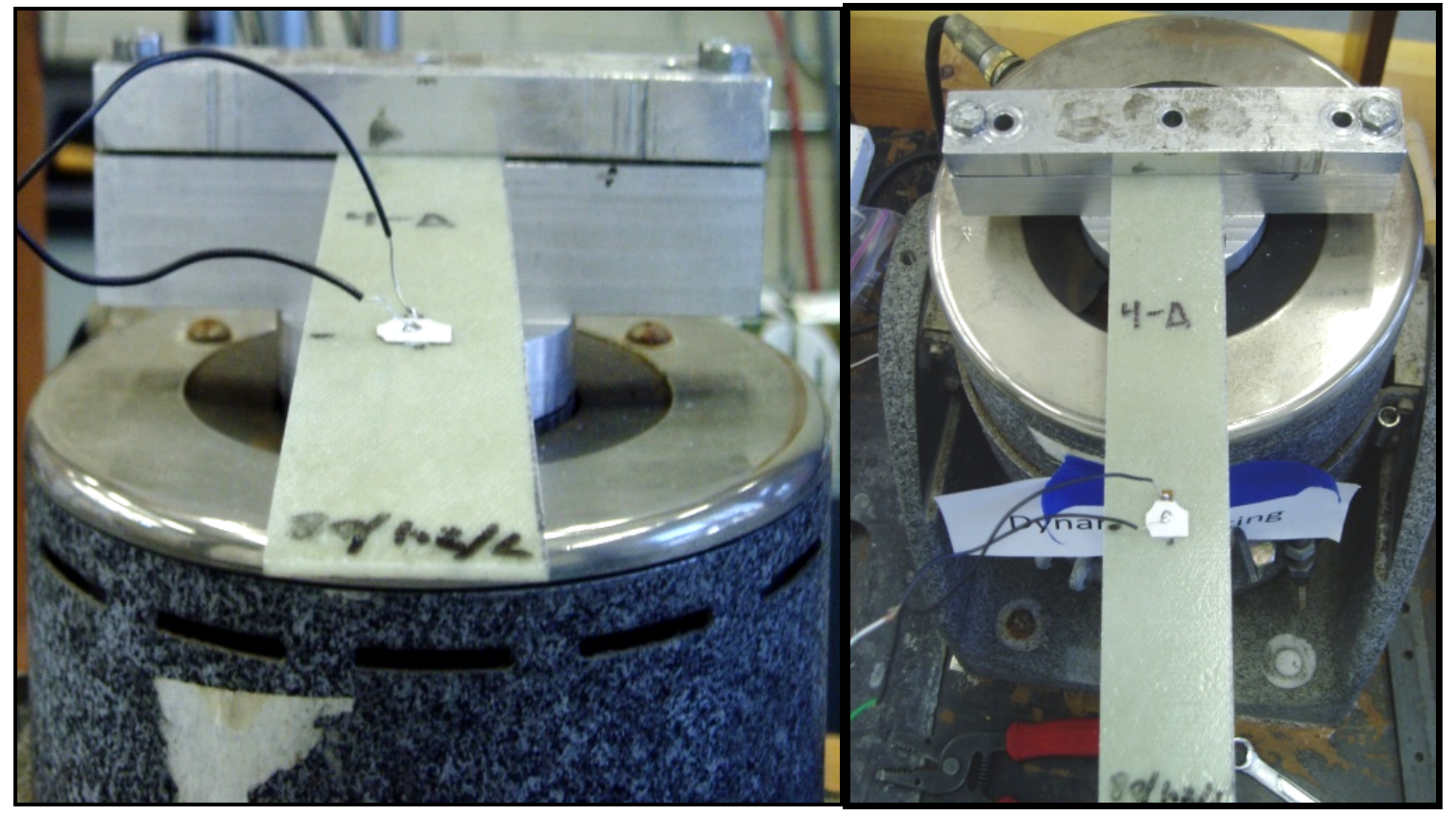

Figure 5.26: Laminated Beam Specimen Attached to Electronic Shaker 
Fig. 5.27 shows the JRS Network Analyzer III console panel made from LabVIEW software program that was used to collect and record the frequency testing results. To verify the natural frequency and time response of the each specimen, a piezoelectric ceramic strain sensor was bonded to the laminate, as seen in Fig. 5.26. Fig. 5.27 shows the frequency and time domain response data collected using LabVIEW software program.

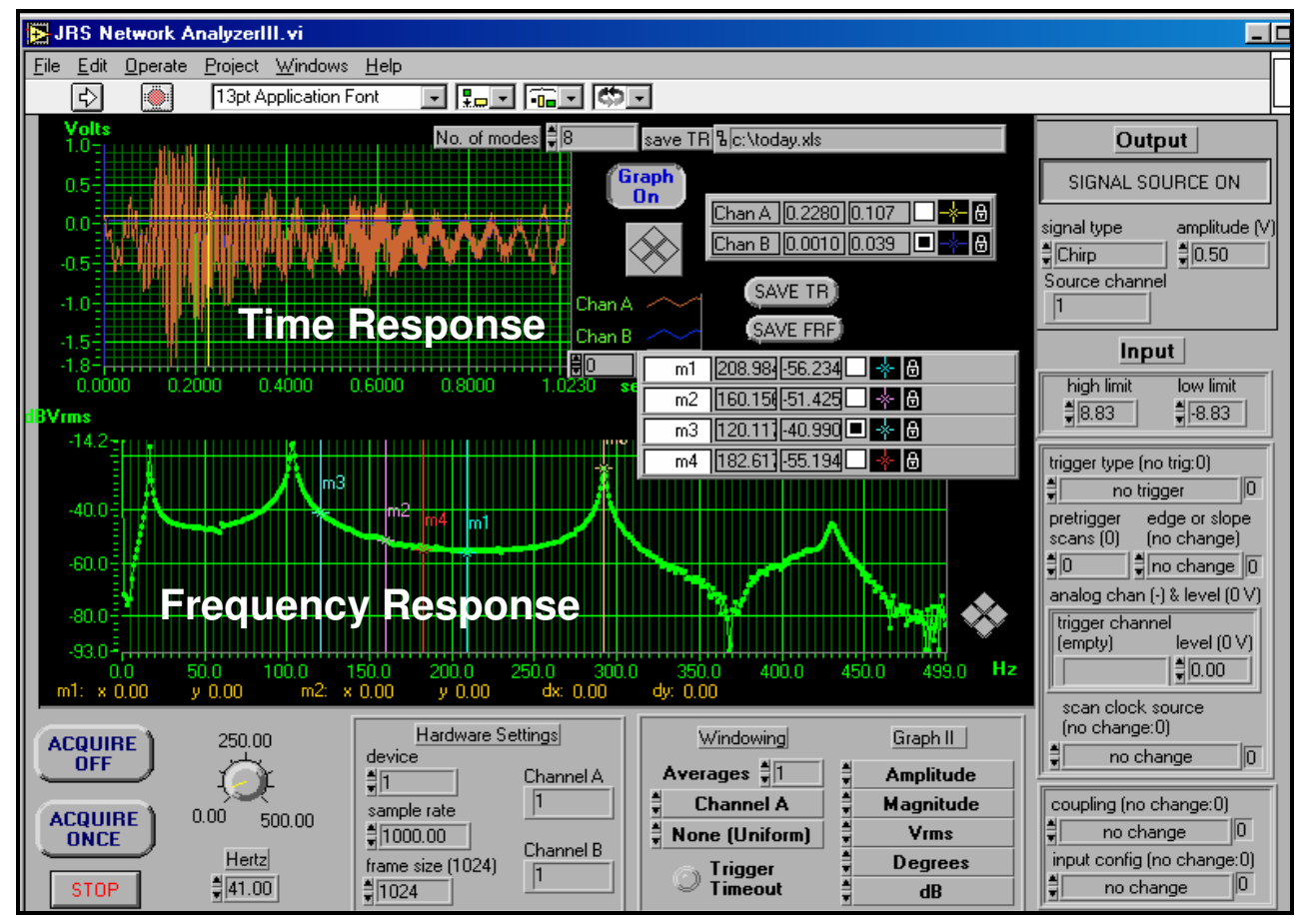

Figure 5.27: Dynamic Testing Software Program

Using LabVIEW, the laminates are subjected to a frequency range from 0 to 500 Hertz to capture the first couple modes of the natural frequencies. The magnitude of the deflection at each frequency was measured using the ceramic strain sensor in which wires connected to the strain sensor were connected to the National Instruments $S C B-100$ which connects the shaker to the LabVIEW program and interfaces the signal. The National Instruments SCB-100 is shown in Fig. 5.28. 


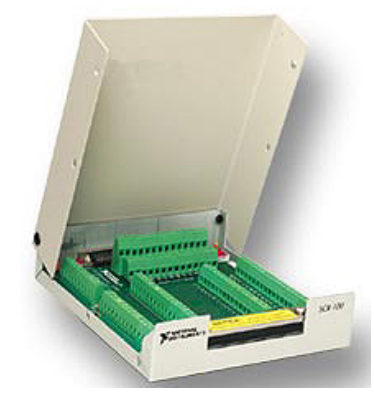

Figure 5.28: National Instruments SCB-100

The LabVIEW program is programmed to control the sweep speed and frequency range that the magnetic shaker was subjected to. The output signal was run through a power amplifier that can be adjusted to the needed voltage, and then run to the shaker. Next the piezoelectric ceramic strain sensor sends a signal directly back to the computer running LabVIEW, which records all the data and plots the amplitude vs. frequency in hertz. In addition to recording the modes of the natural frequencies, the time response data is also captured in which LabVIEW plots the amplitude vs. time in seconds. Fig. 5.29 illustrates the overall setup of the dynamic testing equipment.

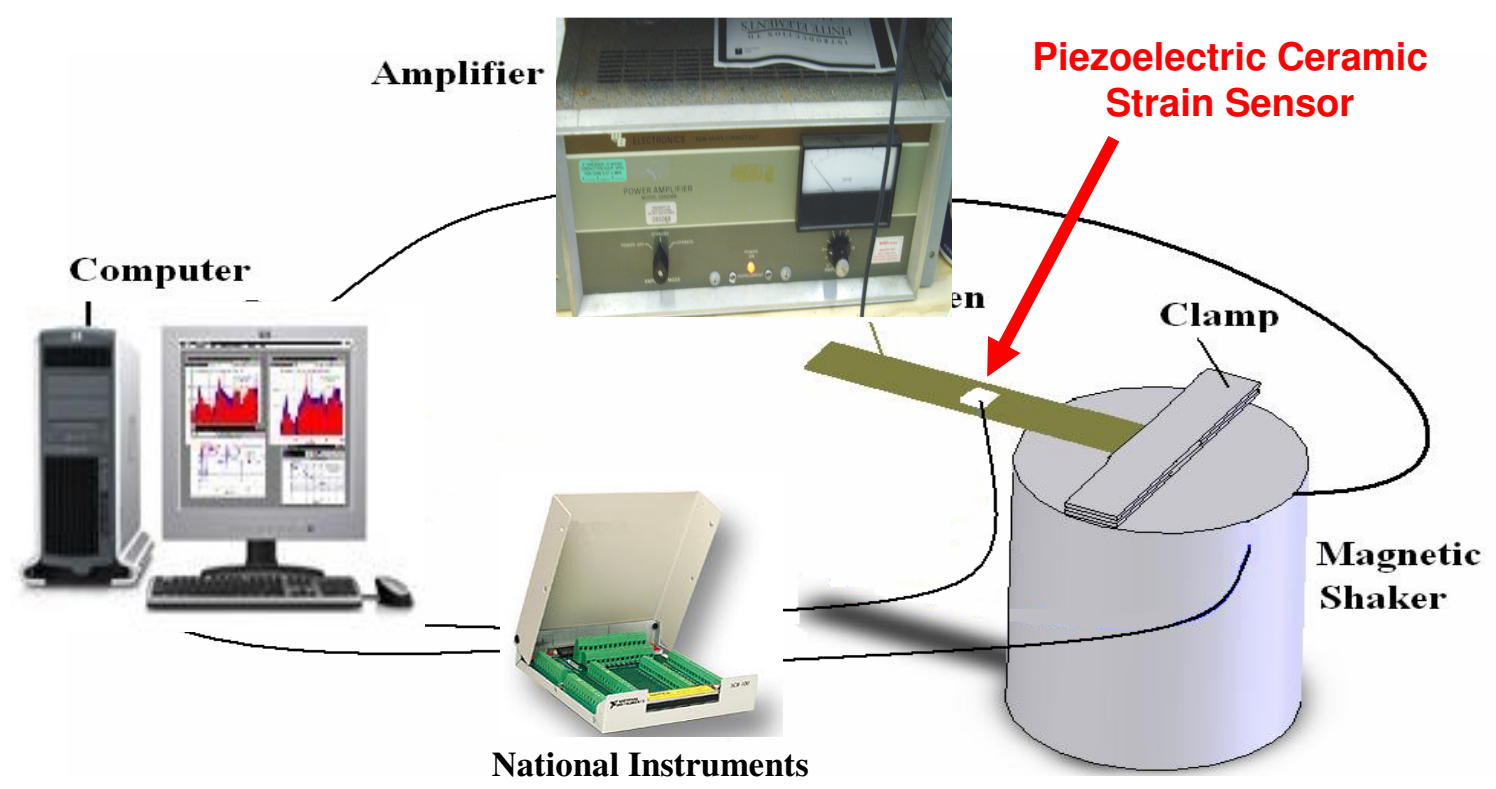

Figure 5.29: Dynamic Testing System 


\section{RESULTS AND DISCUSSION OF EXPERIMENTAL ANALYSIS}

\subsection{Volume Fraction Analysis}

Volume fraction is exclusively used in the theoretical analysis of the composite materials to determine the relative proportions of the matrix and reinforcing materials of the composite. It is used in design to calculate composite properties and almost always refers to fiber content. The maximum volume fraction is achieved when circles in 2D are stack and ordered in a hexagonally close packed array as seen in Fig. 6.1. This is called Hexagonally Close Packed (HCP) because the space-filling hexagons overlapping these circles with the vertices of the hexagons at the centers of each circle.

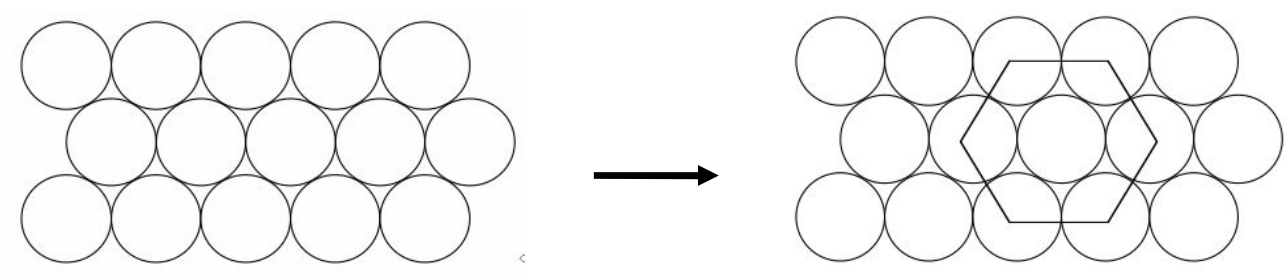

Figure 6.1: Hexagonal Fibers Alignment

The Hexagonal alignment allows for the fibers to be packed tighter and allows for the optimum fraction to reach $90 \%$. Fig.6.2 shows the zoomed portion of this hexagon where a space filling triangle represents a unit-cell from which the volume fraction is calculated.

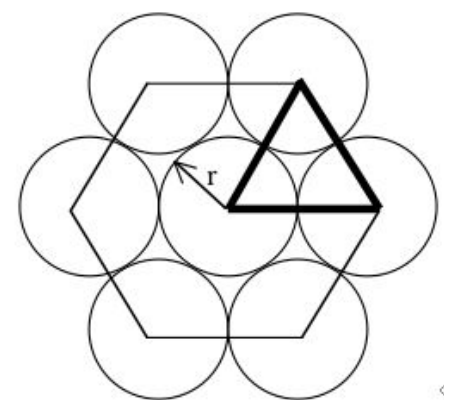

Figure 6.2: Unit-Cell Triangles 
Consequently, it is very difficult to achieve perfect alignment; hence another common packing method is Rectangular array fiber alignment. As seen in Fig. 6.3, rectangular array is extremely simple and common packing method where fibers are stacked on top of another in a rectangular fiber alignment. Generally, the optimum fiber fraction obtainable for this configuration is $75 \%$.

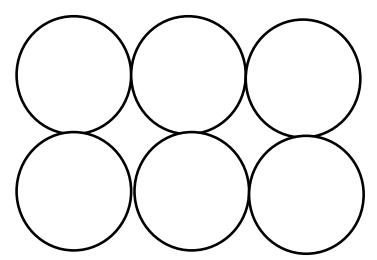

\section{Figure 6.3: Rectangular Array Fiber Alignment}

an extremely simple and common packing method but in theory the maximum volume fraction for a woven roving fiber composite is $91 \%$. However, volume fraction values usually tend to range from $60 \%$ to $70 \%$.

The volume fraction denoted $V_{f}$, is by definition the volume ratio of the fibers compared to the total volume of the composite. Therefore, the weights of the fiber and composite as a whole were measured and from them, the volume fraction of the fibers was calculated using Eqn. 6.1.

$$
V_{f}=\frac{\frac{W_{f}}{\rho_{f}}}{\frac{W_{f}}{\rho_{f}}+\frac{1-W_{f}}{\rho_{m}}}
$$

$\mathrm{W}_{\mathrm{f}}$ is the weight fraction of the fibers and $\rho_{\mathrm{f}}$ and $\rho_{\mathrm{m}}$ represents the density of the fibers and the density of the matrix.

Table 6.Table 6.1 shows the mechanical properties of the specific matrix and fiber used in this experiment. 
Table 6.1: Mechanical Properties of Matrix and Fiber

\begin{tabular}{|l|c|l|c|}
\hline \multicolumn{2}{|c|}{ Matrix } & \multicolumn{2}{c|}{ Fiber } \\
\hline PR2032 (Epoxy Resin) with PH3660 (Hardener) & \multicolumn{2}{l|}{ GS67813 (Woven Roving Fiber) } \\
\hline Density $\left(\mathrm{g} / \mathrm{in}^{3}\right)$ & 19.0509 & Density $\left(\mathrm{g} / \mathrm{in}^{3}\right)$ & 30.8443 \\
\hline Specific Volume $\left(\mathrm{in}^{3} / \mathrm{g}\right)$ & 0.05247 & Specific Volume $\left(\mathrm{in}^{3} / \mathrm{g}\right)$ & 0.02469 \\
\hline Young's Modulus (psi) & $2.8 \times 10^{6}$ & Young's Modulus (psi) & $12.4 \times 10^{6}$ \\
\hline
\end{tabular}

The weight fraction was calculated by dividing the weight of the fibers by the total original weight of the laminate. The final values of the six different plates were less than the average volume fraction. Table 6.2 displays the data and calculations from the volume fraction analysis.

Table 6.2: Volume Fraction Calculations.

\begin{tabular}{|l|c|c|c|c|c|}
\hline Specimen \# & $\mathrm{L}_{20}$ & $\mathrm{~L}_{30}$ & $\mathrm{~L}_{40}$ & $\mathrm{HD}_{30}$ & $\mathrm{LB}_{0}$ \\
\hline Volume $\left(\mathrm{in}^{3}\right.$ ) & 0.038 & 0.049 & 0.060 & 0.047 & 0.032 \\
\hline Mass of Composite (Initial Weight) (g) & 1.0 & 1.0 & 1.3 & 1.2 & 1.0 \\
\hline Mass of Fiber (Final Weight) (g) & 0.69 & 0.67 & 0.81 & 0.71 & 0.61 \\
\hline Mass of Matrix (g) & 0.31 & 0.33 & 0.49 & 0.49 & 0.39 \\
\hline Weight Fraction of Fiber (\%) & 0.69 & 0.67 & 0.62 & 0.59 & 0.61 \\
\hline Volume Fraction of Fiber (\%) & 0.51 & 0.50 & 0.48 & 0.47 & 0.48 \\
\hline
\end{tabular}

As shown above the volume fraction for the laminates ranged from 47 to $51 \%$ which would indicate that the fiber was not hexagonally packed but instead most likely had a simple rectangular array fiber alignment. Although the fiber volume fraction had very similar percentages to make the assumption that all test specimens had the similar material properties, 
with a 4 to 12 percent difference with the theoretical E-glass woven roving volume fraction. According to the ASM International Handbook, the volume fraction for woven roving fabric range from 30 to $50 \%$ [25]; hence, a theoretical E-glass volume fraction value of $45 \%$ was used for comparison.

\subsection{Static Analysis}

The Cal Poly's Aero-Composite Laboratory’s Instron machine was used to perform static testing in order to determine the tensile strength of all specimens with no delamination. Tensile strength is the stress at which a material permanently deforms and an intensive property used to determine specimen's material properties. Fig. 6.4 shows tensile strength results of different fibers.

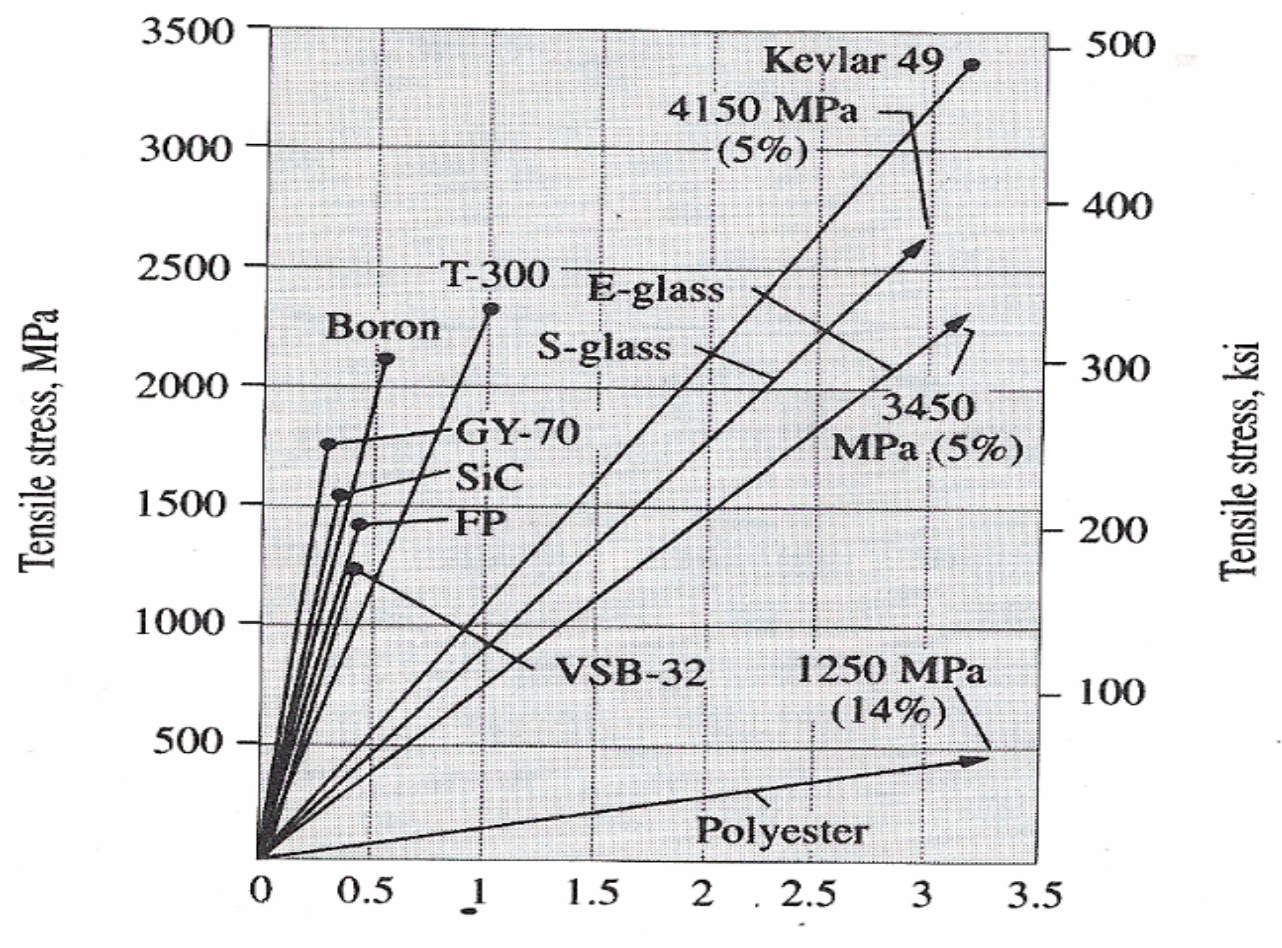

Tensile strain. \%

Figure 6.4: Tensile Stress-Strain Curves for Various Fibers [35]. 
As seen in previous figure, the composite stress-strain curves generally lie between the stress-strain curves of the fibers and the matrix. The actual location of the composite stress-strain curve will depend on the relative volume fractions of the constituents [4]. If the fiber volume is high, the composite stress-strain curve will be closer to the fiber stress-strain curve. On the contrary, if the fiber volume is low, the composite stress-strain curve will be closer to the matrix stress-strain curve due to a higher matrix volume fraction.

\subsubsection{Tensile Test Results}

The Merlin Instron Software Program was used with the Instron machine to record and calculate all tensile strength data. The data was later used to calculate the following material properties: the maximum load or ultimate strength, strain percentage which is the elastic strain percentage prior to fracture and Young's Modulus of Elasticity (or elastic modulus) which describes tensile elasticity and stiffness of the material.

The following equations were used to calculate the material property of the specimens. Using the cross-sectional area, the stresses due to the loads are calculated using Eqn. 6.2.

$$
\sigma=F / A_{c}
$$

$F$ is the load and $A$ is the cross-sectional area. To obtain the Young's Modulus, Eqn. 6.3 was used.

$$
E=\sigma / \varepsilon
$$

$E$ is the Young's Modulus or material rigidity, $\sigma$ is tensile stress and $\varepsilon$ is tensile strain. 
In addition, since glass is isotropic, Shear Modulus of Rigidity is calculated in terms of $E$ and $v$, as seen in Eqn. 6.4.

$$
G=\frac{E}{2(1+v)}
$$

where $E$ is the elastic modulus and $v$ is the Poisson's Ratio, which was assumed to be 0.22 for Eglass fabric.

From the five laminates that were tested, three had varying amounts of limestone filler (20 grams, 30 grams, and 40 grams); whereas, the other two specimens had West System 404 High-Density adhesive filler and no filler. Two sets of five fiberglass laminated composites were tested statically. The Instron Extensometer was used to record the tensile strain only in the longitudinal direction since all laminates were assumed to be isotropic due to the bi-directional property of fiberglass woven roving. Consequently, Poisson's ratio was not calculated from this test since the extensometer only measured the strain in the longitudinal direction. The Poisson's ratio for the E-glass fabric was assumed to be 0.22 [14]. Table 6.3 shows the dimension for all test specimens used for the static analysis.

Table 6.3: Dimension Summary of Fiberglass Laminated Beams

\begin{tabular}{|c|c|c|c|c|c|}
\hline Specimen & Weight (g) & Length (in) & Thickness (in) & Width (in) & Cross Section Area $\left(\mathrm{in}^{2}\right)$ \\
\hline $\mathrm{L}_{20}$ & 104.3 & 9 & 0.050 & 1.471 & 0.074 \\
\hline $\mathrm{L}_{30}$ & 100.5 & 9 & 0.049 & 1.427 & 0.069 \\
\hline $\mathrm{L}_{40}$ & 108.1 & 9 & 0.052 & 1.389 & 0.072 \\
\hline $\mathrm{HD}_{30}$ & 119.2 & 9 & 0.049 & 1.423 & 0.069 \\
\hline $\mathrm{LB}_{0}$ & 104.5 & 9 & 0.047 & 1.506 & 0.071 \\
\hline
\end{tabular}

Fig. 6.5 shows the stress-strain curve of specimen $\mathrm{L}_{\mathrm{B} 0}$ with a fiber volume fraction of $48 \%$ before fracture and a cross section area of $0.0708 \mathrm{in}^{2}$. 


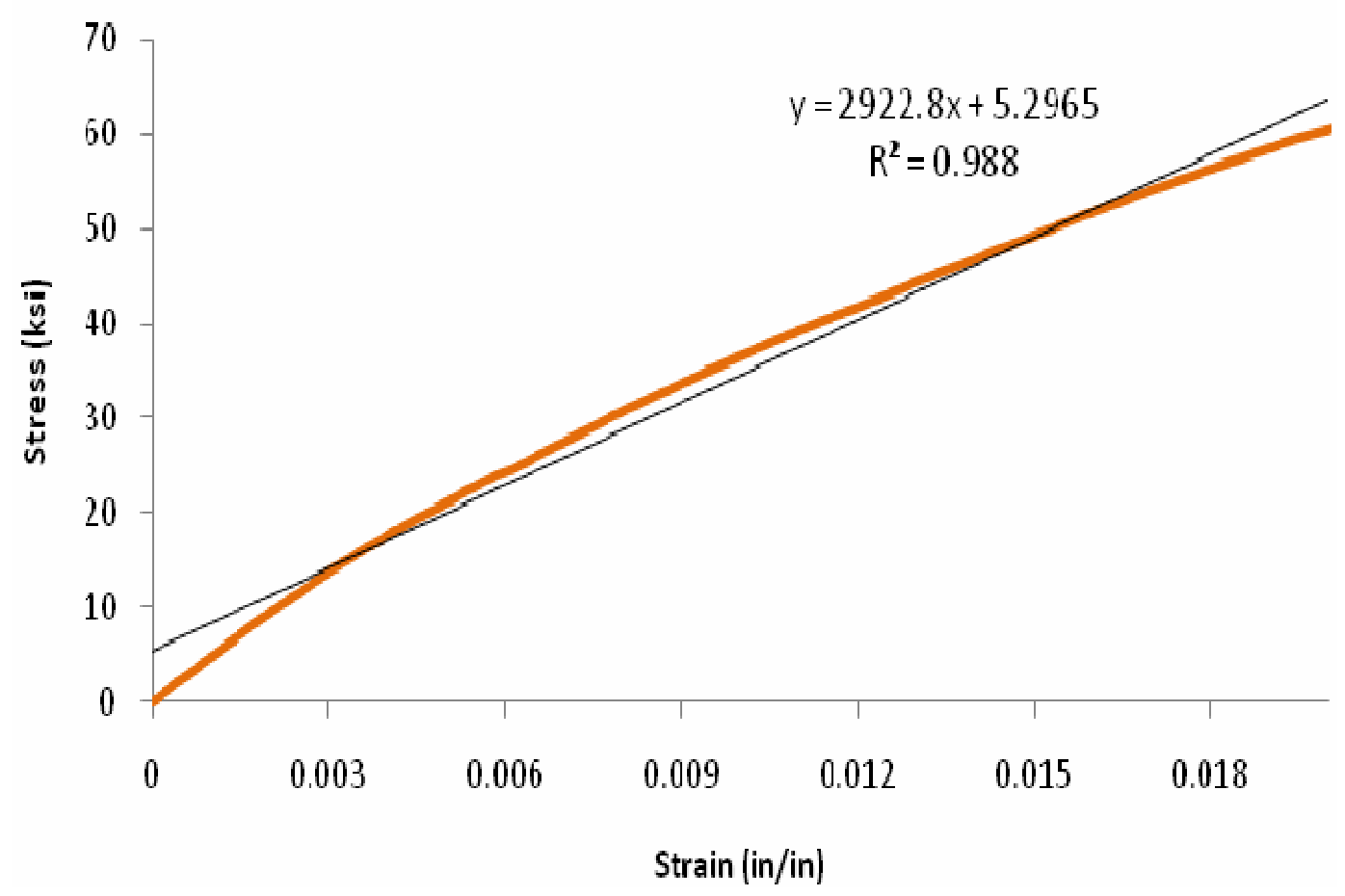

Figure 6.5: Tensile Strength Results for Laminate $L_{B 0}$

The graph above shows a stress-strain curve linear relationship for laminate $\mathrm{L}_{\mathrm{B} 0}$ in which the Young's Modulus was determined by by using the tread line function from the Excel program. The Young's modulus in the longitudinal direction was $2922.8 \mathrm{ksi}$ and R-squared value of 0.988 and the Shear Modulus of Rigidity was 1197.87 ksi. The maximum load before rupture was at $4327.11 \mathrm{lb}_{\mathrm{f}}$ with a corresponding ultimate tensile stress of $61.13 \mathrm{ksi}$ and maximum strain of $0.0203 \mathrm{in}$.

Fig. 6.6 shows the tensile fracture of laminate $\mathrm{L}_{\mathrm{B} 0}$ after static tensile testing. The test specimen $\mathrm{L}_{\mathrm{B} 0}$ experienced failure at its upper sides since it was probably misaligned in the Instron machine or aluminum tabs not placed correctly on specimen during the oven press curing cycle. 


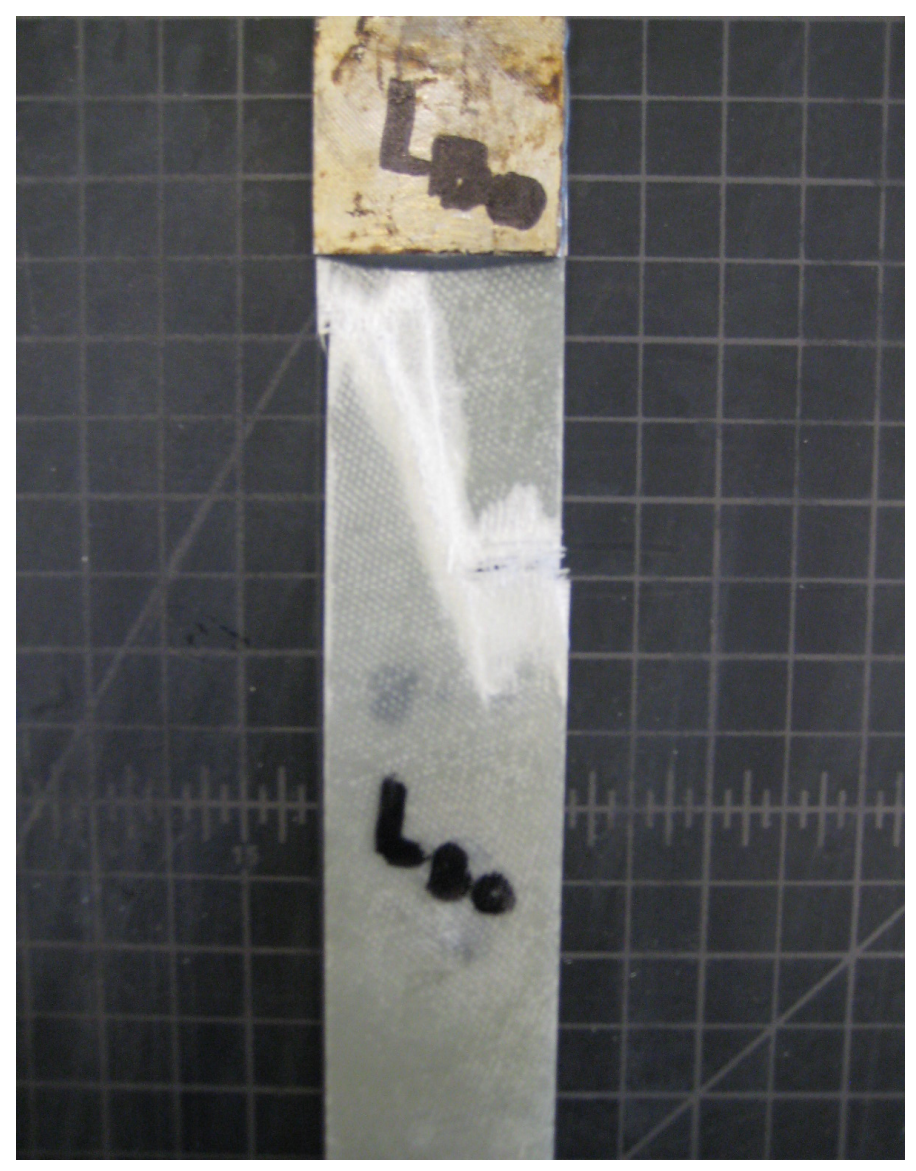

Figure 6.6: Ultimate Failure for Laminate with No Filler

Table 6.4 shows a summary of the tensile test results for both test specimens.

Table 6.4: Tensile Summary for Laminate $L_{B 0}$

\begin{tabular}{|c|c|c|c|c|}
\hline Specimen & $\begin{array}{c}\text { Max. } \\
\text { Load }\left(\mathrm{Ib}_{\mathrm{f}}\right)\end{array}$ & $\begin{array}{c}\text { Young's } \\
\text { Modulus (ksi) }\end{array}$ & $\begin{array}{c}\text { Shear } \\
\text { Modulus (ksi) }\end{array}$ & $\begin{array}{c}\text { Ultimate } \\
\text { Stress (ksi) }\end{array}$ \\
\hline $\mathrm{L}_{\mathrm{B} 0}$ & 4327.11 & 2922.81 & 1197.87 & 61.13 \\
\hline
\end{tabular}

The average elastic modulus was later used as the stiffness property of laminate $\mathrm{L}_{20}$ during the finite element analysis. Fig. 6.7 shows the stress-strain curve of specimen $\mathrm{L}_{20}$ with a fiber volume fraction of $51 \%$ before fracture and a cross section of $0.0735 \mathrm{in}^{2}$. 


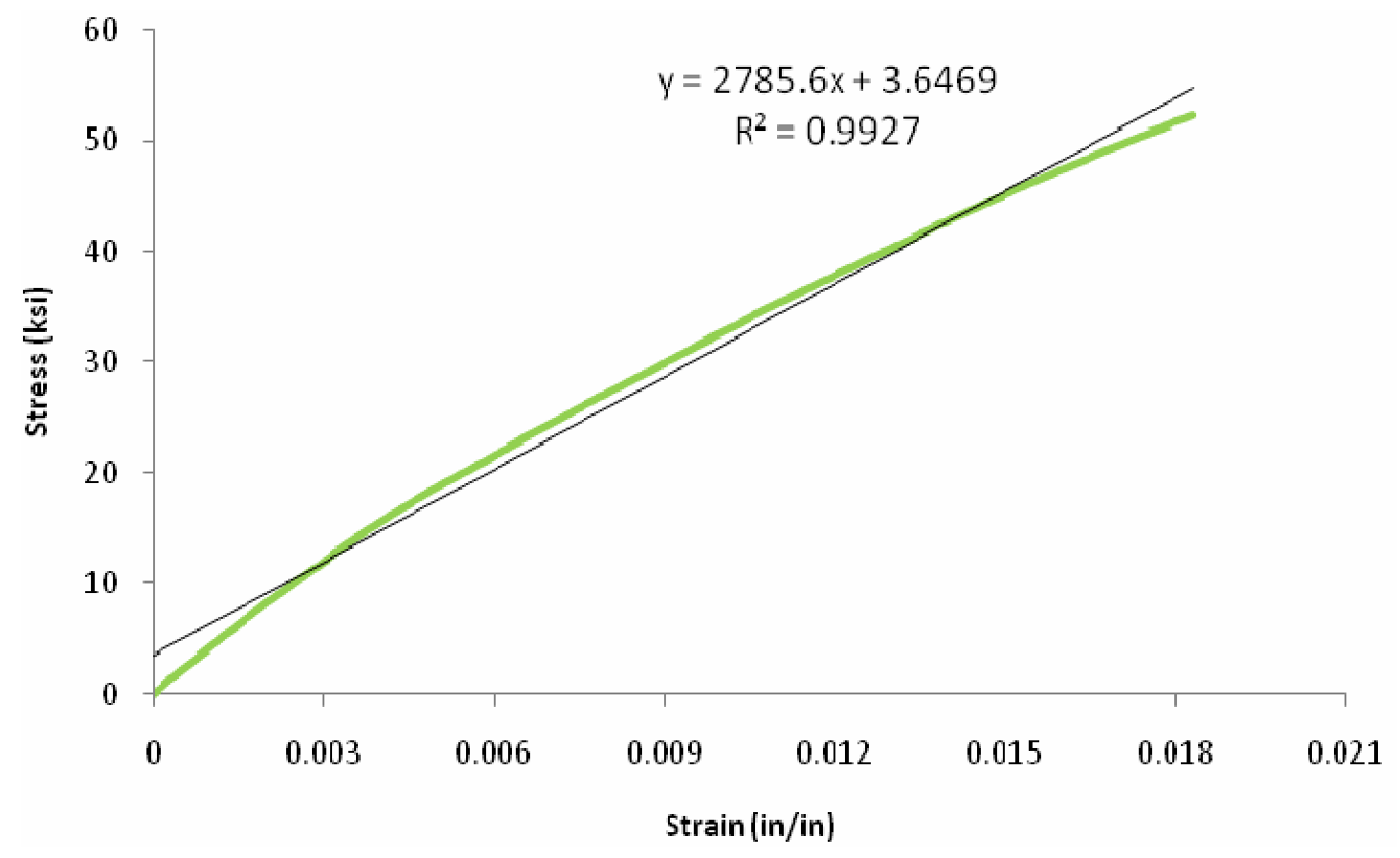

Figure 6.7: Tensile Strength Result for Laminate $L_{20}$

The tensile strength result for laminate $\mathrm{L}_{20}$ is seen above in a stress-strain curve linear relationship. The slope of the tread line was used to calculate the Young's modulus by using the tread line function from the Excel program. The Young's modulus in the longitudinal direction was 2785.6 ksi with an R-squared value of 0.9927 and a shear modulus of 1096.69 ksi.

The elastic-deformation region had a maximum tensile stress of 52.19 ksi with a corresponding strain of 0.0183 . The maximum load before fracture was at $3835.92 \mathrm{lbs}$ with a corresponding ultimate tensile strength of 52.19 ksi. Finally, the yield strength at $20 \%$ offset strain was not calculated since fiberglass laminates were considered brittle materials which involve little or no plastic deformation.

Fig. 6.8 shows the tensile fracture of laminate $\mathrm{L}_{20}$ after static testing. The test specimen $\mathrm{L}_{20}$ ultimate failure's crack propagation was seen to be slanted and not concentrated at its cross- 
section's center which is probably due to the longitudinal tensile load not going thru specimen's cross section because of specimen misalignment or lack of specimen fabrication.

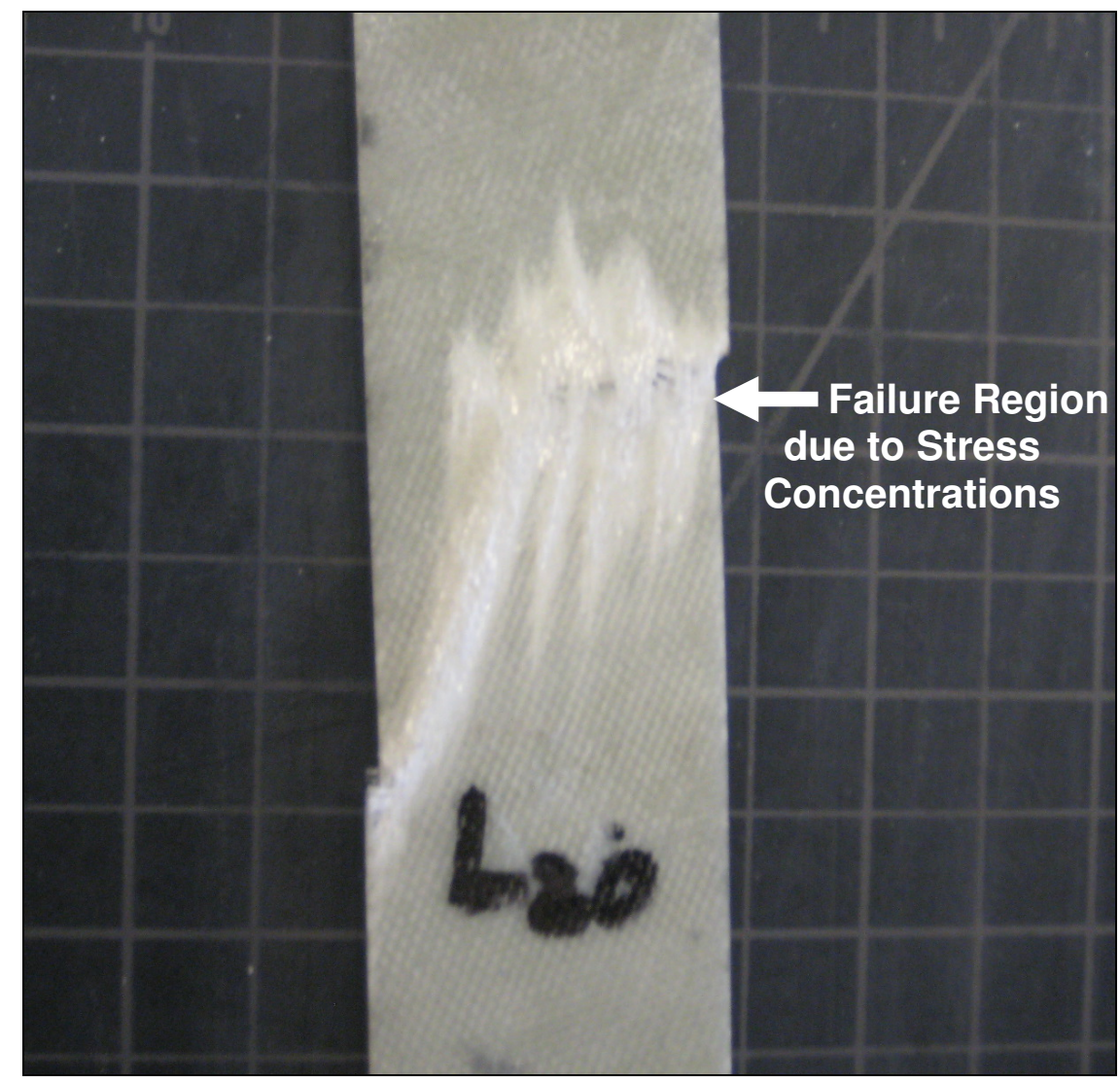

Figure 6.8: Ultimate Failure for Laminate with 20 grams of Limestone Filler

Fig. 6.9 shows the tensile stress vs. strain linear curve comparison of two specimens with 20 grams of limestone filler. 


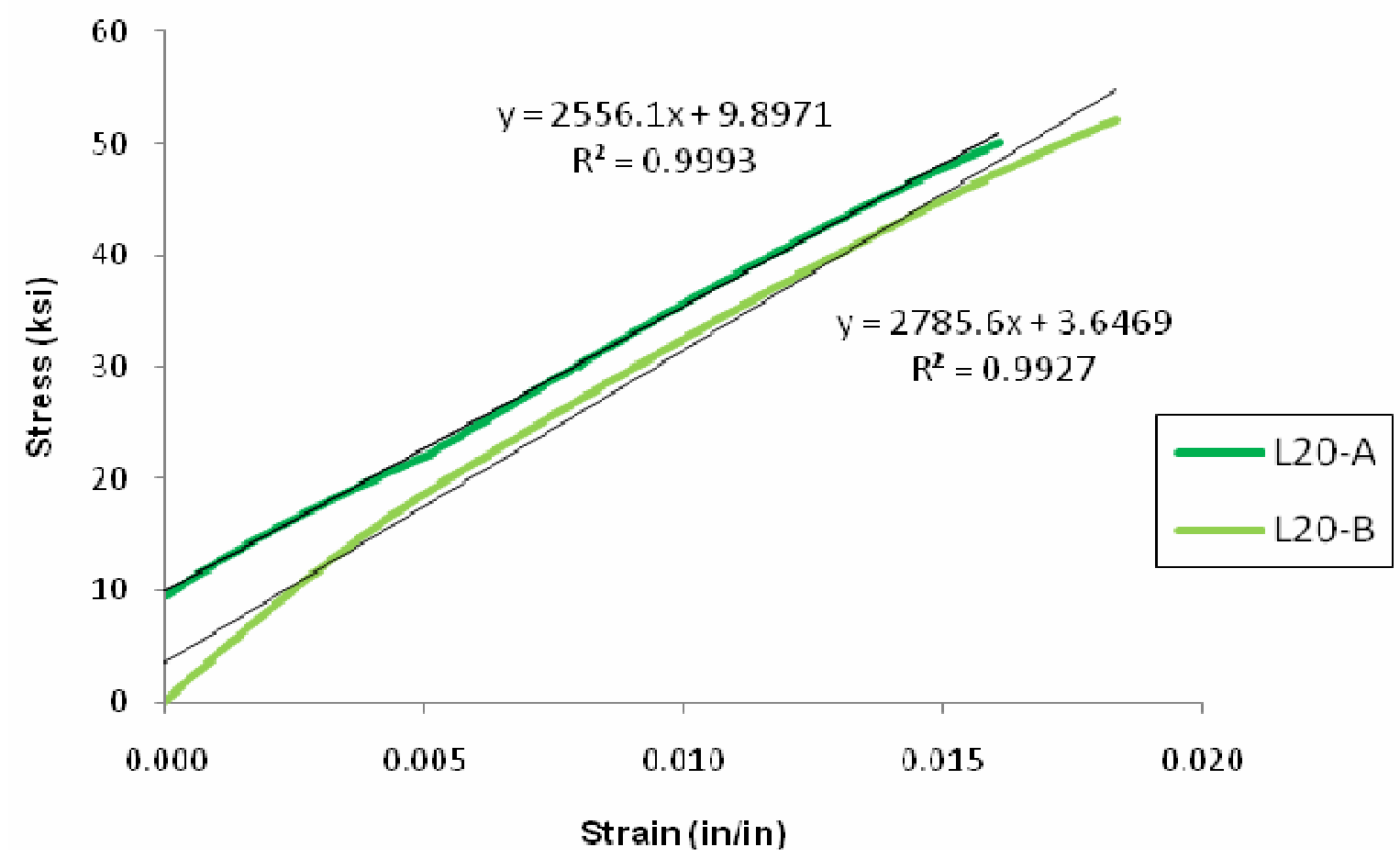

Figure 6.9: Tensile Comparison of Laminates $L_{20-A}$ and $L_{20-B}$

The above graph shows that both laminates had very similar tensile results. Test specimen $\mathrm{L}_{20-\mathrm{A}}$ did not intersect at the origin since the tensile machine started to load and later record data at a tensile stress of $9.54 \mathrm{ksi}$. Table 6.5 shows a summary of the tensile test results for both test specimens.

Table 6.5: Tensile Summary for Laminate $L_{20}$

\begin{tabular}{|c|c|c|c|c|}
\hline Specimen & $\begin{array}{c}\text { Max. } \\
\text { Load }\left(\mathrm{lb}_{\mathrm{f}}\right)\end{array}$ & $\begin{array}{c}\text { Young's } \\
\text { Modulus (ksi) }\end{array}$ & $\begin{array}{c}\text { Shear } \\
\text { Modulus (ksi) }\end{array}$ & $\begin{array}{c}\text { Ultimate } \\
\text { Stress (ksi) }\end{array}$ \\
\hline $\mathrm{L}_{20-\mathrm{A}}$ & 3485.93 & 2556.10 & 1047.58 & 50.19 \\
\hline $\mathrm{L}_{20-\mathrm{B}}$ & 3835.92 & 2785.60 & 1141.64 & 52.19 \\
\hline Avg. & 3660.92 & 2670.85 & 1094.61 & 51.19 \\
\hline
\end{tabular}

The average elastic modulus was later used as the stiffness property of laminate $\mathrm{L}_{20}$ during the finite element analysis. 
Figure 6.10 shows the stress-strain curve of specimen $\mathrm{L}_{30}$ with a fiber volume fraction of $50 \%$ before fracture and a cross section of $0.0685 \mathrm{in}^{2}$.

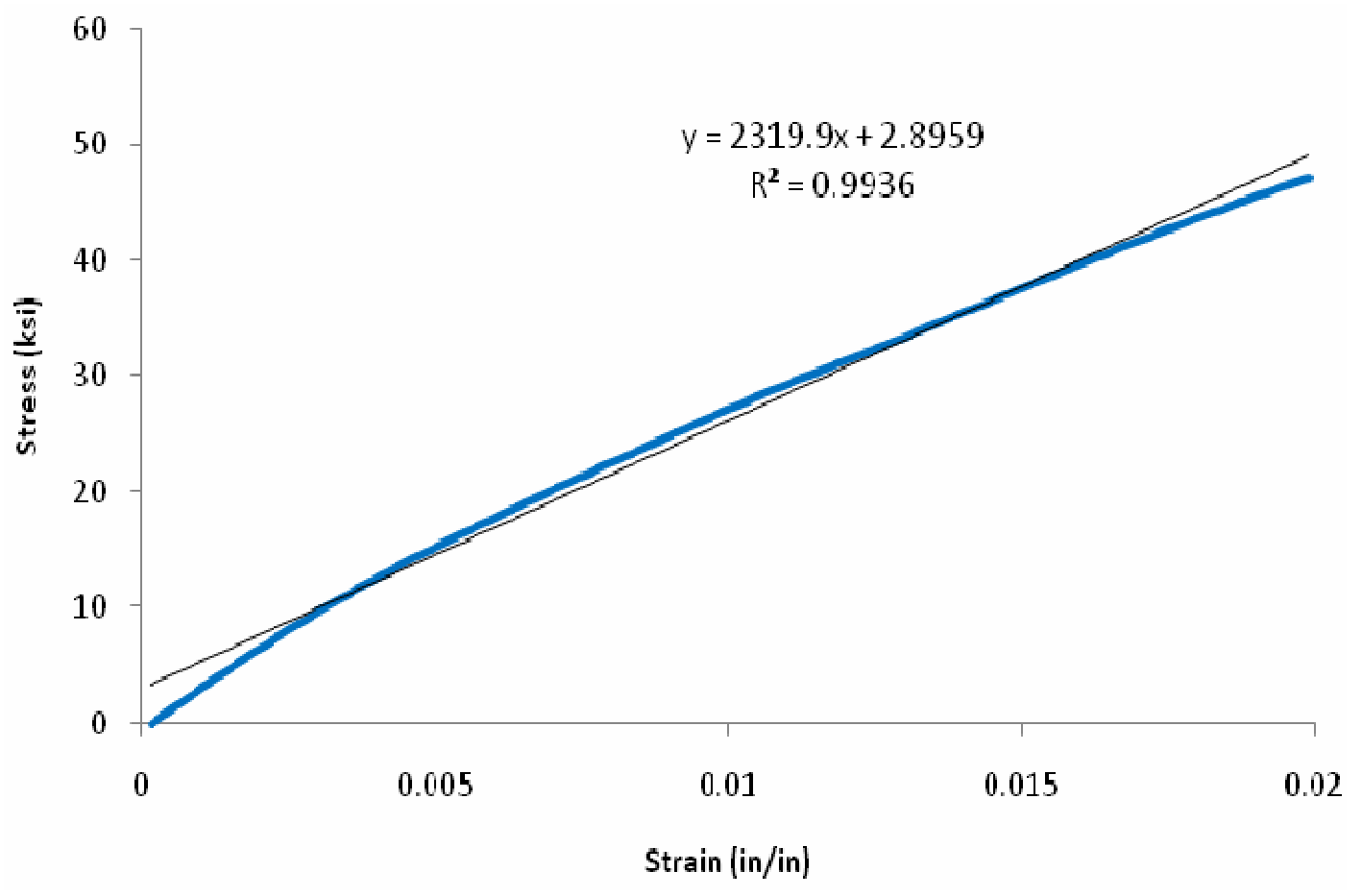

Figure 6.10: Tensile Strength Result for Laminate $L_{30}$

The graph above shows a stress-strain curve linear relationship for laminate $\mathrm{L}_{30}$ in which the Young's modulus was determined by using the tread line function from the Excel program. The Young's modulus in the longitudinal direction was $2319.9 \mathrm{ksi}$ with a R-squared value of 0.9936 and a shear modulus of $950.77 \mathrm{ksi}$. The elastic-deformation region had a maximum tensile stress of $47.16 \mathrm{ksi}$ with a corresponding strain of 0.0198 . The maximum load before rupture was at $3230.03 \mathrm{lb}_{\mathrm{f}}$ with a corresponding ultimate tensile strength of $47.16 \mathrm{ksi}$.

Fig. 6.11 shows the tensile fracture of laminate $\mathrm{L}_{30}$ after static testing. The test specimen $\mathrm{L}_{30}$ experienced failure at its upper and lower sides. Normally failure is seen at the center of the specimen's cross-section due to a uniform longitudinal tensile load. In this case, the load is seen 
to be concentrated at its top side and initial crack propagation at its bottom side which is probably due specimen misalignment in the Instron machine or poor fabrication of test specimen.

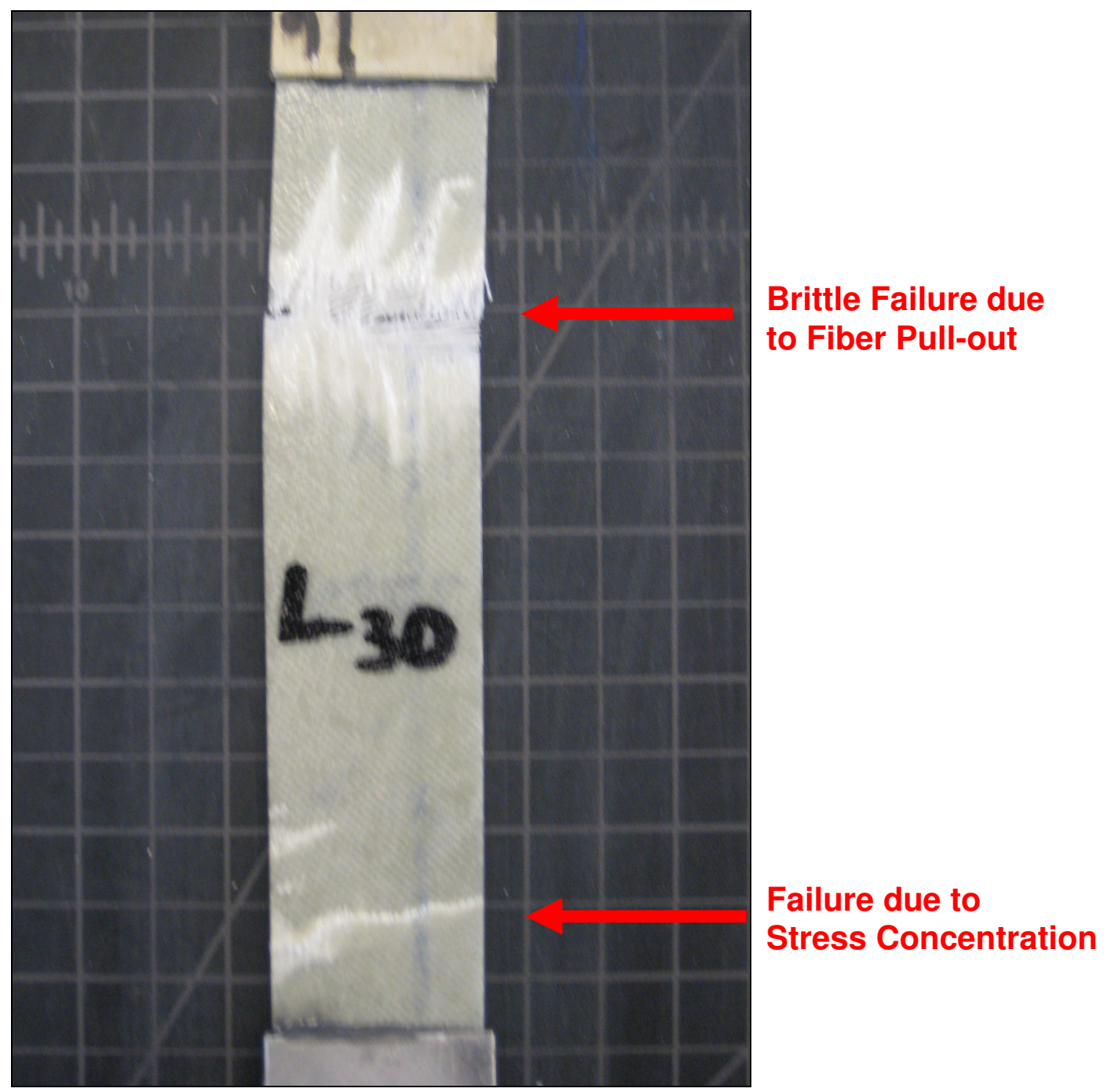

Figure 6.11: Ultimate Failure for Laminates with 30 grams of Limestone Filler.

Fig. 6.12 shows the tensile stress vs. strain linear curve comparison of two specimens with 30 grams of limestone filler. 


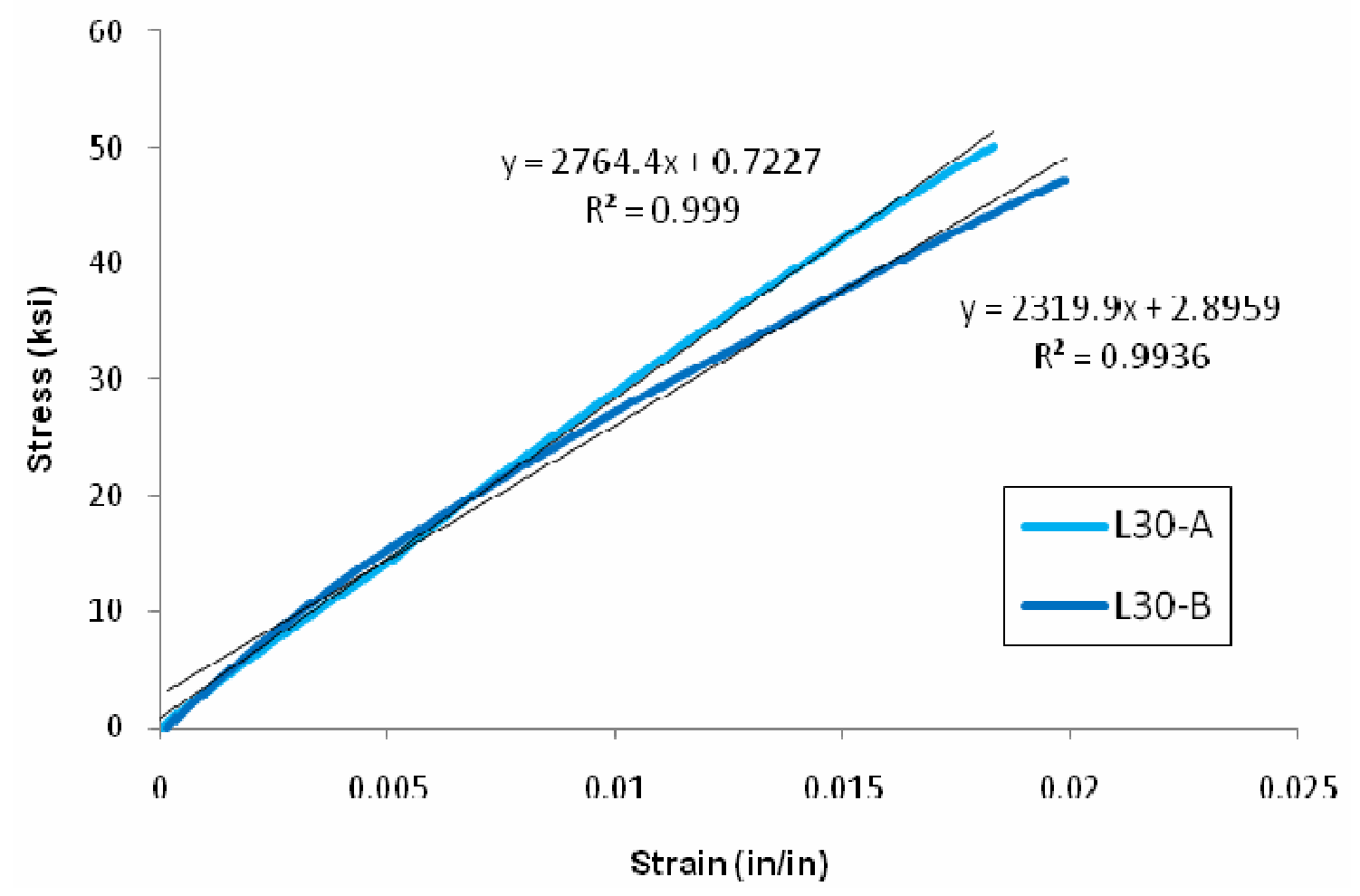

Figure 6.12: Tensile Comparison of Laminates $L_{30-A}$ and $L_{30-B}$

The above graph shows that both laminates had very similar tensile results. Table 6.6 shows a summary of the tensile test results for both test specimens.

Table 6.6: Tensile Summary for Laminates $L_{30-A}$ and $L_{30-B}$

\begin{tabular}{|c|c|c|c|c|}
\hline Specimen & $\begin{array}{c}\text { Max. } \\
\text { Load }\left(\mathrm{Ib}_{\mathrm{f}}\right)\end{array}$ & $\begin{array}{c}\text { Young's } \\
\text { Modulus (ksi) }\end{array}$ & $\begin{array}{c}\text { Shear } \\
\text { Modulus }(\mathrm{ksi})\end{array}$ & $\begin{array}{c}\text { Ultimate } \\
\text { Stress }(\mathrm{ksi})\end{array}$ \\
\hline $\mathrm{L}_{30-\mathrm{A}}$ & 2835.63 & 2764.41 & 1132.95 & 50.58 \\
\hline $\mathrm{L}_{30-\mathrm{B}}$ & 3230.03 & 2319.91 & 950.78 & 47.16 \\
\hline Avg. & 3032.83 & 2542.15 & 1041.87 & 48.87 \\
\hline
\end{tabular}

The average elastic modulus was later used as the stiffness property of laminate $\mathrm{L}_{30}$ during the finite element analysis. 
Figure 6.13 shows the stress-strain curve of specimen $\mathrm{L}_{40}$ with a fiber volume fraction of $48 \%$ before fracture and a cross section of $0.0722 \mathrm{in}^{2}$.

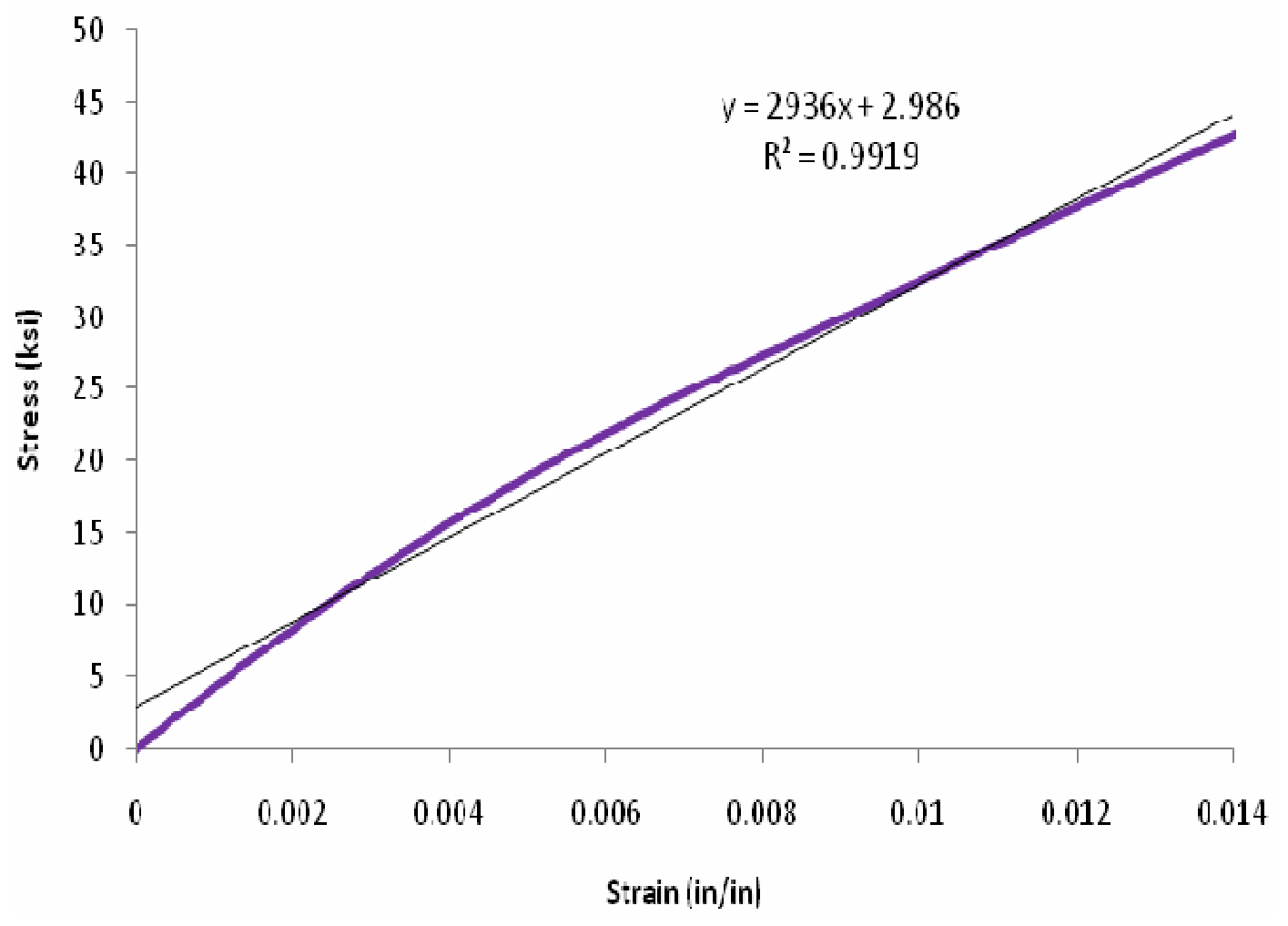

Figure 6.13: Tensile Strength Result for Laminate $L_{40}$

The graph above shows a stress-strain curve linear relationship for laminate $\mathrm{L}_{40}$ in which the Young's modulus was determined by using the tensile data summary of the Merlin-Instron program. The Young's modulus in the longitudinal direction was $2936.2 \mathrm{ksi}$ with an R-squared value of 0.9919 and a shear modulus of $1155.96 \mathrm{ksi}$. The maximum load before fracture was at $3146.32 \mathrm{lb}_{\mathrm{f}}$ with a corresponding ultimate tensile strength of $43.56 \mathrm{ksi}$ and maximum strain of 0.0144 in.

Fig. 6.14 shows the tensile fracture of laminate $\mathrm{L}_{40}$ after static tensile testing. The test specimen $\mathrm{L}_{40}$ experienced failure at its upper and lower sides since it was probably misaligned in 
the Instron machine, aluminum tabs not placed correctly on specimen or lack of fabrication of specimen, thus producing stress concentrations at its ends.

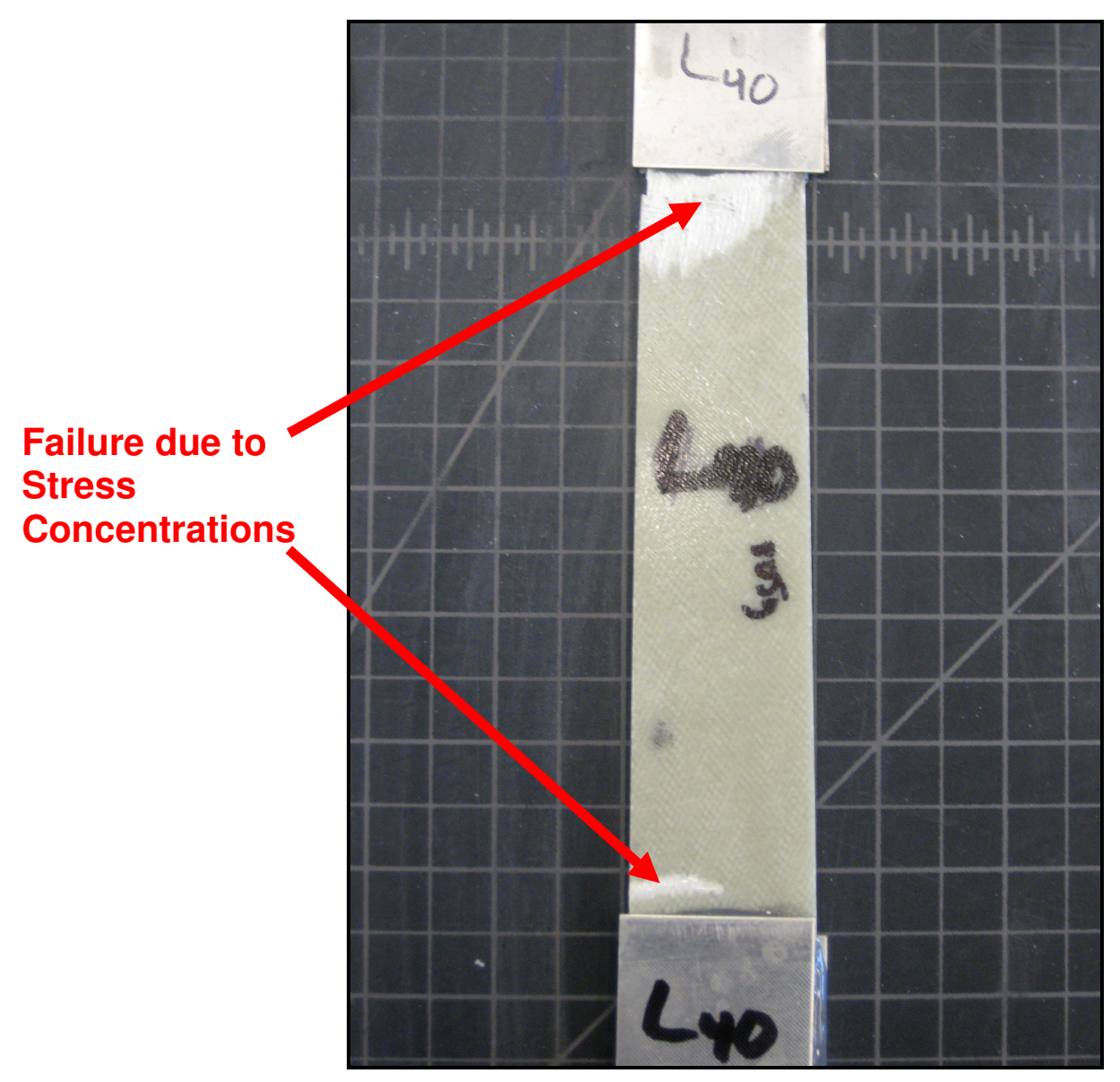

Figure 6.14: Ultimate Failure for Laminates with 40 grams of Limestone Filler

Fig. 6.15 shows the tensile stress vs. strain linear curve comparison of two specimens with 40 grams of limestone filler. 


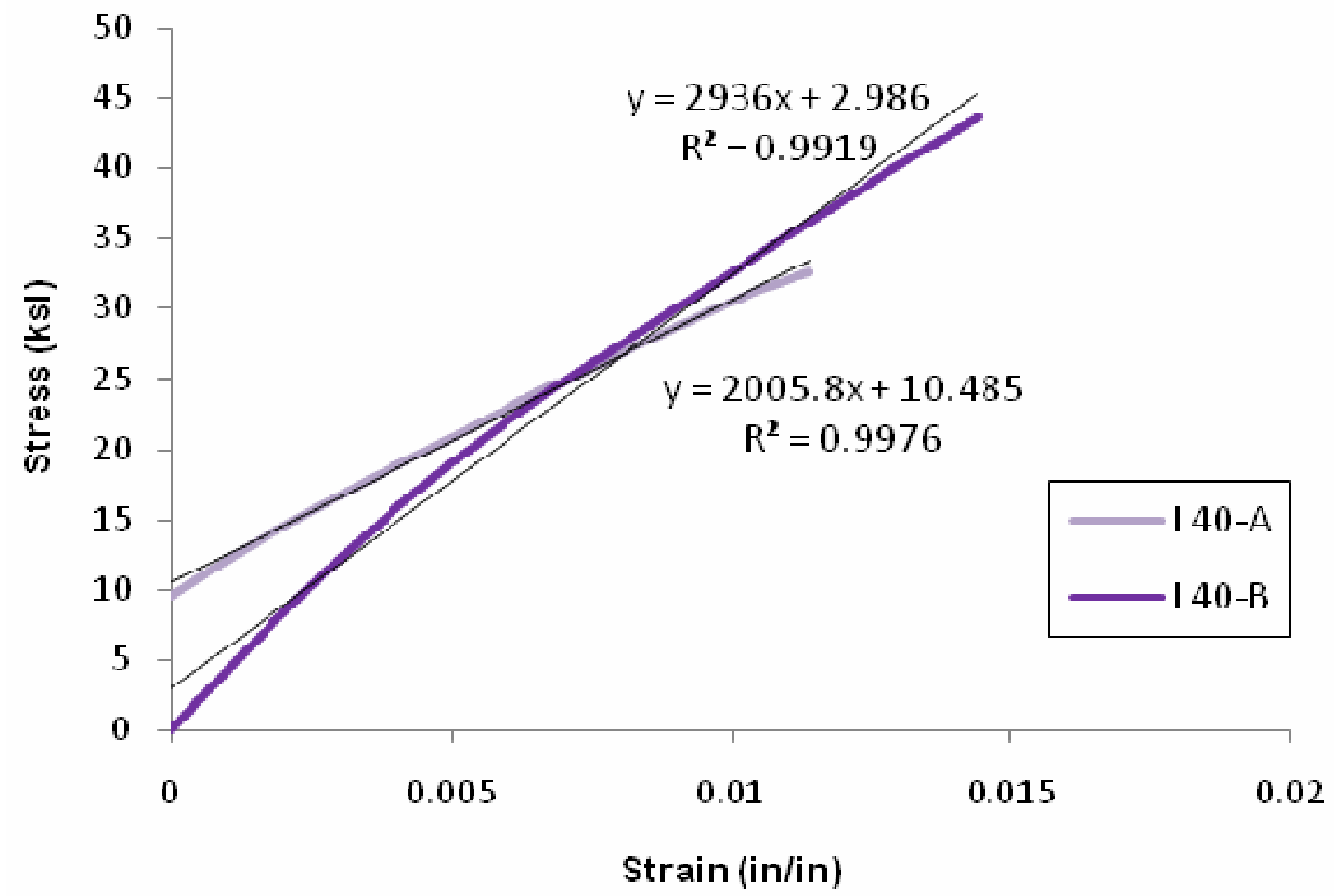

Figure 6.15: Tensile Comparison of Laminates $L_{40-A}$ and $L_{40-B}$

The above graph shows that both laminates had very similar tensile results. Test specimen $\mathrm{L}_{40-\mathrm{A}}$ did not intersect at the origin since the tensile machine started to load and later record data at a tensile stress of $9.54 \mathrm{ksi}$. Table 6.7 shows a summary of the tensile test results for both test specimens.

Table 6.7: Tensile Summary for Laminates $L_{40-A}$ and $L_{40-B}$

\begin{tabular}{|c|c|c|c|c|}
\hline Specimen & $\begin{array}{c}\text { Max. } \\
\text { Load }\left(\mathrm{lb}_{\mathrm{f}}\right)\end{array}$ & $\begin{array}{c}\text { Young's } \\
\text { Modulus }(\mathrm{ksi})\end{array}$ & $\begin{array}{c}\text { Shear } \\
\text { Modulus }(\mathrm{ksi})\end{array}$ & $\begin{array}{c}\text { Ultimate } \\
\text { Stress }(\mathrm{ksi})\end{array}$ \\
\hline $\mathrm{L}_{40-\mathrm{A}}$ & 2986.56 & 2936.1 & 1203.28 & 32.63 \\
\hline $\mathrm{L}_{40-\mathrm{B}}$ & 3146.32 & 2005.8 & 822.05 & 43.56 \\
\hline Avg. & 3066.44 & 2470.95 & 1012.67 & 38.09 \\
\hline
\end{tabular}

The average elastic modulus was later used as the stiffness property of laminate $\mathrm{L}_{40}$ during the finite element analysis. 
Fig. 6.16 shows the stress-strain curve of specimen $\mathrm{HD}_{30}$ with a fiber volume fraction of $47 \%$ before fracture and a cross section of $0.06973 \mathrm{in}^{2}$.

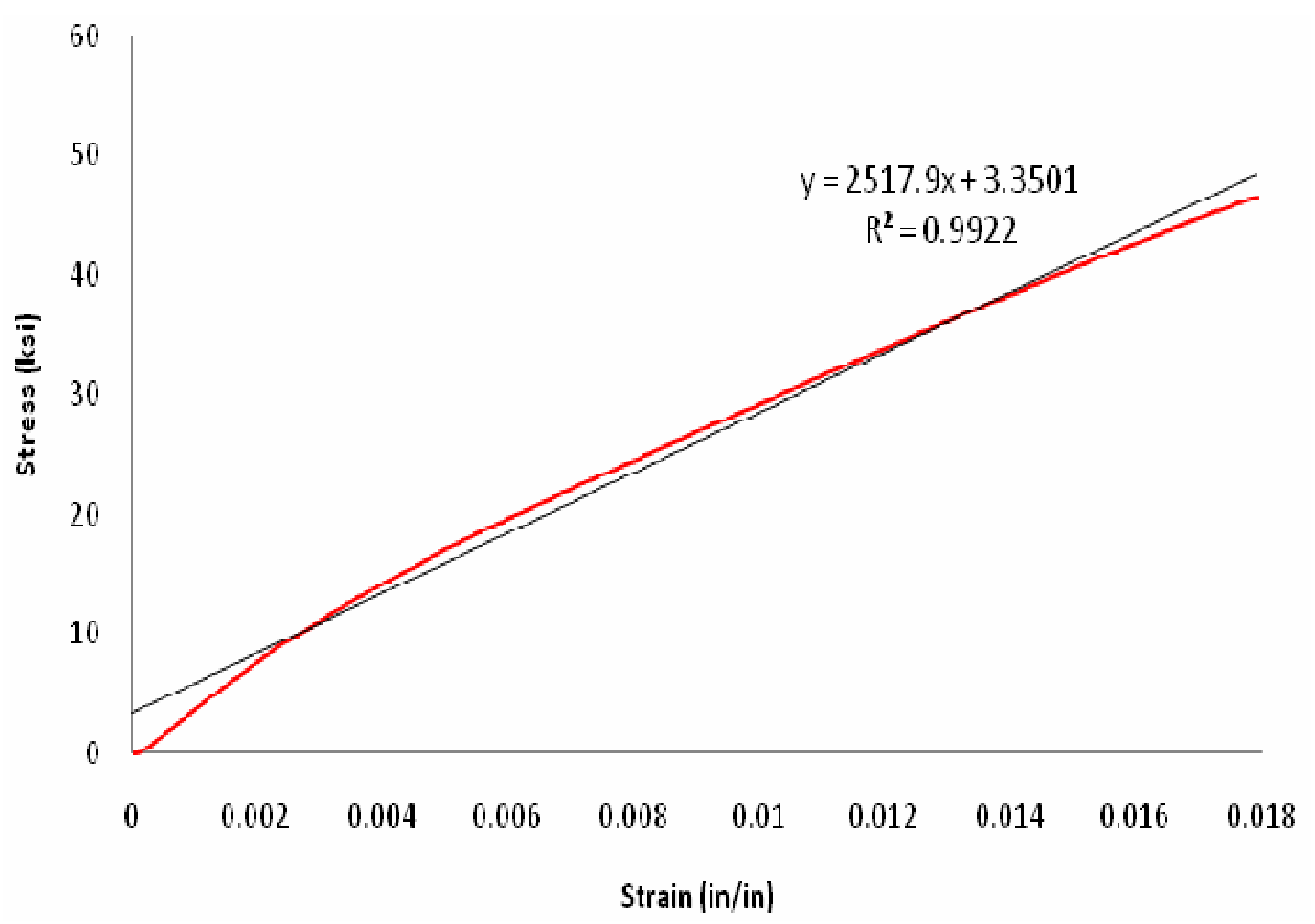

Figure 6.16: Tensile Strength Result for Laminate $\mathrm{HD}_{30}$

The graph above shows a stress-strain curve linear relationship for laminate $\mathrm{HD}_{30}$ in which the Young's modulus was determined by using the tread line function from the Excel program. The Young's modulus in the longitudinal direction was 2517.9 ksi with an R-squared value of 0.9922 and a shear modulus of $991.3 \mathrm{ksi}$. The maximum load before rupture was $3578.11 \mathrm{lb}_{\mathrm{f}}$ with a corresponding ultimate tensile stress of $46.56 \mathrm{ksi}$ and maximum strain of 0.0179 .

Fig. 6.17 shows the tensile fracture of laminate $\mathrm{HD}_{30}$ after static tensile testing. The test specimen $\mathrm{HD}_{30}$ experienced failure at its upper sides since it was probably misaligned in the 
Instron machine or aluminum tabs not placed correctly on specimen during the oven press curing cycle, as seen in figure below.

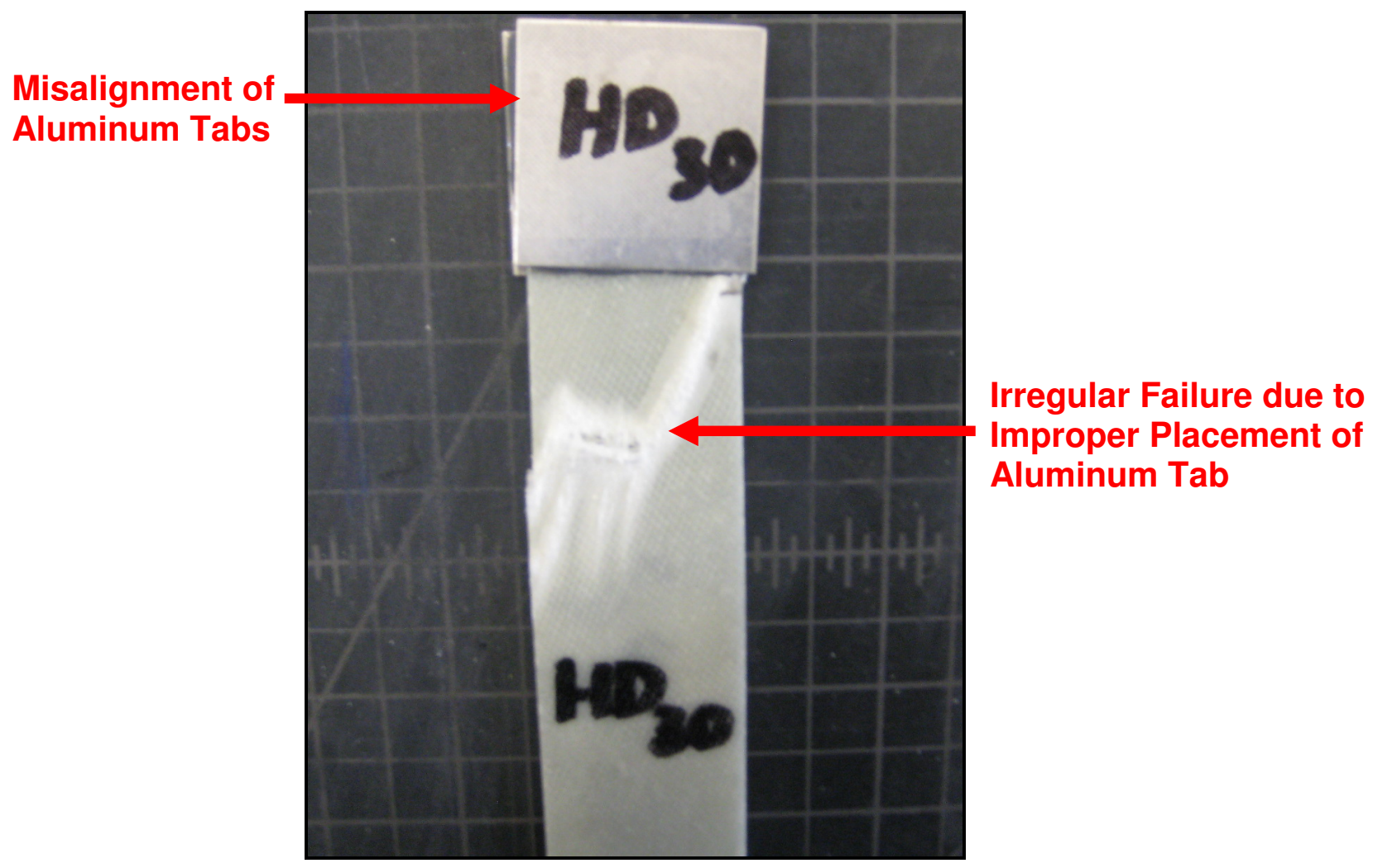

Figure 6.17: Ultimate Failure for Laminates with 30 grams of High-Density Filler

Fig. 6.8 shows a summary of the tensile test results for both test specimens.

Table 6.8: Tensile Summary for Laminates $\mathrm{HD}_{30-A}$ and $\mathrm{HD}_{30-\mathrm{B}}$

\begin{tabular}{|c|c|c|c|c|}
\hline Specimen & $\begin{array}{c}\text { Max. } \\
\text { Load }\left(\mathrm{lb}_{\mathrm{f}}\right)\end{array}$ & $\begin{array}{c}\text { Young's } \\
\text { Modulus }(\mathrm{ksi})\end{array}$ & $\begin{array}{c}\text { Shear } \\
\text { Modulus }(\mathrm{ksi})\end{array}$ & $\begin{array}{c}\text { Ultimate } \\
\text { Stress (ksi) }\end{array}$ \\
\hline $\mathrm{HD}_{30-\mathrm{A}}$ & 3582.63 & 3110.95 & 1274.98 & 54.94 \\
\hline $\mathrm{HD}_{30-\mathrm{B}}$ & 3578.11 & 2517.91 & 1031.93 & 46.56 \\
\hline Avg. & 3580.37 & 2814.42 & 1153.45 & 50.75 \\
\hline
\end{tabular}

The average elastic modulus was later used as the stiffness property of laminate $\mathrm{HD}_{30}$ during the finite element analysis. 
Fig. 6.18 shows the stress-strain curve comparison results between specimens $\mathrm{L}_{30}, \mathrm{~L}_{\mathrm{B} 0}$ and $\mathrm{HD}_{30}$.

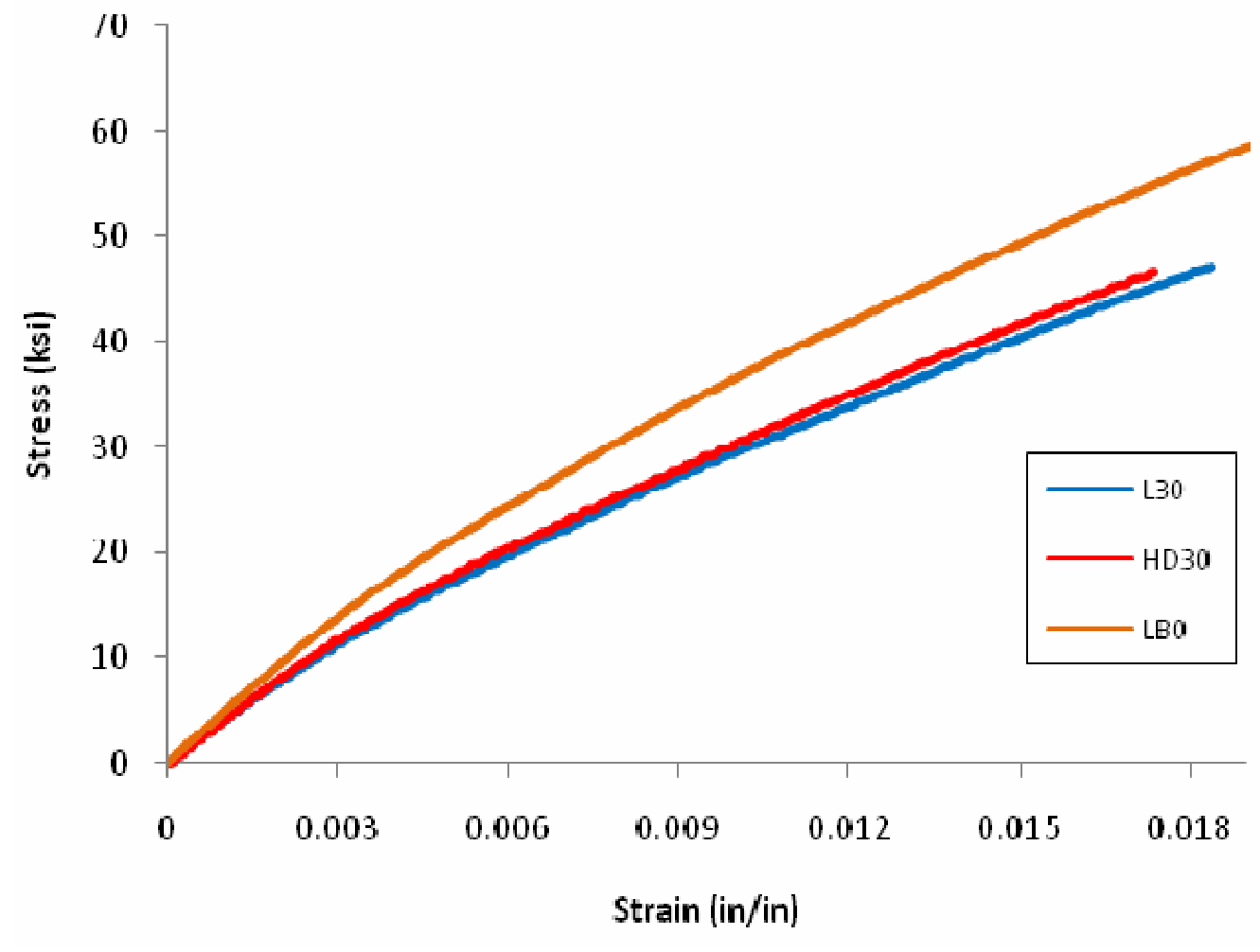

Figure 6.18: Tensile Strength Result Comparison between Laminates $L_{30}, L_{B 0}$ and $H_{30}$

The tensile strength results comparison between test specimens $\mathrm{L}_{30}$ (30 grams of limestone) and $\mathrm{HD}_{30}$ (30 grams of adhesive high-density) are seen in Figure 6.15. Test specimen $\mathrm{L}_{30}$ curve was lower than $\mathrm{HD}_{30}$, which indicate that $\mathrm{HD}_{30}$ had a higher tensile strength value than specimen $\mathrm{L}_{30}$ ) due to its higher strength bond properties. The high-density filler laminate had higher stiffness compared to test specimen $\mathrm{L}_{30}$; hence, making it more brittle. Laminate $\mathrm{L}_{\mathrm{B} 0}$ had the highest strength performance overall. Table 6.9 shows the comparison tensile result values between test specimen $\mathrm{L}_{30}, \mathrm{~L}_{\mathrm{B} 0}$ and $\mathrm{HD}_{30}$. 
Table 6.9: Tensile Strength Summary of Laminates $L_{30}, L_{B 0}$ and $H D_{30}$

\begin{tabular}{|c|c|c|c|c|c|c|}
\hline Specimen & $\begin{array}{c}\text { Max. } \\
\text { Load }\left(\mathrm{Ib}_{\mathrm{f}}\right)\end{array}$ & $\begin{array}{c}\text { Young's } \\
\text { Modulus (ksi) }\end{array}$ & $\begin{array}{c}\text { Rigidity } \\
\text { Modulus (ksi) }\end{array}$ & $\begin{array}{c}\text { Tensile } \\
\text { Strength (ksi) }\end{array}$ & $\begin{array}{c}\text { Ultimate } \\
\text { Stress (ksi) }\end{array}$ & $\begin{array}{c}\text { Fiber Vol. } \\
\text { Fraction (\%) }\end{array}$ \\
\hline $\mathrm{L}_{30}$ & 3230.03 & 2896.95 & 913.35 & 251.50 & 47.16 & 50 \\
\hline $\mathrm{HD}_{30}$ & 3578.12 & 3237.85 & 991.31 & 278.77 & 46.56 & 47 \\
\hline $\mathrm{LB}_{0}$ & 4327.11 & 2922.81 & 1141.64 & 319.25 & 61.13 & 48 \\
\hline
\end{tabular}

The tensile strength results for all specimens shows the calculated averages of all laminated test specimens. Test specimen $\mathrm{L}_{\mathrm{B} 0}$ 's average was not calculated.

Table 6.10: Experimental Tensile Summary of All Laminated Beams

\begin{tabular}{|c|c|c|c|c|c|}
\hline Specimen & $\begin{array}{c}\text { Max. } \\
\text { Load }\left(\mathrm{lb}_{\mathrm{f}}\right)\end{array}$ & $\begin{array}{c}\text { Young's } \\
\text { Modulus (ksi) }\end{array}$ & $\begin{array}{c}\text { Shear } \\
\text { Modulus (ksi) }\end{array}$ & $\begin{array}{c}\text { Ultimate } \\
\text { Stress (ksi) }\end{array}$ & $\begin{array}{c}\text { Fiber Vol. } \\
\text { Fraction (\%) }\end{array}$ \\
\hline $\mathrm{L}_{20}$ & 3660.92 & 2670.85 & 1094.61 & 51.19 & 51 \\
\hline $\mathrm{L}_{30}$ & 3032.83 & 2542.15 & 1041.87 & 48.87 & 50 \\
\hline $\mathrm{L}_{40}$ & 3066.44 & 2470.95 & 1012.67 & 38.09 & 48 \\
\hline $\mathrm{HD}_{30}$ & 3580.37 & 2814.42 & 1153.45 & 50.75 & 47 \\
\hline $\mathrm{L}_{\mathrm{B} 0}$ & 4327.11 & 3110.95 & 1150.39 & 61.13 & 48 \\
\hline
\end{tabular}

The above table shows the correlation between increasing tensile strength with increasing tensile stress needed to deform and fracture the composite material for the second set of test specimens. After analyzing the tensile results of the static testing for all specimens, it was also interesting to note that all test laminates had very low elastic modulus values compared to test specimen $\mathrm{L}_{\mathrm{B} 0}$ which has no filler content. Test specimen $\mathrm{L}_{\mathrm{B} 0}$ had the highest values for maximum load, elastic modulus, and ultimate stress. Test specimen $\mathrm{L}_{20}$ displayed the highest stiffness behavior for the test specimens made of limestone filler; whereas, test specimen $\mathrm{L}_{40}$ had the 
lowest performance. Therefore it was observed that increasing the filler percentage in the laminates decreased their stiffness and rigidity and made them more brittle.

Laminate $\mathrm{HD}_{30}$ also had higher stiffness and rigidity values compared with test specimen $\mathrm{L}_{30}$ and was the most brittle of all materials. Laminate $\mathrm{HD}_{30}$ brittleness property was observed by the fiber/matrix breakage sound after rupture of test specimen $\mathrm{HD}_{30}$ during the static tensile test. This was anticipated since laminate $\mathrm{HD}_{30}$ was made from West System 404 high-density filler which is a thickening additive developed for maximum physical properties in hardware bonding applications.

The results of all the test specimens were located in the middle region of the stress-strain graphs. This was expected since all laminates had very similar fiber-volume fraction percentages. Table 6.11 shows the percent difference calculated for each laminate compared with laminate $\mathrm{L}_{\mathrm{B} 0}$.

Table 6.11: Tensile Testing Percent Difference Summary

\begin{tabular}{|c|c|c|c|}
\hline Specimen & Young's Modulus (\%) & Shear Modulus (\%) & Ultimate Stress (\%) \\
\hline $\mathrm{L}_{20}$ & 14.1 & 4.85 & 16.3 \\
\hline $\mathrm{L}_{30}$ & 18.3 & 9.43 & 20.1 \\
\hline $\mathrm{L}_{40}$ & 20.2 & 11.97 & 37.7 \\
\hline $\mathrm{HD}_{30}$ & 9.53 & 0.266 & 16.9 \\
\hline
\end{tabular}

According to the above table, specimen $\mathrm{HD}_{30}$ had the lowest percent difference in all categories, specifically in the shear modulus with a value of $0.27 \%$. Test specimen $\mathrm{L}_{40}$ had the overall highest percent difference. The material property with the largest percent difference was the ultimate stress.

There are several assumptions and factors that might explain why the test specimens had higher percent differences than test specimen $\mathrm{L}_{\mathrm{B} 0}$. One assumption was that usually lower 
stiffness and strength matrix acts to dilute the overall apparent strength. Although the matrix is necessary to bind everything together, the strength of the fiber composite in the fiber direction is generally reduced to the ratio of the matrix's area to the total cross-sectional area of the composite, hence decreasing the overall strength of the material. Consequently, it was observed that the test specimens when subjected to increasing longitudinal tensile load, failure was initiated by fiber breakage at their weakest cross sections, thus causing a complete rupture of the fiberglass laminated plates.

For all static testing, specimens were created with limestone and high-density filler which might have weaken the fiber's strength instead of enhancing its material properties. This was observed during static testing, when the laminates experienced brittle failure and fiber pullout, as seen in Fig. 6.19. The pullout of fibers from the matrix depends on the bond strength and the load-transfer mechanism from matrix to fiber.

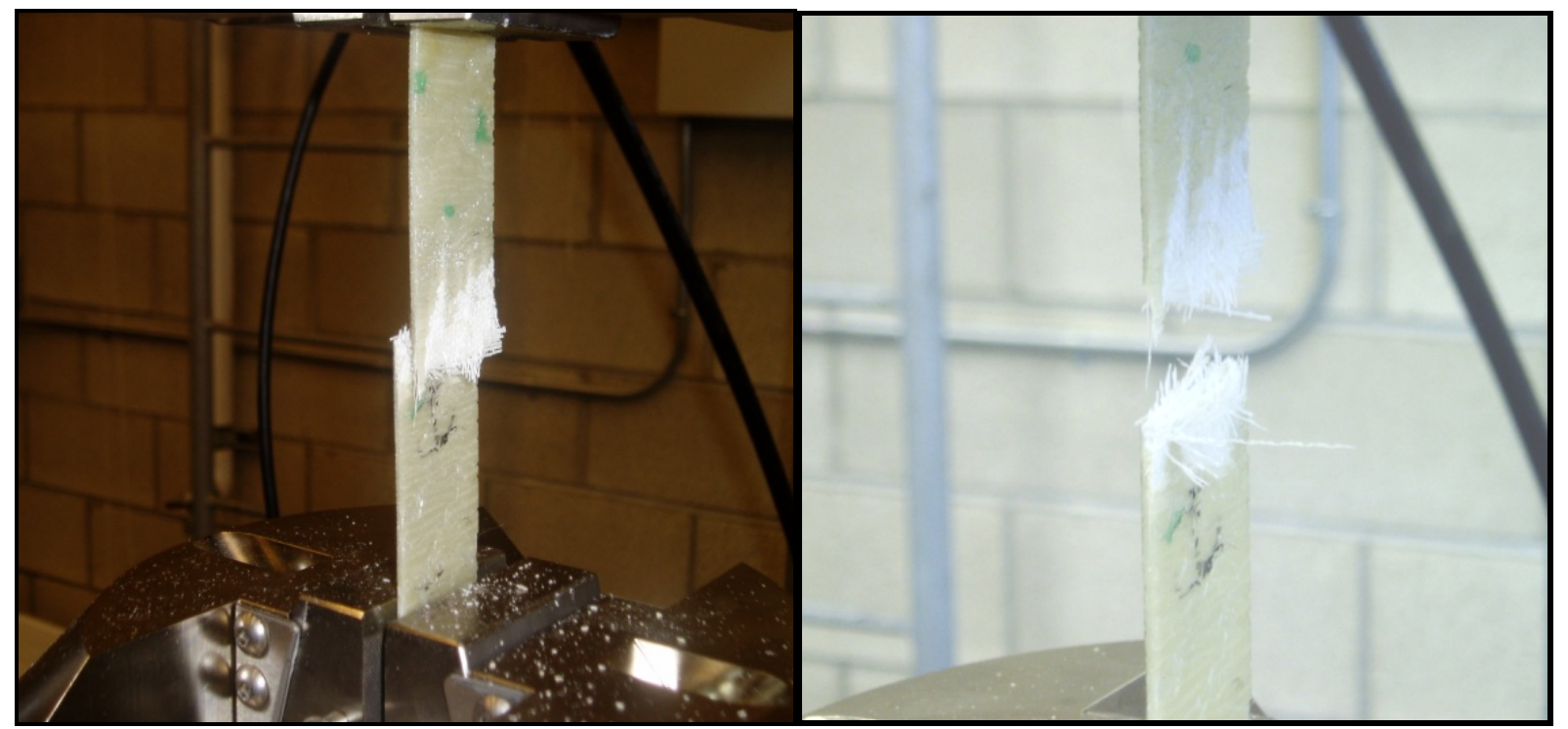

Figure 6.19: Brittle Failure with Fiber Pullout due to Longitudinal Tensile Loading 
As seen in the figure above, the test specimen failing under longitudinal tensile load was due to the initiation of cracks at different cross sections which resulted in ultimate failure. Fiberglass composites having lower fiber volume fractions $\left(\mathrm{V}_{\mathrm{f}}<0.40\right)$ exhibit predominantly the brittle-type failure mode, while composites with intermediate fiber volume fraction $\left(0.40<\mathrm{V}_{\mathrm{f}}<0.65\right)$ exhibit failure with fiber pullout. As seen previously in Table 6.2, the test specimens had an intermediate fiber volume fraction $\left(0.47<\mathrm{V}_{\mathrm{f}}<0.51\right)$ which explained why test specimens experienced brittle failure with fiber pullout during tensile testing.

A second major assumption in strength reduction was probably due to transverse shear loading. Composite structures typically must have fibers oriented in more than one direction. Although the E-glass roving woven material have adequate shear loading capability, shear loads typically are carried by \pm 45 degrees fibers, or at least fibers with components other 0 and 90 degrees which would require the matrix to carry the shear load. The test specimens did not have \pm 45 degrees fiber orientation thus would be susceptible to fail under transverse loading. In addition, this could have been result of improper layup and bagging techniques, or misalignment of the specimen inside the Instron machine which may also create torsion or bending failure, as seen in Fig. 6.20. 


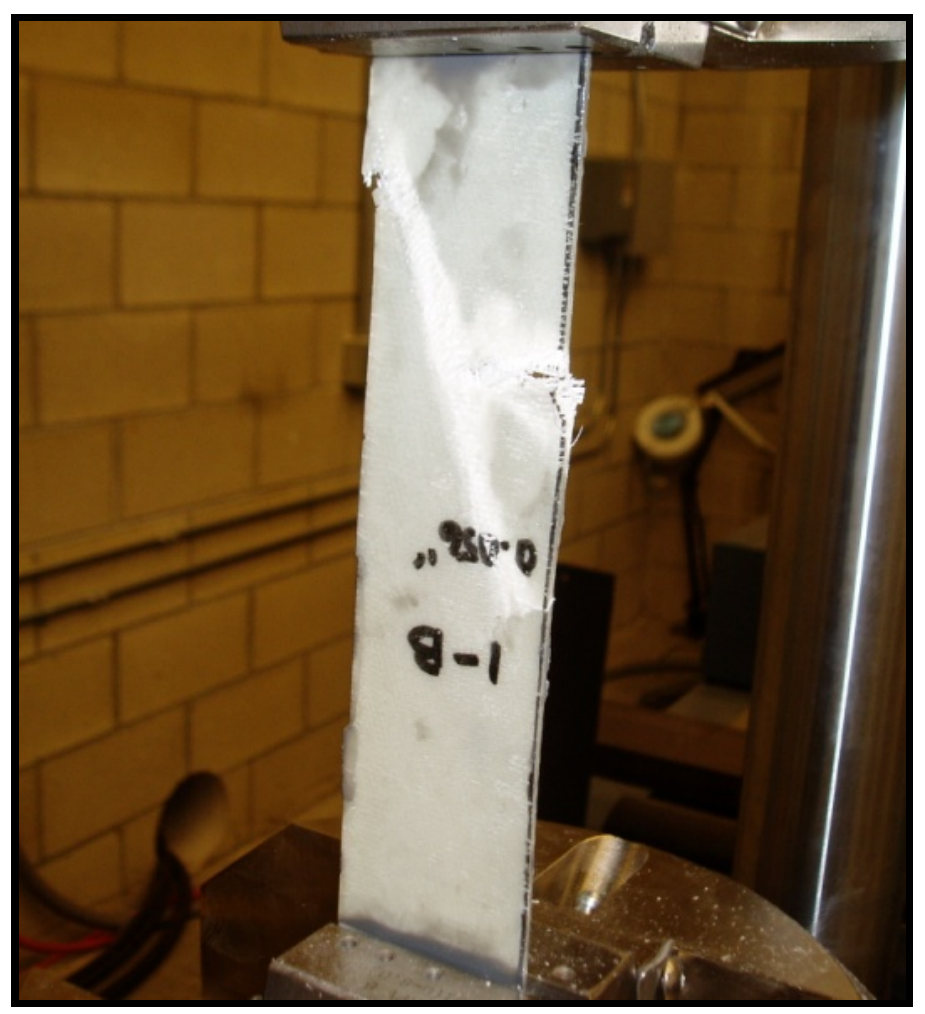

\section{Figure 6.20: Fiber Failure due to Misalignment of Test Specimen}

A third assumption was that the tensile strength, which is an intensive property and does not depend on the size of the test specimen, could have been reduced due to improper preparation of the specimen, material, and test environment. The fabrication process used to make fibrous composites inherently produces residual stresses in the constituents and at the interface [4]. The residual stresses are caused by two primary reasons the difference in the coefficients of thermal expansion for the constituents and the difference in fabrication temperature and the temperatures at which they are used. Moreover, in laminates, residual stresses are present because of the difference in thermal expansion of the individual plies. During tensile testing, the Cal Poly Aero-Composite lab had a temperature and humidity of $59^{\circ} \mathrm{F}$ and $86 \%$, respectively. Consequently, specimen preparation and testing environmental conditions 
may have created residual stresses in the fiberglass laminates, thus affecting the strength of the composite by reducing its low elastic modulus as well as its response to mechanical loads.

\subsubsection{Bending Moment in General}

In engineering mechanics, bending (also known as flexure) characterizes the behavior of a structural element subjected to an external load applied perpendicular to the axis of the element. A structural element subjected to bending is known as a beam. In this thesis investigation, experimental tests of moment bending were performed on test specimens in order to determine the dynamic behavior under bending loads of each laminate structure, especially the flexural strength.

Bending produces reactive forces inside a beam as the beam attempts to accommodate the flexural load; the material at the top of the beam is being compressed while the material at the bottom is being stretched. There are three notable internal forces caused by lateral loads: shear parallel to the lateral loading, compression along the top of the beam, and tension along the bottom of the beam. These last two forces form a couple or moment as they are equal in magnitude and opposite in direction. This bending moment produces the sagging deformation characteristic of compression members experiencing bending. This stress distribution is dependent on a number of assumptions. First, plane sections remain plane thus implying that any deformation due to shear across the section is not accounted for (no shear deformation). Also, this linear distribution is only applicable if the maximum stress is less than the yield stress of the material. For stresses that exceed yield, refer to article plastic bending.

Fig. 6.21 shows an illustration of load producing bending stresses that creates compression on the top and tension on the bottom of the beam. 


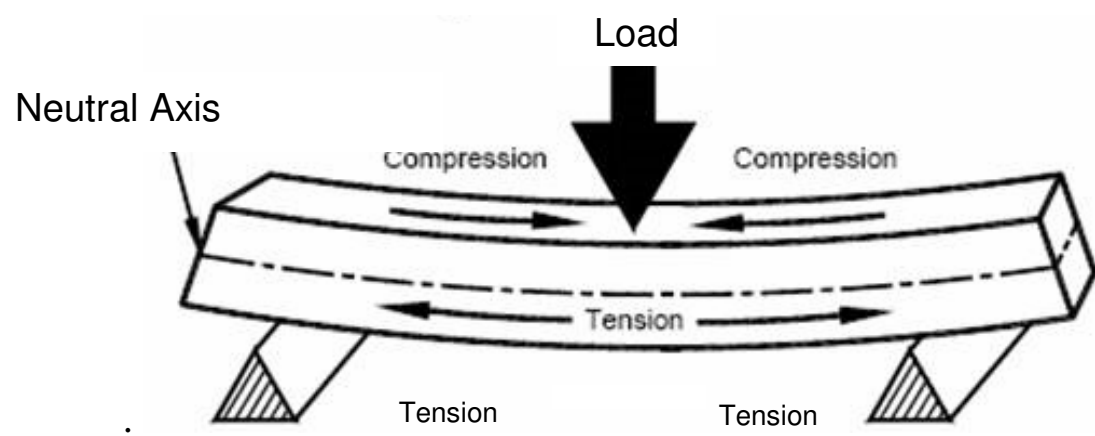

Figure 6.21: Schematic of Compressive and Tensile Bending Stresses on Beam

The maximum compressive stress is found at the uppermost edge of the beam while the maximum tensile stress is located at the lower edge of the beam. Since the stresses between these two opposing maxima vary linearly, there therefore exists a point on the linear path between them where there is no bending stress. The locus of these points is the neutral axis. Because of this area with no stress and the adjacent areas with low stress, using uniform cross section beams in bending is not a particularly efficient means of supporting a load as it does not use the full capacity of the beam until it is on the brink of collapse. Wide-flange beams (I-Beams) and truss girders effectively address this inefficiency as they minimize the amount of material in this under-stressed region.

\subsubsection{Bending Test Results}

A total of five laminated manhole cover specimens were statically tested by using the MTS 322 Flex Frame software and hydraulic actuator system. The maximum bending moment was calculated by assuming a straight-line stress-strain relation to failure. The laminated test specimens, which represented simply supported fiberglass-filler manhole covers (thin laminated plates), experienced concentrated-uniform axial loads at constant loading rate of $0.5 \mathrm{in} / \mathrm{min}$ and sampling rate of $0.5 \mathrm{~s}(20$ hertz). A trial test was performed to calibrate the bending test 
apparatus before proceeding with testing the 4-plied thin fiberglass laminated test specimens. The support span length of the Christy H-8 support fixture was measured to be approximately 11 in. For this bending test, the bending moment on the plate was assumed to vary linearly from zero at the supports to a maximum value at the center, as seen in figure above. The shear force, and, therefore, the interlaminar shear stress at the mid-plane, is uniform all along its length. Fig. 6.22 shows variations across the plate thickness of normal stress (often called bending stress) due to the bending moment and shear stress due to shear force, where the cross section of the beam has been assumed rectangular.
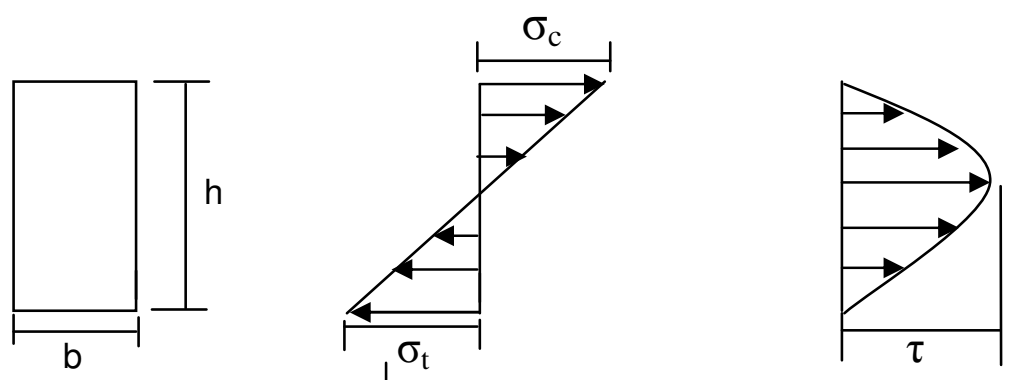

\section{Figure 6.22: Variations of Normal Stress and Shear Stress for a Rectangular Cross Section}

Material properties for this experimental bending analysis were also assumed uniform through the thickness and quasi-isotropic materials. The normal stress varies linearly from maximum compression on one surface of the laminated plate to an equal tensile value on the other surface, being zero at the mid-plane or neutral axis; hence, both compressive and tensile stresses are equal to the normal stress. For a test specimen of homogeneous and isotropic, the elastic material is tested in flexure as a plate simply supported at its ends and loaded at the midpoint, the maximum normal stress at outer surface occurs at mid-span.

The Flexural Chord Modulus was obtained from the axial force $F$ vs. midspan deflection $\delta$ or the slope of forcer versus deflection.

$$
E_{f}=\frac{\Delta F}{\Delta \delta}
$$


where $\Delta \mathrm{F} / \Delta \delta$ is the slope of the curve in the elastic linear (Hookean) region whereby the midspan deflection of the specimen varies linearly with applied forces. The maximum flexural is located directly under the center force application member and the resultant shear force is everywhere on the specimen except under the mid-point force application. Consequently, to obtain the correct value of flexural strength, it should be ensured that the failure takes place by breaking of fibers and not by interlaminar shear.

The center load applied to the specimen for this bending test was very similar to the threepoint bending configuration with the exception that the tested specimen was a plate and not a beam. The difference between both methods is their geometry and boundary conditions since the three-point test involves two reaction forces acting on a rectangular cross-section, whereas, the test specimens for this investigation involved reaction forces acting along on a circular crosssection. Although the test specimens for this thesis project had circular cross sections, it was still assumed that the flexural test method followed the three-point bending configuration in order to simplify the work.

Table 6.12 shows the dimensions of laminated manhole cover specimens for the bending analysis.

Table 6.12: Dimension Summary of Fiberglass Laminated Manhole Cover Specimens

\begin{tabular}{|c|c|c|c|c|}
\hline Specimen & Weight $(\mathrm{g})$ & Thickness (in) & Diameter (in) & Cross Section Area $\left(\mathrm{in}^{2}\right)$ \\
\hline $\mathrm{L}_{\mathrm{B} 0}$ & 117.5 & 0.058 & 10.95 & 94.12 \\
\hline $\mathrm{L}_{20}$ & 118.3 & 0.061 & 10.91 & 93.48 \\
\hline $\mathrm{L}_{30}$ & 117.2 & 0.066 & 11.0 & 94.99 \\
\hline $\mathrm{L}_{40}$ & 107.8 & 0.062 & 10.98 & 94.69 \\
\hline $\mathrm{HD}_{30}$ & 106.9 & 0.063 & 11.0 & 95.03 \\
\hline
\end{tabular}


Fig. 6.23 shows the force-displacement curve of specimen $\mathrm{L}_{\mathrm{B} 0}$ with a fiber volume fraction of 48 percent before fracture.

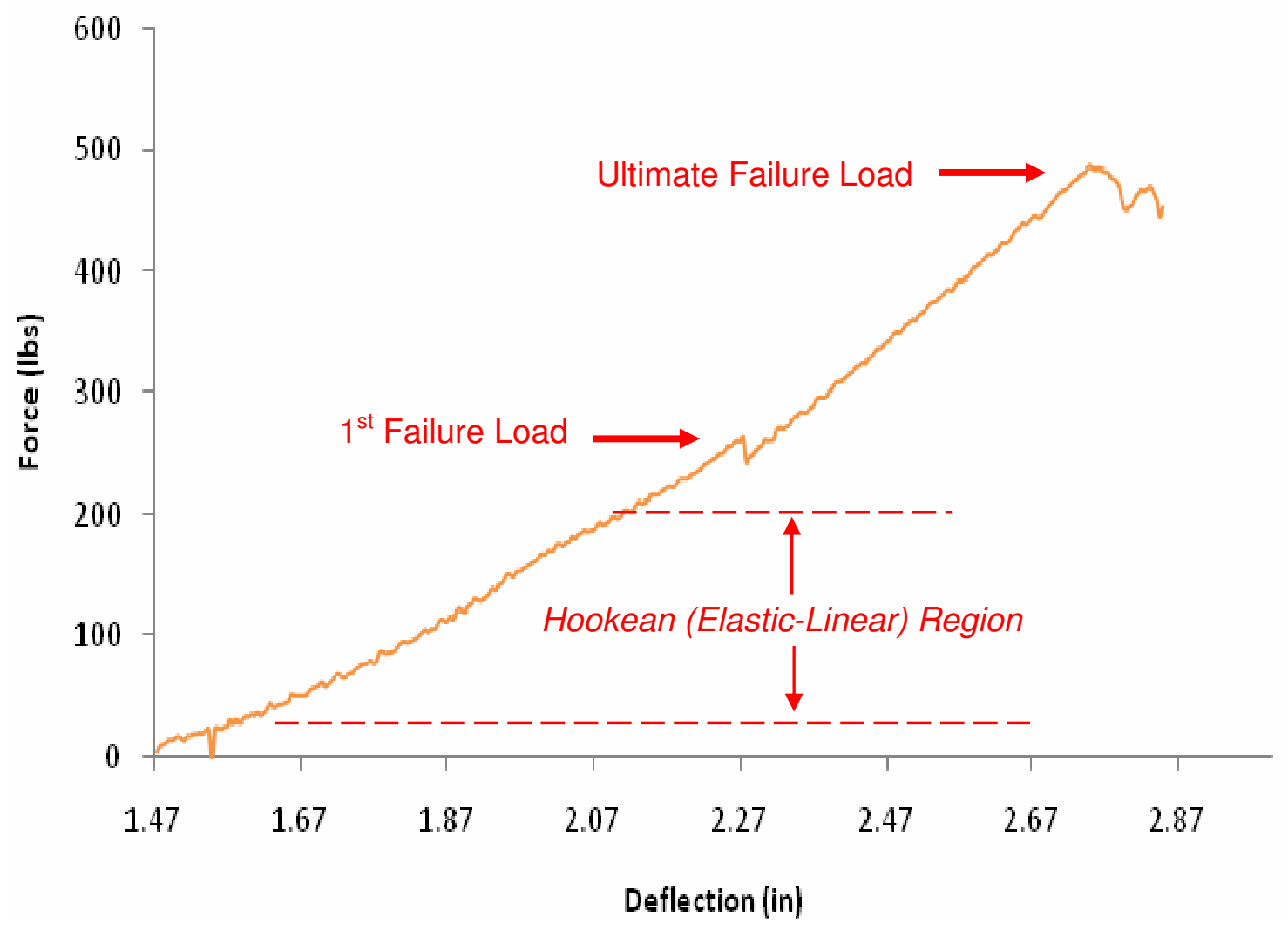

Figure 6.23: Flexural Response for Laminate $L_{B 0}$

The graph above shows a force-deflection linear curve relationship for laminate $\mathrm{L}_{\mathrm{B} 0}$ in which used the flexural data recorded from the Flex Test software program. The $1^{\text {st }}$ failure or drop load was found to be $256.74 \mathrm{lbf}$ at a displacement of $2.25 \mathrm{in}$. The maximum axial load was 488.08 lbf with a corresponding mid-span deflection of $2.75 \mathrm{in}$. The graph suggests that the plate failed predominately in tension/compression matrix failure and fiber/matrix shearing because of the lack sudden drops in load associated with fiber breakage failures. The Hookean (elastic linear) region was considered between $20 \mathrm{lbf}$ and $200 \mathrm{lbf}$ with elastic chord and shear modulus of 49,857 and 20,433 ksi respectively. 
Fig. 6.24 shows the bending test result for laminate $\mathrm{L}_{\mathrm{B} 0}$. The test specimen $\mathrm{L}_{\mathrm{B} 0}$ experienced failure at support region due to stress concentrations created by the axial-uniform bending load of the head piece. A compression/tension failure is the most probable explanation since both delamination and fiber cracks were observed on both sides of the test specimen. Matrix cracks were also assumed to be associated with the fracture features along the specimen's surface since delamination is normally initiated by matrix crack propagation. In addition, the laminated manhole cover specimen was probably misaligned in the support fixture; hence, contributing to the delamination and fiber/matrix failure.

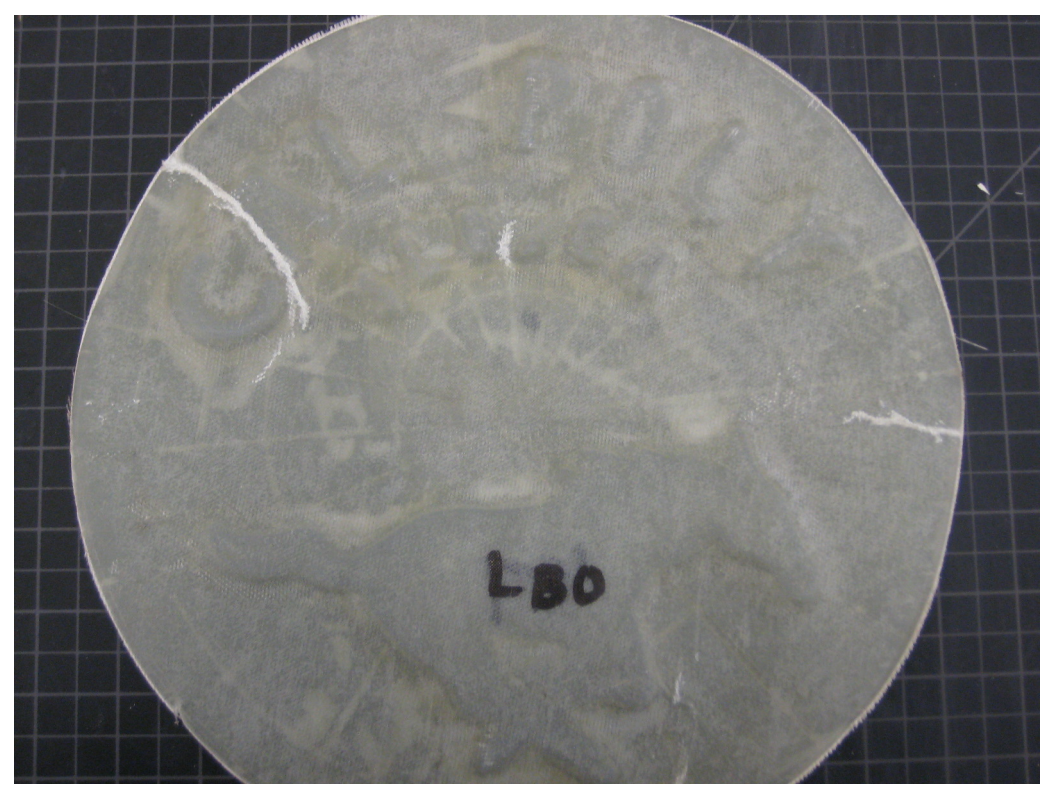

Figure 6.24: Failure at Support Region for Laminate $L_{B o}$

Fig. 6.25 shows the force-displacement curve of specimen $\mathrm{L}_{20}$ with a fiber volume fraction of 51 percent before fracture. 


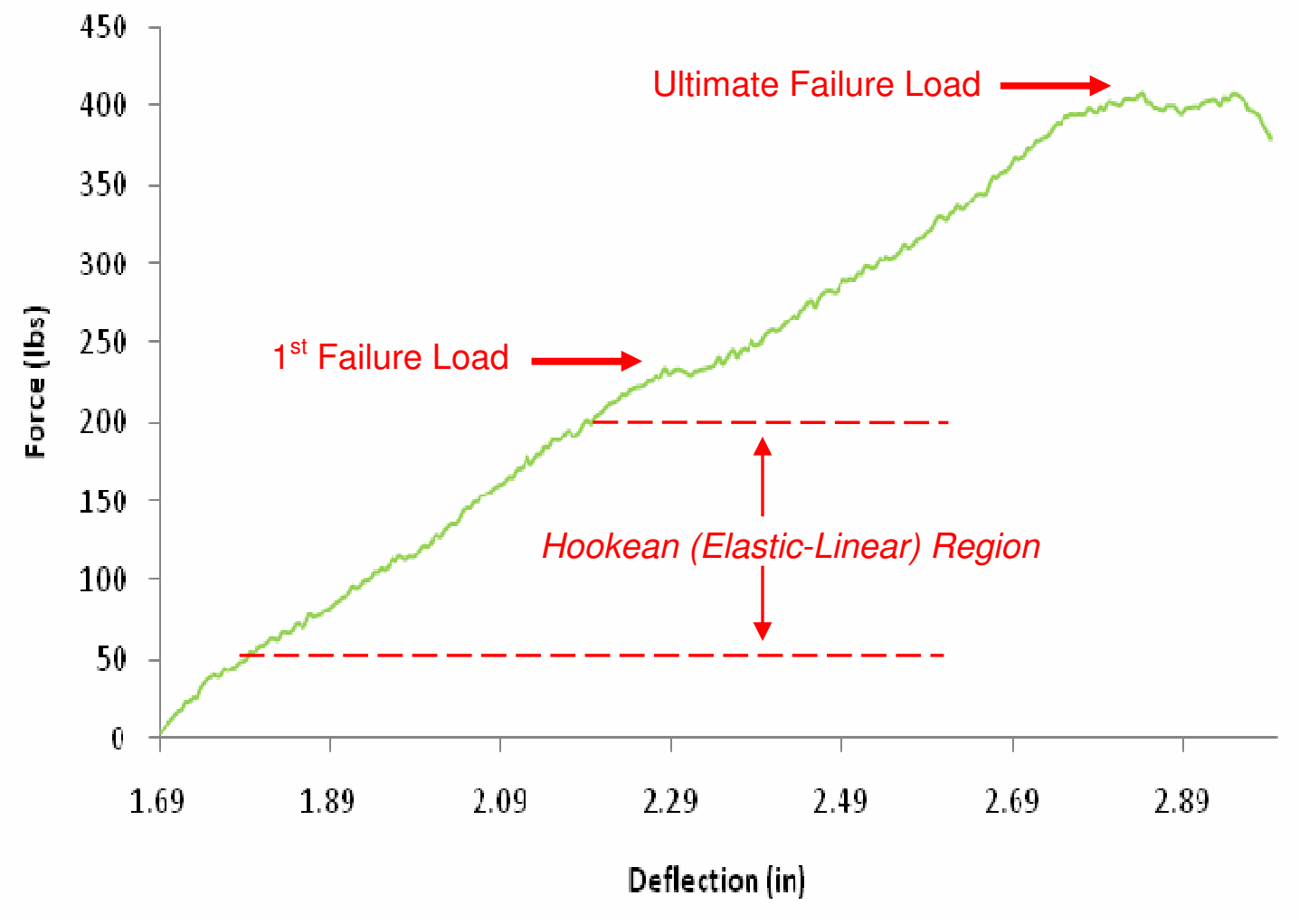

Figure 6.25: Flexural Response for Laminate $L_{20}$

The graph above shows a force-deflection linear curve relationship for laminate $\mathrm{L}_{\mathrm{B} 0}$ which used flexural data from the Flex Test software program. The $1^{\text {st }}$ failure or drop load was found to be $247 \mathrm{lbf}$ at a displacement of $2.28 \mathrm{in}$. The maximum axial load was $427.88 \mathrm{lbf}$ with a corresponding mid-span deflection of 2.75 in. The Hookean region was considered between 50 lbf and $200 \mathrm{lbf}$ with elastic chord and shear modulus of 43,708 and 53.09 ksi respectively.

Fig. 6.26 shows the bending test result for laminate $\mathrm{L}_{20}$. The test specimen $\mathrm{L}_{20}$ experienced compression failure at support region due to stress concentrations created by the axial-uniform bending load of the head piece. The failure of test specimen had symmetry along the line-of-action since it was positioned correctly inside the support fixture. 


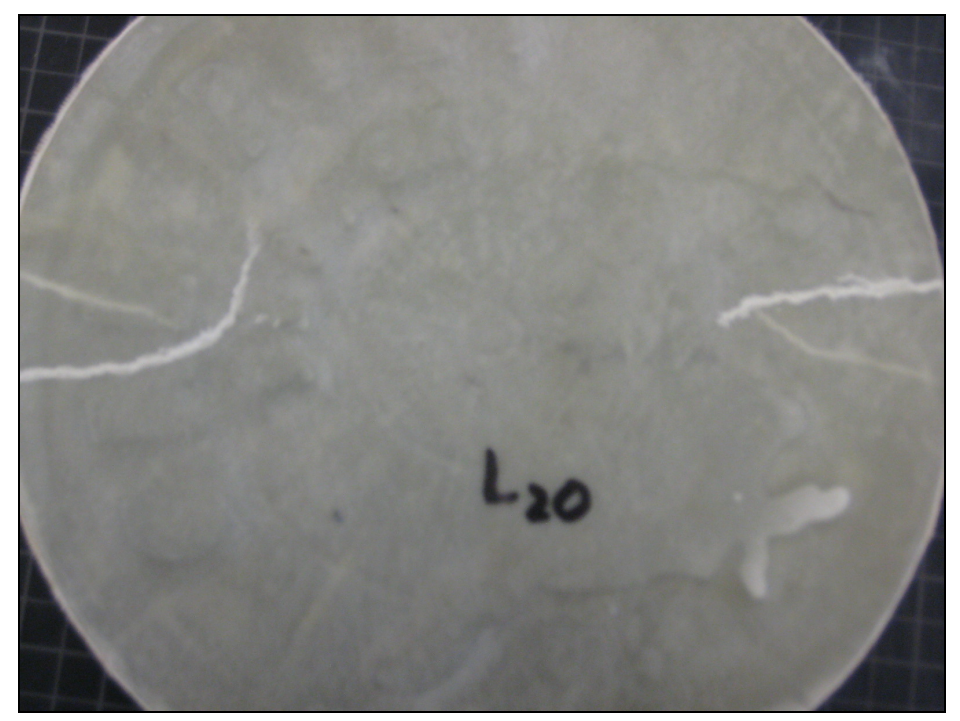

Figure 6.26: Failure at Support Regions for Laminate $L_{20}$

Fig. 6.27 shows the force-displacement curve of specimen $\mathrm{L}_{30}$ with a fiber volume fraction of 50 percent before facture.

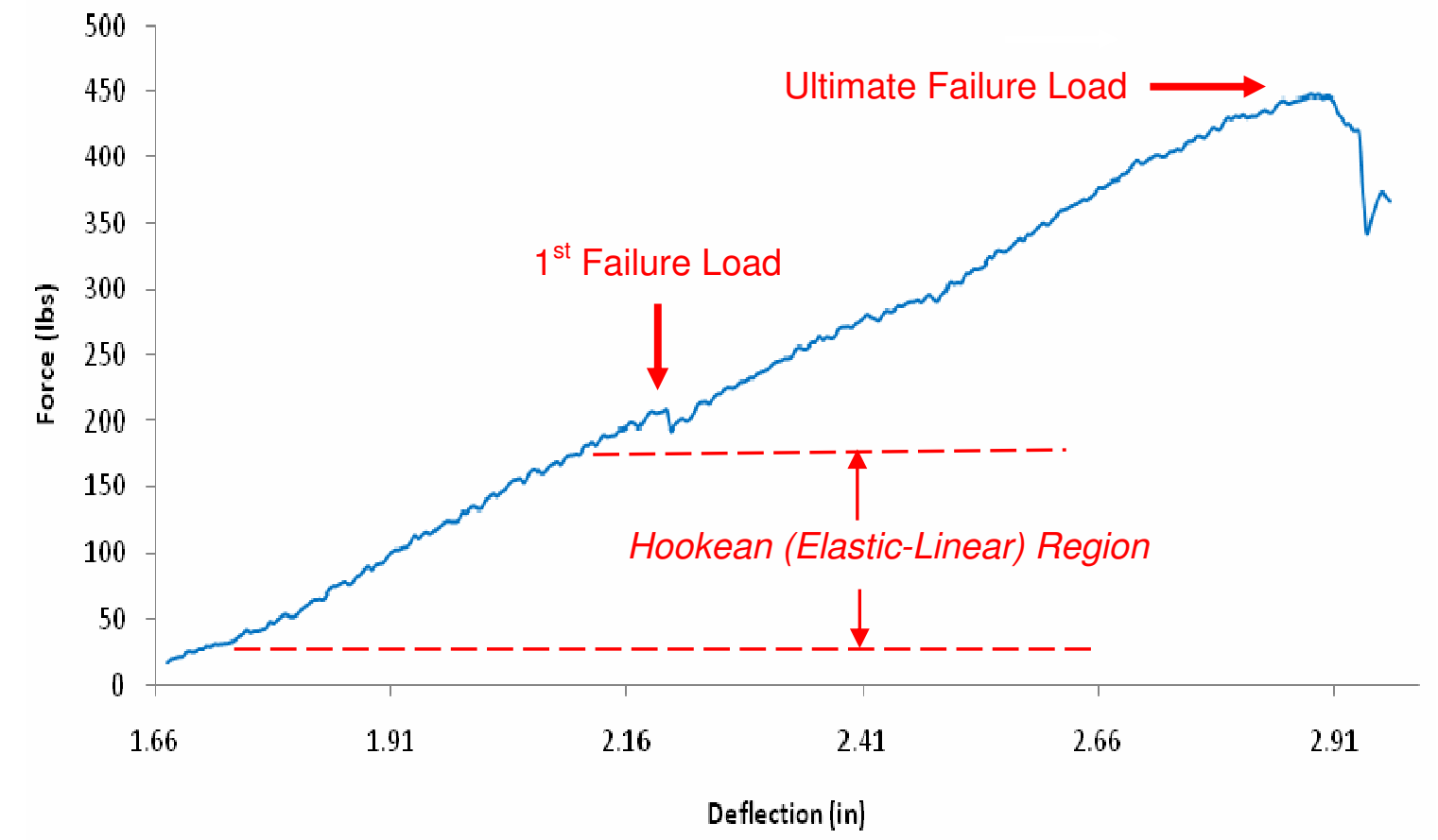

Figure 6.27: Flexural Response for Laminate $L_{30}$

The graph above shows a force-deflection linear curve relationship for laminate $\mathrm{L}_{30}$ which used flexural data from the Flex Test software program. The $1^{\text {st }}$ failure or drop load was 
found to be $200 \mathrm{lbf}$ at a displacement of $2.18 \mathrm{in}$. The maximum axial load was $447.81 \mathrm{lbs}$ with a corresponding mid-span deflection of 2.89 in. The Hookean region was considered between 20 lbf and $200 \mathrm{lbf}$ with a flexural chord and shear modulus of 40,981 and $64.01 \mathrm{ksi}$, respectively.

Fig. 6.28 shows the bending test result of laminate $\mathrm{L}_{30}$. The test specimen $\mathrm{L}_{30}$ experienced compression failure at support region due to stress concentrations created by the axial-uniform bending load of the head piece. The failure of test specimen had symmetry along the line-ofaction since it was positioned correctly inside the support fixture.

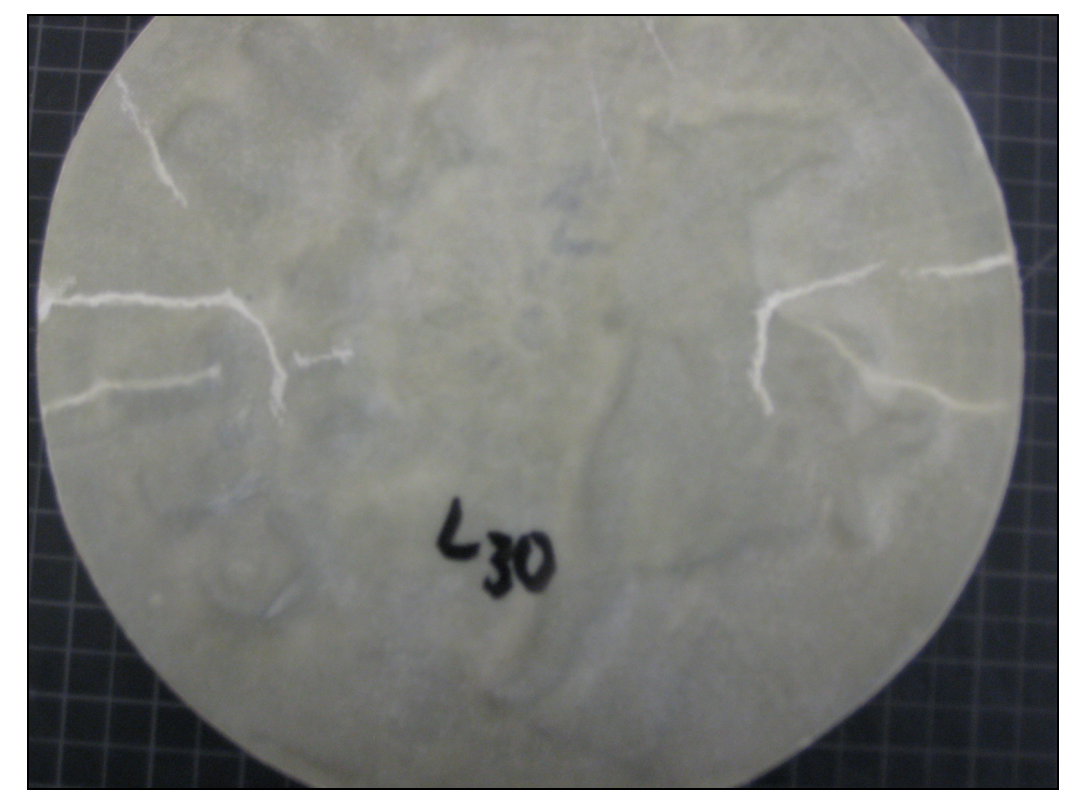

Figure 6.28: Failure at Support Region of Laminate $L_{30}$

Fig. 6.29 shows the force-displacement curve of specimen $\mathrm{L}_{40}$ with a fiber volume fraction of 48 percent before facture. 


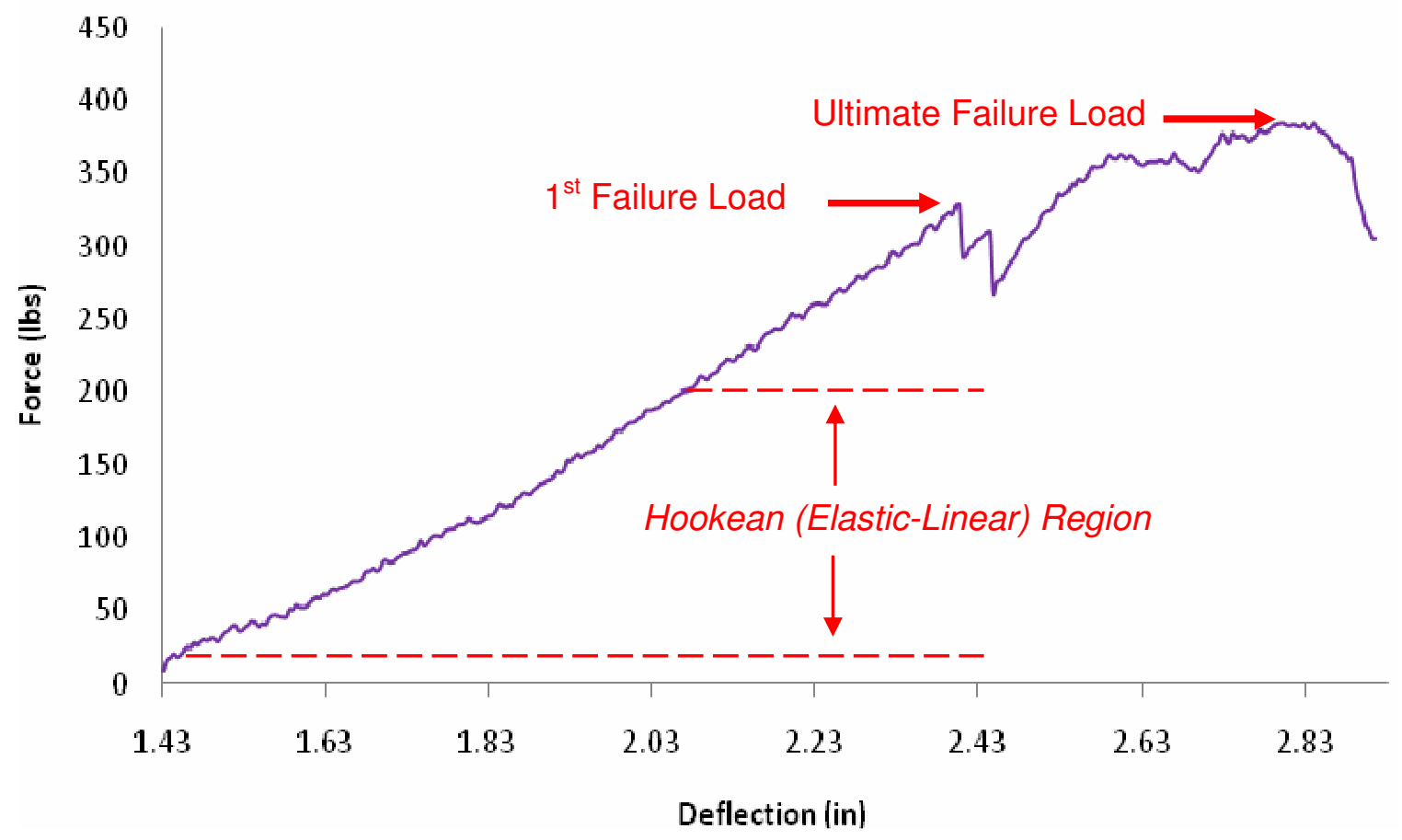

Figure 6.29: Flexural Response for Laminate $L_{40}$

The graph above shows a force-deflection linear curve relationship for laminate $\mathrm{L}_{40}$ which used flexural data from the Flex Test software program. The $1^{\text {st }}$ bending failure or drop load was found to be $320 \mathrm{lbf}$ at a displacement of $2.39 \mathrm{in}$. The maximum axial load was 385.19 lbs with a corresponding mid-span deflection of 2.84 in. The Hookean region was considered between $10 \mathrm{lbf}$ and $200 \mathrm{lbf}$ with a flexural chord and shear modulus of 37,102 and $51.57 \mathrm{ksi}$, respectively.

Fig. 6.30 shows the bending test result for laminate $\mathrm{L}_{40}$. The test specimen $\mathrm{L}_{40}$ experienced tension/compression failure at support region due to the concentrated-uniform bending load exerted by the loading nose. It did not have symmetric failure since the test specimen was probably not aligned correctly inside the support fixture. 


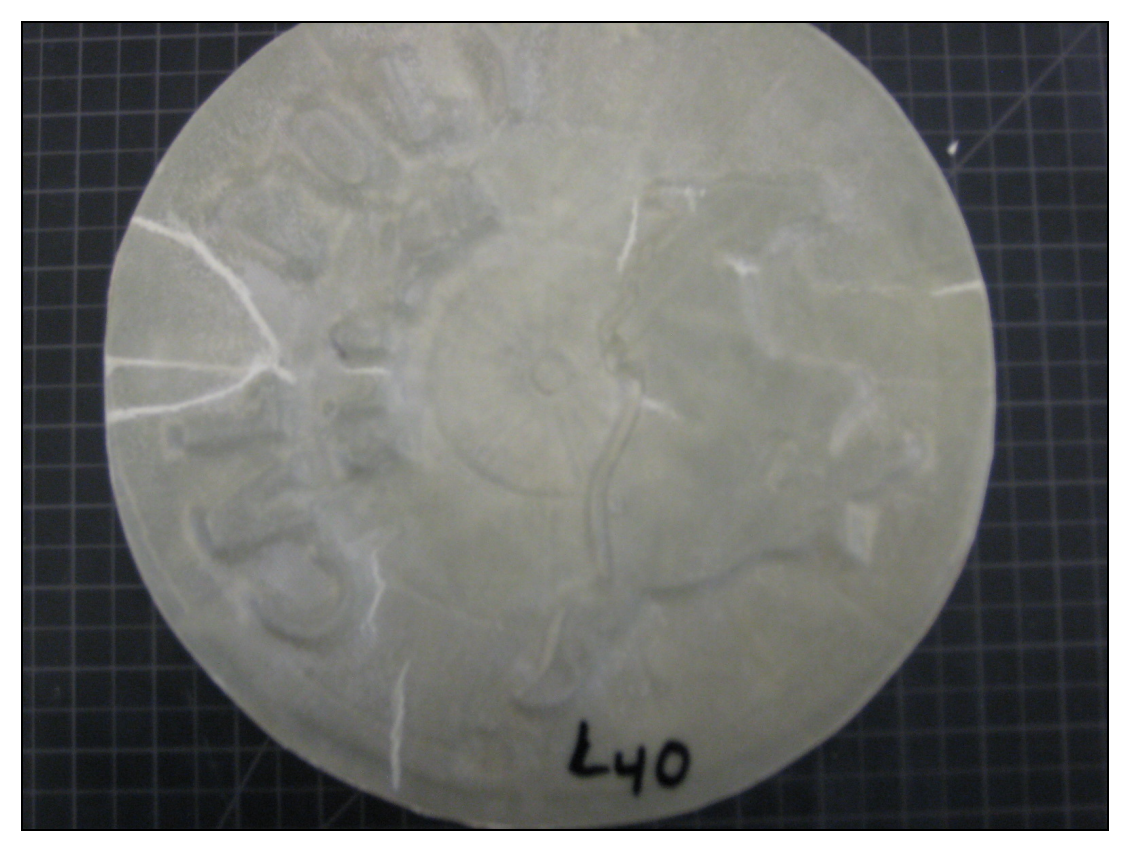

Figure 6.30: Failure at Several Support Regions for Laminate $L_{40}$

Fig. 6.31 shows the force-displacement curve of specimen $\mathrm{HD}_{30}$ with a fiber volume fraction of 47 percent before facture.

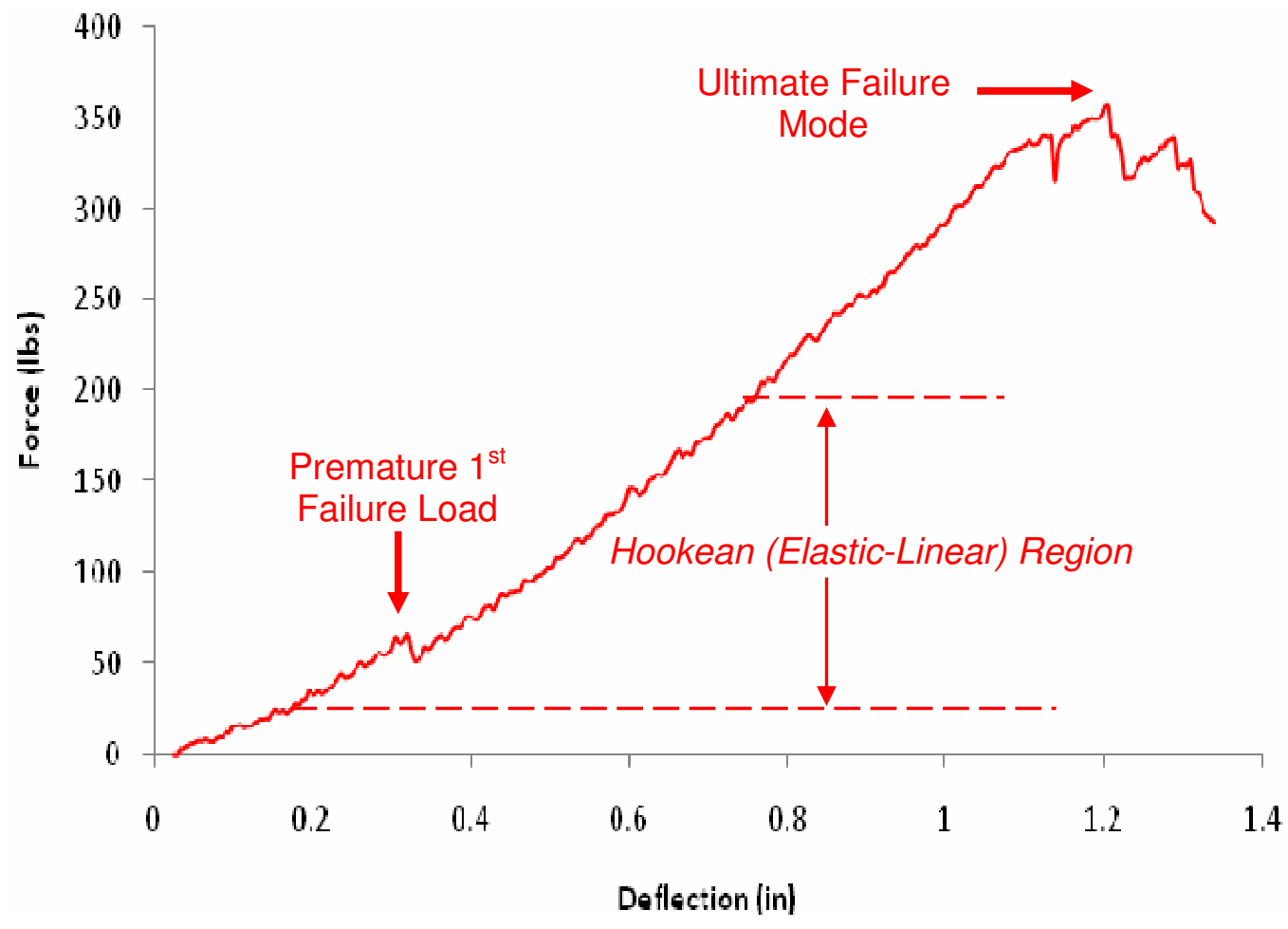

Figure 6.31: Flexural Response for Laminate $\mathrm{HD}_{30}$ 
The graph above shows a force-deflection linear curve relationship for laminate $\mathrm{HD}_{30}$ which used flexural data from the Flex Test software program. The $1^{\text {st }}$ failure load was found to be $45.92 \mathrm{lbf}$ at a displacement of 0.305 in. The maximum axial load was $357.06 \mathrm{lbf}$ with a corresponding mid-span deflection of 1.21 in. The Hookean region was considered between 35 lbf and $200 \mathrm{lbf}$ with a flexural chord and rigidity modulus of 41,642 and $61.63 \mathrm{ksi}$, respectively.

Fig. 6.32 shows the bending test result for laminate $\mathrm{HD}_{30}$. The laminate's low $1^{\text {st }}$ failure load value was probably due to premature compression failure occurring at the top surface region, as seen in Fig. 6.31. This type of failure might be as result of ply-level buckling which was later preceded by delamination of the outer ply. The test specimen was most likely not aligned properly with inside the support fixture correctly or the loading nose.

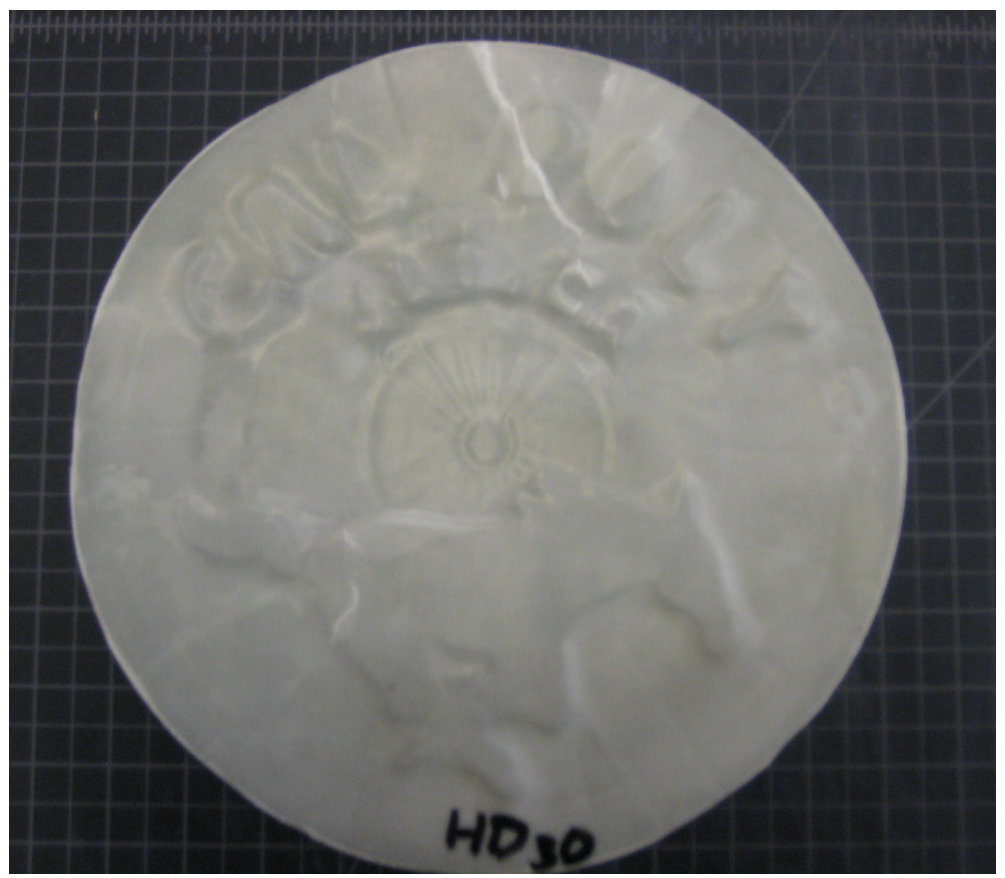

Figure 6.32: Failure Result for Laminate $\mathrm{HD}_{30}$ 


\subsubsection{Comparison of Bending Test Results}

As seen in Figure 6.33, both test specimens $\mathrm{L}_{20}$ and $\mathrm{L}_{30}$ followed a similar trend, whereas, laminate $\mathrm{L}_{40}$ was considered the outlier for the limestone filler test specimens. The highest load and deflection for $1^{\text {st }}$ failure occurred in specimen $\mathrm{L}_{40}$. However the plate that exhibited the highest ultimate load for the limestone filler laminates was specimen $\mathrm{L}_{30}$. The difference in maximum load between plates $\mathrm{L}_{30}$ and $\mathrm{L}_{20}$ was $21 \mathrm{lbf}$; however, the displacement was different between plates $\mathrm{L}_{30}$ and $\mathrm{L}_{20}$ with a difference of 0.14 in. Figure below shows the force versus deflection comparison for the laminated plates with limestone filler.

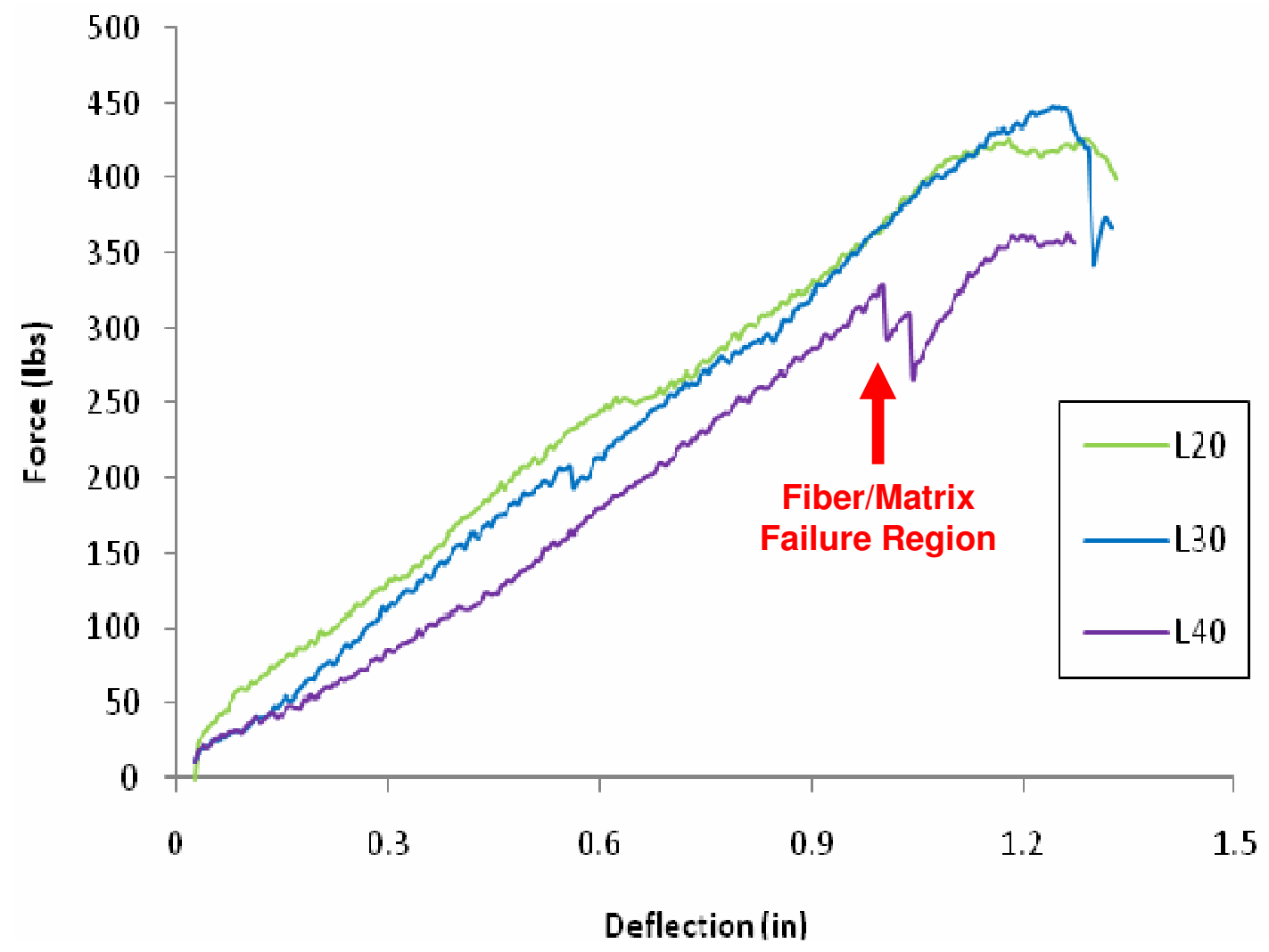

Figure 6.33: Flexural Response Comparison for Laminates with Limestone Filler

Although plate $\mathrm{L}_{40}$ had the highest $1^{\text {st }}$ failure load, it had the worst performance since it had the lowest ultimate load and flexural modulus. Normally increasing the thickness of a 
laminate would increase the indentation limit. In the case of plate $\mathrm{L}_{40}$, the composite was made with more filler which made it more brittle and susceptible to experience fracture at a lower indentation limit. Plot also shows that the plate $\mathrm{L}_{40}$ experienced a large decrease in the sudden drop after the $1^{\text {st }}$ failure load, thus corresponding to fiber/matrix failure. The laminated plate $\mathrm{L}_{40}$ overall had the lowest stiffness and strength properties out of the three limestone filler laminates.

Table 6.13 shows material property summary for all laminated fiberglass/filler plates.

Table 6.13: Material Properties for All Plates under Bending Loads

\begin{tabular}{|c|c|c|}
\hline Specimen & Flexural Modulus (ksi) & Flexural Rigidity (ksi) \\
\hline $\mathrm{L}_{20}$ & 43.7 & 17.9 \\
\hline $\mathrm{L}_{30}$ & 40.9 & 16.8 \\
\hline $\mathrm{L}_{40}$ & 37.1 & 15.2 \\
\hline $\mathrm{HD}_{30}$ & 41.6 & 17.1 \\
\hline $\mathrm{L}_{\mathrm{B} 0}$ & 49.9 & 20.4. \\
\hline
\end{tabular}

As predicted, laminate $\mathrm{L}_{\mathrm{B} 0}$ had the highest overall flexural chord/shear modulus since it had no filler, whereas laminate $\mathrm{L}_{40}$ had the lowest flexural/shear modulus since it had the most filler content. Although test specimens $\mathrm{L}_{30}$ and $\mathrm{HD}_{30}$ had very similar material properties results, specimen $\mathrm{HD}_{30}$ had a greater difference of $1.7 \%$. 
Table 6.14: Summary of Maximum Deflections due to Bending Loads

\begin{tabular}{|c|c|c|c|c|}
\hline Specimen & $1^{\mathrm{ST}}$ Failure Load (Ibf) & Deflection (in) & Max. Failure Load (lbf) & Deflection (in) \\
\hline $\mathrm{L}_{20}$ & 247 & 2.28 & 428 & 2.75 \\
\hline $\mathrm{L}_{30}$ & 200 & 2.18 & 449 & 2.89 \\
\hline $\mathrm{L}_{40}$ & 320 & 2.39 & 385 & 2.84 \\
\hline $\mathrm{HD}_{30}$ & 46 & 0.305 & 357 & 1.21 \\
\hline $\mathrm{L}_{\mathrm{B} 0}$ & 257 & 2.25 & 488 & 2.75 \\
\hline
\end{tabular}

All test specimens experienced a common flexural trend as expected. The experiment analysis showed all laminated plates experienced first damage mode which indicated delamination was initiated by fiber/matrix cracks. This caused the stiffness of the laminates to decrease when the contact force was increased to an ultimate load. Some delaminations were initiated by fiber/matrix cracks located at the opposites sides of test specimen's surface was observed in all laminates. Some tests experienced different delaminations on different locations of the fiberglass laminates which were initiated by fiber/matrix cracks which propagated with increasing loading and extended fully throughout the entire plate.

In addition, test specimen $\mathrm{HD}_{30}$ had worst performance since it experienced premature $1^{\text {st }}$ failure loading. The contact force applied by the loading nose increased until the matrix cracks induced delaminations which created a premature sudden drop; hence, decreasing the overall stiffness of the plate and reducing the load required for a higher maximum failure. This may be as a result of plate $\mathrm{HD}_{30}$ was not fabricated properly during the wet layup/curing process or the indenter was not aligned properly during the static bending test. Consequently, plate $\mathrm{HD}_{30}$ resulted as the outlier of all laminated test specimens since it had the lowest $1^{\text {st }}$ failure load and deflection values. 


\subsection{Dynamic Analysis}

For the dynamic analysis all five fiberglass laminates with no delamination were tested on the MB Electronics Shaker using piezoceramic strain gages and the LabVIEW software to collect the data and record the results. The shaker was used to excite the structure according to its amplified input signal. The excitation and response signals are then compared in the frequency domain (using LabVIEW) to reveal how the object moves or vibrates at modal frequencies. These frequencies help to find the sine sweep and random frequency vibration profiles in order to determine Frequency Response Function (FRF) and then characterize the system.

\subsubsection{Modal Analysis}

Shaker frequency analysis, or more accurately experimental modal analysis, determines the vibration mode shapes and corresponding natural frequencies of a vibrating system. It studies the dynamic properties or "structural characteristics" of a mechanical structure under excitation by an input or forced load; hence, measuring and analyzing the dynamic response of structures by resonant frequency, mode shapes, and damping. The resonant frequency is the frequency at which any excitation produces an exaggerated response. This is essential to understand since excitation close to a structure's resonant frequency will often produce adverse effects. Mode shapes describe the expected curvature (or displacement) of a surface vibrating at a particular mode and damping has to do with dissipating energy by eventually bringing a vibrating system to rest.

For the simplicity of the dynamic analysis, the vibration system followed a single degree of freedom (SDOF) model since it was assumed the mass only moved vertically. In addition, the shaker created a forced vibration with damping due to its movement restriction of the clamp; hence, producing a forced frequency and vibration modes. The vibration modes were graphed 
using the LabVIEW program. Fiberglass specimens were subjected to a frequency range from 0 to $500 \mathrm{Hertz}$ in order to capture the first modes of the natural frequencies. Fig. 6.34 shows the frequency response for the laminate $\mathrm{L}_{20}$.

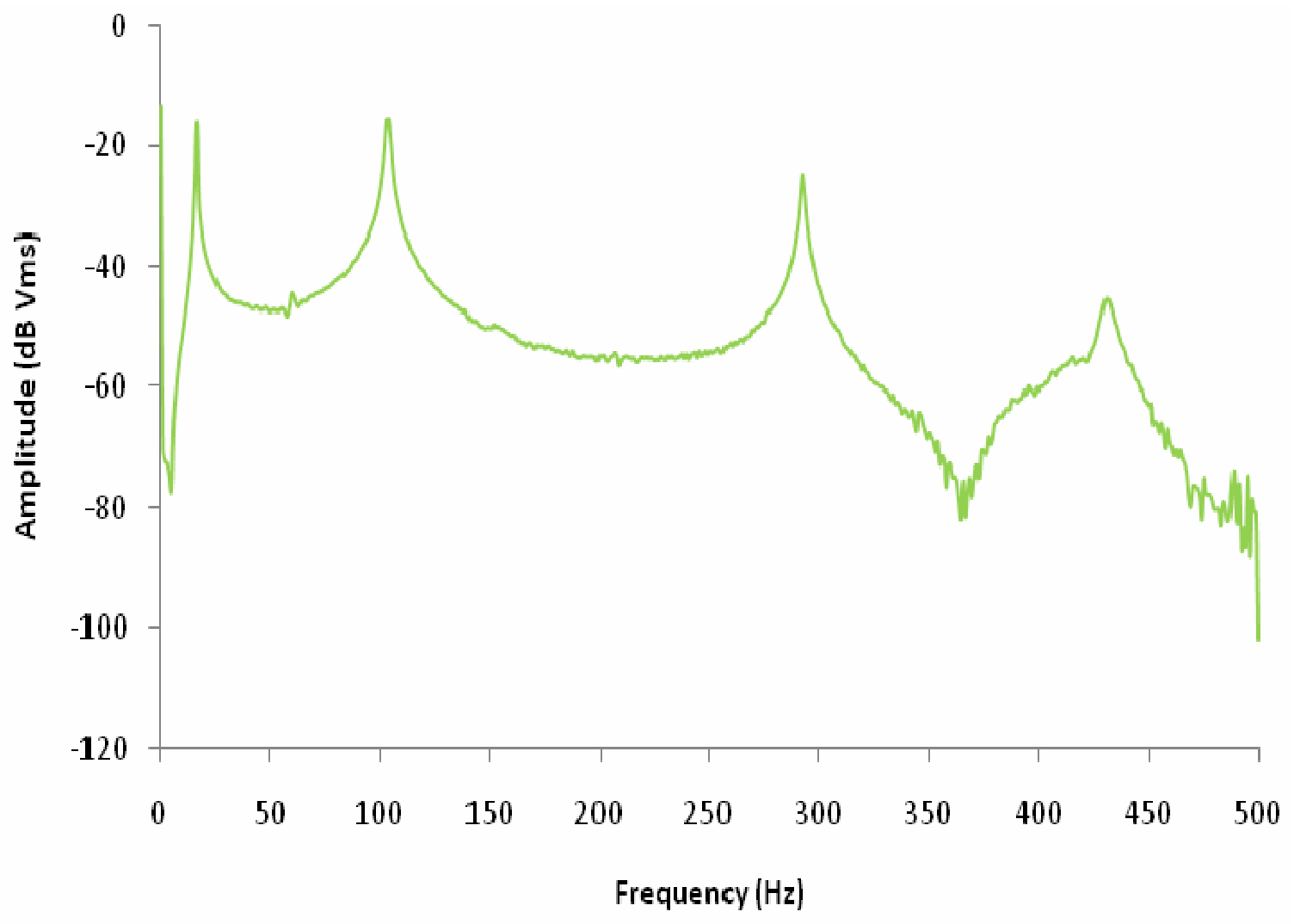

Figure 6.34: Modal Analysis Results of Laminate $L_{20}$

In a lightly damped system when the forcing frequency nears the natural frequency the amplitude of the vibration can get extremely high. This phenomenon is called resonance (subsequently the natural frequency of a system or often referred to as the resonant frequency). For the laminate $\mathrm{L}_{20}$, the resonance frequency was measured at $103.46 \mathrm{~Hz}$ at amplitude of -15.74 dB Vms. As seen in graph, both first and second modes had very similar amplitudes of -15.98 and -15.74 dB Vms, respectively, but with very different natural frequencies of 17.57 and 103.46 
Hertz. The fourth mode with the highest frequency of $429.44 \mathrm{~Hz}$ had amplitude of $-46.74 \mathrm{~dB}$ Vms. Table 6.5 shows the dynamic response results for $\mathrm{L}_{20}$ with no delamination.

Table 6.5: Natural Frequency and Amplitude Response for Composite $L_{20}$.

\begin{tabular}{|c|c|c|}
\hline Bending Mode & Frequency (Hertz) & Amplitude (dB Vms) \\
\hline $1^{\text {st }}$ & 17.57 & -15.98 \\
\hline $2^{\text {nd }}$ & 103.46 & -15.74 \\
\hline $3^{\text {rd }}$ & 291.82 & -24.67 \\
\hline $4^{\text {th }}$ & 429.44 & -46.74 \\
\hline
\end{tabular}

Fig. 6.35 shows the frequency response for the laminate $\mathrm{L}_{30}$ with no delamination.

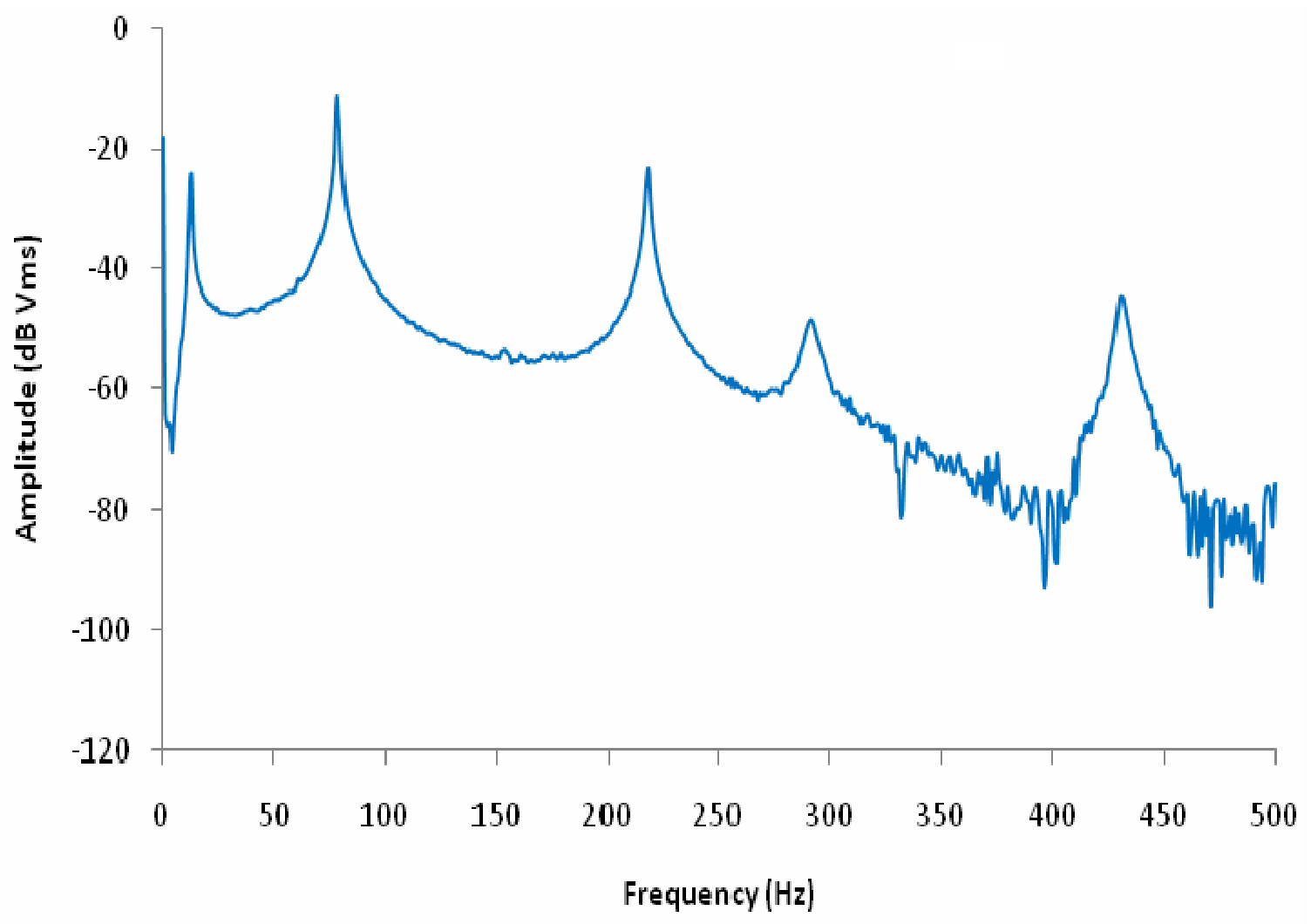

Figure 6.35: Modal Analysis Results of Laminate $L_{30}$

For the laminate $\mathrm{L}_{30}$, the resonance frequency was measured at $429.54 \mathrm{~Hz}$ with amplitude of $-46.80 \mathrm{~dB} \mathrm{Vms}$. As seen in graph, both first and third modes had very similar amplitudes of - 
24.13 and $-23.23 \mathrm{~dB}$ Vms, respectively, but with very different natural frequencies of 13.66 and 218.62 Hertz. The fourth mode had the highest frequency of 429.54 Hertz at amplitude of -46.80 dB Vms. Table 6.16 shows the dynamic response results for $\mathrm{L}_{30}$ with no delamination.

Table 6.16: Natural Frequency and Amplitude Response for Composite $L_{30}$.

\begin{tabular}{|c|c|c|}
\hline Bending Mode & Frequency (Hertz) & Amplitude (dB Vms) \\
\hline $1^{\text {st }}$ & 13.66 & -24.13 \\
\hline $2^{\text {nd }}$ & 79.06 & -11.57 \\
\hline $3^{\text {rd }}$ & 218.62 & -23.23 \\
\hline $4^{\text {th }}$ & 429.54 & -46.80 \\
\hline
\end{tabular}

Fig. 6.36 shows the frequency response for the laminate $\mathrm{L}_{40}$ with no delamination.

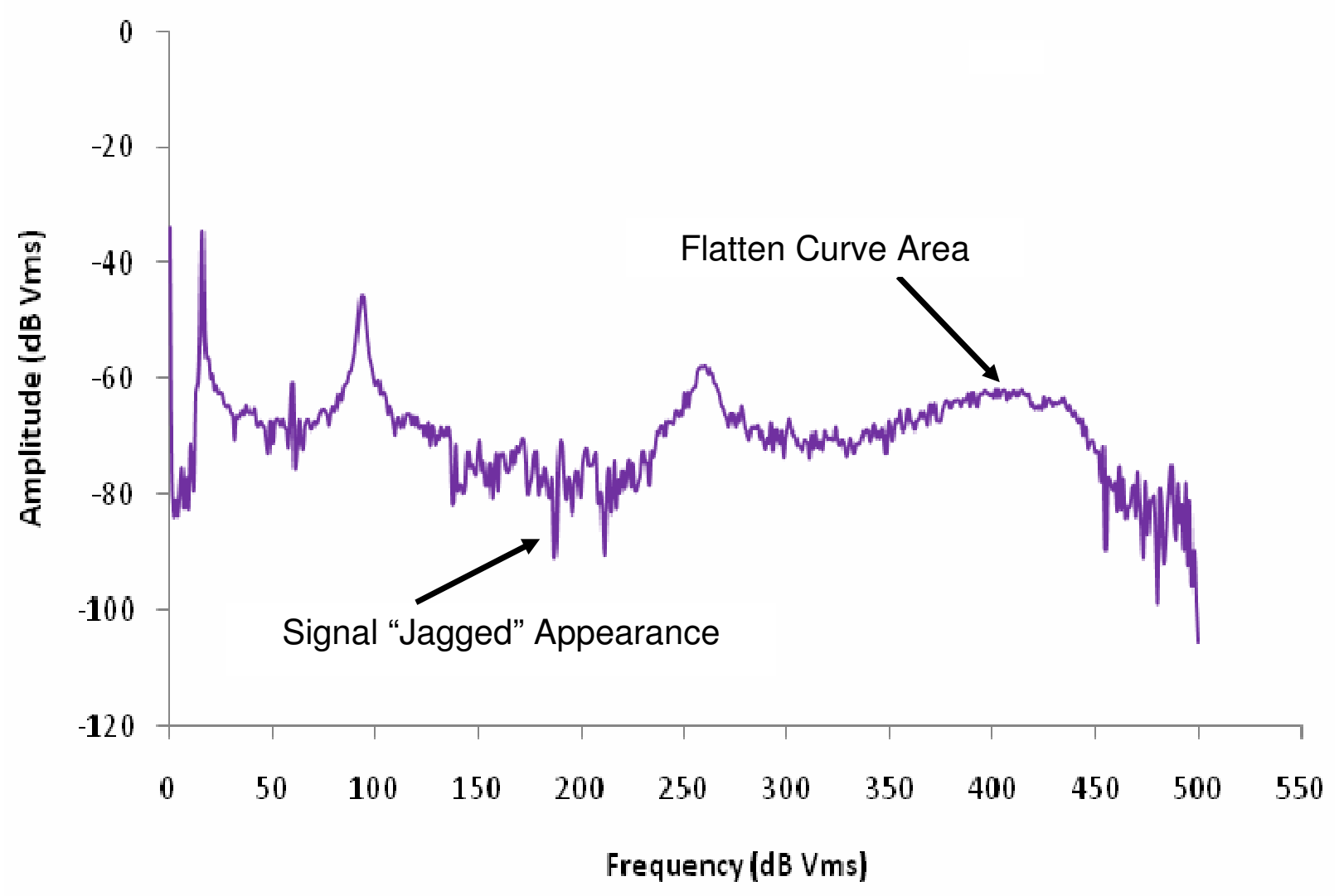

Figure 6.36: Modal Analysis Results of Laminate $L_{40}$ 
For the laminate $\mathrm{L}_{40}$, the resonance frequency was measured at $16.59 \mathrm{~Hz}$. As seen in graph, both first and second modes had very similar amplitudes of -52.94 and $-45.63 \mathrm{~dB}$ Vms, respectively, but with very different natural frequencies of 16.59 and $93.69 \mathrm{~Hz}$. The fourth mode had the highest frequency of $418.70 \mathrm{~Hz}$ at amplitude of $-64.66 \mathrm{~dB}$ Vms. It was also noticed that specimen $\mathrm{L}_{40}$ had a flatten curve area in the fourth mode region which might suggest possible unwanted damping or other effects that may underestimate the amplitudes. Also, the jagged appearance of the frequency signal output was probably due to electrical noise pollution introduced in the system during modal analysis. Table 6.17 shows the dynamic response results for $\mathrm{L}_{40}$ with no delamination.

\section{Table 6.17: Natural Frequency and Amplitude Response for Composite $L_{40}$}

\begin{tabular}{|c|c|c|}
\hline Bending Mode & Frequency (Hertz) & Amplitude (dB Vms) \\
\hline $1^{\text {st }}$ & 16.59 & -52.94 \\
\hline $2^{\text {nd }}$ & 93.69 & -45.63 \\
\hline $3^{\text {rd }}$ & 261.58 & -58.71 \\
\hline $4^{\text {th }}$ & 418.70 & -64.66 \\
\hline
\end{tabular}

Fig. 6.37 shows the frequency response comparison for the all test specimens with only limestone filler and no delamination. 


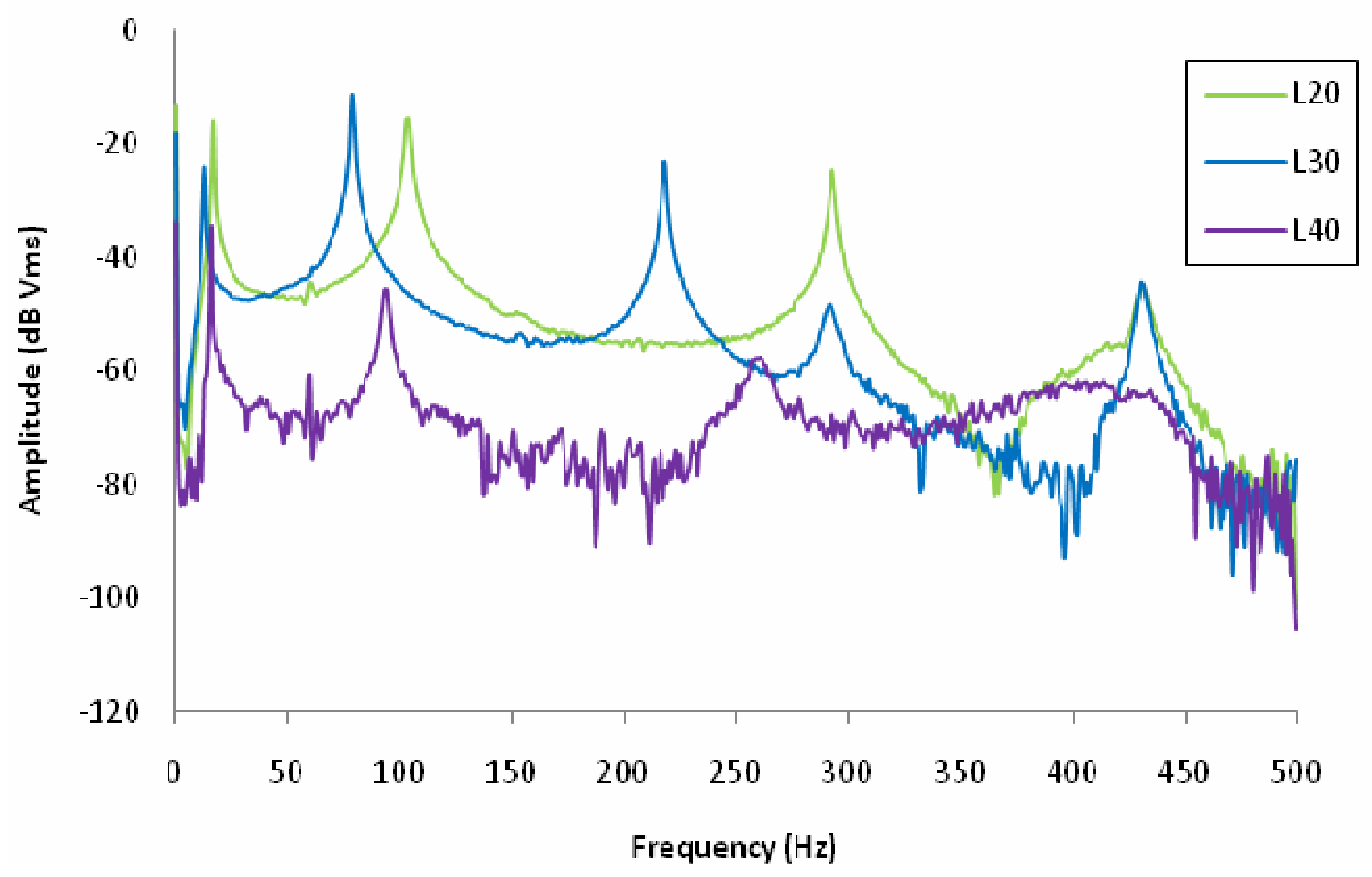

Figure 6.37: Modal Analysis Comparison of Laminates with Limestone Filler

As seen in graph, all test specimens had similar trend in mode shape, amplitude, and natural frequency response. The lowest discrepancy between frequencies of different limestone filler specimens occurred in the fourth mode frequencies with a value of 0.2 , whereas, the third modes had the highest frequency difference of $73 \mathrm{~Hz}$. The high frequency inconsistency was due to specimen $\mathrm{L}_{20}$ 's low frequency of $218.62 \mathrm{~Hz}$. The lowest amplitude difference, $18 \mathrm{~dB} \mathrm{Vms}$, was found in mode 4 . Consequently, modes 1,2, and 3 all had similar high amplitude differences of 37, 34, and $36 \mathrm{~dB}$ Vms, respectively. Specimen $\mathrm{L}_{40}$ had the highest amplitude difference mainly due to the flattened curve in the fourth mode, thus contributing to the lowest amplitude and erroneous data results. Table 6.18 shows the dynamic response results for $\mathrm{L}_{40}$ with no delamination. 
Table 6.18: Frequency Extraction Analysis Comparison with Limestone Filler

\begin{tabular}{|c|c|c|c|c|}
\hline \multicolumn{5}{|c|}{ Natural Frequency $(\mathrm{Hz})$} \\
\hline Specimen & Mode 1 & Mode 2 & Mode 3 & Mode 4 \\
\hline $\mathrm{L}_{20}$ & 17.57 & 103.46 & 291.82 & 429.44 \\
\hline $\mathrm{L}_{30}$ & 13.66 & 79.06 & 218.62 & 429.54 \\
\hline $\mathrm{L}_{40}$ & 16.59 & 93.69 & 261.58 & 429.34 \\
\hline \multicolumn{5}{|c|}{ Amplitude (dB Vms) } \\
\hline Specimen & Mode 1 & Mode 2 & Mode 3 & Mode 4 \\
\hline $\mathrm{L}_{20}$ & -15.98 & -15.74 & -24.67 & -46.74 \\
\hline $\mathrm{L}_{30}$ & -24.13 & -11.57 & -23.23 & -46.80 \\
\hline $\mathrm{L}_{40}$ & -52.94 & -45.63 & -58.71 & -64.71 \\
\hline
\end{tabular}

Fig. 6.38 shows the frequency response for the laminate $\mathrm{HD}_{30}$ with no delamination.

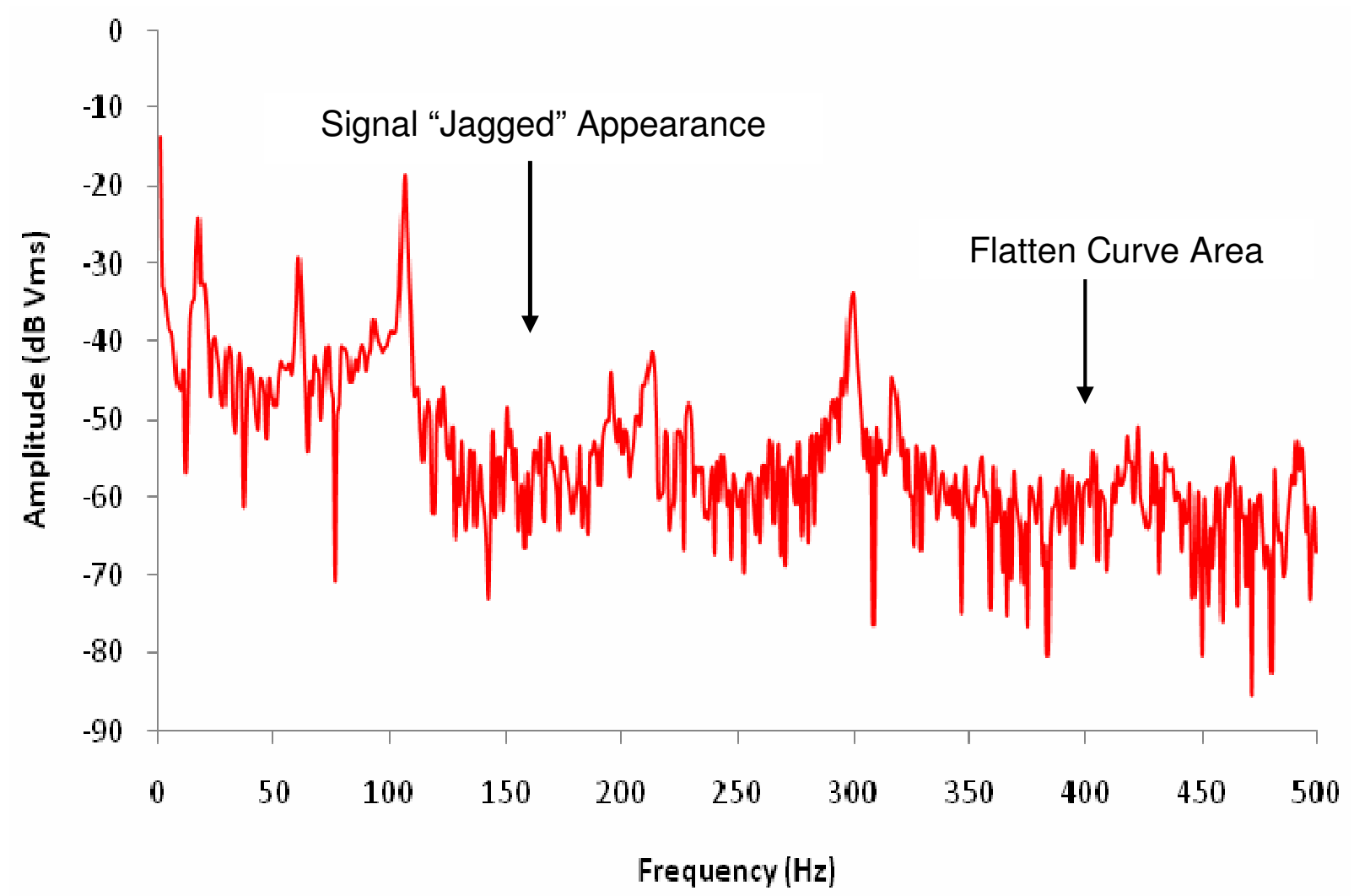

Figure 6.38: Modal Analysis Results of Laminate $\mathrm{HD}_{30}$ 
For the laminate $\mathrm{HD}_{30}$, the resonance frequency was measured at $106.09 \mathrm{~Hz}$. As seen in graph, the first mode had the lowest natural frequency of 17.01 Hertz with amplitude of -24.26 $\mathrm{dB}$ Vms. The fourth mode had the highest frequency of 418.10 Hertz with amplitude of -51.99 $\mathrm{dB}$ Vms. As observed in the graph above, specimen $\mathrm{HD}_{30}$ did not follow the same trend and mode shape of the other specimens. The peaks of the modes were more narrowed and closer together, thus giving a "jagged appearance" to the generated output frequency of the specimen. This was probably due to electrical noise pollution introduced in the system during modal testing. In addition, mode 4 was also more difficult to distinguish due to the flatten curve of the signal response. Table 6.19 shows the dynamic response results for $\mathrm{HD}_{30}$ with no delamination.

Table 6.19: Natural Frequency and Amplitude Response for Composite $\mathrm{HD}_{30}$

\begin{tabular}{|c|c|c|}
\hline Bending Mode & Frequency (Hertz) & Amplitude (dB Vms) \\
\hline $1^{\text {st }}$ & 17.01 & -24.26 \\
\hline $2^{\text {nd }}$ & 106.09 & -18.53 \\
\hline $3^{\text {rd }}$ & 298.18 & -37.33 \\
\hline $4^{\text {th }}$ & 418.10 & -51.99 \\
\hline
\end{tabular}

Fig. 6.39 shows the frequency response for the laminate $\mathrm{HD}_{30}$ and $\mathrm{L}_{30}$ with no delamination. 


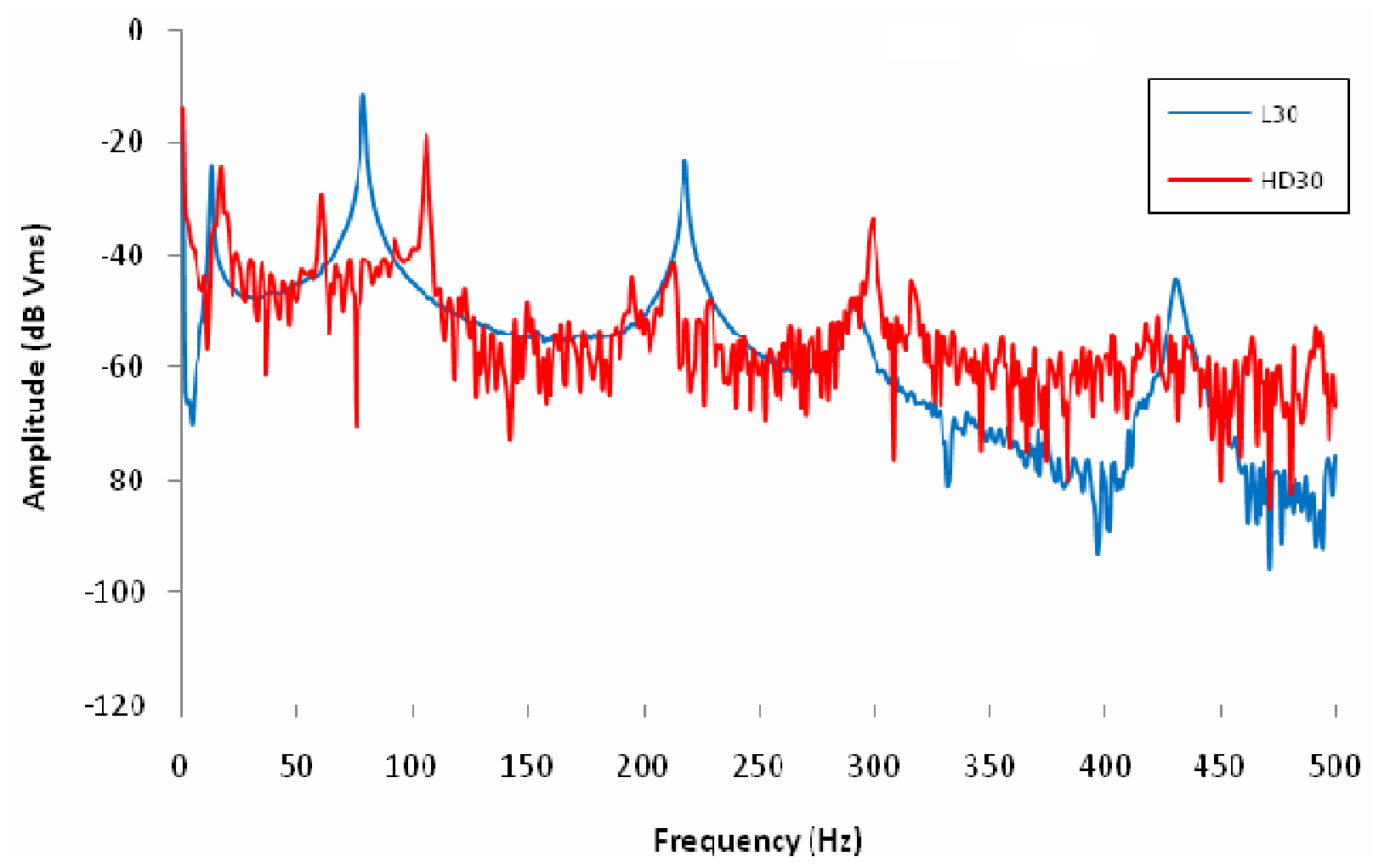

Figure 6.39: Modal Analysis Comparison of Laminates $H_{30}$ and $L_{30}$

The resonance frequency for laminates $\mathrm{HD}_{30}$ and $\mathrm{L}_{30}$ in mode 1 was 17.01 and $13.66 \mathrm{~Hz}$, respectively. Both specimens also had very similar amplitudes of -24.26 and $-24.13 \mathrm{~dB}$ Vms in mode 1, respectively. As seen in graph, the second mode had the largest natural frequency difference between specimen $\mathrm{HD}_{30}$ and $\mathrm{L}_{30}$ with a frequency of 106.09 and $79.06 \mathrm{~Hz}$, respectively. In contrast to specimen $\mathrm{L}_{30}$, the signal response of specimen $\mathrm{HD}_{30}$ had a very jagged appearance and flatten curve located in the fourth mode which was due to electronic noise introduced in the system during dynamic testing. The electronic noise could be removed by increasing the amplitude

Table 6.20 shows the dynamic response comparison for $\mathrm{HD}_{30}$ and $\mathrm{L}_{30}$ with no delamination. 
Table 6.20: Modal Analysis Comparison with Limestone Filler

\begin{tabular}{|c|c|c|c|c|}
\hline \multicolumn{5}{|c|}{ Natural Frequency $(\mathrm{Hz})$} \\
\hline Specimen & Mode 1 & Mode 2 & Mode 3 & Mode 4 \\
\hline $\mathrm{HD}_{30}$ & 17.01 & 106.09 & 298.18 & 418.10 \\
\hline $\mathrm{L}_{30}$ & 13.66 & 79.06 & 218.62 & 429.54 \\
\hline \multicolumn{5}{|c|}{ Amplitude (dB Vms) } \\
\hline Specimen & Mode 1 & Mode 2 & Mode 3 & Mode 4 \\
\hline $\mathrm{HD}_{30}$ & -24.26 & -18.53 & -37.33 & -51.99 \\
\hline $\mathrm{L}_{30}$ & -24.13 & -11.57 & -23.23 & -46.80 \\
\hline
\end{tabular}

Figure 6.40 shows the frequency response for the laminate $\mathrm{L}_{\mathrm{B} 0}$ with no delamination.

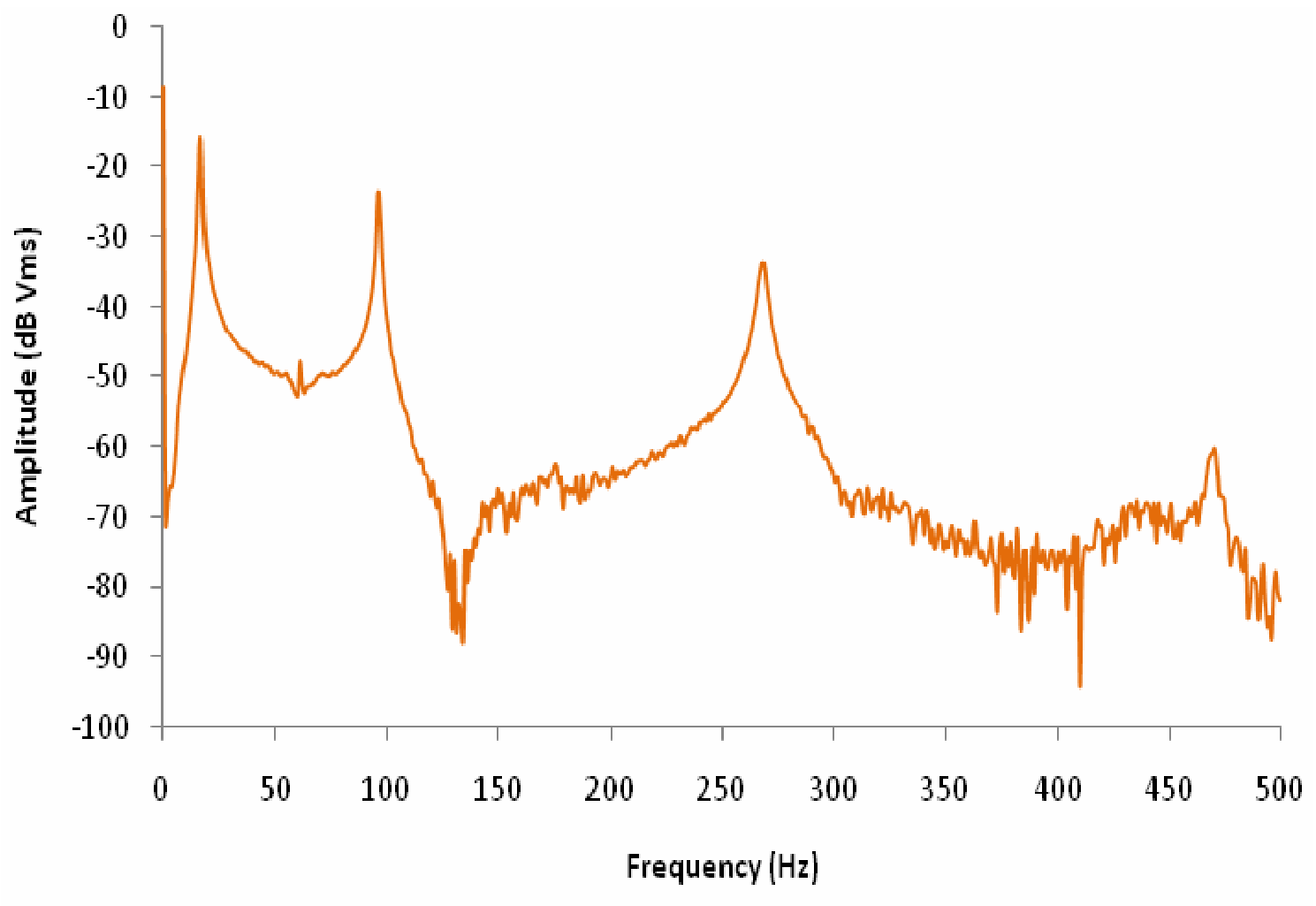

Figure 6.40: Modal Analysis Results of Laminate $L_{B 0}$

For the laminate $\mathrm{L}_{\mathrm{B} 0}$, as seen in above, the first mode had the lowest natural frequency of 17.57 Hertz with amplitude of $-15.76 \mathrm{~dB}$ Vms. The fourth mode had the highest frequency of 467.51 Hertz with amplitude of -61.79 dB Vms. 
Table 6.21 shows the dynamic response results for $\mathrm{L}_{\mathrm{B} 0}$ with no delamination.

Table 6.21: Natural Frequency and Amplitude Response for Composite $L_{B 0}$

\begin{tabular}{|c|c|c|}
\hline Bending Mode & Frequency (Hertz) & Amplitude (dB Vms) \\
\hline $1^{\text {st }}$ & 17.57 & -15.76 \\
\hline $2^{\text {nd }}$ & 96.62 & -23.61 \\
\hline $3^{\text {rd }}$ & 267.42 & -34.54 \\
\hline $4^{\text {th }}$ & 467.51 & -61.79 \\
\hline
\end{tabular}

Figure 6.41 shows the amplitude and frequency response comparison for all test specimens.

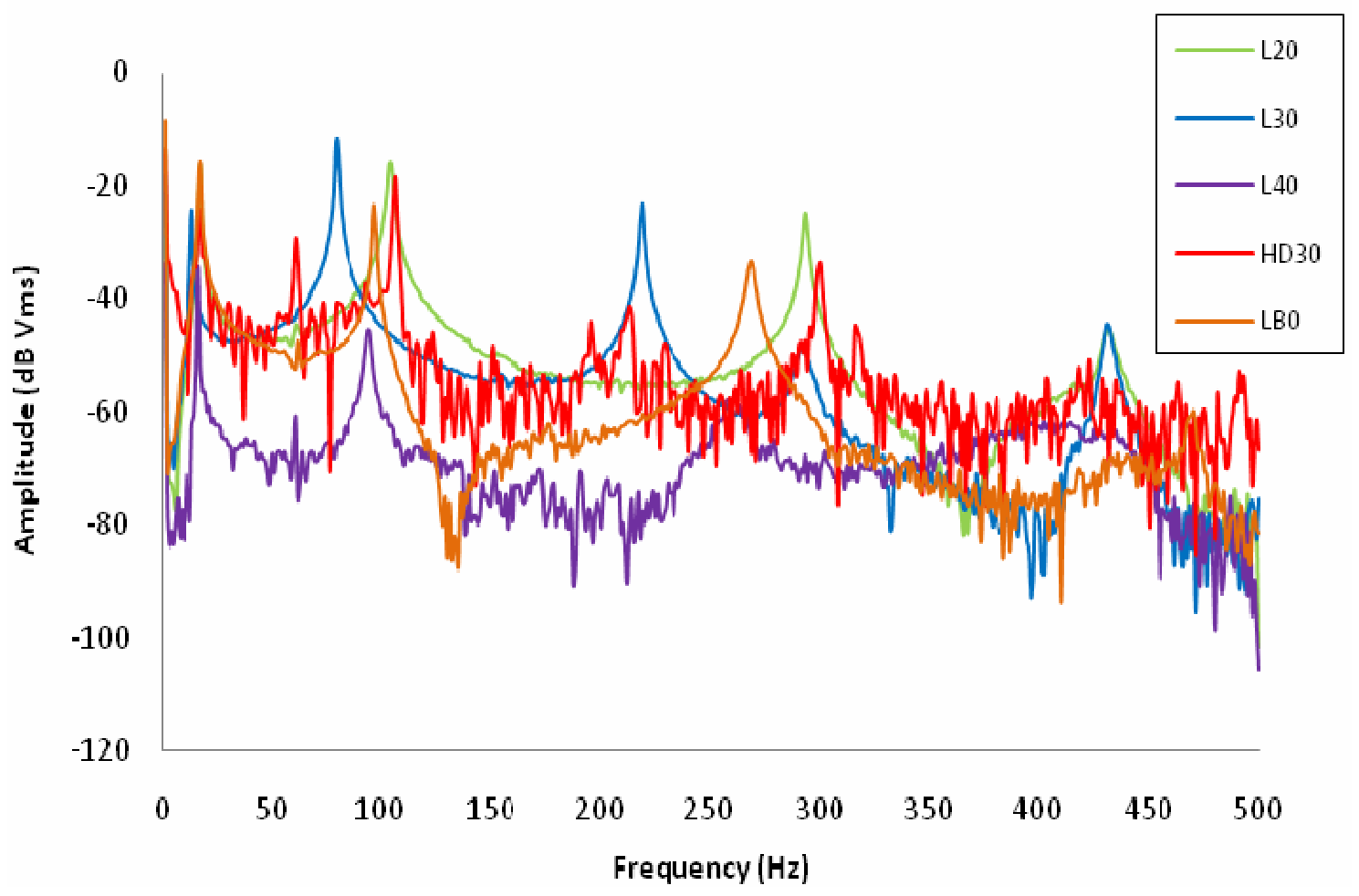

Figure 6.41: Frequency Analysis Summary of All Laminated Beams

The frequency extraction analysis results showed an expected trend in amplitude and frequency response. Each bending mode was entirely independent of all other modes. Thus all modes had different frequencies (with lower modes having lower frequencies) and different mode shapes (with lower modes having greater amplitude). In addition, since the lower modes 
tend to vibrate with greater amplitude, they were of major concern since they create the most displacement and stress in a structure.

The natural frequency of a system is dependent only on the stiffness of the structure and the mass which participates with the structure (including self-weight). This was seen in the graph, where specimen $\mathrm{H}_{30}$ had the highest elastic modulus value and not dependent on the load function. Some laminates were difficult to detect what frequency the mode actually occurred at since the measurement output for higher frequency had flatter curves. This was basically true for specimen $\mathrm{L}_{40}$ and $\mathrm{HD}_{30}$ which experienced flatten curves in the fourth mode. They also had a jagged shaped frequency response (due to electrical noise pollution) compared to the rest of test specimens. It was also very difficult to determine which mode had the greatest amplitude from the modal vibration response using LabVIEW since the generated plot did not identify clearly the amplitudes. The laminates were more susceptible to torsional effects at higher frequencies, which may contribute to the lowering of the modal frequency detected. In addition, the mass concentrations of the strain gauge and on how the wires were constrained may also affect the results obtained from the modal analysis by creating torsional effects observed at the higher frequencies.

Table 6.22 shows the modal response summary for all test specimens with no delamination. 
Table 6.22: Different Bending Loading Comparison for Laminated Beams

\begin{tabular}{|c|c|c|c|c|}
\hline \multicolumn{5}{|c|}{ Natural Frequency (Hz) } \\
\hline Specimen & Mode 1 & Mode 2 & Mode 3 & Mode 4 \\
\hline $\mathrm{L}_{20}$ & 17.57 & 103.46 & 291.82 & 429.44 \\
\hline $\mathrm{L}_{30}$ & 13.66 & 79.06 & 218.62 & 429.54 \\
\hline $\mathrm{L}_{40}$ & 16.59 & 93.69 & 261.58 & 429.34 \\
\hline $\mathrm{HD}_{30}$ & 17.01 & 106.09 & 298.18 & 418.10 \\
\hline $\mathrm{L}_{\mathrm{B} 0}$ & 17.57 & 96.62 & 267.42 & 467.51 \\
\hline \multicolumn{5}{|c|}{ Amplitude (dB Vms) } \\
\hline Specimen & Mode 1 & Mode 2 & Mode 3 & Mode 4 \\
\hline $\mathrm{L}_{20}$ & -15.98 & -15.74 & -24.67 & -46.74 \\
\hline $\mathrm{L}_{30}$ & -24.13 & -11.57 & -23.23 & -46.80 \\
\hline $\mathrm{L}_{40}$ & -52.94 & -45.63 & -58.71 & -64.71 \\
\hline $\mathrm{HD}_{30}$ & -24.26 & -18.53 & -37.33 & -51.99 \\
\hline $\mathrm{L}_{\mathrm{B} 0}$ & -15.76 & -23.61 & -34.54 & -61.79 \\
\hline
\end{tabular}

\subsubsection{Time Response}

The time response showed the amplitude as a function of time. The amplitude has units of volts because the piezoelectric ceramic strain sensor outputs voltage to the computer. The LabVIEW program then converted the voltage inputs to amplitude. In order to analyze the information the data had to be normalized. During the experiment the force applied was kept constant but the time the data was captured at differed slightly because it was done manually. The data was normalized so that the data could be compared and analyzed correctly, therefore, the time response's time interval of 1 second ranged from -1.5 to 1.5 volts. All fiberglass laminates were tested to determine their time response. 


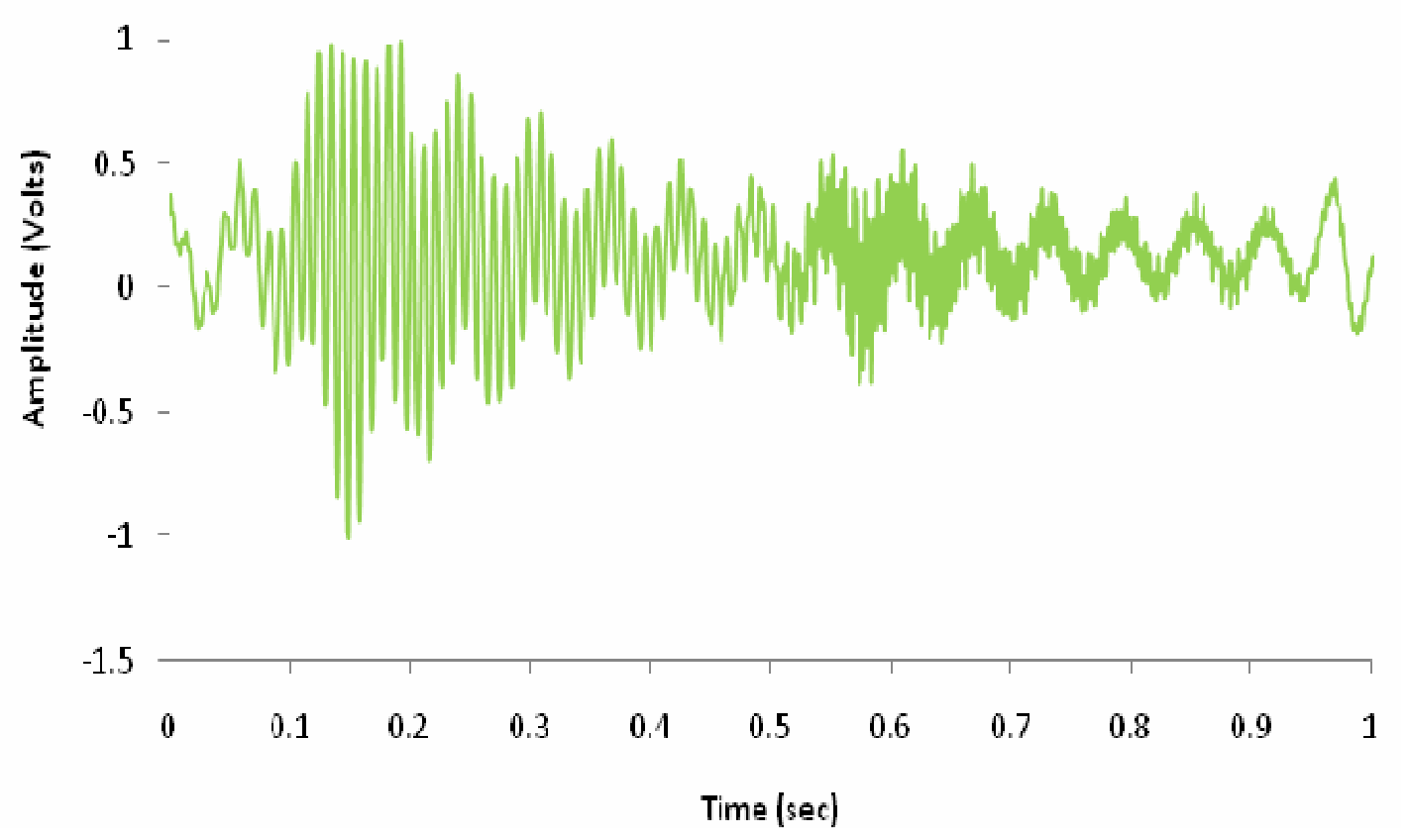

Figure 6.42: Time Response of Laminate $L_{20}$

According to the graph, the amplitude was 1 volt at 0.1 seconds. The graph did not show the settling time which is the time it took for laminate to damp out. This force vibration system was damped due to the decaying oscillatory motion of the natural frequency response. The graph showed a cosine signal with a lot of electronic noise pollution. Fig. 6.43 shows the time response of specimen $\mathrm{L}_{30}$ with no delamination. 


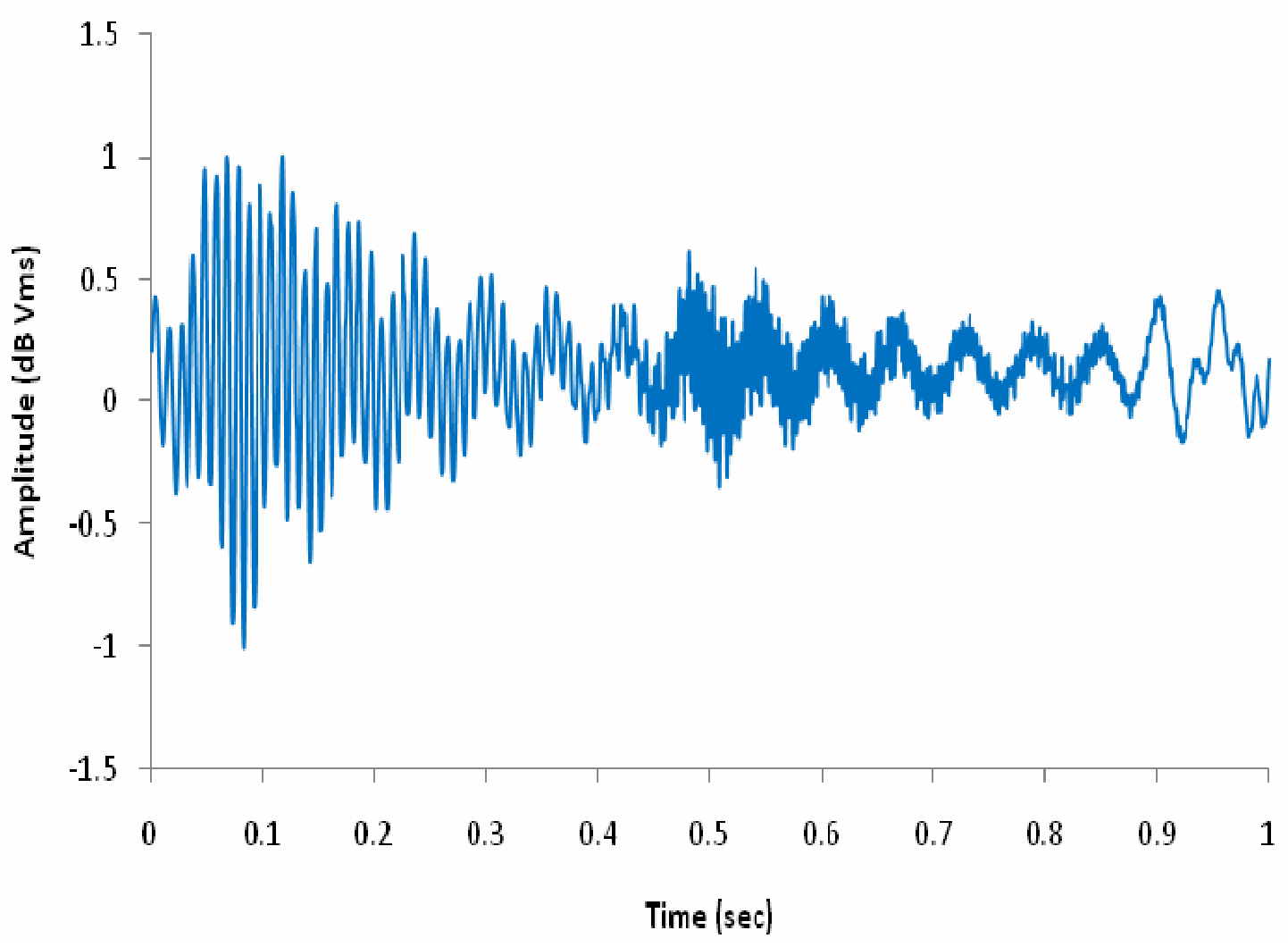

Figure 6.43: Time Response of Laminate $L_{30}$

According to figure above, the amplitude was 1 volt at 0.1 seconds. The graph did not show the settling time which is the time it took for laminate to damp out. It had a natural frequency very similar to specimen $\mathrm{L}_{20}$. It had an damped frequency response. The graph showed a cosine signal output and electronic noise pollution. Fig. 6.44 shows the time response of specimen $\mathrm{L}_{40}$ with no delamination. 


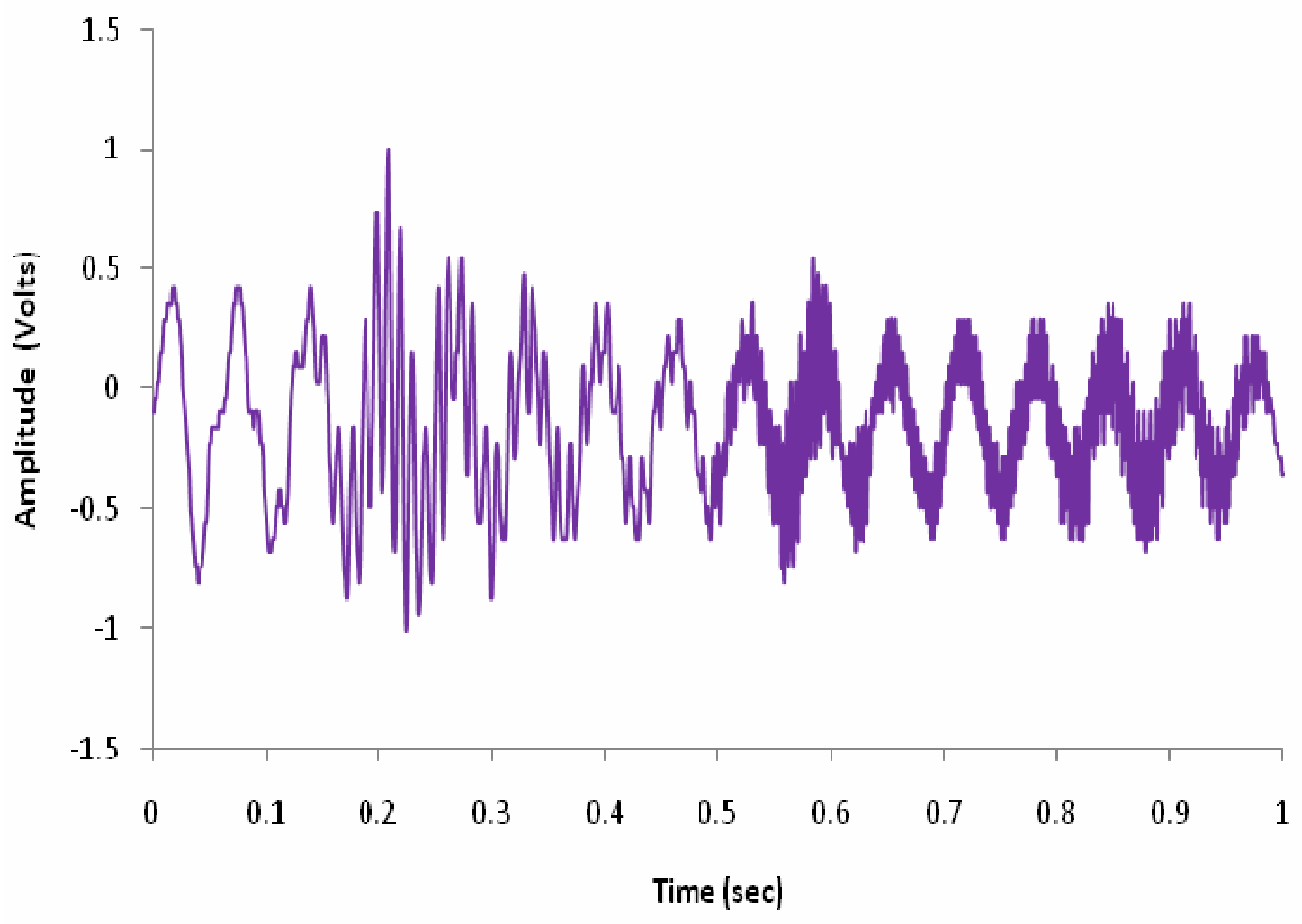

Figure 6.44: Time Response of Laminate $L_{40}$

According to Figure $\mathrm{L}_{40}$, the maximum amplitude was 1 volt at 0.1 seconds. It does not show the settling time which is the time it took for laminate to damp out. This force vibration system was also damped due to the decaying oscillatory motion of the natural frequency response. The graph showed a sinusoidal signal output with a lot of electronic noise pollution. Fig. 6.45 shows the time response of specimen $\mathrm{HD}_{30}$ with no delamination. 


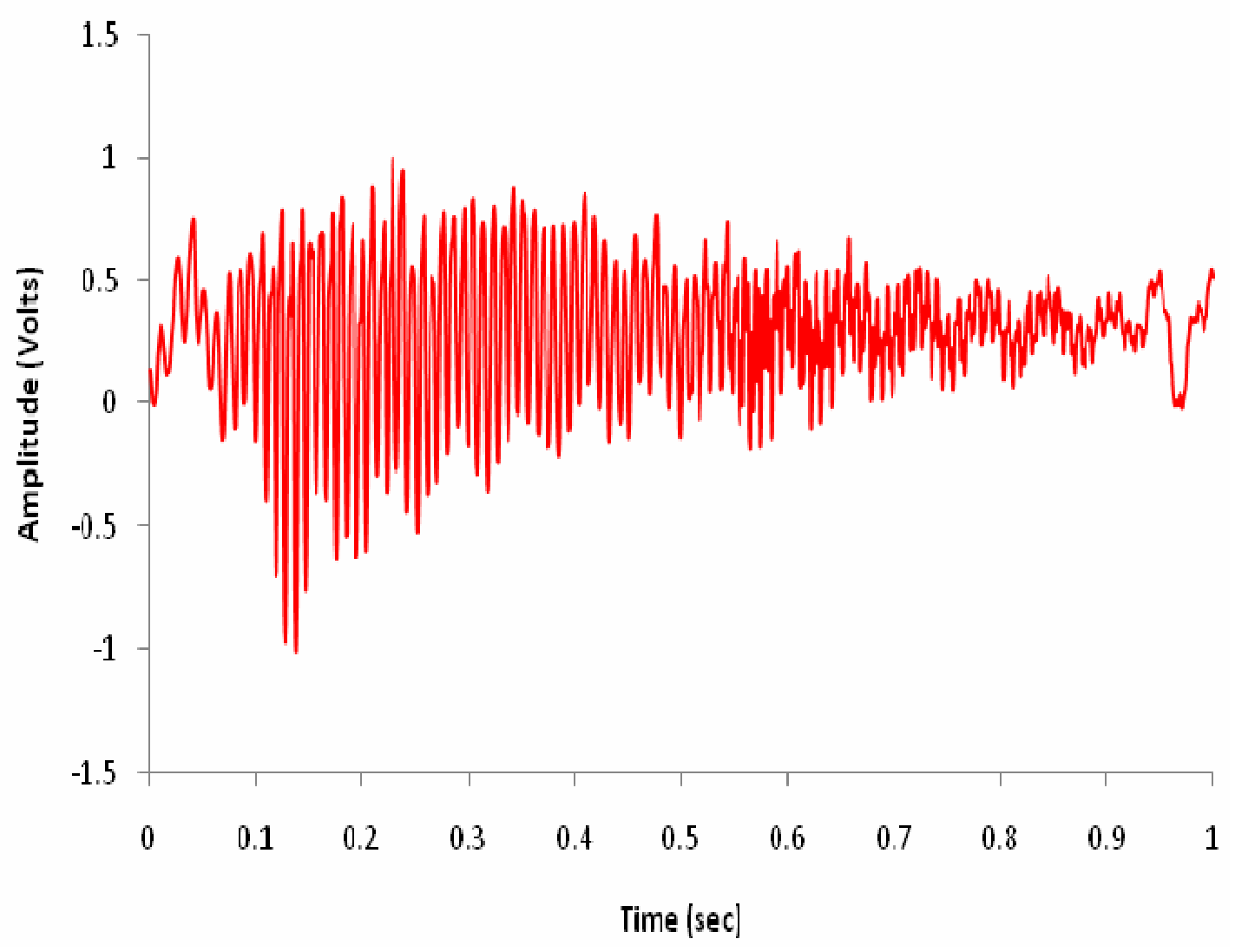

Figure 6.45: Time Response of Laminate $\mathrm{HD}_{30}$

Figure above shows the maximum amplitude was 1 volt at 0.1 seconds. This force vibration system was also damped due to the decaying oscillatory motion of the natural frequency response. It was difficult to obtain the settling time which it took for laminate to damp out. The graph showed a sinusoid signal output with a lot of electronic noise pollution. Fig. 6.46 shows the time response of specimen $\mathrm{L}_{30}$ and $\mathrm{HD}_{30}$ with no delamination. 


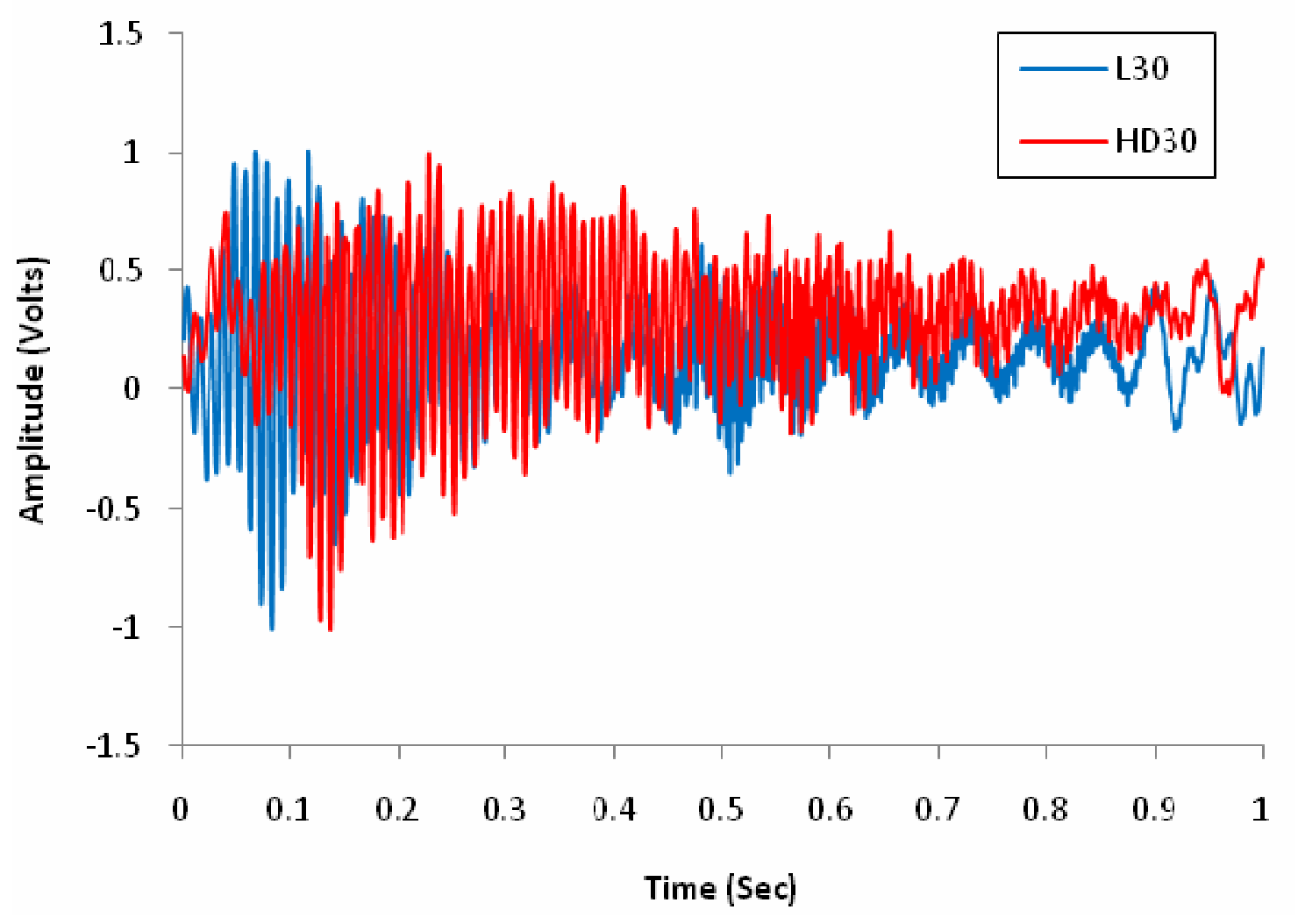

Figure 6.46: Time Response Comparison of Laminates $\mathrm{L}_{30}$ and $\mathrm{HD}_{30}$

According to the graph, both test specimens showed amplitude of 1 volt at 0.1 seconds. Although both specimens experienced decaying oscillatory motion responses, the plotted data laminate with high-density filler exhibited less damping than test specimen with limestone filler. This was not expected since specimen $\mathrm{HD}_{30}$ had a higher stiffness characteristic compared to specimen $\mathrm{L}_{30}$ which both had an elastic modulus of 2518 and $2319 \mathrm{ksi}$, respectively. The graph also shows that test specimen $\mathrm{HD}_{30}$ displayed more electronic noise than test specimen $\mathrm{L}_{30}$. Fig. 6.47 shows the time response of specimen $\mathrm{L}_{\mathrm{B} 0}$ with no delamination 


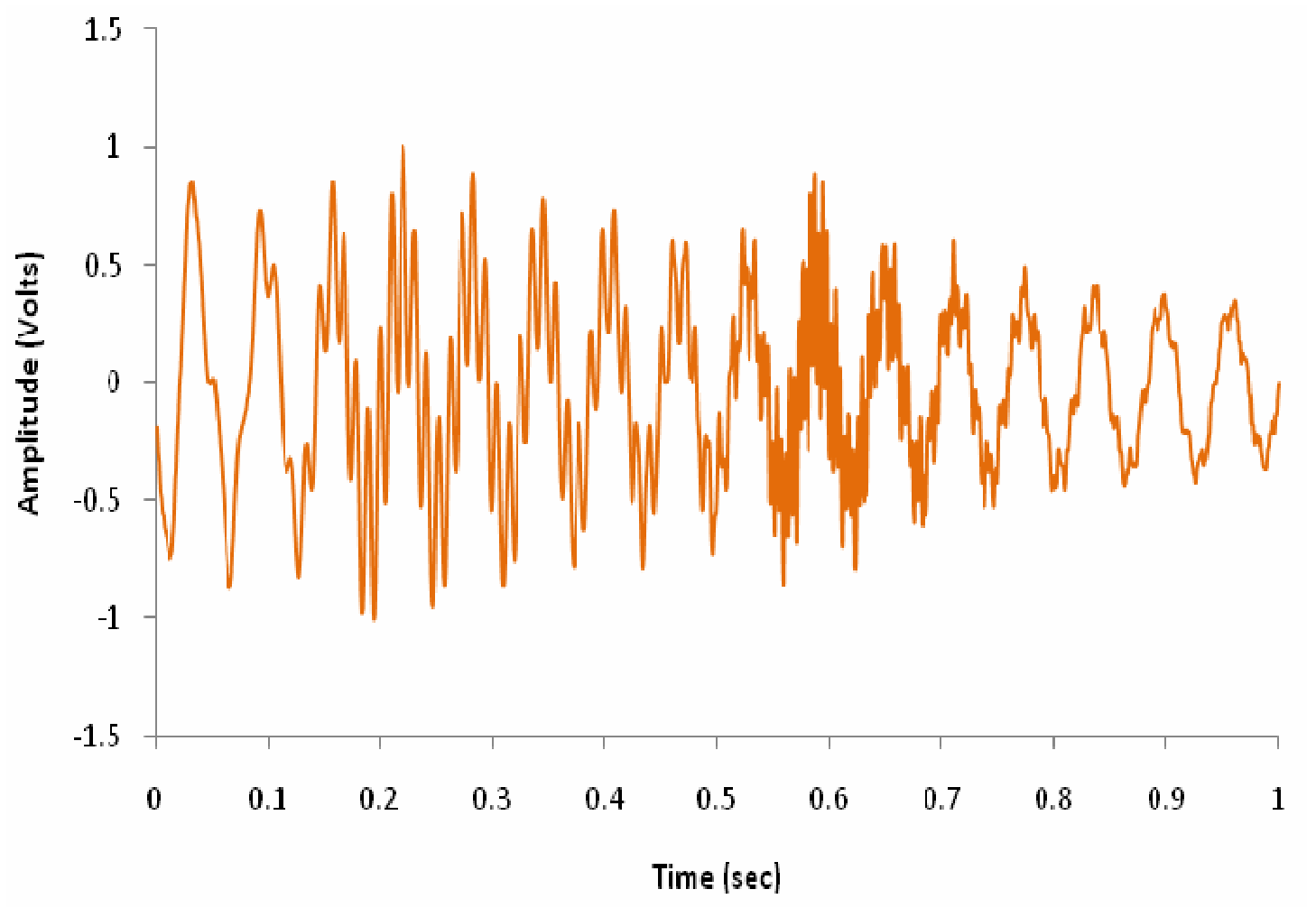

Figure 6.47: Time Response of Laminate $L_{B 0}$

According to above graph, the maximum amplitude was 1 volt at time of 0.2 seconds. The sinusoid signal showed a light damped response as expected. The fiberglass laminate with no filler also had noticeable electronic noise pollution. Fig. 6.48 shows the time response comparison of all laminates with no delamination. 


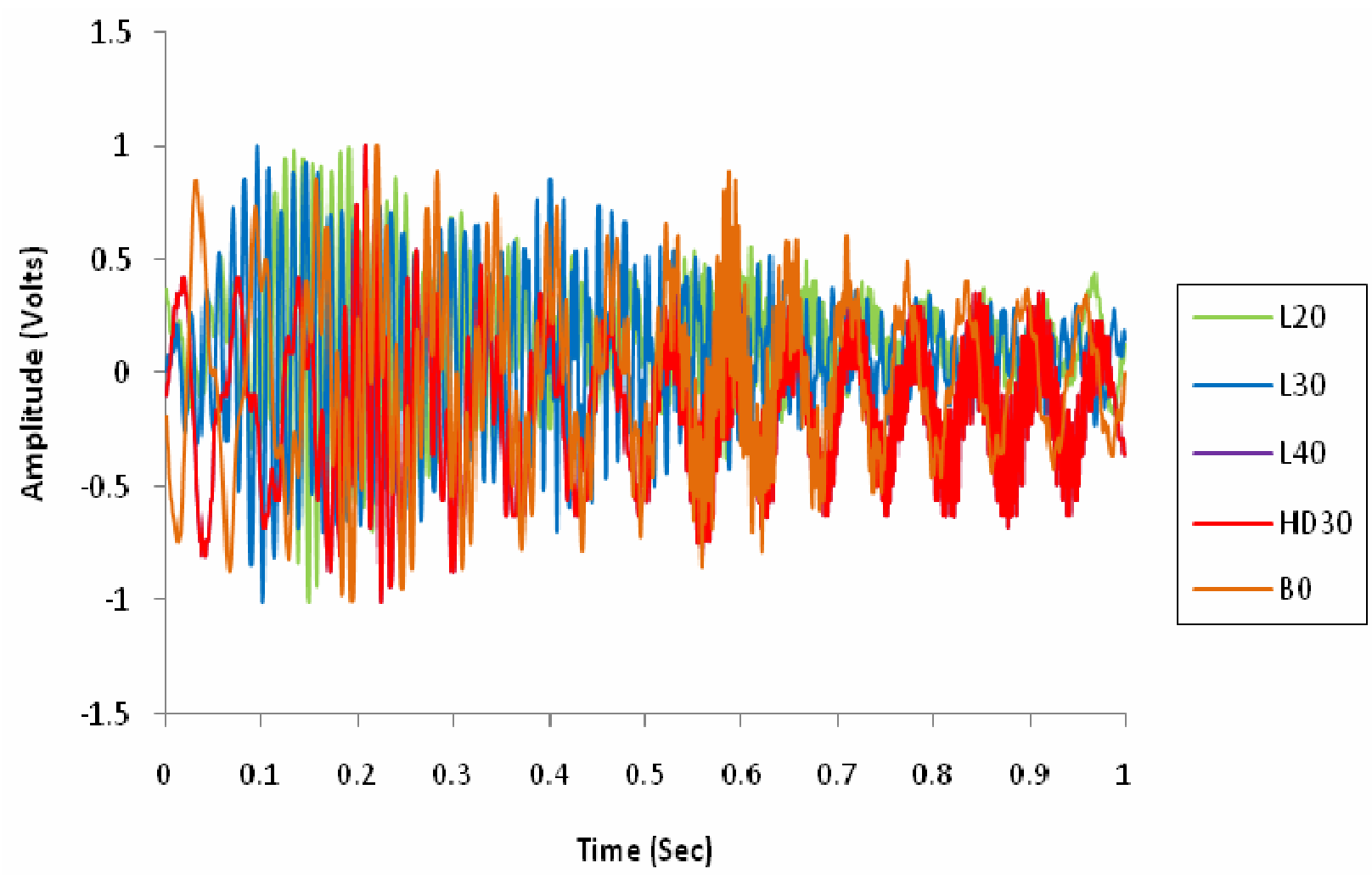

Figure 6.48: Time Response Comparison of All Fiberglass Laminates

The time response results for all test specimens showed an expected trend in amplitude versus time. All test specimens had the same maximum amplitude of 1 volt at 0.1 seconds. Since the natural frequency of a system is dependent only on the stiffness and mass of the structure, then it was expected to observe more damping on laminates that had more filler. Test specimens $\mathrm{L}_{20}, \mathrm{~L}_{30}$, and $\mathrm{HD}_{30}$ exhibited the most damping-sinusoidal frequency response due to the decaying oscillatory motion, as seen in graph above. In addition, it was difficult to detect which test specimen had the greatest amplitude from the time response using LabVIEW since it the amplitudes were not clear to read. This was probably to the high electronic noise pollution observed in all test specimens. 
In order to further improve the results obtained from the modal testing, several things need to be considered. The fabrication technique would need to be improved by making sure the laminates are aligned properly and restricted from moving while placed inside the oven press during curing. Proper specimen preparation and dynamic setup would be essential in order to prevent dire results from the modal analysis. For example, piezoelectric ceramic strain sensors must be placed and aligned properly on specimens, wires connected to the strain sensor need to be connected correctly to the National Instruments SCB-100 which connects the shaker to the LabVIEW program, and piezoelectric ceramic strain sensor require to be cut properly into 1 x 1 in squares. Proper specimen fabrication and dynamic setup will also reduce the electronic noise pollution by making it easier to read and correlate data from the frequency/time response graphs.

Another option of improving data results is by using the Unholtz Dickie Electrodynamic Shaker Table. This vibration testing system is composed of transducers (typically accelerometers and load cells), an analog-to-digital converter (to digitize analog instrumentation signals) and a host PC (Vwin software) to view data and analyze it. This modal testing apparatus has ability to analyze the data in multiple degrees of freedom (MODF) - adding degrees of freedom to represent a more realistic vibration model; hence, improving results obtained from the modal testing. Finally, finite element analysis of no delaminations on a laminate was later used to compare the experimental values with the numerical values. 


\section{RESULTS AND DISCUSSION OF NUMERICAL ANALYSIS}

\subsection{Finite Element Analysis}

The ability to accurately predict the behavior of composite materials during vibration and bending required the use of material models that represent multiple physical mechanisms. There are many failure modes in composites materials, including fiber tensile and compressive failure, matrix tensile and compressive failure, delamination, and others. The model that will work best for a given real world problem depends on a number of factors, including structural loading, impact velocity and boundary conditions. Therefore, having the ability to incorporate the most applicable damage and failure model for the problem is of great benefit for the analysis process.

For this thesis investigation, the Finite Element Method (FEM) was used to provide this functionality, by modeling and simulating the dynamic and static behavior of a fiberglass-filler woven roving laminates under vibration and bending loads. Therefore two FEM models were designed - a laminated beam to verify the bending modes and dynamic response for the different fiberglass-filler test specimens, and compare the flexural characteristics of the various fiberglassfiller manhole cover thin plates under bending loading. The numerical analysis of both fiberglass laminated beams and plates will be described in the following sections.

\subsubsection{Vibration Analysis for Beam Laminate}

The finite element model for the beam laminate was constructed using Abaqus/Standard Version 6.8-Student Version. A total of four ply layers with different dimensions were modeled individually using 3-D, deformable shell continuum elements and hourglass control. The beams were meshed with first order, reduced integration and linear quadrilateral (S4R) elements which reduced the overall running time of the analysis. This assumed a 4-node doubly curved thin or 
thick shell, finite membrane strains. The continuum elements were used to model pure bending with the assumption that plane cross-sections remain plane throughout the deformation and therefore there is no membrane shear strain The composite ply layup used for this simulation was a simple isotropic design, $[0,0,0,0]$, as seen in Fig 7.1 .

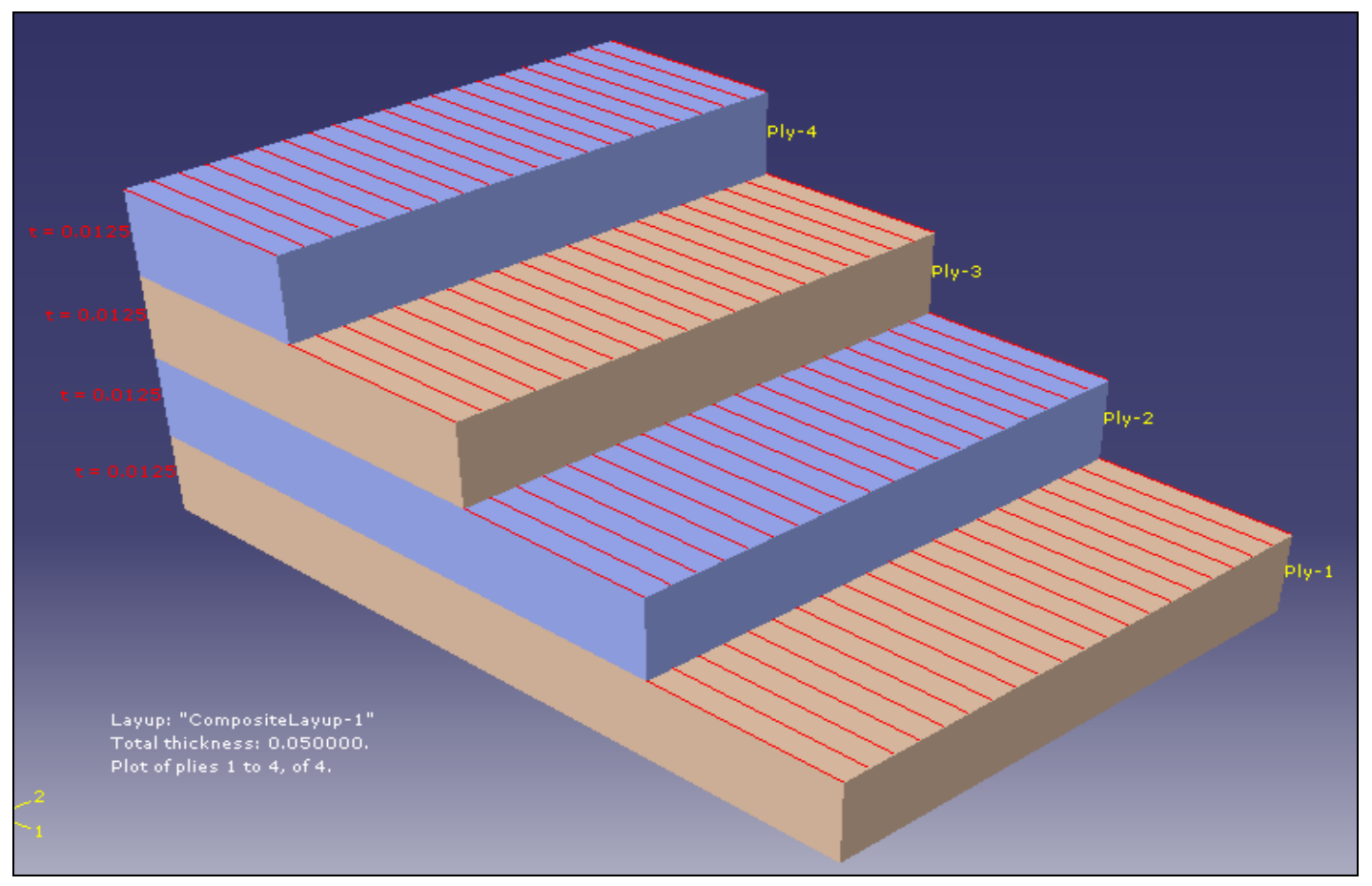

Figure 7.1: Ply Layup for Beam Laminates

Since all fiberglass laminates were assumed to be isotropic due to the bi-directional property of fiberglass woven roving, the measured elastic modulus from the static tensile test results was used as the material property. Poisson's ratio used for the all E-glass laminates was 0.22. The laminated beams were sketched by using the same specimen dimensions as in the experimental analysis. Initially, each beam length was subtracted 1 inch from the original length since the clamp's width was 1 inch from the specimen's edge. This method did not improve the results since the bending modes where measured at the low frequency spectrum. Therefore, the beam length was reduced to 5.7 inches which coincided with the piezoceramic strain gauge 
location. This might be explained since the beam located inside the clamp was attached too tightly, thus reducing frequency of the excitation composite structure. Table 7.1 shows a summary of the dimensions used for the vibration analysis.

Table 7.1: Dimensions Used for Composite Beams Dynamic Simulation

\begin{tabular}{|c|c|c|c|c|c|c|}
\hline Specimen & Weight (g) & Length (in) & Thickness (in) & Width (in) & Volume (in $\left.{ }^{3}\right)$ & Density $\left(\mathrm{Ib}_{\mathrm{f}} \mathrm{s}^{2} / \mathrm{in}^{4}\right)$ \\
\hline $\mathrm{L}_{20}$ & 104.3 & 8 & 0.050 & 1.471 & 0.6619 & 0.00101 \\
\hline $\mathrm{L}_{30}$ & 100.5 & 8 & 0.049 & 1.427 & 0.6293 & 0.00103 \\
\hline $\mathrm{L}_{40}$ & 108.1 & 8 & 0.052 & 1.389 & 0.6500 & 0.00107 \\
\hline $\mathrm{HD}_{30}$ & 119.2 & 8 & 0.049 & 1.423 & 0.6275 & 0.00122 \\
\hline $\mathrm{LB}_{0}$ & 104.5 & 8 & 0.047 & 1.506 & 0.6317 & 0.00105 \\
\hline
\end{tabular}

The density values were calculated by using the laminate total mass and volume for each laminated beam. The mass units were converted from grams to slugs in order to obtain the units for mass density $\left(\mathrm{lb}_{\mathrm{f}}-\mathrm{s}^{2} / \mathrm{in}^{4}\right)$. Fig. 7.2 shows the laminated beam model used for the frequency analysis.

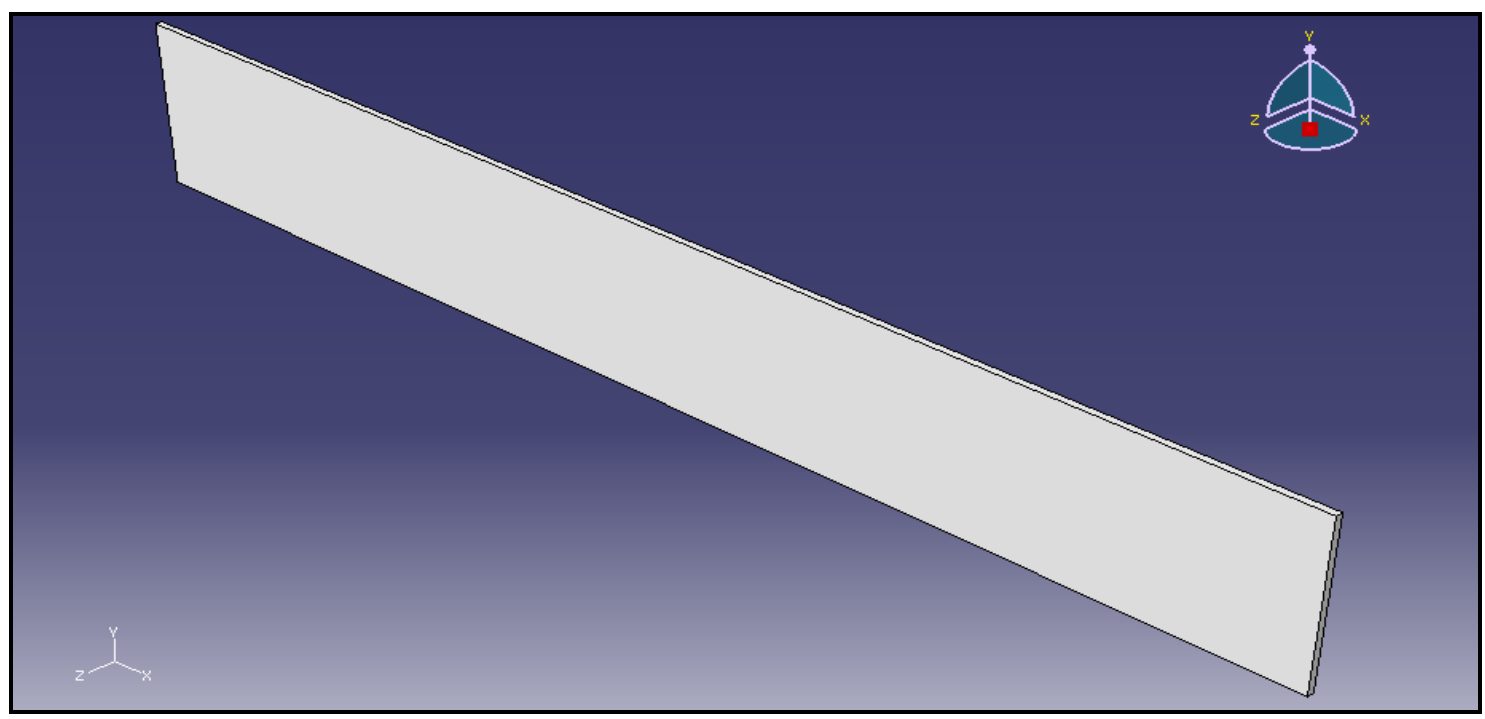

Figure 7.2: Geometry Used for Composite Beam Dynamic Simulation 
Fig. 7.3 shows the mesh's element shape to be linear quadrilateral elements of type S4R. The mesh consisted of 95 total nodes and 72 total elements with an approximate global seed size of 05 .

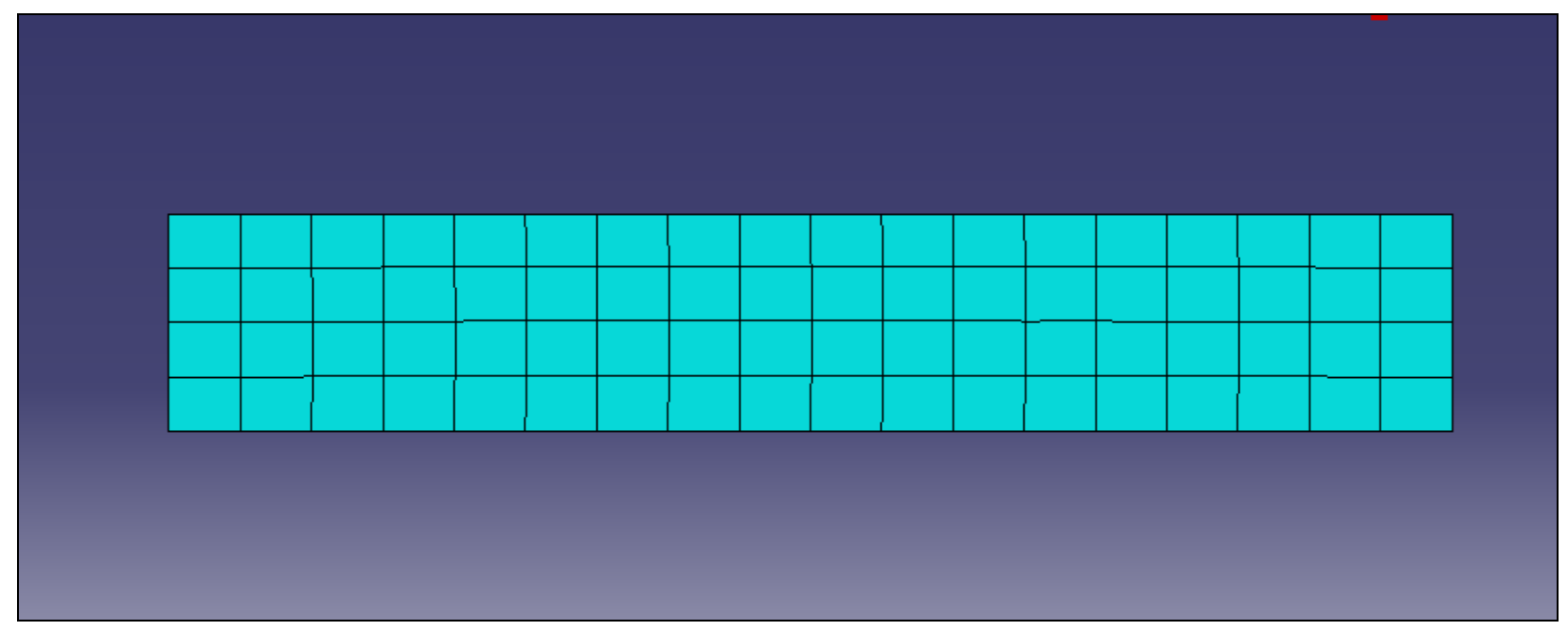

Figure 7.3: Finite Element Mesh for Laminated Beam

The deformed elements seed size was selected based on a mesh refinement and convergence trade study. This showed that reducing global seed size increased the number of elements and made a finer mesh but also created several distorted quadrilateral elements.

The frequency extraction of the linear steady-state dynamic model for each test specimen was performed by eigenvalue extraction. The dynamic-linear perturbation method was selected and used to calculate the natural frequencies and the corresponding mode shapes of the system. Eqn 7.1 is the eigenvalue extraction equation used for the natural frequencies of an undamped finite element models:

$$
\left(-\omega^{2} M^{M N}+K^{M N}\right) \phi^{N}=0
$$

where $M^{M N}$ is the mass matrix (which is symmetric and positive definite), $K^{M N}$ is the stiffness matrix (which includes initial stiffness effects if the base state included the effects of nonlinear 
geometry); $\varphi^{N}$ is the eigenvector (the mode of vibration); and superscripts $M$ an $N$ are degrees of freedom. The frequency domain was set with a maximum frequency of interest from 0 to 500 Hz. The Lanczos eigensolver was used to request 100 eigenvalues.

For the boundary condition, symmetric/encastre (fully built-in or fixed) was selected since it was assumed that the aluminum clamp constrained the beam's movement in all six degrees of freedom (displacement/rotation). Fig. 7.4 shows the beam having a fixed boundary condition. Each beam model length later was subtracted 1 inch from the edge representing the region of the clamp's width. Therefore the laminated beam had a total length of 8 inch.

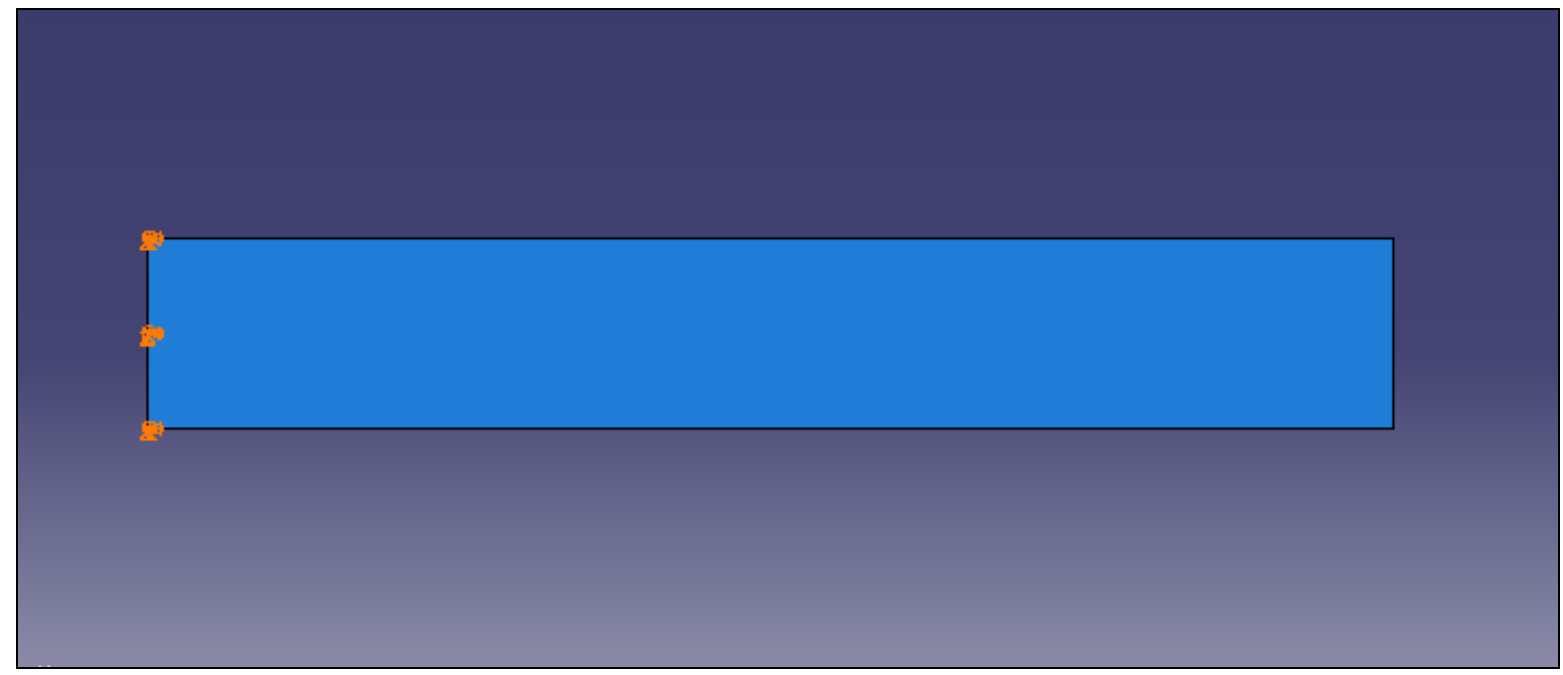

Figure 7.4: Top View of Fixed Boundary Condition at Beam's Edge

Once the boundary condition was determined, the frequency extraction was performed for the each test specimen. Table 7.2 shows the material properties used for the dynamic analysis of test specimen $\mathrm{L}_{20}$.

Table 7.2: Material Properties for Laminate $L_{20}$

\begin{tabular}{|c|c|}
\hline$E$ & $v$ \\
\hline $2670.9 \mathrm{ksi}$ & 0.22 \\
\hline
\end{tabular}


Fig. 7.5 shows the side view of the first bending mode of the test specimen $L_{20}$.

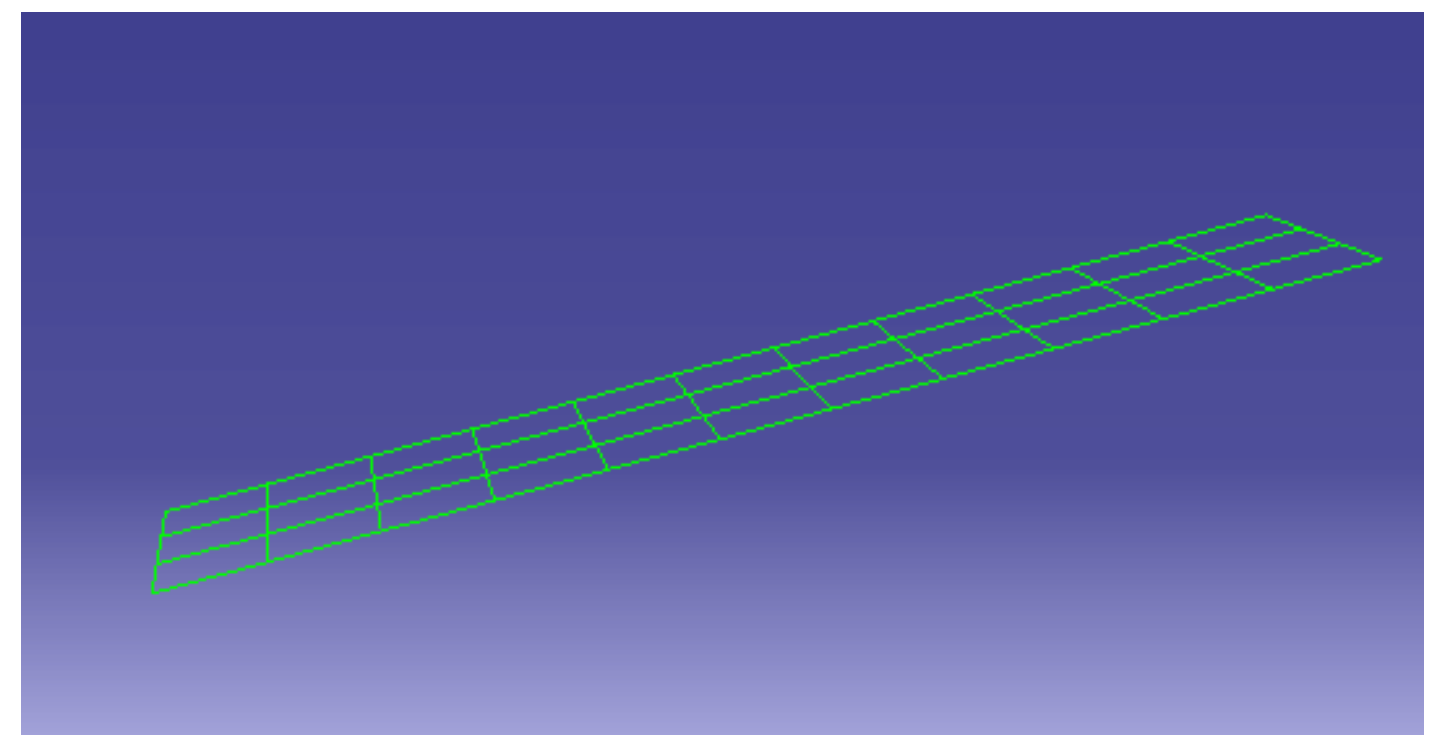

Figure 7.5: $1^{\text {st }}$ Bending Mode for Laminate $L_{20}$

The first bending mode for laminate $\mathrm{L}_{20}$ was approximately 12.569 hertz with a deformation scale factor of 0.08 . Fig 7.6 shows the second bending mode of laminate $\mathrm{L}_{20}$.

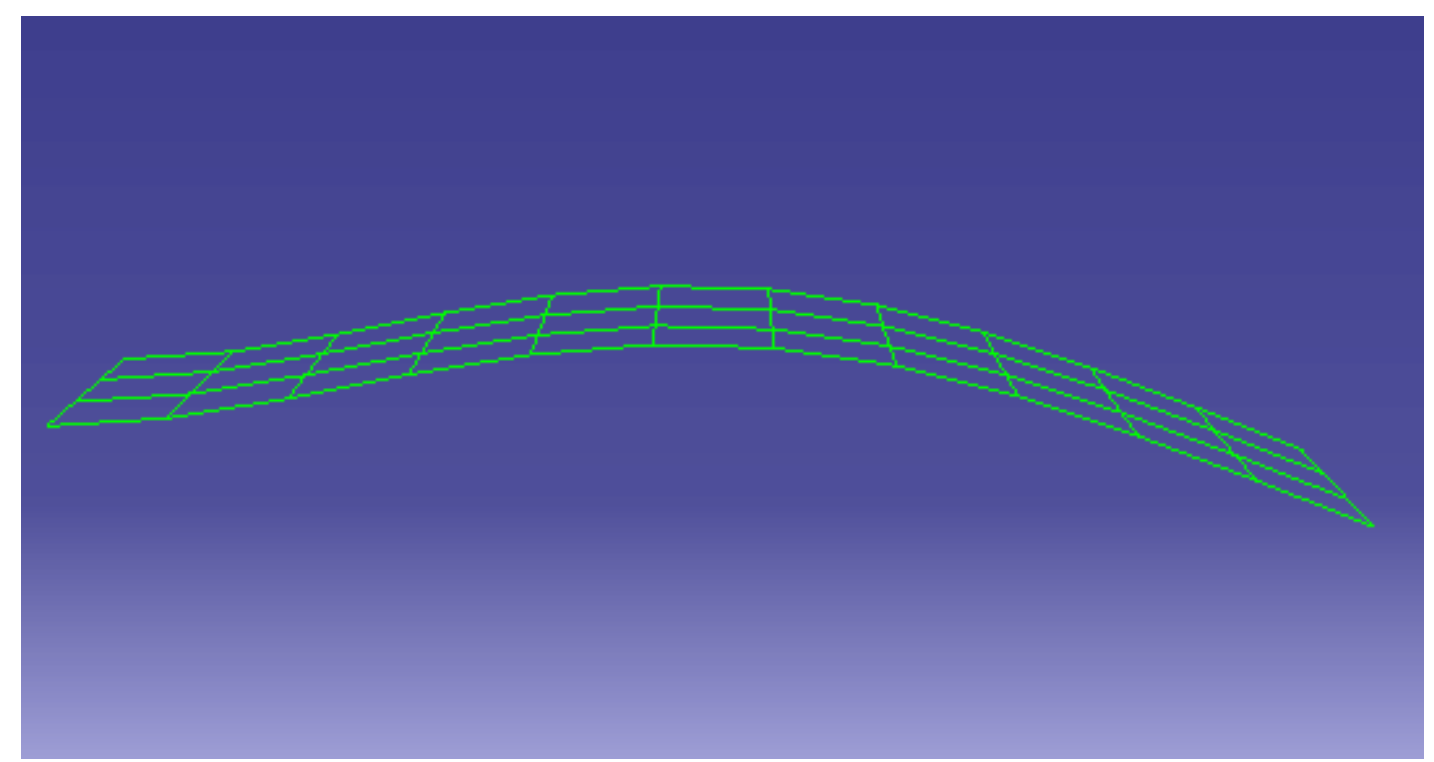

Figure 7.6: $2^{\text {nd }}$ Bending Mode for Laminate $L_{20}$ 
The second bending mode for laminate $L_{20}$ was approximately 79.617 hertz with a deformation scale factor of 0.08 . Fig 7.7 shows the third bending mode of laminate $\mathrm{L}_{20}$.

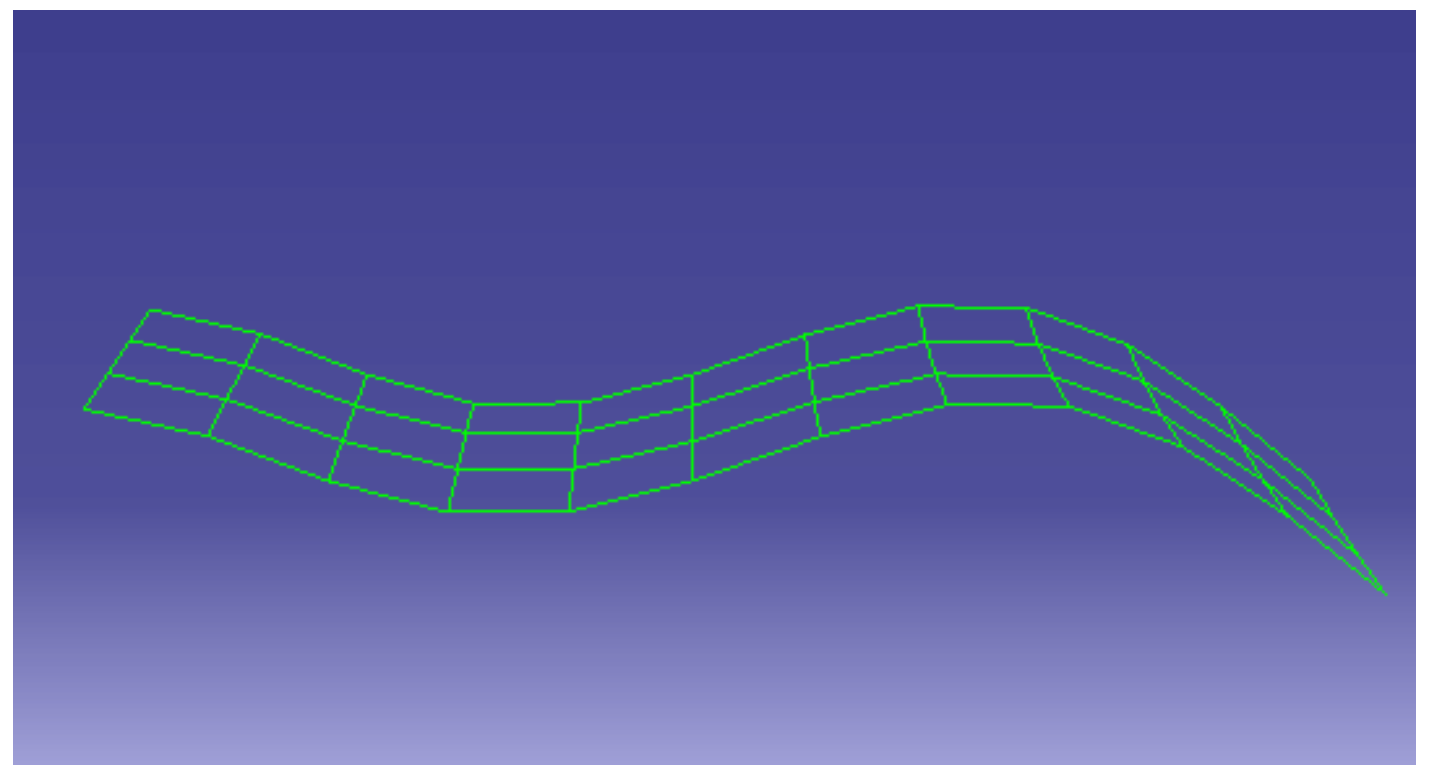

Figure 7.7: $3^{\text {rd }}$ Bending Mode for Laminate $L_{20}$

The third bending mode for laminate $\mathrm{L}_{20}$ was approximately 228.47 hertz with a deformation scale factor of 0.08 . Fig 7.8 shows the fourth bending mode of laminate $\mathrm{L}_{20}$.

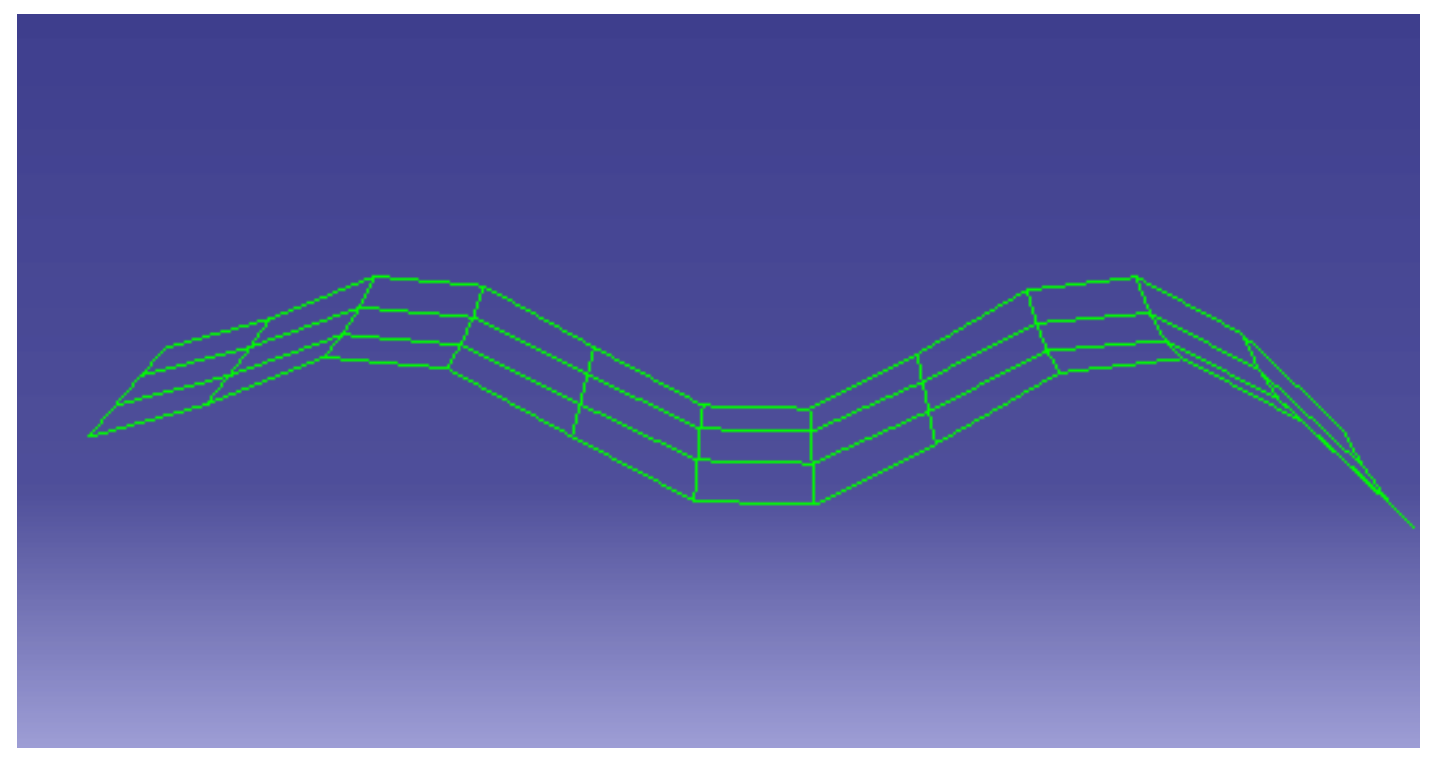

Figure 7.8: $4^{\text {th }}$ Bending Mode for Laminate $L_{20}$ 
The fourth bending mode for laminate $\mathrm{L}_{20}$ was approximately 465.27 hertz with a deformation scale factor of 0.08 . Table 7.3 shows the shows the dynamic response results for laminate $\mathrm{L}_{20}$.

\section{Table 7.3: Natural Frequency for Laminate $L_{20}$}

\begin{tabular}{|c|c|}
\hline Bending Mode & Frequency (Hertz) \\
\hline $1^{\text {st }}$ & 12.569 \\
\hline $2^{\text {nd }}$ & 79.617 \\
\hline $3^{\text {rd }}$ & 228.47 \\
\hline $4^{\text {th }}$ & 465.27 \\
\hline
\end{tabular}

It was observed that the natural frequencies of laminate $L_{20}$ were extremely low compared to the experimental results. This was probably due to incorrect material properties used for the numerical analysis, specifically, Possion's ratio, elastic modulus, and density. The fixed or built-in boundary condition may also contribute to the erroneous data since improper boundary condition can influence the overall dynamic response of the composite material. Table 7.4 shows the material properties used for the dynamic analysis of test specimen $\mathrm{L}_{30}$.

Table 7.4: Material Properties for Laminate $L_{30}$

\begin{tabular}{|c|c|}
\hline$E$ & $v$ \\
\hline $2542.2 \mathrm{ksi}$ & 0.22 \\
\hline
\end{tabular}

The laminate $\mathrm{L}_{30}$ had the same mode shape as laminate $\mathrm{L}_{30}$. Table 7.5 shows the frequency response summary for laminate $\mathrm{L}_{30}$. 
Table 7.5: Natural Frequency for Laminate $L_{30}$

\begin{tabular}{|c|c|}
\hline Bending Mode & Frequency (Hertz) \\
\hline $1^{\text {st }}$ & 12.482 \\
\hline $2^{\text {nd }}$ & 79.071 \\
\hline $3^{\text {rd }}$ & 226.89 \\
\hline $4^{\text {th }}$ & 462.03 \\
\hline
\end{tabular}

Table 7.6 shows the material properties used for the dynamic analysis of test specimen $\mathrm{L}_{40}$.

Table 7.6: Material Properties for Laminate $L_{40}$

\begin{tabular}{|c|c|}
\hline$E$ & $v$ \\
\hline $2470.95 \mathrm{ksi}$ & 0.22 \\
\hline
\end{tabular}

Table 7.7 shows the bending mode response for laminate $\mathrm{L}_{40}$.

Table 7.7: Natural Frequency for Laminate $L_{40}$

\begin{tabular}{|c|c|}
\hline Bending Mode & Frequency (Hertz) \\
\hline $1^{\text {st }}$ & 12.060 \\
\hline $2^{\text {nd }}$ & 76.737 \\
\hline $3^{\text {rd }}$ & 222.09 \\
\hline $4^{\text {th }}$ & 458.54 \\
\hline
\end{tabular}

Table 7.8 shows the material properties used for the dynamic analysis of test specimen $\mathrm{HD}_{30}$.

Table 7.8: Material Properties for Laminate $\mathrm{HD}_{30}$

\begin{tabular}{|c|c|}
\hline$E$ & $v$ \\
\hline $2814.42 \mathrm{ksi}$ & 0.22 \\
\hline
\end{tabular}

Table 7.9 shows the bending mode response summary for laminate $\mathrm{HD}_{30}$. 


\section{Table 7.9: Natural Frequency for Laminate $\mathrm{HD}_{30}$}

\begin{tabular}{|c|c|}
\hline Bending Mode & Frequency (Hertz) \\
\hline $1^{\text {st }}$ & 12.045 \\
\hline $2^{\text {nd }}$ & 76.638 \\
\hline $3^{\text {rd }}$ & 221.81 \\
\hline $4^{\text {th }}$ & 457.96 \\
\hline
\end{tabular}

Table 7.10 shows the material properties used for the dynamic analysis of test specimen $\mathrm{L}_{\mathrm{B} 0}$.

Table 7.10: Material Properties for Laminate $L_{B 0}$

\begin{tabular}{|c|c|}
\hline$E$ & $V$ \\
\hline $3110.95 \mathrm{ksi}$ & 0.22 \\
\hline
\end{tabular}

Table 7.11 shows the bending mode response summary for laminate $\mathrm{L}_{\mathrm{B} 0}$.

Table 7.11: Natural Frequency for Laminate $L_{B 0}$

\begin{tabular}{|c|c|}
\hline Bending Mode & Frequency (Hertz) \\
\hline $1^{\text {st }}$ & 13.635 \\
\hline $2^{\text {nd }}$ & 87.011 \\
\hline $3^{\text {rd }}$ & 253.41 \\
\hline $4^{\text {th }}$ & 528.47 \\
\hline
\end{tabular}

Table 7.12 shows the frequency response summary for all test specimens. 
Table 7.12: Frequency Comparison for Isotropic Laminated Beams

\begin{tabular}{|c|c|c|c|c|}
\hline \multicolumn{5}{|c|}{ Natural Frequency (Hz) } \\
\hline Specimen & Mode 1 & Mode 2 & Mode 3 & Mode 4 \\
\hline $\mathrm{L}_{20}$ & 12.569 & 79.617 & 228.47 & 465.27 \\
\hline $\mathrm{L}_{30}$ & 12.482 & 79.071 & 226.89 & 462.03 \\
\hline $\mathrm{L}_{40}$ & 12.060 & 76.737 & 222.09 & 458.54 \\
\hline $\mathrm{HD}_{30}$ & 12.045 & 76.638 & 221.81 & 457.96 \\
\hline $\mathrm{L}_{\mathrm{B} 0}$ & 13.635 & 87.011 & 253.41 & 528.47 \\
\hline
\end{tabular}

The numerical frequency extraction analysis results showed an expected trend in amplitude and frequency response. Both laminated beams $\mathrm{L}_{20}$ and $\mathrm{L}_{30}$ had similar bending modes. Laminates $\mathrm{L}_{\mathrm{B} 0}$ and $\mathrm{HD}_{30}$ also had similar bending modes with a mode difference of 0.8195 , specifically in modes 1 and 2. Test specimen $\mathrm{L}_{\mathrm{B} 0}$ had the highest frequency range which was clearly seen in mode 4 which exceed the maximum frequency mode of interest. It was observed that laminated beams made with filler experienced lower frequencies. This was expected since the material property of filler increases stiffness and damping behavior in composite structures.

\subsubsection{Bending Analysis for Manhole Cover Plate}

The finite element model for the laminated plate was also constructed using Abaqus/Standard Version 6.8-Student Version. A total of four ply layers with different dimensions were modeled individually using 3-D, deformable shell continuum elements and hourglass control. The plates were meshed with first order, reduced integration and linear quadrilateral (S4R) elements. The continuum elements were used to model pure bending with the assumption that plane cross-sections remain plane throughout the deformation and therefore there is no membrane shear strain The composite ply layup used for this simulation was a simple isotropic design, $[0,0,0,0]$, as seen previously in Fig 7.1. 
All fiberglass laminates were again assumed to be isotropic due to the bi-directional property of fiberglass woven roving. The elastic modulus from the static tensile test results and a Poisson's ratio of 0.22 was used as the material properties for the laminated plates. The laminated plates were sketched by using the specimen specifications from the manhole cover test specimens, as previously described in the experimental analysis for bending. Table 7.13 shows a summary of the plate dimensions used for the bending analysis.

Table 7.13: Dimensions Used for Composite Plate Bending Simulation

\begin{tabular}{|c|c|c|c|c|c|c|}
\hline Specimen & Weight $\left(\mathrm{Ib}_{\mathrm{f}}{ }^{2} / \mathrm{in}\right)$ & $\begin{array}{c}\text { Diameter } \\
(\mathrm{in})\end{array}$ & $\begin{array}{c}\text { Thickness } \\
(\mathrm{in})\end{array}$ & $\begin{array}{c}\text { Cross Section } \\
\text { Area }\left(\mathrm{in}^{2}\right)\end{array}$ & Volume $\left(\mathrm{in}^{3}\right)$ & $\begin{array}{c}\text { Density } \\
\left(\mathrm{lb}_{\mathrm{f}}-\mathrm{s}^{2} / \mathrm{in}^{4}\right)\end{array}$ \\
\hline $\mathrm{L}_{20}$ & 0.000675 & 10.95 & 0.061 & 94.17 & 5.742 & 0.000118 \\
\hline $\mathrm{L}_{30}$ & 0.000669 & 10.91 & 0.066 & 93.48 & 6.167 & 0.000109 \\
\hline $\mathrm{L}_{40}$ & 0.0006155 & 11.0 & 0.062 & 94.69 & 5.889 & 0.0001045 \\
\hline $\mathrm{HD}_{30}$ & 0.00061 & 10.98 & 0.063 & 95.03 & 5.962 & 0.000102 \\
\hline $\mathrm{LB}_{0}$ & 0.00067093 & 10.95 & 0.058 & 94.12 & 5.459 & 0.0001229 \\
\hline
\end{tabular}

The density values were calculated by using the laminate total mass and volume for each laminated beam. The mass units were converted from grams to slugs in order to obtain the units for mass density $\left(\mathrm{lb}_{\mathrm{f}}-\mathrm{s}^{2} / \mathrm{in}^{4}\right)$. The plate geometry was partitioned to include a central concentrated uniform load applied by the loading nose or instrumentation plunger, as seen in Fig. 7.9. 


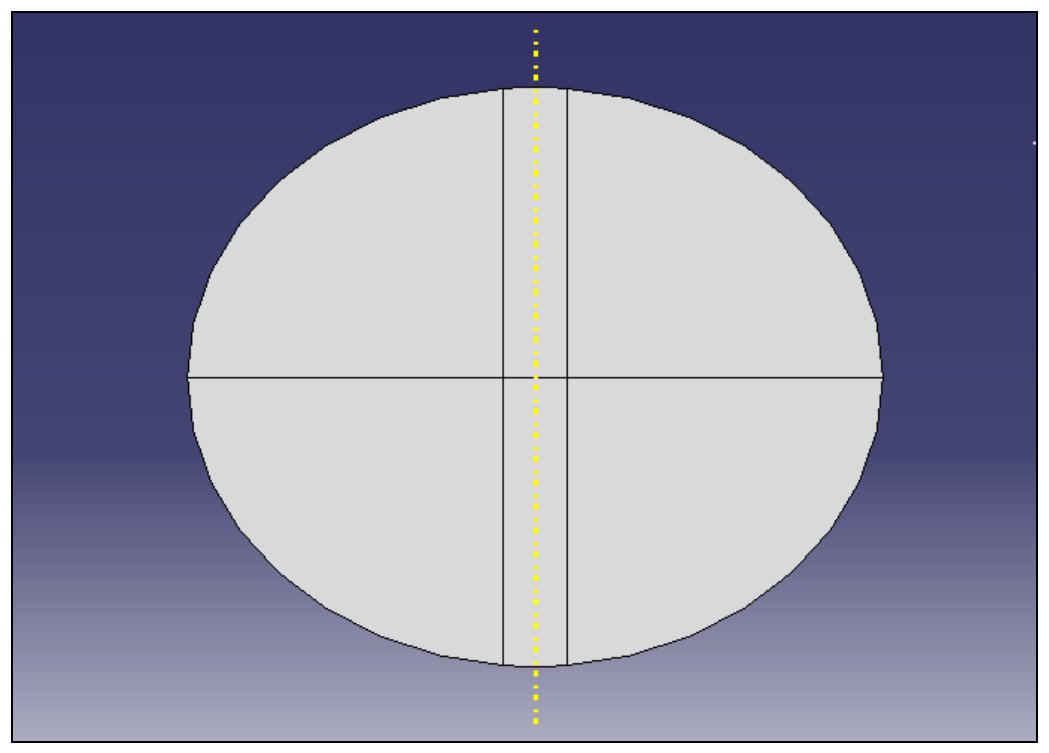

Figure 7.9: Partition Used for Manhole Cover Plate

The partition was designed in order to meet the 1-inch diameter specification of the head piece. The bending analysis was simulated by varying the axial load in this region from $20 \mathrm{lbf}$ to $200 \mathrm{lbf}$ (at $40 \mathrm{lbf}$ increments). This was performed to simulate the increasing force being exerted by the hydraulic plunger in a direction normal to the plane of the plate.

The model configuration of the mesh's element shape was linear quadrilateral element of type S4R. The mesh type was structured. The mesh consisted of 793 total nodes and 748 total elements with an approximate global seed size of 0.4 and a maximum deviation factor of 0.1.Fig. 7.10 shows the mesh's total elements in blue and nodes in red. 


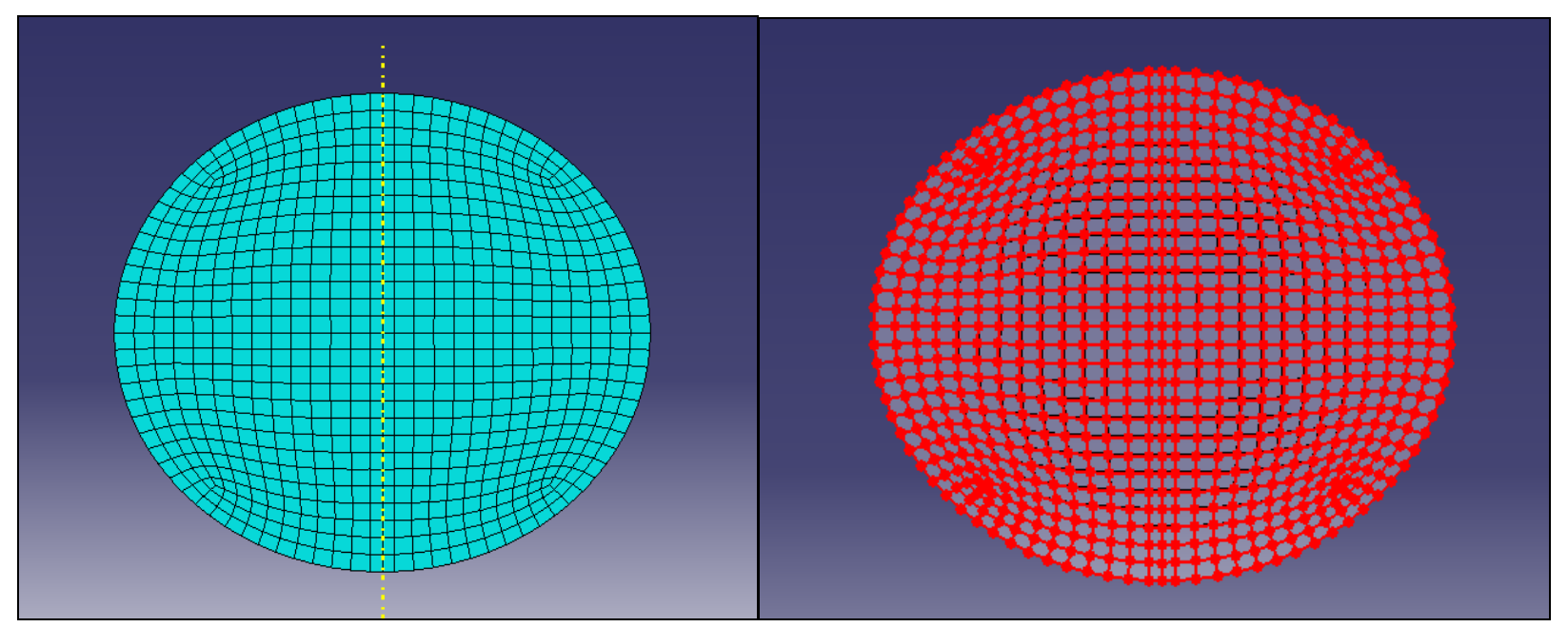

Figure 7.10: Detail of Finite Element Mesh Applied to Fiberglass Plate

The model configuration is shown above. The material properties in Table 7.14 were used for the fiberglass-filler laminated beams/plate the numerical simulation analysis.

Pinned boundary condition was selected for all test specimens since it was assumed that the manhole cover plate was constrained in $\mathrm{u}_{1}=\mathrm{u}_{2}=\mathrm{u}_{3}=0$. The specimen support fixture's ring restricted the manhole cover plate from movement since it was placed inside the Christy H-8 fixture with negligible space margin. Fig. 7.11 shows the pinned boundary condition for the plate.

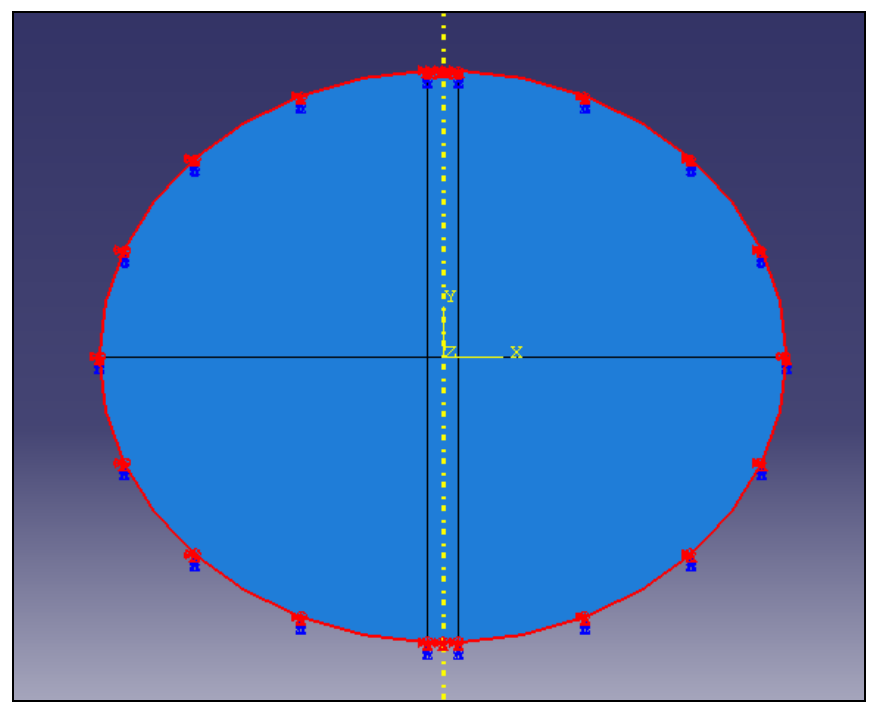

Figure 7.11: Pinned Boundary Condition 
For the experimental analysis, the force was applied to the specimen and resulted in deflection at the center of span where it was then measured and recorded until the first and ultimate failure occurred on either one of the outer surfaces. For the numerical bending analysis, the specimen maximum deformation was dictated by the pre-determined values from the experimental bending analysis. Therefore, the same elastic modulus values from the bending experiment were used in the numerical analysis as "input parameters" for the material property. Although Poisson's ratio of 0.22 was kept the same for all test specimens, the material property for each specimen varied since each plate had a different corresponding elastic modulus.

In addition, the Hookean region was also selected since it is the region where the material did not experience permanent deformation due to elastic-linear behavior. It was also assumed that due to all plates had very small thickness; therefore, there were no shear deformation effects.

The initial loading condition ranged from 20 to $180 \mathrm{lbf}$ with a load increment of $40 \mathrm{lbf}$. Therefore five sets of loading conditions were performed within the Hookean region. The $1^{\text {st }}$ and ultimate failure load was also simulated in the numerical analysis. Fig. 7.12 shows the uniformpressure load being distributed along the center of the manhole cover model.

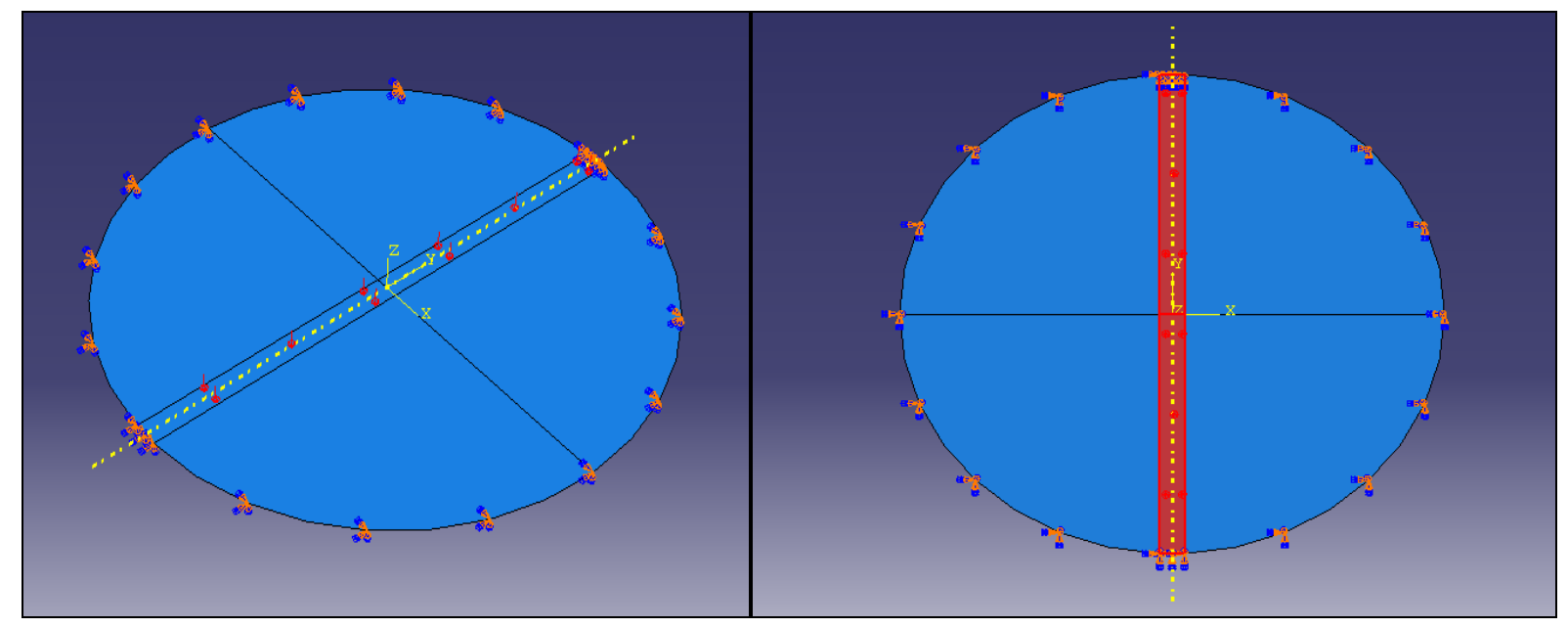

Figure 7.12: Uniform-Pressure Load Condition 
The figure above displays the type of load condition used to simulate the concentrateduniform axial load exerted by the head piece or loading nose. The same dimensions of the loading nose were used in the model to accurately simulate the concentrated-uniform load.

Fig. 7.13 shows the side view contour plot for laminate $\mathrm{L}_{20}$ 's maximum deflection. This maximum nodal displacement was at 0.608 with an uniform-pressure load of $20 \mathrm{lb}$ in the z-axis direction

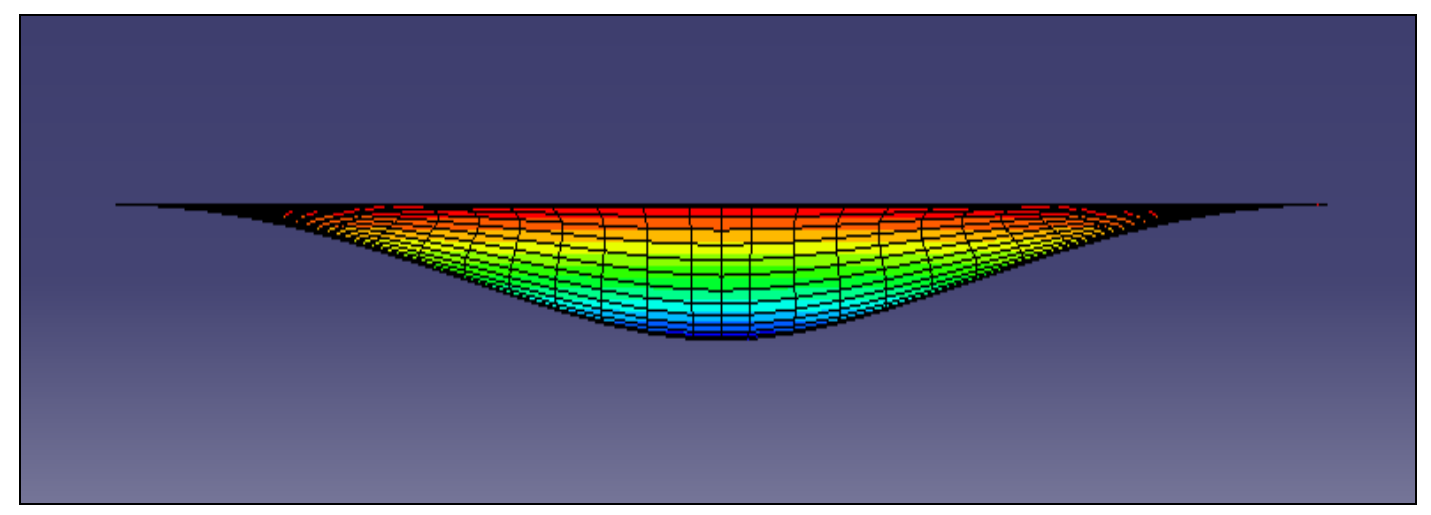

Figure 7.13: Maximum Deflection at $20 \mathrm{lb}_{f}$

The contour plot was categorized as follows, "blue" representing maximum displacement and "red" representing no displacement. Fig. 7.14 shows the side view contour plot for laminate $\mathrm{L}_{20}$ 's maximum deflection. This maximum nodal displacement was 1.736 in at a pressureuniform force of $60 \mathrm{lb}$ in the $\mathrm{z}$-axis direction.

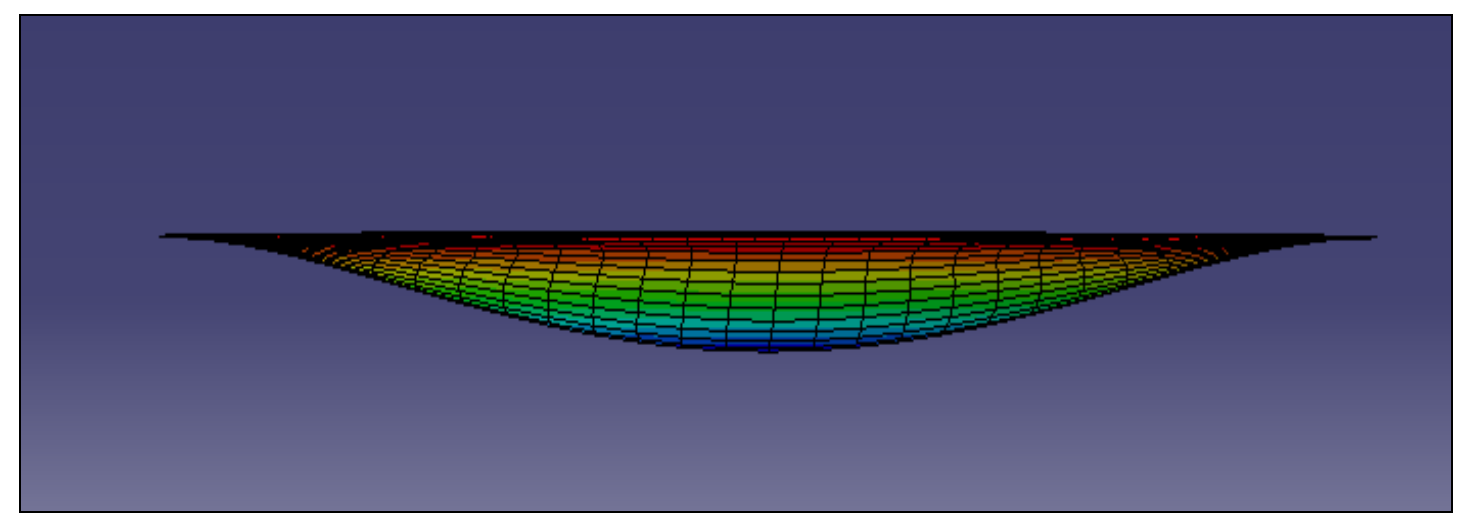

Figure 7.14: Maximum Deflection at $60 \mathrm{lb}_{f}$ 
Fig. 7.15 shows the front view contour plot for laminate $\mathrm{L}_{20}$ 's maximum deflection. This maximum nodal displacement was 2.894 in at a pressure-uniform force of $100 \mathrm{lb}_{\mathrm{f}}$ in the $\mathrm{z}$-axis direction.

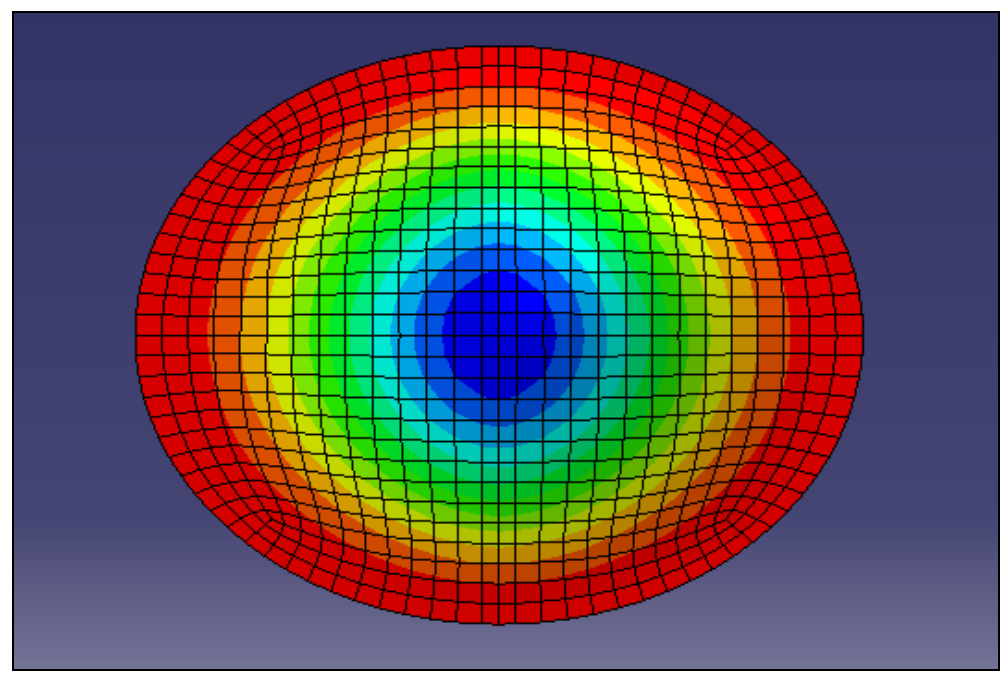

Figure 7.15: Maximum Deflection at $100 \mathrm{lb}_{f}$

The contour plot shows no failure at the outer edges or surfaces which implied that there was no pure bending. This was due to the pinned boundary condition which restricted the manhole cover plate from rotating in three degrees-of-freedom; hence, resulting specimen deflection at center of span. Fig. 7.16 shows the stress Von Mises contour plot of the plate's outer stress surface at a load of $100 \mathrm{lb}_{\mathrm{f}}$.

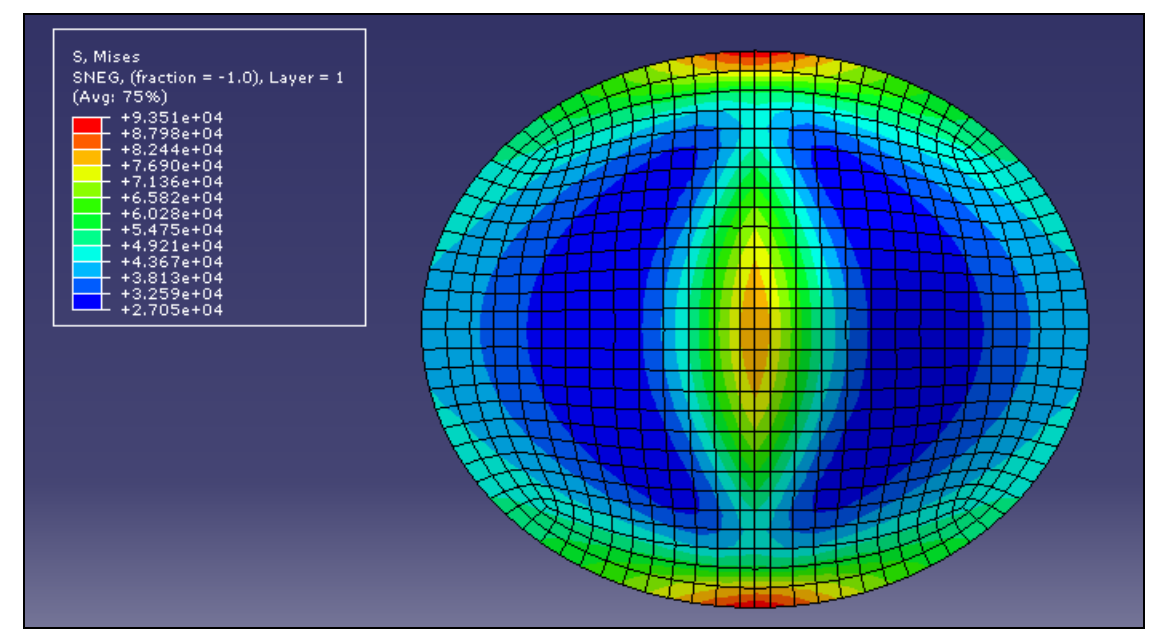

Figure 7.16: Stress Von Mises Contour Plot for $100 \mathrm{lb}_{f}$ 
It was observed that higher stress concentrations were experienced at plate's the center and ends as a result of the bending moments exerted by the loading nose. The maximum and minimum stress concentrations occurred at $93.51 \mathrm{ksi}$ and 28.05 ksi respectively.

Consequently, all test specimens had the similar force-deflection contour plot where the maximum displacement was located at the middle. This was performed by finding the spatial displacement at the node of the element. Table 7.15 shows a summary of laminate $\mathrm{L}_{20}$ 's maximum displacement for five loading case.

Table 7.15: Flexural Summary for Laminate $L_{20}$

\begin{tabular}{|c|c|c|c|c|c|c|c|}
\hline Failure Mode & \multicolumn{5}{|c|}{ Hookean (Elastic-Linear) Region } & $1^{\text {st }}$ Failure & Ultimate Failure \\
\hline Axial Force $\left(\mathrm{lb}_{\mathrm{f}}\right)$ & 20 & 60 & 100 & 140 & 180 & 247 & 428 \\
\hline Max Deflection (in) & 0.579 & 1.74 & 2.89 & 4.05 & 5.21 & 7.15 & 12.4 \\
\hline
\end{tabular}

The maximum displacement in the elastic region ranged was from 0.579 to $5.21 \mathrm{in}$. The average deflection interval between each loading case was approximately $1.16 \mathrm{in}$. The forcedisplacement trend was as expected since displacement increased with increasing load. The first failure load had a corresponding displacement of 7.15 in. Finally, the ultimate failure load had a maximum deflection of 12.4 in.

Four more bending conditions were repeated for the other test specimens. Table 7.16 shows a summary of laminate $\mathrm{L}_{30}$ 's maximum deflection for the different loading cases.

Table 7.16: Flexural Summary for Laminate $L_{30}$

\begin{tabular}{|c|c|c|c|c|c|c|c|}
\hline Failure Mode & \multicolumn{5}{|c|}{ Hookean (Elastic-Linear) Region } & $1^{\text {st }}$ Failure & Ultimate Failure \\
\hline Force $\left(\mathrm{Ib}_{\mathrm{f}}\right)$ & 20 & 60 & 100 & 140 & 180 & 200 & 449 \\
\hline Max Deflection (in) & 0.608 & 1.82 & 3.04 & 4.26 & 5.47 & 6.08 & 13.7 \\
\hline
\end{tabular}


The maximum displacement in the elastic region ranged was from 0.608 to $5.47 \mathrm{in}$. The average deflection interval between each loading case was approximately $1.21 \mathrm{in}$. The first failure load had a corresponding displacement of $6.08 \mathrm{in}$. The ultimate failure load had a maximum deflection of 13.7 in. Table 7.17 shows a summary of laminate $\mathrm{L}_{40}$ 's maximum deflection for the different loading cases.

Table 7.17: Maximum Flexural Summary for Laminate $L_{40}$

\begin{tabular}{|c|c|c|c|c|c|c|c|}
\hline Failure Mode & \multicolumn{5}{|c|}{ Hookean (Elastic-Linear) Region } & $1^{\text {st }}$ Failure & Ultimate Failure \\
\hline Force $\left(\mathrm{lb}_{\mathrm{f}}\right)$ & 20 & 60 & 100 & 140 & 180 & 320 & 385 \\
\hline Max Deflection (in) & 0.626 & 1.88 & 3.13 & 4.38 & 5.63 & 10.0 & 12.0 \\
\hline
\end{tabular}

The maximum displacement in the Hookean region ranged was from 0.63 to 5.63 in. The average deflection interval between each loading case in the elastic region was approximately 1.25 in. The first failure load had a corresponding displacement of $10 \mathrm{in}$. Finally, the ultimate failure load had a maximum deflection of $12.4 \mathrm{in}$. Table 7.18 shows a summary of laminate $\mathrm{HD}_{30}$ 's maximum deflection for the different loading cases.

Table 7.18: Maximum Flexural Summary for Laminate $\mathrm{HD}_{30}$

\begin{tabular}{|c|c|c|c|c|c|c|c|}
\hline Failure Mode & \multicolumn{5}{|c|}{ Hookean (Elastic-Linear) Region } & $1^{\text {st }}$ Failure & Ultimate Failure \\
\hline Force $\left(\mathrm{lb}_{\mathrm{f}}\right)$ & 20 & 60 & 100 & 140 & 180 & 46 & 357 \\
\hline Max Deflection (in) & 0.549 & 1.65 & 2.75 & 3.85 & 4.94 & 1.28 & 9.80 \\
\hline
\end{tabular}

The maximum displacement in the elastic region ranged was from 0.549 to $4.94 \mathrm{in}$. The average deflection interval between each loading case was approximately $1.10 \mathrm{in}$. The first failure load had a corresponding displacement of 1.28 in. Finally, the ultimate failure load had a maximum deflection of 9.8 in. Table 7.19 shows a summary of laminate $\mathrm{L}_{\mathrm{B} 0}$ 's maximum deflection for the different loading cases. 
Table 7.19: Flexural Summary for Laminate $L_{B 0}$

\begin{tabular}{|c|c|c|c|c|c|c|c|}
\hline Failure Mode & \multicolumn{5}{|c|}{ Hookean (Elastic-Linear) Region } & $1^{\text {st }}$ Failure & Ultimate Failure \\
\hline Force $\left(\mathrm{lb}_{\mathrm{f}}\right)$ & 20 & 60 & 100 & 140 & 180 & 257 & 488 \\
\hline Max Deflection (in) & 0.497 & 1.49 & 2.48 & 3.48 & 4.72 & 6.39 & 12.1 \\
\hline
\end{tabular}

The maximum displacement in the elastic region ranged from 0.497 to $4.72 \mathrm{in}$. The average deflection interval between each loading case was approximately $0.993 \mathrm{in}$. The forcedisplacement trend was as expected since displacement increased with increasing load. The first failure load had a corresponding displacement of 6.39 in. The ultimate failure load had a maximum deflection of $12.1 \mathrm{in}$.

Table 7.20 shows the summary of maximum displacement for the different loading cases of each laminated plate.

Table 7.20: Comparison of Maximum Deflection for Isotropic Plates at Different Loads

\begin{tabular}{|c|c|c|c|c|c|c|c|}
\hline Specimen & $20 \mathrm{lbf}$ & $60 \mathrm{lbf}$ & $100 \mathrm{lbf}$ & $140 \mathrm{lbf}$ & $180 \mathrm{lbf}$ & $1^{\text {st }}$ Failure & $\begin{array}{c}\text { Ultimate } \\
\text { Failure }\end{array}$ \\
\hline $\mathrm{L}_{20}$ & $0.6 \mathrm{in}$ & $1.7 \mathrm{in}$ & $2.9 \mathrm{in}$ & $4.1 \mathrm{in}$ & $5.2 \mathrm{in}$ & $7.2 \mathrm{in}$ & $12 \mathrm{in}$ \\
\hline $\mathrm{L}_{30}$ & $0.6 \mathrm{in}$ & $1.8 \mathrm{in}$ & $3.0 \mathrm{in}$ & $4.3 \mathrm{in}$ & $5.5 \mathrm{in}$ & $6.1 \mathrm{in}$ & $14 \mathrm{in}$ \\
\hline $\mathrm{L}_{40}$ & $0.6 \mathrm{in}$ & $1.9 \mathrm{in}$ & $3.1 \mathrm{in}$ & $4.4 \mathrm{in}$ & $5.6 \mathrm{in}$ & $10 \mathrm{in}$ & $12 \mathrm{in}$ \\
\hline $\mathrm{HD}_{30}$ & $0.5 \mathrm{in}$ & $1.7 \mathrm{in}$ & $2.8 \mathrm{in}$ & $3.9 \mathrm{in}$ & $4.9 \mathrm{in}$ & $1.3 \mathrm{in}$ & $10 \mathrm{in}$ \\
\hline $\mathrm{L}_{\mathrm{B} 0}$ & $0.5 \mathrm{in}$ & $1.5 \mathrm{in}$ & $2.5 \mathrm{in}$ & $3.5 \mathrm{in}$ & $4.7 \mathrm{in}$ & $6.4 \mathrm{in}$ & $12 \mathrm{in}$ \\
\hline
\end{tabular}

According to the table, all laminated plates showed a linear trend within the Hookean region. This meant that laminated plates within the elastic load region were able to resist ample deflection without experiencing permanent deformation. In each case, there was consistency within the same elastic failure load region. For example, in the load 20 case, the limestone filled 
plates had similar maximum deflections of 0.6 in; whereas, plates $\mathrm{HD}_{30}$ and $\mathrm{L}_{\mathrm{B} 0}$ also had approximate displacements of 0.5 within the same load failure mode, consequently, there was a 0.1 difference between them. This is explained by the assumption that an isotropic material is modeled to have a linear elastic behavior. This was unexpected since plate $\mathrm{L}_{40}$ had a lower elastic modulus and hence, a lower stiffness than plate $\mathrm{L}_{30}$. This might be a consequence of the large mass difference between plate $\mathrm{L}_{40}$ and plate $\mathrm{L}_{30}$. Consequently, all test specimens with limestone filler exhibited highest maximum deflection. Plate $\mathrm{HD}_{30}$ also experienced a lower deflection compared to plate $\mathrm{L}_{30}$ in all the loading cases, within the linear elastic region. This was unexpected since composite $\mathrm{HD}_{30}$ usually out-performed composite $\mathrm{L}_{30}$ in the experimental bending analysis. Plate $\mathrm{LB}_{0}$ experienced the lowest deflection.

The laminated plates $\mathrm{L}_{20}, \mathrm{~L}_{40}$, and $\mathrm{L}_{\mathrm{B} 0}$ had the lowest ultimate failure load. Plate $\mathrm{L}_{30}$ had the highest ultimate failure load deflection of all laminated plates while $\mathrm{HD}_{30}$ had the lowest value. For the first failure mode plate $\mathrm{HD}_{30}$ had the smallest value of maximum displacement at 1.3 in. 


\section{RESULTS AND DISCUSSION OF ANALYTICAL ANALYSIS}

\subsection{Classical Plate Theory}

A plate can be considered the two-dimensional extension of a beam in simple bending. Both plates and beams support loads transverse or perpendicular to their plane and through bending action. A plate is a flat (if it were curved, it would be a shell). A beam has a single bending moment resistance, while a plate resists bending about two axes and has a twisting moment as described in the Classical Thin-Plate Theory or Kirchhoff plate theory.

The relationships between bending and twisting moments and plate deflection are employed in establishing the general differential-governing equation for the solution of a thin rectangular or circular plate supporting a distributed transverse load of intensity $p$ per unit area as seen in Fig. 8.1 The distributed load may, in general, vary over the surface of the plate and is therefore a function of $\mathrm{x}$ and $\mathrm{y}[25]$. Considering a thin plate in the $\mathrm{x}-\mathrm{y}$ plane of thickness $t$ measured in the z-direction, the plate surfaces at $(\mathrm{z}= \pm t / 2)$ and its midsurface is at $\mathrm{z}=0$. The basic geometry restrictions of the plate are the following: the plate thickness is much smaller than its in-plane dimensions and the deflection $w$ is much smaller than the thickness $t(w / t<<1)$.

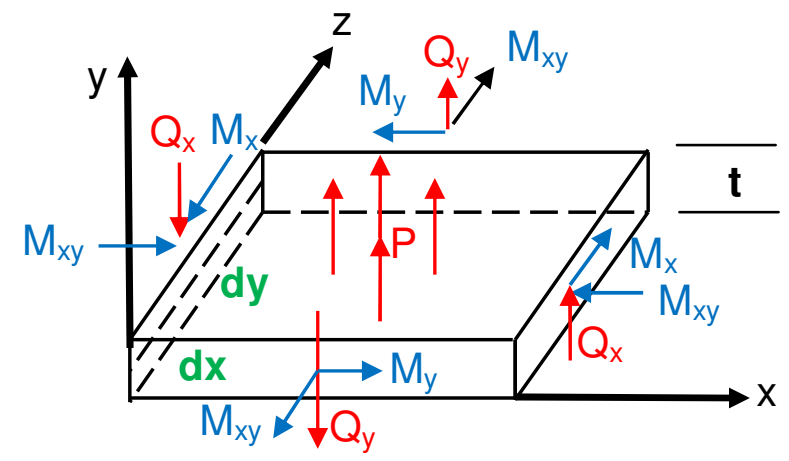

Figure 8.1: Plate Element Subjected to Bending, Twisting and Transverse Loads 
According to the Kirchhoff assumptions, it is assumed that the middle plane of the plate is the neutral plane (where the in-plane deflections in the $\mathrm{x}$ and $\mathrm{y}$ directions at the midsurface are assumed to be zero) and that the plate deforms such that plane sections remain plane after bending (where the transverse shear strains $\gamma_{\mathrm{xz}}$ and $\gamma_{\mathrm{yz}}=0$ and $\gamma_{\mathrm{xy}} \neq 0$; hence, implying that the plate may twist in the plane but right angles in the plate's plane may not remain right angles after loading) [25]. Other assumptions to consider are the following: thickness changes can be neglected and normals undergo no extension $\left(\varepsilon_{\mathrm{z}}=0\right)$.

The classical plate equation arises from a combination of four distinct subsets of plate theory: the kinematic, constitutive, force resultant, and equilibrium equations. Eqn. 8.1 shows the kinematic equations re-arranged in a matrix format showing the definitions for in-plane strains/displacement equations, along with the curvature relationships.

$$
\left[\begin{array}{c}
\varepsilon_{x} \\
\varepsilon_{y} \\
\gamma_{x y}
\end{array}\right]=z\left[\begin{array}{c}
\kappa_{x} \\
\kappa_{y} \\
2 \kappa_{x y}
\end{array}\right]=-z\left[\begin{array}{c}
\frac{\partial^{2} w_{0}}{\partial x^{2}} \\
\frac{\partial^{2} w_{0}}{\partial y^{2}} \\
2 \frac{\partial^{2} w_{0}}{\partial x \partial y}
\end{array}\right]
$$

The curvatures of the plate $k$ are given as the rate of change of the angular displacements of the normals and where $w_{0}$ is the displacement of the middle plane in $z$ direction. Based on the third Kirchoff assumption, the constitutive matrix of plane strain equations that relate in-plane strains to in-plane stresses for an isotropic material is shown below:

$$
\left[\begin{array}{c}
\varepsilon_{x} \\
\varepsilon_{y} \\
p_{x y}
\end{array}\right]=\frac{1}{E}\left[\begin{array}{ccc}
1 & -v & 0 \\
-v & 1 & 0 \\
0 & 0 & 2(1+v)
\end{array}\right]\left[\begin{array}{l}
\sigma_{x} \\
\sigma_{y} \\
\sigma_{x y}
\end{array}\right]
$$


Similar to the stress variation in a beam, the stresses vary linearly in the z-direction from the midsurface of the plate. The transverse shear stresses, $\sigma_{\mathrm{yz}}$ and $\sigma_{\mathrm{xz}}$ are also present while the transverse shear deformation is neglected; therefore, the resultant shear forces $\mathrm{Q}_{\mathrm{x}} \delta_{\mathrm{y}}$ and $\mathrm{Q}_{\mathrm{y}} \delta_{\mathrm{x}}$ are assumed to act through the centroid of the faces of the element, as seen in Eqn. 8.3. These stresses vary quadratically through the plate thickness.

$$
\left[\begin{array}{l}
M_{x} \\
M_{y} \\
M_{x y}
\end{array}\right]=\int_{-t / 2}^{t / 2} z\left[\begin{array}{l}
\sigma_{x} \\
\sigma_{y} \\
\sigma_{x y}
\end{array}\right] d z \quad\left[\begin{array}{l}
Q_{x z} \\
Q_{y z}
\end{array}\right]=\int_{-t / 2}^{t / 2}\left[\begin{array}{l}
\sigma_{x z} \\
\sigma_{y z}
\end{array}\right] d z
$$

where $M_{x}, M_{y}$, and $M_{x y}$ are the bending moments acting along the edge of the plate, while $Q_{x}$ and $Q_{y}$ are the vertical shear forces per unit length on faces perpendicular to the $\mathrm{x}$ and $\mathrm{y}$ axes, respectively.

The equilibrium equations for plate bending are important in selecting the element displacement fields. The governing differential equations are the following:

$$
Q_{y z}=\frac{\partial M_{x p}}{\partial x}+\frac{\partial M_{y}}{\partial y}, Q_{x z}=\frac{\partial M_{x}}{\partial x}+\frac{\partial M_{y x}}{\partial y} \frac{\partial Q_{x z}}{\partial x}+\frac{\partial Q_{y z}}{\partial y}=-p_{z}
$$

where $p$ is the transverse distributed loading and $Q_{x}$ and $Q_{y}$ are the transverse shear line loads. The 3 governing differential equations are then combined to eliminate $Q_{x z}$ and $Q_{y z}$, and form the following equation:

$$
\frac{\partial^{2} M_{x}}{\partial x^{2}}+2 \frac{\partial^{2} M_{x y}}{\partial x \partial y}+\frac{\partial^{2} M_{y}}{\partial y^{2}}=-p_{z}
$$


To relate the plate's out-of-plane displacement $w_{0}$ to its pressure loading $p_{z}$, the results of the four plate subcategories are combined. The plate is also assumed to be constructed by isotropic material and subjected to transverse loading.

Eqns. 8.6 shows how the moment resultants are replaced with its definition in terms of the direct stress while assuming uniform thickness:

$$
\int_{-t / 2}^{t / 2} z\left(\frac{\partial^{2} \sigma_{x}}{\partial x^{2}}+2 \frac{\partial^{2} \sigma_{x y}}{\partial x \partial y}+\frac{\partial^{2} \sigma_{y}}{\partial y^{2}}\right) d z=-p_{z}
$$

After using the constitutive relation to eliminate stress for strain and the kinematic matrix to replace strain for normal displacement $w_{0}$, the equation of equilibrium can then be expressed in terms of the normal displacement $w_{0}$ :

$$
\int_{-t / 2}^{f / 2} \frac{E z^{2}}{1-v^{2}}\left(\left(\frac{\theta^{4} w_{0}}{\partial x^{4}}+v \frac{\partial^{4} w_{0}}{\partial x^{2} \partial y^{2}}\right)+2(1-v) \frac{\partial^{4} w_{0}}{\partial x^{2} \partial y^{2}}+\left(\frac{\partial^{4} w_{0}}{\partial y^{4}}+v \frac{\partial^{4} w_{0}}{\partial x^{2} \partial y^{2}}\right)\right) d z=p_{z}
$$

which yields

$$
\int_{-t / 2}^{t / 2} \frac{E z^{2}}{1-v^{2}} d z\left(\frac{\partial^{4} w_{0}}{\partial x^{4}}+2 \frac{\partial^{4} w_{0}}{\partial x^{2} \partial y^{2}}+\frac{\partial^{4} w_{0}}{\partial y^{4}}\right)=p_{z}
$$

After assuming homogeneous material along the thickness of the plate $(x$ and $y$ directions), the bending stiffness of the plate can be written as

$$
D=\int_{-t / 2}^{t / 2} \frac{E}{\left(1-v^{2}\right)} z^{2} \alpha z=\frac{E t^{3}}{12\left(1-v^{2}\right)}
$$


where $D$ is the bending/flexual rigidity of the plate. Substituting the bending rigidity term back into Eq. 8.10, the governing partial differential equation for isotropic, thin-plate bending may be derived as the Classical Plate Equation:

$$
D\left(\frac{\partial^{4}}{\partial x^{4}}+2 \frac{\partial^{4}}{\partial x^{2} \partial y^{2}}+\frac{\partial^{4}}{\partial y^{4}}\right) w_{0}=p_{z}
$$

The operator $\left(\partial^{2} / \partial x^{2}+\partial^{2} / \partial y^{2}\right)$ is the well-known Laplace operator in two dimensions. Furthermore, Eqn. 8.11 shows the differential operator $\nabla^{2}$ which is called the Laplacian differential operator:

$$
\Delta \equiv \nabla^{2}=\left\{\begin{array}{c}
\frac{\partial^{2}}{\partial r^{2}}+\frac{1}{r^{2}} \frac{\partial^{2}}{\partial \varphi^{2}}+\frac{1}{r} \frac{\partial}{\partial r} \\
\frac{\partial^{2}}{\partial x^{2}}+\frac{\partial^{2}}{\partial y^{2}}
\end{array}\right.
$$

where the first set of equations are used for circular plates and related to the cylindrical coordinate system, whereas, the latter set of equations is used for rectangular plates and related to the Cartesian coordinate system. Substituting the Laplacian differential operator into the classical plate equation is as follows:

$$
\nabla^{2} D \nabla^{2} w=p
$$

where the solution to the thin-plate bending is a function of the transverse displacement $w$. If the differentiation with respect to y-direction is neglected, then Eqn. 8.12 simplifies to beam equation and flexural rigidity $D$ of the plate reduces to the $E I$ of the beam when Poisson's effect is set to zero [25]. 
If the bending rigidity $D$ is constant throughout the plate, the plate equation can be simplified to:

$$
\nabla^{4}=\frac{p}{D}
$$

where $\nabla^{4}=\nabla^{2} \nabla^{2}=\Delta \Delta$ is called the biharmonic differential operator.

Finally, the exact solution for the displacement at the center of the plate is

$$
w=0.0056 \frac{P L^{2}}{D}
$$

where $P$ is the loading pressure and $L$ is the span length.

\subsection{Analytical Results}

Table 8.1 shows the results derived from using the classical thin plate theory. The first and ultimate failure load values were pre-determined from the experimental results. The analytical results will be discussed in more detail in the following section.

Table 8.1: Delfection Summary for Isotropic Plates under Bending Loading

\begin{tabular}{|c|c|c|c|c|c|c|c|}
\hline Specimen & $20 \mathrm{lbf}$ & $60 \mathrm{lbf}$ & $100 \mathrm{lbf}$ & $140 \mathrm{lbf}$ & $180 \mathrm{lbf}$ & $1^{\text {st }}$ Failure & $\begin{array}{c}\text { Ultimate } \\
\text { Failure }\end{array}$ \\
\hline $\mathrm{L}_{20}$ & $0.253 \mathrm{in}$ & $0.506 \mathrm{in}$ & $1.26 \mathrm{in}$ & $1.77 \mathrm{in}$ & 3.04 & $7.2 \mathrm{in}$ & 5.41 \\
\hline $\mathrm{L}_{30}$ & $0.208 \mathrm{in}$ & $0.417 \mathrm{in}$ & $1.04 \mathrm{in}$ & $1.46 \mathrm{in}$ & 2.08 & $6.1 \mathrm{in}$ & 4.68 \\
\hline $\mathrm{L}_{40}$ & $0.263 \mathrm{in}$ & $0.526 \mathrm{in}$ & $1.31 \mathrm{in}$ & $1.84 \mathrm{in}$ & 4.20 & $10 \mathrm{in}$ & 5.06 \\
\hline $\mathrm{HD}_{30}$ & $0.219 \mathrm{in}$ & $0.438 \mathrm{in}$ & $1.09 \mathrm{in}$ & $1.54 \mathrm{in}$ & 0.50 & $1.3 \mathrm{in}$ & 3.91 \\
\hline $\mathrm{L}_{\mathrm{B} 0}$ & $0.253 \mathrm{in}$ & $0.505 \mathrm{in}$ & $1.26 \mathrm{in}$ & $1.77 \mathrm{in}$ & 3.25 & $6.4 \mathrm{in}$ & 6.16 \\
\hline
\end{tabular}




\section{COMPARISON OF STATIC AND DYNAMIC RESULTS}

\subsection{Static Analysis}

\subsubsection{Comparison of Elastic and Flexural Modulus}

For this thesis investigation, it was shown that for most brittle materials, the ultimate strength in compression or bending is much larger the ultimate strength in tension. This due to the presence of flaws, such as microscopic cracks or cavities, which tend to weaken the material in tension, while not appreciably affecting its resistance to compressive failure [20]. Table 9.1 shows the material properties results for the beam/plate specimens which were derived from the tensile and bending test methods.

Table 9.1: Material Property Summary for Isotropic Beams and Plates

\begin{tabular}{|c|c|c|c|c|}
\hline \multirow{2}{*}{ Specimen } & \multicolumn{2}{|c|}{ Beam } & \multicolumn{2}{c|}{ Plate } \\
\hline & Youngs' Modulus (ksi) & Shear Modulus (ksi) & Flexural Modulus (ksi) & Shear Modulus (ksi) \\
\hline $\mathrm{L}_{20}$ & 2671 & 1095 & 43,708 & 53.1 \\
\hline $\mathrm{L}_{30}$ & 2542 & 1042 & 40,981 & 64.0 \\
\hline $\mathrm{L}_{40}$ & 2471 & 1013 & 37,102 & 51.6 \\
\hline $\mathrm{HD}_{30}$ & 2814 & 1154 & 41,642 & 61.6 \\
\hline $\mathrm{L}_{\mathrm{B} 0}$ & 3111 & 1151 & 49,867 & 53.2 \\
\hline
\end{tabular}

As expected, it was observed that the Young's modulus values were lower than the flexural modulus values for the beam specimen, and the flexural modulus values were extremely high compared to the rigidity modulus. This was as expected since the ASTM D-3753 test results of elastic and flexural modulus also showed to be greater than Young's modulus. The rigidity modulus values were low as expected due to its very high span length-to-thickness ratio. In addition, all test specimens were assumed isotropic and homogenous. 
Both test specimens $\mathrm{L}_{30}$ and $\mathrm{HD}_{30}$ had very similar flexural modulus values of 36.5 and 36.6 Msi, respectively, specimen $\mathrm{L}_{30}$ did not performed as expected. Table 9.1 also shows a noticeable deficiency in stiffness compared to plate $\mathrm{L}_{30}$. This was unexpected since it was assumed that the plate $\mathrm{HD}_{30}$ was going to experience a similar bending behavior as plate $\mathrm{L}_{30}$.

Test specimen with the highest "stiffness," or ability to resist a deformation within the linear range was laminated plate $\mathrm{L}_{\mathrm{B} 0}$. It also had the highest flexural and shear modulus. The test specimen with the lowest elastic, flexural, and shear modulus was laminate $\mathrm{L}_{40}$. An explanation for this result is that laminate $\mathrm{L}_{40}$, had the smallest cross-sectional area thus decreasing the elastic and shear modulus, and the overall strength of the laminate. It was also observed that laminate $\mathrm{HD}_{30}$ exhibited more tensile and flexural strength to resist axial loadings. This is primarily due to the high adhesive-density bonding properties that allow the fiber embedded within the matrix material to resist higher axial and bending loads.

It was also noticed that the composite material under tensile and bending loading did not obtain the greatest possible strength as predicted. The fibers in layers were most likely not orientated in the same direction as the axial load or the matrix (filler) material thus not strong enough to prevent fibers from kinking or buckling. The test specimens experienced premature rupture and which caused the elastic modulus not to be very accurate since the elastic limit was exceeded.

\subsubsection{Comparison of Bending Load and Maximum Deflection}

There was considerable error shown in all of the plates between the finite element

analysis and experimental data in both determining the failure load of the plate and of the stiffness of each plate. The error in determining the failure load is largely due to two main factors which are both related to the strength parameters used in the model. The first has to do with how 
the material properties of fiberglass/filler were obtained in the experimental analysis. The second has to do with the selection of load/boundary condition in the numerical analysis.

A comparison of all the failure loads of all five plates can be seen in Table 9.2. The deflection value corresponded to the displacement at which the load fails. Both first and maximum failure loads were pre-determined values in order to compare the experimental deflection with numerical results.

Table 9.2: Maximum Deflection Summary due to Bending Loads

\begin{tabular}{|c|c|c|c|c|}
\hline \multicolumn{5}{|c|}{ Experimental Analysis Results } \\
\hline Specimen & $\begin{array}{l}1^{\text {ST }} \text { Failure } \\
\text { Load (lbf) }\end{array}$ & Deflection (in) & $\begin{array}{c}\text { Max. Failure } \\
\text { Load (lbf) }\end{array}$ & Deflection (in) \\
\hline $\mathrm{L}_{20}$ & 247 & 2.28 & 428 & 2.75 \\
\hline $\mathrm{L}_{30}$ & 200 & 2.18 & 449 & 2.89 \\
\hline $\mathrm{L}_{40}$ & 320 & 2.39 & 385 & 2.84 \\
\hline $\mathrm{HD}_{30}$ & 46 & 0.31 & 357 & 1.21 \\
\hline $\mathrm{L}_{\mathrm{B} 0}$ & 257 & 2.25 & 488 & 2.75 \\
\hline \multicolumn{5}{|c|}{ Numerical Analysis Results } \\
\hline Specimen & $\begin{array}{l}1^{\mathrm{ST}} \text { Failure } \\
\text { Load (lbf) }\end{array}$ & Deflection (in) & $\begin{array}{l}\text { Max. Failure } \\
\text { Load (lbf) }\end{array}$ & Deflection (in) \\
\hline $\mathrm{L}_{20}$ & 247 & 7.2 & 428 & 12 \\
\hline $\mathrm{L}_{30}$ & 200 & 6.1 & 449 & 14 \\
\hline $\mathrm{L}_{40}$ & 320 & 10 & 385 & 12 \\
\hline $\mathrm{HD}_{30}$ & 46 & 1.3 & 357 & 10 \\
\hline $\mathrm{L}_{\mathrm{B} 0}$ & 257 & 6.4 & 488 & 12 \\
\hline \multicolumn{5}{|c|}{ Analytical Analysis Results } \\
\hline Specimen & $\begin{array}{l}1^{\text {ST }} \text { Failure } \\
\text { Load (lbf) }\end{array}$ & Deflection (in) & $\begin{array}{l}1^{\text {ST }} \text { Failure } \\
\text { Load (lbf) }\end{array}$ & Deflection (in) \\
\hline $\mathrm{L}_{20}$ & 247 & 3.04 & 247 & 5.41 \\
\hline $\mathrm{L}_{30}$ & 200 & 2.08 & 200 & 4.68 \\
\hline $\mathrm{L}_{40}$ & 320 & 4.20 & 320 & 5.06 \\
\hline $\mathrm{HD}_{30}$ & 46 & 0.50 & 46 & 3.91 \\
\hline $\mathrm{L}_{\mathrm{BO}}$ & 257 & 3.25 & 257 & 6.16 \\
\hline
\end{tabular}


According to the table above, test specimen $\mathrm{L}_{30}$ experienced the highest maximum deflection at the maximum failure load case for both experimental and numerical. This was probably because plate $\mathrm{L}_{30}$ had the greatest thickness, hence adding more resistant to compression failure.

Although plate $\mathrm{L}_{40}$ had the highest $1^{\text {st }}$ failure load, it had the worst performance since it had the lowest ultimate load and flexural modulus. Normally increasing the thickness of a laminate would increase the indentation limit. In the case of plate $\mathrm{L}_{40}$, the composite was made with more filler which made it more brittle and susceptible to experience fracture at a lower indentation limit. Above figure, also shows that the plate $\mathrm{L}_{40}$ experienced a large decrease in the sudden drop after the $1^{\text {st }}$ failure load, thus corresponding to fiber/matrix failure. Overall, plate $\mathrm{L}_{40}$ had the lowest stiffness and strength properties out of the three limestone filler laminates.

For the analytical analysis, test specimen $\mathrm{L}_{\mathrm{B} 0}$ had the highest deflection, whereas, specimen $\mathrm{HD}_{30}$ had the lowest maximum deflection. The analytical result implied that the filler material did provide additional strength to the composite structures, thus allowing them to resist higher bending loads. This created a discrepancy with the other test methods since their material property results suggested the opposite.

In order to compare the result accuracy for the bending analysis, the percentage error was calculated to see how close the test methods matched with each other. The experimental, numerical, and analytical results were all compared to each other and the error percentage was then calculated. Table 9.3 displays the error percentage summary for the deflection analysis of each plate. 
Table 9.3: Percent Error Summary for Isotropic Plate Subjected to Bending Loads

\begin{tabular}{|c|c|c|c|c|c|c|}
\hline & \multicolumn{2}{|c|}{ Exp. vs. Num } & \multicolumn{2}{c|}{ Analytical vs. Exp } & \multicolumn{2}{c|}{ Analytical vs. Num } \\
\hline Specimen & $\begin{array}{c}1^{\text {st }} \text { Failure } \\
\text { Error } \%\end{array}$ & $\begin{array}{c}\text { Ultimate Failure } \\
\text { Error } \%\end{array}$ & $\begin{array}{c}1^{\text {st }} \text { Failure } \\
\text { Error } \%\end{array}$ & $\begin{array}{c}\text { Ultimate } \\
\text { Failure Error } \%\end{array}$ & $\begin{array}{c}1^{\text {st }} \text { Failure } \\
\text { Error } \%\end{array}$ & $\begin{array}{c}\text { Ultimate Failure } \\
\text { Error } \%\end{array}$ \\
\hline $\mathrm{L}_{20}$ & 68 & 77 & 25 & 49 & 58 & 55 \\
\hline $\mathrm{L}_{30}$ & 64 & 79 & 4.8 & 38 & 66 & 67 \\
\hline $\mathrm{L}_{40}$ & 76 & 76 & 43 & 44 & 76 & 58 \\
\hline $\mathrm{HD}_{30}$ & 77 & 88 & 38 & 69 & 62 & 61 \\
\hline $\mathrm{L}_{\mathrm{B} 0}$ & 65 & 77 & 31 & 55 & 49 & 49 \\
\hline
\end{tabular}

According to the table shown above, test specimen $\mathrm{HD}_{30}$ experienced the highest percent error in both failure modes. The high percent error was probably due to the premature compression failure occurring at the top surface region. This type of failure leads to ply-level buckling which is later preceded by delamination of the outer ply failure. The experimental versus numerical results had the greatest percent error. This was highly due to the boundary condition discrepancy between the specimen and support fixture observed in the experimental and numerical analysis.

The analytical versus experimental results had the least percentage error. The high percentage error was probably due to the material property calculations. For the experimental analysis, the elastic modulus values were found by using the linear relationship of the stress vs. strain curves of the laminated beam specimens after static testing. The shear modulus of rigidity was also calculated for a beam while assuming it was made from isotropic- homogeneous material. For the numerical analysis, the shear modulus was determined by assuming an isotropic-homogeneous plate. In addition, the experimental bending analysis was performed by following the third-point loading test method for flexural properties of polymer matrix composite materials. Although this test method is usually used for beam with rectangular cross sections, it was still used with the assumption that laminated plates with circular cross section will 
experience the same flexural behavior found in laminated beams. Therefore, this discrepancy of material properties and assumptions might explain the high percentage error. The analytical versus numerical results also exhibited high percentage errors. Although both methods used the same material properties, the discrepancy of results was mainly due to the incorrect selection of boundary conditions used during numerical analysis. FEA showed that both failure modes experienced higher maximum deflection than that of the experimental results. This consequently created very high error percentages for both failure modes. In addition, the elastic modulus values used in this analysis were from tensile testing data. The results were not very accurate since the test specimens were not fully constrained inside the sub-frame support fixture during the experimental analysis, as seen in Fig. 9.1.

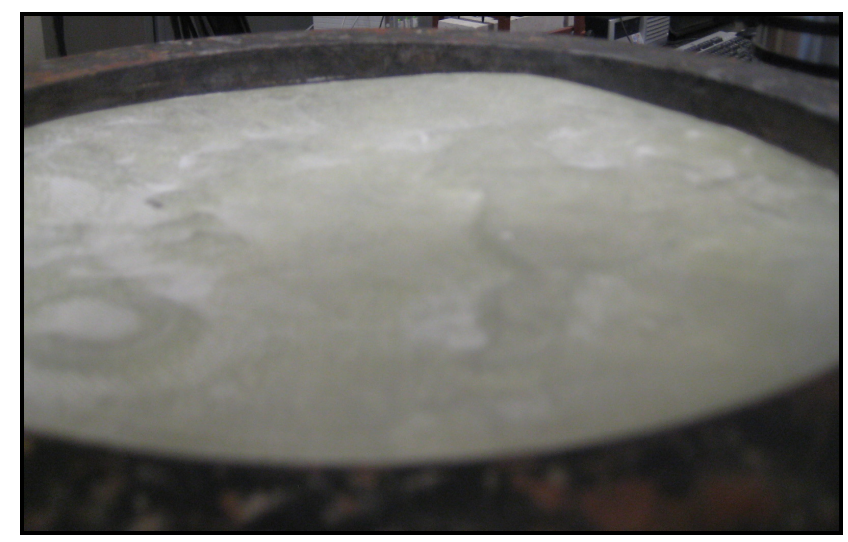

Figure 9.1: Simply Supported Plate inside Sub-Frame Support Fixture.

Fig. 9.2 shows the laminated plate experiencing high deformation due to the lack boundary restriction. 


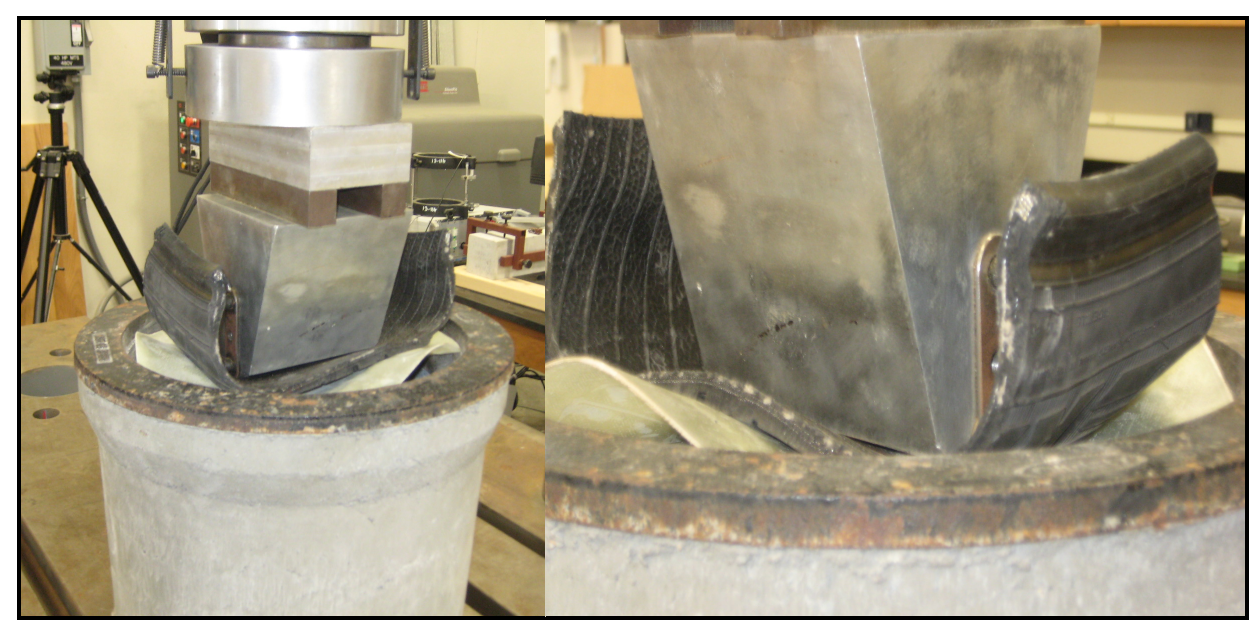

Figure 9.2: Simply Constrained Plate Subjected to Axial Loading

This would obviously create a discrepancy between the experimental and numerical analysis. Although the standard span-to-thickness ratio for a beam made from continuous-fiberreinforced polymer matrix composites is $32: 1$, the span-to-thickness for this the flat laminate plate was 183.3 .

For flexural strength properties, the standard support span-to-thickness ratio is essential since it is selected such that failure occurs at the outer surface of the specimens, due only to bending moment. Therefore, the high support span-to-thickness ratio decreased the accuracy and validity of the flexural property data since the laminated composite probably did not experience pure bending moment. Instead interlaminar shear failure was most probably introduced and thus produced significant deviations for measuring the mid-span deflection.

The experiment analysis also showed that all laminated plates experienced first damage mode which indicated delamination was initiated by fiber/matrix cracks from the loading. This caused the stiffness of the laminates to decrease when the contact force was increased to an ultimate load. Some delaminations were initiated by fiber/matrix cracks as seen at opposite ends of the laminated plate's surface. Several bending tests created different delaminations on 
different locations of the fiberglass laminates which were initiated by fiber/matrix cracks; hence, propagating with increasing loading and extending fully throughout the entire plate.

This would give incorrect data involved in determining the flexural strengths of a material. For fiberglass GS67813 (Woven Roving Fiber), the compressive transverse strength could have been several times higher than the tensile transverse strength, thus changing the overall strength properties of the material. Therefore, static compressive tests need to be performed in order to verify this discrepancy.

For all of the plates the stiffness of the finite element model resulted higher than the experimental data stiffness within the linear region. This elastic region is independent of any discrepancies between the strength of the FEA and the experimental data since laminated plates were able to resist ample deflection without experiencing permanent deformation. In each case, there was consistency within the same elastic failure load region.

\subsection{Dynamic Analysis}

In order to compare the numerical results with the experimental results for the frequency analysis, the percentage error was calculated to see how close the experimental results matched with the numerical results. The experimental results were compared to the numerical results and the error percentage was calculated. Table 9.4 displays the error percentage for the different bending load modes for each laminated beam. 
Table 9.4: Different Bending Loading Comparison for Laminated Beams

\begin{tabular}{|c|c|c|c|c|}
\hline \multicolumn{5}{|c|}{ Natural Frequency Experimental Results } \\
\hline Specimen & Mode 1 & Mode 2 & Mode 3 & Mode 4 \\
\hline $\mathrm{L}_{20}$ & 17.57 & 103.46 & 291.82 & 429.44 \\
\hline $\mathrm{L}_{30}$ & 13.66 & 79.06 & 218.62 & 429.54 \\
\hline $\mathrm{L}_{40}$ & 16.59 & 93.69 & 261.58 & 429.34 \\
\hline $\mathrm{HD}_{30}$ & 17.01 & 106.09 & 298.18 & 418.10 \\
\hline $\mathrm{L}_{\mathrm{B} 0}$ & 17.57 & 96.62 & 267.42 & 467.51 \\
\hline \multicolumn{5}{|c|}{ Natural Frequency Numerical Results } \\
\hline Specimen & Mode 1 & Mode 2 & Mode 3 & Mode 4 \\
\hline $\mathrm{L}_{20}$ & 12.569 & 79.617 & 228.47 & 465.27 \\
\hline $\mathrm{L}_{30}$ & 12.482 & 79.071 & 226.89 & 462.03 \\
\hline $\mathrm{L}_{40}$ & 12.060 & 76.737 & 222.09 & 458.54 \\
\hline $\mathrm{HD}_{30}$ & 12.045 & 76.638 & 221.81 & 457.96 \\
\hline $\mathrm{L}_{\mathrm{B} 0}$ & 13.635 & 87.011 & 253.41 & 528.47 \\
\hline \multicolumn{5}{|c|}{ Error Percentage (\%) } \\
\hline $\mathrm{L}_{20}$ & 28.5 & 23.05 & 21.7 & 7.71 \\
\hline $\mathrm{L}_{30}$ & 8.62 & 1.39 & 3.64 & 7.03 \\
\hline $\mathrm{L}_{40}$ & 27.3 & 18.1 & 15.1 & 6.37 \\
\hline $\mathrm{HD}_{30}$ & 29.2 & 27.8 & 6.45 & 8.71 \\
\hline $\mathrm{L}_{\mathrm{B} 0}$ & 22.4 & 9.94 & 5.24 & 11.5 \\
\hline
\end{tabular}

According to the graph above, beam $\mathrm{L}_{30}$ had the lowest percent error which was found in mode 2; whereas, test specimen $\mathrm{HD}_{30}$ had the highest error percentage. This was due to the uneven mass distributions of the test specimens made it very difficult to see the trend within the various test specimens, particularly in modes 2 and 3 of the experimental analysis. This was clearly observed in specimen $\mathrm{L}_{40}$ which had a higher frequency response than specimen $\mathrm{L}_{30}$. This was unexpected since it was assumed that laminated beams made with filler, increase mass distribution and experience lower frequencies since damping properties usually increase in modern composite fiber-reinforced materials, where the energy loss occurs through plastic or 
viscoelastic phenomena as well as from friction at the interfaces between the matrix and reinforcement.

The frequency extraction in the numerical analysis did show this trend. As predicted, specimen $\mathrm{L}_{\mathrm{B} 0}$ had the highest frequency response of all laminated beams. It experienced very little damping compared to the other beams since it did not have any filler content. In addition, Mode 4 had the lowest error percentage for all test specimens, as seen in Table 9.4

The natural frequencies found in modes 1, 2, and 3 for the experimental analysis overall resulted higher than the numerical analysis. This is due to the fact that beams on the magnetic shaker might not been setup correctly or the laminated beam specimens had manufacturing defectives which contribute to the high error percentage. In addition, the beam modeled in Abaqus also contributed to the higher error percentage since it was observed that the natural frequencies of the beams simulated in the Abaqus program were extremely low compared to the experimental results. This was probably due to the imperfections of the beam test specimens created during fabrication which were later used to determine the material properties from the experimental tensile tests. The erroneous data values derived from the tensile test would then contribute for the high error percentage difference found in both the experimental and numerical methods.

Also, the piezoelectric ceramic strain gages additional weight of 0.5 grams was not accounted for in the overall weight of the laminated beam; hence, the increase in mass distribution slightly affected the results. In addition, the piezoelectric ceramic strain gages were also not symmetrical since they were very fragile and difficult to cut, and therefore, further contributed to erroneous data by measuring frequency signals incorrectly. 
The fixed or built-in boundary condition may also contribute to the erroneous data since improper boundary condition can influence the overall dynamic response of the composite material. In the model, the laminated beams were assumed to be fully/symmetrically constrained to the magnetic shaker, which may not be the real case. Instead the beam can experience unwanted transverse-harmonic loads if it is not aligned correctly or secured tightly inside the clamp thus changing the frequency response of the structure. Although test specimens with increased filler had the lowest frequency response due the stiffness and damping behavior, it was still very difficult to quantify the source of a system's damping since it usually comes from other sources simultaneously, such as, energy loss during harmonic loading and not having the correct viscoelastic material properties of the epoxy. Also, variations in mass distributions and thickness of test specimens created a higher percentage error difference between the experimental and numerical analysis. 


\section{CONCLUSION}

This thesis investigation involved the development of fiberglass-filler laminated manhole covers and to study the static and dynamic behavior of the material by performing experimental and numerical analysis. First part of this study was to design a press mold of manhole cover by using Solid Works software which was later used to build several negative and positive molds from urethane liquid rubber, and develop procedures on how to manufacture the mold and composite specimens.

For specimen preparation, ten laminated beams of fiberglass with limestone/high-density adhesive filler were made and used to perform static and dynamic tests to determine mechanical properties of material. All test specimens had 4 plies of E-glass woven roving fabric and 3 to 1 epoxy ratio which was later mixed with different limestone filler quantities of 20,30 , and 40 grams and a high-density adhesive filler quantity of 30 grams. In addition, ten 11-inch diameter fiberglass-filler manhole cover plates were also created and used to perform experimental tests of flexural strength in order to study the monotonic behavior under bending loads of each fiberglass polymer matrix composite structure. A 13 x 13 in aluminum frame with a thickness of 0.2 inch was also used to secure and control the added filler's thickness for each laminated specimen during the curing process. Second part of this study was to obtain numerical results by using Abaqus software for finite element analysis and compare them with experimental analysis.

Test specimens for this thesis investigation did not follow the ASTM D-3753 standards due to the limited accessibility of testing equipment. Instead several 11-inch fiberglass/filler flat plates were constructed in order to represent an 11-inch diameter iron cast meter manhole cover. The laminated manhole covers were made from actual pieces of fiberglass-polymer material was consistent with the ASTM D-3753 requirements of FRP manhole component construction. 
The static/dynamic test results showed that the laminates made with fiberglass and filler experienced lower performance in stiffness and flexural strength. The test specimen made with 20 grams of limestone filler had a better strength results under tensile and bending loads than the other limestone laminates. Laminates made with 30 grams of high density filler had better results than laminates with 30 grams limestone due to its high-density filler properties; hence obtaining a higher elastic/shear modulus and less deflection. Consequently, test specimen with Eglass/filler had the highest overall performance in stiffness and flexural properties.

Test specimens had an intermediate fiber volume fraction $\left(0.47<\mathrm{V}_{\mathrm{f}}<0.51\right)$ which explained why test specimens experienced brittle failure with fiber pullout during tensile testing. A second major assumption in strength reduction was probably due to transverse shear loading. Since E-glass roving woven material have adequate shear loading capability, shear loads typically are carried by \pm 45 degrees fibers, or at least fibers with components other 0 and 90 degrees which would require the matrix to carry the shear load. The test specimens did not have \pm 45 degrees fiber orientation thus would be susceptible to fail under transverse loading. In addition, this could have been result of improper layup and bagging techniques, or misalignment of the specimen inside the Instron machine which may also create torsion or bending failure.

Test specimens followed a similar trend in mode shapes, natural frequencies, and damping behavior during vibration analysis. The experimental results showed that laminates with 20 grams of limestone and no filler experienced higher modes within the specified frequency range. This was expected since the material property of filler increased the stiffness and damping behavior in composite material.

In addition, it was also shown that for most brittle materials, the ultimate strength in compression or bending was much larger the ultimate strength in tension. This was due to the 
presence of flaws, such as microscopic cracks or cavities, which tend to weaken the material in tension, while not appreciably affecting its resistance to compressive failure.

Flexural properties may also vary depending on which surface of the specimen is in compression, as no laminate is perfectly symmetric such differences will shift the neutral axis and will be further affected by the even modest asymmetry in the laminate. In addition, flexural properties may also vary with specimen thickness, conditioning and/or testing environments, and rate of straining.

For the numerical analysis, laminated plates with higher filler content showed the lowest strength. However the experimental data also showed high strengths for fiberglass laminate with no filler but with high deflections. The discrepancy between the strength of the FEA models and the experimental data is attributed to inaccurate strength properties. High error percentages was also found between experimental and FEA in predicting the trend of stiffness of the plates.

In addition to the tension and compression test results from the supporting analysis, laminate $\mathrm{L}_{259}$ experienced the highest maximum load and strength. This was largely due to the increase modification of the 9-ply increase and the added limestone filler of 259 grams. Not only did it increase the test specimen's thickness but also provided significant strength and stiffness improvements in both tension and compression.

The indentation test results from the supporting analysis indicated that laminate $\mathrm{HD}_{30}$ experienced the highest maximum load with a corresponding maximum displacement of 0.8899 in. This result was as expected due since the laminate's high-density adhesive filler properties which provided substantial strength and stiffness qualities. As expected, laminate $\mathrm{L}_{\mathrm{B} 0}$ had the lowest overall performance because its polymer matrix composition did not have any filler; and therefore, lack in overall strength. Laminate $\mathrm{HD}_{30}$ had the best performance of the limestone 
filler laminates. It exhibited a corresponding maximum load and displacement of $645 \mathrm{lbf}$ and 0.7476 in respectively. Although both laminates $\mathrm{HD}_{30}$ and $\mathrm{L}_{30}$ had similar results, laminate $\mathrm{HD}_{30}$ still managed to experience better performance with an approximate load difference of $23 \mathrm{lbf}$. Therefore, although test specimen $\mathrm{HD}_{30}$ had a better performance, the overall production cost savings of limestone filler, makes it a more economical reinforcing filler option for creating laminated manhole covers.

Table 10.1 shows the overall cost summary for making the press molds. As seen in table below, the fabrication method described in the thesis investigation resulted very economical compared to the private industry's mold method since it had an overall cost saving of approximately $\$ 4700$.

Table 2: Press Mold Fabrication Cost Summary

\begin{tabular}{|c|c|c|}
\hline Expense & Private Company & Cal Poly SLO \\
\hline CNC Mill Labor & $\$ 3,826.88$ & $\$ 0$ \\
\hline Material Supply & $\$ 1,014.57$ & $\$ 178.23$ \\
\hline Overall & $\$ 4841.445$ & $\$ 178.23$ \\
\hline
\end{tabular}




\section{FUTURE WORK}

Since the test specimens for this thesis investigation did not follow the ASTM D-3753 standards due to the limited accessibility of testing equipment it would be recommended to fabricate 11-inch diameter laminated plates from actual pieces of fiberglass-reinforced material consistent with the ASTM D-3753 requirements of FRP manhole component construction. Flexural tests on the thick-resin fiberglass need to be inside the Christy H-8 support fixture. The flexural results will need to be compared with the FEA results in order to validate and compare the accuracy of the data.

Fiberglass-filler polymer matrix composite laminated plates and their damage resistance (involving their energy absorption, fracture toughness, failure mechanisms, and strength reduction) subjected to a drop-weight impact event need to be investigated. The following are different types of impact test methods that can be used to verify the impact resistance of the material: Charpy, drop-weight (ASTM D-7136), and Izod tests. Additional test methods for determining the compressive properties of fiberglass polymer matrix materials (ASTM D-695) need to be further researched.

Different failure criteria also need to be considered for testing manhole cover designs in order to find fiber/matrix failure modes. An example is examining the in situ strengths of the fiberglass/filler laminates and the Hashin damage criterion which provides a good prediction of fiber material damage for longitudinal tensile bending and impact [Hashin]. Greater examination of the effect of interlaminar shear on the strength of the plates needs also to be addressed. Different manhole cover orientations and the effect of the laminate thickness should be examined. 
More FEA's need to be performed by creating more realistic boundary constrains and different loading conditions needed to be simulated correctly in order to obtain more accurate results. For example using a concentrated load instead of uniform-pressure force or modeling a sub-frame specimen support fixture can also improve the results of the numerical analysis. In addition, laminated specimens need to be pinned onto the Christy H-8 specimen support fixture in order to obtain more accurate data during experimental testing. Also, laminated specimens need to use orthotropic and non-homogeneous properties which create a more realistic simulation of the material property in order obtain better numerical results.

Another option for improving frequency data results is by using the Unholtz Dickie Electrodynamic Shaker Table. This vibration testing system is composed of transducers (typically accelerometers and load cells), an analog-to-digital converter (to digitize analog instrumentation signals) and a host PC (Vwin software) to view data and analyze it. This modal testing apparatus has ability to analyze the data in multiple degrees of freedom (MODF) - adding degrees of freedom to represent a more realistic vibration model; hence, improving results obtained from the modal testing. 


\section{APPENDICES}

\section{Appendix A: Static Tensile Test Settings for Instron Merlin Software}

The following are screenshots of the Instron Merlin software steps used for performing static tensile test on laminated beams.

\section{General Menu}

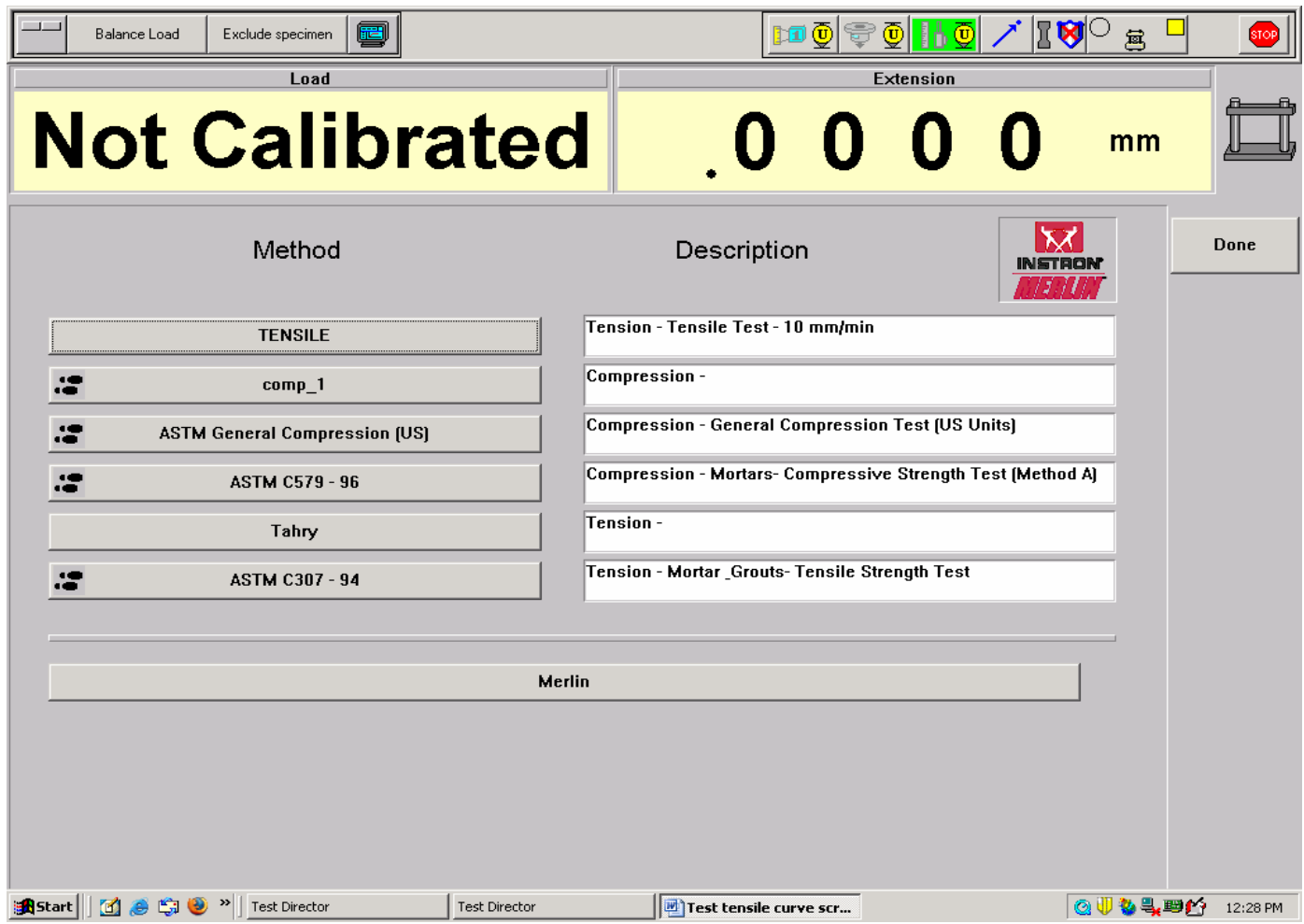

\section{Defining Specimen Menu}

\begin{tabular}{|c|c|c|c|}
\hline Sample - Ter & & & $-\square \underline{x}$ \\
\hline Define & \multirow{5}{*}{$\begin{array}{l}\text { Name: } \\
\text { Geometry: } \\
\text { Number of specimens: } \\
\text { Specimens tested: }\end{array}$} & \multirow{2}{*}{$\begin{array}{l}\text { Composite } \mathrm{L}_{30} \\
\text { Rectangular }\end{array}$} & Edit... \\
\hline Specimen & & & Resume... \\
\hline Notes & & & Replay... \\
\hline \multirow[t]{2}{*}{ User Inputs } & & $<5$ & End \\
\hline & & 0 & End\&Save... \\
\hline
\end{tabular}


Specimen Dimension Menu

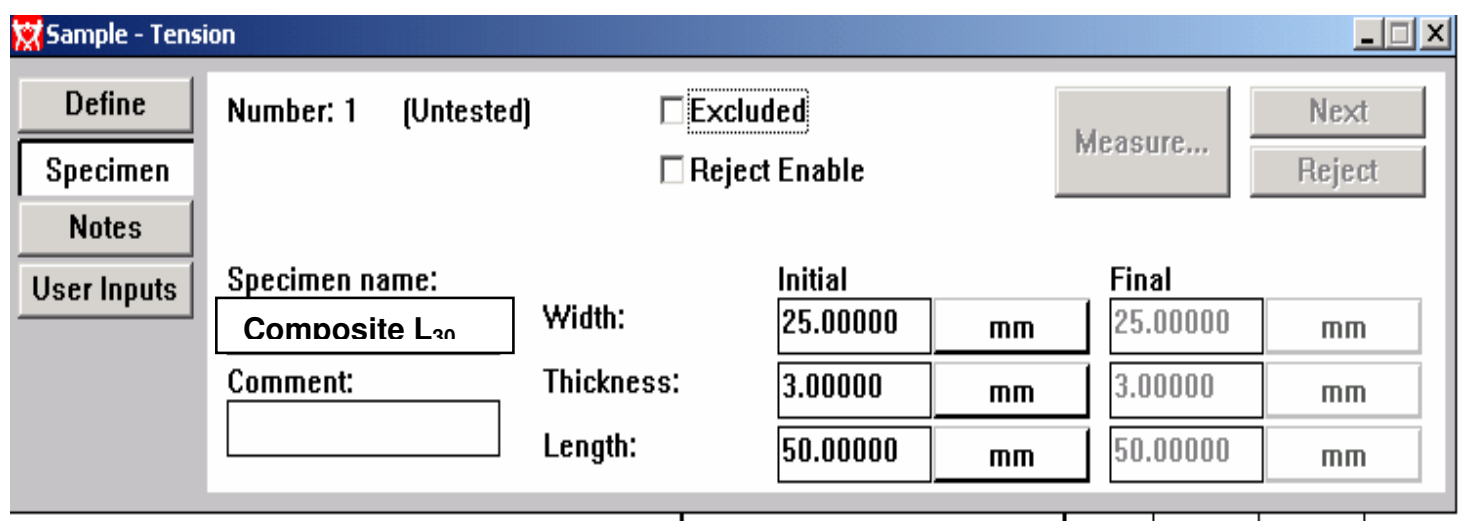

Specimen Notes Menu

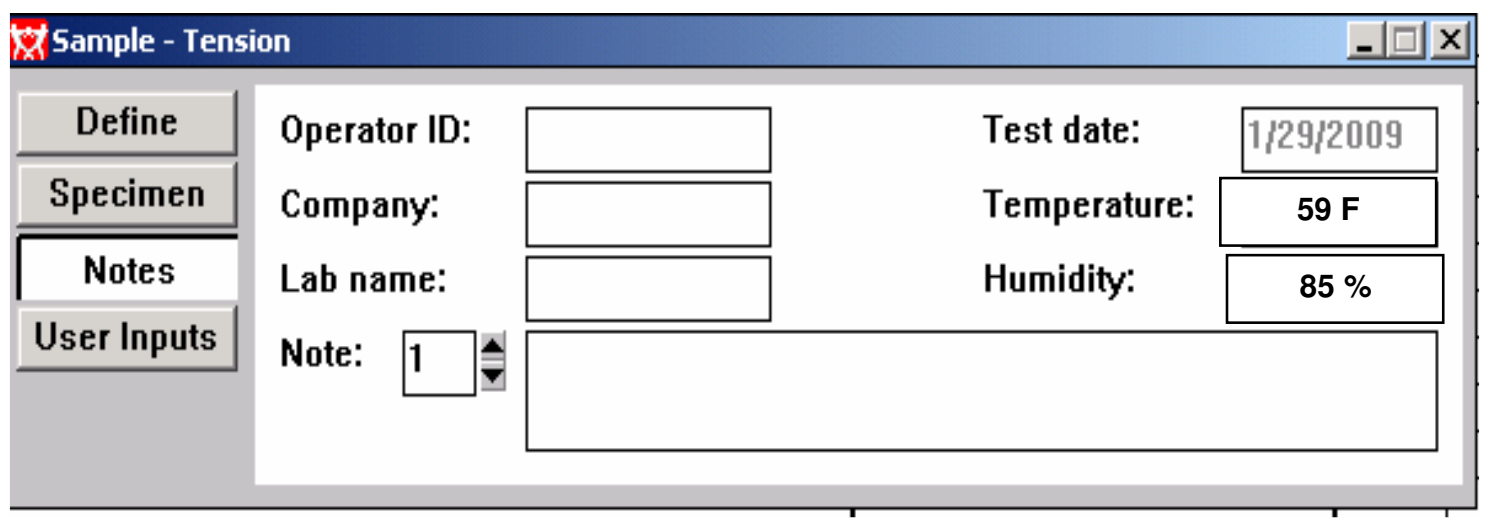

The following screenshots show the summary of the tensile tests. They display how the material properties were obtained and used to calculate the shear modulus and Young's modulus of elasticity. The following tensile result properties are listed in the menu below: maximum load, extension at break, elastic modulus, tensile stress at $0.2 \%$ yield, and tensile strength. 
Composite $L_{30}$ (Limestone Filler 30g) Tensile Test Result Menu

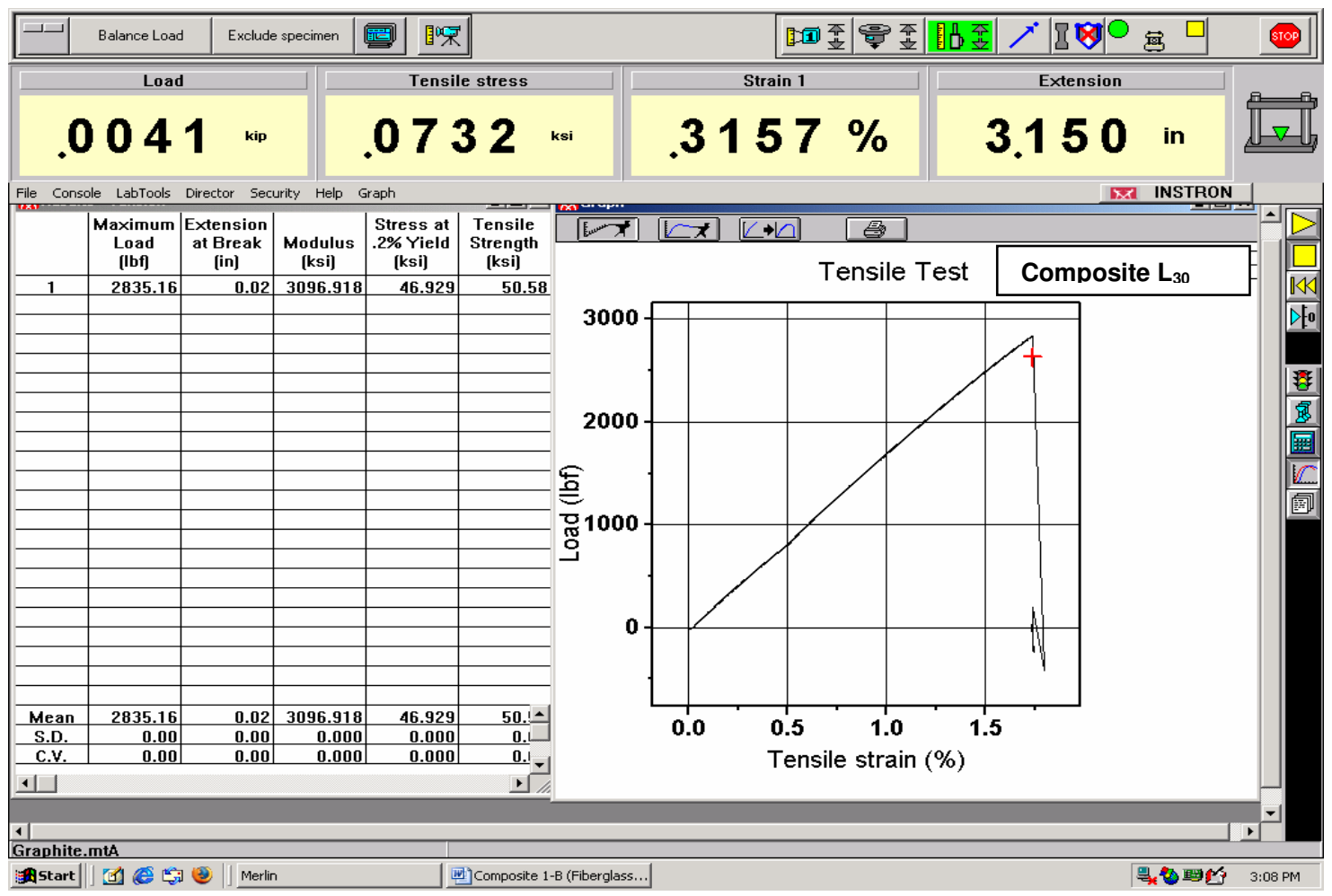

Composite $L_{B O}$ (Fiberglass Only) Tensile Test Result Menu

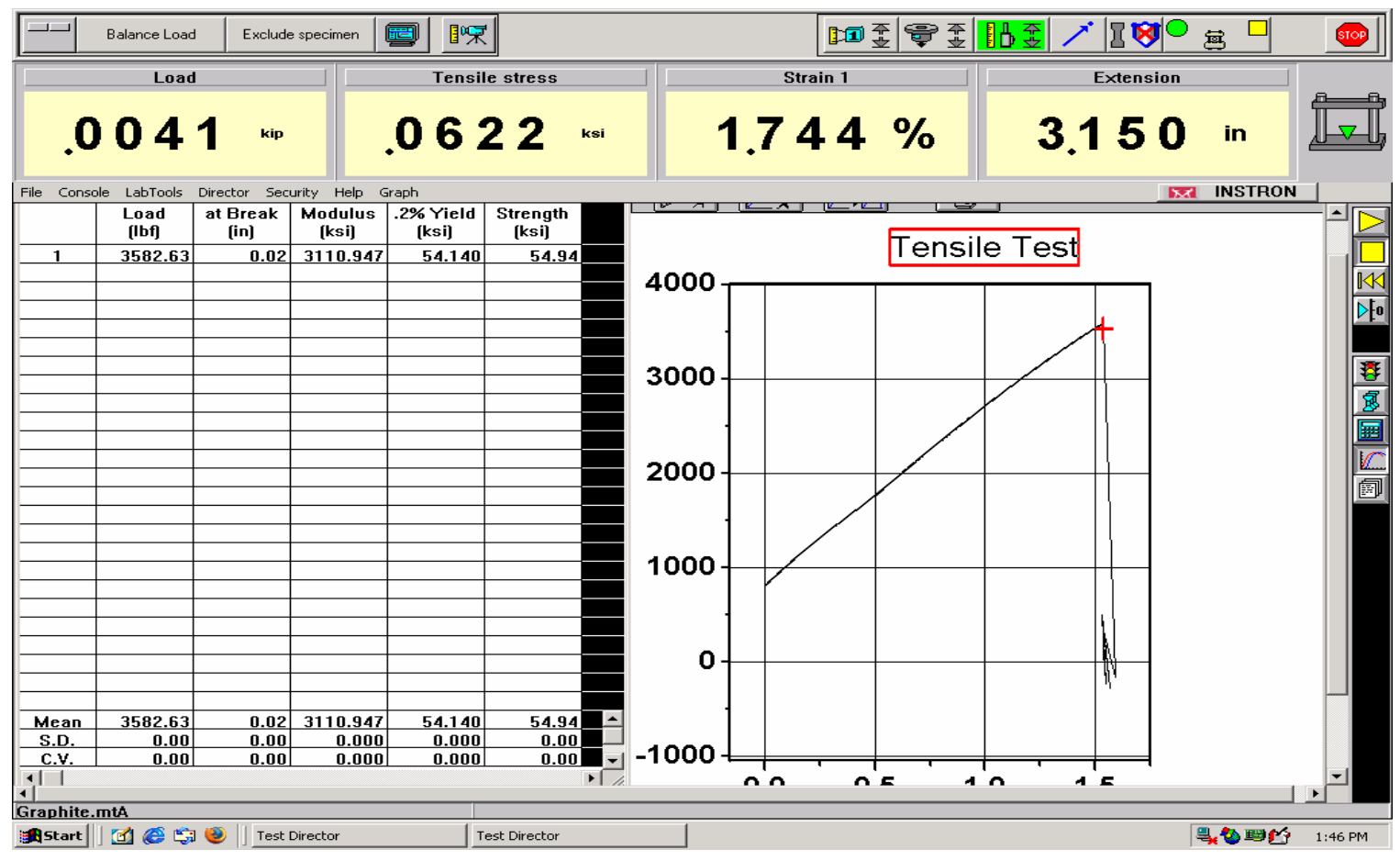


Composite $L_{40}$ (Limestone 40g Filler) Tensile Test Result Menu

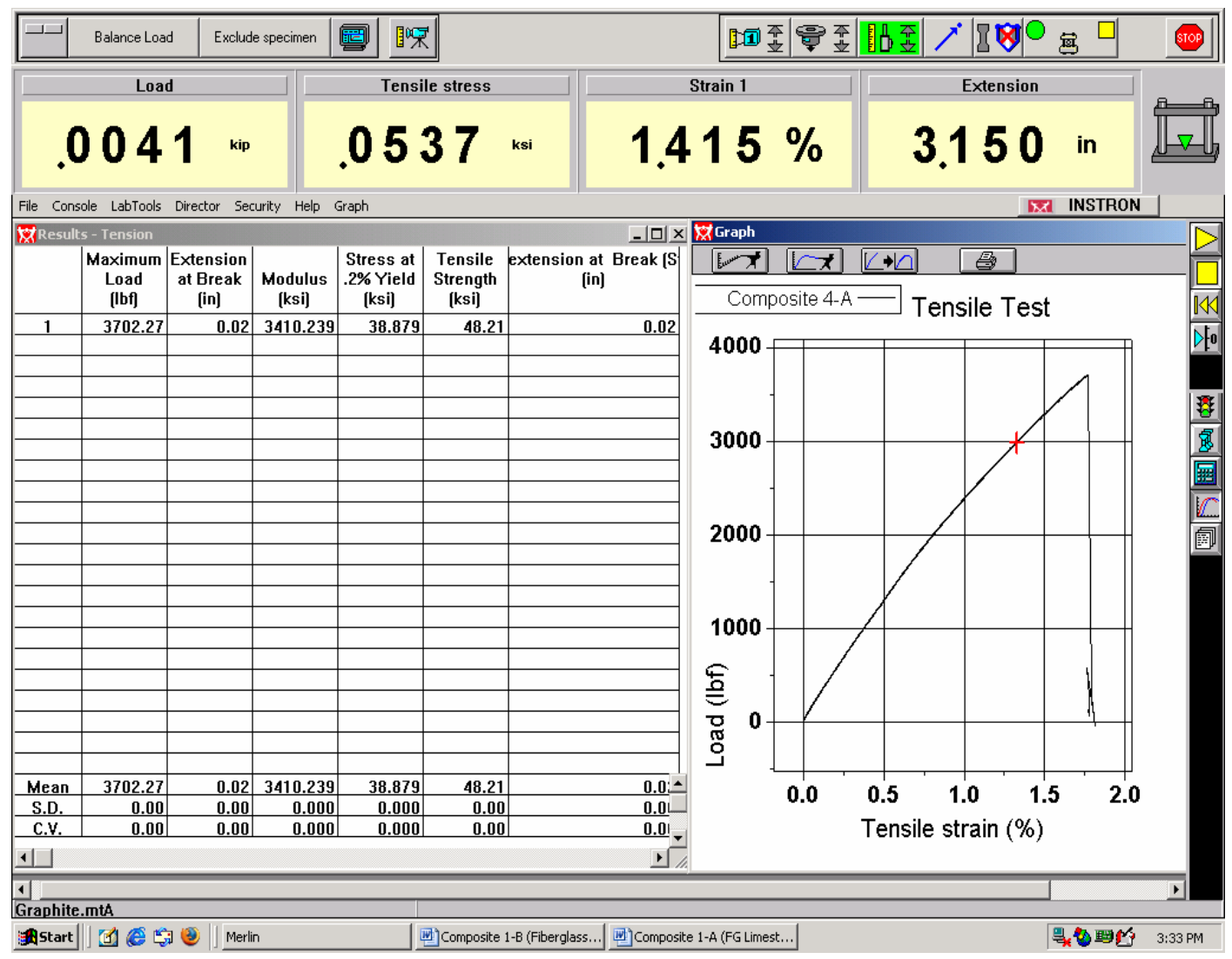

\section{Appendix B: Static Tensile Test Data}

The following are Excel spreadsheet displaying static test data. This was used to graph the stress versus strain curve and determine the elastic modulus of each test specimen.

\begin{tabular}{|l|r|l|l|r|}
\hline Specimen name: & Composite $\mathbf{L}_{\mathbf{2 0}}$ & & Extensometer & 0.0254 \\
\hline Width: & 1.447 & $\mathrm{In}$ & Final Thickness: & 0.048 \\
\hline Thickness: & 0.048 & $\mathrm{In}$ & Final Length: & 9 \\
\hline Length: & 9 & $\mathrm{In}$ & Final Diameter: & 0.03937 \\
\hline Diameter: & 0.03937 & $\mathrm{In}$ & Final Inner diameter: & 0.019685 \\
\hline Area: & 13.023 & in^2 & Final Outer diameter: & 0.03937 \\
\hline Inner diameter: & 0.019685 & $\mathrm{In}$ & Temperature: & 59 \\
\hline Outer diameter: & 0.03937 & In & Humidity: & 86 \\
\cline { 1 - 4 } Area: & 0.069456 & in*in & &
\end{tabular}




\begin{tabular}{|l|l|l|}
\cline { 2 - 3 } \multicolumn{1}{c|}{} & \multicolumn{2}{c|}{ Theoretical Values } \\
\cline { 2 - 3 } & Youngs Modulus ksi & 10500 \\
\cline { 2 - 3 } & Max. Stress ksi & 500 \\
\cline { 2 - 3 } & \multicolumn{2}{|c|}{ Experimental Values } \\
\cline { 2 - 3 } $\begin{array}{c}\text { Melvin Instron } \\
\text { Calculated }\end{array}$ & Max Load Ibf & $3485.926 \mathrm{lbf}$ \\
\cline { 2 - 3 } & Max Stress ksi & 267.67 \\
\cline { 2 - 3 } & Youngs Modulus ksi & 2785.2 \\
\cline { 2 - 3 } & Youngs Modulus ksi & 134.9 \\
\cline { 2 - 3 } & \multicolumn{2}{|c|}{ Percent Error \% } \\
\hline Youngs Modulus & Percent Diff \% & 73.47428571 \\
\hline Youngs Modulus & Percent Diff \% & 98.71535298 \\
\hline Max. Stress & Percent Diff \% & 46.466 \\
\hline
\end{tabular}

\begin{tabular}{|c|c|c|c|c|c|}
\hline Time sec & Extension in & Load lbf & Tensile Stress & Tensile strain $\%$ & Youngs Modulus ksi \\
\hline 0 & 2.058704 & 662.3718 & 50.86169085 & 6.44E-05 & 4.05E-02 \\
\hline 1 & 2.059722 & 690.8112 & 53.04547339 & 0.01228807 & 3.88E-02 \\
\hline 2 & 2.060397 & 715.9034 & 54.97223374 & 0.02406473 & $3.75 \mathrm{E}-02$ \\
\hline 2.0138 & 2.060443 & 720.4218 & 55.31918913 & 0.02432222 & 3.72E-02 \\
\hline 3 & 2.06121 & 744.6001 & 57.17577363 & 0.03676526 & $3.61 \mathrm{E}-02$ \\
\hline 4 & 2.062135 & 770.156 & 59.13814021 & 0.04869689 & $3.49 \mathrm{E}-02$ \\
\hline 4.1848 & 2.062262 & 772.9538 & 59.3529755 & 0.05094399 & 3.47E-02 \\
\hline 5 & 2.062826 & 795.961 & 61.11963449 & 0.06092059 & $3.38 \mathrm{E}-02$ \\
\hline 6 & 2.063714 & 820.4797 & 63.00235737 & 0.07250413 & $3.28 \mathrm{E}-02$ \\
\hline 6.4168 & 2.064071 & 829.8085 & 63.71869001 & 0.0782965 & $3.24 \mathrm{E}-02$ \\
\hline 7 & 2.064578 & 843.1653 & 64.74432158 & 0.08555276 & $3.19 \mathrm{E}-02$ \\
\hline 8 & 2.065344 & 868.429 & 66.68425094 & 0.09628277 & $3.10 \mathrm{E}-02$ \\
\hline 8.7288 & 2.065967 & 886.063 & 68.03831682 & 0.1051138 & 3.04E-02 \\
\hline 9 & 2.066244 & 891.3532 & 68.44453659 & 0.1093242 & $3.02 \mathrm{E}-02$ \\
\hline 10 & 2.067024 & 917.3914 & 70.44393765 & 0.1206455 & 2.93E-02 \\
\hline 11 & 2.067908 & 939.6428 & 72.15256085 & 0.1328406 & $2.87 \mathrm{E}-02$ \\
\hline 11.2068 & 2.068018 & 943.4671 & 72.44621823 & 0.1347384 & $2.85 E-02$ \\
\hline 12 & 2.068836 & 960.4686 & 73.75171619 & 0.1444849 & $2.81 \mathrm{E}-02$ \\
\hline 13 & 2.069626 & 984.7622 & 75.61715427 & 0.1572415 & $2.74 \mathrm{E}-02$ \\
\hline 13.6948 & 2.070088 & 998.3173 & 76.65801275 & 0.1655182 & $2.70 \mathrm{E}-02$ \\
\hline 14 & 2.070413 & 1007.911 & 77.39468632 & 0.1693138 & $2.68 \mathrm{E}-02$ \\
\hline 15 & 2.071249 & 1028.737 & 78.99385702 & 0.181615 & $2.62 \mathrm{E}-02$ \\
\hline 16 & 2.072087 & 1049.33 & 80.5751363 & 0.1937481 & 2.57E-02 \\
\hline 16.2568 & 2.072242 & 1055.025 & 81.01243953 & 0.1969155 & $2.56 \mathrm{E}-02$ \\
\hline 17 & 2.07295 & 1072.482 & 82.35291408 & 0.2063032 & $2.52 \mathrm{E}-02$ \\
\hline 18 & 2.07381 & 1094.902 & 84.07448361 & 0.2179511 & 2.47E-02 \\
\hline 18.8228 & 2.074437 & 1110.231 & 85.25155494 & 0.2284653 & $2.43 \mathrm{E}-02$ \\
\hline 19 & 2.074566 & 1115.915 & 85.68801351 & 0.2302344 & $2.42 \mathrm{E}-02$ \\
\hline
\end{tabular}




\begin{tabular}{|c|c|c|c|c|c|}
\hline 0 & 2.075392 & 1136.087 & 87.23696537 & 0.2420909 & 2.38E-02 \\
\hline 21 & 2.076181 & 1156.615 & 88.81325347 & 0.254416 & 2.34E-02 \\
\hline 21.5618 & 2.076736 & 1167.59 & 89.65599324 & 0.2620584 & 2.32E-02 \\
\hline 22 & 2.077086 & 1177.974 & 90.45335176 & 0.2668864 & 2.30E-02 \\
\hline 23 & 2.077932 & 1198.259 & 92.01098057 & 0.279432 & $2.26 \mathrm{E}-02$ \\
\hline 24 & 2.078713 & 1216.85 & 93.43853183 & 0.2908593 & 2.22E-02 \\
\hline 24.3508 & 2.078945 & 1223.161 & 93.92313599 & 0.2954024 & 2.21E-02 \\
\hline 25 & 2.079575 & 1237.064 & 94.99070875 & 0.303542 & 2.19E-02 \\
\hline 26 & 2.080408 & 1258.083 & 96.60469938 & 0.3166717 & 2.15E-02 \\
\hline 27 & 2.081228 & 1277.585 & 98.10220379 & 0.3283649 & 2.12E-02 \\
\hline 27.1618 & 2.081439 & 1278.938 & 98.20609691 & 0.3300386 & $2.12 \mathrm{E}-02$ \\
\hline 28 & 2.082117 & 1296.955 & 99.5895723 & 0.341168 & 2.09E-02 \\
\hline 29 & 2.082918 & 1318.223 & 101.2226829 & 0.3531401 & $2.06 \mathrm{E}-02$ \\
\hline 30 & 2.083735 & 1337.208 & 102.6804884 & 0.3663687 & $2.03 \mathrm{E}-02$ \\
\hline 30.0218 & 2.083787 & 1335.128 & 102.5207709 & 0.3663175 & $2.03 \mathrm{E}-02$ \\
\hline 31 & 2.084559 & 1354.22 & 103.9867926 & 0.3779618 & $2.00 \mathrm{E}-02$ \\
\hline 32 & 2.085451 & 1373.253 & 105.4482838 & 0.3911487 & $1.98 \mathrm{E}-02$ \\
\hline 32.9658 & 2.086215 & 1390.756 & 106.7922906 & 0.4032747 & 1.95E-02 \\
\hline 33 & 2.086315 & 1393.318 & 106.9890194 & 0.4041294 & 1.95E-02 \\
\hline 34 & 2.087127 & 1410.697 & 108.3235046 & 0.4168454 & 1.93E-02 \\
\hline 35 & 2.08792 & 1431.448 & 109.9169162 & 0.4286853 & $1.90 \mathrm{E}-02$ \\
\hline 36 & 2.088635 & 1447.166 & 111.1238578 & 0.4413345 & $1.88 \mathrm{E}-02$ \\
\hline 36.0218 & 2.088727 & 1446.587 & 111.079398 & 0.4418007 & 1.88E-02 \\
\hline 37 & 2.089538 & 1466.965 & 112.644168 & 0.4541686 & $1.85 \mathrm{E}-02$ \\
\hline 38 & 2.090401 & 1485.933 & 114.100668 & 0.4671946 & 1.83E-02 \\
\hline 39 & 2.091258 & 1503.632 & 115.4597251 & 0.4792835 & $1.81 \mathrm{E}-02$ \\
\hline 39.0918 & 2.091156 & 1505.157 & 115.5768256 & 0.4803803 & $1.81 \mathrm{E}-02$ \\
\hline 40 & 2.092058 & 1522.815 & 116.9327344 & 0.4923846 & $1.79 \mathrm{E}-02$ \\
\hline 41 & 2.092907 & 1541.011 & 118.3299547 & 0.5061461 & 1.77E-02 \\
\hline 41.4088 & 2.093239 & 1546.894 & 118.7816939 & 0.5098416 & 1.76E-02 \\
\hline 42 & 2.093758 & 1558.828 & 119.6980726 & 0.5155994 & 1.75E-02 \\
\hline 42.1338 & 2.093791 & 1560.331 & 119.8134838 & 0.515973 & $1.75 \mathrm{E}-02$ \\
\hline 43 & 2.094494 & 1579.174 & 121.2603855 & 0.5237852 & 1.73E-02 \\
\hline 44 & 2.095431 & 1596.85 & 122.6176764 & 0.5341961 & $1.71 \mathrm{E}-02$ \\
\hline 45 & 2.096259 & 1613.796 & 123.9189127 & 0.5433912 & $1.69 \mathrm{E}-02$ \\
\hline 45.1408 & 2.096419 & 1616.476 & 124.1247024 & 0.5451713 & $1.69 \mathrm{E}-02$ \\
\hline 46 & 2.097099 & 1633.279 & 125.4149582 & 0.5527253 & 1.67E-02 \\
\hline 47 & 2.097933 & 1649.894 & 126.6907779 & 0.5619958 & $1.66 \mathrm{E}-02$ \\
\hline 48 & 2.098706 & 1667.903 & 128.0736389 & 0.5705868 & 1.64E-02 \\
\hline 48.2638 & 2.098925 & 1671.205 & 128.3271904 & 0.5730187 & 1.64E-02 \\
\hline 49 & 2.099522 & 1687.499 & 129.5783614 & 0.5796507 & 1.62E-02 \\
\hline 50 & 2.100385 & 1704.144 & 130.8564847 & 0.5892351 & $1.61 \mathrm{E}-02$ \\
\hline
\end{tabular}




\begin{tabular}{|l|r|l|r|l|r|}
\hline Specimen name: & Composite $\mathrm{L}_{\mathbf{3 0}}$ & Sled weight: & 35.273959 & Extensometer & 0.0254 \\
\hline Sample Type & E-Fiberglass & Loading span: & 0 & Final Width: & 1.52 \\
\hline Width: & 1.52 & Support span: & 1 & Final Thickness: & 0.056 \\
\hline Thickness: & 0.056 & Span ratio: & 2 & Final Length: & 9 \\
\hline Length: & 9 & Temperature: & $59 \mathrm{~F}$ & Final Diameter: & 0.03937 \\
\hline Diameter: & 0.03937 & Humidity: & $86 \%$ & Final Inner diameter: & 0.019685 \\
\hline Inner diameter: & 0.019685 & Geometry: & Rectangular & Final Outer diameter: & 0.03937 \\
\hline Outer diameter: & 0.03937 & & & Final Wall thickness: & 0.019685 \\
\hline
\end{tabular}

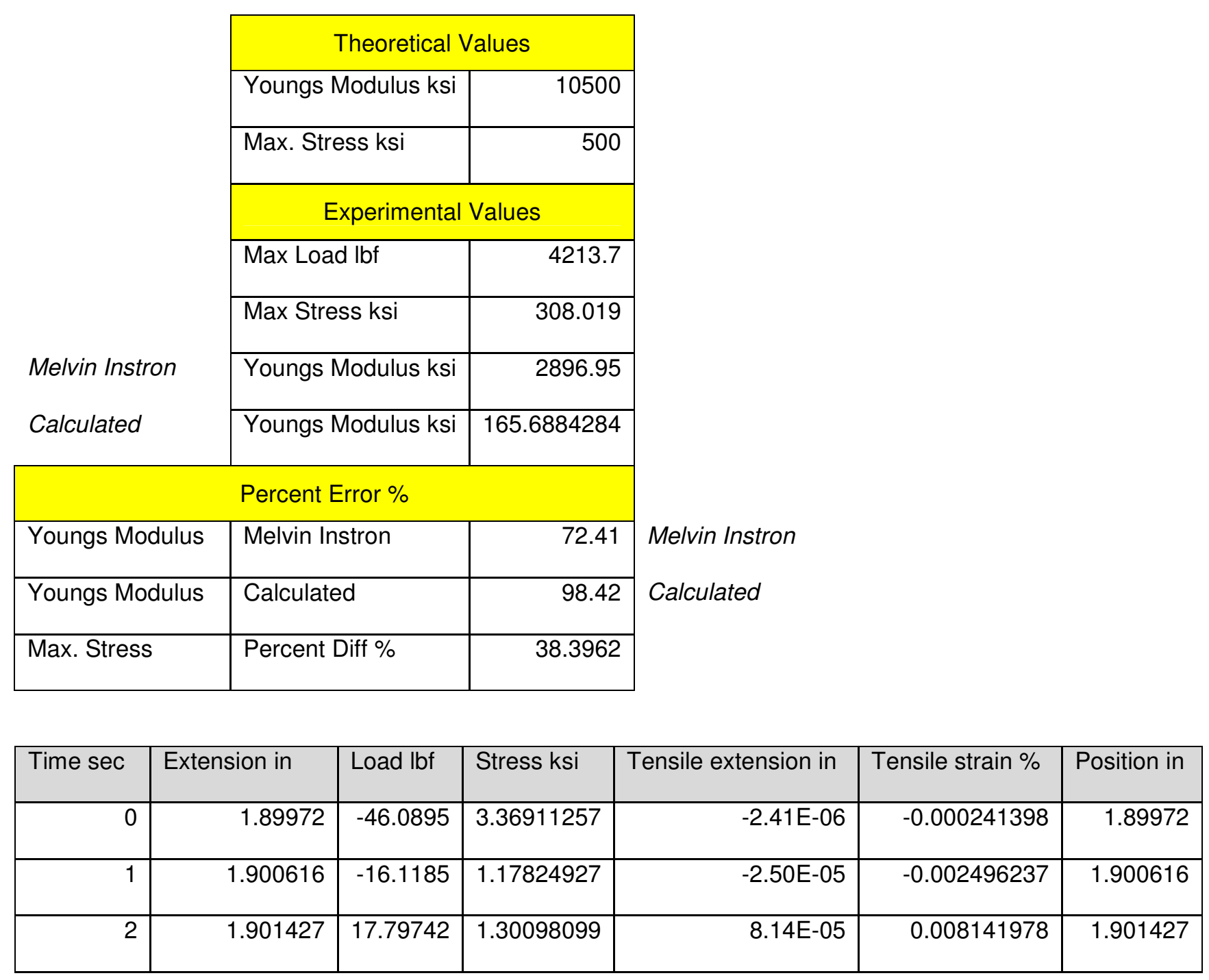




\begin{tabular}{|c|c|c|c|c|c|c|}
\hline 3 & 1.90235 & 53.63346 & 3.92057456 & 0.000201917 & 0.02019163 & 1.90235 \\
\hline 4 & 1.903079 & 86.79225 & 6.34446272 & 0.000325048 & 0.03250473 & 1.903079 \\
\hline 5 & 1.90399 & 121.5831 & 8.88765351 & 0.000453496 & 0.0453495 & 1.90399 \\
\hline 6 & 1.904804 & 154.3962 & 11.2862719 & 0.000579166 & 0.05791652 & 1.904804 \\
\hline 7 & 1.905598 & 186.0194 & 13.5979094 & 0.000696731 & 0.06967292 & 1.905598 \\
\hline 8 & 1.906418 & 214.558 & 15.6840643 & 0.0008214 & 0.0821398 & 1.906418 \\
\hline 9 & 1.907285 & 249.6276 & 18.2476316 & 0.000954092 & 0.09540896 & 1.907285 \\
\hline 10 & 1.908149 & 280.5379 & 20.5071564 & 0.001074934 & 0.1074932 & 1.908149 \\
\hline 11 & 1.908903 & 313.9245 & 22.9476974 & 0.00119431 & 0.1194308 & 1.908903 \\
\hline 12 & 1.909729 & 346.7938 & 25.350424 & 0.001329458 & 0.1329455 & 1.909729 \\
\hline 13 & 1.910719 & 379.4059 & 27.7343494 & 0.001466549 & 0.1466545 & 1.910719 \\
\hline 14 & 1.911382 & 409.9062 & 29.9639035 & 0.001584041 & 0.1584038 & 1.911382 \\
\hline 15 & 1.912262 & 439.7178 & 32.143114 & 0.00170728 & 0.1707276 & 1.912262 \\
\hline 16 & 1.913079 & 473.769 & 34.6322368 & 0.001842952 & 0.1842948 & 1.913079 \\
\hline 17 & 1.914052 & 505.9201 & 36.9824635 & 0.00197289 & 0.1972886 & 1.914052 \\
\hline 18 & 1.914817 & 533.3304 & 38.9861404 & 0.00209043 & 0.2090426 & 1.914817 \\
\hline 19 & 1.915619 & 565.0769 & 41.3067909 & 0.002219725 & 0.221972 & 1.915619 \\
\hline 21 & 1.917286 & 626.442 & 45.7925439 & 0.002460527 & 0.2460522 & 1.917287 \\
\hline 22 & 1.91812 & 654.7581 & 47.8624342 & 0.002587211 & 0.2587206 & 1.918121 \\
\hline 23 & 1.918906 & 683.8782 & 49.9910965 & 0.002722979 & 0.2722973 & 1.918906 \\
\hline 25 & 1.920578 & 745.0959 & 54.4660746 & 0.00297029 & 0.2970284 & 1.920578 \\
\hline 26 & 1.921448 & 776.2019 & 56.739905 & 0.003096545 & 0.3096538 & 1.921448 \\
\hline 28 & 1.923071 & 833.4559 & 60.9251389 & 0.003348493 & 0.3348487 & 1.923071 \\
\hline 29 & 1.923967 & 862.9727 & 63.0827997 & 0.003478932 & 0.3478925 & 1.923967 \\
\hline 31 & 1.925628 & 918.9886 & 67.1775292 & 0.00372653 & 0.3726523 & 1.925628 \\
\hline 32 & 1.926434 & 948.3071 & 69.3206944 & 0.003846777 & 0.3846769 & 1.926434 \\
\hline 34 & 1.928141 & 1004.302 & 73.4138889 & 0.004099989 & 0.4099981 & 1.928141 \\
\hline
\end{tabular}




\begin{tabular}{|r|r|r|r|r|r|r|}
\hline 35 & 1.92901 & 1035.209 & 75.6731725 & 0.004231977 & 0.4231969 & 1.92901 \\
\hline 37 & 1.930582 & 1087.473 & 79.4936404 & 0.004478824 & 0.4478815 & 1.930582 \\
\hline 38 & 1.931458 & 1116.826 & 81.6393275 & 0.00460887 & 0.460886 & 1.931458 \\
\hline 39 & 1.932294 & 1144.368 & 83.6526316 & 0.00472182 & 0.4721811 & 1.932294 \\
\hline 40 & 1.93313 & 1172.724 & 85.7254386 & 0.004847682 & 0.4847672 & 1.933131 \\
\hline 41 & 1.93392 & 1198.838 & 87.6343567 & 0.004970872 & 0.4970862 & 1.93392 \\
\hline 42 & 1.934859 & 1225.648 & 89.594152 & 0.005100692 & 0.5100681 & 1.934859 \\
\hline 43 & 1.935572 & 1247.326 & 91.1788012 & 0.005179887 & 0.5179876 & 1.935572 \\
\hline 44 & 1.936335 & 1275.369 & 93.2287281 & 0.005264724 & 0.5264713 & 1.936335 \\
\hline 45 & 1.93714 & 1301.099 & 95.109576 & 0.005354092 & 0.5354081 & 1.93714 \\
\hline 46 & 1.938 & 1326.657 & 96.9778509 & 0.005449698 & 0.5449687 & 1.938 \\
\hline 47 & 1.938859 & 1350.76 & 98.7397661 & 0.005545184 & 0.5545173 & 1.938859 \\
\hline 48 & 1.939654 & 1379.278 & 100.824415 & 0.005633519 & 0.5633508 & 1.939654 \\
\hline 49 & 1.940483 & 1402.882 & 102.549854 & 0.005725629 & 0.5725617 & 1.940483 \\
\hline 50 & 1.941305 & 1429.789 & 104.51674 & 0.005816904 & 0.5816892 & 1.941305 \\
\hline
\end{tabular}

\begin{tabular}{|c|c|c|c|c|c|}
\hline Specimen name: & Composite $\mathrm{L}_{40}$ & & Geometry: & Rectangular & \\
\hline Sample Type & (E-glass) & & Extensometer & $0.0254^{* \star} \mathrm{m}$ & \\
\hline Width: & 1.408 & in & Final Width: & 1.408 & in \\
\hline Thickness: & 0.065 & in & Final Thickness: & 0.065 & in \\
\hline Length: & 9 & in & Final Length: & 9 & in \\
\hline Area: & 12.672 & & Final Diameter: & 0.03937 & in \\
\hline Diameter: & 0.03937 & in & Final Inner diameter: & 0.019685 & in \\
\hline Inner diameter: & 0.019685 & in & Final Outer diameter: & 0.03937 & in \\
\hline Outer diameter: & 0.03937 & in & Final Wall thickness: & 0.019685 & in \\
\hline Wall thickness: & 0.019685 & in & Final Area: & 0.09152 & in*in \\
\hline
\end{tabular}




\begin{tabular}{|l|r|r|l|r|l|}
\hline Area: & 0.09152 & in*in & Final Linear density: & & den \\
\hline
\end{tabular}

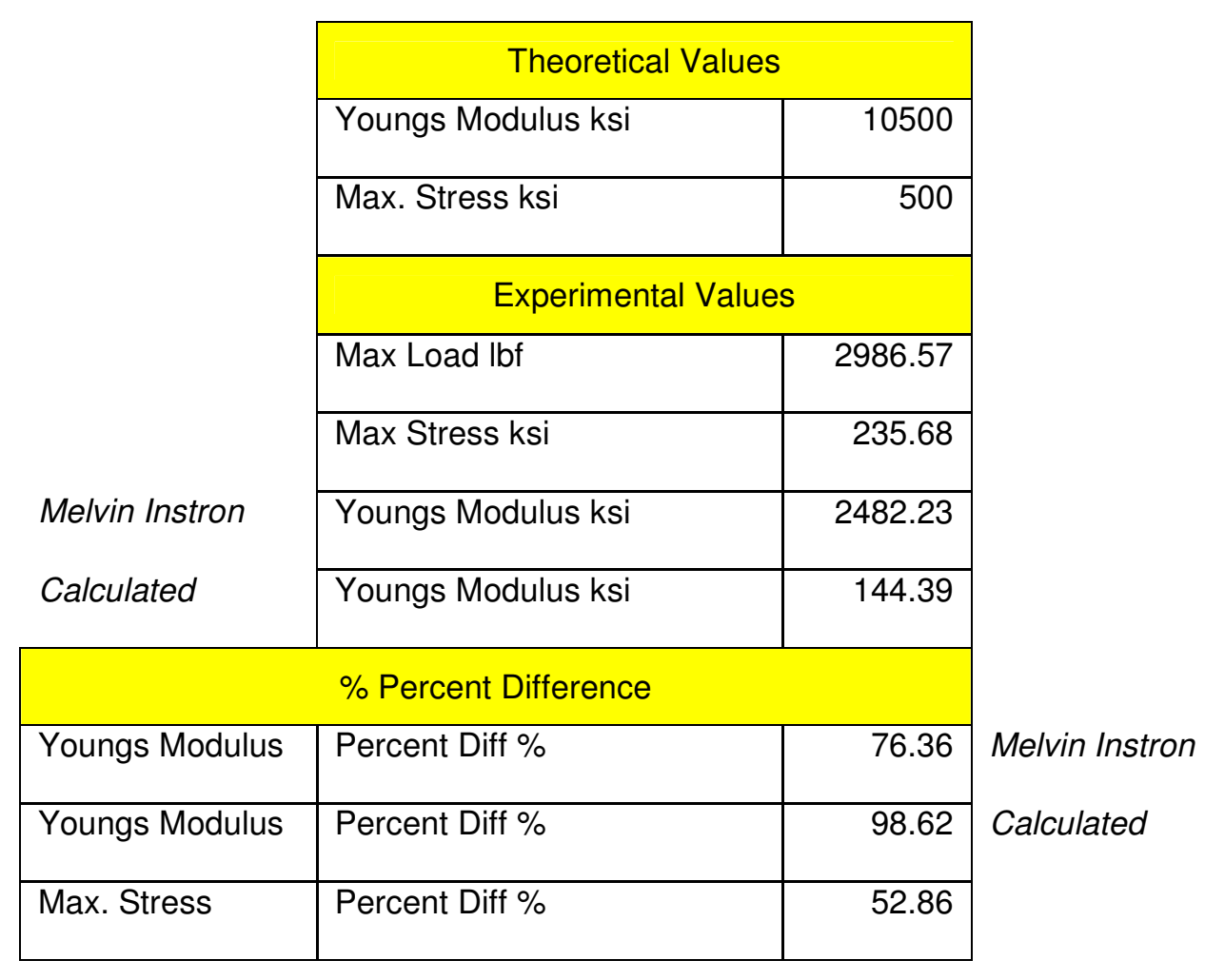

\begin{tabular}{|r|r|r|r|r|r|}
\hline Time sec & Extension in & \multicolumn{1}{c|}{ Load lbf } & \multicolumn{1}{c|}{ Stress Ksi } & Tensile extension & Tensile strain \% \\
\hline 0 & 2.09137 & 873.2958 & 68.9153883 & $-7.51 \mathrm{E}-07$ & $-7.51 \mathrm{E}-05$ \\
\hline 1 & 2.092226 & 905.5032 & 71.4570076 & 0.000132513 & 0.01325128 \\
\hline 2 & 2.092986 & 931.729 & 73.5265941 & 0.000248671 & 0.02486701 \\
\hline 3 & 2.093878 & 960.0907 & 75.7647333 & 0.000359535 & 0.03595345 \\
\hline 4 & 2.094707 & 988.833 & 78.0329072 & 0.000483394 & 0.04833927 \\
\hline 5 & 2.095541 & 1017.546 & 80.2987689 & 0.000602293 & 0.06022918 \\
\hline 6 & 2.09641 & 1047.022 & 82.6248422 & 0.000720394 & 0.07203922 \\
\hline 7 & 2.097248 & 1071.573 & 84.5622633 & 0.000830269 & 0.08302671 \\
\hline 8 & 2.098074 & 1097.981 & 86.6462279 & 0.000949121 & 0.09491186 \\
\hline 9 & 2.098893 & 1128.262 & 89.035827 & 0.001071632 & 0.107163 \\
\hline
\end{tabular}




\begin{tabular}{|c|c|c|c|c|c|}
\hline 10 & 2.099659 & 1149.768 & 90.7329545 & 0.001174426 & 0.1174424 \\
\hline 11 & 2.100507 & 1171.765 & 92.4688289 & 0.001273847 & 0.1273844 \\
\hline 12 & 2.10141 & 1197.168 & 94.4734848 & 0.001390684 & 0.1390681 \\
\hline 13 & 2.102194 & 1219.339 & 96.2230903 & 0.001486254 & 0.1486251 \\
\hline 14 & 2.103074 & 1244.742 & 98.2277462 & 0.00160737 & 0.1607367 \\
\hline 15 & 2.1039 & 1267.104 & 99.9924242 & 0.001717234 & 0.171723 \\
\hline 16 & 2.104717 & 1291.566 & 101.922822 & 0.001835883 & 0.1835879 \\
\hline 17 & 2.105512 & 1311.475 & 103.493924 & 0.001937342 & 0.1937338 \\
\hline 18 & 2.106433 & 1332.925 & 105.186632 & 0.0020419 & 0.2041896 \\
\hline 19 & 2.107216 & 1354.577 & 106.895281 & 0.002148676 & 0.2148672 \\
\hline 20 & 2.108041 & 1375.413 & 108.539536 & 0.00225066 & 0.2250655 \\
\hline 21 & 2.108873 & 1398.723 & 110.379025 & 0.002362228 & 0.2362223 \\
\hline 22 & 2.109709 & 1419.793 & 112.041746 & 0.002473402 & 0.2473397 \\
\hline 23 & 2.110577 & 1443.8 & 113.936237 & 0.002586901 & 0.2586896 \\
\hline 24 & 2.111435 & 1460.865 & 115.282907 & 0.002680206 & 0.2680201 \\
\hline 25 & 2.112217 & 1482.074 & 116.956597 & 0.002787304 & 0.2787298 \\
\hline 26 & 2.113031 & 1501.281 & 118.472301 & 0.002882612 & 0.2882606 \\
\hline 27 & 2.113873 & 1519.234 & 119.889047 & 0.002967608 & 0.2967602 \\
\hline 28 & 2.114704 & 1537.334 & 121.317393 & 0.003058076 & 0.305807 \\
\hline 29 & 2.115528 & 1556.45 & 122.825915 & 0.003155184 & 0.3155177 \\
\hline 30 & 2.116396 & 1575.679 & 124.343355 & 0.003260982 & 0.3260975 \\
\hline 31 & 2.117222 & 1597.831 & 126.091461 & 0.003363228 & 0.3363221 \\
\hline 32 & 2.118065 & 1617.306 & 127.628314 & 0.003461444 & 0.3461437 \\
\hline 33 & 2.118892 & 1635.425 & 129.05816 & 0.00356462 & 0.3564613 \\
\hline 34 & 2.119626 & 1656.034 & 130.684501 & 0.003668654 & 0.3668647 \\
\hline 35 & 2.120611 & 1674.223 & 132.119871 & 0.003766549 & 0.3766541 \\
\hline 36 & 2.1213 & 1691.213 & 133.460622 & 0.003870917 & 0.3870909 \\
\hline
\end{tabular}




\begin{tabular}{|r|r|r|r|r|r|}
\hline 37 & 2.122243 & 1713.559 & 135.224037 & 0.0039783 & 0.3978292 \\
\hline 39 & 2.123878 & 1749.765 & 138.081203 & 0.004181635 & 0.4181627 \\
\hline 40 & 2.124691 & 1770.226 & 139.695865 & 0.004278982 & 0.4278973 \\
\hline 41 & 2.125537 & 1787.825 & 141.084675 & 0.004390311 & 0.4390302 \\
\hline 42 & 2.126412 & 1805.874 & 142.508996 & 0.004491365 & 0.4491356 \\
\hline 43 & 2.127174 & 1827.18 & 144.190341 & 0.004594398 & 0.4594388 \\
\hline 44 & 2.127992 & 1846.411 & 145.707939 & 0.004708171 & 0.4708161 \\
\hline 45 & 2.128916 & 1863.581 & 147.062895 & 0.004801691 & 0.4801681 \\
\hline 46 & 2.129682 & 1883.271 & 148.616714 & 0.004909646 & 0.4909636 \\
\hline 47 & 2.130573 & 1902.609 & 150.142756 & 0.005008149 & 0.5008139 \\
\hline 48 & 2.131368 & 1918.74 & 151.41572 & 0.00510937 & 0.510936 \\
\hline 49 & 2.132199 & 1938.585 & 152.981771 & 0.005201757 & 0.5201747 \\
\hline 50 & 2.133034 & 1952.901 & 154.111506 & 0.005294542 & 0.5294532 \\
\hline
\end{tabular}

\section{Material Properties of Test Specimens}

The following Excel spreadsheet was used to calculate the material properties and exact solution of displacement for the beam. Mass and density units were calculated and later converted in lbf-s ${ }^{2} /$ in and $\mathrm{lbf}-\mathrm{s}^{2} / \mathrm{in}^{4}$.

\begin{tabular}{|l|r|r|r|r|r|}
\hline \multicolumn{1}{|c|}{ Beam } & \multicolumn{1}{c|}{ L20 } & \multicolumn{1}{c|}{ L30 } & \multicolumn{1}{c|}{ L40 } & \multicolumn{1}{c|}{ HD30 } & \multicolumn{1}{c|}{ LB0 } \\
\hline Mass (lbf s2/in) & 0.0005956 & 0.000573859 & 0.000617 & 0.000681 & 0.0005967 \\
Length (in) & 8 & 8 & 8 & 8 & 8 \\
Width (in) & 1.471 & 1.427 & 1.389 & 1.423 & 1.506 \\
Thickness (in) & 0.05 & 0.049 & 0.052 & 0.049 & 0.047 \\
Volume (in3) & 0.5884 & 0.559384 & 0.577824 & 0.557816 & 0.566256 \\
Density (Ibf s2/in4) & 0.0010122 & 0.001025877 & 0.001068 & 0.00122 & 0.0010538 \\
Cross-Section & 0.07355 & 0.069923 & 0.072228 & 0.069727 & 0.070782 \\
\hline
\end{tabular}


The following Excel spreadsheet was used to calculate the material properties and exact solution of displacement for the plate. Mass and density units were calculated and later converted in $1 b f-\mathrm{s}^{2} /$ in and $\mathrm{lbf}-\mathrm{s}^{2} / \mathrm{in}^{4}$.

\begin{tabular}{|c|c|c|c|c|c|}
\hline Plate & L20 & L30 & L40 & HD30 & LBO \\
\hline Mass (Ibf s2/in) & 0.000675 & 0.000669 & 0.0006155 & 0.00061 & 0.00067093 \\
\hline Diameter(in) & .95 & 10.91 & 11 & 10.98 & 0.95 \\
\hline Radius (in) & 475 & 5.455 & 5.5 & 5.49 & 5.475 \\
\hline Thickness (in) & 0.061 & 0.066 & 0.062 & 0.063 & 0.058 \\
\hline Area (in2) & 94.12346 & 93.43706 & 94.985 & 94.63991 & 94.1234625 \\
\hline Volume (in3) & .741531 & 6.166846 & 5.88907 & 5.962315 & 5.459160825 \\
\hline Density (Ik & 000118 & 0.000109 & 0.0001045 & 0.000102 & 0.0001229 \\
\hline $\begin{array}{l}\text { Possions Ratio } \\
\text { Elastic Modulus }\end{array}$ & 0.22 & 0.22 & 0.22 & 0.22 & 0.22 \\
\hline $\begin{array}{l}\text { (psi) } \\
\text { Flexural Rigidity }\end{array}$ & 2670900 & $2.54 \mathrm{E}+06$ & $2.47 E+06$ & $2.81 \mathrm{E}+06$ & $3.11 E+06$ \\
\hline (psi) & 53.08984 & 64.00255 & 51.570738 & 61.62755 & 53.1546585 \\
\hline Shear Modulus (psi) & 1094631 & 1041865 & 1012684.4 & 1153451 & 1274979.508 \\
\hline 1st Fail load (lbf) & 240 & 200 & 320 & 46 & 257 \\
\hline Ultimate Fail Load & 428 & 449 & 385 & 357 & 488 \\
\hline 1st Fail Displ (in) & 3.035401 & 2.082909 & 4.2045549 & 0.503936 & 3.24644505 \\
\hline $\begin{array}{l}\text { Ultimate Fail Displ } \\
\text { (in) }\end{array}$ & 5.413132 & 4.67613 & 5.0586051 & 3.910984 & 6.164455971 \\
\hline
\end{tabular}




\section{Appendix C: Dynamic Test Procedures for LabView}

The following screenshots of LabVIEW 5.0 software program display the steps in order to operate and setup the frequency analysis for the laminated test specimens.

\section{General Menu}

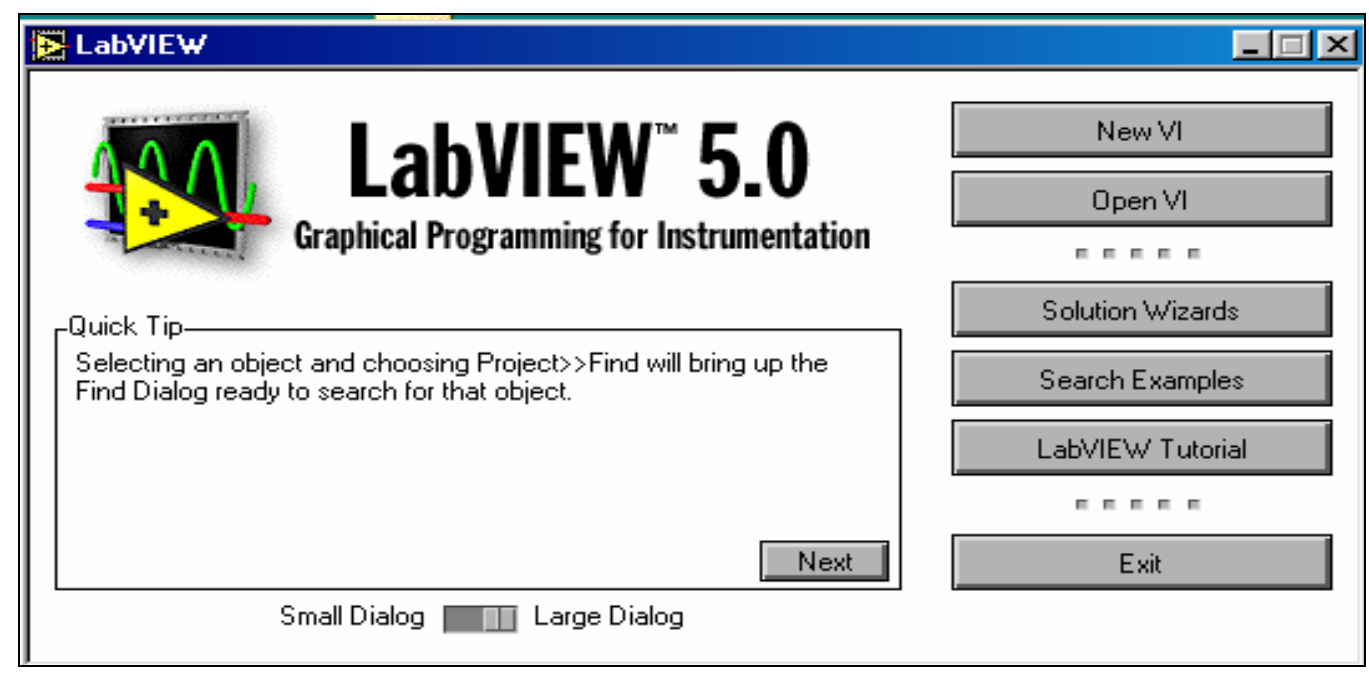

Opening C: Drive and Selecting Program Files

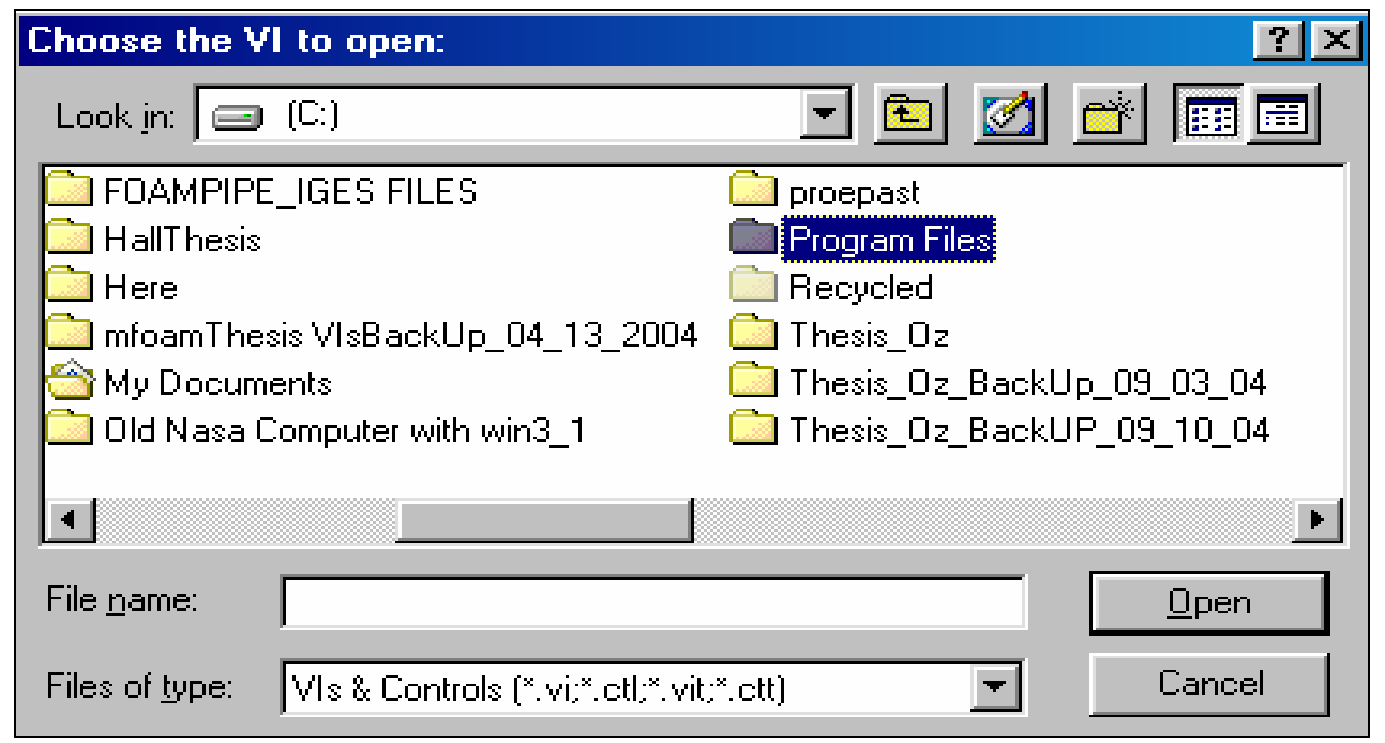




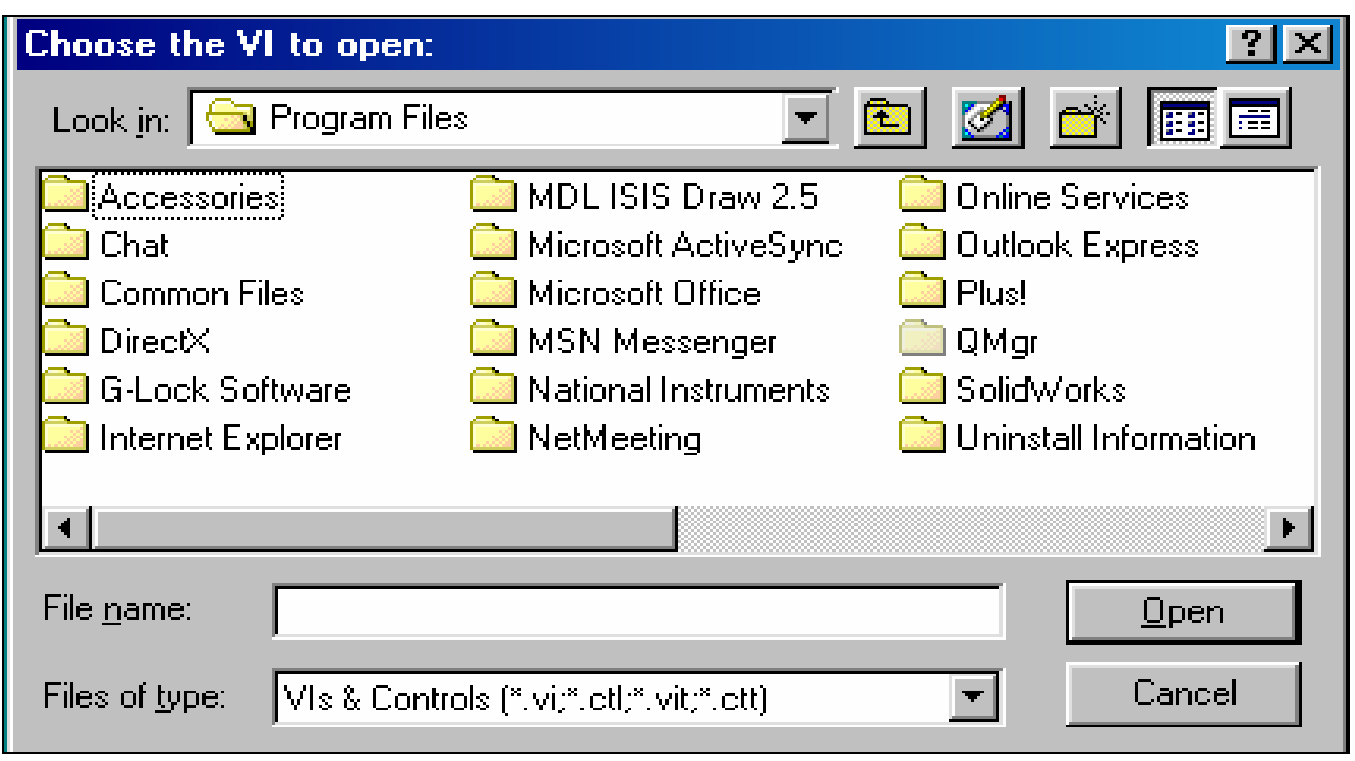

\section{National Instruments Folder}

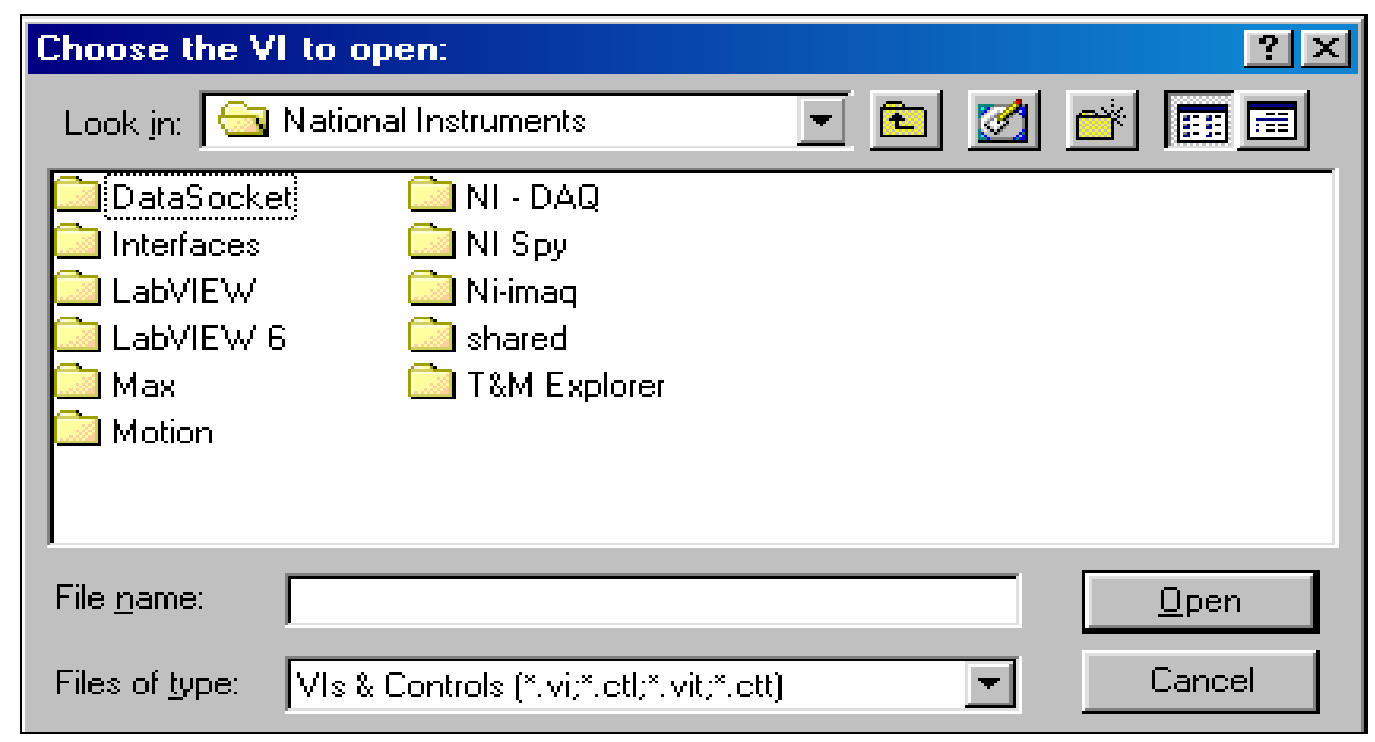


Opening LabVIEW Folder

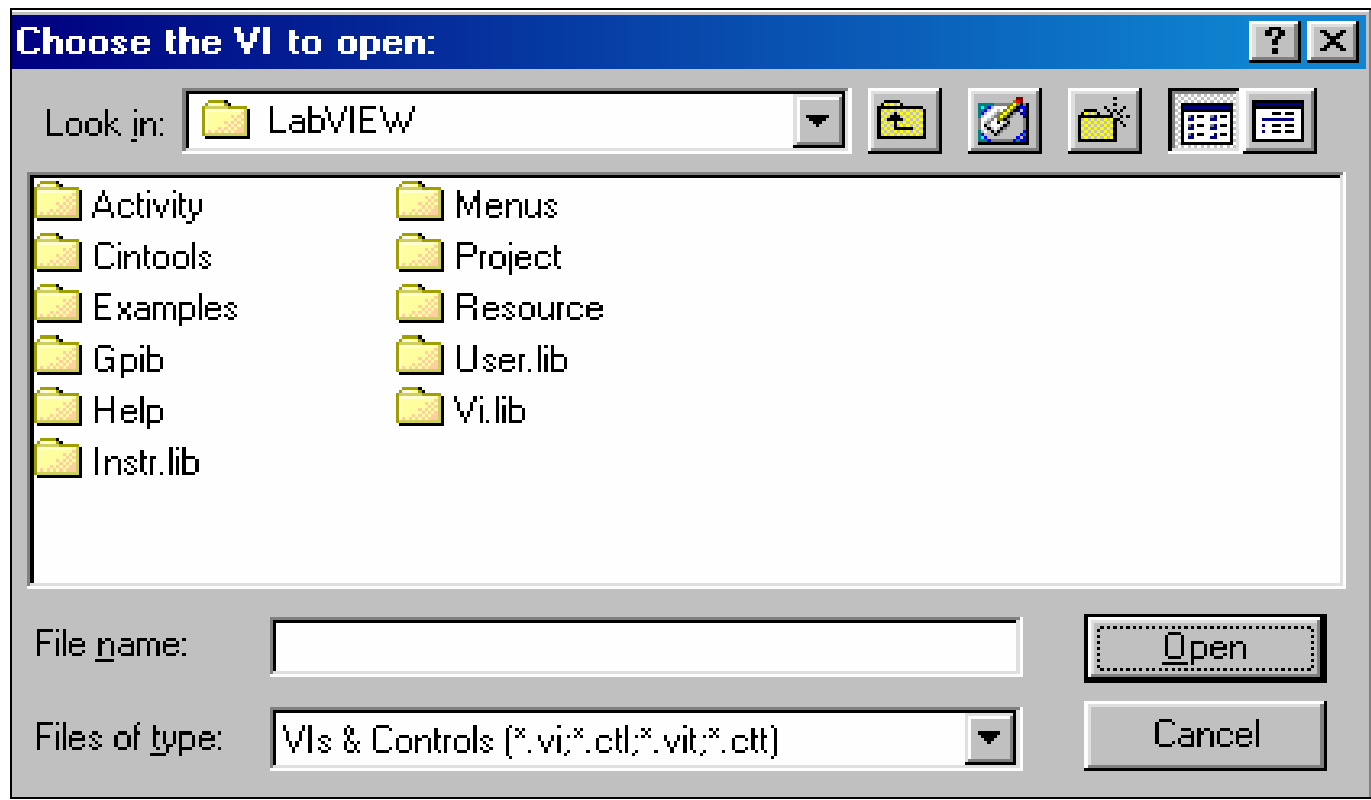

Opening Examples Folder

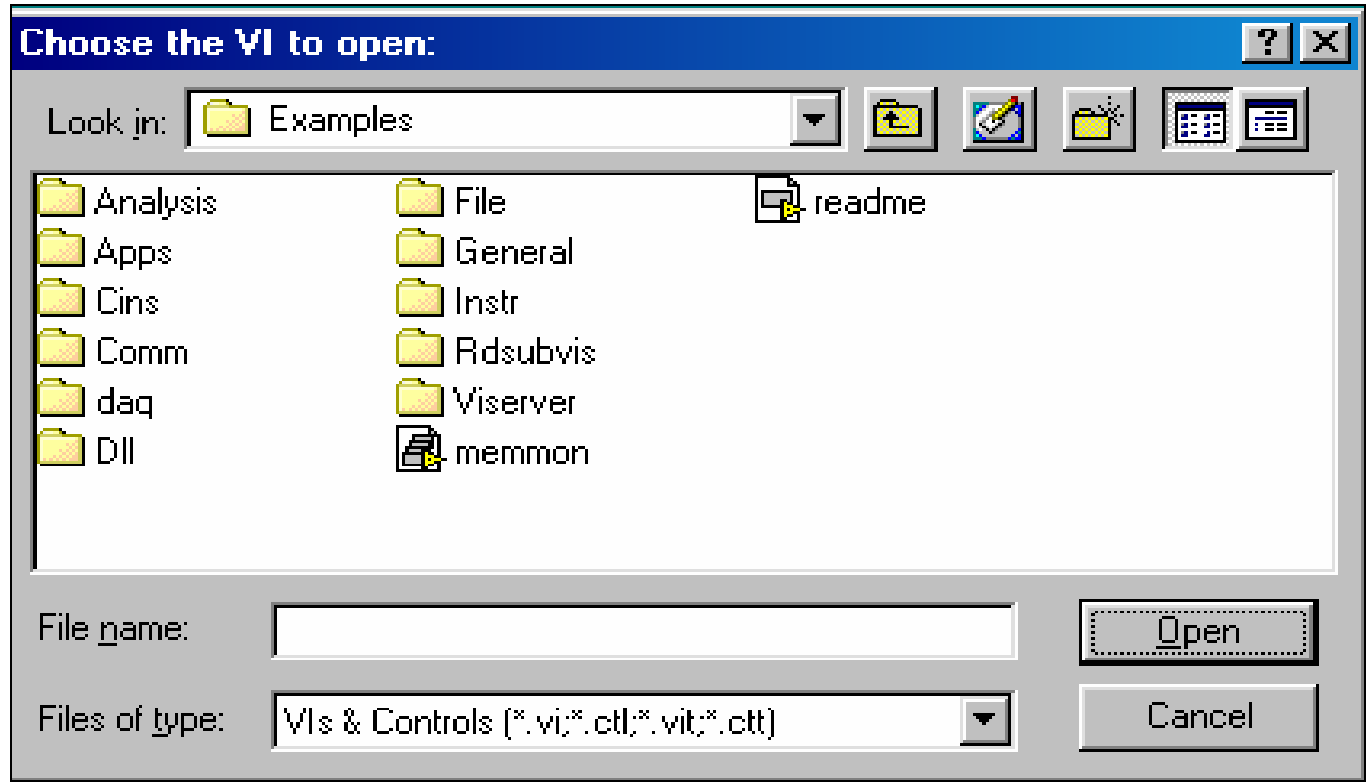


Opening Analysis Folder

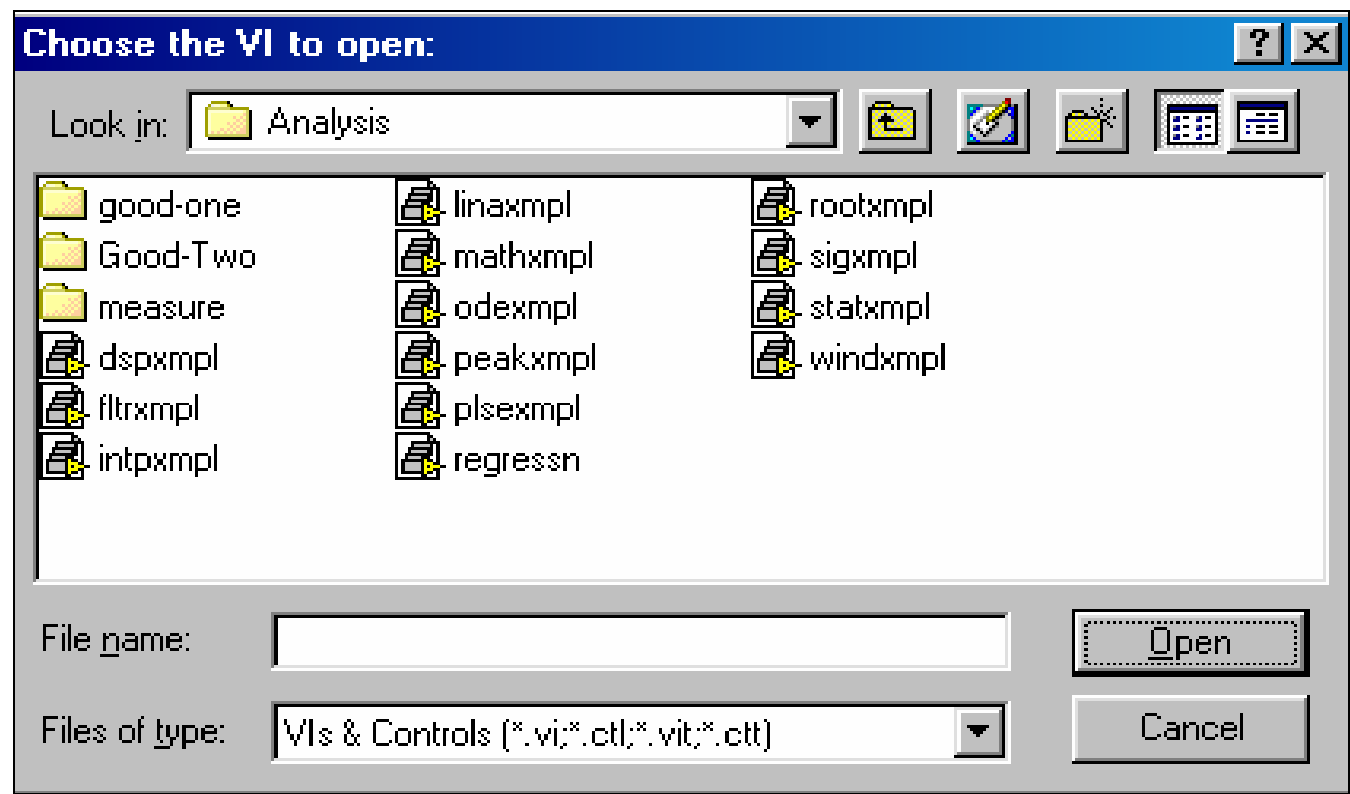

Opening Good-One Folder

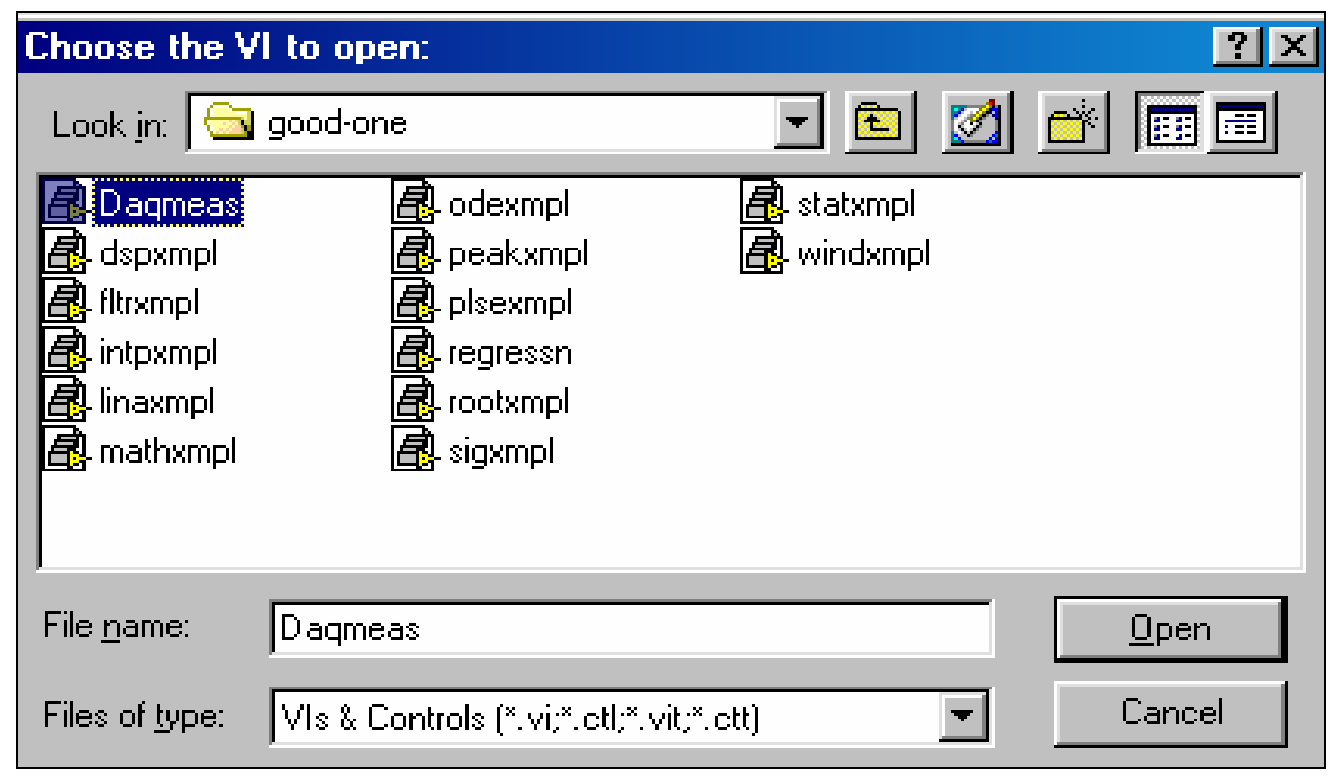


Opening Daqmeas and Selecting JRS Network Analyzer III Program

\begin{tabular}{|c|c|c|}
\hline fis File Dialog & & $\times$ \\
\hline Daqmeas.llb & - & - \\
\hline 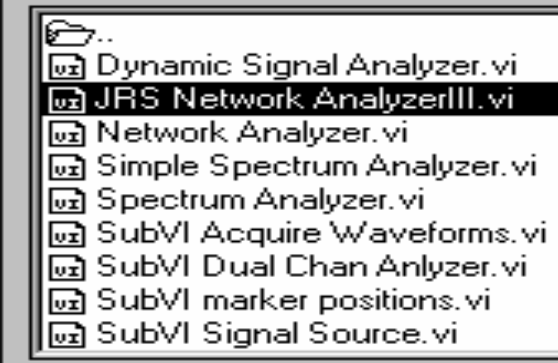 & $\Delta$ & \\
\hline Choose the VI to open: & & OK \\
\hline JRS Network AnalyzerllI. vi & & Cancel \\
\hline VIs \& Controls & - & \\
\hline
\end{tabular}

\section{JRS Network Analyzer III Console}

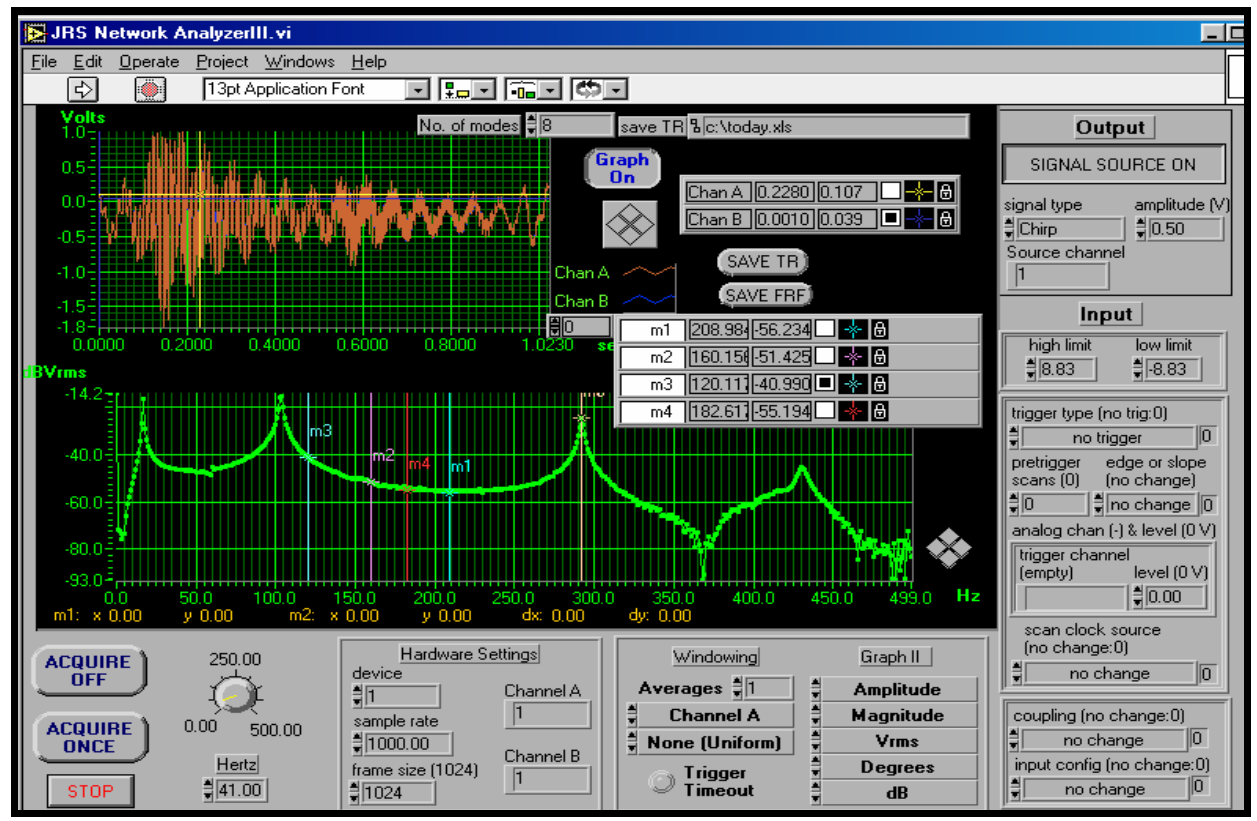




\section{Appendix D: Material Characteristics of Glass Fiber}

Fiberglass composite material also known as Fiber-Reinforced Polymers (FRP) is composed of fine fibers and used as a reinforcing agent for many polymer products. Composed of thin-strands of silica-based, $\mathrm{SiO}_{2}$ and its pure form exists as a polymer $\left(\mathrm{SiO}_{2}\right)_{\mathrm{n}}$; hence, the molecular form of the polymer consists of a center silicon atom with four oxygen atoms. Glass is unlike other polymers since it has little crystalline structure which starts to degrade approximately 2000 degrees Celsius. Figure below shows the various types of fiberglass with the corresponding materials properties that are beneficial for different applications.

\section{Different Types of Fiberglass}

\begin{tabular}{|l|c|}
\hline A-glass & Not very resistant to alkali \\
\hline E-glass & $\begin{array}{c}\text { Alunino-borosilicate glass used for electrical } \\
\text { applications }\end{array}$ \\
\hline S-glass & High tensile strength formulation \\
\hline C-glass & Chemical resistant \\
\hline
\end{tabular}

Fiberglass is heat resistant, good tensile strength, and lightweight which is ideal for electronic circuit boards, support structures for complex machinery, home insulation and etc. Glass fiber strength properties diminish when fiber surface is damages. Also, humidity affects the tensile strength of fiberglass since moisture is easily absorbed, worsen microscopic cracks and surface defects, and lessen firmness.

Fiberglass composites are the most diversely used and are manufactured in the largest quantities of all fiber-reinforced composites due to simple manufacturing and relatively low cost. 
Glass is easily drawn into a filament from the molten state and is then coated with a "size" compound that protects the glass fibers until they are placed in the matrix and facilitates bonding between the fiber and the matrix. These filaments can then be used to make yarn, roving, and different woven fabrics that are later suspended in some type of polymer matrix.

\section{D.1 Unidirectional Direct Roving}

Direct roving is made in one manufacturing step with a special reinforcement sizing 2000 strands or 4000 strands of filaments are bonded efficiently into a single strand. The tension of each glass fiber in the strand is uniform. Figure below shows a picture of fiberglass unidirectional direct roving.

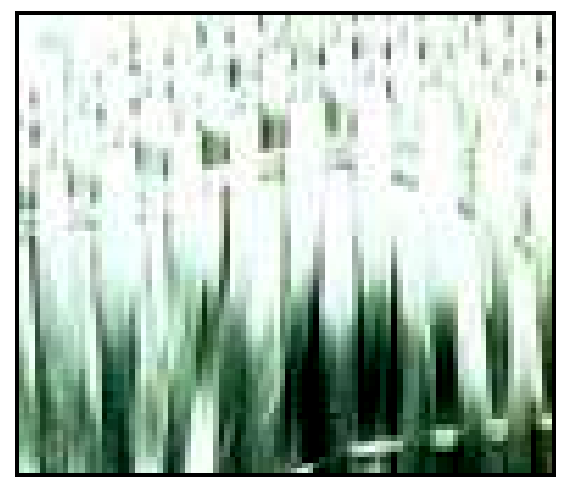

\section{Fiberglass Unidirectional Direct Roving}

Direct Roving are single ended and treated with silane (a chemical compound with chemical formula $\mathrm{SiH}_{4}$ ) based sizing. They are largely used for Filament Winding and Pultrusion process. Direct roving has excellent mechanical and electrical properties and ideal for low fuzz applications with multiple resins. Direct roving is primarily used in filament winding but also used in Pultrusion (such as pultruded rod, pipe, tanks, etc) and other fiberglass products (such as woven roving and chemical resistant grating). Direct roving should be stored dry and in its 
original packaging. The best conditions are temperature between 10 and $35 \square$ and at a relative humidity between 35 and $85 \%$.

\section{D.2 Copped Strand Mat}

Chopped strand mat contains a binder which prevents proper bonding with any epoxy resins. Figure below shows an example of fiberglass chopped strand mat.

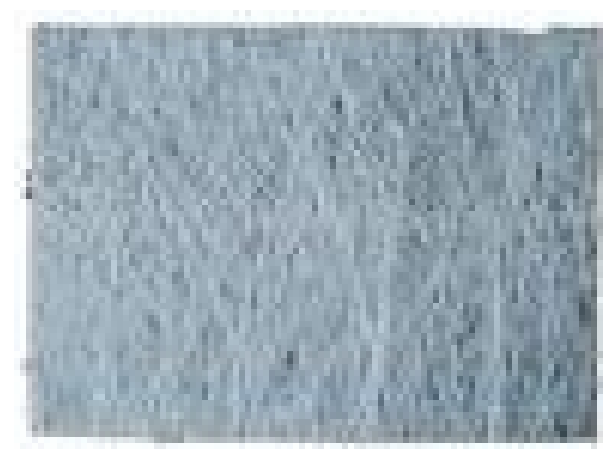

Fiberglass Chopped Strand Mat

Chopped strand mat can be used alone or in conjunction with fiberglass fabrics or woven roving in larger fabrications. Mat is commonly used for buildup such as plywood decking and between layers of fabric when molding.

\section{D.3 Woven Roving}

Woven roving, also known as "cross weave" are bi-directional fabric made by interweaving roving (a collection of specific numbers of untwisted continuous filaments). Fiberglass woven roving is basically a heavier version of fiberglass cloth. Due to higher fiber content, woven roving's lamination has excellent tensile strength and impact-resistant property. As woven roving easily wets out, provides great tensile and flexural strength, it is often used between layers of fiberglass mat in laminates. It can also be used with chopped strand mat to fabricate large size objects, such as boats, vehicle components, pressure tank, house, etc. Woven 
roving is compatible with many resin systems such as polyester, vinyl ester and epoxy resins. They are high-performance reinforcement widely used in hand layup and automated processes for the production of boats, vessels, plane and automotive parts, furniture, and sport facilities.

For this project, fiberglass woven roving was mainly used for the fiberglass manhole and test specimens due its excellent tensile strength and bending-resistant property and also since it was generously provided by the Cal Poly's Aero-Composite Laboratory.

\section{Appendix E: Composite Matrices in General}

The matrix material plays an important role in the overall function of the composite and must satisfy a number of somewhat conflicting demands regarding strength, toughness, moisture and environmental resistance, elevated temperature properties, and cost. A number of alternatives have evolved for different applications.

\section{E.1 Thermosets and Thermoplastics}

The polymeric matrices can be classified into two general categories thermosets and thermoplastics. The thermosets, including epoxies, cure by chemical reaction, and the cure is a one-time irreversible process. The thermoplastics can be formed repeatedly by heating to an elevated temperature at which softening occurs. The manufacturing process for the composite parts in general will be quite different for thermoplastic and thermoset matrices.

The thermoset polymers have been heavily utilized and a large amount of characterization data is available for these materials. Lower-cost materials are polyester and vinyl ester with similar but somewhat improved mechanical properties and improved solvent resistance. Table below gives further general overview and comparison of glass-fiber resin 
composites in various forms. It should be noted that fiber reinforcement dominates many of the properties listed, and thus the properties reflect both resin and fiber properties.

\section{Typical Properties of Glass-Polyester Composites in Various Forms}

\begin{tabular}{|c|c|c|c|}
\hline Form & Density & Tensile Strength & Tensile Modulus \\
\hline Unidirectional Roving & $7.23 \times 10^{-8} \mathrm{lb} / \mathrm{in}^{3}$ & $100 \mathrm{ksi}$ & $5.81 \mathrm{Msi}$ \\
\hline Woven Glass Fabric & $6.87 \times 10^{-8} \mathrm{lb} / \mathrm{in}^{3}$ & $4.79 \mathrm{ksi}$ & $3.77 \mathrm{Msi}$ \\
\hline Chopped Strand Mat & $6.14 \times 10^{-8} \mathrm{lb} / \mathrm{in}^{3}$ & $4.21 \mathrm{ksi}$ & $2.42 \mathrm{Msi}$ \\
\hline
\end{tabular}

It also can be seen by comparing the values listed in the table above that the composite stiffness and strength properties are less than that of the fiber itself, because of the dilution by the weaker matrix and also because of the need to orient fibers in different directions. It also can be seen that the properties can depend on the form of the fiber reinforcement, with chopped-fiber composites having lower stiffness and strength relative to continuous-fiber composites.

\section{E.2 Epoxy Resins}

The epoxy resins are widely used thermosets that offer superior performance, but are more costly relative to polyesters. Typical cure temperatures for the epoxies are in the range of 121 to $177^{\circ} \mathrm{F}\left(250\right.$ to $\left.350^{\circ} \mathrm{F}\right)$. Variables to consider are the interlaminar shear strength, which is a laminate property related to the shear strength of the matrix, the brittleness or toughness of the matrix, moisture and environmental resistance, and the range of elevated temperature properties if that is part of the product requirement. Early aerospace epoxies used in pre-pregs emphasized resistance to hot, wet conditions, and while achieving these objectives tended to brittle and subject to damage from accidental impact. More recent developments have been the hightoughness epoxies, available at higher cost. 


\section{E.3 Thermoplastic Resins}

Thermoplastics resins soften at elevated temperature, and thus can be formed and then cooled to manufacture the final item; they do not use a cure cycle. An advantage of this process is that in theory parts can be reformed and repaired. The manufacturing process is thus quite different than that used in thermoset matrix. Thermoplastic resins range from the common engineering plastics to other specifically developed to be used in high performance fiber composites.

Materials such as polypropylene and nylon, for example, are commonly used with chopped glass fiber. The product is processed much as it would be without the fiber, such as by injection molding, for example; the process gives a finished material with higher mechanical properties than from the thermoplastic alone, but considerably lower than with the continuousfiber composites.

A process developed for continuous-fiber composites with thermoplastic resins would involve softening layers of combined fiber and resin at elevated temperature, and then placing them in a mold to be formed, similar to metal stamping. The higher-performance, higher-cost thermoplastics have excellent toughness properties.

The use of thermoplastics in combination with continuous-fiber systems has been held back because of a general lack of experience, and in some cases high material costs. They are likely to increase in use due to the increased toughness that they may offer, as well as the potential for advanced manufacturing techniques.

\section{E.4 Additives}

A wide variety of additives are used in composites to modify materials properties and tailor the laminate's performance. Although these materials are generally used in relatively low 
quantity by weight compared to resins, reinforcements and fillers, they perform critical functions.

Additive used in thermoset and thermoplastic composites include the following:

- Low shrink/low profile: when parts with smooth surfaces are required, a special thermoplastic resin, which moderates resin shrinkage, can be added to thermoset resins.

- Fire resistance: combustion resistance is improved by proper choice of resin, use of fillers or flame retardant additives.

- Air release: most laminating resins, gel coats and other polyester resins might entrap air (air voids) during processing and application; thus, air release additives reduce such entrapment to enhance fiber wet-out.

- Emission control: in open mold applications, styrene emission suppressants are used to lower emissions for air quality compliance.

Viscosity control: in many composites types, it is critical to have a low, workable viscosity during production. These additives facilitate the wet-out and dispersion of fillers resulting in lower viscosity (and/or higher filler loading).

- Electrical Conductivity: most composites do not conduct electricity; hence, electromagnetic interference shielding can be achieved by incorporating conductive materials by the addition of metal, carbon particles or conductive fillers.

- Toughness: can be enhanced by the addition of reinforcements. It can also be improved by special additives such as certain rubber or other elastomeric materials.

- Antioxidants: plastics are sometimes modified with antioxidants, which retard or inhibit polymer oxidation and the resulting degradation of the polymer. 
- Antistatic agents: are added to polymers to reduce their tendency to attract electrical charge. Control of static electricity is essential in certain plastics processing and handling operations since static charges on plastics can produce shocks, fire hazard, and attract dust.

- Foaming agents: are chemicals that are added to polymers during processing to form minute cells throughout the resin. Foamed plastics exhibit lower density, decrease material costs, improve electrical and thermal insulation, increase strength-to-weight ratio and reduce shrinkage and part warping.

- Plasticizers: are added to compounds to improve processing characteristics and offer a wider range of physical and mechanical properties.

- Slip and blocking agents: provide surface lubrication. This results in reduced coefficient of friction on part surfaces and enhances release of parts from the mold.

- Heat stabilizers: are used in thermoplastic systems to inhibit polymer degradation that results from exposure to heat.

- Ultraviolet stabilizers: both thermoset and thermoplastic composites may use special materials which are added to prevent loss of gloss, crazing, chalking, discoloration, changes in electrical characteristics, embrittlement and disintegration due to ultraviolet (UV) radiation. Materials, which protect the polymer, are known as ultraviolet stabilizers.

\section{E.5 Catalysts and Inhibitors}

In polyesters, the most important additive is catalyst or initiator. Typically, organic peroxide such as methylethylketone peroxide (MEKP) is used for room temperature cured processes, or benzoyl peroxide is added to resin for heat-cured molding. When triggered by heat, 
or used in conjunction with a promoter (such as cobalt napthenate), peroxides convert to a reactive state (exhibiting free radicals), causing the unsaturated resin to react (cross-link) and become solid. Some additives such as TBC (tertiary butyl catechol) are used to slow the rate of reaction and are called inhibitors. Accelerators such as DMA (dimethyl aniline) speed curing.

\section{Appendix F: Inorgranic Fillers in General}

The main purpose of inorganic fillers is not only to reduce the cost of composites, but also frequently to enhance performance improvements of a composite that might not otherwise be achieved by the reinforcement and resin ingredients alone. Fillers in a composite retain their identities (they do not dissolve or merge completely into each other) while acting in concert to provide a host of benefits ideal for structural applications.

Fillers can improve mechanical properties including fire and smoke performance by reducing organic content in composite laminates. Also, filled resins shrink less than unfilled resins, thereby improving the dimensional control of molded parts. Important properties, including water resistance, weathering, surface smoothness, stiffness, dimensional stability and temperature resistance, can all be improved through the proper use of fillers.

The thermosetting resin segment of the composite industry has taken advantage of the properties of fillers for many years. More recently, the thermoplastic industry has begun to make widespread use of inorganic fillers. Breakthroughs in chemical treatment of fillers that can provide higher loadings and improved laminate performance are accelerating this trend.

Fillers are use to thicken basic resin and hardener mixture from specific application. The two common filler mixtures are adhesive (high-density) or fairing (low-density). Adhesive filler mixtures cure to a strong, hard-to-sand plastic useful in structural applications like bonding, filleting, and hardware bonding [3]. In addition, high-viscosity adhesives have greater gap filling 
abilities; whereas, low-viscosity adhesives have lower gap filling abilities. Fairing filler mixtures cure to light, easily sandable material use for cosmetic or surface applications such as shaping, filling, or fairing [3].

Thixotropic agents are fillers that convert epoxy into a thixotropic fluid. They flow under stress and thicken when stress is removed. Some consistency examples of thixotropic agents are ketchup and latex house paints. [13].

Bulking agents are fillers that have "Bulk-out" epoxy properties thus, making a lightweight, putty-like mixture. They are used with thixotropic agent (silica thickener) makes a great compound for fairing and filleting. Bulking agents are not recommended for gluing. [13].

Fibrous agents are fillers incorporated into structural fillets to improve tensile strength. There highest tensile strength is obtained with chopped glass strand, second with milled glass fiber, and third with plastic mini-fibers [13].

\section{F.1 Applications of Fillers}

Calcium Carbonate is the most widely used inorganic filler. It is available at low cost in a variety of particle sizes and treatments from well-established regional suppliers, especially for composite applications. Most common grades of calcium carbonate filler are derived from limestone or marble. Common applications include: synthetic/cultured marble, ceramic floor tiles, caulking compound, building products, grouting and thin set mortars, sealants, adhesives, water-based paints, animal feeds, and PVC pipes.

Kaolin (hydrous aluminum silicate) Clay which is the second most commonly used filler. It is known throughout the industry by its common material name, clay. Mined clays are processed either by air flotation or by water washing to remove impurities and to classify the product for use in composites. A wide range of particle size is available. 


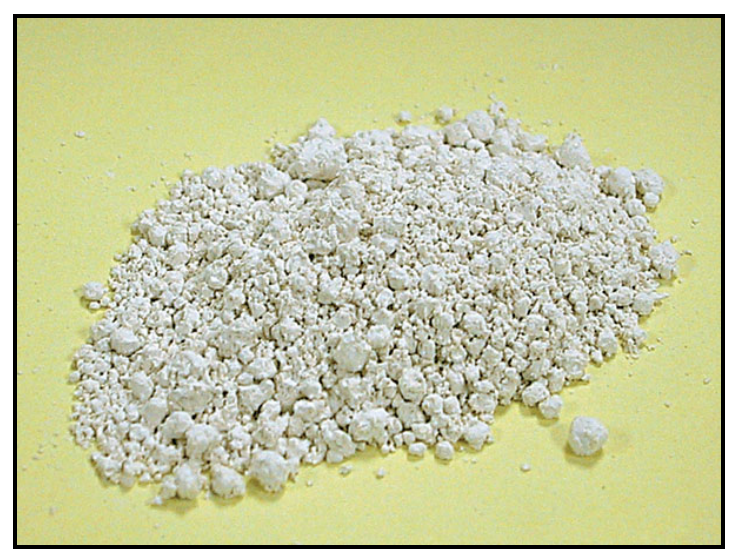

Kaolin Clay [31]

Alumina Tri-hydrate which is frequently used when improved fire/smoke performance is required. When exposed to high temperature, this filler gives-off water (hydration), thereby reducing the flame spread and development of smoke. Composite plumbing fixture applications such as bathtubs, shower stalls and related building products often contain alumina tri-hydrate for this purpose.

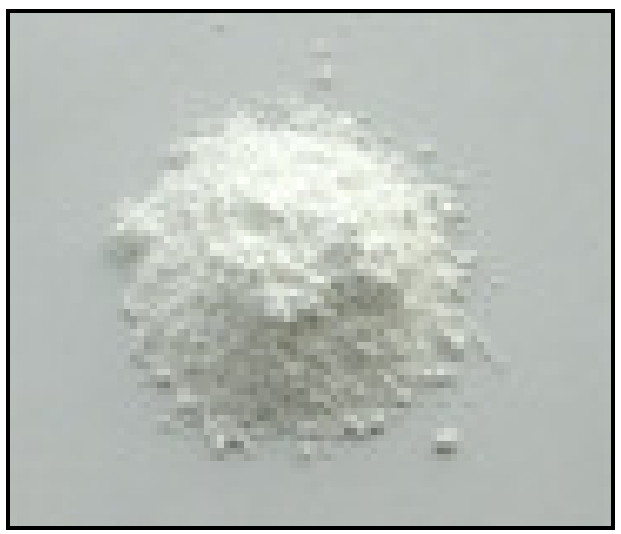

Figure 12: Alumina Tri-hydrate [31]

Calcium Sulfate - a major flame/smoke retarding filler used by the tub/shower industry. It has fewer waters of hydration, and water is released at a lower temperature. This mineral filler offers a low cost flame/smoke retarding filler. 


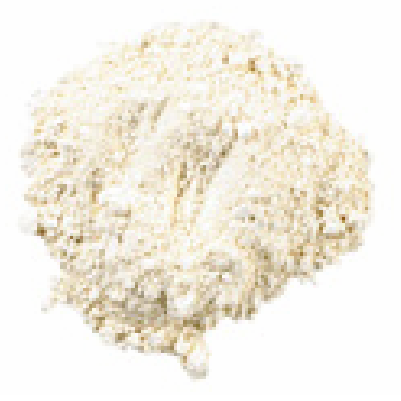

Calcium Sulfate [31]

Talc Filler is a white platy hydrated magnesium silicate. It is sandable filler added for fairing and smoothing the finished of the fiberglass laminations. Talc is the softest filler and has a slippery texture. The major markets for Talc are ceramics, paint, paper, plastics, cosmetics, and roofing materials.

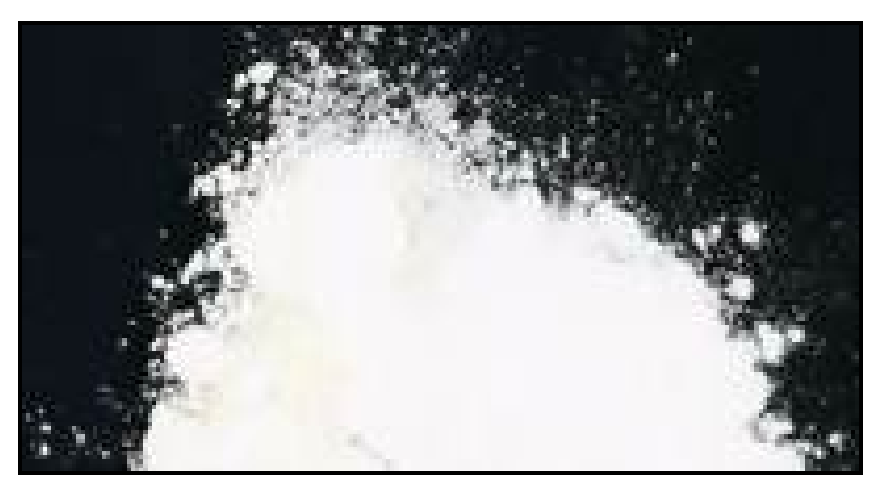

Talc Filler [31]

Thixotropic Silica is a fine grade fumed silica thickening agent similar to Cab-O-Sil and is added to resin systems to prevent run-off and sags on vertical surfaces [31]. 


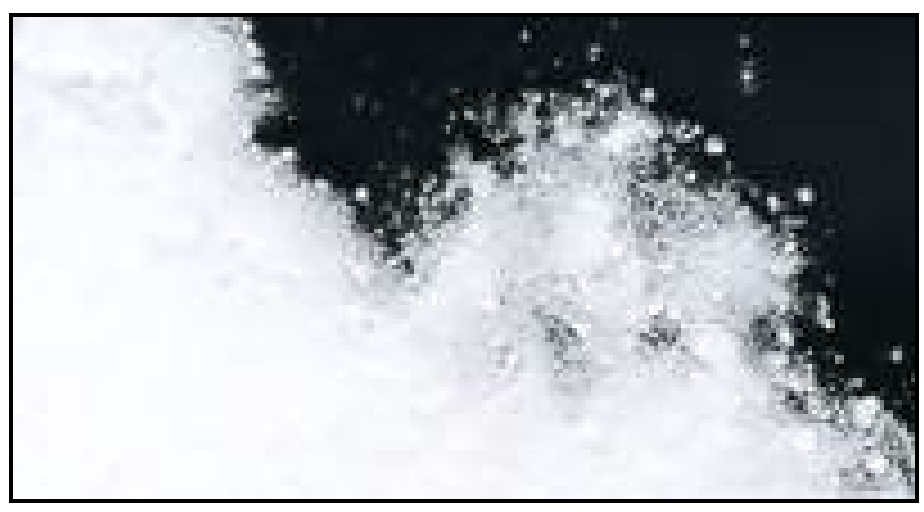

Thixotropic Silica [31]

Glass Microspheres are hollow glass spheres that make lightweight sandable filler when blended with resin, as seen in figure above.

Use to fill fabric weave, shallow blisters, and surfaces of core materials. The average bubble is less than 70 microns, about a quarter of a grain of salt. Small particle size makes the paste very easy to spread evenly [31].

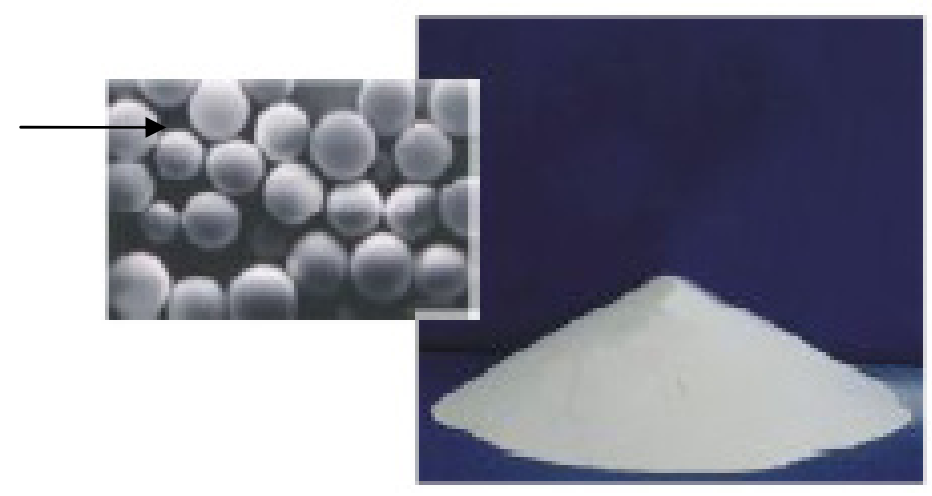

\section{Glass Microspheres Filler [31]}

Chopped Glass Fiber which is a fibrous agent that has longer glass fibers used to increased tensile and compressive properties of any resin, even concrete. This coarse mixture can strengthen castings and reinforce fillets in difficult to laminate areas of parts [31]. 


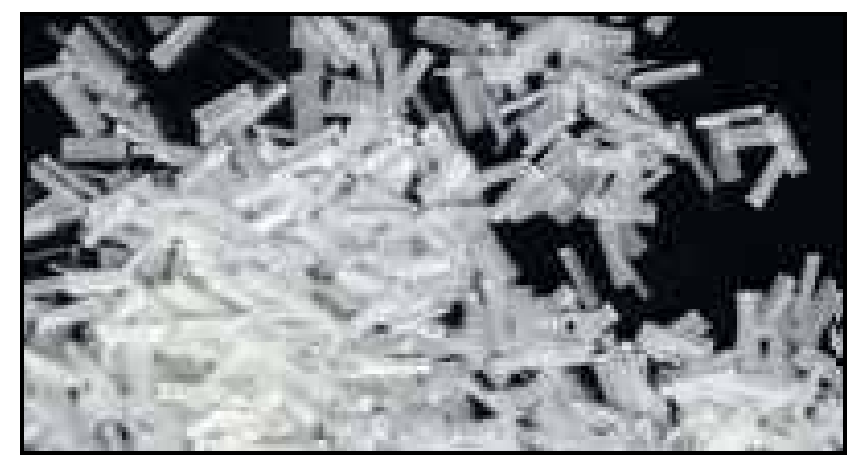

Chopped Fiberglass Filler [31]

Milled Glass Fiber, is a fibrous agent that has shorter fibers that offer high strength results in order to improve finishing characteristics for surfaced applications. This type of filler is great to reinforce detailed castings, or blend with epoxy to make a stronger outer surface coats. Blend with vinyl ester resin to create strong and corrosion resistance blister repair putty for deeper hull damage. Mix to a ketchup consistency for best corrosion protection [31].

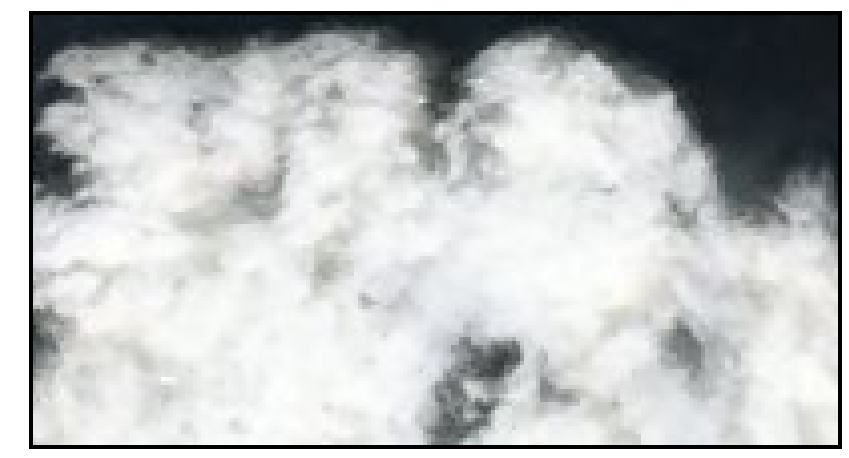

Figure 13: Milled Fiberglass Filler [31]

Chopped Graphite Fiber is an economical alternative for localized reinforcement of high performance parts requiring optimal electrical conductivity, high strength and moduli. Excellent for reducing voids in difficult vacuum bagging applications [31]. 


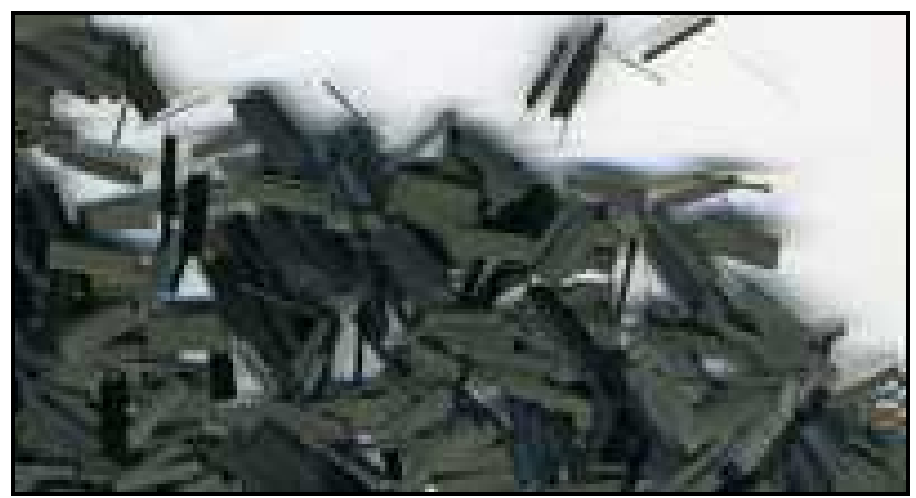

Figure 14: Chopped Graphite Fiber Filler [31]

Kevlar Pulp Filler highly abrasion resistant. Areas of high impact can easily be reinforced with this strong and durable material. Use to make beveled fillets along edges of honeycomb cores to smooth the transition of fabric skin and is recommended to use with epoxy or vinyl ester resin.

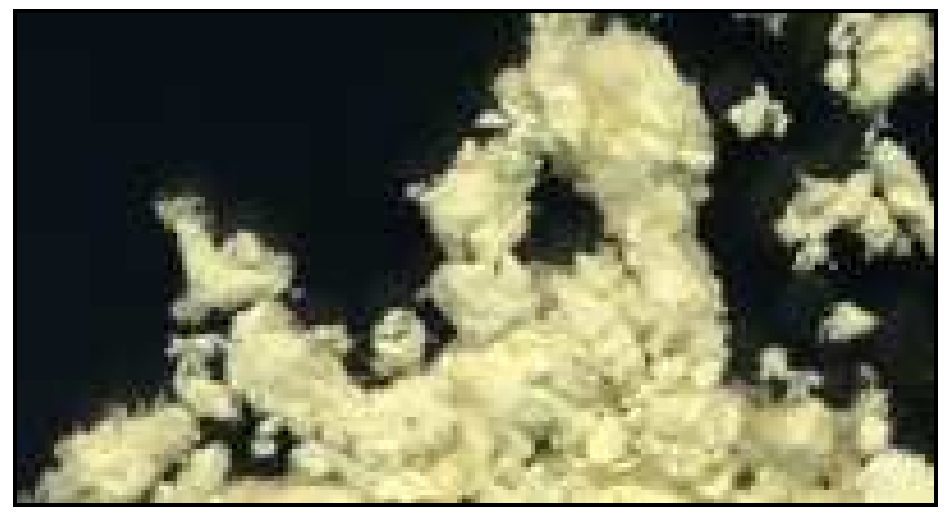

Kevlar Pulp Filler [31]

\section{F.2 Particulate Fillers for Polymers}

Each filler has different properties thus are influenced in the particle size, shape and surface chemistry. Filler characteristics are discussed from costs to particle morphology. Particle specific surface and packing are important aspects. Average particle size on data sheets can be 
misleading and may not accurately reflect particle size distribution. Principal fillers include: carbon black, natural mineral fillers and synthetic mineral fillers.

Filler surface modification is very crucial. Most particulate fillers are inorganic and polar, which can give rise to poor compatibility with hydrocarbon polymers and processing problems. The main types of modifying agent range from fatty acids to functionalized polymers. Since PVC has plasticizer, the filler has little effect on processing which allows relatively high filler levels to be incorporated [10]. The following are some of the benefits of fillers in polymers:

- Cost reduction

- Improved processing

- Density control

- Optical effects

- Thermal expansion control

- Thermal conductivity enhanced

- Electrical properties

- Magnetic properties

- Flame retardancy

- Improved mechanical properties (hardness/ tear resistance) 


\section{Appendix G: Material Charactersitics of Limestone}

Limestone is calcareous sedimentary rocks formed at the bottom of lakes and seas with the accumulation of shells, bones and other calcium rich goods. It is composed of calcite $\left(\mathrm{CaCO}_{3}\right)$. The organic matter is preserved as fossils and is usually found in lakes or oceans. Over thousands and millions of years, layer after layer is built up adding weight. The heat and pressure causes chemical reaction at the bottom and the sediments turn into solid stone.

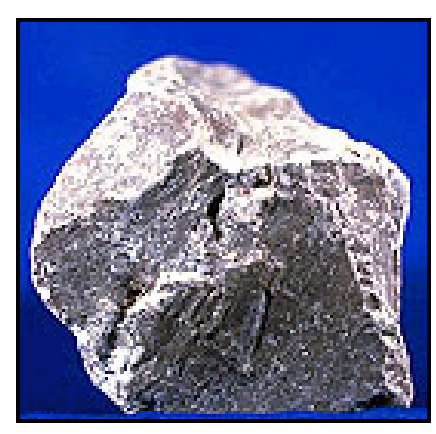

Limestone Rock

\section{G.1 Properties of Calcium Carbonate}

The rock is known as high-calcium limestone which contains more than $95 \%$ of calcium carbonate. In additional, all limestone reacts with strong acids, such as, sulfuric acid and hydrochloric acid, releasing carbon dioxide as a byproduct.

$$
\mathrm{CaCO}_{3(s)}+2 \mathrm{HCl}_{(a q)} \rightarrow \mathrm{CaCl}_{2(a q)}+\mathrm{CO}_{2(g)}+\mathrm{H}_{2} \mathrm{O}_{(l)}
$$


It also releases carbon dioxide on heating (to above $840{ }^{\circ} \mathrm{C}$ in the case of $\mathrm{CaCO}_{3}$ ), to form calcium oxide, commonly called quicklime, with reaction enthalpy $178 \mathrm{~kJ} /$ mole:

$$
\mathrm{CaCO}_{3(s)} \rightarrow \mathrm{CaO}_{(s)}+\mathrm{CO}_{2(g)}
$$

The following table shows the chemical and material properties of limestone:

\section{Typical Properties of Limestone}

\begin{tabular}{|c|c|c|c|c|c|c|}
\hline $\begin{array}{c}\text { Lime } \\
(\mathrm{CaO} \%)\end{array}$ & $\begin{array}{c}\text { Silica } \\
\left(\mathrm{SiO}_{2} \%\right)\end{array}$ & $\begin{array}{c}\text { Alumina } \\
\left(\mathrm{Al}_{2} \mathrm{O}_{3} \%\right)\end{array}$ & $\begin{array}{c}\text { Density } \\
\left(\mathrm{lb} / \mathrm{in}^{3}\right)\end{array}$ & $\begin{array}{c}\text { Compressive } \\
\text { Strength }\left(\mathrm{lb} / \mathrm{in}^{2}\right)\end{array}$ & $\begin{array}{c}\text { Weather } \\
\text { Impact }\end{array}$ & $\begin{array}{c}\text { Melting } \\
\left.\text { Point ( }{ }^{\circ} \mathrm{F}\right)\end{array}$ \\
\hline $38-42$ & $20-25$ & $2-4$ & 9.79 & 4,000 to 20,000 & Resistant & 1517 \\
\hline
\end{tabular}

\section{G.2 Applications of Calcium Carbonate}

The main use of calcium carbonate (calcite) is in the construction industry, either as a building material in its own right (e.g. marble) or limestone aggregate for roadbuilding or as an ingredient of cement or as the starting material for the preparation of builder's lime by burning in a kiln. Calcium carbonate is also used in the following applications: purification of iron from iron ore in a blast furnace, oil industry in drilling fluids, growing Seacrete or Biorock, paints, babies' diapers, adhesives and sealants, production of glossy paper, blackboard chalk, and dietary calcium supplement or antacid.

Calcium carbonate is also widely used as filler in plastics. For example, calcium carbonate is used in PVC drain pipes, window profiles, and cables since it improves mechanical properties (tensile strength and elongation) and electrical properties (volume resistivity). Currently, a material company, called Solvay, use coated precipitated calcium carbonate (CPCC) in order to improve gelation and processing, surface finish and impact resistance in extrusion 
profile PVC compounds. CPCC is a unique additive which can provide both a processing aid and impact modification function without any adverse effects.

[28].

In addition, L.F. Manufacturing, Inc also uses calcium carbonate to build fiberglass reinforced manholes. The limestone powder filler and additives help to improve the mechanical properties of the fiberglass manhole by adding tensile strength and anti-corrosive properties that reduces the need to install and repair; thus making it very economical. Consequently, the scope of work for this thesis involved using calcium carbonate filler to create laminated manhole covers for the previous mentioned reasons.

\section{Appendix H: Initial Design Consideration for Bending Test Apparatus}

The Aero-Composite lab's customized bending test apparatus was initially considered. Figure 5.25 shows the different components and corresponding dimensions of the bending test apparatus that was initially considered for testing the fiberglass laminated manhole covers.

Top View

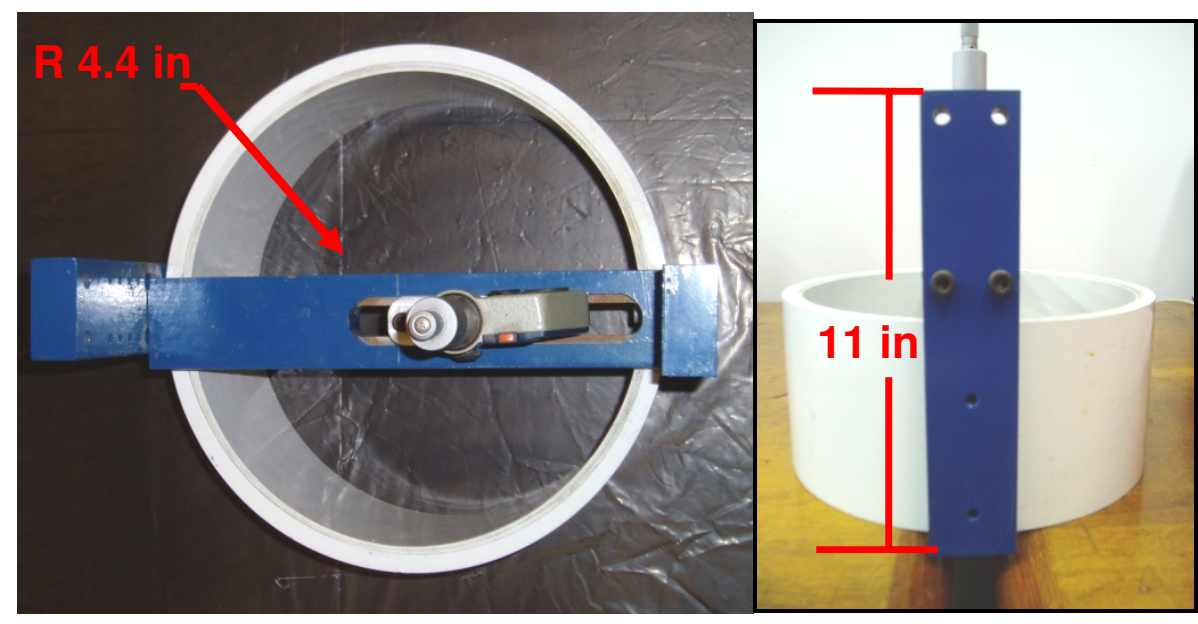

Side View 


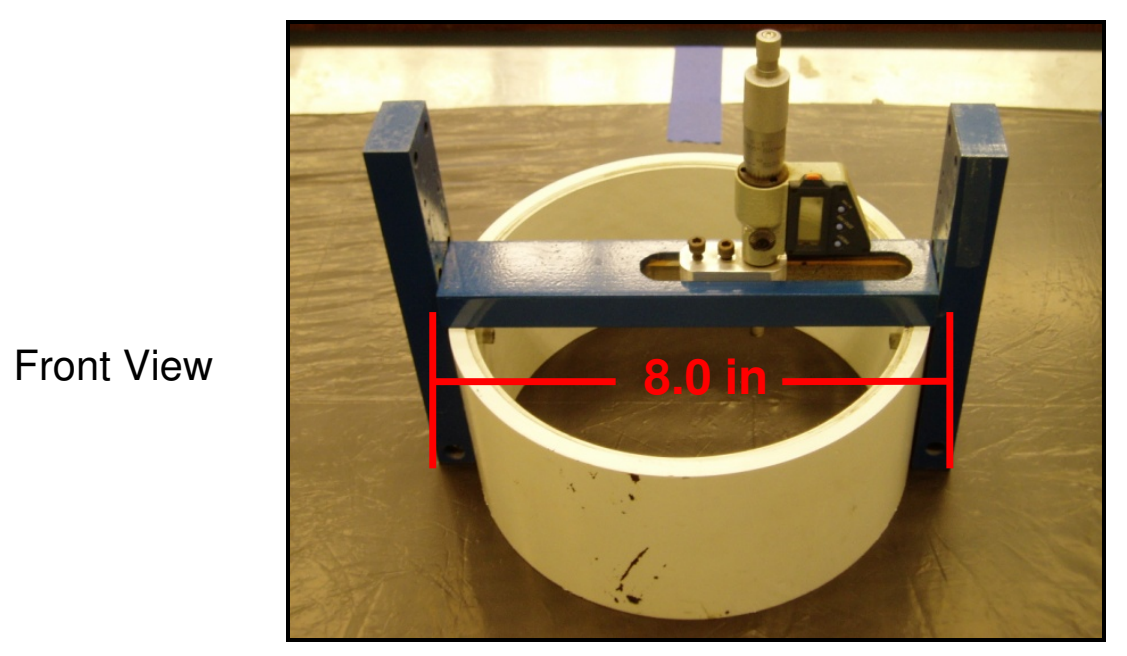

\section{Apparatus Used for Performing Bending Test}

As seen in previous figure, it consisted of three 8-inch aluminum beams, a 1-inch thick PVC pipe with an inner diameter of 4.4 inches, and digital-dial indicator located on top of the cantilever beam, as seen below.

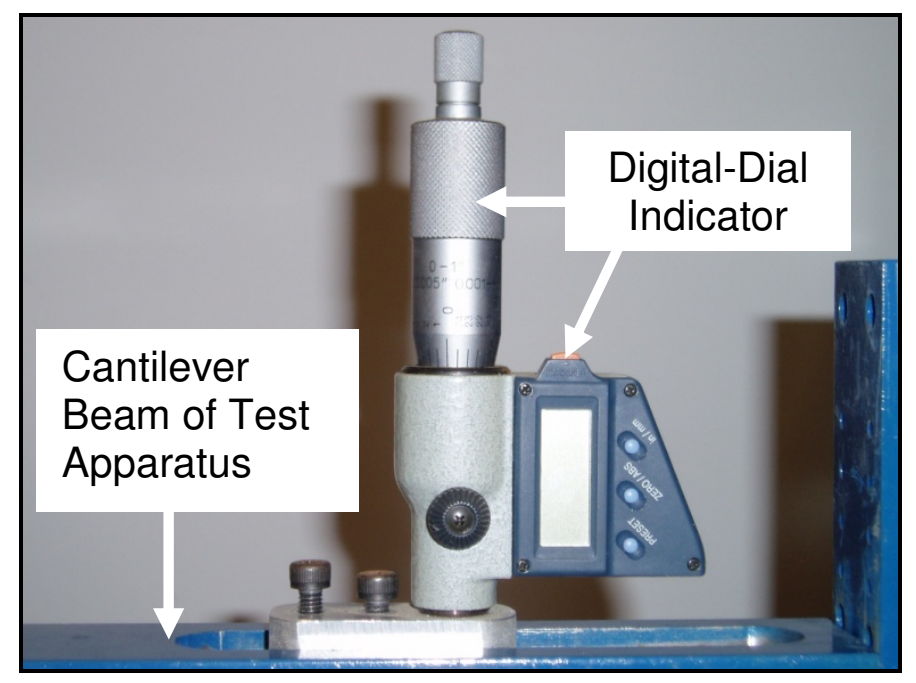

\section{Digital-Dial Indicator Used to Measure Deflection on Test Specimens}

The digital-dial indicator was used to measure the amount of bending moment and deflection inserted on each test specimen. Although the 1-inch thick PVC pipe was intended to support the fiberglass manhole test specimen during the bending tests, it was redesigned since the test 
manhole specimen's diameter of 11 inch was larger than the 5.4 inch inner diameter of the PVC pipe. The aluminum beam of bending test apparatus was used to find several bending and deflection measurements at different locations of the test specimens which were also redesigned using Solid Works program. The beam's original size of 8 inch was going to be replaced by an 11 inch aluminum beam provided by Stanley's Steel Corp. of San Luis Obispo, which will be further discussed in the next section.

\section{H.1 Beam Design}

The bending test apparatus goal was to measured deflection on different locations along the radius of the manhole cover test specimens. The aluminum beam's groove used to measure deflection was modified to a new specification of 5.5 inches since the fiberglass manhole cover specimens had a larger radius than expected. The overall beam length was also increased to 11 inches. Schematic below shows the new dimensions of the aluminum beam used to measured test specimens during bending testing.

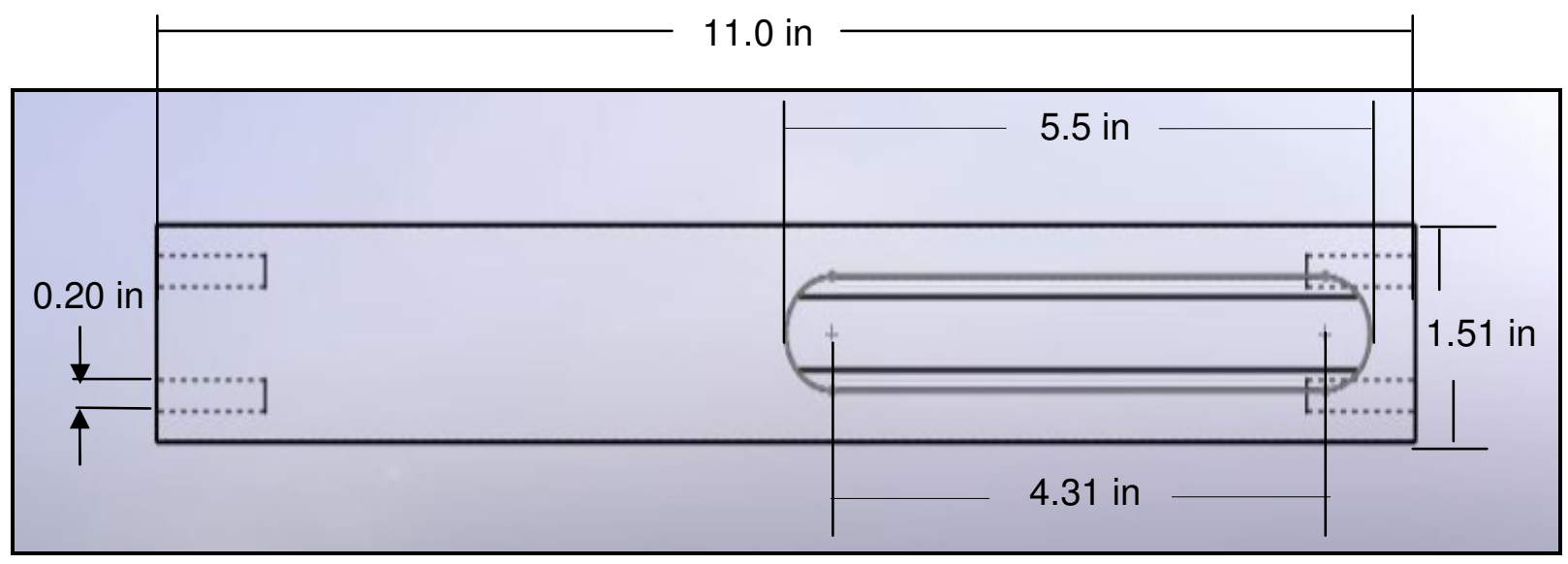

Dimensions of New Beam Design 
The following figures were initially modeled using the Solid Work program. They represented the different views of the beam's new design for the bending apparatus. The aluminum beam would be purchased from Stanley's Steel Corp. of San Luis Obispo. Bolt holes were designed with 0.20 inch diameter which would be drilled into the aluminum beam's sides, as seen in figure above. Figure below show different views of the aluminum cantilever beam design for bending test apparatus.

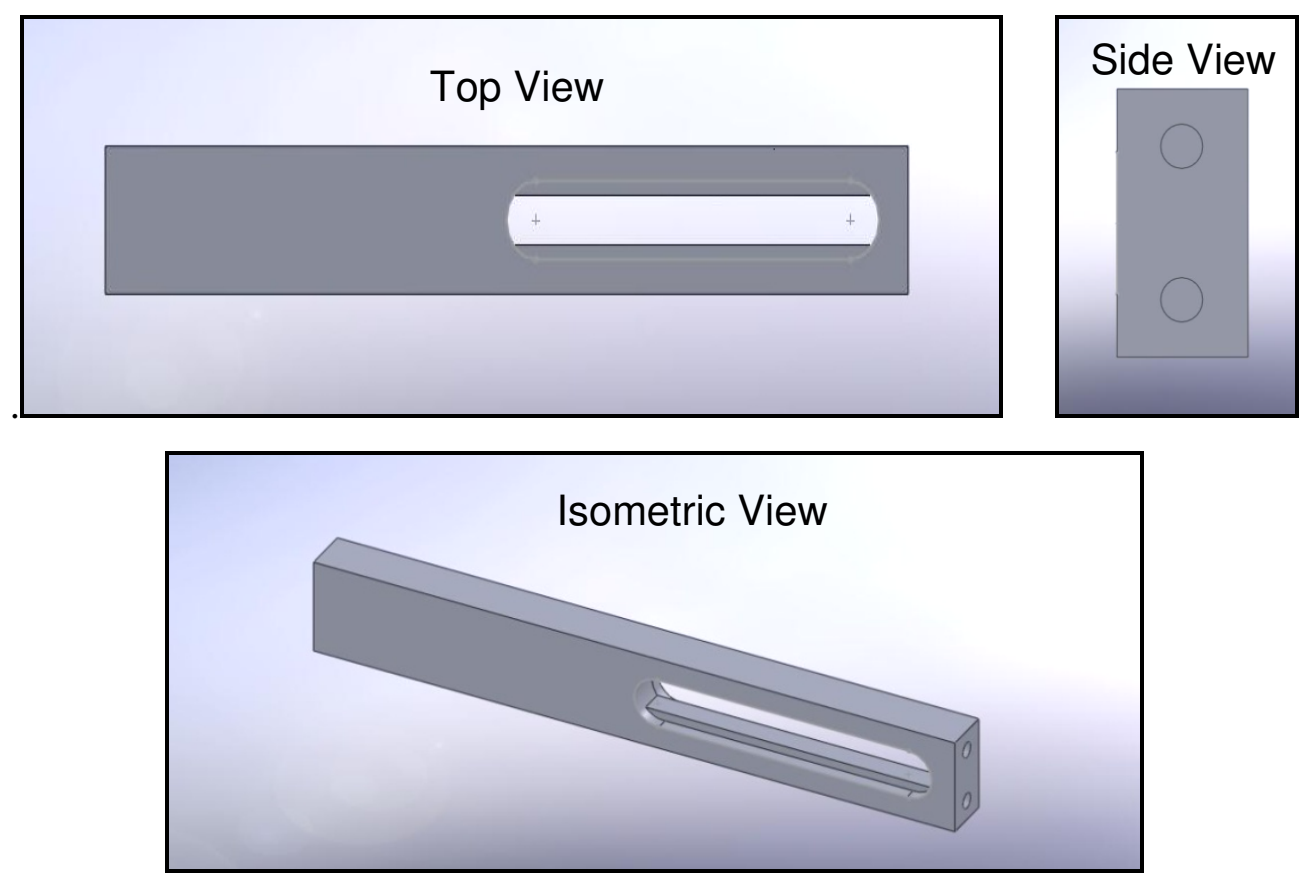

Different Views of New Beam Design

The new beam design was never implemented since the bending tester was not used for the experimental bending analysis since it was a rudimentary method to obtain results and did not follow the ASTM standard test method for flexural properties of polymer matrix composite materials. Instead the MTS 322 Flex Frame machine from Cal Poly's Civil Engineering Department was used to measure deflection by performing punch and flexural tests. 


\section{Appendix I: Supporting Static Analysis for Thin-Laminated Manhole Cover Plates}

\section{I.1 Indentation Force Test System}

Experimental tests of bending were performed in order to determine the dynamic behavior under bending loads of each laminate structure, specifically both 4 and 9-plied fiberglass manhole cover test specimens. The composite structure will also be tested under bending on different constraints. This will be further discussed in the bending testing analysis section. The Instron tensile machine (not used) was originally intended to perform the bending experiment by using a roller fixture attachment that would apply axial loads on the test specimens; therefore Cal Poly Civil Engineering Department's hydraulic actuator bending system was used for the indentation force and bending analysis of this investigation.

The concentrated quasi-static indentation force method is a low-speed test and generally used for obtaining quantitative measurements of the damage resistance of a continuous-fiber reinforced composite materials. The indentation force is applied to the specimen by slowly pressing an indenter (instrumentation plunger) into the test specimen's surface for penetration and perforation. The test requires that the specimen is designed so that it can be simply supported to a stationary fixture. Although these tests may be used to screen material for damage tolerance resistance, it is limited to use with composites consisting of layers of unidirectional fibers or layers of fabric. Loading is applied by device capable of delivering a constant speed loading rate at a maximum load of $80,000 \mathrm{lbs}$. The loading rate was $0.5 \mathrm{in} / \mathrm{min}$ with a sampling rate of $0.5 \mathrm{sec}$ (20 hertz). For this project, the test was performed by using the MTS 322 Flex Frame apparatus, as seen in figure below. 


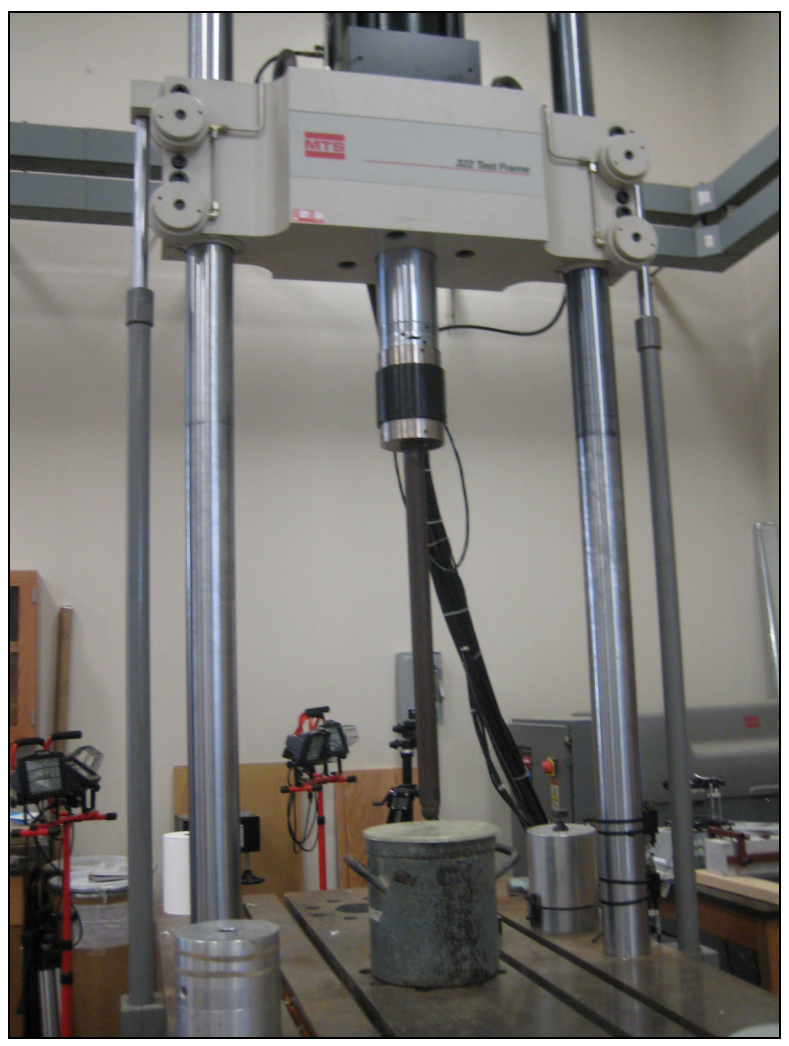

\section{Hydraulic Actuator System Used for Indentation Testing}

The indentation force machine was used to measure the axial deflection or displacement created by the concentrated load applied at the center of each laminated specimen. The MTS 322 model consist of the following: an instrumented plunger with a 1.5 inch diameter steel ball located at its end, a mandrel which is used to clamp, secure, and load vertically the plunger, a steel table to press and hold specimens, data acquisition and hydraulic actuator control system. The actuator control system uses a MTS Flex Test SE software program to run the specified commands from computer (data acquisition system) and reads adjustments from the MTS 322 machine. The computer is used to measure the applied point load and displacement in the axial direction. It used the software program called "Station Manager" to read measure and collect all testing data. 
Figure below shows the 11-inch diameter steel-rigid fixture used for simply supporting the 4plied fiberglass manhole cover plates during punch testing.

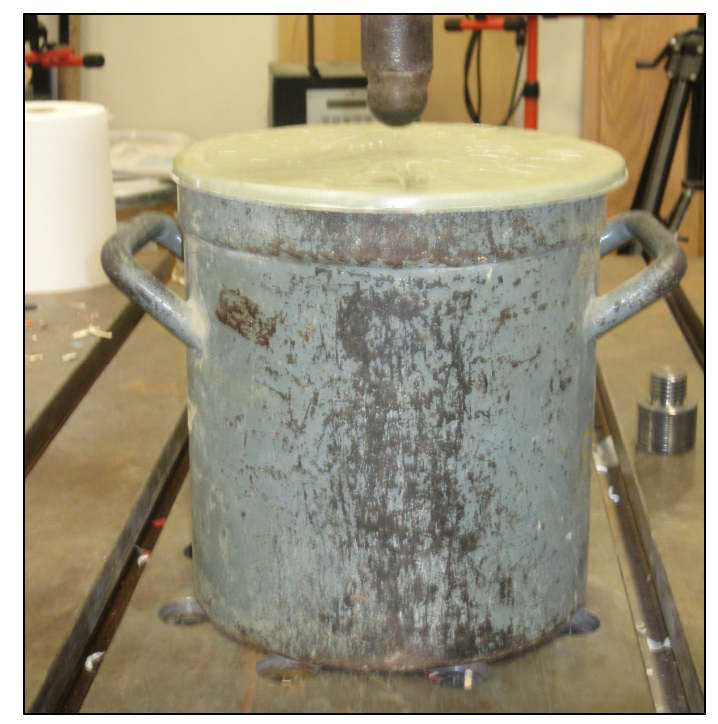

\section{Steel Fixture Used During Punch Testing.}

Although the indenter was not hemispherical nor the test specimens had square geometries, they still follow several accepted procedures from the ASTM Standard D-6264 guidelines for tested materials involving weaves and fiber-reinforced polymer-matrix laminates.

\section{I.2 Indentation Test Results}

The center load applied to the specimen for this bending test was very similar to the threepoint bending configuration. The maximum flexural is located directly under the center force application member and the resultant shear force is everywhere on the specimen except under the mid-point force application. The difference between both methods is their geometry and boundary conditions since the three-point test involves two reaction forces acting on a rectangular cross-section, whereas, this investigation involved reaction forces acting along on a circular cross-section. Consequently for this thesis project, it was assumed that indentation or 
punch test method followed a three-point bending configuration. A trial test was performed to calibrate the indentation test apparatus before proceeding with testing the fiberglass laminated flat test specimens, as seen below.

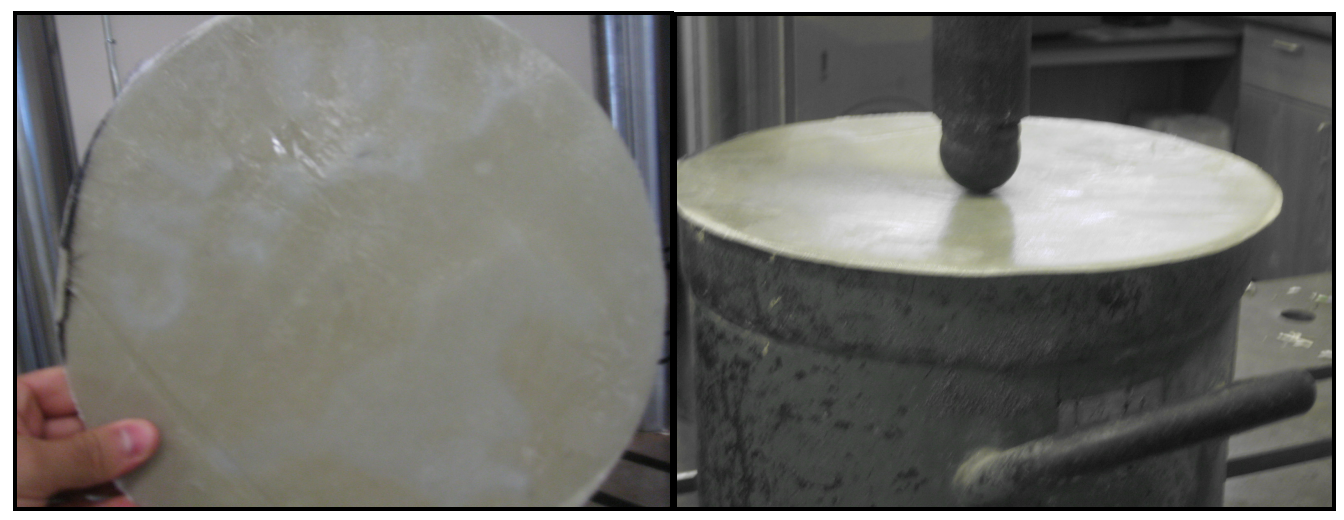

Test Trial for Calibrating Indentation Apparatus

The figure below shows different views of laminated plate after indentation testing.

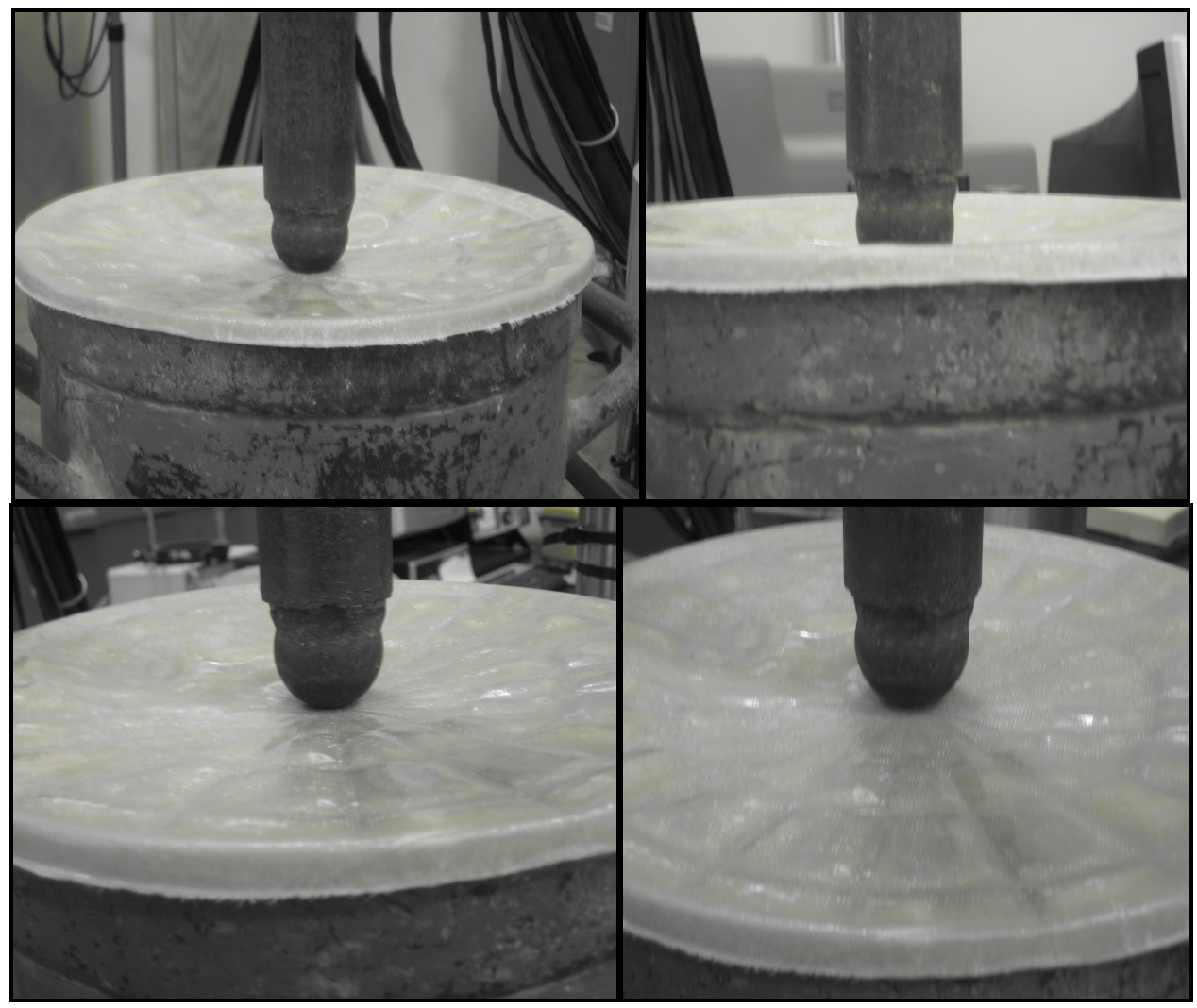

Different Views of Specimen During Indentation Test 
The figure below shows the force vs. displacement curve for specimen $\mathrm{L}_{20}$ after indentation testing.

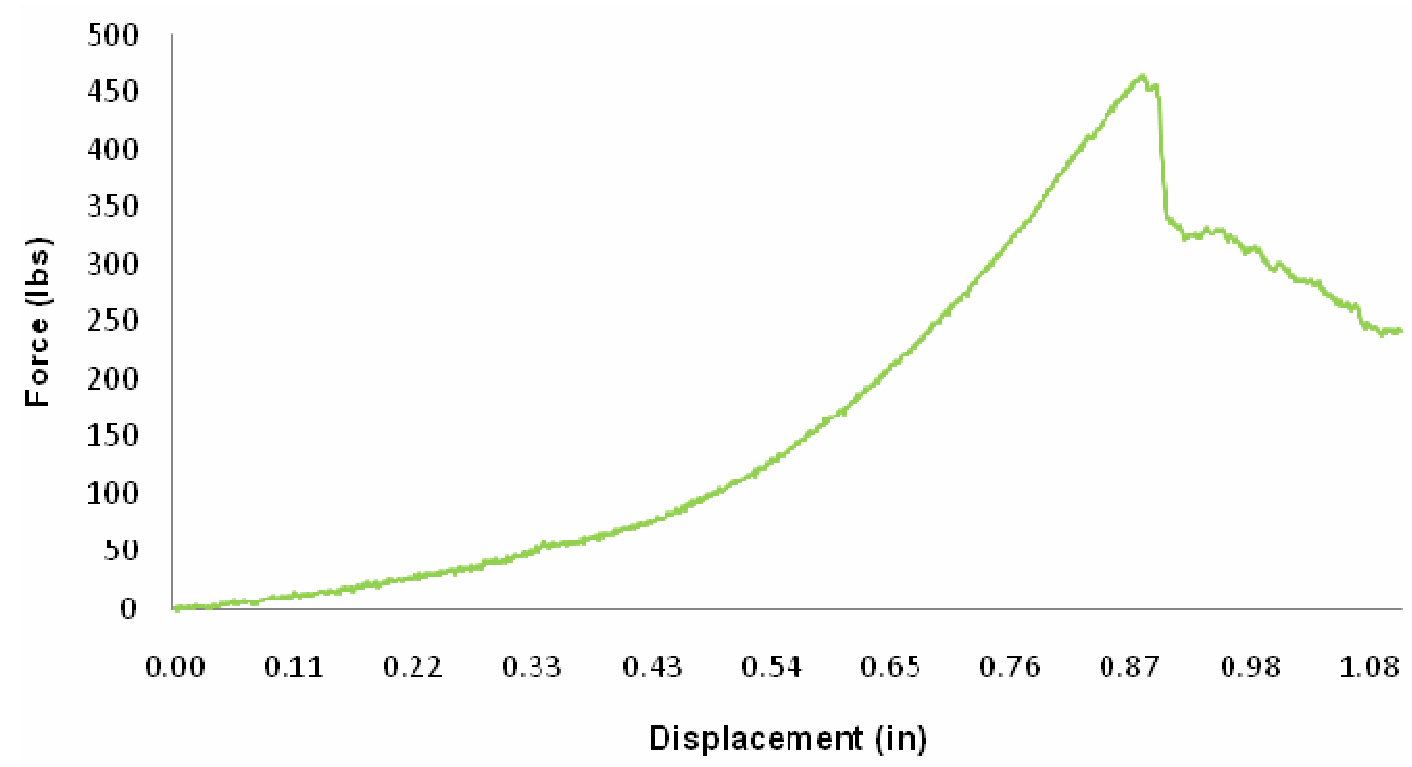

\section{Indentation Result for Test Specimen with 20 grams of Limestone Filler}

The figure below shows the damage created to specimen $\mathrm{L}_{20}$ after indentation testing.

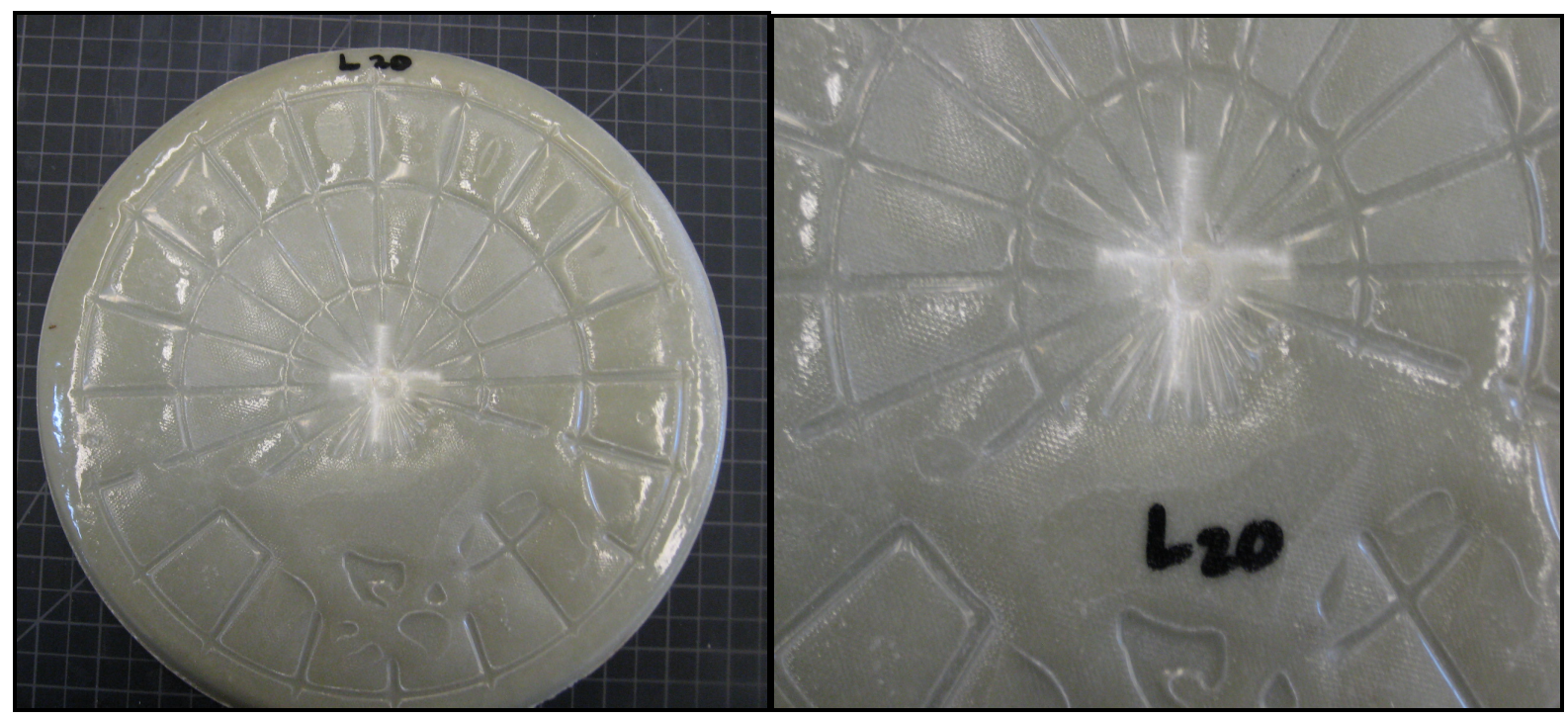

Ultimate Failure for Specimen L20 After Indentation Test

The figure below shows the force vs. displacement curve for specimen $\mathrm{L}_{30}$ after indentation testing. 


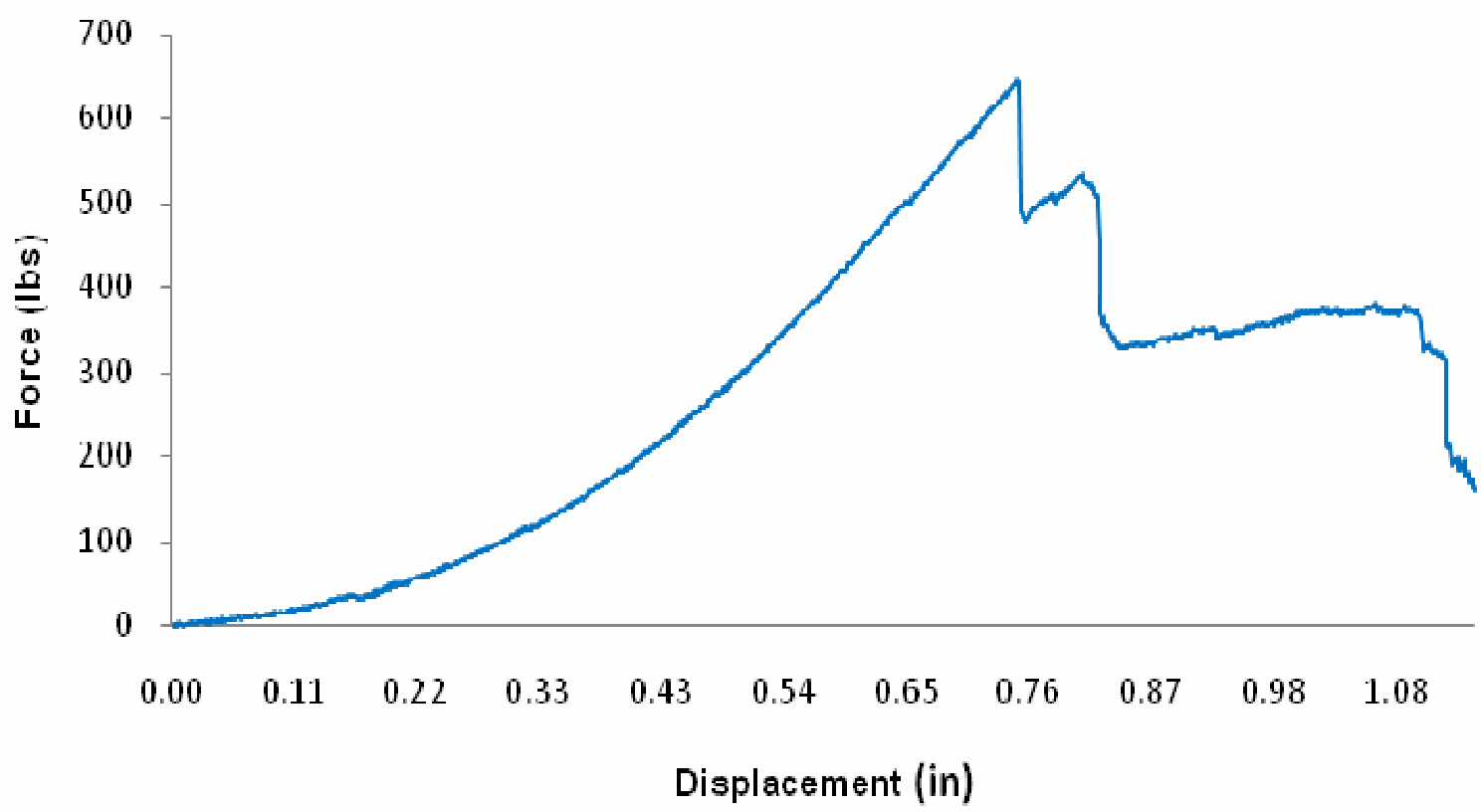

Indentation Result for Test Specimen with 30 grams of Limestone Filler

After data measurements were recorded for ultimate force of specimen $\mathrm{L}_{30}$, the plunger continued to indent the test specimen in order to observe the worst case scenario of permanent failure. Figure below shows the plunger loaded until the laminated manhole cover specimen's center had a 3-inch diameter hole.

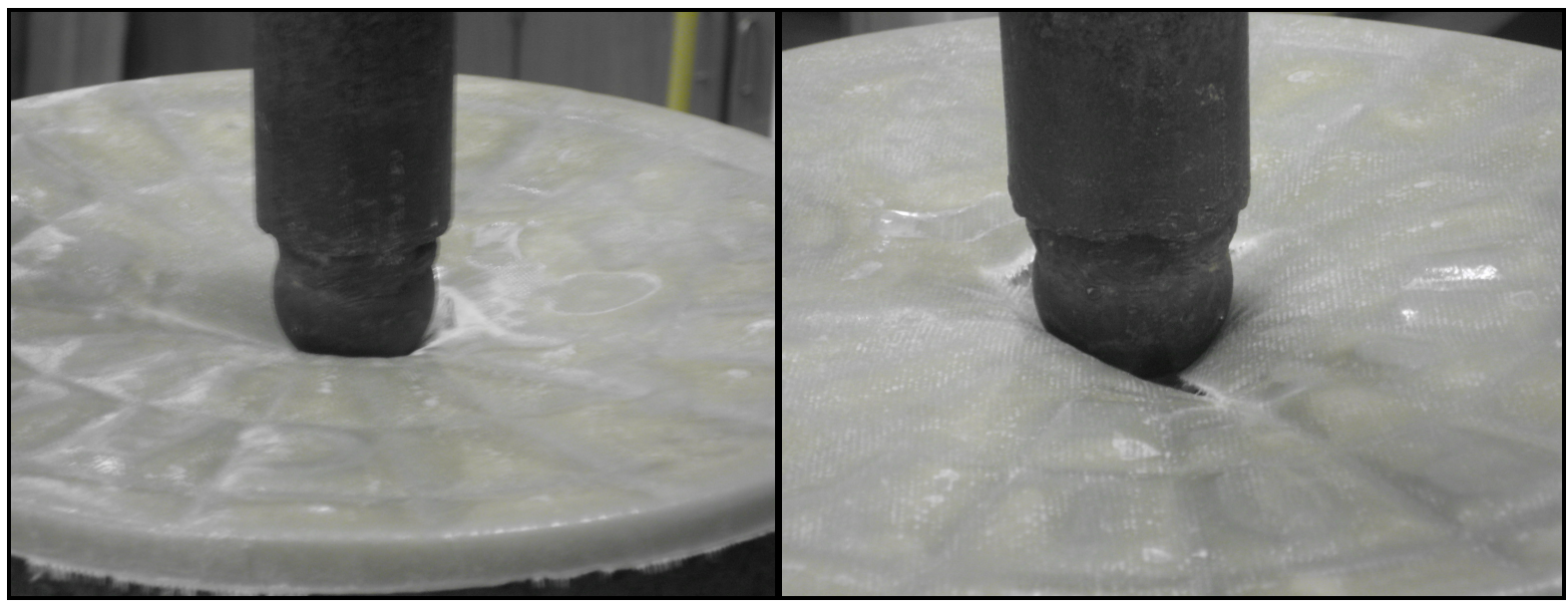

Plunger Creating Hole for Worst Case Scenario

The figure below shows the excessive fiber damage created to specimen $\mathrm{L}_{30}$ after indentation testing. 


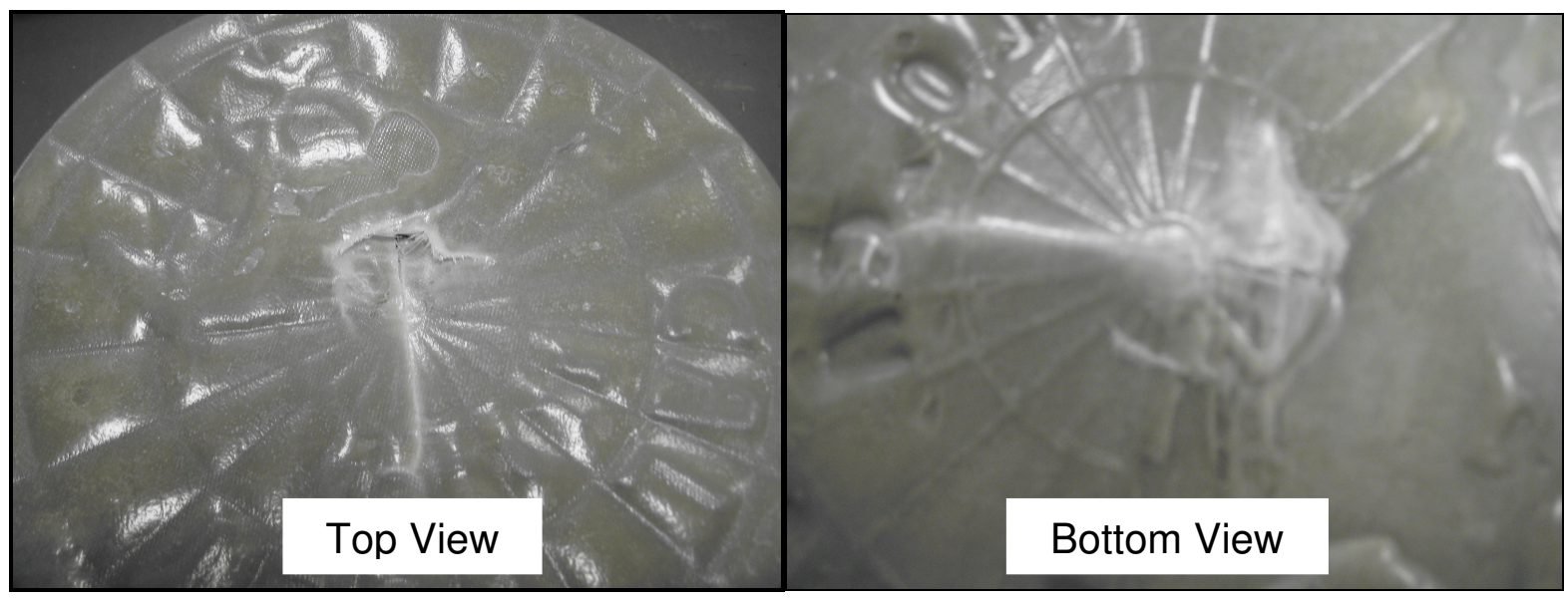

Different Views of Permanent Fiber Failure due to Severe Concentrated Loading

The following graph shows the indentation results for test specimen with 40 grams of limestone filler.

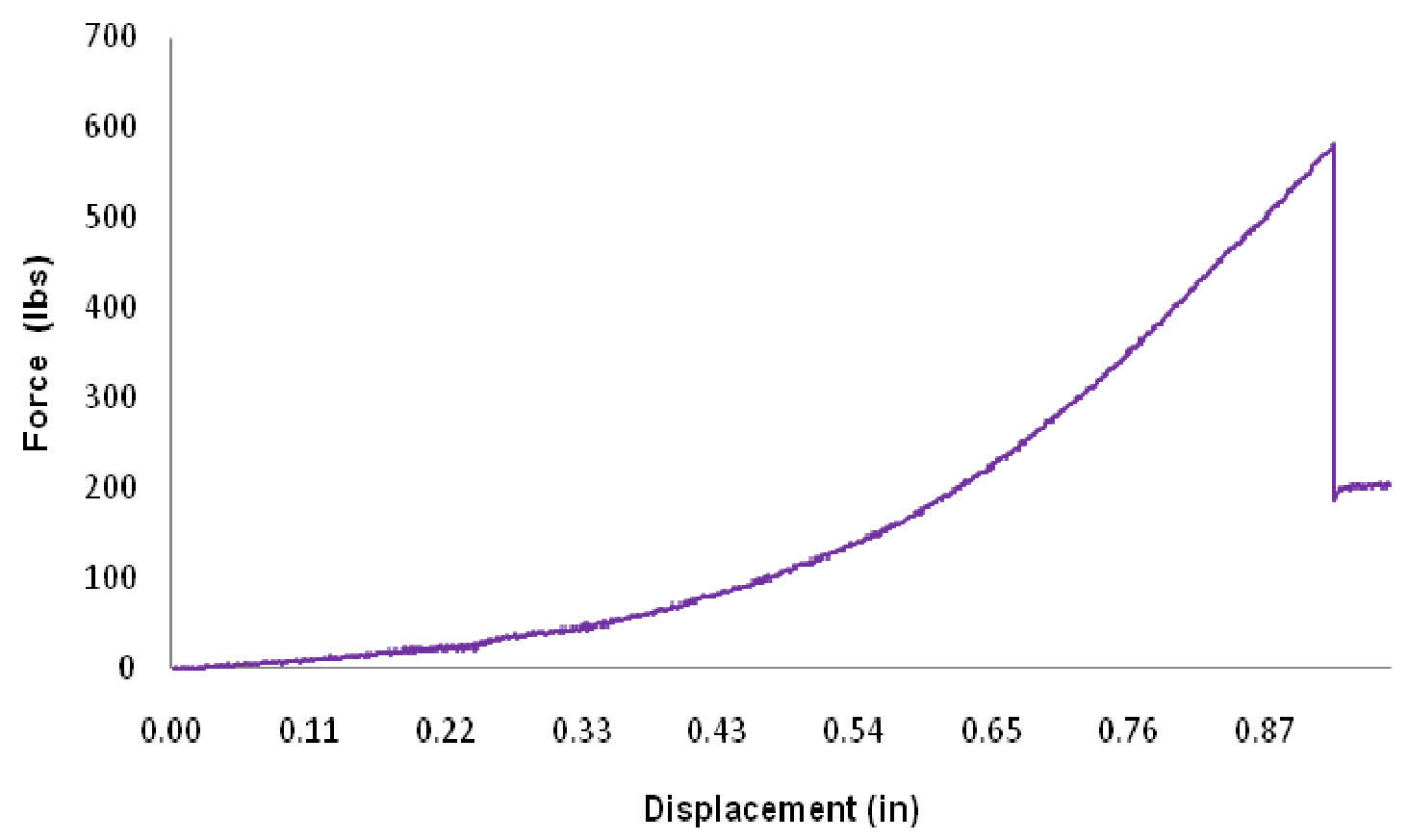

Indentation Result for Test Specimen with 40 grams of Limestone Filler

The figure below shows the damage created to specimen $\mathrm{L}_{40}$ after indentation testing. 


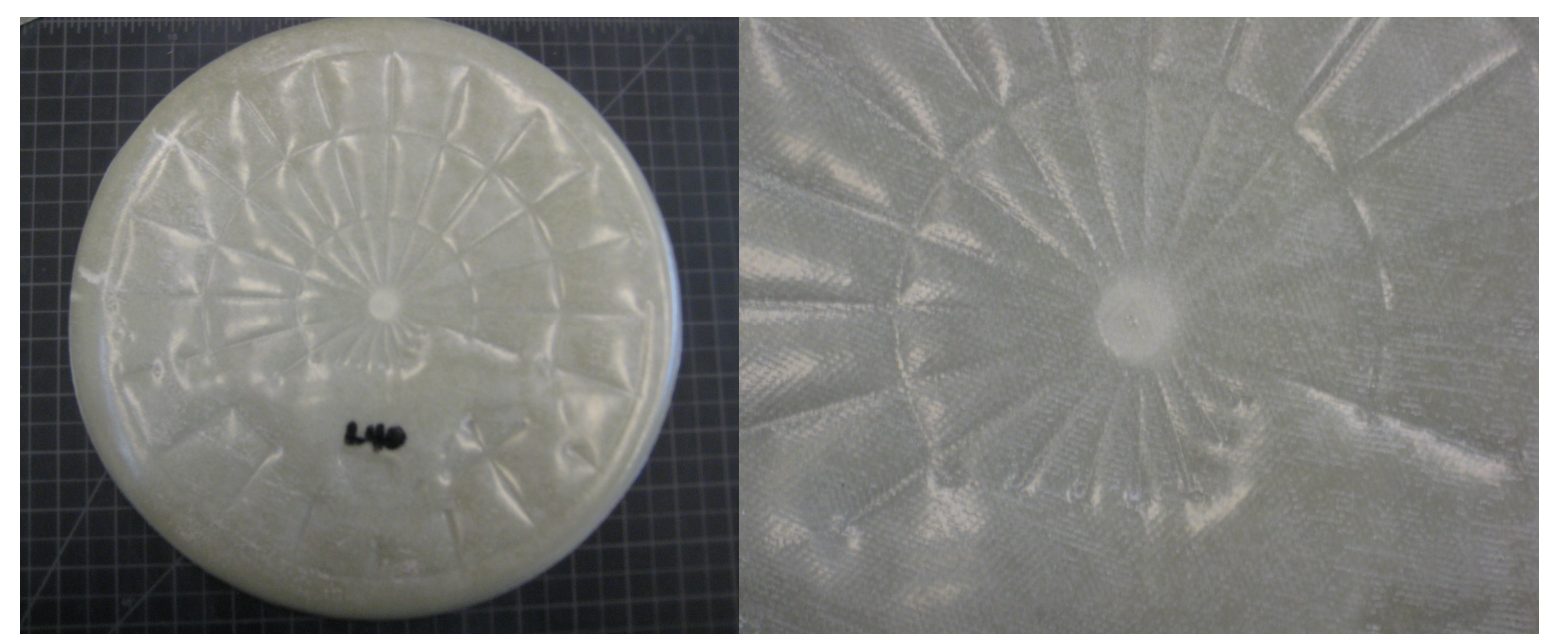

Ultimate Failure for Specimen $L_{40}$ After Indentation Test

The following graph shows the indentation results for test specimen with 30 grams of highdensity filler.

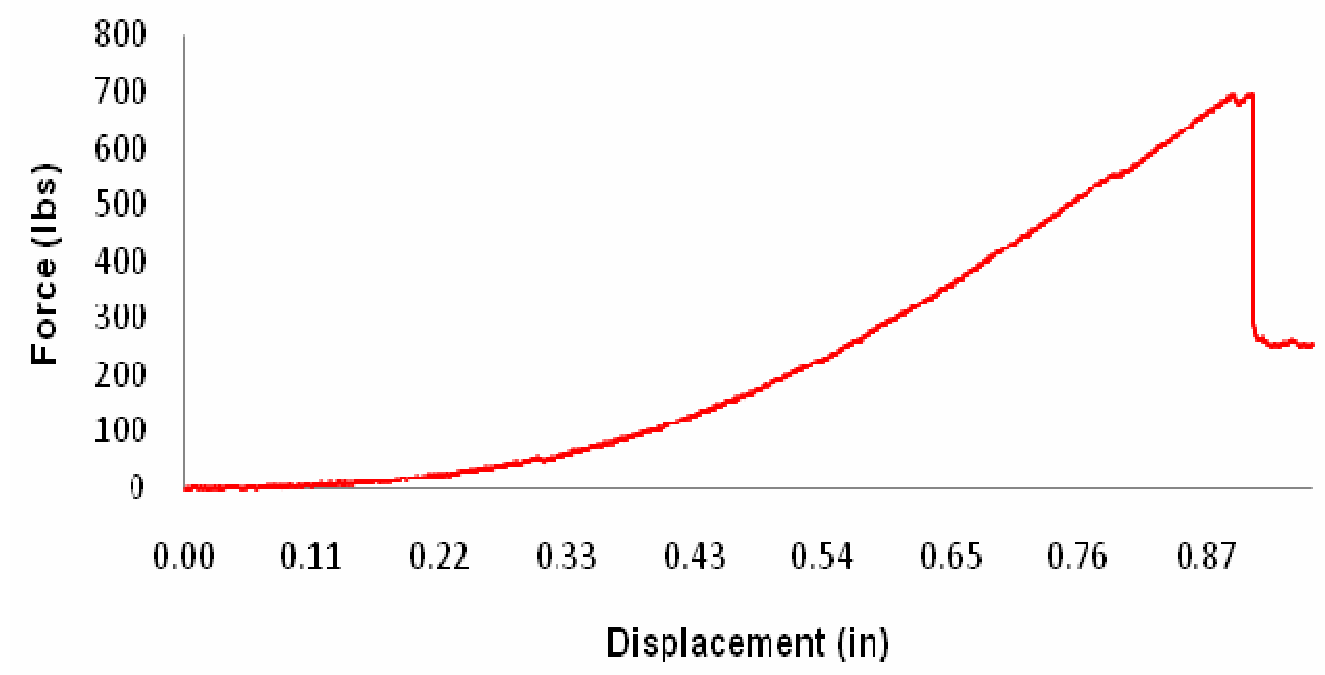

Indentation Result for Test Specimen with 30 grams of High-Density Filler

The figure below shows the damage created to specimen $\mathrm{HD}_{30}$ after indentation testing. 


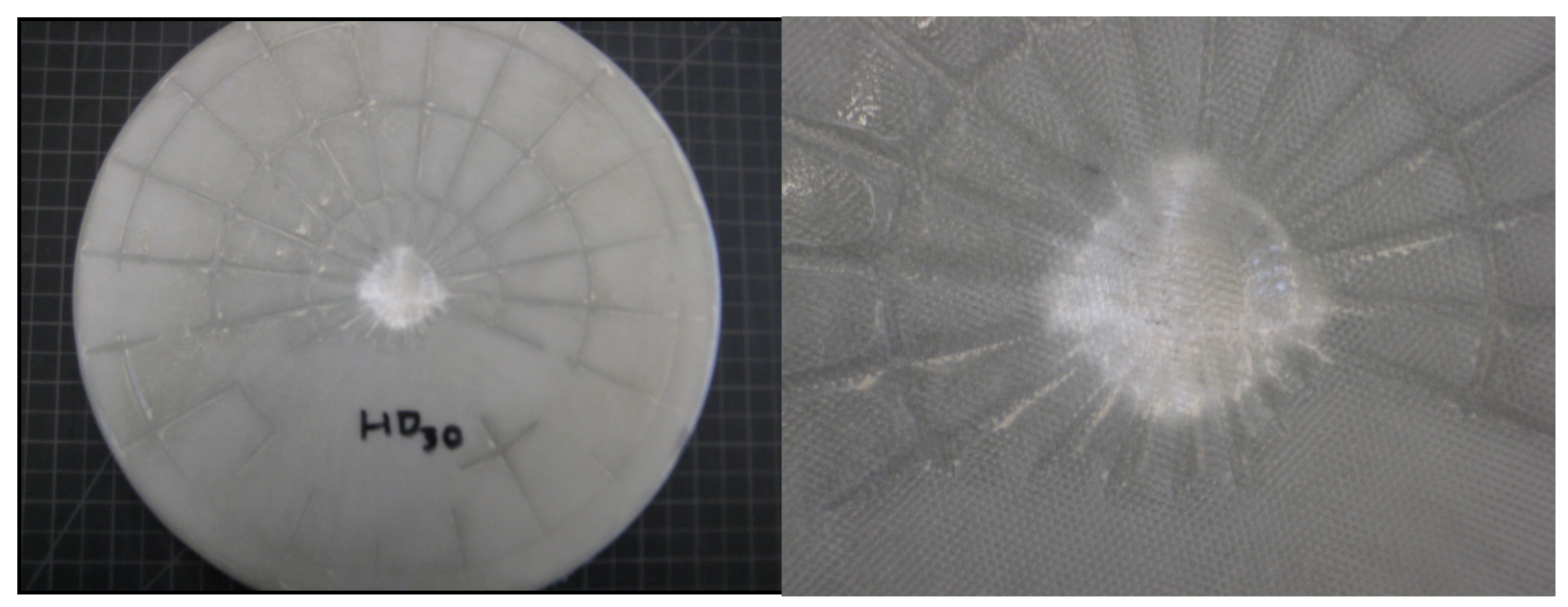

Ultimate Failure for Specimen $L_{B 0}$ After Indentation Test

The following graph shows the indentation results for test specimen with no filler.

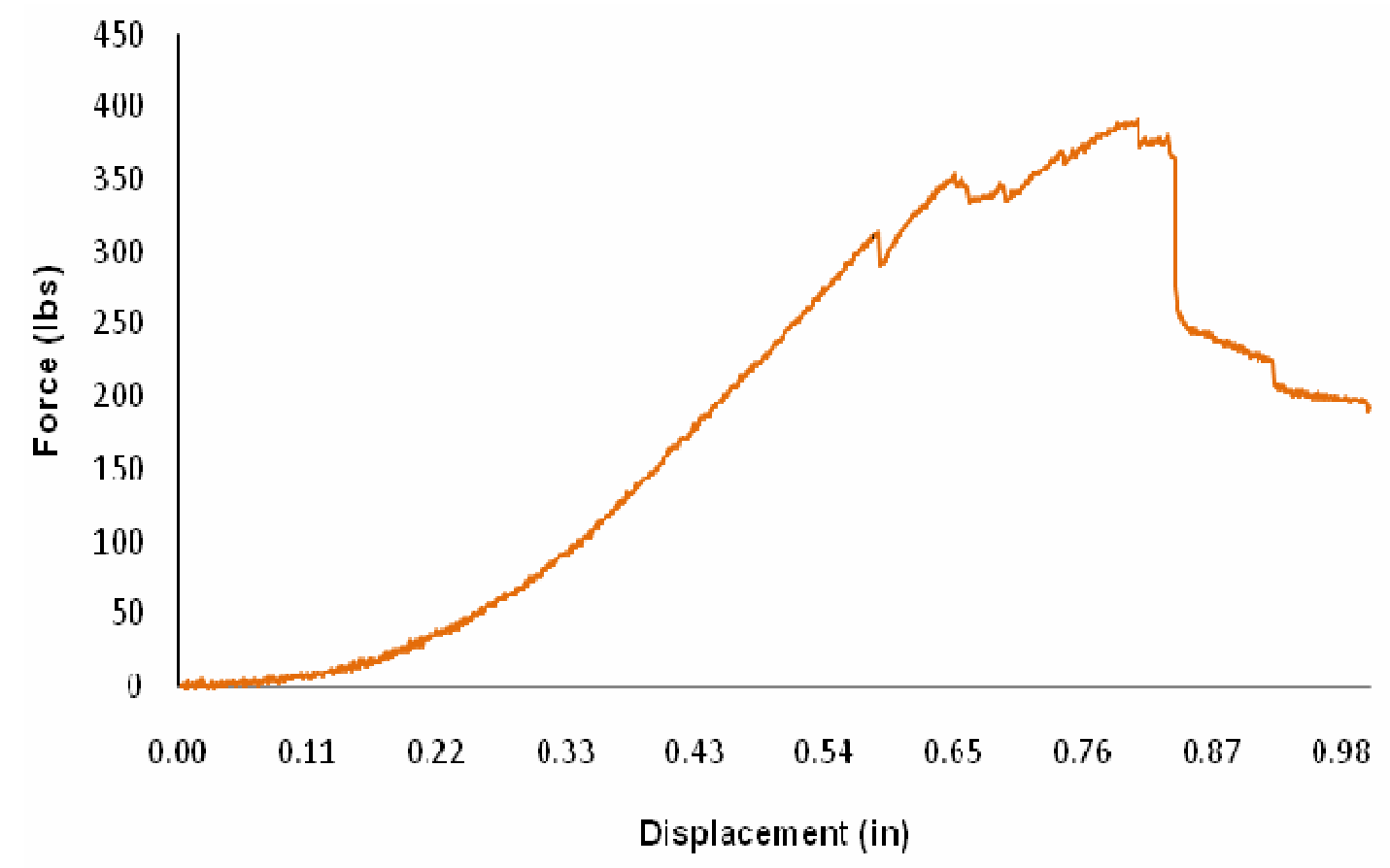

\section{Indentation Result for Test Specimen with No Filler}

The following graph shows the indentation summary for test specimens $\mathrm{L}_{30}$ and $\mathrm{HD}_{30}$. 


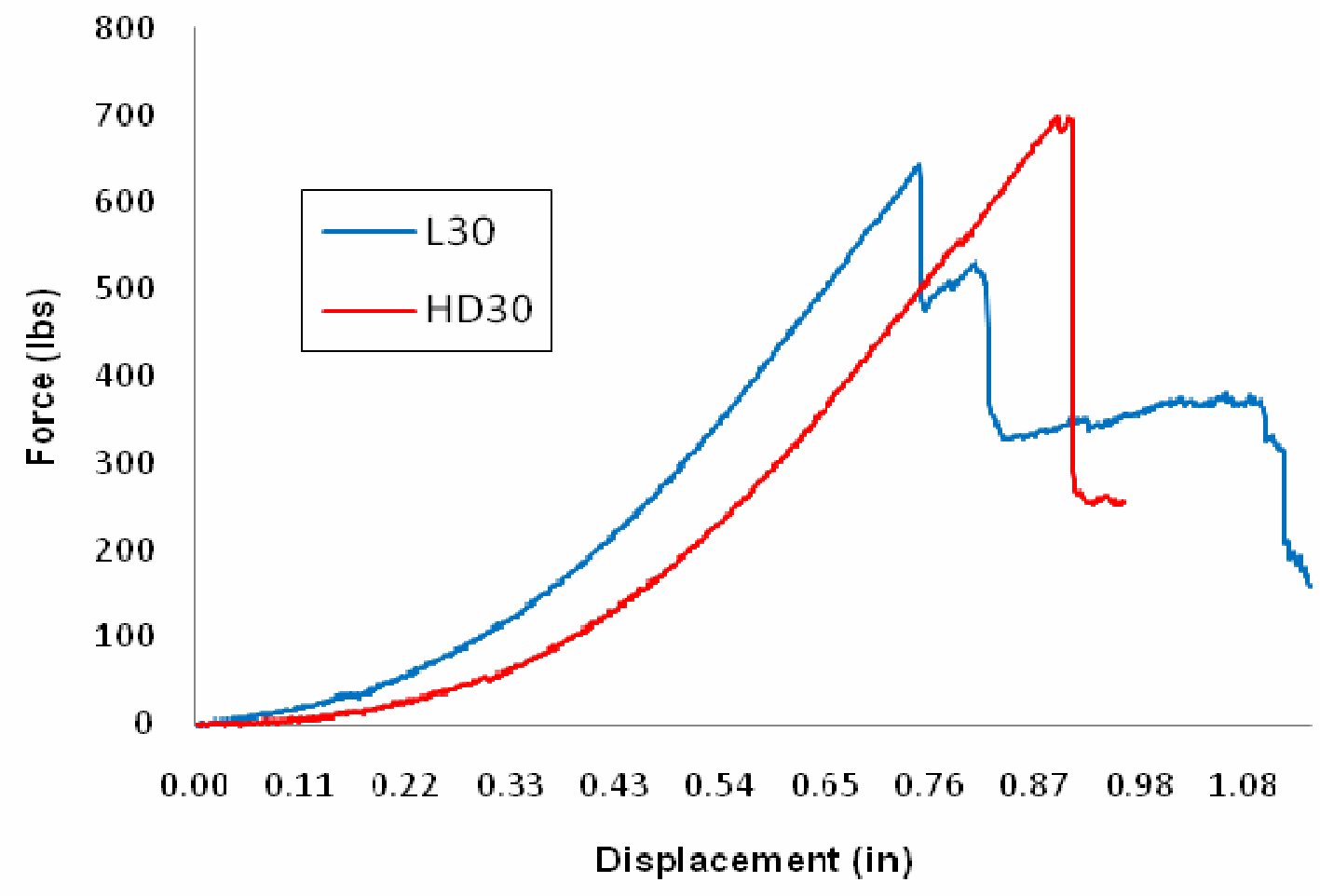

Indentation Result Comparison for Specimens $\mathrm{L}_{30}$ and $\mathrm{HD}_{30}$

The following table shows the indentation results for test specimens $\mathrm{L}_{30}$ and $\mathrm{HD}_{30}$.

Indentation Test Summary for Specimens $\mathrm{L}_{30}$ and $\mathrm{HD}_{30}$

\begin{tabular}{|c|c|c|}
\hline Specimen & Max. Load (lbs) & Displacement (in) \\
\hline $\mathrm{L}_{30}$ & 644.97 & 0.74756533 \\
\hline $\mathrm{HD}_{30}$ & 697.24 & 0.88993704 \\
\hline
\end{tabular}

The following graph shows the indentation summary for all test specimens. 


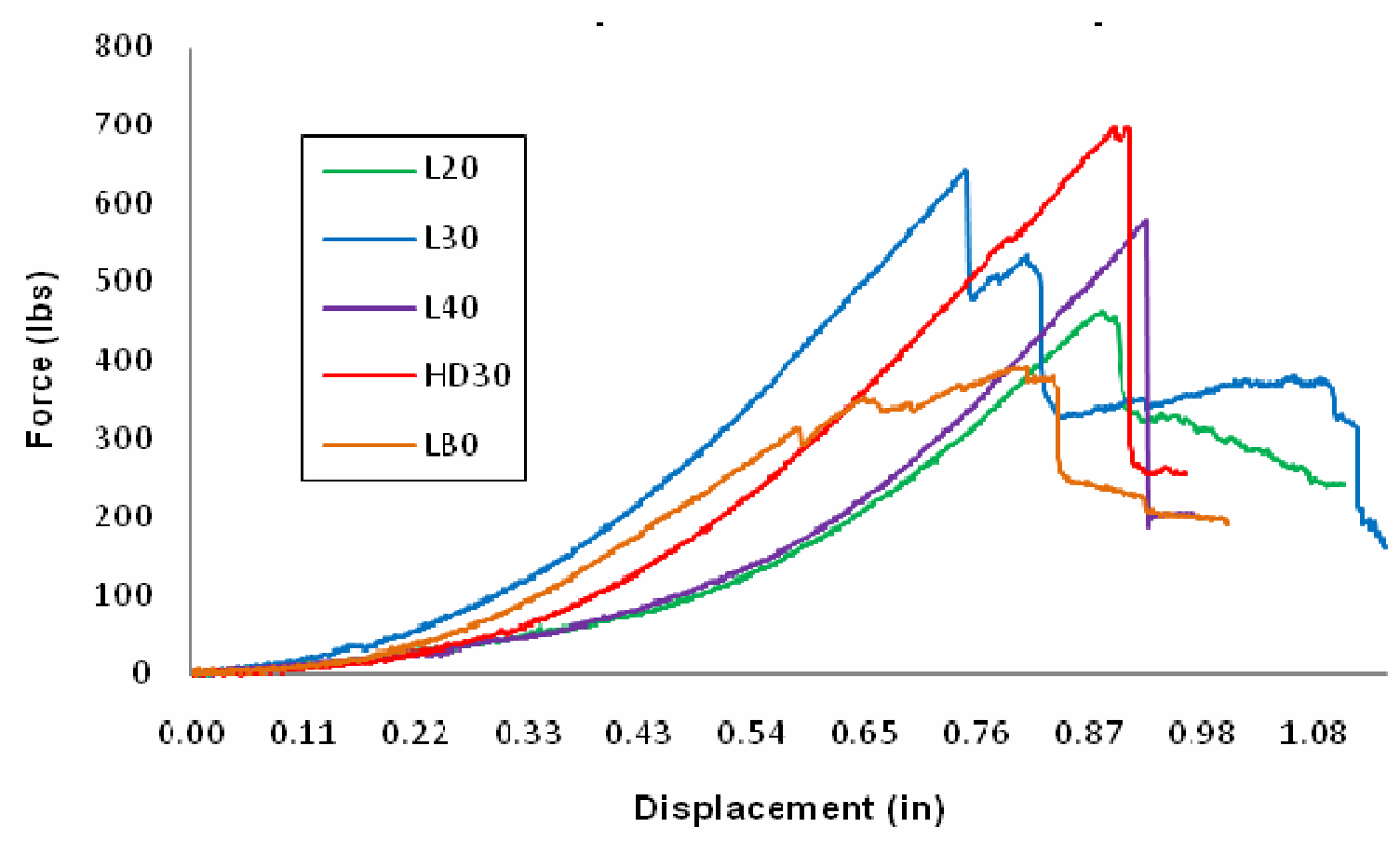

\section{Indentation Result Comparison for All Test Specimens}

Consequently, the above graph show the indentation test summary which involved a concentrated point load located at the center of each laminated test specimen. Table shows the maximum load and displacement indentation summary for all composites

\section{Indentation Test Summary for All Composites}

\begin{tabular}{|c|c|c|}
\hline Specimen & Max. Load (lbs) & Displacement (in) \\
\hline $\mathrm{L}_{20}$ & 464.21 & 0.88000405 \\
\hline $\mathrm{L}_{30}$ & 644.97 & 0.74756533 \\
\hline $\mathrm{L}_{40}$ & 580.85 & 0.92161196 \\
\hline $\mathrm{HD}_{30}$ & 697.24 & 0.88993704 \\
\hline $\mathrm{L}_{\mathrm{BO}}$ & 390.66 & 0.80497622 \\
\hline
\end{tabular}


According to the indentation test summary, laminate $\mathrm{HD}_{30}$ experienced the highest maximum load with a corresponding maximum displacement of 0.8899 in. This result was as expected due since the laminate's high-density adhesive filler properties which provided substantial strength and stiffness qualities. As expected, laminate $\mathrm{L}_{\mathrm{B} 0}$ had the lowest overall performance because its polymer matrix composition did not have any filler; and therefore, lack in overall strength. Laminate $\mathrm{HD}_{30}$ had the best performance of the limestone filler laminates. It exhibited a corresponding maximum load and displacement of $645 \mathrm{lbf}$ and 0.7476 in respectively. Although both laminates $\mathrm{HD}_{30}$ and $\mathrm{L}_{30}$ had similar results, laminate $\mathrm{HD}_{30}$ still managed to experience better performance with an approximate load difference of $23 \mathrm{lbf}$. Therefore, although test specimen $\mathrm{HD}_{30}$ had a better performance, the limestone filler overall cost savings makes it more economical reinforcing filler option for creating laminated manhole covers. 


\section{Appendix J: Supporting Static Analysis for Thick-Resin Laminated Manhole Cover}

\section{Specimens}

\section{J.1 Tensile Test Results}

Tensile Testing for the fiberglass thick-resin manhole cover was also performed using the Merlin Instron Software Program and the Instron machine to record all tensile strength data. The data was later used to calculate the following material properties: the maximum load or ultimate strength, strain percentage which is the elastic strain percentage prior to fracture and Young's Modulus of Elasticity (or elastic modulus) which describes tensile elasticity and stiffness of the material. Table shows a summary of the all test specimens used for the tensile analysis.

\section{Dimension Summary of All Laminated Beams Used for Tensile Tests}

\begin{tabular}{|c|c|c|c|c|c|}
\hline Specimen & Weight (g) & Length (in) & Thickness (in) & Width (in) & Cross Section Area $\left(\mathrm{in}^{2}\right)$ \\
\hline $\mathrm{L}_{20}$ & 104.3 & 9 & 0.050 & 1.471 & 0.074 \\
\hline $\mathrm{L}_{30}$ & 100.5 & 9 & 0.049 & 1.427 & 0.069 \\
\hline $\mathrm{L}_{40}$ & 108.1 & 9 & 0.052 & 1.389 & 0.072 \\
\hline $\mathrm{HD}_{30}$ & 119.2 & 9 & 0.049 & 1.423 & 0.069 \\
\hline $\mathrm{LB}_{0}$ & 104.5 & 9 & 0.047 & 1.506 & 0.071 \\
\hline $\mathrm{L}_{259}$ & 62.6 & 8 & 0.269 & 1.216 & 0.327 \\
\hline
\end{tabular}

Although test specimen $\mathrm{L}_{259}$ had the lowest weight and width of all test specimens, it had the highest thickness value of 0.269 with an averaged thickness difference of 0.219 in.

Graph below shows the stress-strain curve of specimen $\mathrm{L}_{259}$ with a fiber volume fraction of 50 percent before fracture. 


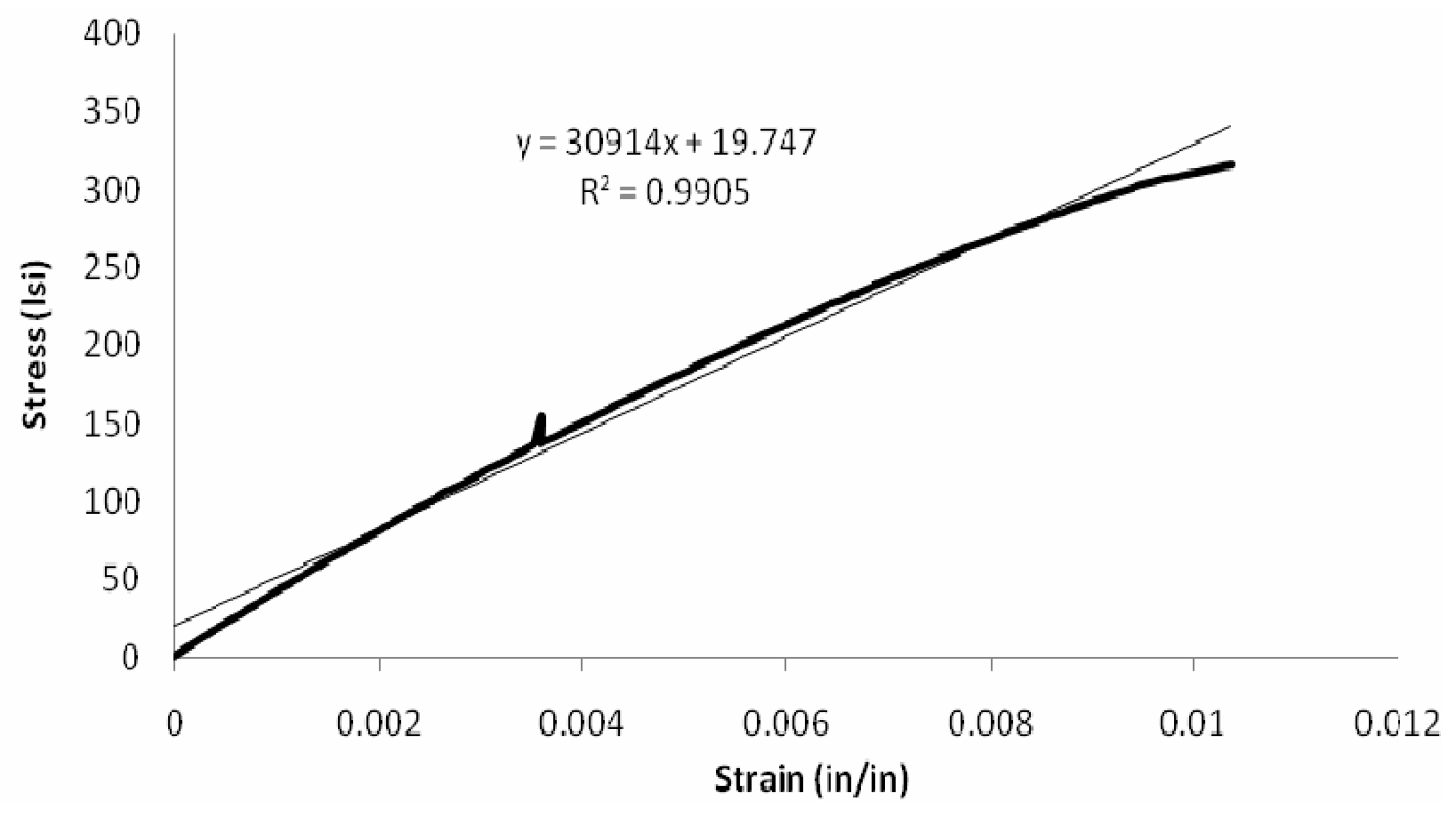

Stress vs. Strain with 259 grams of Limestone Filler

The tensile strength result for laminate $\mathrm{L}_{20}$ was seen above in the stress-strain curve linear relationship. The slope of the tread line was used to calculate the Young's modulus by using the tread line function from the Excel program. The Young's modulus in the longitudinal direction was 30,914 ksi with an R-squared value of 0.9905 and a shear modulus of 52,695.84 ksi.

The elastic-deformation region had a ultimate tensile stress of $315.67 \mathrm{ksi}$ with a corresponding strain of 0.0104 . The maximum load before fracture was at $3659.2 \mathrm{lbs}$. The peak seen in the graph occurred at $154.63 \mathrm{lbf}$ with a corresponding strain of 0.0036 . This peak was probably due to the tensile stress distribution moving through air voids and other fabrication impurities located within the laminate's cross-section.

Figure below shows the failure damage created to thick-resin limestone filler specimen after indentation testing. 


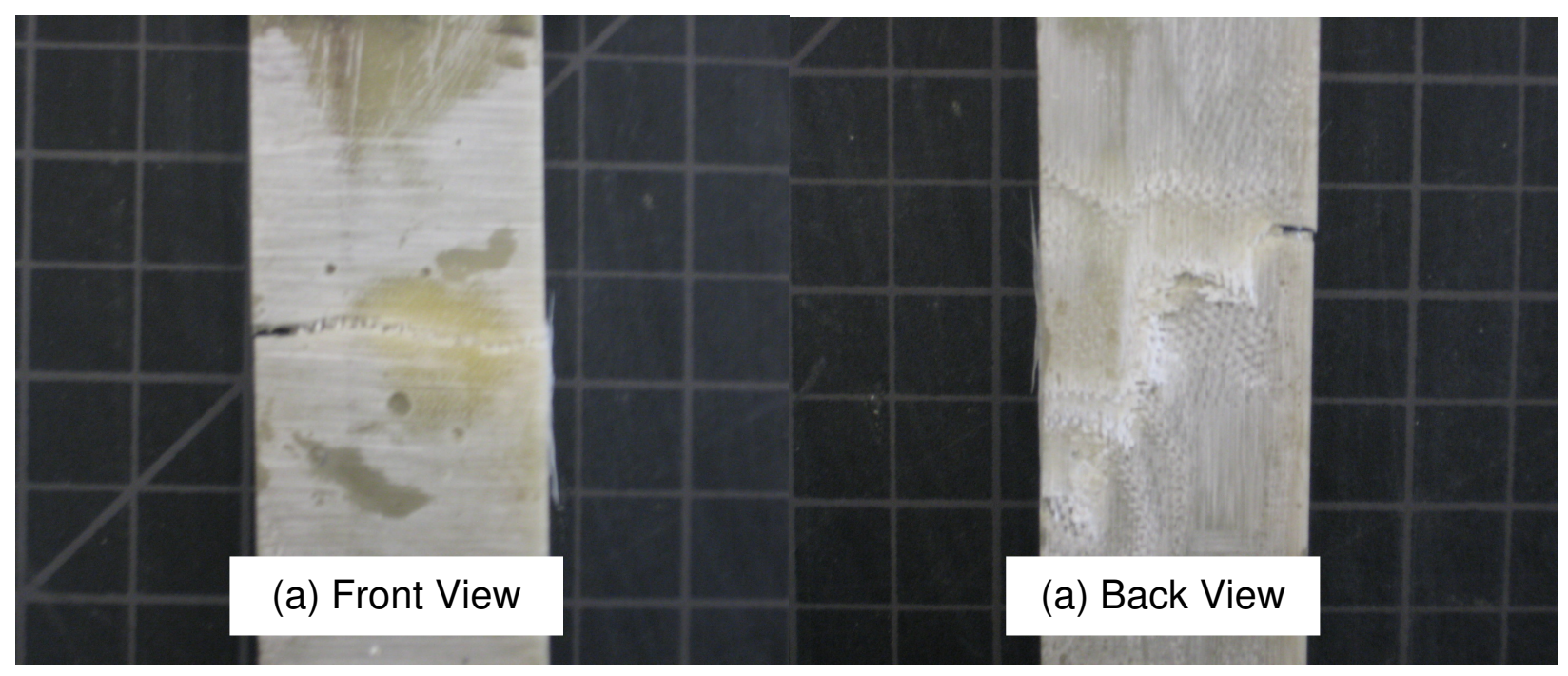

Ultimate Failure for Test Specimen with 259 grams of Limestone Filler

Figure below shows the stress-strain curve comparison of all specimens ${ }_{30}$,

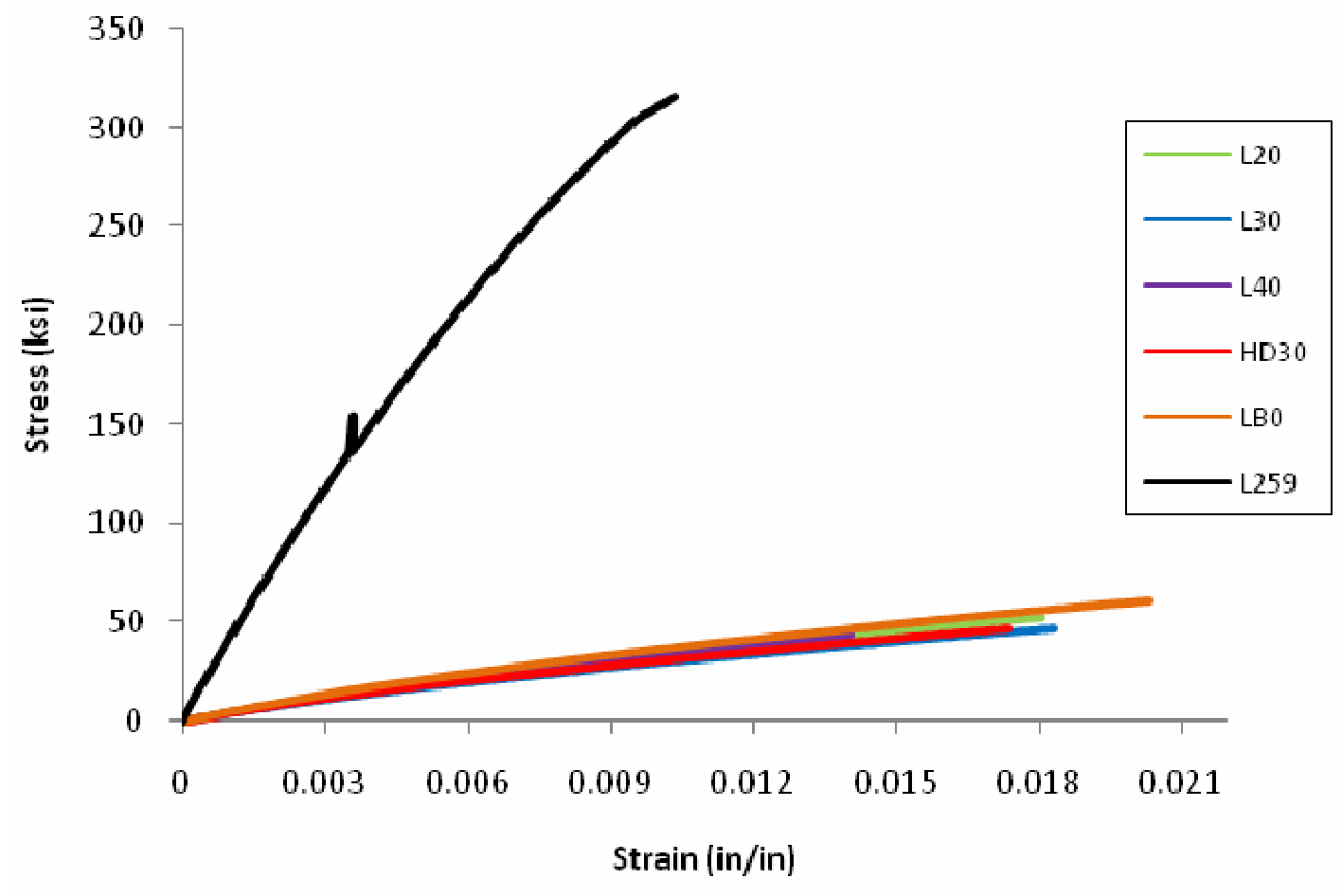

Tensile Test Summary 
The above graph shows the correlation between increasing tensile strength with increasing tensile stress needed to deform and fracture the composite material. As expected, the laminate L 259 's high elastic modulus which easily surpassed the other test specimens values. Although test specimen $\mathrm{L}_{259}$ had the lowest weight and width of all test specimens, it had the highest thickness value of 0.269 with an averaged thickness difference of 0.219 in. This thickness dramatically increased the composite's stiffness and strength which is clearly seen above.

Table 6.10: Experimental Tensile Summary of All Laminated Beams

\begin{tabular}{|c|c|c|c|c|c|}
\hline Specimen & $\begin{array}{c}\text { Max. } \\
\text { Load }\left(\mathrm{lb}_{\mathrm{f}}\right)\end{array}$ & $\begin{array}{c}\text { Young's } \\
\text { Modulus (ksi) }\end{array}$ & $\begin{array}{c}\text { Shear } \\
\text { Modulus (ksi) }\end{array}$ & $\begin{array}{c}\text { Ultimate } \\
\text { Stress (ksi) }\end{array}$ & $\begin{array}{c}\text { Fiber Vol. } \\
\text { Fraction (\%) }\end{array}$ \\
\hline $\mathrm{L}_{20}$ & 3660.92 & 2670.85 & 1094.61 & 51.19 & 51 \\
\hline $\mathrm{L}_{30}$ & 3032.83 & 2542.15 & 1041.87 & 48.87 & 50 \\
\hline $\mathrm{L}_{40}$ & 3066.44 & 2470.95 & 1012.67 & 38.09 & 48 \\
\hline $\mathrm{L}_{259}$ & 3659.21 & $30,914.21$ & $52,695.84$ & 315.67 & 50 \\
\hline $\mathrm{HD}_{30}$ & 3580.37 & 2814.42 & 1153.45 & 50.75 & 47 \\
\hline $\mathrm{L}_{\mathrm{B} 0}$ & 4327.11 & 3110.95 & 1150.39 & 61.13 & 48 \\
\hline
\end{tabular}

\section{J.2 Compression Testing System}

Standard test method for compression properties of polymer matrix composite materials was also conducted for test laminates. The compression test method was very similar to the tensile testing procedure discussed in previous section. The compression test was only performed for the 9-plied manhole cover test specimen since it had a larger width than the 4-plied specimens which made them more stable when placed inside the testing apparatus. Six 1 by 2 -inch specimens of 
the 9-plied fiberglass laminated manhole cover was cut and tested. Two 8 by 8 -inch aluminum flat plates were used to compress the test specimens, as seen in figures below.

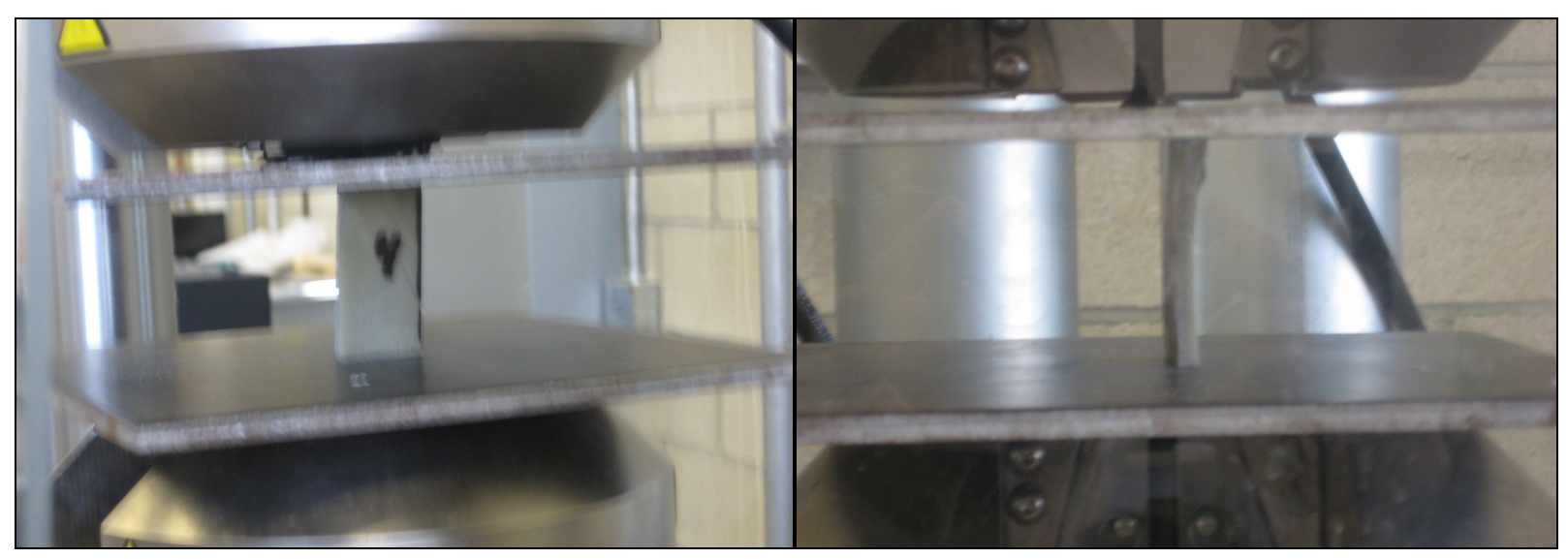

\section{Compression Test Setup}

The extensometer was not used for the compression testing since the test specimen's height was too small. Finally, the results obtained from tests were later used to measure the stress and mechanical properties of the manhole cover during compression.

\section{J.3 Compression Test Results}

The following section shows the compressive stress versus strain curve graphs with corresponding figures showing some failure characteristics for six test specimens made from the same 259 grams of limestone filler material. 


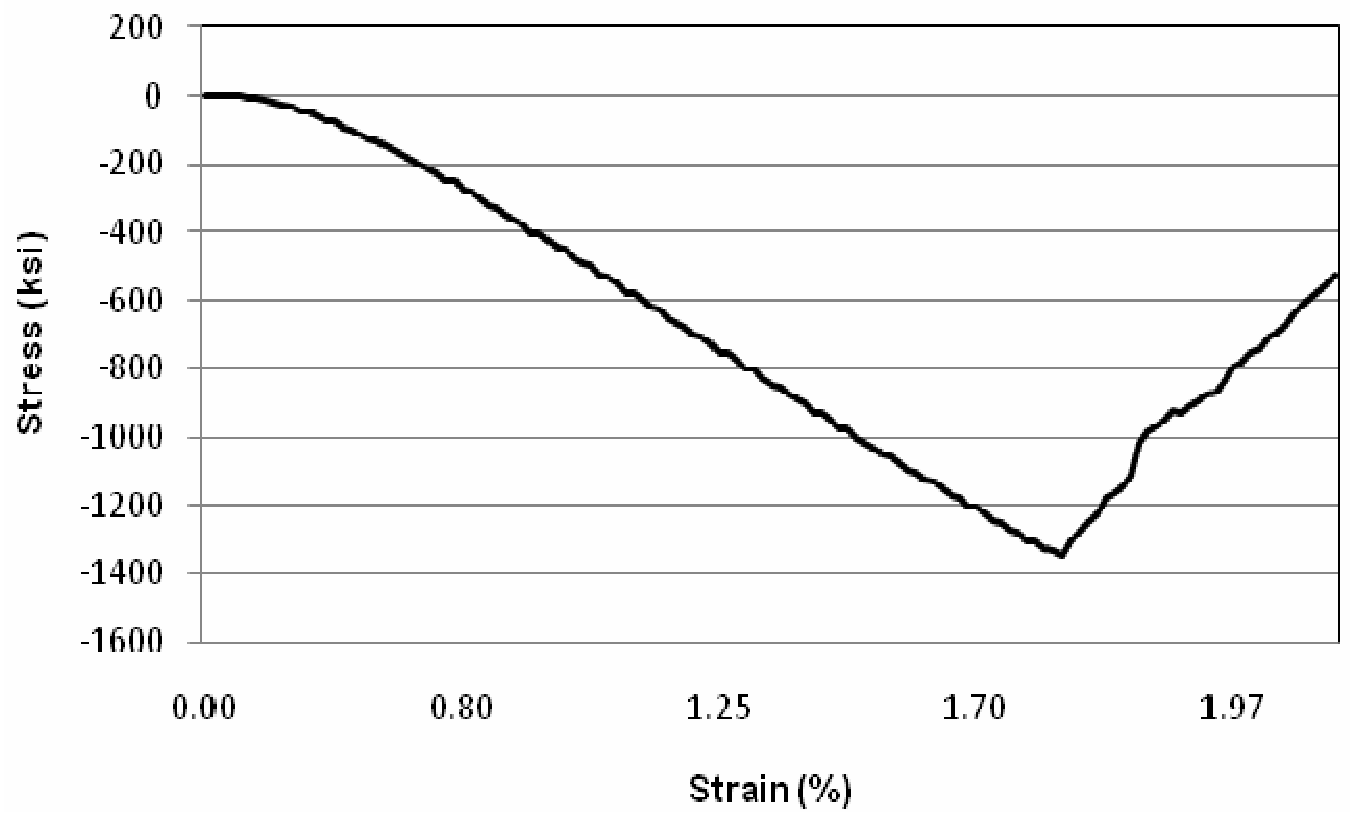

Compression Result for Test Specimen 1 with 259 grams of Limestone Filler

The figure below shows the failure damage created to thick-resin limestone filler specimen 1 after compression testing.

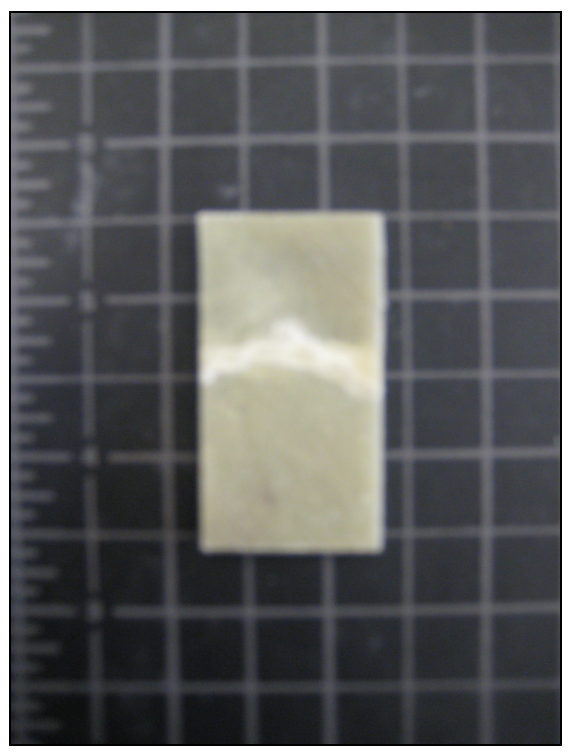

Compression Failure for Test Specimen 1 with 259 grams of Limestone Filler

The plot below shows the stress versus strain for thick-resin limestone filler specimen after compression testing. 


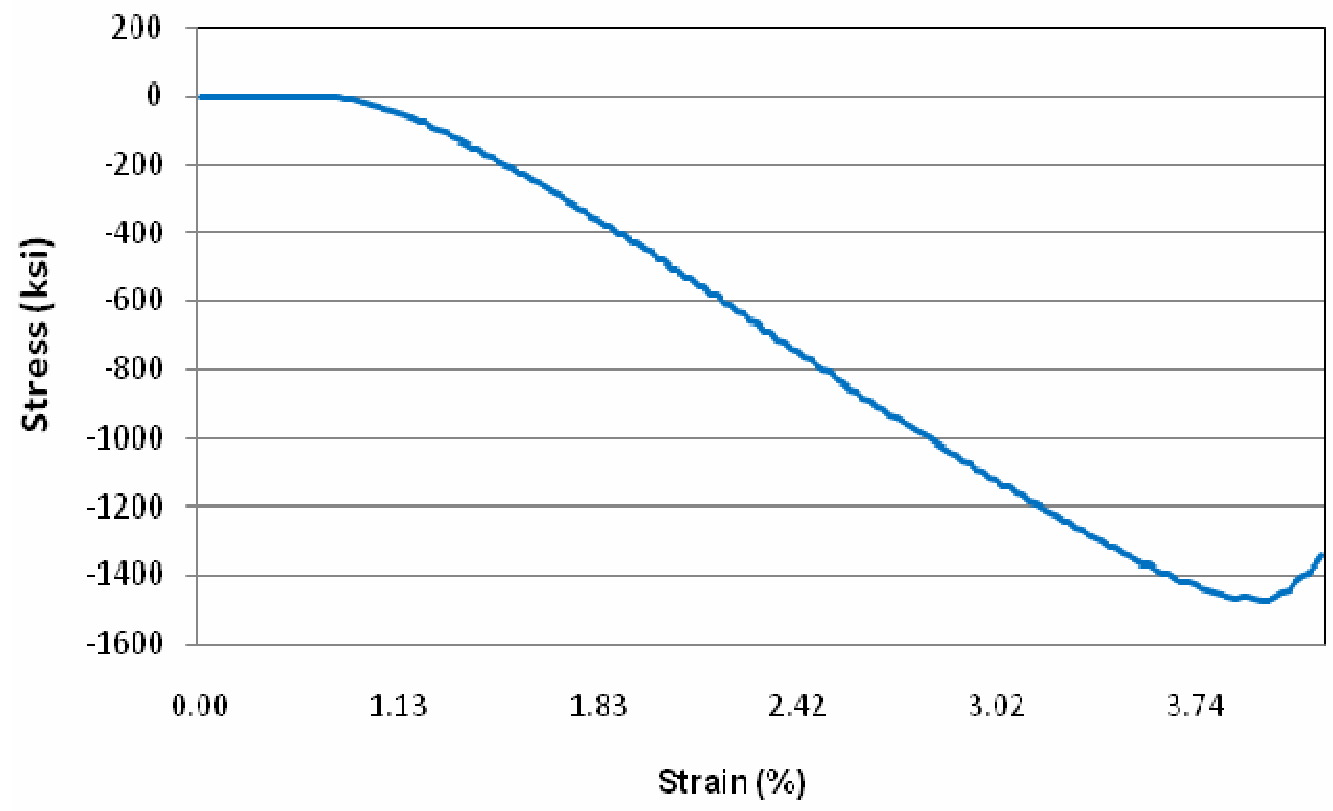

Compression Result for Test Specimen 2 with 259 grams of Limestone Filler

The figure below shows the failure damage created to thick-resin limestone filler specimen 2 after compression testing.

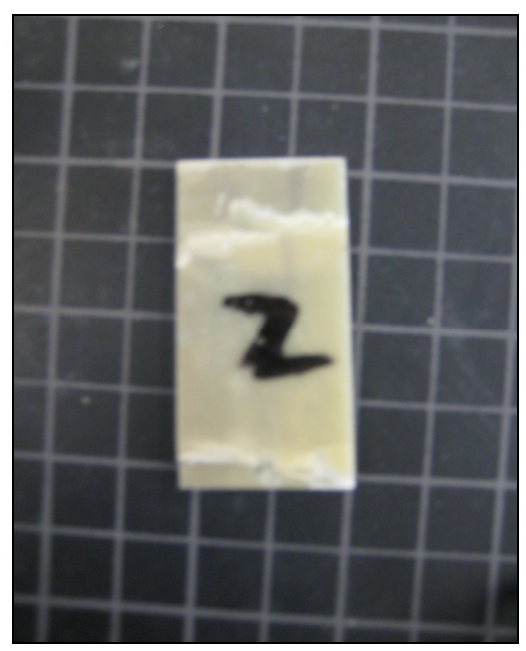

Compression Failure for Test Specimen 2 with 259 grams of Limestone Filler

The figure below shows the failure damage created to thick-resin limestone filler specimen 3 after compression testing. 


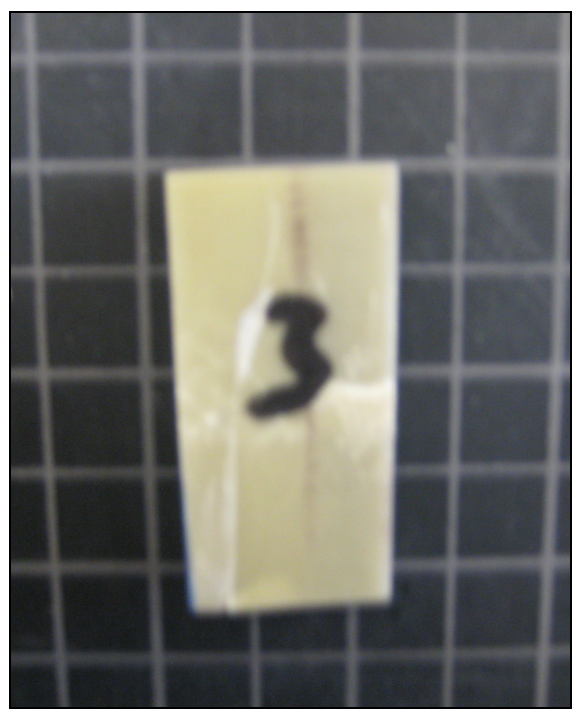

Compression Failure for Test Specimen 3 with 259 grams of Limestone Filler

The graph below shows the failure damage created to thick-resin limestone filler specimen 4 after compression testing.

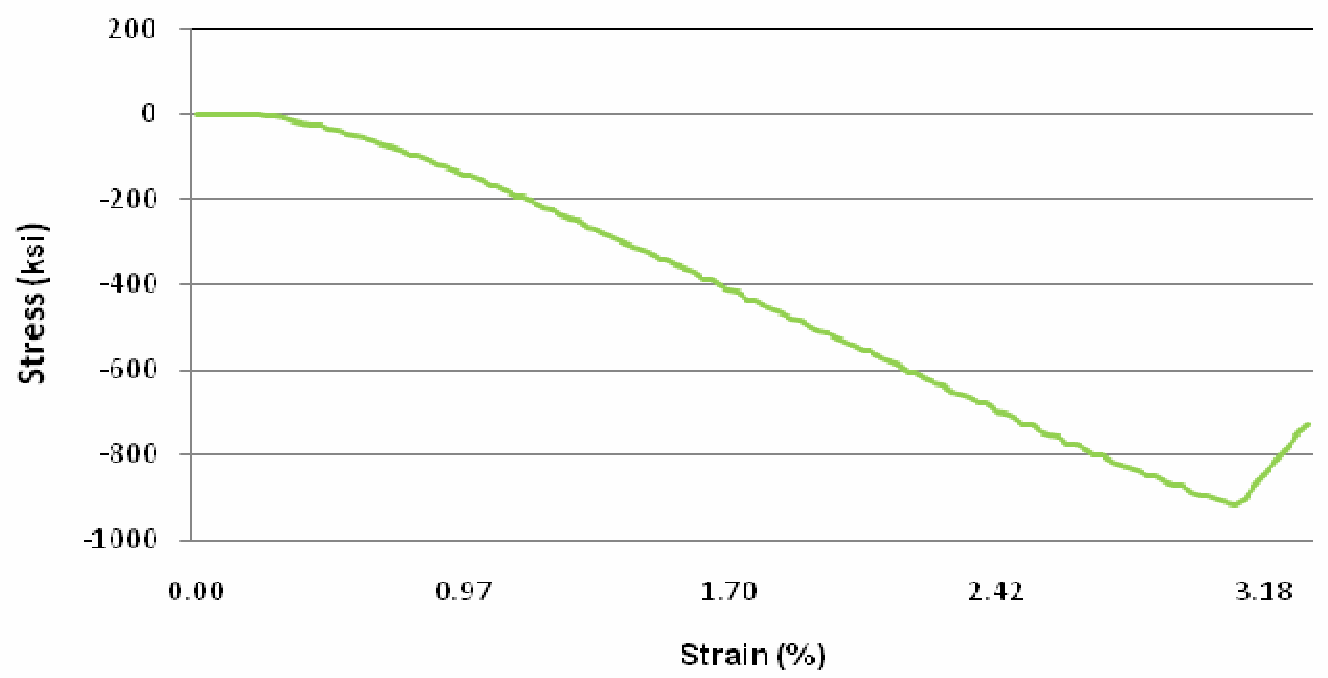

Compression Result for Test Specimen 4 with 259 grams of Limestone Filler

The figure below shows the failure damage created to thick-resin limestone filler specimen 4 after compression testing. 


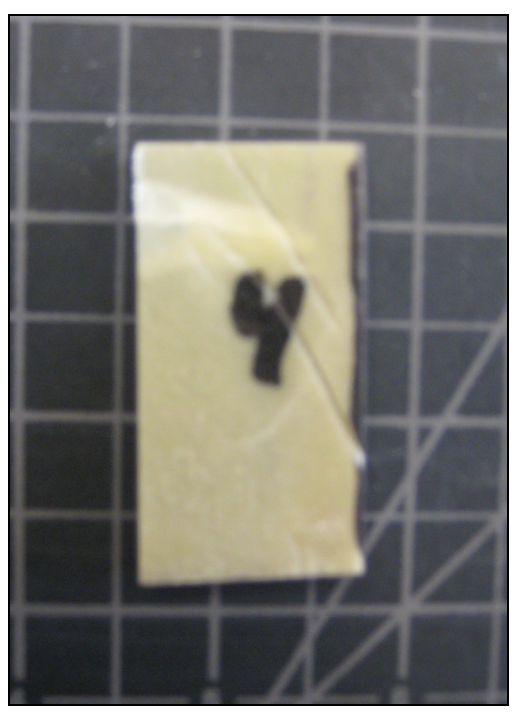

Compression Failure for Test Specimen 4 with 259 grams of Limestone Filler

The figure below shows the failure damage created to thick-resin limestone filler specimen 4 after compression testing. Test specimen 4 had the lowest results.

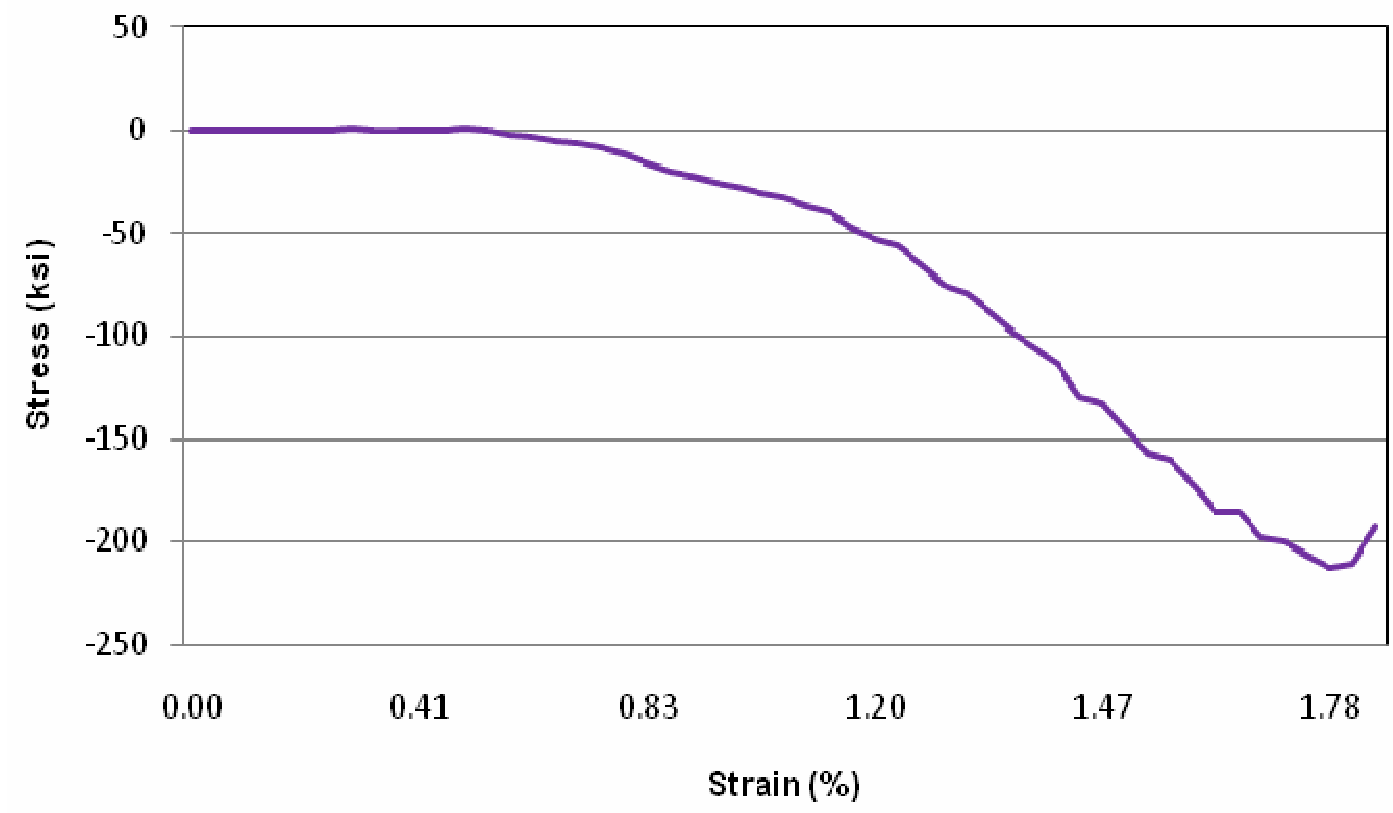

Compression Result for Test Specimen 4 with 259 grams of Limestone Filler

The figure below shows the failure damage created to thick-resin limestone filler specimen 5 after compression testing. 


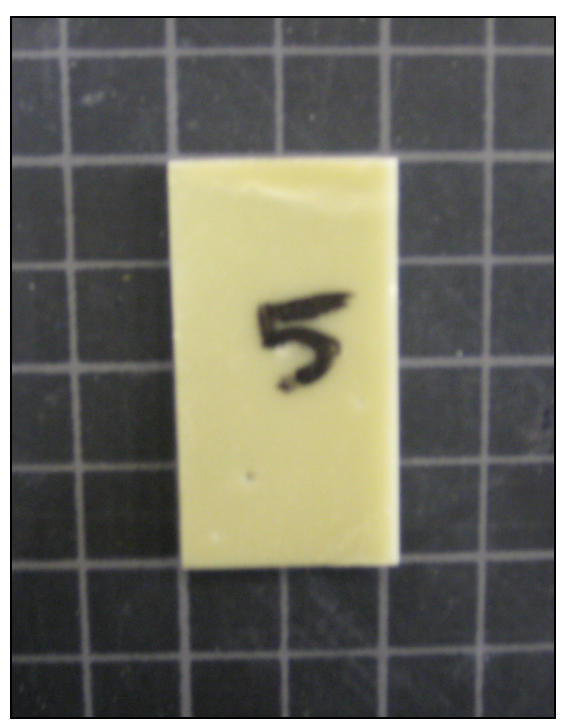

Compression Failure for Test Specimen 5 with 259 grams of Limestone Filler

The figure below shows the failure damage created to thick-resin limestone filler specimen 6 after compression testing.

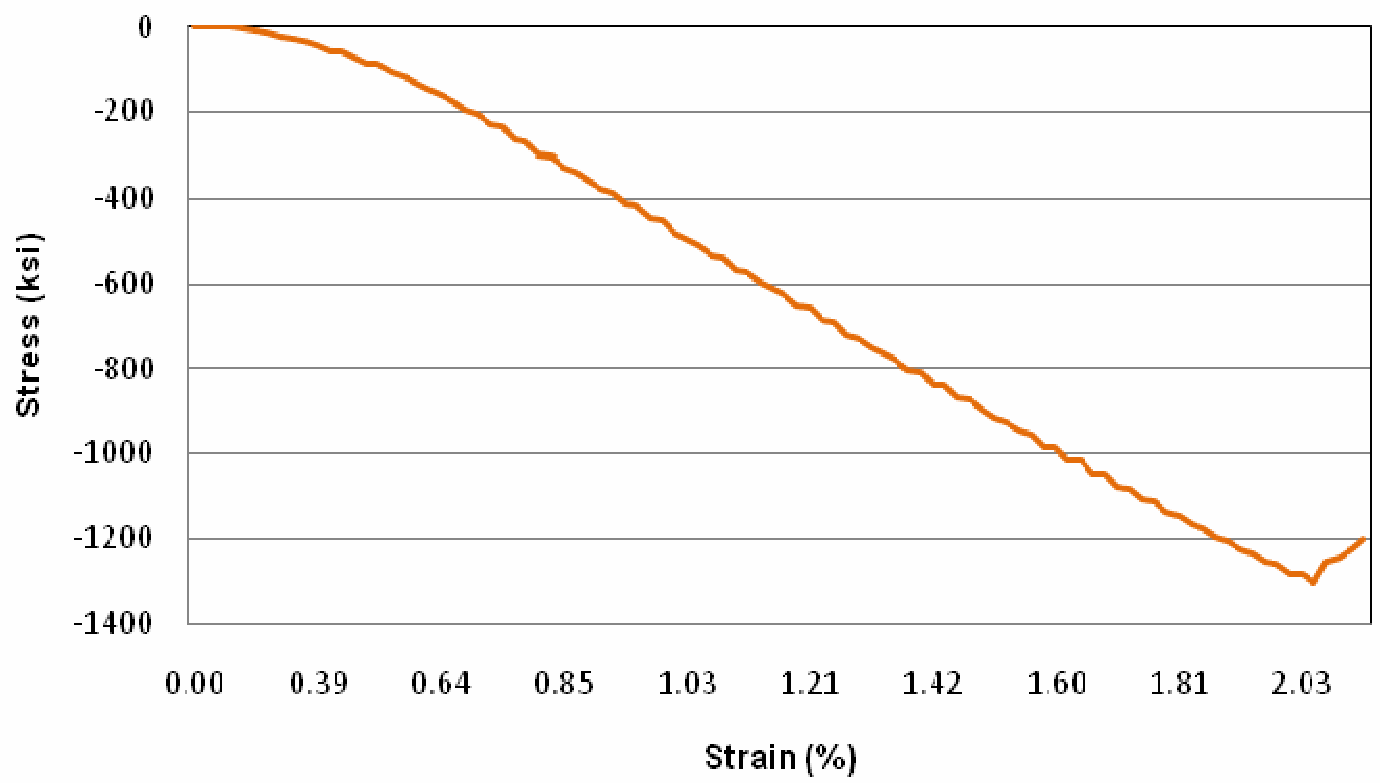

Compression Result for Test Specimen 6 with 259 grams of Limestone Filler

The figure below shows the failure damage created to thick-resin limestone filler specimen 6 after compression testing. 


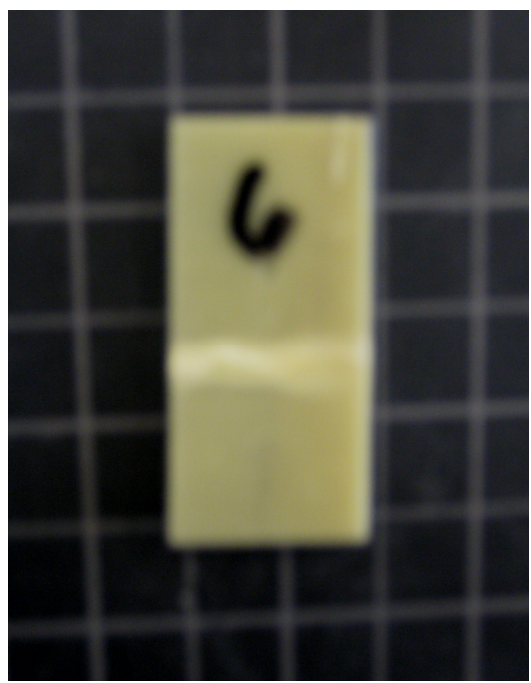

Compression Failure for Test Specimen 6 with 259 grams of Limestone Filler

Plot below shows the compressive results of all six composite laminates.

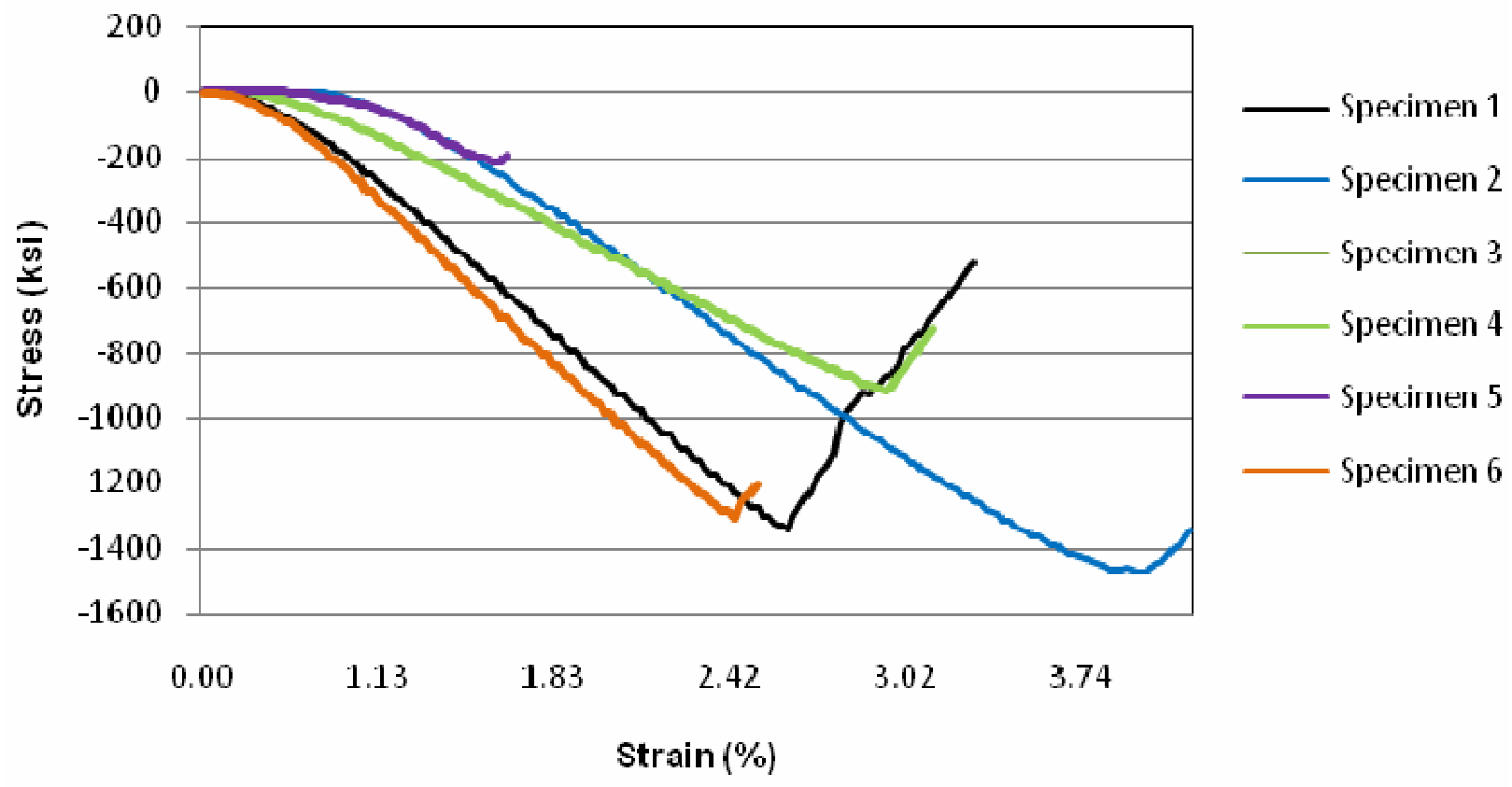

Compression Result for All Test Specimens with 259 grams of Limestone Filler

The average compressive stress and strain found from the six test specimens seen in graph above, were later used to calculate the average ultimate compressive stress and strain for 
test specimen $\mathrm{L}_{259}$. The strain percentage was also converted into the dimensionless units of in/in.

According to the graph, the maximum compressive stress ranged between 1250 to 1430 ksi. The ultimate compressive stress was dramatically higher than the ultimate tensile stress result.

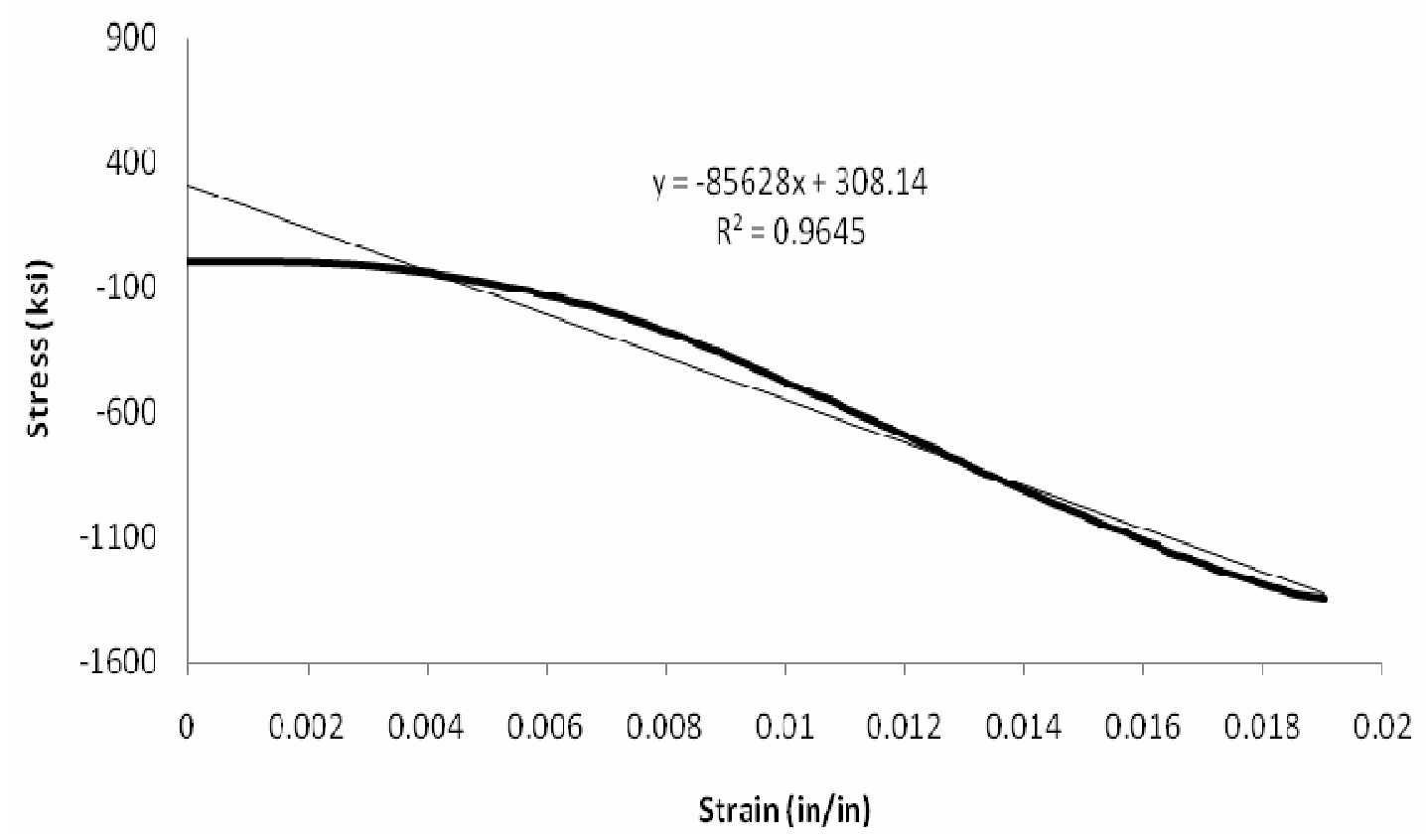

Stress vs. Strain Curve for Test Specimen $L_{259-1}$

The tensile strength result for test specimen 1 was seen above in the stress-strain curve linear relationship. The slope of the tread line was used to calculate the compressive modulus by using the tread line function from the Excel program. The compressive modulus in the longitudinal direction was $85,628 \mathrm{ksi}$ with an R-squared value of 0.9645 and a shear modulus of 35,093.44 ksi.The elastic-deformation region had an ultimate compressive stress of $3019.21 \mathrm{ksi}$ with a corresponding strain of 0.019 . The maximum load before fracture was at $-1345.93 \mathrm{lbf}$.

The figure below shows the failure damage created to all six thick-resin limestone filler specimens after compression testing. 


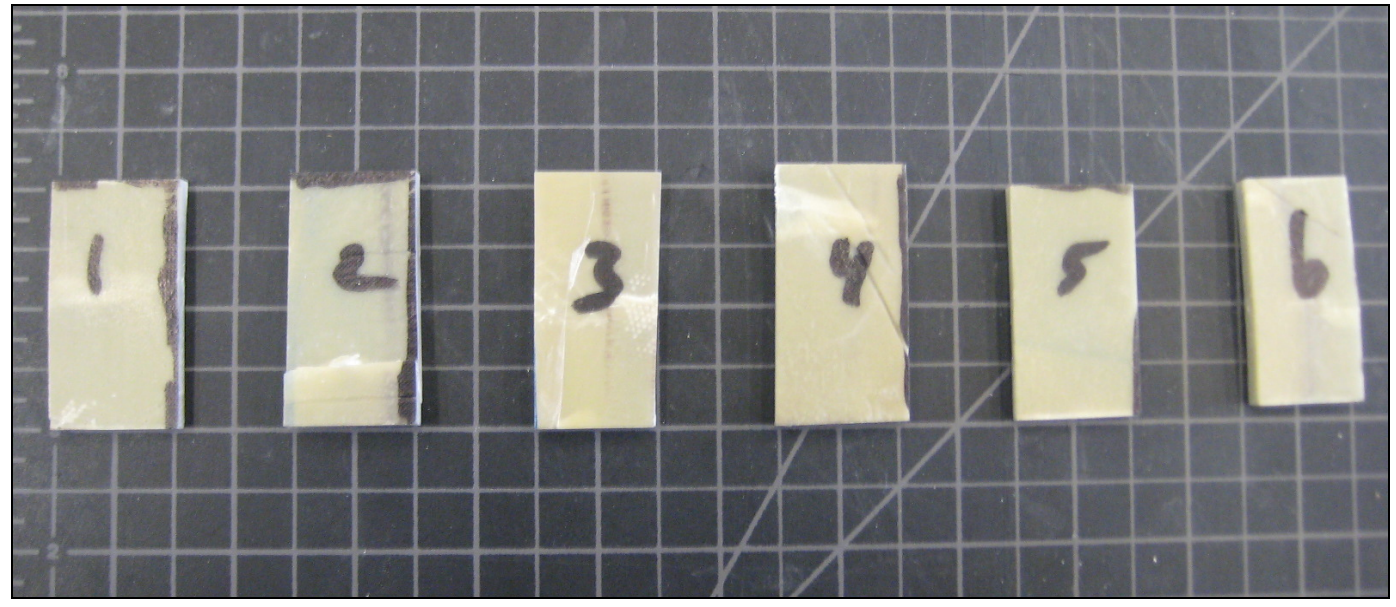

Compression Failure of All Test Specimens with 259 grams of Limestone Filler 


\section{REFERENCES}

1. Abrate, Serge. Impact on Composite Structures. Cambridge University Press. New York, 1998. pp. 158-185.

2. Aero 432: Composite Design Class. Comparison of Theoretical and Experimental Analysis Unidirectional/Cross-Ply Composite Laminate Plates. Cal Poly State University of San Luis Obispo. Winter 2007. pp. 15-34.

3. “Adhesive Filler Bonding." Plastics Care Inc. Google.com. Jan. 4, 2007. [www.plastics careinc/system/Three Fillets.html].

4. Agarwal, B.D. and Broutman, L.J. Analysis and Performance of Fiber Composites. $2^{\text {nd }}$ Edition, John Wiley \& Sons, 1990. pp. 314-380.

5. "ASTM D 3753 Standard Specification for Glass-Fiber-Reinforced Polyester Manholes and Wetwells."International ASTM. American Society for Testing and Materials, Philadelphia, Pa., 2005. pp. 123-136.

6. Beer, Ferdinand P. Mechanics of Materials. $3^{\text {rd }}$ Edition, McGraw Hill, New York. 2002. pp. 47-51.

7. “Calcium Carbonate: Calcite." Online Materials Information Resource. MatWeb.com. Jun. 12 2008. [www. matweb.com / search / DataSheet/calcite].

8. “Calcium Carbonate." Jun 12. 2008. Wikipedia.com.[wikipedia.com/calciumcarbonate .com].

9. “Charpy Tester: Impact Toughness." Online NDT Resource Center. Google.com. Mar 10, 2009. [www.ndt-ed.org/ImpactToughness.htm].

10. "Chemical Analysis of Rubbers and Plastics." Smithers Rapra Technology Ltd. Google.com. Jan. 22 2007. [www.rapra.net/analysis/polymers]. 
11. "Compilation of ASTM Standards Relating to Wastewater and Stormwater." Annual Book of ASTM Standards. American Society for Testing and Materials, Philadelphia, Pa., 2004.

12. "Composite Materials" Instron. 2007. Instron Corporation. Google.com. Mar. 172007. [http://www.instron.us/wa/applications/composites].

13. "Epoxy/Filler-Agents". Hernon Manufacturing High Performance Adhesives and Sealants. Google.com. Jan. 4, 2007 [www. hernonmfg.com/categories/cyanoancy.html].

14. "Generic E-Glass/Epoxy Unidirectional Prepreg." About.com Mar. 11, 2009. [www. composite.about.com/od/data/l/blg_egepoxy.htm].

15. "Fiberglass Manhole Cover." Hunan Timelion Composite Material Co., Ltd. Google.com March 25, 2008. [www.easybizchina.com/product/Manhole_Cover.html].

16. Hashin, Z., "Failure Criteria for Unidirectional Fiber Composites", Journal of Applied Mechanics, Vol. 47, 1980, pp. 329-334.

17. Hiermaier, Stefan. "Structures under Crash and Impact: Continuum Mechanics, Discretization and Experimental Characterization." Springer Press, New York, 2008. pp. 410-413.

18. "Impact Pendulum Test Systems." Instron Corporation. Impact Pendulum Test Systems Brochure, 2005. pp. 1-8.

19. "Introduction to Composite Materials". Efunda Engineering Fundamentals. Google.com. Mar. 17 2007. [www.efunda.com/solid/mechanics/composites.html]

20. Jones, Robert M. Mechanics of Composite Materials. McGraw Hill, Philadelphia, 1999. pp. 23-31, pp. 50-56.

21. Kolkailah, Faysal A. "Aero 432: Composite Design - Class Notes". Cal Poly State University of San Luis Obispo. Winter 2007. pp. 10-54. 
22. "Manhole and Manhole Covers." Global Spec: The Engineering Search Engine. Google.com.[www.globalspec.com/SpecSearch/Building/Construction/Manhole/Covers].

23. "Manhole Inspection and Rehabilitation." The Committee on Manhole Rehabilitation of the Pipeline Division of the American Society of Civil Engineers. ASCE Manuals and Reports on Engineering Practice. No. 92. New York, 1997.

24. "Manhole Rehabilitation." Pascon: P\&S Construction Co. Inc. Google.com May 3, 2008. [www.pascon.biz/ps/manhole_rehab.asp].

25. Meagson, T.H.G., Aircraft Structures for Engineering Students., Butterworth-Heinemann Ltd, 1999, Edition 3, pp. 129-141.

26. Melnick, Robert A. Manhole Covers. MIT Press. Cambridge, Mass, 1994. pp.15-78.

27. Miracle, Daniel B. and Donaldson, Steven L., "Representative Component Properties." ASM Handbook: Composites, Vol. 21, 2001. pp. 513-515.

28. Mule, Nicholas. "Design and Implementation of a Pendulum Bumper Impact Tester Support Fixture with Integrated Instrumentation for Data Acquisition." Thesis (M.S.) California Polytechnic State University. Cal Poly of San Luis Obispo, 2007.

29. "Performance Testing of Fiberglass Manholes in Compliance with ASTM D 3753, Standard Specification for Glass Fiber-Reinforced Polyester Manholes (42", 48" Internal Diameter)." Containment Solutions, Inc. Google.com, Aug 27, 2008. [www.containmentsolutions.com/lit/ Manholes-Wetwells].

30. "Precipitated Calcium Carbonate." Solvay Corporation. Google.com. Jun 172007. [www.solvay /precipitated/calciumcarbonate/application.html].

31. "Punch Tester." Saudi Basic Industries Corporation. Google.com Mar 92009. [www.sabic.com].

32. Reno, Jamie. "Thefts of Manhole Covers Increase As Metals Prices Soar." Newsweek Web Exclusive. Newsweek.com. May 19 2008.[www.newsweek.com/id/37822]. 
33. "Resin Additives \& Fillers." Fibre-Glast Development Corporation. Jan. 6, 2007. Google.com. [www.fibreglast.com/category.php].

34. Sade, Carole. Form and Style: Research Papers, Reports, and Theses. Houghton-Mifflin Co., Boston, 1997.

35. "Standard Fiberglass Manholes.” L.F. Manufacturing, Inc. Jan 12, 2007. [www.lfm-frp.com/categories/products/standard-fiberglass-manholes.html].

36. Swanson, Stephen R. Introduction to Design and Analysis with Advanced Composite Materials. Prentice-Hall, Inc., 1997. pp. 2-94.

33. Thomson, William T., Theory of Vibration with Applications, $2^{\text {nd }}$ ed., Prentice-Hall, New Jersey, 1981.pp. 32-46.

34. "Urethane Liquid Rubber.” Reynolds Advanced Materials. Google.com. Jun 19, 2008. [www. reynoldsam.com/index.php].

35. Vaitsekhovich, S.M., "A Press Mold for Pressing Right-Angled Blanks by Uniform Compression." Journal of Powder Metallurgy and Metal Ceramics. Vol. 31, July, 1992. pp. 94-97.

36. "Water Tight Fiberglass Manholes.” L.F. Manufacturing, Inc. Jan 12, 2007. [www.lfmfrp.com/categories/products/water-tight-fiberglass-manholes.html]. 